Bamberger Beiträge zur Linguistik

\title{
Der Verein Deutsche Sprache
}

Hintergrund, Entstehung, Arbeit und Organisation eines deutschen Sprachvereins

von Karoline Wirth

UNIVERSITY OF

BAMBERG

PRESS 
Bamberger Beiträge zur Linguistik 


\section{Bamberger Beiträge zur Linguistik}

hrsg. von Thomas Becker, Martin Haase,

Sebastian Kempgen, Manfred Krug und Patrizia Noel Aziz Hanna

\section{Band 1}

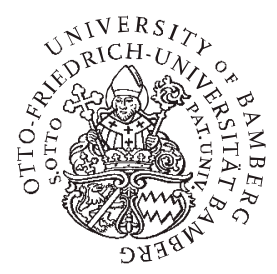

University of Bamberg Press 2010 


\section{Der Verein Deutsche Sprache}

Hintergrund, Entstehung, Arbeit und Organisation eines deutschen Sprachvereins

von Karoline Wirth

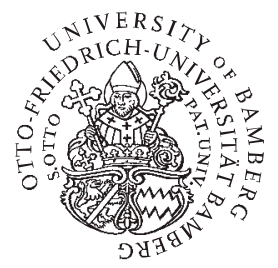

University of Bamberg Press 2010 
Bibliographische Information der Deutschen Nationalbibliothek

Die Deutsche Nationalbibliothek verzeichnet diese Publikation in der

Deutschen Nationalbibliographie; detaillierte bibliographische Informationen sind im Internet über http://dnb.ddb.de/ abrufbar

Diese Arbeit hat der Fakultät Geistes- und Kulturwissenschaften der Otto-Friedrich-

Universität als Dissertation vorgelegen

1. Gutachter: Prof. Dr. Helmut Glück

2. Gutachter: PD Dr. Friederike Schmöe

Tag der mündlichen Prüfung: 2. Juli 2009

Dieses Werk ist als freie Onlineversion über den HochschulschriftenServer (OPUS; http://www.opus-bayern.de/uni-bamberg/) der Universitätsbibliothek Bamberg erreichbar. Kopien und Ausdrucke dürfen nur zum privaten und sonstigen eigenen Gebrauch angefertigt werden.

Herstellung und Druck: docupoint GmbH, Magdeburg Umschlaggestaltung: Dezernat Kommunikation und Alumni

(C) University of Bamberg Press Bamberg 2010

http://www.uni-bamberg.de/ubp/

ISSN: $2190-3298$

ISBN: 978-3-923507-65-8

eISBN: 978-3-923507-66-5

URN: urn:nbn:de:bvb:473-opus-2415 


\section{Danksagung}

Herzlicher Dank geht an Prof. Dr. Helmut Glück, der diese Arbeit betreut hat, und an PD Dr. Friederike Schmöe, meine Zweitgutachterin.

Danken möchte ich auch Prof. Dr. Walter Krämer, der mir für die Recherchen seine Archive zur Verfügung gestellt hat und mir erlaubt hat, alle Materialien auch zu verwenden.

Außerdem danke ich den Mitarbeiterinnen und Mitarbeitern der Vereinszentrale für ihre Hilfe bei den Recherchen, allen voran Christiane Dahl, Sabine Riga, Monika Elias und Dr. Holger Klatte, die mir in all den Jahren auch bei zeitraubenden Recherchen immer wieder geholfen haben.

Ebenso sei der Otto-Friedrich-Universität Bamberg gedankt, die die Recherchen für diese Arbeit finanziell unterstützt hat.

Für kritische Anmerkungen und für ihre Hilfe danken möchte ich auch meinen Eltern und Geschwistern sowie Dr. Wieland Eins, Katrin Sell M.A., Björn Schimmeyer und den Bamberger Freunden des Problems.

Karoline Wirth 



\section{Vorwort}

In diesem Buch geht es um einen deutschen Sprachverein, der kurz vor dem Ende des 20. Jahrhunderts gegründet wurde. Der Anlaß für diese Gründung war ein verbreitetes Mißvergnügen an der damaligen Sprachentwicklung, namentlich an der Vielzahl der Anglizismen in der alltäglichen Sprachverwendung. Die Gründer dieses Vereins kamen aus verschiedenen Berufen, Germanistikprofessoren waren nicht darunter. Sie nannten ihren Verein anfangs „Verein zur Wahrung der deutschen Sprache“. Recht bald strich man das Attribut „zur Wahrung“ und nannte ihn kurz und knapp „Verein Deutsche Sprache“ (VDS). Über diese Namensänderung wurde viel diskutiert, weil einige Kommentatoren glaub(t)en, mittels der Vokabel Wahrung einen anachronistischen Gesinnungsnachweis führen zu können: wer etwas (be-)wahren will, so die Unterstellung, muss rückwärtsgerichtet und fortschrittsfeindlich sein. Der VDS wuchs rasch und ist seit Jahren der an Mitgliedern weitaus reichste deutsche Sprachverein.

Der VDS entstand aus einem weiteren Mißvergnügen heraus. Seine Gründer waren der Auffassung, dass der „offiziöse“ deutsche Sprachverein, die "Gesellschaft für deutsche Sprache“ (GfdS), sich zu wenig Sorgen mache im Hinblick auf die Sprachentwicklung, vor allem wiederum im Hinblick auf die Anglizismen. Als "offiziös“ kann man die GfdS deshalb bezeichnen, weil sie, anders als der VDS, im wesentlichen aus öffentlichen Mitteln finanziert wurde und wird. Eigentlich wollten die VDS-Gründer die GfdS dazu bewegen, sich stärker mit der Anglizismen-Frage zu befassen. Als ihnen klar wurde, dass ihnen das nicht gelingen würde, schritten sie zur Gründung eines eigenen Vereins.

Dieses Buch behandelt die Gründungsphase und die ersten zehn Jahre der Existenz des VDS, beginnt aber mit germanistischen Erörterungen und Analysen. Es referiert die weit zurückreichenden Bemühungen um kategorial angemessene und funktional brauchbare Definitionen der zentralen Beschreibungsbegriffe „Fremdwort“ und „Lehnwort“, diskutiert die (wenig fruchtbaren) Versuche, „Anglizismus“, „Britizismus“ und "Angloamerikanismus“ voneinander abzugrenzen und gibt einen Überblick über die Terminologie der rezenten Sprachpflegedebatten. Karoline Keßler (sie heißt seit 2009 Karoline Wirth) zeigt hier, wie prob- 
lematisch und theorieabhängig bereits die Terminologie ist und erklärt es für nützlich, konzeptionell zwischen „Fremdwort“ und „fremdem Wort" zu unterscheiden.

Im weiteren Verlauf der Arbeit wird immer wieder der Vorwurf referiert, linguistische Laien hätten keinen elaborierten Fremdwortbegriff und sollten deshalb lieber ganz den Mund halten. Dieser Vorwurf relativiert sich erheblich durch den Sachverhalt, dass sich die Germanistik ihrerseits damit schwertut und den Begriff „Fremdwort“ seit Peter von Polenz' (1967) Verdikt immer wieder für obsolet, fremdenfeindlich oder sonstwie politisch unkorrekt erklärte. Man hat verschiedentlich das Fremdwort einfach wegdefiniert. Die Fremdwörter waren dann allenfalls noch als „schwere Wörter" im Rahmen der Verständlichkeitsforschung und in der "Internationalismenforschung“ als Sache, nicht aber als Terminus geduldet. Allerdings sind weder „schwere Wörter“ noch „Internationalismen“ deckungsgleich mit dem, was der hergebrachte Fremdwortbegriff meint. Im „Metzler Lexikon Sprache“ definiert Friederike Schmöe „Fremdwort“ so:

Fremdwort Entlehnung aus einer fremden Sprache, die nicht oder nur sehr gering in das phonologische, morphologische und graphematische System der Nehmersprache integriert ist. Fremdwörter gelten (im Dt.) zumeist als akzeptiert, wenn sie einer Fachsprache zuzurechnen sind. Insbesondere Latinismen und Gräzismen werden als >gebildete< Ausdrucksweisen geschätzt. Dagegen werden alltagssprachliche Fremdwörter (z. B. aus dem Engl., siehe Anglizismus) seit einigen Jahren wieder stärker negativ belegt, da sie in den Augen mancher das Deutsche >überfremden<, lächerlich wirken oder nicht verständlich sind; siehe Denglisch, siehe Fremdwortdiskussion, siehe Verein Deutsche Sprache.

Schmöe spricht von „Integrieren“. Integration ist ein Vorgang, ein Prozess, der eine zeitliche Ausdehnung hat, bei dem ein Vorzustand von einem Nachzustand zu unterscheiden ist. Sprachhistorische Gesichtspunkte, nach denen Wörter in erster Linie auf ihre Herkunft untersucht und danach in native Wörter, Lehn- und Fremdwörter eingeteilt werden, spielen allerdings in vielen neueren Untersuchungen leider keine Rolle mehr. Damit ist nicht gesagt, dass solche „synchronen“ Herangehensweisen bei lexikologischen Untersuchungen aus methodischen Gründen prinzipiell verwerflich wären. Es ist damit allerdings gesagt, dass sie für die Bearbeitung von sprachlichen Austausch- und Beeinflussungsprozessen ungeeignet sind, denn wenn nach der Herkunft von Affixen, 
Wörtern, Wendungen usw. gefragt wird, ist eine „diachrone“ Perspektive unvermeidlich. Gerhard Stickels Aufruf: „Werft das Fremdwort zum alten Eisen!” (1985) geht deshalb an der Sache vorbei: Man kann einen faktisch vorhandenen, historisch gewordenen linguistischen Gegenstand nicht dadurch entsorgen, dass man seine Existenz bestreitet, ihn begrifflich weghext. Das mag in einem Voodoo-Ritual funktionieren, ist aber keine rationale Methodik in der Sprachforschung.

Die Essener Schule der Internationalismus-Forschung nahm Stickels Aufruf wörtlich. Sie wollte das Konzept des Fremdworts durch das des Internationalismus ersetzen. Man solle „Internationalismen“ mittels eines „rein synchron argumentierende[n], deskriptiv-strukturelle[n] Konzept[s]" untersuchen, weil alle „historischen Kriterien sekundär und für die Klassifikation irrelevant" (Volmert 2003, S. 35) seien. Dieser theoretisch dürftige Ansatz entwertet alle eigensprachlichen Entwicklungen, zu denen nicht zuletzt gezielte Ersetzungen von Internationalismen gehören. Der Absicht, Entlehntes durch natives lexikalisches Material zu ersetzen, liegen in der Regel demokratische, aufklärerische Motive zugrunde: eigensprachliche Bildungen sind nämlich oft, wenn auch keineswegs immer, transparenter und verständlicher als Internationalismen. Vor die Wahl gestellt, einen Dermatologen, einen Ophthalmologen und gar einen Otorhinolaryngologen aufzusuchen, müssten die meisten Leute erst einmal ein Wörterbuch konsultieren, um herauszufinden, zu wem von ihnen man mit welchem Leiden geht, und der sachliche Unterschied zwischen einem Pädiater und einem Päderasten wird auch nicht vielen klar sein. Womit sich ein Hautarzt, ein Augenarzt, ein Hals-, Nasen- und Ohrenarzt oder ein Kinderarzt befasst, verstehen sie sofort, denn das drückt die deutsche Bezeichnung unmittelbar aus.

Es ist deshalb keineswegs ein Gebrechen, dass „sich das Deutsche Eigenbildungen wie Fernsehen, Fernsprecher, Hubschrauber, Rundfunk, Hörfunk [leistet]” (Schaeder 1990, S. 36). Das Deutsche „leistet“ sich allerhand, was aus seiner Geschichte stammt, nicht nur seinen Erbwortschatz, und das tun andere Sprachen auch. Im Tschechischen nennt man das Theater divadlo und den Bahnhof nádrazi, im Russischen heißt letzterer vokzal, im Kroatischen kolodvor. Sollten sie besser station, stazione usw. heißen? Wieso sollen Internationalismen besser, wertvoller, funktionaler, schöner sein als „Nationalismen“ (dieser denunziatorische 
Ausdruck wurde in Essen tatsächlich „terminologisiert“)? Das theorielose Essener Konzept der „Internationalismen“ propagiert einen blutleeren newspeak, den man schon aus sprachästhetischen Gründen nicht wollen kann. Für die Fremdwortdiskussion ist es wertlos.

\section{$* * *$}

Die Darstellung der Fremdwortdiskussion in Deutschland beschränkt sich in diesem Buch auf den Zeitraum der beiden Nach-WendeDekaden zwischen 1989 und 2009. Keßler teilt diese Darstellung in drei Abschnitte auf, die drei Domänen oder Kommunikationsbereiche erfassen: die Sprachwissenschaft, die Medien und die Politik. Es handelt sich, wie sie plausibel macht, um drei „Diskurse“, die einander so fremd sind, dass man sie besser getrennt betrachtet. Ein großer Vorzug der Darstellung liegt darin, dass Keßler nicht irgendwelche "Diskurse“ rekonstruiert, dass sie nicht nachträglich interpretiert, was die Schreiber der zugrundegelegten Texte „eigentlich“ sagen wollten, sondern sich auf das sachliche und sachangemessene Referieren beschränkt und es (weitgehend) dem Leser überlässt, seine Schlüsse zu ziehen. Weiterhin fällt auf, dass aus der Fremdwortdiskussion in diesem Zeitraum eine Anglizismendiskussion geworden ist - Fremdes und Entlehntes aus anderen Sprachen als dem Englischen spielt definitiv keine Rolle mehr.

Ein umfangreiches Teilkapitel skizziert die Organisationen, die sich (mit und ohne Anspruch auf wissenschaftliche Dignität) mit Sprachpflege im weiteren Sinn befassen. „Ungezählte Vereine, Initiativen und Preisgerichte sind $\mathrm{zu}$ ihrer [der deutschen Sprache] Rettung angetreten. Ob die Rettung durch solche Initiativen gelingen kann, ist zweifelhaft“, schrieb Wolfgang Frühwald (2009, S. 57), der als Präsident der Deutschen Forschungsgemeinschaft den Auszug ganzer Disziplinen aus der Wissenschaftssprache Deutsch eher schweigsam begleitete. Keßler hat diese Vereine und Initiativen der Reihe nach dargestellt. Sie sind gar nicht so zahlreich, wie Frühwald annimmt. Und nicht alle wollen pauschal die deutsche Sprache retten, manche haben halbwegs differenzierte sprachpolitische Programme. Auch das stellt die Verfasserin in der notwendigen Genauigkeit und der gebotenen Distanz dar. Dieser Abschnitt er- 
möglicht vergleichende Einschätzungen des institutionellen und fachlichen Gewichts und der Programmatik der verschiedenen Einrichtungen und Organisationen.

Er beginnt mit einem Exkurs über den (historischen) (Allgemeinen) Deutschen Sprachverein und dessen Fremdwort-Begriff. Es folgen Skizzen von Geschichte und Gegenwart der Gesellschaft für deutsche Sprache, des Instituts für deutsche Sprache und der Deutschen Akademie für Sprache und Dichtung, soweit sie sich praktisch oder programmatisch mit Fragen der Sprachentwicklung befassen. Es geht dort aber auch um den dubiosen „Verein für Sprachpflege“ und andere kleine Vereine aus dem rechten Spektrum. Daran schließen sich Exkurse über die Sprachpflege-Vereine der Schweiz und in Österreich; letztere sind offenbar durchgängig rechtsgerichtet. Es folgen kurze Beschreibungen der Stiftungen, die sich mit sprachlichen Dingen befassen, und einiger lokaler Sprach-Initiativen. Nicht alle der in diesem Abschnitt beschriebenen Einrichtungen werden sich darüber freuen, dort berücksichtigt worden zu sein.

$* * *$

Diese Dissertation ist das erste Buch, das sich mit den Methoden der zeitgeschichtlichen Forschung mit dem Verein Deutsche Sprache auseinandersetzt. Dazu war das Studium ganzer Berge von Akten vonnöten. Dabei hatte es die Autorin nicht mit Akten in einem professionell verwalteten Archiv zu tun hatte, sondern mit Regalen voller Leitzordner (über 600) in einem Dortmunder Keller. Über ein wirkliches Archiv verfügt der VDS nicht. Darüber hinaus hat die Autorin eine Vielzahl von Korrespondenzen, Gesprächen und Interviews geführt und dokumentiert, Dutzende von Internetpräsenzen aufgesucht und ausgewertet, Hunderte von Presseberichten und journalistischen Beiträge über den und aus dem VDS ausgewertet. Auf diese Weise ist eine Art „Vollerhebung" zustandegekommen. Keßler kann für sich in Anspruch nehmen, alle Dokumente, die für die Entstehung und die ersten Jahre der Existenz des VDS relevant sind (und eine Vielzahl an Dokumenten, die einschlägig, aber weniger relevant sind) zu kennen und ausgewertet $\mathrm{zu}$ ha- 
ben. Aus diesem Grund kann ihre Untersuchung mit einiger Plausibilität den Anspruch auf Vollständigkeit erheben.

Keßlers Arbeit ist aber nicht das erste Buch, das sich mit einem deutschen Sprachverein beschäftigt. Silke Wiechers (2004) hat eine umfassende Studie über die GfdS vorgelegt, die Standards gesetzt hat. Falco Pfalzgraf (2006) hat Verbindungen zwischen einigen Sprachpflegevereinen und der rechtsradikalen Szene aufgedeckt; seine Arbeit ist allerdings eher soziologisch und politisch als germanistisch von Interesse. Jürgen Spitzmüller (2005) hat mit den fragwürdigen Verfahren der Diskursanalyse und ohne Kenntnis elementarer statistischer Methoden die öffentlichen Diskussionen über die Anglizismenproblematik darzustellen versucht und, vor allem, als politischer Linienrichter unentwegt bewertet. Die Untersuchungen zum (Allgemeinen) Deutschen Sprachverein und den Protagonisten der älteren, puristischen Sprachpflege in Deutschland sind zahlreicher. Unter ihnen ragt die Arbeit über Eduard Engel (1845-1938) hervor, die Anke Sauter (2000) vorgelegt hat. Er wurde seit 1933 von den Nationalsozialisten verfolgt, weil er jüdischer Herkunft war. Der Deutsche Sprachverein distanzierte sich nach der "Machtergreifung“ schleunigst von seinem Ehrenmitglied Engel. Seine Nachfolgerin, die GfdS, hat Sauters Arbeit bis heute ignoriert. Sie ist der GfdS - mit Recht - peinlich.

Die vorliegende Arbeit beschränkt sich, wie bereits erwähnt, aus guten Gründen auf die allerjüngste Geschichte der deutschen „Fremdwortdiskussion“, nämlich die letzten zwanzig Jahre. Näheres zur Forschungslage auf diesem Gebiet kann man im Abschnitt über den Stand der Forschung (1.4.3) nachlesen.

$* * * *$

Wie soll man die vorliegende Arbeit innerhalb der germanistischen Forschung einordnen? Es ist eine Arbeit, die sich mit einer (sehr jungen) Organisation befasst, gleichzeitig und sehr zentral aber mit geistigen Befindlichkeiten und Kontroversen, die ihr Entstehen verursachten und das erste Jahrzehnt ihres Bestehens begleiteten. Wäre ein gewisser zeitlicher Abstand gegeben, müsste man diese Arbeit als Beitrag zur deut- 
schen Geistesgeschichte der Jahrtausendwende einordnen. Weil dieser Abstand (noch) nicht besteht, wird man eher davon sprechen, dass sie die Organisationsgeschichte eines Sprachvereins, die Zeitgeschichte und aktuelle politische und weltanschauliche Überzeugungen sowie die Debatten darüber zum Gegenstand hat, namentlich Überzeugungen und Debatten, die die deutsche Sprache betreffen und um sie kreisen. In diesen Debatten wird nicht nur argumentiert. Das soll das folgende Beispiel verdeutlichen.

Die Mitglieder des VDS werden oft als "selbsternannte Sprachpfleger“ oder „selbsternannte Sprachschützer“ bezeichnet. Das Attribut „selbsternannt" hat den Hautgout von Anmaßung: es bezeichnet einen Dilettanten, der sich eine Qualifikation zuschreibt, die er nicht hat, der sich in einer Angelegenheit für kompetent erklärt, für die er nicht kompetent ist. Dieses Attribut legt verschiedene Fragen nahe:

1. Gibt es fremdernannte Sprachpfleger oder Sprachschützer?

2. Muss/soll sich ein Sprachpfleger überhaupt ernennen lassen, und wer hätte gegebenenfalls das Recht, das zu tun?

3. Bedarf es für sprachpflegerische Aktivitäten der Genehmigung einer Behörde, etwa des nächstgelegenen germanistischen Instituts?

Ad 1. Es gibt Sprachpflegeprogramme in manchen Behörden, z. B. in der deutschen Bundesregierung. Sie hat 2009 die GfdS im Rahmen eines befristeten Projekts damit beauftragt, Gesetzentwürfe sprachlich zu prüfen und ggf. zu verbessern. Das Vorbild war offenbar die Sektion Terminologie der zentralen Sprachdienste der Schweizerischen Bundeskanzlei, die Entwürfe von Gesetzen und Verordnungen der Schweizer Regierung mit großem Erfolg sprachlich „optimiert“. Das Vorhandensein bzw. das Fehlen staatlicher Zuschüsse ist in einer offenen Bürgergesellschaft jedoch kein Argument für die Qualität einer Einrichtung. Die GfdS ist nicht schon deshalb, weil sie aus öffentlichen Kassen finanziert wird, ein fachlich besonders legitimierter Sprachverein.

Ad 2. „Sprachpfleger“ oder "Sprachschützer“ sind keine Berufe, keine geschützten Tätigkeiten, keine staatlicherseits verwalteten Qualifikationen. Es gibt bislang nicht einmal einen Bachelor-Studiengang, in dem man sich dazu ausbilden lassen könnte. Das sollte auch so bleiben. Deshalb kann jeder und jede, der oder die das will, die Sprache nach 
Herzenslust pflegen, bewahren oder schützen, aber auch verhunzen und mißhandeln. Kritik an seinem bzw. ihrem Tun muss er bzw. sie sich allerdings gefallen lassen.

Ad 3. Natürlich bedarf es keiner Genehmigung dieser Art, auch wenn mancher Germanist sich das heimlich wünscht. Die deutsche Sprache ist ein öffentliches Gut, dessen sich jeder bedienen kann und muss, der in einem deutschsprachigen Land lebt. Es ist ein Bürgerrecht, das zu tun, auch wenn es für manche Migranten eher eine lästige Pflicht sein mag. Ein weiteres Bürgerrecht besteht darin, sich über diese Sprache Gedanken zu machen und sich über ihre Verwendung und Entwicklung öffentlich zu äußern, positiv wie negativ. Es ist das Recht jedes Bürgers, Anglizismen $\mathrm{zu}$ verwenden, soviel er will, und es ist das Recht jedes Bürgers, sich über Anglizismen aufzuregen und ihren Gebrauch zu verdammen.

Viele Linguisten sind der Meinung, dass Sprachkritik allenfalls von ihnen selbst nach Kriterien erfolgen dürfe, die sie selbst entwickelt und für wissenschaftlich erklärt haben. Über diesen Anspruch wurden ganze Dissertationen geschrieben (z. B. Schwinn 1997). Außerhalb der Germanistik, in den Sprachecken der Zeitungen etwa, beim „Streiflicht“ der Süddeutschen Zeitung oder bei den „SprachSpielen“ der WELT, stieß und stößt dieser Anspruch eher auf Heiterkeit. Die wissenschaftlich gepanzerten Theoretiker der germanistischen Sprachkritik können nämlich in der Regel keine Sprachglosse verfassen, die irgendeine eine Zeitung drucken oder irgendein Sender ausstrahlen würde.

Diese Germanisten sollten wissen, dass man Nicht-Fachleuten lieber nicht verbieten sollte, sich mit der deutschen Sprache auseinanderzusetzen: man sollte das begrüßen und sie dabei beratend unterstützen, wenn sie das wünschen. Keinem Botaniker würde es einfallen, Hobbygärtnern beim Erfahrungsaustausch über Lausbefall an Rosentrieben reinzureden. Kein Mediziner wird Wartezimmergespräche über Hausmittel gegen Schlaflosigkeit unterbinden, kein Pfarrer wird seinen Konfirmanden Erörterungen von Gottesbeweisen untersagen, kein Jurist wird es ungehörig finden, wenn Nichtjuristen sich über den Unterschied zwischen Recht und Gerechtigkeit streiten. Anders in den meisten germanistischen Diskursen über Sprachpflege. Dort nimmt man Laiendebatten über Zustand und Zukunft unserer Sprache mit Stirn- 
runzeln zur Kenntnis, erklärt sie mit erhobenem Zeigefinger und erkennbar geniert für unwissenschaftlich und lässt sich indigniert über den Sachverhalt aus, dass Laien vieles laienhaft sehen. Das ist ihr gutes Recht. Als Wissenschaftler muss man sie korrigieren, wenn sie Falsches behaupten, wenn sie Zusammenhänge übersehen, wenn sie Komplexes versimpeln, aber man darf ihnen nicht den Mund verbieten.

***

Die letzten 65 Jahre waren eine Nachkriegszeit. Sie war, in sprachlicher Hinsicht, davon geprägt, dass der Einfluss des Englischen auf das Deutsche massiv zunahm. Es sind allerdings nicht die Sprachen, die Einfluss aufeinander nehmen, sondern die Sprecher und Schreiber von Sprachen. In den letzten 65 Jahren haben sich die Zonen, in denen Sprecher und Schreiber des Deutschen mit dem Englischen in Berührung kamen, stark ausgedehnt. In der unmittelbaren Nachkriegszeit waren das alle Lebensbereiche, in denen die Deutschen mit den anglophonen Besatzungsregierungen zu tun hatten, etwa die öffentliche Verwaltung, Wirtschaft und Politik, Presse und Rundfunk. Bis in die 1970er Jahre waren die britischen und amerikanischen Militärsender AFS und BFBS für (west-)deutsche Jugendliche musikalisch stilbildend. Die U-Musik der (west-)deutschen Sender wechselte in den 1960er Jahren allmählich die Sprache. Deutschsprachige Liedtexte wurden seltener, doch gab es immer wieder erfolgreiche Gegenbewegungen. Udo Lindenberg wäre wahrscheinlich erfolglos geblieben, hätte er seine Lieder auf englisch gesungen.

In den Jahren des Wirtschaftswunders orientierten sich ganze Branchen der Industrie am Vorbild der USA. Das entsprach technischen und wirtschaftlichen Notwendigkeiten. Aber es hatte auch zur Folge, dass in vielen Bereichen existierende deutsche Terminologien außer Kurs gerieten und in neu entstehenden Produktionszweigen deutschsprachige Terminologien erst gar nicht geschaffen wurden. Seit den 1980er Jahren vollzieht sich auf der ganzen Welt die sogenannte Globalisierung. Im Zuge dieser Entwicklung wurden bestimmte Ausprägungen des Englischen $\mathrm{zu}$ einer weltweiten lingua franca, einer Verständigungssprache, bei der 
es vor allem auf das reibungslose Funktionieren und nicht auf Eleganz, Stilsicherheit und Eloquenz ankommt. Große Bereiche von Wirtschaft, Politik und Gesellschaft durchliefen eine Internationalisierung, die eine Nationalisierung, nämlich eine Anglisierung war und ist (vgl. Knapp 1990). Viele Menschen müssen inzwischen auf Englisch kommunizieren, um ihren Beruf oder ihre Hobbies ausüben zu können. Luftfahrt, Tourismus und Diplomatie, fast alle internationalen Organisationen, viele international operierende Firmen, die großen Banken und Versicherungen, der Großteil der Wissenschaften, die Musikszene und die internationale Jugendkultur haben Englisch zu ihrer Arbeitssprache gemacht. Anfang 2010 wurde der erste Vorstoß unternommen, das Englische in NRW und Hamburg in „Kammern für internationale Handelssachen“ bei einigen Landgerichten als Gerichtssprache zuzulassen.

Gesellschaftlich gefestigt wurde die Position des Englischen durch seine Einführung als obligatorische Fremdsprache in die Volks- und Hauptschulen in den 1960er Jahren. So gut wie jeder Erwachsene in den alten Bundesländern, der heute jünger ist als etwa 55 Jahre, hat einige Jahre Englischunterricht in der Schule gehabt. Das ist eine wesentliche Voraussetzung dafür, dass Englisches nicht nur in die Fachsprachen, sondern in viele Bereiche der Alltagssprache Eingang finden konnte. Fast alle Leute verstehen nämlich ungefähr, was mit meeting point auf einem Bahnhof und mit selected fine tobaccos auf einer Zigarettenschachtel gemeint ist. Diese Englischkenntnisse sind die Grundlage dafür, dass viele Anglizismen unübersetzt adaptiert werden können. Viele Deutschsprachige verfügen über Grundkenntnisse der englischen Phonologie und Morphologie, und sie beherrschen elementare Wortschätze des Englischen. Wäre das nicht der Fall, könnten es sich die Werbung und die Massenmedien gar nicht leisten, allzu viele Anglizismen zu verwenden. Sie sind nämlich darauf angewiesen, dass sie einigermaßen verstanden werden. Die Allgegenwart der Massenmedien hat andererseits dafür gesorgt, dass die von ihnen verbreiteten Sprachmuster alle Schichten und Altersgruppen erreichen, dass ihre Verbreitung keine sozialen Grenzen mehr kennt. Insofern unterscheidet sich die Situation von der um 1750, als die höheren Stände Französisch sprachen, nicht aber das Volk. 
Die Greifswalder Anglistin Amei Koll-Stobbe ist der Meinung, die „jüngere Generation“ in Deutschland könne heute als „funktional bilingual“ betrachtet werden (2009, S. 29f.), wenn man nicht die „enge Definition von Bilingualismus im Sinne des Strukturalisten Bloomfield“ (ebd.) zugrundelege. Bloomfields einschlägige Definition ist allerdings nicht „eng“, und ein Besuch einer vorpommerschen Hauptschule würde ihr schnell zeigen, dass die Annahme, das Englische werde bei uns von den Jungen "quasi indirekt natürlich“ (ebd. S. 30) gelernt, auch bei einer „weiten“ Definition von Bilingualismus unhaltbar ist. Richtig ist allerdings, dass die Verbreitung von Englischkenntnissen in allen sozialen Schichten im Laufe der letzen vierzig (Westdeutschland, Österreich, Schweiz) bzw. zwanzig Jahre (neue Bundesländer) die Adaptation von Anglizismen in allen Lebensbereichen befördert hat. Das ist eine wesentliche Voraussetzung, wahrscheinlich: die wesentliche Voraussetzung dafür, dass die Anglizismen im Deutschen in den vergangenen 65 Jahren quantitativ und qualitativ zugenommen haben (vgl. Burmasova 2010).

Vor fast 400 Jahren bemühten sich adlige und bürgerliche Patrioten darum, das Deutsche zu einer funktional vollwertigen Hoch- und Literatursprache $z u$ entwickeln, die dem Französischen gleichwertig werden sollte. Zu diesem Zweck gründeten sie im 17. Jahrhundert Sprachgesellschaften, und sie veranlassten die Erarbeitung von deutschen Grammatiken, Wörterbüchern, Poetiken und Stillehren.

Vor gut 100 Jahren wurde der Allgemeine Deutsche Sprachverein ins Leben gerufen, der die inzwischen etablierte Hoch- und Literatursprache Deutsch von fremden Einflüssen bewahren und reinigen wollte. Das Deutsche sollte dem Französischen und dem Englischen ebenbürtig bleiben. Der ADSV hat Bleibendes geleistet durch die Verdeutschung wichtiger Terminologien und Wortschätze, etwa der Rechtssprache oder der Post- und Eisenbahnterminologie. Seine soziale Basis war das selbstbewußte wilhelminische Bürgertum, das sich - vor allem im Ersten Weltkrieg - sprachchauvinistische Delirien leistete, die das Anliegen, die deutsche Sprache zu pflegen und zu bewahren, in anhaltenden Mißkredit brachten. Er ging sang-, klang- und ruhmlos während des 2. Weltkriegs zugrunde. Sein unmittelbarer Nachfolger wurde die Ge- 
sellschaft für deutsche Sprache (gegründet 1947), deren Geschichte Silke Wiechers (2004) dargestellt hat.

Ende des 20. Jahrhunderts hat sich mit dem VDS eine Bürgerbewegung herausgebildet, deren Anliegen die Bewahrung, aber auch die Weiterentwicklung der Hoch- und Literatursprache Deutsch ist. Ihre soziale Basis ist wiederum das gebildete Bürgertum. Sprachchauvinistischen Anwandlungen ist der VDS bislang nicht erlegen, alle Versuche, ihn in die rechte Ecke zu stellen, haben sich bisher als gegenstandslos erwiesen. Dieses Buch stellt dar, wie eine große Bürgerinitiative entstanden ist, die ein sprachliches Anliegen verfolgt. So etwas ist selten. Solche Initiativen geraten schnell in sektiererisches Fahrwasser und werden bedeutungslos. Das hat der VDS bislang mit Geschick und nicht ohne innere Konflikte vermieden. Schon daher lohnt sich die Beschäftigung mit ihm.

Deshalb wurde dieses Buch geschrieben. Wer verstehen will, weshalb mitten in der postmodernen Beliebigkeit des letzten fin de siècle die deutsche Sprache ein kampagnenfähiges Thema werden konnte, das Zehntausende fasziniert, sollte dieses Buch lesen.

Helmut Glück 


\section{Zitierte Literatur}

Burmasova, Svetlana, Empirische Untersuchung der Anglizismen im Deutschen: am Material der Zeitung Die WELT (Jahrgänge 1994 und 2004). Bamberg 2010.

Duden Die deutsche Rechtschreibung. Mannheim usw. 24. Auflage 2006.

Frühwald, Wolfgang, Die deutsche Sprache und die Sprache der Deutschen. Über Galliko- und Anglomanie. Vortrag gehalten am 15. Januar 2009 bei einer Veranstaltung der Hans-Seidel-Stiftung zur „Zukunft der deutschen Sprache“. In: Glanzlichter der Wissenschaft. Ein Almanach. Hg. vom Deutschen Hochschulverband. Redaktion Felix Grigat. Bonn 2009, S. 57-65.

Henne, Helmut - Mentrup, Wolfgang (Hg.), Wortschatz und Verständigungsprobleme. Was sind „schwere Wörter“ im Deutschen? Jahrbuch 1982 des IdS, Bd. 57. Düsseldorf 1983.

Knapp, Karlfried, Zurück von Babel? Zur Zukunft der Weltsprache Englisch. In: Zeitschrift für Literaturwissenschaft und Linguistik 20, 1990, Heft 79, S. 18-42.

Koll-Stobbe, Amei, Anglizismen sind Bullshit: Entlehnungsprozesse und interkulturelle Identität. In: dies. (Hg.), Zwischen den Sprachen, zwischen den Kulturen. Transfer- und Interferenzprozesse in europäischen Sprachen (= Sprachkönnen und Sprachbewusstheit in Europa, Bd. 1). Frankfurt am Main 2009.

Metzler Lexikon Sprache. Hg. von Helmut Glück. Stuttgart, Weimar 1993, 3. Aufl. 2005.

Pfalzgraf, Falco, Neopurismus in Deutschland nach der Wende. Frankfurt am Main usw. 2006.

von Polenz, Peter, Fremdwort und Lehnwort sprachwissenschaftlich betrachtet. In: Muttersprache 1967, H. 3/4. Wieder abgedruckt in: Peter Braun (Hg.), Fremdwortdiskussion. München 1979, S. 9-31.

Sauter, Anke, Eduard Engel. Literaturhistoriker, Stillehrer, Sprachreiniger. Bamberg 2000. 
Schaeder, Burkhard, Versuch einer theoretischen Grundlegung der Internationalismenforschung. In: Internationalismen. Studien zur interlingualen Lexikologie und Lexikographie. Hg. von Peter Braun - Burkhard Schaeder - Johannes Volmert. Tübingen 1990, S. 34-46.

Schmitz, Heinz-Günther, Das Versagen der deutschen Sprachwissenschaft und Sprachpflege in der Fremdwortfrage. In: Ein See - drei Länder - eine Sprache. Tagungsband der Sprachvereine im „Netzwerk Deutsche Sprache“, hg. von Hermann Zabel. Paderborn 2001, S. 23-31.

Spitzmüller, Jürgen, Metasprachdiskurse: Einstellungen zu Anglizismen und ihre wissenschaftliche Rezeption. Berlin, New York 2005.

Stickel, Gerhard, Werft das „Fremdwort” zum alten Eisen! In: Sprachreport, Nullnummer, 1985.

Strauß, Gerhard - Zifonun, Gisela, Die Semantik schwerer Wörter im Deutschen. 2 Bände. Forschungsberichte des IdS, Bd. 58. Tübingen 1985.

Volmert, Johannes, Internationalismen und die Rolle des Lateins als „Muttersprache Europas”. In: Internationalismen II. Studien zur interlingualen Lexikologie und Lexikographie. Hg. von Peter Braun - Burkhard Schaeder - Johannes Volmert. Tübingen 2003, S. 23-50.

Wiechers, Silke, Die Gesellschaft für deutsche Sprache. Vorgeschichte, Geschichte und Arbeit eines deutschen Sprachvereins. Frankfurt am Main usw. 2004. 
1.1 Einführung in die Thematik...........................................................7

$1.2 \quad$ Ziel und Vorgehensweise .........................................................11

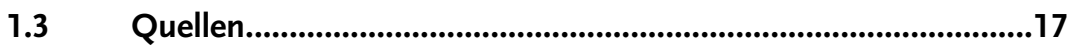

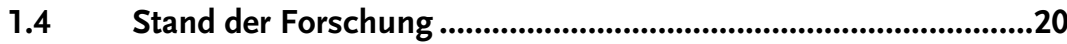

1.4.1 Untersuchungen zur Gliederung von Lehngut .....................20

1.4.2 Untersuchungen zu Anglizismen in der deutschen Sprache ...........................................................26

1.4.3 Untersuchungen zur Fremdwortdiskussion, zum Purismus und zu sprachpflegenden Vereinigungen ...............................40

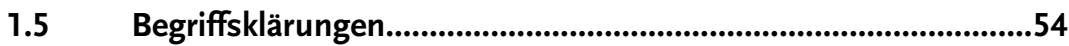

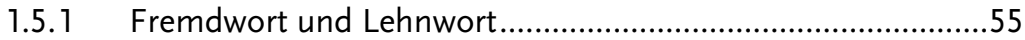

1.5.2 Anglizismus, Britizismus und Anglo-Amerikanismus.............58

1.5.3 Denglisch und Engleutsch..................................................59

1.5.4 Sprachreinigung - Purismus - Sprachpflege - Sprachkritik ..61

1.6 Die Fremdwortdiskussion in Deutschland von 1989 bis zur

Gegenwart.................................................................................64

1.6.1 Die Fremdwortdiskussion in der Sprachwissenschaft ...........65

1.6.2 Die Fremdwortdiskussion in den Medien..............................86

1.6.3 Die Fremdwortdiskussion in der Politik.................................91

\subsection{Sprachpflegende Vereinigungen und Institutionen sowie}

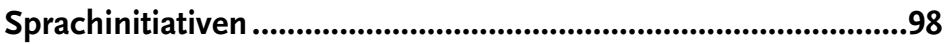

1.7.1 Exkurs: Allgemeiner Deutscher Sprachverein/Deutscher

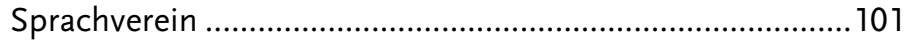

1.7.2 Gesellschaft für deutsche Sprache ........................................ 108

1.7.3 Institut für Deutsche Sprache .............................................. 115

1.7.4 Deutsche Akademie für Sprache und Dichtung ................... 118

1.7.5 Verein für Sprachpflege/Deutsche Sprachwelt ......................121

1.7.6 Verein für Rechtschreibung und Sprachpflege .................... 126

1.7.7 Bund für deutsche Schrift und Sprache ............................... 128 


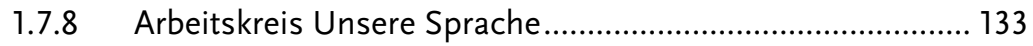

1.7.9 Exkurs: Institutionen in Österreich....................................... 134

1.7.9.1 Verein Muttersprache ........................................................ 134

1.7.9.2 Interessengemeinschaft Muttersprache .................... 136

1.7.10 Exkurs: Institutionen in der Schweiz............................... 138

1.7.10.1 Schweizerischer Verein für die deutsche Sprache ...... 138

1.7.10.2 Sprachkreis Deutsch............................................... 140

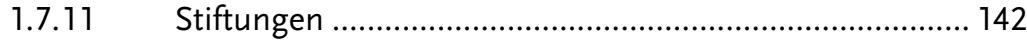

1.7.11.1 Theo-Münch-Stiftung...................................................... 142

1.7.11.2 Henning-Kaufmann-Stiftung .................................... 142

1.7.12 Lokale Gruppierungen .................................................. 144

1.7.12.1 Senioreninitiative Nürnberg ...................................... 145

1.7.12.2 Sprachrettungsklub Bautzen/Oberlausitz .................. 145

1.7.12.3 Aktion Deutsche Sprache ........................................... 146

1.7.12.4 Verein für Rechtschreibung und Sprachpflege ........... 147

1.7.13 Der Deutsche Sprachrat ................................................. 148

1.7.14 Netzwerk Deutsche Sprache ............................................. 149

1.7.15 Neue Fruchtbringende Gesellschaft ............................... 153

2 Der Verein Deutsche Sprache ........................................................... 157

2.1 Anfänge des Vereins Deutsche Sprache.................................... 157

2.1.1 Gründer und Vorsitzender Walter Krämer .......................... 157

2.1.2 Von der Idee bis zur Entstehung ........................................ 160

2.1.3 Etablierung der Vereinsstruktur......................................... 163

2.1.4 Namensgebung: Vom Verein zur Rettung der deutschen Sprache zum Verein Deutsche Sprache ............................... 170

$2.2 \quad$ Organisation ................................................................................... 174

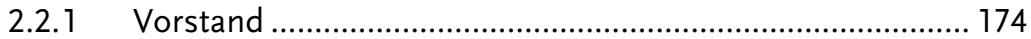

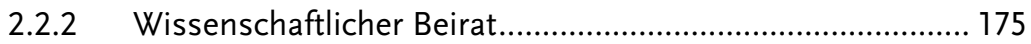

2.2.2.1 Thesen des wissenschaftlichen Beirats..................... 180

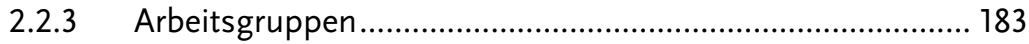

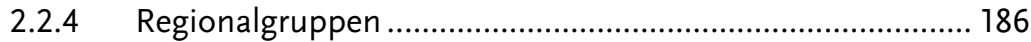

2.2.5 Mitglieder ........................................................................ 187

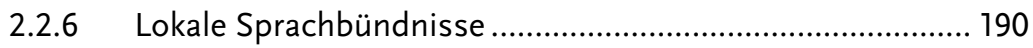


2.3 Selbstverständnis, Ziele und Leitlinien des Vereins

2.3.1 Selbstverständnis

2.3.2 Ziele und Leitlinien

2.4 Fremdwort und Anglizismus in der Arbeit des VDS und der Sprachgebrauch des Vereins

2.4.1 Fremdwort und Anglizismus ..............................................202

2.4.2 Diskurs, Metaphorik und Argumentation des VDS..............208

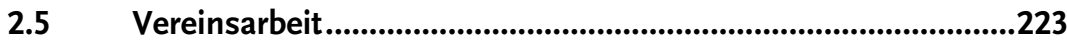

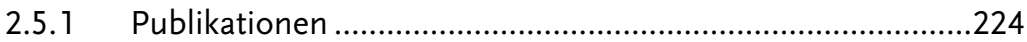

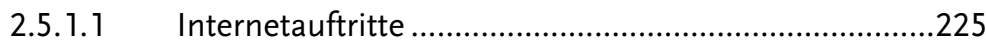

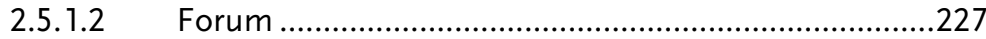

2.5.1.3 Anglizismenliste/Anglizismen-Index.........................229

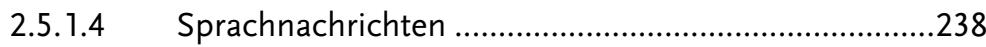

2.5.1.5 Lichtblicke - VDS-Tagebuch .....................................253

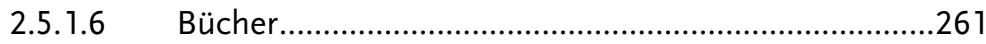

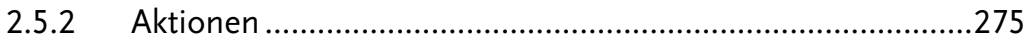

2.5.3 Tag der deutschen Sprache ................................................289

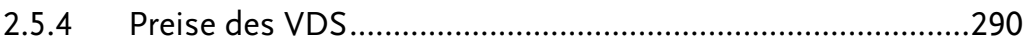

2.5.4.1 Sprachschuster und Sprachpanscher .........................290

2.5.4.2 Sprachhunzer ............................................................294

2.5.4.3 Kulturpreis Deutsche Sprache .....................................296

2.5.4.4 Weitere Preise...............................................................300

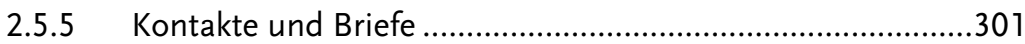

2.5.5.1 Briefwechsel mit Firmen und Organisationen .............304

2.5.5.2 Kontakte und Briefwechsel mit Journalisten und

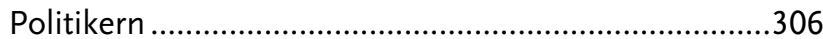

2.5.6 Medienauftritte und Pressearbeit.........................................310

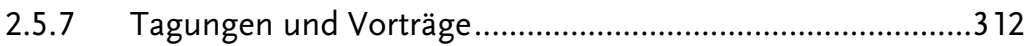

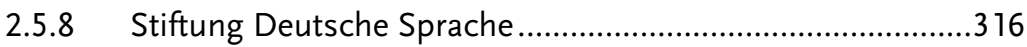

2.5.9 Weiteres Engagement des VDS ..........................................322

\subsection{Der Verein Deutsche Sprache und}


2.7 Der Verein Deutsche Sprache und sein Verhältnis zur Sprachwissenschaft.

2.8 Der Verein Deutsche Sprache und die Gesellschaft für deutsche Sprache.

2.9 Der Verein Deutsche Sprache und das Institut für Deutsche Sprache

2.10 Der Verein Deutsche Sprache und die Deutsche Sprachwelt... 345

2.11 Der Verein Deutsche Sprache und der Arbeitskreis Unsere Sprache 348

2.12 Der Verein Deutsche Sprache im Netzwerk Deutsche Sprache. 348

3 Zusammenfassung und Ausblick. 351

Bibliographie. 360

Literatur 360

Amtliche Dokumente 400

Gespräche und Schreiben 402 Internetpräsenzen. 404

Berichterstattung in den Medien und Pressemitteilungen

Dokumente des Vereins Deutsche Sprache, Dortmund 455

Weitere Materialien der Vereine und Organisationen 464 Abbildungsverzeichnis 465 
Abkürzungsverzeichnis................................................................................466

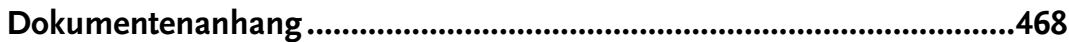





\section{$1 \quad$ Einleitung}

Das Deutsche ist eine wunderbare, kraftvolle, vielseitige Sprache und bedarf keines außersprachlichen Schutzes. Peter Eisenberg

\subsection{Einführung in die Thematik}

„Briefumschlag“ und „Bahnsteig“ sind für jeden Deutschsprachigen gebräuchliche Begriffe. Sie kommen uns heute im gleichen Maße normal vor, wie wir "Jungfernzwinger" für Kloster, „Kahlkopfverlegenheitsabhelfer" für Perücke oder "Starkschwachfingerschlagtonkasten“ für Klavier als lächerlich empfinden. Dabei sind Briefumschlag und Bahnsteig ebenso künstliche Bildungen wie die anderen genannten Beispiele. Im Gegensatz zu diesen haben sie sich aber durchgesetzt und jeweils ein Fremdwort verdrängt. Bestrebungen, die eigene Sprache von Einflüssen anderer Sprachen frei zu halten, haben in Deutschland eine lange Tradition und sind aus der Geschichte der deutschen Sprache nicht wegzudenken (vgl. Kirkness 1975: 10ff.). ${ }^{1}$ Schon im 15. und 16. Jahrhundert begannen die Humanisten, Volkssprachen in verschiedenen Wissensgebieten zu verwenden. Da es im Deutschen die benötigten Wortschätze nicht gab, wurden neue Wörter terminologisiert, darunter "datum" von Sigismund Meisterlin (ca. 1435 bis nach 1487) oder „würffel“ von Albrecht Dürer (1471 bis 1528) (vgl. Glück 2008a: 9). Mit Verdeutschungen befasst waren beispielsweise auch die frühen Lexikographen wie Simon Roth, ebenso Dichter wie Martin Opitz. In seiner Schrift „Aristarchus sive de contemptu linguae Teutonicae“ von 1617 lobte er seine germanischen Vorfahren, die ihre Sprache rein gehalten hätten, wies aber auch auf die Entlehnungen hin, die in die deutsche Sprache gelangt seien. Zu dieser Zeit wurde Sprachpflege vor allem als

\footnotetext{
${ }^{1}$ An dieser Stelle soll nur ein kurzer Überblick über die Sprachpflege und Sprachreinigung im Deutschen gegeben werden. Ausführlich werden diese Themen beispielsweise bei Kirkness (1975) oder Greule/Ahlvers-Liebel (1986) behandelt. Der Einsatz für die Sprachreinigung ist kein rein deutsches Phänomen. Auch in vielen anderen Ländern wie Frankreich oder Italien hat dieser Einsatz Tradition (vgl. u.a. Jones 1998: 33ff., Laurent 1988, Klein-Zirbes 2001, Raffaelli 1983).
} 
Sprachreinigung verstanden (vgl. Plümer 2000: 71). Die These von der Reinheit und der Ursprünglichkeit der deutschen Sprache, die nicht nur lexikalisch, sondern auch grammatisch und im moralischen Sinne verstanden wurde, vertraten neben Opitz noch andere Gelehrte, so G.P. Harsdörffer und Justus Georg Schottelius:

aus unbetrachteter Frömdgierigkeit diese unsere angeborne / vollkommene / reine / wortreichste Muttersprache / so gar deutlos / wortarm / und zur bettlerischen Sclavinn machen / und guten Teihls ausreuten wollen / als die ihre eigene, so eigentliche und prächtige Wörter nicht dürfe / noch vermöge gebrauchen: Dadurch also unsere Teutsche Wörter (durch eingeschobene ausländische Brokken) $\mathrm{zu}$ unwörteren / die teutsche Sprache sprachlos / der Teutsche Geist entfrömdet / die rechte Art verunartet / verstaltet / und in eine gantz andere Form gegossen wird (Schottelius 1663 in Hecht 1967: 167).

Bereits im Zeitalter des Barock gab es die ersten Sprachgesellschaften wie die „Fruchtbringende Gesellschaft“ in Weimar (gegründet 1617 in Weimar), deren Hauptaugenmerk auf der Pflege eines „deutschgesinnten Tugendmuts“ lag, und die einen wesentlichen Beitrag zur Sprachpflege jener Zeit leistete (vgl. u.a. Olt 1991: 17f.).

Später folgten Schriftsteller wie Joachim Heinrich Campe, der unermüdlich Verdeutschungsvorschläge machte. Er veröffentlichte im Jahr 1801 das „Wörterbuch zur Erklärung und Verdeutschung der unserer Sprache aufgedrungenen deutschen Ausdrücke“ (wiederaufgelegt 1813, vgl. Campe 1813) und gilt als einer der eifrigsten und prominentesten Puristen (vgl. Munske 2001: 22). ${ }^{2}$ Ein weiterer Sprachpurist war Friedrich Ludwig Jahn, ebenfalls Urheber vieler Verdeutschungen (vgl. u.a. Jahn/Eiselen 1916). ${ }^{3}$

Die Geschichte zeigt, dass sich die deutsche Sprache stetig weiterentwickelt hat und weiterentwickelt. Das Lateinische, Französische, Italienische oder das Jiddische haben die Sprache unterschiedlich stark beeinflusst. Seit dem 19. Jahrhundert gelangen immer mehr Übernahmen

\footnotetext{
${ }^{2} \mathrm{Zu}$ einer ausführlichen Darstellung, auch bezüglich der Intention und den Zielen Campes, die in erster Linie erzieherisch waren vgl. Sauter (2000: 173).

${ }^{3}$ Kramer spricht generell von „verschiedenen Wellen des Purismus“: Diese richteten sich einerseits gegen Latinismen und Gräzismen, andererseits gegen Gallizismen und damit gegen die Alamode-Sprache: „Beide Gruppen sind nicht leicht zu unterscheiden, aber in der Intention gibt es doch einen wichtigen Unterschied: Der Kampf gegen die Latinismen hat meist einen pädagogischen Beigeschmack [...], wohingegen die Ausmerzung des Französischen stets unter nationalen Gesichtspunkten gesehen wurde [...] (Kramer 1992: 114).
} 
aus dem Englischen ins Deutsche, die englische Sprache übt derzeit den stärksten Einfluss auf die deutsche Sprache aus.

Die englische Sprache wird insgesamt zunehmend bedeutender (vgl. u.a. Stickel 2007: 140). ${ }^{4}$ Im beginnenden 21. Jahrhundert ist sie schließlich zur weltweit dominanten Sprache geworden. Egal, ob in Bombay oder Shanghai, in Göteborg oder Madrid: Englisch ist die Sprache der internationalen Beziehungen und Kontakte. Viele Sprachwissenschaftler sehen die englische Sprache deshalb als die lingua franca unserer Zeit an (vgl. u.a. Trabant 1995: 19, McArthur 2002: 2, Busse 2007: 1715).

Einige Sprachwissenschaftler meinen sogar, dass keine andere Sprache jemals mehr Einfluss auf das Deutsche ausgeübt hat und heute ausübt als das Englische (vgl. u.a. Carstensen 1984: 43). Der englischsprachige Einfluss und damit einhergehend die Anglizismenkritik ${ }^{6}$ sind in den letzten Jahren wieder stärker in die Öffentlichkeit und den öffentlichen Diskurs gerückt, unter anderem durch die zunehmende Präsenz des Themas in den Medien. So ruft beispielsweise der Autor Wolf Schneider seinen Lesern zu: „Wer zu oft mit Popcorn und Vanilla Fudge gefüttert worden ist, bekommt schließlich Appetit auf Vollkornbrot. Write German! Nothing beats it“ (Schneider 2008: 14). ${ }^{7}$ Selbst die Musik hat das Thema bereits erreicht, wie die Gruppe „wise guys“ in ihrem Song „Denglisch“ zeigt:

Oh Lord please gib mir meine Language back, ich krieg hier bald die crisis, man, it has doch keinen Zweck Let us noch a word verstehen, it goes me on the Geist Und gib, dass „Microsoft" bald wieder „kleinweich“ heißt (wise guys 2006).

\footnotetext{
${ }^{4}$ Stickel führt aus, dass zwischen verschiedensprachigen Menschen meist Englisch, und zwar oft eine „reduzierte, amerikanisch geprägte Form des Englischen“ verwendet wird (Stickel 2007: 140).

${ }^{5}$ In seinem Aufsatz: „Englisch als Lingua Franca: Fluch oder Segen für Englisch und andere Sprachen?" geht Busse detailliert auf die Diskussion um die englische Sprache als Weltverkehrssprache und die damit zusammenhängenden Entwicklungen ein (Busse 2007).

${ }^{6}$ Auf die Begriffe Anglizismus und Amerikanismus wird in Kapitel 1.5.2 ausführlich eingegangen.

${ }^{7}$ Hervorhebungen im Original.
} 
Auch in der Politik, angeregt durch die Sprachgesetzgebung in Frankreich (die „Loi Toubon" ${ }^{\text {) }}$ ) und in Polen, wurde der englische Einfluss in jüngster Zeit thematisiert. Es ist des Weiteren ein stärkeres Engagement der Bevölkerung zu beobachten: Gegen den Einfluss des Englischen wehren sich Sprachvereine und -initiativen: Dies äußert sich zudem in einer seit Anfang der 1990er Jahre steigenden Zahl an privaten Organisationen, die sich mit der Verteidigung der Muttersprache beschäftigen. Dabei zeigt sich schon bei oberflächlicher Betrachtung, dass es sich nicht im eigentlichen Sinne um eine „Fremdwort“-Diskussion handelt, sondern um eine Diskussion über Anglizismen im Deutschen. In den ersten Jahren nach dem Zweiten Weltkrieg war die Fremdwortdiskussion in Deutschland noch maßgeblich von der Haltung des Allgemeinen Deutschen Sprachverein (ADSV), später Deutschen Sprachverein (DSV), vor und während des Krieges geprägt. Weisgerber beispielsweise kritisierte noch 1960, dass Fremdwörter die heimischen Wörter ihrer „Lebenskraft“ beraubt hätten (vgl. Weisgerber 1960: 1ff.). ${ }^{9}$ Auch die Vorschläge von Ludwig Reiners in seiner "Stilkunst“ (Reiners 1944: 442ff.), erstmals erschienen im Jahr 1943, der unter anderem forderte, das Fremdwort zu vermeiden, wurden von einer breiten Öffentlichkeit unkritisch aufgenommen (vgl. Förster 2000a: 150f.).

In den 1960er Jahren deutete sich ein Umdenken in der Fremdwortfrage an, und der Deutsche Germanistentag im Jahr 1966 brachte dann vollends die Wende, weg von einer Kritik des Fremdworts hin zu einer liberalen Haltung (vgl. u.a. Jung 1995: 252). Peter von Polenz bezeichnete den Purismus während des Nationalsozialismus als „hemmungslose [...] Ekstase vulgärwissenschaftlicher Sprachkritik“ (von Polenz 1967a: 79). Die Sprachwissenschaft hielt sich in den Jahren nach dem Germanistentag stark zurück, auch, da die Fremdwortkritik durch die Bemühungen des ADSV/DSV zur Zeit des Nationalsozialismus emotional belastet war, der Purismus war gewissermaßen stigmatisiert. Weitestgehend haben Linguisten und Gelehrte die Fremdwörter und damit zu dieser Zeit schon hauptsächlich die Anglizismen im Deutschen verteidigt, so Theodor W. Adorno in seinem Aufsatz „Wörter aus

\footnotetext{
${ }^{8}$ Für eine ausführliche Darstellung des Gesetzes und seiner Entwicklung vgl. Trabant (2002: 76ff.).

${ }^{9}$ Vgl. dazu ausführlicher auch Jung (1995: 250).
} 
der Fremde“ (Adorno 1979: 198ff.). Die Trennung zwischen der deskriptiven Sprachwissenschaft einerseits und einer wertenden Beratung von Laien wurde zunehmend deutlicher (vgl. Jung 1995: 254). ${ }^{10}$

Die derzeitige Entwicklung mit der Neugründung von Sprachvereinen ist als neue Phase des sprachlichen Purismus ${ }^{11}$ in Deutschland zu sehen, ein halbes Jahrhundert nachdem es so aussah, als ob es dieses Phänomen hier nicht mehr geben (vgl. u.a. Pfalzgraf 2006), oder es zumindest nicht derart im Fokus der Öffentlichkeit stehen würde, dass es als Thema auch wahrgenommen wird. Einige Sprachwissenschaftler sprechen von der „Möglichkeit einer neokonservativen Rückkehr zur puristisch-normativen Tradition“ (Kirkness 1983: 14). Die neueste Forschung spricht von „Neopurismus“12 (vgl. u.a. Pfalzgraf 2006, hier ist der Begriff schon im Titel der Publikation aufgegriffen, vgl. auch MLS 2005: 436). Die größte Vereinigung, die sich gegen Anglizismen im Deutschen wehrt, ist der 1997 gegründete Dortmunder Verein Deutsche Sprache (VDS). Er steht daher im Mittelpunkt dieser Untersuchung.

\subsection{Ziel und Vorgehensweise}

Die Arbeit soll einen detaillierten Überblick über die Gründung und die ersten Jahre des Vereins Deutsche Sprache mit Sitz in Dortmund liefern und eine erste Bilanz zur Arbeit des VDS vorlegen. Dabei möchte die Untersuchung auch einen Erklärungsversuch liefern, wie es zur Gründung dieses Vereins, dessen Ziel der Kampf gegen den Anglizismus ist,

\footnotetext{
${ }^{10}$ Interessant ist jedoch, dass die Stillehren, in denen die Fremdwortfrage eine große Rolle spielt, nach wie vor großen Zuspruch erfahren: Ludwig Reiners „Stilkunst“ erscheint 1943 (Reiners 1943), es wird 17-mal aufgelegt zwischen 1944 und 1991, 1951 kam eine gekürzte Version dazu: „Der sichere Weg zum guten Deutsch“ (Reiners 1951), später die Stilfibel (Reiners 1959), die bereits 1970 ihr 320. Tausend erreichte (vgl. dazu auch Trabold 1993: 74).

${ }^{11}$ Der Terminus „Purismus“ wird im Folgenden als analytischer Terminus verwendet, nicht als Schimpfwort (vgl. Kapitel 1.5.4).

12 Pfalzgraf verwendet den Begriff „Neopurismus“ aufgrund der Annahme, dass das Phänomen des Purismus lange Zeit kaum mehr vorhanden war, seit der deutschen Wiedervereinigung in Deutschland aber eine Renaissance erlebe. Ich bleibe beim Terminus „Purismus“, denn der heutige Purismus unterscheidet sich nicht wesentlich vom Purismus beispielsweise des ADSV/DSV. Zu beachten ist hier auch, dass das Präfix „neo-“ in aller Regel abwertend gemeint ist.
} 
kam und warum er sich mittlerweile so großer Beliebtheit erfreut. Zudem soll der öffentliche Diskurs über die Fremdwörter und die Anglizismen dargestellt werden. ${ }^{13}$ Das bedeutet, die Entstehung und die Arbeit des VDS wird nicht isoliert betrachtet, sondern ist vor dem Hintergrund der Diskussion über das Fremdwort und die Anglizismen in Deutschland in der Zeit nach 1989, vor dem Hintergrund puristischer Traditionen in Deutschland und vor dem Hintergrund der Arbeit bestehender Sprachvereinigungen zu sehen.

Der bibliographische Forschungsbericht, der thematisch und innerhalb der Unterkapitel chronologisch angeordnet ist, gibt in Kapitel 1.4.1 einen Überblick über die bisherige Lehngutforschung. Diese Werke behandeln die verschiedenen Möglichkeiten zur Gliederung lexikalischen Lehnguts. Die Gliederungen sollen im Detail vorgestellt werden, denn sie veranschaulichen eine der Schwierigkeiten der Diskussion: Die Herangehensweise der Sprachwissenschaftler unterscheidet sich von der linguistischer Laien, die sich oftmals in sprachpflegerischen Vereinigungen und auch im Verein Deutsche Sprache engagieren. ${ }^{14}$

Des Weiteren werden in Kapitel 1.4.2 Arbeiten über das Vorkommen von Anglizismen in der deutschen Sprache vorgestellt. Hierbei handelt es sich häufig um empirische Untersuchungen der Sprache von Printmedien. In Kapitel 1.4.3 werden Untersuchungen über sprachpflegerische Vereinigungen sowie über die Fremdwortdiskussion präsentiert. Hier zeigt sich, dass beide Themen in den vergangenen Jahren stärker in den Blickpunkt der Forschung gerückt sind. Die Forschungsarbeiten insgesamt zeigen, wann und in welchen Gebieten der Fremdwortforschung Untersuchungen durchgeführt wurden. ${ }^{15}$

Ebenfalls unverzichtbar ist aufzuzeigen, welche Schwierigkeiten der Begriff „Fremdwort“ birgt (Kapitel 1.5.1). Daher werden Ansätze der Fremdwortdefinition vorgestellt. Dieser erst Anfang des 19. Jahrhunderts geprägte Terminus „Fremdwort“ (vorher war vom „ausländischen“

\footnotetext{
${ }^{13}$ Vgl. zu dieser Thematik auch Spitzmüller (2002: 262).

${ }^{14}$ Dies ist keine Besonderheit der Sprachthemen, sondern auch in anderen Wissenschaftler-Laien-Beziehungen zu beobachten. Die sich daraus ergebenden Diskussionsansätze werden aber immer wieder Thema in dieser Arbeit sein.

${ }^{15}$ Zahlreiche Untersuchungen zu einem Thema deuten darauf hin, dass dieses in der Wissenschaft einen hohen Stellenwert genießt.
} 
oder „fremden Wort“ die Rede) liegt der Fremdwortdiskussion zugrunde. In Kapitel 1.5.2 werden die diskussionsprägenden Begriffe „Anglizismus“, „Britizismus“ und „Amerikanismus“, erläutert. Kapitel 1.5.3 setzt sich mit den Begriffen „Denglisch“ und „Engleutsch“ auseinander, die in den Publikationen sprachpflegerischer Vereinigungen regelmäßig auftauchen. Auch eine Begriffsbeschreibung des Terminus „Purismus“ wird geliefert.

In Kapitel 1.6 wird die öffentliche Diskussion über das Fremdwort und die Anglizismen in der Bundesrepublik Deutschland nach der Wiedervereinigung dargestellt, davon ausgehend, dass die Anglizismendebatte mittlerweile neben der Diskussion um die Rechtschreibreform $^{16} \mathrm{zu}$ einer der intensivsten laien- oder volkslinguistischen Debatte geworden ist, die in Nachkriegsdeutschland geführt wird. Hinzu kommt, dass die Wiedervereinigung, möglicherweise aufgrund einer Neuorientierung bezüglich Nation und Nationalität, für die Belebung der Diskussion wohl mitursächlich ist. Ebenso wird diskutiert, inwieweit sprachpuristische Bemühungen mit Nationalismus zusammenhängen, sie werden beispielsweise häufig als "deutschtümelnd“ oder als „Deutschtümelei“17 bezeichnet. An der Diskussion beteiligen sich verschiedene Gruppen, Puristen (sprachwissenschaftliche Laien), Linguisten und Journalisten, (vgl. Blommaert 1999a: 9, Spitzmüller 2007: $262)^{18}$, und, ab einem gewissen Zeitpunkt, auch die Politik. Anhand verschiedener Quellen werden Argumente und Einstellungen dieser Gruppen vorgestellt.

Es wird das spannungsgeladene Verhältnis von Sprachwissenschaft und Sprachkritik aufgezeigt, das in der Fremdwortdiskussion eine große Rolle spielt. Das „Sich-Raushalten“ der Wissenschaft aus diesem Bereich - das auch der VDS beispielsweise immer wieder anführt - soll

\footnotetext{
${ }^{16}$ Beispielsweise mit der Rechtschreibreform wird der Gebrauch von Sprache verordnet.

${ }^{17}$ Unter „Deutschtümelei“ wird in dieser Arbeit mit dem Duden Universalwörterbuch „die übertriebene Betonung deutscher Wesensart“ verstanden (Drosdowski et al. 1996: 337). Zu diesem Themenkomplex zählt auch die Hinwendung rechtsextremer Gruppierungen und Personen zu sprachpuristischen Aktivitäten.

${ }_{18}$ Blommaert spricht bei diesen drei Gruppen von „ideology brokers“ (Blommaert 1999: 9), also von den Gruppen, die ihre Ideologien verbreiten.
} 
erst zur Gründung von Sprachvereinen geführt haben. ${ }^{19}$ Neben der Diskussion der Wissenschaftler wird auf die Diskussion in den Medien eingegangen. Vornehmlich sollen die deutschen Leitmedien ${ }^{20}$ aus dem Printbereich wie der Spiegel oder die Süddeutsche Zeitung im Blickfeld stehen, es werden aber auch Artikel aus regionalen Medien sowie Beiträge aus dem Internet und aus Radio und Fernsehen zur Analyse hinzugezogen (für die Erläuterung der Quellen vgl. das folgende Kapitel). ${ }^{21}$ In der Zeit nach der Wiedervereinigung wird ebenfalls auf Sprachkritiker wie Bastian Sick Bezug genommen, denn die Diskussion in den Medien spiegelt einen Teil des öffentlichen Diskurses. ${ }^{22}$ Auch wird die Diskussion in der Politik behandelt, dort wurden in den letzten Jahren Forderungen nach einem Sprachgesetz vergleichbar mit der französischen Loi Toubon erhoben.

Des Weiteren wird erörtert, ob es sich bei dieser Diskussion, die - neben der Debatte um die Rechtschreibreform - eine der wichtigsten metalinguistischen Debatten in der Öffentlichkeit darstellt, um eine Fremdwortdiskussion handelt, oder ob nicht von einer Anglizismendiskussion gesprochen werden sollte, wie dies in jüngsten Forschungsarbeiten bereits aufgeführt wird (vgl. u.a. Spitzmüller 2007: 261).

Ein geschichtlicher Abriss über den sprachpuristischen Allgemeinen Deutschen Sprachverein/Deutschen Sprachverein in Kapitel 1.7 soll die

${ }^{19}$ Die Verunsicherung hinsichtlich der Legitimation von Sprachpflege zeigt sich auch deutlich im Vergleich der Vorwörter des Grammatik-Dudens im Laufe der Jahre (vgl. dazu Kolde 1986: 173f.).

${ }^{20}$ Darunter werden zum einen die überregionalen Qualitätszeitungen verstanden, die sich durch Umfang und Qualität der Berichterstattung auszeichnen, aber auch durch ihre Verbreitung, Beispiele sind die Süddeutsche Zeitung (Meyn spricht hier von „journalistischer Brillianz“ (Meyn 2004: 94), die Frankfurter Allgemeine Zeitung, Die Welt, aber auch Wochenzeitungen und Magazine wie Die Zeit und Der Spiegel, die durch „überdurchschnittliches Niveau und die überregionale Verbreitung einen gewichtigen Beitrag zur Diskussion politischer, wirtschaftlicher und kultureller Probleme in der Bundesrepublik“ liefern und so zu Leitmedien werden (vgl. Meyn 2004: 101f., zu Massenmedien in Deutschland ausführlich Meyn 2004).

${ }^{21}$ Dieser Teil der Untersuchung ist weitgehend auf die Arbeiten von Jung (1995) und Spitzmüller $(2005,2007)$ gestützt. Hier wird keine Vollerhebung geleistet, dieser Abschnitt der Arbeit soll die Situation in Deutschland lediglich skizzieren.

${ }^{22}$ Spitzmüller sieht die Diskussion sogar als die wichtigste metalinguistische Debatte in der Öffentlichkeit an. Doch auch die Debatte um die Rechtschreibreform sorgte für viel Aufsehen und Echo in den Medien (vgl. u.a. Glück/Sauer 1997: 174ff.). 
sprachpflegerische Tradition aufzeigen, in der sich der Verein Deutsche Sprache bewegt. Der ADSV/DSV hatte bis in die 1940er Jahre großen Einfluss. Es wird auch betrachtet, inwieweit der VDS in dieser Tradition verankert ist. Es ist anzunehmen, dass der VDS als puristische Sprachvereinigung ${ }^{23}$ einzuordnen ist.

Neben dem VDS existieren verschiedene Vereinigungen in Deutschland, die sich mit Sprache und Sprachpflege auseinandersetzen, darunter die Gesellschaft für deutsche Sprache, das Institut für Deutsche Sprache, die Deutsche Akademie für Sprache und Dichtung ${ }^{24}$ und Vereine, vom Verein für Rechtschreibung und Sprachpflege bis zum Bund für deutsche Schrift und Sprache. Diese werden anhand ihrer Strukturen, ihrer Arbeit, ihrer Publikationen und ihrer Ziele ebenfalls in Kapitel 1.7 vorgestellt.

Im Vordergrund der Untersuchung (Kapitel 2) steht der VDS, der mittlerweile größte sprachpflegerische Verein in Deutschland. 1997 wurde der Verein gegründet, er blickt also auf eine über zehnjährige Vereinsgeschichte zurück. Die Untersuchung soll eine erste Darstellung des Vereins und seiner Aktivitäten sein. Es ist eine Arbeit, die anhand von Quellen des VDS und über den VDS seine Entstehung und die ersten Jahre der Vereinsarbeit nachzeichnet, auch wenn die Quellenlage teilweise nicht einfach ist. Für die Untersuchung wurde eine Vollerhebung aller Dokumente des Bundesvorstands des Vereins in Dortmund durchgeführt. Der Sprachverein, von dem Statistiker Professor Walter Krämer gegründet, verzeichnet stetig wachsende Mitgliederzahlen und erfährt mittlerweile vermehrt Zuspruch von jungen Leuten. Derzeit hat der VDS etwa 31000 Mitglieder im In- und Ausland.

Die Entstehung des Vereins von der Idee bis heute wird in dieser Arbeit in Kapitel 2.1) ausführlich dokumentiert, von der Gründungsphase über die Anfänge mit den ersten Regionalgruppen bis hin zu der größten Vereinigung dieser Art, die der VDS heute darstellt. Denn relativ zeitgleich mit dem VDS wurden in Deutschland mehrere andere Sprachvereine gegründet. Diese sind teilweise im VDS aufgegangen, kein Verein

${ }^{23} \mathrm{Zu}$ „Purismus“ vgl. Kapitel 1.5.4.

${ }^{24}$ Weder beim Institut für Deutsche Sprache noch bei der Deutschen Akademie für Sprache und Dichtung steht die Sprachpflege im Vordergrund (vgl. Kapitel 1.7.3 und 1.7.4). 
hat jedoch so viele Mitglieder wie der VDS. Kapitel 2.1.1 stellt den Gründer des Vereins, Prof. Dr. Walter Krämer, vor. Es wird die Frage gestellt, was ihn bewogen hat, den Verein zu gründen und zwar zu diesem speziellen Zeitpunkt. Kapitel 2.1.2 setzt sich mit dem Prozess von der Idee bis zur Entstehung auseinander, in Kapitel 2.1.3 wird die Etablierung der Vereinsstruktur näher betrachtet. Kapitel 2.1.4 behandelt die Namensgebung des Vereins, der einige Zeit „Verein zur Wahrung der deutschen Sprache“ hieß. Kapitel 2.2 stellt die Organisation des Vereins vor, vom Vorstand über den wissenschaftlichen Beirat bis hin zu den Mitgliedern und der Finanzierung. In Kapitel 2.3 werden das Selbstverständnis und die Ziele des Vereins aufgezeigt. Das Fremdwort und der Anglizismus in der Arbeit und Sprachgebrauch des Vereins ist Thema von Kapitel 2.4. Als Quellen dienen zumeist Publikationen und Dokumente des VDS, diese werden in Kapitel 1.3 erläutert. Des Weiteren sollen die Ziele und die Struktur des Vereins vorgestellt werden, mit den Regionalgruppen, die über Deutschland und das Ausland verteilt sind, ebenso die Projekte des Vereins.

In Kapitel 2.5 werden Aktionen betrachtet, wie die Preisverleihung zum Sprachpanscher des Jahres sowie die Verleihung des Kulturpreises Deutsche Sprache. Auch die Veranstaltungen zum Tag der deutschen Sprache werden dargestellt. Auf Kampagnen einzelner Regionalgruppen soll exemplarisch eingegangen werden. Ebenso untersucht werden die Publikationen des Vereins, allen voran die Zeitschrift Sprachnachrichten. Hier liegt das Augenmerk darauf, ob sich Inhalt, Erscheinungsbild und Diskurs im Laufe der Jahre verändert haben. Diskurs, Metaphorik sowie die Argumentation des Vereins werden anhand von Beispielen aus Publikationen des VDS dargestellt. Auch die Bücher des VDS selbst beziehungsweise die von VDS-Funktionären zu Anglizismen im Deutschen vorgelegten Bücher sowie der VDS-Anglizismen-Index werden näher betrachtet.

Bezug genommen wird auf das zentrale Aufgabengebiet des Vereins, nämlich den Umgang mit Fremdwörtern beziehungsweise Anglizismen. Auch auf die Wahrnehmung des Vereins in der Öffentlichkeit wird eingegangen. Außerdem wird untersucht, ob die Vereinsarbeit heute mit der in den Anfangsjahren des Vereins zu vergleichen ist. Dabei liegt das Augenmerk auf der Stiftung Deutsche Sprache, einer aus 
und mit dem VDS gegründeten Stiftung, und deren Arbeit. Auch auf die Problematik, dass der Verein Zuspruch von Personen aus rechten Kreisen erhält, wird Bezug genommen (Kapitel 2.6). Hier rücken Ausschlussverfahren gegen Einzelpersonen sowie das Netzwerk Deutsche Sprache in den Blickpunkt des Interesses.

Das teils schwierige Verhältnis des VDS zu anderen Sprachvereinigungen und zur Sprachwissenschaft wird, größtenteils anhand der Korrespondenz zwischen den Vereinigungen, aber auch anhand von Veröffentlichungen über die Vereinigungen beleuchtet (vgl. Kapitel 2.7 bis 2.12). Aus all diesen Faktoren ergibt sich ein Gesamtbild des Vereins - vom Gründungsjahr 1997 an bis heute.

\subsection{Quellen}

Ausgangs- und Endpunkt der vorliegenden Arbeit ist der VDS. Zugrunde liegt jedoch die Überzeugung, dass der derzeit größte deutsche Sprachverein nicht isoliert betrachtet werden sollte, sondern vor dem Hintergrund der Anglizismendebatte und der Situation der sprachpflegenden Vereine in Deutschland nach 1989, also dem Jahr der Wiedervereinigung. Bei der vorliegenden Untersuchung handelt es sich um eine deskriptive Arbeit, die die Situation häufig nur exemplarisch darstellen kann. Grundsätzlich wurden als Forschungsmethode Literaturund Quellenstudien angewendet. Für die Darstellung der Fremdwortdiskussion umfasst die ausgewertete Literatur wissenschaftliche Arbeiten in Monographien und Aufsätzen über die Gliederung von Lehngut, über Purismus, Sprachpflege und Sprachkritik und über sprachpflegende Vereinigungen, ebenso weitere Quellen wie Aufzeichnungen von Podiumsdiskussionen zu Sprachthemen oder Interviews in Medien. Grundlegend für die Darstellung der Fremdwort- und Anglizismendiskussion in den Medien waren die Untersuchungen von Jung (1995) und Spitzmüller (2005). Daneben steht ein offenes Korpus aus aktuellen Belegen, die verschiedenen Tages- und Wochenzeitungen entnommen wurden, dabei liegt der Schwerpunkt auf den Leitmedien. Recherchegrundlage war der Pressespiegel des VDS. Als politische Quellen dienten Eingaben in den Bundestag und Reden von Politikern ebenso wie 
Medienberichte über Aussagen von Politikern $\mathrm{zu}$ Fremdwörtern und/oder Anglizismen.

Die Darstellung sprachpflegender Vereinigungen in Deutschland, Österreich und der Schweiz soll den VDS in die aktuelle Situation einbetten. Dafür wurde auf die Literatur Bezug genommen (vgl. Kapitel 1.4.3). Ebenso dienten die verschiedenen Publikationen der Vereine, gedruckt und im Internet, als Quellen. Außerdem wurden, wenn nötig, telefonisch und per E-Mail aktuelle Informationen, beispielsweise über die Zahl der jeweiligen Mitglieder, eingeholt.

Beim VDS wurden in einer Vollerhebung alle Materialien des Bundesvorstands verwendet. Dies waren zum einen die Sprachnachrichten, die Zeitung des Vereins. ${ }^{25}$ Hier war es möglich, alle Ausgaben in die Untersuchung mit einzubeziehen. Damit sind die VWDS-Nachrichten, wie die ersten Ausgaben noch hießen, bzw. die Sprachnachrichten eine der wichtigsten Quellen für Informationen über Aktionen und Argumente des VDS über die Jahre 1999 (dem Jahr, in dem die erste Ausgabe gedruckt wurde) bis heute. Zum anderen dienen die Sitzungsprotokolle von VDS-Vorstandssitzungen (auch hier wurden alle Protokolle seit Gründung des Vereins bis zum Jahr 2007 einbezogen), ${ }^{26}$ Hauptversammlungen und Delegiertenversammlungen, und die Korrespondenz des Vereins, sowohl die interne als auch die externe, ${ }^{27}$ als Quellen. Auch Flyer, Aufkleber (hier wiederum in einer Vollerhebung) und Werbematerialien des VDS haben in diese Untersuchung Eingang gefunden. Die Darstellung der Thematik in der Presse wird ebenfalls hinzugezogen, geht es doch darum aufzuzeigen, dass das Thema Anglizismen immer wieder in öffentlichen Diskussionen auftaucht, und herauszuarbeiten, welche Einstellungen den Veröffentlichungen zugrunde liegen. Der Fokus liegt auch hier auf den Leitmedien der Bundesrepublik Deutschland; in die Untersuchung sind aber auch Belege aus regionalen Medien

\footnotetext{
${ }^{25}$ Diese sind vollständig in den Räumen der Vereinszentrale im Martin-Schmeißer-Weg 11, 44227 Dortmund vorhanden. 2008 ist die Vereinszentrale im gleichen Gebäude in ein größeres Büro im Erdgeschoss umgezogen.

${ }^{26}$ Die Protokolle ab dem Jahr 2008 gibt die Geschäftsstelle des Vereins nicht mehr heraus.

${ }^{27}$ Hierbei handelt es sich um aufbewahrte Briefe ebenso wie um E-Mails, die in ausgedruckter Form aufbewahrt werden. Wurden Briefe in dieser Arbeit zitiert, so wurden sie in der Regel anonymisiert.
} 
mit eingegangen. Grundlage war wiederum der Pressespiegel des VDS, der, wie Stichproben zeigten, durchaus auch für den Verein wenig schmeichelhafte Berichte enthält. Inwiefern dieser Pressespiegel als vollständig zu bewerten ist, kann nicht abschließend geklärt werden, zumindest ist er sehr ausführlich und in der Auswahl der dokumentierten Medien breit gefächert. Die für diese Analysen wichtigsten Schriftstücke finden sich in einem Dokumentenanhang. ${ }^{28}$ Problematisch an der Quellenlage ist: Insgesamt kann man nicht von archivierten Quellen ausgehen. Die Schriftstücke befinden sich in verschiedenen Ordnern, sind zum Teil nach Themengebieten sortiert, teilweise aber auch unsortiert. Einige Schriftstücke existieren doppelt, andere, gerade aus den Anfangsjahren, fehlen laut Aussagen der Mitarbeiter der Geschäftsstelle oder sind nicht mehr auffindbar. ${ }^{29}$ Die Schriftstücke sind weder nummeriert noch dokumentiert, können also nicht als archiviert bezeichnet werden. Daher hat die Verfasserin dieser Arbeit alle 610 Ordner an den verschiedenen Standorten (einschließlich der Kellerräume) durchgesehen und die für diese Arbeit relevanten Schriftstücke kopiert. Der Recherchezeitraum erstreckte sich über die Jahre 2004 bis $2008 .{ }^{30}$ Methodisch stellt sich hier das Problem, dass nur mit einem offenen Korpus, also einer offenen Materialsammlung gearbeitet werden kann. Aufgrund der schwierigen Quellenlage ist trotz sorgfältiger Recherchen nicht auszuschließen, dass eventuell relevante Aspekte und Dokumente übersehen wurden. Weitere Quellen sind aufgezeichnete Interviews mit Professor Dr. Walter Krämer und Thilo Machotta, dem ersten Moderator des VDS-Forums, sowie Antworten auf Anfragen der Verfasserin, unter anderem an Professor Dr. Ulrich Knoop, ehemaliger Vorsitzender des wissenschaftlichen Beirats des VDS, und Dr. Holger Klatte, Geschäfts-

\footnotetext{
${ }^{28}$ Diese Unterlagen und Dokumente befinden sich überwiegend ebenfalls in den Räumen der Vereinszentrale, mit Ausnahme der Korrespondenz des Vorsitzenden Krämer, die sich teilweise in dessen Büro an der Universität Dortmund befindet. Teilweise befanden sich diese Dokumente aber auch in den Kellerräumen des Instituts für Statistik an der Universität Dortmund, beides CDI-Gebäude, Vogelpothsweg 78, 44227 Dortmund. Doch diese Dokumente sind im Jahr 2008 nach einem Wasserschaden entsorgt worden. Für diese Untersuchung wurden jedoch viele dieser Dokumente kopiert, so dass nun zwar keine Originale, wohl aber noch die Kopien existieren.

${ }^{29}$ Gespräch mit Christiane Dahl, VDS-Geschäftsstelle, 25. März 2005.

${ }^{30}$ Ein Großteil der Materialsammlung entstammt zwei Rechercheaufenthalten im Archiv des VDS in den Jahren 2004 und 2008.
} 
führer des Vereins. Bei der vorliegenden Arbeit handelt es sich um die erste zusammenfassende Untersuchung des VDS, seiner Ziele, Strukturen und Vereinsarbeit, also um eine erste Bestandsaufnahme dieses sich ständig weiterentwickelnden Vereins.

\subsection{Stand der Forschung}

Ein Überblick über die Forschung soll der Untersuchung über den Verein Deutsche Sprache vorangestellt werden. Darin wird der Stand der für diese Untersuchung relevanten Forschung skizziert, wobei jeweils nur kurz auf die verschiedenen Forschungsgebiete, die Gliederung von Lehngut, die Untersuchungen über Anglizismen in der deutschen Sprache sowie die Untersuchungen zur Fremdwortdiskussion, zum Purismus oder Untersuchungen über sprachpflegende Vereinigungen eingegangen wird. Innerhalb der einzelnen Unterkapitel sind die Arbeiten chronologisch angeordnet. Eine Ausnahme bildet das Kapitel zu den Untersuchungen von Anglizismen in der deutschen Sprache. Analysen zur Sprache der DDR werden nach den Untersuchungen in der Sprache der BRD dargestellt, dann aber wieder chronologisch geordnet.

\subsubsection{Untersuchungen zur Gliederung von Lehngut}

Eine wichtige Untersuchung über die Gliederung von Lehngut ist die Arbeit von Werner Betz, ursprünglich aus dem Jahr 1936. Hier wird auf die Fassung aus dem Jahr 1974 Bezug genommen (vgl. Betz 1974: 135ff.). ${ }^{31}$ Betz gliedert das lexikalische Lehngut unmittelbar in Lehnwort und Lehnprägung. Beim Lehnwort unterscheidet er zwischen Fremdwort und assimiliertem Lehnwort. Unter einem Fremdwort versteht er ein Wort, das „in seiner fremden Lautgestalt bewahrt“ (Betz 1974: 136) wird, während das assimilierte Lehnwort „lautlich seiner neuen Umgebung angepaßt“ (Betz 1974: 136) wird. Auch die Lehnprägung unterteilt Betz noch einmal; zunächst in Lehnbildung und Lehnbedeutung, wobei

${ }^{31}$ Betz hat seine Lehngutgliederung schon im Jahre 1936 erstellt (vgl. Betz 1936) und immer wieder überarbeitet (z.B. Betz 1949: 25ff.). 
er ein Wort dann in die Kategorie der Lehnbedeutung rechnet, wenn nur die Bedeutung eines modellsprachlichen Wortes „für ein Wort der eigenen Sprache entlehnt“ (Betz 1974: 136) wird. Unter einer Lehnbildung versteht Betz das Nach- oder Neubilden eines Wortes mit dem Material der Replikasprache. Dies kann entweder mit modellsprachlichem Vorbild geschehen, dann spricht er von einer Lehnformung, oder ohne Vorbild als „formal unabhängige Neubildung“ (Betz 1974: 136), die Betz eine Lehnschöpfung nennt. Die Lehnformung lässt sich noch ein weiteres Mal gliedern. Ist die Lehnformung eine „Glied-für-GliedÜbersetzung“ (Betz 1974: 136), gehört sie zur Kategorie der Lehnübersetzung; ist sie eine freiere Teilübertragung, gehört sie zur Kategorie der Lehnübertragung (vgl. Betz 1974: 136f.).

Betz beschäftigt sich detailliert mit dem Bereich der Lehnprägungen, also dem inneren Lehngut. Den Bereich der Lehnwörter dagegen unterteilt er nur grob. Das Hauptkriterium seiner Unterteilung ist immer die Integriertheit. Diese Differenzierung ist sinnvoll.

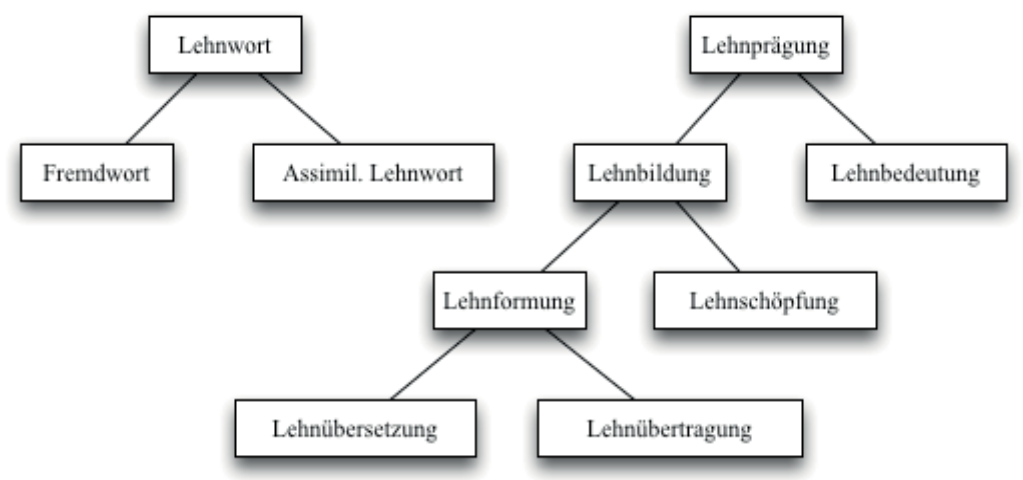

Abbildung 1: Lehngutgliederung nach Betz (1974: 137)

Die Lehngutgliederung von Betz, die in der Anglizismenforschung am häufigsten verwendet wird, ist im Laufe der Jahre immer wieder kritisiert, überarbeitet und erweitert worden. So haben zum Beispiel Cars- 
tensen (1968), ${ }^{32}$ Lüllwitz (1972), Bäcker (1975), Tesch (1978) und Yang $(1990)^{33}$ die Betzsche Lehngutgliederung beschrieben und ergänzt. In den 1990er Jahren hat die Gliederung massive Kritik erfahren, hauptsächlich von Carstensen, der 1993 im Anglizismen-Wörterbuch einen anderen Gliederungsvorschlag macht ${ }^{34}$, auf den ich in diesem Kapitel noch ausführlich eingehen werde.

Eine weitere wichtige Arbeit in Zusammenhang mit der Gliederung des Lehnguts stammt von Einar Haugen (1950). Er kommt zu folgenden drei Gruppen lexikalischen Lehnguts: In die erste Gruppe ordnet er die „morphemic importation/loanwords“ ein: Darunter fallen Entlehnungen, die durch eine vollständige Übernahme des Morphemmaterials gekennzeichnet sind. Die zweite Gruppe ist die Gruppe der „morphemic substitution and importation/loanblends": Darunter werden partielle Übernahmen des modellsprachlichen Vorbilds sowie auch partielle Ersetzungen subsumiert. Bei den „loanblends“ gibt es drei Möglichkeiten: Die des „blended stem“, des „blended derivative“ und die des „blended compound“. In die dritte Gruppe werden „morphemic substitution/loanshifts“ eingeordnet. Diese sind gekennzeichnet durch vollständige Nachahmung eines modellsprachlichen Vorbilds in der Replikasprache (vgl. Haugen 1950: 214f., für die deutsche Übersetzung siehe Allenbacher 1999: 37 und Bäcker 1975: 43ff.) $)^{35}$ Auf die Gliederung von

32 Die Gliederung von Carstensen aus dem Jahr 1968 führt den Begriff Fremdwendung ein: Carstensen bezeichnet mit diesem Terminus die direkte Übernahme einer Wendung oder eines Satzes aus einer fremden Sprache (vgl. Carstensen 1968: 37f.), d.h., dass erstmals in einer Lehngutgliederung nicht nur einzelne Wörter berücksichtigt werden, sondern auch Wendungen und Phrasen, die als Ganzes aus dem Englischen übernommen werden.

${ }^{33}$ Yang unterteilt das äußere Lehngut in direkte Entlehnungen, Mischkomposita und Scheinentlehnungen. Die direkten Entlehnungen gliedert er wiederum in Fremdwort, Lehnwort und Fremdes Wort, die Scheinentlehnungen in lexikalische Scheinentlehnungen, Lehnveränderungen und semantische Scheinentlehnungen. Bei den Mischkomposita unterscheidet er zusätzlich zwischen Mischkomposita mit modellsprachlichem Vorbild und Mischkomposita ohne modellsprachliches Vorbild (vgl. Yang 1990: 15). Bei der Gliederung des inneren Lehnguts übernimmt Yang weitestgehend die Einteilung von Betz, auf Affixe wird in der Einteilung nicht eingegangen.

${ }^{34}$ Carstensen kritisiert im Anglizismen-Wörterbuch, dass die Gliederung von Betz kein klares System darstellt und für die Entlehnungen nach 1945 nicht zu gebrauchen sei (AWb 1993: 53).

${ }^{35}$ Weinreichs Gliederung - erstmals erschienen 1953 - stützt sich weitestgehend auf die Gliederung von Haugen, aber er hat nicht drei Kategorien sondern nur zwei. Weinreich 
Haugen stützt sich Fink mit seinem Vorschlag aus dem Jahr 1970. ${ }^{36}$ Bei ihm steht ebenfalls der Grad der Substitution im Vordergrund, er unterteilt in Keine Substitution oder Nullsubstitution, Teilsubstitution und Vollsubstitution. Problematisch ist m.E. an dieser Einteilung die relative Grobheit des Rasters (vgl. Fink 1970: 9ff.).

Einen anderen Ansatz verfolgt Carstensen mit seinem zweiten Vorschlag zur Lehngutgliederung, der an sich selbst den Anspruch stellt, das „Chaos in unserer gegenwärtigen Gliederung“ (Carstensen 1968: 32) $\mathrm{zu}$ ordnen und stattdessen eine einfache und allgemein gültige Gliederung aufzustellen. Im Anglizismen-Wörterbuch findet sich folgende Einteilung:

aus engl. $\mathrm{x}$, wobei $\mathrm{x}$ ein ins Deutsche übernommenes englisches Sprachzeichen ist, z.B. dt. Job aus engl. job

nach engl. $\mathrm{x}$, wobei das englische Sprachzeichen nicht mehr erkennbar ist, sondern das englische Vorbild mit deutschem Sprachmaterial nachgebildet wird, z.B. Erste Dame nach engl. first lady

$\mathrm{zu}$ engl. $\mathrm{x}$, wobei ein englisches Sprachzeichen als Ausgangspunkt der Entlehnung erkennbar ist, das aber im Deutschen morphologisch verändert worden ist, z.B. dt. Twen zu engl. twenty (AWb 1993: 59).

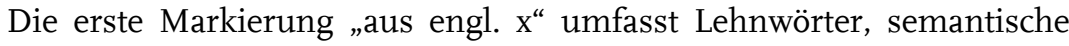
Scheinentlehnungen und lexikalische Scheinentlehnungen. Die zweite Markierung umfasst das, was sonst oft als inneres Lehngut bezeichnet wird. Hier geht Carstensen gesondert auf die „Wahrscheinlichkeitsgrade der Entlehnung“ (AWb 1993: 62) ein: Er unterscheidet drei Grade von Wahrscheinlichkeit. Der erste ist „nach engl. x“, der zweite „wahrscheinlich nach engl. $x^{\prime \prime}$ und der dritte „eventuell nach engl. $x^{\prime \prime ~(v g l . ~}$ AWb 1993: 62). Überprüfbare Kriterien für diese Einteilung gibt Carstensen aber nicht. In die dritte Markierung fallen alle Sonderformen.

Auch das Problem der Komposita, Mischkomposita und der Ableitungen führt Carstensen auf, ebenso geht er auf Phraseologismen ein. Bei

geht von „simple words“ und „compounds and phrases“ aus. Die „simple words“ unterteilt er in "word transfer" und "semantic extension“, die "semantic extension" wiederum in „homonymy“ und „polysemy“. Die „compounds and phrases“ gliedert er in drei Gruppen: "reproduction/loan translation“, ,transfer in analyzed form“ und „hybrid compound“. Die „hybrid compounds“ spalten sich auf in vier verschiedene Typen. Wie Haugen unterscheidet Weinreich bei den Ableitungen "transfer of stem “ und "transfer of derivative“. Die Komposita differenziert er in zwei Gruppen, „hybrid compound“ und „one element transferred and reproduced“ (vgl. Weinreich 1974: 47ff.).

${ }^{36}$ Die Dissertation wurde 1968 vorgelegt, die Druckversion 1970. 
den Mischkomposita unterscheidet er fünf Kategorien: Mischkomposita mit modellsprachlichem Vorbild, Mischkomposita mit modellsprachlichem Vorbild, das aber nicht im Wörterbuch gefunden werden konnte, Mischkomposita ohne modellsprachliches Vorbild, Mischkomposita, „in denen ein englisches mit einem nicht-englischen und gleichzeitig nichtdeutschen Lexem eine Verbindung eingeht“ (AWb 1993: 67) und Eigenbildungen des Deutschen (vgl. AWb 1993: 67). ${ }^{37}$

Daneben existieren weitere Vorschläge, wie der von Duckworth $(1977)^{38}$, Allenbacher (1999) ${ }^{39}$ oder Jansen $(2005)^{40}$, diese haben aber keine weite Verbreitung gefunden.

${ }^{37}$ Nicht ersichtlich aus dieser Einteilung ist jedoch der Unterschied zwischen Gruppe 3, den Mischkomposita ohne modellsprachliches Vorbild und Gruppe 5, den Eigenbildungen des Deutschen.

${ }^{38}$ Duckworth unterteilt das Lehngut in Übernahmen, Teilersetzungen und Ersetzungen. Die Übernahme ist wiederum ein „entlehntes Wort“, hierfür führt er zwei Möglichkeiten an: „Fremdwort“ und „Lehnwort“ ,wobei unter „Fremdwort“ auch die Entlehnung von Wendungen gefasst wird. Die Teilersetzung definiert er als „Lehnverbindung“, auch hier sind wieder Wendungen inbegriffen. Die Ersetzung beschreibt er näher als „Lehnprägung“ einerseits oder „Lehnbedeutung“ andererseits. Die „Lehnprägung“ gliedert sich in "Lehnformung“ und „Lehnschöpfung“ („Ein Wort wird neu geschaffen, um ein fremdes Wort wiederzugeben, ohne sich formal in irgendeiner Weise an dieses fremde Wort anzulehnen“) wobei sich die „Lehnformung“ wiederum unterteilt in „Lehnübersetzung“ („Ein Wort wird nach dem Vorbild eines fremdsprachlichen Wortes neu gebildet, indem es dieses Vorbild genau mit eigensprachlichem Stoff nachbildet.“) und „Lehnübertragung“ („Ein Wort wird nach dem Vorbild eines fremdsprachlichen Wortes neu gebildet, indem es mit eigensprachlichem Stoff dieses Vorbild in freier, teilweiser Anlehnung nachbildet"). Auch hier werden Wendungen mit einbezogen (Duckworth 1977: 40ff.). Insgesamt greift Duckworth die Vorschläge von Betz, Carstensen und Haugen auf und vereinigt diese zu einer neuen Klassifikation.

${ }^{39}$ Allenbacher unterteilt entgegen den bisherigen Gliederungen das Lehngut in primäres Lehngut, sekundäres Lehngut und tertiäres Lehngut. In die Kategorie des primären Lehnguts fallen Lehnwort, Mischverbindung mit modellsprachlichem Vorbild, Lehnbedeutung und Lehnübersetzung. Sekundäres Lehngut sind Mischverbindung ohne modellsprachliches Vorbild, lexikalische Scheinentlehnung, Lehnveränderung und semantische Scheinentlehnung. Unter tertiärem Lehngut versteht er „replikasprachliche Neubildungen auf der Grundlage des Sekundären Lehnguts“ (Allenbacher 1999: 65), also ausdrucksseitig englische oder zum Teil englische Lexeme, für deren Bildung ein Lexem des Sekundären Lehnguts die einzige Erklärung ist.

${ }^{40}$ Silke Jansen erstellt in ihrer Publikation „Sprachliches Lehngut im world wide web aus dem Jahr 2005“ abermals eine neue Lehngutgliederung, wobei sie die Interpretation des Lehnworts mit Betz übereinstimmend vornimmt. Das innere Lehngut gliedert Jansen neu: Lehngut, Lehnübersetzung und Lehnübertragung, die Betz einzeln kategorisierte, fasst Jansen zusammen, mit der Begründung, dass Erscheinungen, die nach identischen 
Ein wichtiger Kritikpunkt in der neueren Forschung an all diesen Schemata ist, dass eine systematische Analyse im Hinblick auf die einzelnen grammatischen Ebenen nicht möglich sei.

Peter Eisenberg und Jürgen Baurmann haben bereits im Jahr 1984 gemeinsam einen Aufsatz mit dem Titel „Fremdwörter - fremde Wörter“ veröffentlicht, in dem sie nicht nur dafür plädieren, den Begriff „Fremdwort“ durch „fremdes Wort“ zu ersetzen. Vielmehr weisen sie, wie schon vorher Klaus Heller (1966), dessen Einteilung sie geringfügig verändern, darauf hin, dass eine Unterscheidung von Wörtern hinsichtlich von vier Merkmalspaaren sinnvoll wäre. In diesem Sinn wäre nach Eisenberg und Baurmann ein diachron entlehntes Wort, das synchron fremd „erscheint“, als fremdes Wort zu bezeichnen, ein nicht entlehntes Wort, das fremd erscheint, als Pseudo-fremdes-Wort, ein entlehntes und nicht fremd erscheinendes Wort als Lehnwort und ein nicht entlehntes und nicht fremd erscheinendes Wort als Erbwort (vgl. Eisenberg/Baurmann 1984: 16). Auffälligkeiten von Wörtern hinsichtlich von Lauten und Silben, Akzent, Wortbildung, Orthographie oder Genus führen dazu, Wörter als fremd zu empfinden und so zu charakterisieren.

In seiner Publikation aus dem Jahr 2004 beschäftigt sich Eisenberg mit dem Verhalten von Anglizismen hinsichtlich der deutschen Flexion. Er stellt fest, dass sich Adjektive diesbezüglich heterogen verhalten, da es Adjektive gibt, die vollständig nach deutschen Regeln flektiert werden, wie zum Beispiel fair oder tough oder cool. Daneben gibt es Adjektive, die in ihrer Flexion teilweise oder auch gar nicht integriert sind. Er unterteilt die Adjektive in acht Gruppen, je nach Grad und Art ihrer Integration (vgl. Eisenberg 2004b: 128ff.). Bei den Verben unterscheidet Eisenberg fünf Gruppen, bei den Substantiven drei, wobei er darauf verweist, dass der wichtigste Schritt zur Integration die Zuweisung eines Genus ist (vgl. Eisenberg 2004b: 131ff.). Insgesamt kommt Eisenberg zu dem Ergebnis, dass Anglizismen nicht immer problemlos ins Deutsche in-

sprachlichen Mechanismen gebildet wurden, unterschiedlichen Kategorien zugewiesen wurden. Damit gliedert sie nur noch in Code-Switching bzw. kontaktinduzierte Systemerweiterung, kontaktinduzierte Normabweichung, und unabhängige Normabweichung. Diese bezeichnet sie auch als Lehnwort, Übersetzung und unabhängigen Neologismus und begründet dies mit der Komplexität der Formulierungen bei Verwendung der zahlreichen Termini bisheriger Lehngutgliederungen (vgl. Jansen 2005: 126ff.). 
tegriert werden. Es sei aber nicht davon auszugehen, dass Anglizismen im Deutschen, anders als lateinische und französische Lexeme, das deutsche Flexionssystem nachhaltig verändern werden (vgl. Eisenberg 2004b: 134).

Dieser Überblick über den Stand der Forschung bei der Gliederung lexikalischen Lehnguts zeigt bereits eine der wesentlichen Schwierigkeiten der Fremdwort-Thematik auf: Schon innerhalb der Sprachwissenschaft existieren verschiedene Ansätze bezüglich der Klassifizierung von Lehngut. Für einen sprachwissenschaftlichen Laien sind die verschiedenen Kategorisierungen von Lehngut - und damit die Frage, was als Fremdwort klassifiziert wird - wohl nur schwer nachzuvollziehen.

\subsubsection{Untersuchungen zu Anglizismen in der deutschen Sprache}

Im Jahr 1899 hielt Hermann Dunger, ein Gymnasiallehrer aus Dresden, einen Vortrag mit dem Titel „Wider die Engländerei in der deutschen Sprache“. ${ }^{41}$ Dies ist wohl die erste Arbeit, die Anglizismen im Deutschen zum Gegenstand hat. 1936 erschien Agnes Bain Stivens „Englands Einfluß auf den deutschen Wortschatz“, 421950 folgte „The Influence of English on the German Vocabulary“ von Philipp Palmer.

Auf diese Arbeiten, die sich mit Anglizismen im Deutschen in der Zeit vor dem Zweiten Weltkrieg beschäftigen, soll nicht weiter eingegangen werden, für eine Untersuchung des VDS sind diese nicht von Belang. Stattdessen ist Horst Zindlers Dissertation „Anglizismen in der deutschen Presse“ aus dem Jahr 1959 die erste Arbeit, die hier näher vorgestellt wird, denn sie ist die erste Untersuchung von Anglizismen für die Zeit nach dem Zweiten Weltkrieg. Zindler versucht in seiner Dissertation, „einen Überblick über den englischen Worteinfluß auf die deutsche Pressesprache nach $1945 \mathrm{zu}$ verschaffen“ (Zindler 1959: 1). Problema-

${ }^{41}$ Dunger wird in der Literatur oft als Dresdener Germanistikprofessor bezeichnet (vgl. u.a. von Polenz 1999a: 272). Dies berichtigt Viereck (vgl. Viereck 1989: 1), siehe dazu auch Greule/Ahlvers-Liebel (1986: 29) und Wiechers (2004: 18). Zu diesem Text vgl. Kapitel 1.7.2.

${ }^{42}$ An einigen Stellen dieses Buches kommt nationalsozialistisches Gedankengut zum Vorschein. 
tisch daran ist, dass Zindlers Untersuchungskorpus, das verschiedenen Tages- und Wochenzeitungen und einigen Illustrierten entnommen wurde, nicht systematisch exzerpiert wurde. Dennoch war Zindlers Dissertation nach Meinung einiger Sprachwissenschaftler richtungweisend für die nachfolgende Forschung. ${ }^{43}$ Er fand unter anderem heraus, dass ungefähr ein Drittel der Anglizismen mit nur einem Teil ihrer Bedeutung ins Deutsche übernommen wurden (Zindler 1959: 19).

1965 erschien Broder Carstensens Arbeit „Englische Einflüsse auf die deutsche Sprache nach 1945“. Diese Untersuchung, die sich ebenfalls mit Anglizismen in Zeitungen, vor allem aber im Nachrichtenmagazin Der Spiegel in den Jahren 1961 bis 1964 auseinandersetzt, gilt als Standardwerk der älteren Anglizismenforschung. Carstensen ist der Auffassung, dass die deutsche Presse als der Hauptvermittler von Anglizismen $\mathrm{zu}$ sehen ist (vgl. Carstensen 1965: 22). Zum ersten Mal werden nicht nur lexikalische Einflüsse, sondern auch englische Einflüsse auf die Phonologie, Graphie, Morphologie und Syntax des Deutschen untersucht. Dennoch kommt Carstensen zu dem Ergebnis, dass die englische Sprache die deutsche hauptsächlich im Bereich der Lexik beeinflusst.

Hermann Finks Dissertation „Amerikanismen im Wortschatz der deutschen Tagespresse“ ist ebenfalls von Bedeutung für die Anglizismenforschung. Fink analysiert das Vorkommen von Anglizismen in den drei überregionalen Zeitungen Süddeutsche Zeitung, Frankfurter Allgemeine Zeitung und Die Welt. Aus acht Wochenendausgaben der Zeitungen von 1963 bildete er ein Korpus aus über sieben Millionen Wörtern und untersucht, ob bei der Aufnahmebereitschaft von Anglizismen ein regionaler Unterschied besteht und ob die Gründe für die Aufnahme eher „sachlich“ oder "gefühlsmäßig“ sind (Fink 1970: 440ff.). ${ }^{44}$ Nach seiner Auffassung ist eine Differenzierung der Gründe oftmals nicht möglich. Diese Arbeit wurde von einigen Sprachwissenschaftlern als bahnbrechend angesehen. Laut Galinsky ist sie die „methodisch stichhaltigste und inhaltlich ertragreichste“ Arbeit des ganzen Berichtszeitraumes 1945 bis 1975 (vgl. Galinsky 1977: 474).

${ }^{43}$ Diese Auffassung findet man z.B. bei Plümer (2000: 11) und Yang (1990: 5).

${ }^{44}$ Fink hat sich immer wieder mit Anglizismen auseinandergesetzt. Vgl. auch Fink (1983) oder Fink (2001). 
Die erste computergestützte Untersuchung erscheint 1976. Barbara Engels untersucht in ihrer Dissertation zwei Jahrgänge der Zeitung Die Welt auf das Vorkommen von lexikalisch-semantischen Amerikanismen. ${ }^{45}$ Sie stellt fest, dass im Jahr 1954 nur jedes sechshundertste Wort ein Amerikanismus ist, im Jahr 1964 dagegen schon jedes zweihundertste (vgl. Engels 1976: 49f.). Engels stützt ihre Arbeit auf das von Fink verwendete Korpus. Daraus ergibt sich, dass eventuell von Fink übersehene Amerikanismen auch in der Arbeit von Engels keinen Niederschlag finden. ${ }^{46}$

Hans Galinsky wagt sich mit seiner Arbeit „Stylistic Aspects of Linguistic Borrowing “47, in der er Entlehnungsvorgänge und ihre stilistischen Aspekte untersucht, auf ein bis dahin wenig erforschtes Gebiet. Er geht der Frage nach, warum Anglizismen bzw. Amerikanismen in der deutschen Sprache verwendet werden. Hauptmotivationsgründe sind laut Galinsky

providing national color of settings, actions and characters, establishing or enhancing precision, offering or faciliating intentional disguise, effecting brevity to the point of terseness, producing vividness, often by way of metaphor, conveying tone, its gamut ranging from humorous playfulness to sneering parody on America and 'Americanized' Germany (Galinsky 1975: 71).

Jürgen Pfitzner beschäftigt sich in seiner Arbeit „Der Anglizismus im Deutschen: Ein Beitrag zur Bestimmung seiner stilistischen Funktion in der heutigen Pressesprache“ mit Entlehnungsvorgängen und ihren stilistischen Aspekten. Pfitzner stellt fünf Motivationsgründe auf: Kolorit, sprachliche Ausdruckskraft, Sprachökonomie, Ton und Affekt (vgl. Pfitzner 1978: 35). Er kommt zu dem Ergebnis, dass die meisten in Zeitungen gebrauchten Anglizismen „im Dienste der Koloritzeichnung“ (Pfitzner 1978: 223) verwendet werden.

$\mathrm{Zu}$ den beiden letztgenannten Untersuchungen ist $\mathrm{zu}$ bemerken, dass es sich bei Faktoren wie „humorous playfulness“ oder „Ton“ und „Affekt“ mehr um Impressionen als um linguistische Kategorien handelt.

\footnotetext{
${ }^{45}$ Im Gegensatz zu den bisher erwähnten Arbeiten geht es hier explizit um Amerikanismen. Zur Schwierigkeit der Unterscheidung siehe Kapitel 1.5.2.

${ }^{46}$ Dies wendet K. Viereck zu Recht ein (1980: 1). Diesem Einwand haben sich z.B. auch Yang (1990: 6) und Plümer (2000: 12) angeschlossen.

${ }^{47}$ Die Untersuchung ist erstmals im Jahr 1967 erschienen.
} 
In ihrer Arbeit „Englisches Wortgut, seine Häufigkeit und Integration in der österreichischen und bundesdeutschen Pressesprache“ untersucht Karin Viereck die Wochenendausgaben der österreichischen Zeitungen Die Presse und Kleine Zeitung sowie die Wochenendausgabe der in München erscheinenden Süddeutschen Zeitung auf das Vorkommen von englischem Wortgut und vergleicht die Ergebnisse. Dadurch kann sie den Sprachstil der Süddeutschen Zeitung als einer der großen deutschen Tageszeitungen mit dem österreichischer Zeitungen vergleichen und Unterschiede zwischen der Sprache regionaler und überregionaler Presse in Österreich herausarbeiten (vgl. K. Viereck 1980: 2). Viereck konstatiert, dass Die Presse die meisten Anglizismen aufweist, die Süddeutsche an zweiter Stelle kommt und die Kleine Zeitung die wenigsten Anglizismen verwendet. Damit waren keine regionalen Unterschiede aufzuzeigen.

Wenliang Yang untersucht in seiner Arbeit „Anglizismen im Deutschen: Am Beispiel des Nachrichtenmagazins DER SPIEGEL“ den redaktionellen Teil von insgesamt 24 Spiegel-Ausgaben aus den Jahren 1950, 1960, 1970 und 1980, insgesamt also ein eher kleines Korpus. Dies ist als Schwäche dieser ansonsten sehr interessanten Arbeit zu sehen. Dabei richtet er sein Augenmerk sowohl auf Frequenz, Semantik, Wortbildung und Integration als auch auf die stilistische Funktion der Anglizismen (vgl. Yang 1990: 3). Yang ermittelt einen Durchschnittswert von drei Anglizismen pro Seite, umgerechnet auf alle untersuchten Jahrgänge, wobei die Zahl der verwendeten Anglizismen kontinuierlich zunimmt und die meisten Anglizismen im Bereich des Sports zu finden sind.

Im Jahr 1993 erscheint das „Anglizismen-Wörterbuch. Der Einfluß des Englischen auf den deutschen Wortschatz nach 1945“ (AWb), begründet von Broder Carstensen, fortgeführt von Ulrich Busse. Dieses dreibändige Wörterbuch ist nach Angaben der Autoren weder ein einsprachiges noch ein zweisprachiges Wörterbuch. Es enthält Belege von Anglizismen im Deutschen, die nicht fachsprachlich sind, keine Exotismen (zu den Exotismen siehe ausführlich Kapitel 1.5.1) sind und nicht vor 1945 ins Deutsche entlehnt wurden. Auch Phraseologismen sowie Prä- und Suffixe aus dem Englischen werden behandelt. Dabei lag nach Angaben der Autoren dem AWb mit verschiedenen Korpora, wie dem Paderbor- 
ner Korpus, dem Mannheimer Korpus und den Belegen aus der (bereits vorgestellten) Untersuchung von Karin Viereck, kein als repräsentativ anzusehendes Korpus zugrunde. Vielmehr sei die Hauptaufgabe dieses dreibändigen Wörterbuchs, „im gegenwärtigen Deutsch häufiger vorkommende Anglizismen zu erfassen und die vielen bisher völlig übersehenen Fälle des ,inneren' Lehnguts aufzuzeigen und erstmalig zu erörtern“ (AWb 1993: 32ff.). ${ }^{48}$ Die Einteilung der Lemmata folgt dabei einem eigenen Prinzip, das bereits in Kapitel 1.4.1 vorgestellt wurde. In den einzelnen Artikeln werden jeweils das Lemma, Schreibvarianten, Angaben zu Aussprache, Wortart, Grammatik und Markierung des Anglizismus, Definitionen, der Erstbeleg im Korpus, die Erstbuchung in deutschen Wörterbüchern, der Entlehnungsweg, die englische Aussprache sowie weitere Informationen zum Lemma, wie zum Beispiel ein sprachhistorischer Kommentar zum Entlehnungsprozess mit aufgeführt. Außerdem werden Synonyme, eventuell Vergleiche und der Beleg aufgeführt. Etwa 100000 Belege liegen dem AWb zugrunde, das eine wertvolle Informationsquelle zu Anglizismen im Deutschen in der Zeit von 1945 bis 1993 bildet. Zudem beinhaltet das AWb eine ausführliche Bibliographie der Anglizismenforschung, ebenfalls bis 1993.

Heidemarie Langner beschäftigt sich mit der Orthographie englischer Entlehnungen im Deutschen, ihre Analyse bezieht sich auf die Allgemeinsprache. In ihrer 1995 erschienenen Dissertation untersucht sie anhand aller Dudenauflagen vor 1945, aller Mannheimer Dudenauflagen nach 1945 inklusive der gesamtdeutschen Auflage von 1991 und anhand der letzten Leipziger Dudenauflage die Entwicklung der Schreibung von Anglizismen. Dabei kommt sie zu dem Schluss, dass ältere Entlehnungen häufig integriert wurden, in jüngerer Zeit aber die Tendenz zur unveränderten Übernahme besteht (vgl. Langner 1995: 178).

Ninja Langer untersucht in ihrer Arbeit die Pressesprache, mit besonderem Augenmerk auf der Sprache der Wirtschaft. Anhand der Wirtschaftsmagazine DM und Capital geht sie auf das Vorkommen von Anglizismen und deren Funktion ein. Langer stellt fest, dass im Jahr 1996 in den beiden Wirtschaftsmagazinen ungefähr jedes 70. Wort ein Angli-

${ }^{48}$ Hervorhebung im Original. 
zismus ist (vgl. Langer 1996: 70). Sie erklärt den sehr hohen Anteil an Anglizismen in der Wirtschaftssprache damit, dass die Übernahmen einen hohen Gebrauchswert haben, da sie speziell die Wirtschaftssprache als Fachsprache bereichern, denn für viele dieser Anglizismen gibt es in der deutschen Sprache kein Synonym. Dadurch würden umständliche Umschreibungen verhindert (Langer 1996: 59f.), da die Anglizismen diesen Umschreibungen an Kürze und Prägnanz überlegen seien (Langer 1996: 82).

In seiner Publikation „Von Kuh-Look bis Fit for Fun: Anglizismen in der heutigen deutschen Allgemein- und Werbesprache“ aus dem Jahr 1997 beschäftigt sich Fink (Fink 1997) anhand eines kleinen offenen Korpus mit Anglizismen in verschiedenen Zeitungen, Zeitschriften und Werbeprospekten. Problematisch an dieser Publikation ist, dass es sich keinesfalls um repräsentative Ergebnisse im Sinne einer stichhaltigen Analyse handelt, sondern immer nur ein Exemplar der Schriftstücke untersucht wurde. Deshalb ist diese Untersuchung als quantitative Erhebung methodisch nicht überzeugend durchgeführt. Fink beschreibt das Vorkommen von Anglizismen beispielsweise in der SUPER ILLU und der FREUNDIN ebenso wie in der BILD und in Die Welt. Gegenstand seiner Analyse sind sowohl redaktionelle Inhalte als auch Anzeigen. Außerdem untersucht er Prospekte, z.B. von „Kaufhof“, „real“ und „NKD“. In seiner Studie kommt Fink zu dem Ergebnis, dass sowohl die deutsche Allgemeinsprache als auch die deutsche Werbesprache viele Anglizismen enthalten. Dies gilt auch für die Jugendpressesprache. Die Arbeit erschien in der Reihe „Freiberger Beiträge“. In dieser Reihe sind noch weitere Arbeiten zur Anglizismenforschung erschienen: „Das Verständnis wirtschaftsspezifischer Anglizismen in der deutschen Sprache bei Unternehmern, Führungskräften und Mitarbeitern der neuen Bundesländer" von Andrea Effertz und Ulrike Vieth ist eine Untersuchung über mögliche Verständnisschwierigkeiten aufgrund von Anglizismen in der Sprache der Wirtschaft. Effertz und Vieth wählten 15 Anglizismen aus, die in der Wirtschaftspresse und in Fachbüchern häufig verwendet werden. Dies waren die Begriffe „Assessment Center“, „Break-Even-Point“, "Broker“, „Dumping“, „Factoring“, „Incoterms“, „Job Sharing“, „Joint Venture, „MBO”, „Management by Exception”, „Payoff-Period”, „Profit Center”, „PR”, „Rack Jobber” und „Sales Promotion” (vgl. Effertz/Vieth 
1996: 31ff.). Sie befragten 300 Personen aus Unternehmen, davon 140 aus den neuen und 160 aus den alten Bundesländern, die an Seminaren verschiedener Bildungsträger teilnahmen (vgl. Effertz/Vieth 1996: 49ff.). Dabei stellten sie fest, dass das Verständnis der Probanden aus Westdeutschland mit 62 Prozent höher war als das der Probanden aus Ostdeutschland mit 46,4 Prozent. Bei den meisten Termini lag die Differenz sogar über 20 Prozent. Effertz und Vieth kamen zu dem Ergebnis, inwieweit Anglizismen verstanden werden, hänge signifikant davon ab, ob Erhebungen in den alten oder neuen Bundesländern durchgeführt werden (vgl. Effertz/Vieth 1996: 175).

Ebenfalls in der Reihe der Freiberger Beiträge erschienen ist die Publikation "Anglizismen in der Sprache der Neuen Bundesländer" von Hermann Fink, Liane Fijas und Danielle Schons. Hierbei handelt es sich um eine Untersuchung von Quellen sowohl zum "geschriebenen Wort" als auch zum "gesprochenen Wort" (vgl. Fink/Fijas/Schons 1997: 21). Die Analyse umfasst den Zeitraum zwischen dem 1. und 31. Dezember 1994. Untersucht wurden überregionale, regionale und lokale Publikationen sowie Werbeschriften. Insgesamt wurden 1534 Seiten durchgesehen, darunter waren das Neue Deutschland, die Sächsische Zeitung, die Freiberger Ausgabe der Freien Presse sowie die lokalen Wochenblätter Freiberger Anzeiger und Freiberger Blick. Des Weiteren wurden 450 Seiten Werbeprospekte und ein Katalog verwertet sowie Sendungen des öffentlich-rechtlichen Senders MDR (vgl. Fink/Fijas/Schons 1997: 21ff.). Insgesamt ist dieses offene Korpus aufgrund der Willkürlichkeit bei der Auswahl wenig überzeugend. Die Autoren kamen zu dem Ergebnis, dass nur jeder zweite bis dritte Anglizismus im Schnitt einmal wiederverwendet wurde. Es wurden 5425 Anglizismen ausgemacht, davon wurden 3525 je nur einmal verwendet. Die Substantive dominierten mit 91 Prozent (Fink/Fijas/Schons 1997: 85). Nach ihren Forschungen wird im Rundfunk im Schnitt nur alle drei Minuten und vier Sekunden ein Anglizismus verwendet. Daraus folgern die Autoren eine „eher zögerliche und wohl überlegte Verwendung“ (Fink/Fijas/Schons 1997: 77). Außerdem wurde anhand eines Fragebogens die Rezeption von Anglizismen in den neuen Bundesländern untersucht. Befragt wurden 162 Probanden, davon 138 Ostdeutsche und eine Kontrollgruppe aus 24 Westdeutschen. Etwa ein Fünftel der Ost- 
deutschen hält den englischen Einfluss auf die Muttersprache für schlecht, 16 Prozent möchten „die Verwendung von Anglizismen eingeschränkt sehen“, aber nur sehr wenige Befragte glauben daran, dass englische Entlehnungen die deutsche Kultur zerstörten (vgl. Fink/Fijas/Schons 1997: 107f.).

Bemerkenswert an dieser Publikation ist die Einleitung, die unschwer die Einstellung der Autoren gegenüber Anglizismen in der deutschen Sprache und auch gegenüber Amerika erkennen lässt. Dort heißt es u.a.:

In den letzten Jahren machte Amerika wieder fette Schlagzeilen, sei es durch seine (z.T. erfolgreichen) Friedensinitiativen [...], sei es durch die Zahlungsunfähigkeitserklärung der U.S.-Regierung gegenüber ihrem öffentlichen Dienst, durch statistische Höchstzahlen von Verbrechen [...]. Unter solchen [...] Sensationsberichten gehen die Symptome der vielfach von den Vereinigten Staaten schon seit Jahren ausgehenden sonstigen, teilweise wie eine medikamentöse Einschleichung beobachtbaren Einflüsse auf Wirtschaft und Kultur praktisch aller Länder der Erde unter. [...] Aus der Reihe der angepaßten Völker und Individuen tanzt aber immer wieder Frankreich [...] (Fink/Fijas/Schons 1997: 1).

Peter Allenbacher hat die Fachsprache des Fernsehjournalismus in Redaktion und Technik in Hinblick auf das Vorkommen von Anglizismen untersucht, wobei auch mündliches Belegmaterial - teilweise als Aufzeichnungen belegt - berücksichtigt wurde. Dazu hat Allenbacher, der selbst beim Fernsehen arbeitet (zum Zeitpunkt der Erhebung in der Sat.1, SatellitenFernsehenGmbH), zwischen Dezember 1991 und Ende Oktober 1996 verdeckte Beobachtungen durchgeführt. Neben diesen Beobachtungen greift er auf eine offene Belegsammlung aus internen Schulungsmaterialien, Dispositionsunterlagen, Sendeablaufplänen und weiteren Schriften aus dem Arbeitsalltag beim Fernsehen zurück. Des Weiteren untersucht er fachinterne Artikel in Fachzeitschriften, Handbücher der Fernsehtechnik sowie Stichwortartikel in Fachlexika (vgl. Allenbacher 1999: 91ff.). Die schriftlichen Fachtextsorten wurden zweimal nach den Anglizismen durchforscht, die in Allenbachers Korpus mündlich belegt waren. Damit hat Allenbachers Untersuchung eine methodische Schwäche hinsichtlich der Repräsentativität der Ergebnisse. ${ }^{49}$ Allenbacher bescheinigt der Sprache des Fernsehens „eine starke Ten-

\footnotetext{
${ }^{49}$ Doch eine statistisch repräsentative Belegsammlung leistet nicht einmal das Anglizismen-Wörterbuch (vgl. AWb 1993: 53).
} 
denz zur Verwendung ausdrucksseitig engl. Sprachmaterials“ (Allenbacher 1999: 283), Fachbegriffe werden in der Regel einfach aus dem Englischen übernommen und nicht mehr übersetzt. Zusätzlich stellt er fest, dass mehr und mehr einheimisch-deutsche Begriffe durch englische Begriffe oder die Bildung von Scheinentlehnungen ersetzt werden (vgl. Allenbacher 1999: 283). An dieser Stelle ist anzumerken, dass es sich um eine synchrone Untersuchung handelt, es gibt keinen Vergleich zur Fernsehsprache früherer Jahrzehnte.

Die Dissertation „Anglizismus - Purismus - Sprachliche Identität“ von Nicole Plümer ist eine Untersuchung zu den Anglizismen in der deutschen und französischen Mediensprache. Plümer setzt sich mit dem Einfluss des Englischen auf das Deutsche und auf das Französische auseinander und vergleicht diese vor dem Hintergrund der unterschiedlichen Sprachpolitik beider Länder. Als Untersuchungsgegenstand dienen ihr deutsche und französische überregionale Printmedien sowie die heute-Nachrichten des ZDF und die Hauptnachrichtensendung von France 3.

Untersucht hat sie im Einzelnen den Mantelteil von Le Monde, Figaro, der Süddeutschen Zeitung und der FAZ im Zeitraum von 18./19. April bis zum 24. April 1993 und vom 2/3. Mai bis zum 8. Mai 1993 (vgl. Plümer 2000: 100). Dabei hat sie sich auf den Mantel der Zeitungen beschränkt, da die Spezialsegmente wie Wirtschaft und Sport eine besonders stark angelsächsische Färbung aufweisen und so laut Plümer nicht als repräsentativ für die Allgemeinsprache gelten können (vgl. Plümer 2000: 89). In der Zeit vom 25. April 1993 bis zum 30. April 1993 und vom 9. Mai 1993 bis zum 14. Mai 1993 (jeweils sechs Tage) untersuchte Plümer das Vorkommen von Anglizismen in den täglichen deutschen heuteNachrichten und in der Hauptnachrichtensendung von France 3 (vgl. Plümer 2000: 100). Der Umfang der französischen Stichprobe belief sich auf 488133 Wörter, der der deutschen auf 515577 Wörter. Plümer kommt zu dem Ergebnis, dass im Französischen deutlich weniger unterschiedliche Anglizismen vorkommen - in ihrer Untersuchung waren es 499 Types im Französischen gegenüber 1047 Types im Deutschen. Insgesamt ergab Plümers EDV-gestützte Auswertung 2593 Anglizismen im französischen Korpus und 3102 im deutschen (vgl. Plümer 2000: 270). Gestützt auf diese Zahlen geht Plümer davon aus, dass die franzö- 
sischen Gesetze zur Sprachpflege durchaus wirkungsvoll sind: Es gelangen weniger Anglizismen in die französische als in die deutsche Mediensprache (vgl. Plümer 2000: 271). Plümer schlussfolgert, durch das französische Sprachgesetz und die damit verbundene sogenannte „franglais-Diskussion“ sei bei der Bevölkerung das Bewusstsein für den englischen Einfluss auf das Französische geschärft worden (vgl. Plümer 2000: 273).

Ebenfalls im Jahr 2000 erscheint Richard Glahns „Der Einfluß des Englischen auf die gesprochene deutsche Gegenwartssprache. Eine Analyse öffentlich gesprochener Sprache am Beispiel von ,Fernsehdeutsch'“. Glahn hat zu diesem Zweck über 30 Fernsehsendungen (Zeitraum September und Oktober 1998) aufgezeichnet und die Sprache auf das Vorkommen von Anglizismen untersucht (vgl. Glahn 2000: 30f.). Glahn versucht, sein Korpus so zu erstellen, dass die Ergebnisse als repräsentativ gelten können. Er definiert zwei Arten von Repräsentativität: Zum einen die „sendungsartenspezifische“, zum anderen die "quantitative“ Repräsentativität. Um beiden Anforderungen gerecht zu werden, nimmt er folgende Sendungsarten in sein Korpus auf: Informationssendungen mit überwiegend politischem und wirtschaftlichem Inhalt, Informationssendungen mit wissenschaftlichem Inhalt, Kindersendungen, Musiksendungen, Serien, Sportübertragungen, Talkshows und Werbesendungen. Er verzichtet nur auf Sendungsarten, die im öffentlichrechtlichen Fernsehen keine ausreichend hohe Frequenz aufweisen, um sie zu berücksichtigen. So achtet er unter anderem darauf, dass ausreichend gesprochener Text zu erheben ist und dass kein Sendungstyp zweimal aufgezeichnet wird. Insgesamt zeichnet er in jeder der Sendungsarten innerhalb von 45 Tagen 135 Minuten Sendezeit auf, dies ergibt ein Gesamtkorpus von 1080 Minuten, erhoben ausschließlich bei den öffentlich-rechtlichen Sendern ARD, ZDF und SWR. Dabei wurden von keiner Einzelsendung mehr als 60 Minuten in die Analyse mit einbezogen (vgl. Glahn 2000: 15ff.). Sein Korpus hat Glahn verschriftlicht und manuell ausgewertet (vgl. Glahn 2000: 25). Insgesamt ist dies wohl eine der ausführlichsten Korpusanalysen dieser Art. Als Schwäche kann man werten, dass die privaten Fernsehsender nicht berücksichtigt wurden. Glahn kommt in seiner quantitativen Analyse zu dem Ergebnis, dass im Durchschnitt in den Fernsehsendungen alle 56,6 Sekunden 
eine Entlehnung verwendet wurde, gemessen an der Gesamtzahl der untersuchten Sendeminuten, wobei er inneres Lehngut ebenso berücksichtigt. Um dieses zu identifizieren, hat Glahn alle aufgezeichneten Sendungen ins Englische übersetzt (vgl. Glahn 2000: 24). Am häufigsten kommen Anglizismen in Werbespots vor (alle 22,7 Sekunden). Glahn konstatiert, dass neben der Werbung die Sprache des Sports am stärksten beeinflusst ist, die wenigsten Anglizismen sind in Serien und in wissenschaftlichen Informationssendungen auszumachen (vgl. Glahn 2000: 181f.). Anhand des Korpus stellt er fest, dass von evidenten Entlehnungen (also äußerem Lehngut) 69,35 Prozent der Entlehnungen wie im Englischen ausgesprochen werden (vgl. Glahn 2000: 182). Er kommt zu dem Ergebnis, dass über 90 Prozent der Entlehnungen Nomina sind und dass syntaktische Beeinflussungen des Deutschen nur in sehr geringem Umfang vorkommen (vgl. Glahn 2000: 183). ${ }^{50}$

In meiner Diplomarbeit „Anglizismen in der Sprache der Jugendpresse am Beispiel von BRAVO GIRL! und Mädchen" habe ich mich ebenfalls mit dem Thema Anglizismen in der Sprache der Presse beschäftigt. Untersucht wurde jeweils der redaktionelle Teil von elf Ausgaben von BRAVO GIRL! und Mädchen, und zwar die Ausgaben 13 bis einschließlich 23 aus dem Jahr 2002. Diese Magazine sind zwischen dem 5. Juni 2002 und dem 23. Oktober $2002 \mathrm{im}$ Zweiwochen-Takt erschienen. Es wurden jeweils die Seiten 5 und 17 untersucht, das Korpus besteht demnach aus 44 Seiten. Dabei wurde festgestellt, dass der Anteil der Anglizismen in der Sprache der Jugendpresse, verglichen mit Presseerzeugnissen für Erwachsene, wesentlich höher liegt. Deutlich wird dies durch den Vergleich mit früheren Untersuchungen. Insgesamt befanden sich auf den 44 untersuchten Seiten 1066 Anglizismen (Tokens), diese verteilen sich auf 522 Types. Bei den Types ergibt sich folgende Verteilung: Nur 42 Types kommen in beiden Zeitschriften vor, so entfallen auf die Mädchen 292 verschiedene Types, auf die BRAVO GIRL! 272. Bei den Tokens stammen 505 Anglizismen aus der Zeitschrift Mädchen, 561 aus der Zeitschrift BRAVO GIRL!. Die 44 untersuchten Seiten ha-

\footnotetext{
${ }^{50}$ Hier zeigt sich eine der Schwierigkeiten bei der Vergleichbarkeit von Ergebnissen: Glahn hat als Maßeinheit die Anglizismen pro Sekunde, in anderen Arbeiten, beispielsweise in der von Kristensen aus dem Jahr 1977 ist die Maßeinheit die Zahl der Anglizismen pro hundert Seiten. Daher sind diese Ergebnisse nicht zu vergleichen.
} 
ben eine Gesamtwortzahl von 17 655, davon sind 1066 Anglizismen. Betrachtet man das Vorkommen der Anglizismen gegenüber der Gesamtwörterzahl, so kann festgestellt werden, dass in etwa jedes 17. Wort ein Anglizismus ist. Dies entspricht einem Prozentsatz von ungefähr sechs Prozent. Die meisten Bildungen tauchen in den 44 untersuchten Seiten nur einmal auf. Daher kann vermutet werden, dass viele okkasionelle Bildungen sind, die sozusagen als Eintagsfliegen auftauchen, wieder verschwinden und nicht dauerhaft Eingang in die Sprache der Jugendpresse und somit eventuell in die deutsche Sprache der Gegenwart finden.

Silke Jansen untersucht in "Sprachliches Lehngut im world wide web“ aus dem Jahr 2005 den englischsprachigen Einfluss auf die Sprache des Internets in Frankreich und Spanien. Ausgehend von den Listen englischer Termini der französischen Terminologiekommission ebenso wie von weiteren Internettermini, die Verwendung finden, analysiert sie internetspezifische Fachzeitschriften. Dabei geht sie auch auf Metaphern ein, inneres Lehngut wird ebenfalls untersucht (vgl. Jansen 2005: 198ff). Ihr Korpus setzt sich für das Französische zusammen aus fünf Zeitschriften zum Thema Internet, Internet Practique 4, Internet en action Nr. 4, Net@ccess Nr.1 und Web Magazine Nr. 19, alle erschienen im November 2000, sowie Internetglossaren (vgl. Jansen 2005: 243). Sie kommt zu dem Ergebnis, dass 45 Prozent der verwendeten Termini Lehnwörter, Kombinationen aus Lehnwort und Übersetzungen sowie Übersetzungen mit Fremdelement sind. Weiterhin gibt es eine Tendenz, metaphorische Ausdrücke zu übersetzen (vgl. Jansen 2005: 265ff.). Ebenso ist Jansen auch mit dem Spanischen verfahren. ${ }^{51}$

Auch in der DDR sind einige Arbeiten zum Thema Anglizismen erschienen: Im Jahr 1964 veröffentlicht Karl Heinz Ihlenburg einen Auf-

\footnotetext{
${ }^{51}$ Sie untersuchte die Zeitschriften @rroba Nr. 52, Januar 2002, Computer Hoy Nr. 85, Januar 2002, Computer !dea Nr. 13, Januar 2002 und PC Today, Nr. 32, Januar 2002 sowie für das mexikanische Spanisch Internet Advisor Nr. 16, Juni 2001, Mundo Internet Nr. 6, Juni 2001, PC Magazine en español, September 2001, PC Media Nr. 6, Juni 2001, WWWVivir en Internet Nr. 19. August 2001. Wiederum wurden auch Internetglossare in die Analyse mit einbezogen (vgl. Jansen 2005: 241ff.). Es zeigt sich, dass auch im Spanischen metaphorische Ausdrücke häufig übersetzt werden, wogegen nicht metaphorische Ausdrücke häufig als Lehnwörter übernommen werden (vgl. Jansen 2005: 337). Warum Jansen nicht Zeitschriften eines Jahrgangs untersucht, ist nicht ersichtlich.
} 
satz zu „Entwicklungstendenzen des Wortschatzes in beiden deutschen Staaten“. Die Arbeit ist eine Untersuchung der Duden-Ausgaben der BRD und der DDR sowie von Zeitungsannoncen. Ihlenburg kommt zu dem Ergebnis, dass für die Sprache der DDR keine Gefahr durch Anglizismen besteht. Er stellt fest, dass mehr Anglizismen in der Sprache Westdeutschlands vorkommen, und hier vor allem in der Werbesprache (Ihlenburg 1964: 372ff.).

Göran Kristensson untersuchte 1977 „Angloamerikanische Einflüsse in DDR-Zeitungstexten unter berücksichtigung semantischer, pragmatischer, gesellschaftlich-ideologischer, entlehnungsprozessualer und quantitativer aspekte" [sic]. ${ }^{52}$ In dieser ersten umfangreichen Analyse des Einflusses der englischen Sprache auf die Sprache der DDR wertet Kristensson zahlreiche Texte aus dem Analysezeitraum 1. bis 31. Oktober 1972 aus, dem Jahr nach der Übernahme der SED-Leitung durch Erich Honecker. Seine Arbeit dreht sich um die Frage nach den Voraussetzungen für die Übernahme und der Funktionalität der Übernahmen. Analysiert werden die Tageszeitungen Neues Deutschland, Junge Welt, die Bezirkszeitungen Berliner Zeitung und Ostsee-Zeitung (insgesamt 111 Ausgaben) sowie Der Morgen, die Neue Zeit und die Nationalzeitung (insgesamt 78 Ausgaben), die Wochenzeitungen Wochenpost und Horizont (insgesamt neun Ausgaben), die Illustrierten Neue Berliner Zeitung, Für Dich, Freie Welt und FFDabei (insgesamt 19 Ausgaben), die Magazine Das Magazin und Neues Leben (insgesamt neun Ausgaben) sowie Publikationen namens Eulenspiegel, Filmspiegel, FDJ Forum, die Zeitung für geistige Probleme der Jugend, Melodie und Rhythmus und die Modezeitschrift Sybille (insgesamt 13 Ausgaben) (Kristensson 1977: 31ff. und 280). Er vergleicht sein Korpus mit früheren Untersuchungen aus den Jahren 1952 und 1962. Dabei findet er heraus, dass sich „eine tendenziell bemerkbare erweiterung der verwendung“ ablesen lässt (Kristensson 1977: 227).

Insgesamt entdeckt er in den Zeitungen 79 Simplizia und 198 Mischkomposita. Die Häufigkeit, mit der diese auftreten, variiert je nach untersuchter Zeitung zwischen 195,8 und 154,4 Anglizismen je hundert Seiten. Die Anglizismen lassen sich verschiedenen Themengebieten

${ }^{52}$ Substantive sind in dieser Arbeit teilweise klein geschrieben. 
zuordnen, die meisten werden im Bereich der Außenpolitik verwendet, auch in der Kulturpolitik, der Wirtschaft und in den Bereichen Freizeit, Reise und Sport finden sich im Verhältnis zu anderen in der Zeitung behandelten Themen viele Anglizismen (vgl. Kristensson 1977: 227f.). Kristensson stellt fest, dass

der einfluss des AE bzw. BE auf die europäischen Sprachen nach dem zweiten weltkrieg nicht an der grenze zur DDR halt macht. Obwohl [...] lexikalische einheiten in der BRD-presse zahlreicher sind und eine höhere neuerungsrate und gebrauchsfrequenz aufweisen (Kristensson 1977: 238).

Wolf Oschlies gibt im Jahr 1988 in seinem Aufsatz „Hat der Dispatcher die Broiler abgecheckt? Anglizismen im sprachlichen Alltag der DDR“ einen Überblick darüber, wie Anglizismen in die Sprache der DDR eingedrungen sind. Denn obwohl in den 1950er Jahren das Englische als Sprache des Klassenfeindes bekämpft worden sei, seien staatliche Restriktionen später wieder fallengelassen worden (vgl. Oschlies 1988: 205f.). Er ist der Auffassung, Anglizismen seien über die Sportberichterstattung, die moderne Unterhaltungsmusik und später über die Computer-Sprache in die Sprache der DDR gekommen. Bei der Arbeit handelt es sich nicht um eine quantitative Analyse: Seine Argumente belegt Oschlies durchgehend anhand eines offenen Korpus mit Einzelbeispielen aus Liedern, aus Gesprächsprotokollen, aus Zeitungen und Zeitschriften sowie aus Romanen. Zudem weist Oschlies darauf hin, dass zahlreiche DDR-Produkte englische Namen tragen (vgl. Oschlies 1988: 211). Er kommt zu dem Schluss, die DDR habe sich „sprachlich dem >>imperialistischen<< Englisch recht hemmungslos in die Arme geworfen"53 (Oschlies 1988: 209), und die Sprache der DDR habe seit den 1970er Jahren bezüglich der Zahl der Anglizismen im Vergleich zur Sprache der Bundesrepublik „mächtig aufgeholt“ (Oschlies 1988: 211).

Martin Lehnert publiziert 1990 „Anglo-Amerikanisches im Sprachgebrauch der DDR“. Diese Untersuchung ist eine Erweiterung von Lehnerts „Der angloamerikanische Einfluss auf die deutsche Sprache der Gegenwart der DDR“ aus dem Jahr 1986. Lehnert nimmt sich die Sprache von DDR-Printmedien in den Jahren 1984 bis 1989 vor und weist den anglo-amerikanischen Einfluss auf die Bereiche Wissenschaft,

\footnotetext{
${ }^{53}$ Hervorhebung im Original.
} 
Technik, Sport, Unterhaltung, Mode, Musik und Ernährung nach. Er stellt fest, dass im Jahr 1986 rund 5000 neue Wörter Eingang in den DDR-Duden gefunden haben. Lehnert liefert zwar keine detaillierte Untersuchung, aber er geht davon aus, dass die meisten davon Anglizismen sind. Nach eigenen Angaben hat er den Duden von 1986 insgesamt nur flüchtig durchgeblättert (vgl. Lehnert 1990: 27), 54 den Buchstaben C jedoch hat er detailliert untersucht und mit der Ausgabe von 1984 verglichen: In der Ausgabe von 1986 sind unter diesem Buchstaben 17 Anglizismen mehr verzeichnet als noch 1984, außerdem ist die eingedeutschte Schreibweise „Kautsch“ für „Couch“, die 1984 noch zu finden war, nicht mehr aufgeführt. Das gleiche gelte für „Kockpit“. Insgesamt kommt Lehnert zu dem Ergebnis, der Einfluss des Englischen auf die DDR-Sprache sei weitaus größer als bisher "gemeinhin“ angenommen (Lehnert 1990: 231).

Ausführliche Bibliographien finden sich unter anderem in Carstensens Anglizismen-Wörterbuch und in der Publikation „Globalization and the Future of German“ aus dem Jahr 2004 (Gardt/Hüppauf 2004).55 Carstensen verweist zudem auf die Problematik, wonach zwar seit dem Zweiten Weltkrieg die Zahl der Arbeiten über den englischen Einfluss auf das Deutsche rasch angewachsen sei, dass es sich jedoch meistens um die Analyse geschriebenen Materials handele, aber dringend weitere Untersuchungen der gesprochenen Sprache vonnöten seien (vgl. AWb 1993: 27f.). Des Weiteren ist festzustellen, dass es anhand der verschiedenen Fremdwortbegriffe und Klassifizierungen schwierig ist, Ergebnisse miteinander zu vergleichen.

\subsubsection{Untersuchungen zur Fremdwort- diskussion, zum Purismus und zu sprach- pflegenden Vereinigungen}

Die Purismusforschung ist kein neues Forschungsgebiet: Einen detaillierten Überblick über historischen Purismus gibt zum Beispiel Alan

\footnotetext{
${ }^{54}$ Vgl. auch Lehnert (1986).

${ }^{55}$ Dies ist nicht die einzige Bibliographie, eine ausführliche Darstellung findet sich beispielsweise auch bei Viereck (1980).
} 
Kirkness in seiner zweibändigen Veröffentlichung aus dem Jahr 1975: „Zur Sprachreinigung im Deutschen, 1789 - 1871“. Kirkness beschreibt die Sprachreinigungsbestrebungen ab Mitte des 17. Jahrhunderts (vgl. Kirkness 1975: 17). Während des ganzen 17. Jahrhunderts blieb dabei nach Kirkness die Satire die schärfste Waffe gegen den „Fremdwortunfug“ (Kirkness 1975: 18). Im Zeitalter des Barock gründeten sich die ersten Sprachgesellschaften ${ }^{56}$, wie die „Fruchtbringende Gesellschaft“ in Weimar, die Fürst Ludwig von Anhalt-Köthen 1617 nach dem Vorbild der italienischen Akademie gegründet hat. Die Intention dieser Gesellschaft war, eine selbstständige deutsche Literatur zu entwickeln sowie „die Pflege eines ,deutschgesinnten Tugendmuts'“ (Kirkness 1975: 24). Die „Fruchtbringende Gesellschaft“ ist als die wichtigste und einflussreichste Sprachgesellschaft dieser Zeit anzusehen (Kirkness 1975: 30). Kirkness verweist zudem auf die Bedeutung von G.P. Harsdörffer (1607 bis 1658), Justus Georg Schottelius (1612 bis 1676) und Philipp von Zesen (1619 bis 1689), deren zahlreiche Verdeutschungen Eingang in die deutsche Sprache gefunden haben (vgl. Kirkness 1975: 32ff.). Auch die Arbeit der Akademie der Wissenschaften zu Berlin wird vorgestellt. Ausführlich geht Kirkness unter anderem auf die Ziele der Sprachwahrer Joachim Heinrich Campe und Friedrich Ludwig Jahn ein. Zu Campe konstatiert er, dass er der erste war, der die Fremdwortfrage systematisch behandelte und zahlreiche Ersatzwörter schuf (vgl. Kirkness 1975: 151). Bezüglich Jahn hebt Kirkness dessen extremen Patriotismus und seinen Hass gegen alles Ausländische hervor. Jahn ließ keinerlei Fremdwörter gelten, nicht einmal Titel für Würdenträger. Einfluss hatte Jahn vor allem auf den turnerischen und den militärischen Wortschatz (vgl. Kirkness 1975: 196ff.). Kirkness geht auch auf die Haltung Johann Wolfgang von Goethes ein, der davon überzeugt war, dass die Puristen die deutsche Sprache ruinierten (vgl. Kirkness 1975: 271ff.). Die Kritik Jacob Grimms am Purismus und im speziellen an Campes Verdeutschungswörterbuch referiert Kirkness ebenfalls, verweist aber auch darauf, dass Grimm die Reinheit der deutschen Sprache am Herzen lag (Kirkness 1975: 282ff.). In seinem Aufsatz aus dem Jahr 1998 „Das Phänomen des Purismus in der Geschichte des Deutschen“ gibt Kirkness

${ }^{56}$ Bei Otto (1972) findet sich ein detaillierter Überblick über die Sprachgesellschaften. 
einen Überblick über den Purismus im Deutschen bis in die 90er Jahre hinein. Er definiert den Purismus als Gegenstand und rollt dessen Geschichte in Deutschland detailliert auf, beginnend mit dem 17., endend im 20. Jahrhundert. Bezogen auf das 20. Jahrhundert kommt er zu dem Ergebnis, dass nach 1945 der national-völkische Purismus nur vereinzelt wieder auflebte, aber die Auseinandersetzung mit Fremdwörtern und mit dem Fremdwort unvermindert im ganzen deutschen Sprachraum anhalte (vgl. Kirkness 1998: 414f.). Insgesamt konstatiert er eine tolerante Haltung gegenüber dem Fremdwort, verweist aber auch darauf, dass insbesondere die Anglizismen „Stein des Anstoßes“ seien (Kirkness 1998: 415). Zudem weist er darauf hin, dass es der Sprachwissenschaft obliege, eine konstruktive Fremdwortkritik weiterzuführen (vgl. Kirkness 1998: 415).

Von Polenz konstatiert in seiner „Deutschen Sprachgeschichte. Vom Spätmittelalter bis zur Gegenwart", dass der Fremdwortpurismus durchaus als typische Art der Sprachkritik bzw. als politische Art der Sprachkritik gesehen werden kann (vgl. von Polenz 1999a: 264). Auch er beschäftigt sich u.a. ausführlich mit dem Allgemeinen Deutschen Sprachverein, vor und während der beiden Weltkriege. Aber nicht nur der ADSV/DSV, auch die GfdS wird bei von Polenz untersucht. Er konstatiert, dass nur einige Zweigvereine der GfdS die Tradition des Fremdwortpurismus fortsetzen, stellt fest, dass eine Abkehr vom Fremdwortpurismus auch in der Duden-Redaktion erkennbar sei und kommt zu dem Ergebnis, dass sich keine neuen fremdwortpuristischen Tendenzen entwickelt haben (vgl. von Polenz 1999a: 271ff.). ${ }^{57}$

In den vergangenen Jahrzehnten entstanden zahlreiche Untersuchungen zur Fremdwortdiskussion ${ }^{58}$ und Untersuchungen über sprachpflegende Vereinigungen.

\footnotetext{
${ }^{57}$ Auf diese Einschätzung und Pfalzgrafs Feststellung, dass sie nicht mehr zu halten ist, werde ich in Kapitel 1.8.3 zurückkommen.

${ }^{58}$ Spitzmüller stellt fest: „Generell ist seit den 60er Jahren, vor allem im Lauf der 80er Jahre, eine Zunahme wissenschaftlichen Interesses an öffentlichen Äußerungen zu Sprache zu verzeichnen." (Spitzmüller 2005: 9). Er verweist darauf, dass mittlerweile Linguisten anfangen zu erkennen, dass Spracheinstellungen und damit die Diskurse „ein Teil individueller und kollektiver Sinnstiftung und mithin ein nicht zu vernachlässigender Faktor sprachlichen Handelns sind“ (Spitzmüller 2005: 10).
} 
Eine davon ist Vural Ülküs Untersuchung „Sprachreinigungsbestrebungen in Deutschland seit den 80er Jahren des 19. Jahrhunderts bis zur Gegenwart“. Ülkü konstatiert

\begin{abstract}
„[...] daß die Sprachreinigung, die schon seit 1940 [...] kein öffentliches Anliegen mehr war, nach dem II. Weltkrieg in den heutigen beiden deutschen Staaten niemals eine Unterstützung der Regierungen und Behörden gefunden hat" (Ülkü 1975: 45).
\end{abstract}

Er kommt zu dem Ergebnis, dass nur Einzelne gegen das Fremdwort bzw. den Anglizismus Stellung nehmen, denn auch in seiner Untersuchung kristallisiert sich heraus: Kritik wird nicht am Fremdwort an sich, sondern insbesondere an Wörtern anglo-amerikanischer Herkunft geäußert (vgl. Ülkü 1975: 45ff.). ${ }^{59}$

Ingrid Hillen analysiert in „Untersuchungen zu Kontinuität und Wandel der Sprachpflege im Deutschen Reich, in der Bundesrepublik und in der DDR (1885 bis zur Gegenwart)“ aus dem Jahr 1982 verschiedene Positionen in der Sprachpflege. Angefangen mit der Sprachpflege von 1885 bis nach dem Ersten Weltkrieg geht sie unter anderem auf die Positionen Hermann Riegels und Hermann Dungers ein ebenso wie auf die Institution des ADSV/DSV. Sie konstatiert eine ungeheure Resonanz der von Dunger initiierten Sprachbemühungen. Für die Zeit des Ersten Weltkriegs stellt sie fest, dass das nationale Moment der Sprachpflege an Bedeutung gewann. Generell ist in diesem Zeitabschnitt die Bekämpfung des Fremdworts wichtigster Gegenstand der Sprachpflege (vgl. Hillen 1982: 15ff.).

Untersucht wird auch die Sprachpflege in der Zeit der Weimarer Republik und in der Zeit des Nationalsozialismus. Für die Zeit des Nationalsozialismus konstatiert Hillen, dass eine Reihe von Sprachpflegern „sich die antisemitische Grundhaltung der Nationalsozialisten $\mathrm{zu}$ eigen macht" (Hillen 1982: 68). Bis in die Zeit der 80er Jahre der BRD geht Hillen davon aus, dass die Fremdwortfrage in der Sprachpflege nicht mehr die Rolle einnimmt wie in den Perioden zuvor. Stattdessen sei die Haltung einzelner Sprachpfleger geprägt von Toleranz und basiere auf einem wissenschaftlichen Fundament. Das Gleiche gelte für die DDR (vgl. Hillen 1982: 116ff.). Hillens Untersuchung ist eine der ersten, die sprachpflegende Institutionen in Deutschland näher beschreibt. Dabei

${ }^{59}$ Ähnlich auch Ülkü 2002. 
geht sie auf die Gesellschaft für deutsche Sprache ein, die sie als bedeutendste sprachpflegerische Institution ansieht (vgl. Hillen 1982: 136). In Zusammenhang mit der Dudenredaktion macht Hillen darauf aufmerksam, dass ein Wirtschaftsunternehmen in der Bundesrepublik die Funktion einer Sprachberatung einnimmt (vgl. Hillen 1982: 138). Ebenfalls vorgestellt werden die Kommission für Fragen der Sprachentwicklung sowie der Verein für Sprachpflege in Hamburg, den Hillen wegen seiner puristischen Komponente als „Erbe[ ] des Allgemeinen Deutschen Sprachvereins“ ansieht (vgl. Hillen 138ff.).

Matthias Jung stellt in seiner Publikation „Amerikanismen, ausländische Wörter, Deutsch in der Welt. Sprachdiskussion als Bewältigung der Vergangenheit und der Gegenwart" aus dem Jahr 1995 fest, dass die "deutschtümelnde Sprachreinheitsideologie nach 1945 zunächst ungebrochen [ist]“ (Jung 1995: 249). Er gibt einen Überblick über die Fremdwortdiskussion von den 1930er Jahren bis in die 1990er Jahre und stellt deutlich heraus, dass nicht, wie oft behauptet, ein sauberer Schnitt nach dem Zweiten Weltkrieg gemacht wurde, sondern dass die puristische Haltung weiter beibehalten wurde. Jung untersucht auch die Thematisierung der Fremdwortdiskussion in der Presse anhand beispielhaft ausgewählter Artikel aus Leitmedien wie Die Zeit oder Der Spiegel hinsichtlich der Diskussion um Anglizismen, und stellt fest, dass sich Purismus nur gegen amerikanischen Einfluss richtet, also selektiv ist (vgl. Jung 1995: 250). Seine Methoden bezüglich der Auswahl der Presseartikel werden nicht expliziert, offensichtlich handelt es sich weitgehend um Zufallsfunde. Jung konstatiert ebenfalls die Verwendung von Flut-, Untergrund- und Krankheitsmetaphorik im Fremdwortdiskurs (vgl. Jung 1995: 253) ${ }^{60}$, er geht sogar von einem „Paradigmenwechsel“ in der Fremdwortdiskussion aus: Sprachkritik werde nur noch versteckt und ironisch-indirekt geäußert (vgl. Jung 1995: 256ff.). ${ }^{61}$

Anke Sauter beschäftigt sich in ihrer 2000 erschienenen Arbeit „Eduard Engel. Literaturhistoriker, Stillehrer, Sprachreiniger. Ein Beitrag zur Geschichte des Purismus in Deutschland“ mit Leben und Werk Eduard

${ }^{60}$ Diese Feststellung wird in späteren Arbeiten über Anglizismen und Purismus im Deutschen immer wieder aufgegriffen.

61 „Paradigmenwechsel“ als Begriff ist für diese Entwicklung übertrieben. 
Engels (1851 bis 1938), der die damalige Gegenwart der Sprache in dunklen Farben zeichnete und schon damals für die Zukunft der deutschen Sprache schwarz sah. Neben Engels Kindheit und Jugend beschreibt Sauter die Zeit seines Studiums und seiner Promotion. Ein Schwerpunkt der Arbeit liegt auf Engel und der Literatur. Sauter weist darauf hin, dass die Literaturgeschichte ein bedeutendes Arbeitsfeld Engels war. Schon seine frühen Buchprojekte waren erfolgreich, ebenso seine Herausgeberschaft des "Magazins für die Literatur des Auslan-

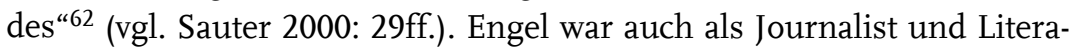
turkritiker aktiv. Zudem hat er 14 Novellen veröffentlicht (vgl. Sauter 2000: 62), heute aber ist er als Sprach- und Stilkritiker bekannter; er gilt als einer der namhaftesten Stillehrer der ersten Hälfte des 20. Jahrhunderts. Seine Veröffentlichung „Die deutsche Stilkunst“ wurde zu einer der wichtigsten Stillehren und war von Anfang an ein Verkaufserfolg (vgl. Sauter 2000: 75ff). Ein Schwerpunkt von Sauters Arbeit liegt auf der Betrachtung der Haltung von Engel zu Fremdwörtern. Engel betrachtete schon in jungen Jahren Fremdwörter als „eine Sprachkrankheit“, ihre Vermeidung stellte er in den Zusammenhang mit der Frage nach gutem Stil (vgl. Sauter 2000: 199). In den Jahren nach 1914 wird Engel zum Vertreter eines „völkischen Purismus“ (Sauter 2000: 214). Ausführlich stellt Sauter das Verhältnis Engels zum ADSV/DSV dar, der Engel zuerst sehr willkommen hieß und zu seinem Ehrenmitglied ernannte zur Zeit des Nationalsozialismus aber fiel Engel, der Jude war, der Linientreue des Vereins zum Opfer. Der Verein brach mit dem einstigen Vorzeigemitglied (vgl. Sauter 2000: 283ff., vgl. dazu auch Kapitel 1.7.1). Schließlich stellt Sauter in ihrer aufschlussreichen Arbeit Wirkung und Nachwirkung Engels dar: Beispielsweise hat Ludwig Reiners ohne jegliche Angabe der Quelle Engels Werk „regelrecht ausgeschlachtet“ (Sauter 2000: 344). Über den Umweg von Reiners Publikationen leben und wirken Engels Ideen und Gedanken beispielsweise auch in den Werken von Wolf Schneider (vgl. Sauter 2000: 349).

Gerade in jüngster Zeit gibt es zahlreiche diskursanalytische Ansätze, die sich mit sprachpflegerischen Vereinigungen, deren Sprache und der Rezeption in den Medien auseinandersetzen. Auf die Arbeiten kann

${ }^{62}$ Später: „Magazin für die Literatur des In- und Auslandes“ (vgl. Sauter 2000: 31). 
nicht verzichtet werden, sind sie doch beinahe die einzigen neueren Arbeiten, die sich mit diesen Thematiken auseinandersetzen. ${ }^{63}$

Auf einen neuen diskursanalytischen Ansatz, den Fremdwortdiskurs zu untergliedern, um ihn dadurch differenzierter untersuchen zu können, möchte ich hier näher eingehen: Andreas Gardt beschäftigt sich damit, "wie von der frühen Neuzeit bis in das 20. Jahrhundert von Autoren deutscher Sprache über Fremdwörter gedacht und geschrieben wurde“ (Gardt 2001a: 30). Dies ist ein interessanter Ansatz, um die Diskurse zu gliedern und somit leichter werten zu können.

In seiner Analyse hat Gardt eine Belegsammlung aus wissenschaftlichen Abhandlungen, Stellungnahmen von Politikern, Korrespondenz von Sprachpflegern, Zeitungsartikeln und Leserbriefen etc. von der Frü-

${ }^{63}$ Es ist nicht möglich, von „der Diskursanalyse“ zu sprechen. Eine Form der Diskursanalyse untersucht sprachliche Ereignisse in ihrem „context of situation“; diese Form wird der Londoner Schule zugeordnet. Daneben steht ein Ansatz, der auch gedankliche Strukturen wie Vorurteile in die Analyse mit einbezieht. In diese Richtung geht auch die Diskursanalyse in Anlehnung an Michel Foucault, der Diskurs als ein Netz, als eine Menge von Aussagen verstand, dahingehend, dass diese einem identischen Formationssystem zugehörig sind (vgl. Foucault 1981: 156, vgl. zum Diskursbegriff Foucaults auch Foucault 1971, für eine Einführung in die Diskursanalyse nach Foucault vgl. u.a. Mills 1997). Vertreter dieser Richtung sind unter anderem Jäger und Maas (vgl. dazu u.a. Jäger 1991, Maas 1984). Der deutschen Diskursanalyse kommt generell eine doppelte Vermittlungsaufgabe zu, einerseits ist der Terminus Oberbegriff für die sprachwissenschaftliche Analyse von Diskursphänomenen, andererseits Bezeichnung einer Teildisziplin aus der linguistischen Pragmatik (vgl. MLS 2005: 149), beispielsweise bei Rehbein: „Das Erkenntnisobjekt ist dabei mehr als nur eine Menge von Sätzen in ihrem ,situativen Kontext', im Gegenteil: Die Methode ermöglicht eine präzise Unterscheidung äußerungsbegreifender Formen und deren Funktionen von solchen, die an einzelne Lautzeichen oder andere sprachliche Formeinheiten unterhalb des Äußerungsakts gebunden sind. Das Analyseverfahren ist keine [...] einszu-eins-Übertragung vorgefertigter Kategorien auf das ,sprachliche Material', sondern ein interpretativer Prozeß auf mehreren Stufen" (Rehbein 2001: 927). Nicht einig sind sich die Sprachwissenschaftler, ob Diskursanalyse als Methode, Methodologie oder als Theorie zu werten ist (vgl. für diese Diskussion ausführlich Reisigl 2007). Reisigl fordert daher für eine zukunftsoffene Entwicklung einer linguistischen Diskursanalyse, „deskriptive Präzision, Sorgfalt in der Suche nach theoretischer und methodischer Anschlussfähigkeit und methodologische Selbstkritik“ (Reisigl 2007: 78). Zudem solle das gegenwärtige Nebeneinander verschiedenster Ansätze in einen kritischen Dialog transformiert werden (vgl. Reisigl 2007: 78). Die Diskursanalyse als Methode wird in der Sprachwissenschaft häufig kritisiert: Etwa an der Auswahl der Korpora, oder dass zugrundegelegt wird, dass der Text an sich als Produkt zu verstehen ist, oder dass Bestandteile der Sprache eine einzige Bedeutung haben, der alle Analysten zustimmen können (vgl. ausführlich z.B. Mills 1997: 132ff.). Darin und in der Subjektivität bei der Auswahl des Korpus liegen Schwierigkeiten. 
hen Neuzeit bis zum Ende des Zweiten Weltkriegs zu der Frage untersucht, welche Formen des Diskurses regelmäßig vorkommen. Gardt unterteilt aufgrund seiner Ergebnisse dieser Analysen den Fremdwortdiskurs bis 1945 in Unterkategorien. Demnach sind Fremdwörter im Deutschen Gegenstand folgender Diskurse:

$$
\begin{aligned}
& \text { - eines sprachstrukturellen Diskurses, in dem grammatische und le- } \\
& \text { xikalische Fragen in Bezug auf Fremdwörter erörtert werden [...] } \\
& \text { - eines sprachideologischen Diskurses, in dessen Kontext der Fremd- } \\
& \text { wortpurismus in seiner kulturpatriotischen bis nationalistischen Be- } \\
& \text { gründung fällt [...] } \\
& \text { - eines sprachpädagogischen und sprachsoziologischen Diskurses, } \\
& \text { der auf die Korrelation von Bildung und Fremdwortbeherrschung } \\
& \text { sowie Kognition und Fremdwortbeherrschung abhebt [...] } \\
& \text { - eines sprachkritischen Diskurses, der 1. Fragen der rhetorisch- } \\
& \text { stilistischen Gestaltung von Sprache durch Fremdwörter thematisiert } \\
& \text { und 2. das Problem einer kommunikativen Ethik aufgreift (Gardt } \\
& \text { 2001a: 30). }{ }^{64}
\end{aligned}
$$

Dieser Ansatz für die Analyse von Diskursen ist gut nachzuvollziehen, wenn auch nicht immer leicht umzusetzen, da die Diskurstypen mitunter schwer voneinander zu unterscheiden sind.

Eine Anwendung der Typen für die Diskurse der sprachpflegerischen Vereinigungen unserer Zeit, auch den des VDS, liefert Pfalzgraf, auf den in diesem Kapitel noch eingegangen wird. Generell zeigt sich gerade in der neuesten Fremdwort- und Anglizismenforschung eine verstärkte Hinwendung zu diskursanalytischen Untersuchungen, trotz aller Schwierigkeiten, die diese Methodik im Hinblick auf die Unterscheidung von Diskurstypen mit sich bringt. Falco Pfalzgraf (2006) und Jürgen Spitzmüller (2005) verwenden in ihren Untersuchungen den diskursanalytischen Ansatz als Methode, dabei erklären sie ihn zu einem methodisch kontrollierbaren Analyseverfahren. Beide Arbeiten beschäftigen sich auch mit dem VDS und werden in diesem Kapitel noch vorgestellt. Von besonderer Bedeutung für meine Arbeit sind die wenigen Untersuchungen, die speziell den VDS zum Gegenstand haben:

Eine der frühesten Arbeiten zum VDS ist Silke Wiechers' Aufsatz: „Wir sind das Sprachvolk!“ erschienen in der Zeitschrift Muttersprache im Jahr 2001. Dieser Aufsatz bietet einen Überblick über verschiedene sprachpflegerische Vereinigungen in Deutschland. Wiechers nennt die

\footnotetext{
${ }^{64}$ Für eine ausführliche Darstellung und Bewertung vgl. Pfalzgraf (2006: 59ff.).
} 
wichtigsten Vereinigungen, deren Ziele und Einstellungen. Anhand von Satzungen, Publikationen, Äußerungen der Vereinsvorsitzenden etc. untersucht sie kritisch die Arbeitsgemeinschaft für deutsche Sprache, den Arbeitskreis Unsere Sprache, den Bund für deutsche Schrift und Sprache e.V., die Bubenberg-Gesellschaft Bern - Sprachkreis Deutsch, die Interessengemeinschaft Muttersprache Österreich Graz e.V., den Verein Muttersprache Wien, den Verein für deutsche Rechtschreibung und Sprachpflege e.V. und den Verein deutsche Sprache. Wiechers setzt sich mit Einstellungen gegenüber der Sprache und Motiven der Sprachpflege auseinander, untersucht also anhand von Publikationen der Vereine, welche Argumente gegen den Anglizismengebrauch und welche Einstellungen erwähnt werden, und beschreibt Verflechtungen der Sprachvereine untereinander. Meines Wissens ist das nach Ingrid Hillens Arbeit von 1982 die erste Analyse, in der anhand von ausführlichen Recherchen die Arbeit verschiedener sprachpflegender Vereinigungen in Deutschland dargestellt wird. Für weitere Forschungsarbeiten auf diesem Gebiet ist sie richtungweisend.

In seinem Aufsatz „Selbstfindung durch Ausgrenzung: Eine kritische Analyse des gegenwärtigen Diskurses zu angloamerikanischen Entlehnungen“ setzt sich Jürgen Spitzmüller im Jahr 2002 kritisch mit dem VDS auseinander. Er stellt fest, dass der Diskurs des VDS eng verbunden ist mit „Identitätsfindung, Selbstfindung und Ausgrenzung“ (Spitzmüller 2002: 259). Er sieht ihn eingebettet in einen größeren Gesamtkontext von Nation und Identität (vgl. Spitzmüller 2002: 262) und setzt den Diskurs in Zusammenhang mit den politischen und sozialen Entwicklungen der Zeit der Wiedervereinigung und danach.

Claudia Law vergleicht in ihrem Aufsatz „Das sprachliche Ringen um die nationale und kulturelle Identität Deutschlands. Puristische Reaktionen im 17. Jahrhundert und Ende des 20. Jahrhunderts“ (Law 2002) den Purismus im 17. Jahrhundert mit den Aktivitäten des VDS, dem „zurzeit wohl prominentesten Vertreter dieser Bewegung [gemeint sind Clubs und Vereine „zur Reinigung und Rettung der deutschen Sprache“65, Anm. d. Verf.]“ (Law 2002: 68). Für das 17. Jahrhundert weist sie darauf hin, dass die sprachreinigenden Bemühungen der Fruchtbrin-

${ }^{65}$ Siehe dazu Law (2002: 68), Hervorhebung im Original. 
genden Gesellschaft vor dem Hintergrund des damaligen Kulturpatriotismus zu verstehen sind (vgl. Law 2002: 75) und dass schon damals das Fremdwort unter drei Gesichtspunkten diskutiert wurde, nämlich hinsichtlich der Sprachstruktur, des Sprachgebrauchs sowie der Sprachkritik (vgl. Law 2002: 74). Für den VDS konstatiert sie eine Widersprüchlichkeit und Beliebigkeit in der Fremdwortauffassung sowie das Außerachtlassen der sprachwissenschaftlichen Erkenntnisse über Anglizismen (vgl. Law 2002: 79ff.). Als eine der ersten stellt sie die Existenz sprachpuristischer Bewegungen in der heutigen Zeit fest.

Im Jahr 2003 setzt sich Markus Nussbaumer in einem Kommentar mit der Veröffentlichung „Die Zukunft der deutschen Sprache“ von Helmut Glück und Walter Krämer auseinander. Sein Augenmerk legt er dabei auf die Thesen des wissenschaftlichen Beirats. Dabei stellt er fest, dass in dieser Publikation die Thematik erschöpfend behandelt wurde, kritisiert aber, dass alle Beiträge ihre Thematik nicht wirklich analytisch angehen. So bemängelt er beispielsweise die fehlende Unterscheidung zwischen Langue und Parole und die Vorstellung einer statischen und einer reinen Sprache, die den Thesen des Beirats zugrunde liege (vgl. Nussbaumer 2003: 111f). Insgesamt bewertet er die Position des VDS und seines wissenschaftlichen Beirats als "sprachpolitischen Populismus“ (Nussbaumer 2003: 117). Des Weiteren führt Nussbaumer aus, dass der VDS den öffentlichen Diskurs „vergifte“ und dass die Sprachwissenschaft sich der öffentlichen Sprachdebatte stellen sollte (Nussbaumer 2003: 118).

2004 erschien Silke Wiechers' Untersuchung „Gesellschaft für deutsche Sprache. Vorgeschichte, Geschichte und Arbeit eines deutschen Sprachvereins." Diese Arbeit beinhaltet eine ausführliche Darstellung des Vereins und seiner Geschichte, von der Geschichte des ADSV/DSV, des Vorläufervereins der GfdS, bis zur Gegenwart, über das Wirken des Vereins sowie die Aufführung seiner Aktionen und Einstellungen gegenüber dem Fremdwort. Wiechers benutzt dazu verschiedene Quellen, insbesondere die interne Korrespondenz des Vereins, aber auch die verschiedenen Publikationen, wie die Zeitschriften Muttersprache und Sprachdienst. Sie beschäftigt sich mit Dichtern und Schriftstellern in der GfdS, dem Einfluss Leo Weisgerbers (zu Weisgerber vgl. Kapitel 1.9.1.) auf die Sprachpflegearbeit der GfdS, dem Fremdwort in der GfdS und 
dem Wirken der Gesellschaft. Sie kommt zu dem Ergebnis, dass die Gründung der GfdS 1947 zwar als Abkehr von den alten Traditionen des ADSV/DSV gesehen worden war, die Haltung der GfdS in den ersten Jahren aber noch stark von der puristischen Tradition des ADSV/DSV geprägt war (vgl. u.a. Wiechers 2004: 329). Wiechers konstatiert, dass die GfdS mittlerweile auf dem Gebiet der Fremdwortfrage eine gemäßigte Haltung eingenommen hat, fürderhin spricht die GfdS sich eindeutig gegen ein Sprachreinigungsgesetz nach französischem Vorbild aus (vgl. u.a. Wiechers 2004: 331). Diese detaillierte und sorgfältig recherchierte Arbeit bietet wichtige Einblicke in eine der bedeutendsten sprachpflegerischen Institutionen Deutschlands.

Jürgen Spitzmüllers „Metasprachdiskurse. Einstellungen zu Anglizismen und ihre wissenschaftliche Rezeption“ aus dem Jahr 2005 ist eine Untersuchung von Diskursen zu Anglizismen. Dabei ist der erste Teil der Arbeit dem öffentlichen Diskurs gewidmet. Spitzmüller analysiert anhand eines Korpus aus 1380 Dokumenten (1116 Zeitungsartikel, 148 Zeitschriftenartikel, 64 Texte aus außerwissenschaftlicher metasprachlicher Literatur, neun Fernsehbeiträge, 16 Hörfunkbeiträge, 26 Internetdokumenten und ein Lied). Das Restkorpus besteht aus Einzelfunden.

Die untersuchten Zeitungen und Zeitschriften waren die Süddeutsche Zeitung, die Frankfurter Allgemeine Zeitung, die taz, Die Welt/Welt am Sonntag, Die Zeit, der Mannheimer Morgen, die Badische Zeitung, der Focus, Der Spiegel und der Stern. Welche Zeitung oder Zeitschrift Spitzmüller in welchem Zeitraum analysierte, war davon abhängig, welche Archive $\mathrm{ab}$ wann online zugänglich waren. Ab diesem Zeitpunkt analysierte Spitzmüller alle Ausgaben innerhalb der Jahrgänge. Dies ist der Praktikabilität geschuldet, eine Recherche in Papier- oder Filmausgaben hätte ungleich länger gedauert (Spitzmüller 2005: 75). Während also die Badische Zeitung beispielsweise ab dem Jahr 1990 untersucht wurde, ging die Frankfurter Allgemeine Zeitung erst ab dem Jahrgang 1993 in die Untersuchung ein (vgl. Spitzmüller 2005: 371). Dabei weist Spitzmüller aber selbst darauf hin, dass die Aussagekraft eines Korpus immer auch stark von der subjektiven Auswahl des Erstellers des Korpus abhängt (vgl. Spitzmüller 2005: 73) - eine Problematik, die sich die Diskursanalyse immer wieder vorwerfen lassen muss. Die Texte seines Korpus unter- 
suchte er systematisch nach Schlagwörtern (darunter angliz*, anglis*, dengli*) (vgl. Spitzmüller 2005: 74ff.).

Spitzmüller erläutert, dass sich hinter „Diskurs“ mehr verbirgt als „ein modisches Synonym für Debatte, Diskussion oder Gespräch"66 (Spitzmüller 2005: 29) Theoretische Grundlage ist für Spitzmüller das Diskurskonzept von Michel Foucault und dessen Ansicht, dass es nicht möglich sei, Aussagen auf eine Menge von Zeichenbedeutungen zu reduzieren. ${ }^{67}$ Eine Aussage sei nie isoliert zu betrachten. Abhängigkeiten von gesellschaftlichen Beziehungen spielten immer eine Rolle (vgl. Spitzmüller 2005: 32ff.). Spitzmüller definiert seinen "Metasprachdiskurs“ als "Gesamtheit aller Aussagen zum Thema Sprache“ (Spitzmüller 2005: 37). ${ }^{68}$ Seine Diskurse unterteilt er in Mikro- und Makrodiskurse, des Weiteren unterscheidet er einen öffentlichen und einen wissenschaftlichen Diskurs (vgl. Spitzmüller 2005: 70) und kommt zu dem Ergebnis, dass in seinem Korpus die anglizismenkritischen Texte überwiegen. Sie machen fast die Hälfte aller Texte aus. Er stellt fest, dass in Textsorten, in denen Wertungen nicht enthalten sein sollten, Wertungen platziert werden (Spitzmüller 2005: 103f.). Für die Jahre 1990 bis 1993 ist eine „[v]erhaltene Anglizismenkritik und Kritik des Purismus“ notiert, auch wenn sich kritische Stimmen mehrten. Ab 1994 bis 1996 kommt es seiner Meinung nach zu einer „zunehmenden Anglizismenkritik“, auch in Zusammenhang mit der Französischen „Loi Toubon“. Ab 1995 geht laut Spitzmüller die Auseinandersetzung mit der französischen Sprachkritik zurück, die kritischen Stimmen aber werden lauter. Von $1997^{69}$ bis 1999 stellt er eine Institutionalisierung der Anglizismenkritik fest, wobei der VDS an dieser Diskussion maßgeblich beteiligt war. Insgesamt kommt er zu dem Ergebnis, dass der Teildiskurs zu Anglizismen im Laufe der 1990er Jahre zugenommen hat, und zwar ebenso kontinuierlich wie deutlich, und dass sich bei der Entwicklung der Spracheinstellung keine Verschiebungen zeigen. Er geht davon aus, dass der Diskurs weitgehend ideologisiert ist (vgl. Spitzmüller 2005: 145f.).

\footnotetext{
${ }^{66}$ Hervorhebungen im Original.

${ }^{67}$ Vgl. oben in diesem Kapitel.

${ }^{68}$ Hervorhebung im Original. Mit dieser Definition folgt Spitzmüller Matthias Jungs Ideen (1996, z.B. auch 2000).

${ }^{69}$ Dem Jahr der Gründung des VDS und anderen sprachpflegerischen Organisationen.
} 
Einen Überblick über die neuesten Entwicklungen gibt Falco Pfalzgraf in seiner Publikation "Neopurismus in Deutschland nach der Wende“ aus dem Jahr 2006. Pfalzgraf bezieht sich auf den diskursanalytischen Ansatz von Gardt (siehe oben in diesem Kapitel). Er untersucht ausgehend von dessen Unterteilung des Fremdwortdiskurses verschiedene sprachpflegerische Vereinigungen, darunter auch den VDS, auf das Vorkommen der jeweiligen Diskurse. Seiner Analyse liegt jeweils ein offenes Korpus der Publikationen der sprachpflegerischen Vereinigungen zugrunde. ${ }^{70}$ Er ermittelt, dass Fremdwortkritik von Sprachschutzvereinen und -organisationen, von der Politik und den Medien sowie von Einzelpersonen betrieben wird. Er konstatiert weiterhin, bei Sprachschutzvereinen und einzelnen Personen sei am häufigsten der sprachideologische Diskurs (nach Gardts Unterscheidungskriterien) zu verzeichnen, die Motivation zur Sprachkritik sei damit ideologisch (vgl. Pfalzgraf 2006: 304ff.). Die Gründe für die neopuristischen Tendenzen in Deutschland seit den 1990er Jahren sieht er unter anderem in der deutschen Wiedervereinigung. Für die puristischen Strömungen in Deutschland führt Pfalzgraf den Begriff des „Neopurismus“ ein (vgl. Kapitel 1.4.3. und 1.6.). Die Dissertation enthält viele aktuelle Informationen zu sprachpflegerischen Vereinigungen und privaten Internetauftritten von Sprachschützern.

Pfalzgraf hat bereits früher zwei Aufsätze publiziert, die die FremdwortThematik in Zusammenhang mit dem Rechtsextremismus stellen. Als erstes sei hier auf den Artikel „Fremdwortdiskussion und Anglizismen“ aus dem Jahr 2003 verwiesen. Der Autor stellt fest, dass seit den 1990er Jahren die Fremdwortdiskussion in Deutschland an Schärfe zugenommen hat (Pfalzgraf 2003a: 102). Außerdem liefert er in dieser Studie eine Darstellung der sprachpflegerischen Institutionen, der Vernetzungen der sprachpflegenden Vereine untereinander und der Kontakte mit rechten Gruppierungen. Er hält es zwar für unangemessen, alle sprachpflegerischen Vereine als rechtsextrem einzustufen, bezüglich des Bundes für deutsche Schrift und Sprache und ARKUS gelte dies aber durchaus (vgl. Pfalzgraf 2003a: 107ff.).

\footnotetext{
${ }^{70}$ Ein offenes Korpus unterliegt immer der Kritik der subjektiven Auswahl des Verfassers, dennoch ist wohl für diese Art der Untersuchung das offene Korpus der einzig gangbare Weg.
} 
In „Recent Developments concerning language protection organizations and right wing-extremism in Germany" untersucht Pfalzgraf die Deutsche Sprachwelt und den Deutschen Sprachkampf (DSK). Er kommt zu dem Ergebnis, dass beide Organisationen Verbindungen zu rechtsextremen Personen oder Organisationen aufweisen und dass der DSK als rechtsextrem angesehen werden muss. Hier verweist Pfalzgraf anhand seiner Internetrecherchen auch darauf, dass sowohl das VDS-Logo als auch VDS-Rundbriefe und eine schlanke Version der VDSAnglizismenliste auf den Seiten des DSK zu finden waren. In der gegenseitigen Anziehung von Sprachpflege und nationalistischer oder konservativer Einstellung sieht er nichts Neues, man müsse aber im Hinterkopf behalten, dass diese beiden Gruppierungen nicht repräsentativ für sprachpflegende Vereine und deren politische Haltung in Deutschland seien (vgl. Pfalzgraf 2003b: 408f.). Diese sehr interessanten, aufwendig recherchierten Arbeiten zeigen Zusammenhänge auf zwischen einigen sprachpflegenden Vereinigungen und der rechtsextremen Szene und liefern einen guten Überblick über personelle Verflechtungen.

Der Aufsatz von Anja Stukenbrock „Aus Liebe zur Muttersprache? Der VDS und die fremdwortpuristische Diskurstradition“, beschäftigt sich mit den „immer wiederkehrenden Topoi sprachkritischer Diskurse“. Stukenbrock sieht die Emotionalität sprachkritischer Diskurse als einen der Gründe für ihr Spannungsverhältnis zur modernen Linguistik (vgl. Stukenbrock 2005a: 222) und spricht von „sprachbezogene[n] Emotionen“ (Stukenbrock 2005a: 222). Sie konstatiert die Verwendung von Kriegs- und Wassermetaphorik, und spricht sogar von einem „bellum verbale“ (Stukenbrock 2005a: 227). Insgesamt sieht sie den VDS und seine Diskurse sehr kritisch und wertet den „Anglizismenpurismus des VDS“ (Stukenbrock 2005a: 243) nicht nur als Sprachpflege, sondern auch als "Gegenbewältigungsstrategie zu existierenden Formen der Vergangenheitsbewältigung, die aufgrund ihrer politischen, ethischmoralischen und generationsspezifischen Diversität keine allgemeinverbindliche Antwort bieten können“ (Stukenbrock 2005a: 243). Sie bescheinigt dem VDS einen „Verbindlichkeitsanspruch“ in der Anglizismenfrage, der auf die politische Ebene übertragen wird (vgl. Stukenbrock 2005a: 243). 
Meine Arbeit soll auf den Ergebnissen von Wiechers, Spitzmüller und Stukenbrock ebenso wie auf den Ergebnissen von Hillen und den Untersuchungen von Pfalzgraf über neopuristische Strömungen in Deutschland aufbauen. Insgesamt ist festzustellen, dass sprachpflegerische Vereinigungen in den letzten Jahren zunehmend in das Interesse der Forschung gerückt sind, darunter auch der VDS, der Gegenstand der vorliegenden Untersuchung ist. Mit den neuesten Veröffentlichungen einher geht ein Wandel in der Sprachwissenschaft bezüglich des Purismus: In den Untersuchungen zeigt sich, dass mittlerweile einige Sprachwissenschaftler das Aufkommen von puristischen Strömungen konstatieren. In diesem Zusammenhang steht auch die Verwendung des Begriffs des Neopurismus, den Pfalzgraf für den Titel seiner Untersuchung gewählt hat. Dieser Begriff ist mittlerweile auch in der Neuauflage des Metzler Lexikons Sprache zu finden. Dort heißt es:

Die in der zweiten Hälfte des 20. Jh. abgeschlossen geglaubte Fremdwortdiskussion flammte nach Meinung vieler Linguisten als sog. Neopurismus in den 1990ern wieder auf und wird seither so gut wie ausschließlich als Anglizismenkritik geführt (MLS 2005: 203).

\subsection{Begriffsklärungen}

In diesem Abschnitt soll gezeigt werden, welche Schwierigkeiten bei der Definition des Fremdworts auftreten. In der deutschen Sprachwissenschaft gibt es eine stark differenzierte Betrachtung des Begriffs Fremdwort. ${ }^{71}$. Auch die Begriffe Anglizismus und Amerikanismus (Kapitel 1.5.2) und die damit verbundene Diskussion werden vorgestellt. Ebenso werden die Begriffe Anglizismus“, „Britizismus“ und „AngloAmerikanismus" definiert. Termini der Diskussion sind auch „Denglisch“ und „Engleutsch“. Diese werden ebenfalls erläutert. Nicht fehlen darf an dieser Stelle eine Übersicht über die Begrifflichkeiten „Sprachpflege“, „Sprachkritik“, „Sprachreinigung“ und „Purismus“ sowie eine Definition des Purismus.

\footnotetext{
${ }^{71}$ Dies gilt nicht immer, auch in der Linguistik gibt es einfache Erklärungsansätze, so bezeichnet Albrecht Greule mit „Deutsches Wort“ „Wörter, die zum Erbwortschatz gehören“, im Gegensatz dazu gibt es „Fremdwörter“, darunter versteht er „Wörter, die nicht zum Erbwortschatz gehören“ (Greule 1980: 267ff.).
} 


\subsubsection{Fremdwort und Lehnwort}

Bei der Fremdwortdiskussion stellt sich die Frage: Was ist eigentlich ein Fremdwort? Eisenberg schreibt: "The distinction between 'Fremdwort' und 'Lehnwort' is by no means uniform and uncontroversial in the literature [...]" (Eisenberg 2004b: 124). Beim Begriff des Fremdworts unterscheidet sich die Sicht der Linguisten stark von der Sicht der linguistischen Laien. Häufig ist zu beobachten, dass linguistischen Laien die Unterscheidung „Fremdwort“ und „deutsches Wort“ genügt, während in der Linguistik verschiedenste Auffassungen zur Klassifikation von Lehngut existieren (vgl. Kapitel 1.4.1). Andere Linguisten haben den Begriff des Fremdworts mittlerweile ganz abgeschafft ${ }^{72}$ oder prognostizieren, dass die Unterscheidung zwischen Fremd- und Lehnwort bald nur noch eine „lexikographische Reminiszenz“ sein wird (vgl. Munske 2001: 27).

Fremdwort und Lehnwort werden auch als direkte Entlehnungen bezeichnet. Die Unterscheidung zwischen Fremdwort und Lehnwort ergibt sich aus einer diachronen Sprachbetrachtung, ausgehend von der Etymologie der Wörter.

Auf diese Unterscheidung soll kurz eingegangen werden, da in der Fremdwortdiskussion bei sprachpflegerischen Vereinigungen oft differenziert wird zwischen Fremdwörtern, die schon lange im Deutschen sind und daher auch für Mitglieder sprachpflegerischer Vereinigungen kein Ärgernis darstellen (diese könnten aus sprachwissenschaftlicher Sicht zu den Lehnwörtern gezählt werden) und Fremdwörtern, die neu ins Deutsche gekommen sind und so von Sprachkritikern abgelehnt werden.

Der Begriff Fremdwort ist vermutlich im 19. Jahrhundert entstanden. Wahrscheinlich ist er das erste Mal belegt bei dem Philosophen K.C.F. Krause im Jahr 1815 (vgl. Korlén 1976: 331). 1816 taucht er bei Friedrich Ludwig Jahn auf (vgl. Jahn/Eiselen 1816: 22, vgl. auch von Polenz 1999a: 265 sowie Kapitel 1.7.2). Schon im 17. Jahrhundert war von „fremden Wörtern“ die Rede (vgl. u.a. Gardt 1997: 391, Kirkness 1975: 235).

72 Vgl. dazu z.B. Polenz (1979), Kirkness (1983 und 1985) sowie Stickel (1985). 
Im Jahr 1819 verwendete Jean Paul den Begriff in der Vorrede zur dritten Auflage seines Romans „Hesperus“:

Wer sich eigentlich an der deutschen Sprache und an denen, welche keine andere verstehen, am Stärksten versündigt, dies sind die $\mathrm{Na}$ turgeschichtsschreiber, welche, wie z.B. Alexander von Humboldt, den ganzen lateinischen Linné mitten in unsere Sprache hineinstellen, ohne andere deutsche Abzeichen, als hinten die Aufschwänzung in deutschen Endungen oder Schwanzfedern, womit sie aber dem bloßen Deutschsprecher so wenig kenntlich werden, als ein Mann einem Fremden hinten durch den bloßen Zopf. [...] Sonst übrigens wird die deutsche Sprache sogar durch die größte Gastfreiheit niemals verarmen und einkriechen. Denn stets zeugt sie (wie alle Wörterbücher beweisen) aus ihren immer frischen Stammbäumen hundertmal mehr Kinder und Enkel und Urenkel, als sie fremde Geburten an Kindes Statt nimmt; so daß nach Jahrhunderten die aus unsern forttreibenden Wurzelwörtern aufgegangene Waldung die nur als Flugsame aufgekeimten Fremd-Wörter ersticken und verschatten muß [...] (Jean Paul 1826: VIIf.).

Unter einem Fremdwort ${ }^{73}$ wird eine „Entlehnung aus einer fremden Sprache verstanden, die nicht oder nur sehr gering in das phonologische, morphologische und graphematische System der Nehmersprache integriert ist“" (MLS 2005: 220). Das heißt, die fremde Herkunft der Wörter ist deutlich zu erkennen (vgl. Yang 1990: 11). Im Unterschied dazu umfasst die Klasse der Lehnwörter „Entlehnung[en], die (im Unterschied zum Fremdwort) in das phonologische, morphologische und graphematische System der Nehmersprache integriert [sind]“ (MLS 2005: 375). ${ }^{74}$ Eine ähnliche Auffassung hat Schönfelder, auf den sich z.B. Carstensen beruft (vgl. Carstensen 1965: 88):

\footnotetext{
${ }^{73}$ Von Fremd- und Lehnwörtern unterscheidet die Sprachwissenschaft teilweise die Exotismen (auch: fremdes Wort): Im allgemeinen wird der Terminus Exotismus für eine Entlehnung verwendet, die einen für die Kultur bzw. Gesellschaft der Gebersprache spezifischen Gegenstand oder Sachverhalt bezeichnet und unübersetzt in andere Sprachen übernommen wird (vgl. MLS 2005: 199).

${ }^{74}$ Die Essener Schule der Internationalismus-Forschung geht davon aus, dass man das Fremdwort-Konzept durch ein Konzept der Internationalismen ersetzen könne, und hat dem Begriff der Internationalismen den der „Nationalismen“ entgegengesetzt (vgl. dazu u.a. Braun 1979b, Grünhoff 1983, Jablonski 1990). Als problematisch an diesem Ansatz wird angesehen, dass er einerseits „historische Kriterien [als] sekundär und für die Klassifikation irrelevant" (Volmert 2003: 35) ansieht, andererseits eigensprachliche Entwicklungen entwertet (vgl. dazu u.a. Schmitz 1995 und Schmitz 2001: 725ff.). Eng verbunden mit dem Begriff des Internationalismus ist der Terminus des Europäismus, wobei Europäismus zweckmäßig als Hyponym zum Internationalismus verwendet wird, aber der Begriff
} 
Als Lehnwort im engeren Sinn bezeichnet man ein Fremdwort, das in lautlicher, grammatischer und teilweise auch in orthographischer Hinsicht so weit an einheimisches Wortgut angeglichen worden ist, daß es von einem philologisch ungebildeten Menschen nicht mehr als Wort fremder Herkunft erkannt wird. (Schönfelder 1956: 57)

Bei Augst heißt es:

Fremd- und Lehnwörter stammen aus fremden Sprachen, sie sind zu irgendeiner Zeit [...] in die germanische bzw. deutsche Sprache eingedrungen. Dabei haben die FW [Fremdwörter, Anm. d. Verf.] ihre fremde Gestalt, Lautung und Morphologie weitgehend bewahrt, während die Lehnwörter sich der äußeren Gestalt (signifiant) der Erbwörter weitgehend angepaßt haben, so daß der Laie sie nicht von deutschen Wörtern unterscheiden kann (Augst 1977: 67).

Der Eindeutschungsgrad eines Wortes ist dafür ausschlaggebend, ob es zu den Fremdwörtern oder zu den Lehnwörtern gerechnet wird:

Das aber heißt, daß die Scheidung zwischen Fremd- und Lehnwort dem Sprachgefühl überlassen bleibt und damit vom Bildungshintergrund des Beurteilers abhängt. Was der eine als Fremdwort erkennt, hält ein anderer für ein deutsches Wort. Eine endgültige Entscheidung ist nicht möglich (Zindler 1959: 10). ${ }^{75}$

Die Frage, ob zwischen Lehnwort und Fremdwort unterschieden werden soll, stellt in der Forschung einen jahrzehntelangen Streitpunkt dar. Sowohl sprachsoziologische als auch historisch-etymologische Faktoren werden dabei in verschiedenen Ansätzen behandelt. ${ }^{76}$ Horst Haider Munske beispielsweise verweist darauf, dass allein die Benennung „Fremdwort“ einen Akt der Ausgrenzung darstellt (Munske 2001: 8). Eine Unterteilung von Fremdwörtern wird in der Wissenschaft meist der Betzschen Tradition folgend vorgenommen. Neuere Ansätze liefern unter anderem Carstensen und Eisenberg (vgl. Kapitel 1.4.1).

Internationalismus nicht selbstverständlich als Hyperonym zu Europäismus angesehen werden kann (vgl. Bergmann 1995: 272).

${ }^{75}$ Insbesondere ausländische Autoren wenden sich gegen die Unterscheidung zwischen Fremdwort und Lehnwort: „The Germans here make a distinction between the Lehnwort, a historical fact, and the Fremdwort, a contemporary fact. But it does not appear just how the line is to be drawn" (Haugen 1950: 230).

${ }^{76}$ Bei Tesch findet man zu dieser Frage den Forschungsstand bis zur Mitte der 1970er Jahre. Tesch fasst die wichtigsten Ansätze zusammen und kommentiert diese (1978: 42ff.). Auch in neueren Untersuchungen zu Entlehnungen im Deutschen wird die Unterscheidung Fremdwort - Lehnwort wieder heftig kritisiert, so z.B. bei Schmöe (1998: 17ff.). 
Eine Definition des Fremdworts ist schwierig, der Diskussion liegen verschiedenste Definitionen zugrunde. ${ }^{77}$ Im Folgenden wird der Begriff "Fremdwort“ im weitesten Sinne verwendet, entsprechend der recht generellen Definition des Instituts für Deutsche Sprache:

[...] prinzipiell und primär Wortentlehnungen aus fremden Sprachen [...] aber auch die sog. Lehnwortbildungen [...], d.h. im Deutschen ganz oder teilweise mit Hilfe von entlehnten Wörtern/Wortstämmen und Affixen geprägte Wörter, die häufig keine Entsprechung, geschweige denn ein Vorbild in einer Fremdsprache haben [...], auch Fremdwörter, die durch Polygenese auf übereinzel-sprachlicher Grundlage entstanden sind, wie z.B. die zahllosen Bildungen mit dem Suffix -ismus bezeichnet (DFWB 2004: 14). ${ }^{78}$

\subsubsection{Anglizismus, Britizismus und Anglo- Amerikanismus}

An dieser Stelle soll der Begriff „Anglizismus“ genau betrachtet werden. Im Deutschen werden darunter Entlehnungen zusammengefasst, die durch englischsprachigen Einfluss entstanden sind. Die wohl bekannteste und häufig zitierte ${ }^{79}$ Anglizismendefinition findet sich bei Zindler:

Ein Anglizismus ist ein Wort aus dem britischen oder amerikanischen Englisch im Deutschen oder eine nicht übliche Wortkomposition, jede Art der Veränderung einer deutschen Wortbedeutung oder Wortverwendung (Lehnbedeutung, Lehnübersetzung, Lehnübertragung, Lehnschöpfung, Frequenzsteigerung, Wiederbelebung) nach britischem oder amerikanischem Vorbild (Zindler 1959: 2).

Eine einfache und umfassende Definition liefert das AWb, dort werden unter Anglizismen alle nach englischem Vorbild entstandenen deutschen Sprachzeichen verstanden (AWb 1993: 28).

Ein Problem in der Anglizismenforschung ist die mögliche Unterscheidung der Begriffe „Anglizismus“, „Britizismus“ und „AngloAmerikanismus“. Schon seit langem wird versucht, die Entlehnungen

\footnotetext{
${ }^{77}$ Falls Vereinigungen andere Auffassungen haben, werde ich im Verlauf der Arbeit bei einzelnen Sprachvereinigungen deren Fremdwortbegriff mit aufführen.

${ }^{78}$ Dies erscheint mir als Arbeitsgrundlage sinnvoll, auch wenn sich im Verlauf dieser Untersuchung herausstellen wird, dass viele Sprachvereinigungen, darunter der VDS, kein Problem mit dem Fremdwort an sich haben, sondern der Begriff Fremdwort teilweise fast synonym zum Begriff Anglizismus verwendet wird. Aus diesem Grund werde ich unter Kapitel 1.5.2 auch auf die Definition des Anglizismus eingehen.

${ }^{79}$ Busse (1993) und Carstensen (1965) folgen z.B. dieser Definition.
} 
nach ihrer Herkunft zu sortieren. ${ }^{80}$ Häufig stößt man bei der Einteilung der Entlehnungen auf Schwierigkeiten.

Zudem dringen immer mehr Amerikanismen in das britische Englisch ein, werden dort aber oft nicht mehr als Amerikanismen empfunden. Dadurch ist meist nicht mehr feststellbar, ob ein Begriff aus Amerika, aus Großbritannien, oder mittelbar über Großbritannien entlehnt wurde (Galinsky 1972: 11).

Der britische oder amerikanische Ursprung der englischen Lexeme und Lexemverbindungen ist schwer eindeutig festzustellen. Diese Meinung findet sich auch bei anderen Sprachwissenschaftlern:

Bei vielen Wörtern läßt sich die Scheidung zwischen $\mathrm{AE}$ und $\mathrm{BE}^{81}$ nur mit Mühe aufrechterhalten, und die philologische Exaktheit wäre hier nicht gewährleistet, wenn man mehr als ,English' sagte (Carstensen 1965: 18).

Ich möchte mich an dieser Stelle der Argumentation von Carstensen anschließen und in meiner Arbeit aus den dargelegten Gründen auf die Unterscheidung zwischen Amerikanismus und Britizismus verzichten und den Begriff Anglizismus verwenden. ${ }^{82}$

Außerdem sollen auch Wörter, die ursprünglich nicht aus dem Englischen kamen, aber über das Englische ins Deutsche entlehnt wurden, als Anglizismen behandelt werden.

\subsubsection{Denglisch und Engleutsch}

Im Zusammenhang mit der Diskussion um Fremdwörter und Anglizismen tauchen in den letzten Jahren immer wieder Begriffe wie „Denglisch“, „Engleutsch“, „Germeng“, „Deutschlisch“, „Deutschlitsch“, "Gerglisch“, „Gerlish“, „Amideutsch“, „Anglo-Deutsch“, „Anglogerm“, „Engldeutsch“ (vgl. z.B. Keßler 2000: 55, Heald 1978: 139ff., vgl. ausführlich Spitzmüller 2005: 188) auf.

\footnotetext{
${ }^{80}$ Barbara Engels z.B. unterscheidet in ihrer Untersuchung die Anglizismen nach Herkunft. Dabei geht sie davon aus, dass in der Regel alle Anglizismen vor 1945 aus dem britischen Englisch kamen, die Anglizismen nach 1945 dagegen aus dem amerikanischen Englisch, außer es konnte in Wörterbüchern eindeutig nachgewiesen werden, dass dem nicht so war. Diese Einteilung ist jedoch nicht sinnvoll.

${ }^{81}$ Gemeint sind amerikanisches Englisch (AE) und britisches Englisch (BE).

82 Auch Zindler (1959), Meyer (1974), Pfitzner (1978), K. Viereck (1980), Steinbach (1984) und Yang (1990) verzichten auf die Unterscheidung.
} 
Sie finden sich in Buchtiteln wie „Denglisch, Nein Danke!“, in Publikationen oder auf Aufklebern von Sprachvereinen. Diese Begriffe sind keine linguistischen Termini, sondern eine deutsche Variante des aus dem französischen stammenden Begriffs „Franglais“, den René Etiemble in seiner Publikation „Parlez-vous franglais?“ aus dem Jahr 1964 prägte (Etiemble 1964). Lehnert sieht allein in der Entstehung dieser Wortbildungen einen Beweis dafür, wie tiefgehend die angloamerikanische Einwirkung auf die verschiedenen Sprachen der Welt ist. Während er im Jahr 1990 noch schrieb, dass „bis auf den geglückten und allgemein bekannten und verwendeten Terminus Franglais die übrigen Wortbildungen sich nicht behauptet haben“ (Lehnert 1990: 19) ${ }^{83}$ hat sich auch der Terminus Denglisch mittlerweile durchgesetzt. Im Metzler Lexikon ist er folgendermaßen definiert:

[...] kritisch-polemische Bezeichnung für Texte bzw. Arten des Sprechens im Deutschen, in denen ein Übermaß an Ausdrücken aus dem Englischen. vorkommt, die wenigstens teilweise nicht allgemein verständlich sind, [...]. Als Motive für die Verwendung dieses [Denglisch] betrachten seine Kritiker mangelnde Beherrschung des Deutschen und den Wunsch, am Prestige des Englischen zu partizipieren (MLS 2005: 129).

Der Begriff „Engleutsch“, den wohl erstmals Rudolf Lubeley im Jahr 1993 aufbrachte (Lubeley 1993, vgl. Klein 2001), ist mittlerweile auch im Metzler Lexikon Sprache verzeichnet (vgl. MLS 2005: 170).

In der Veröffentlichung zur Tagung der Sprachvereine im „Netzwerk Deutsche Sprache“ in Friedrichshafen wurde vorgeschlagen, die Begriffe „Amismen, amistisch“ zu verwenden: Denn „[d]a unser Problem jedoch eindeutig amerikanische Wurzeln hat, verzichten wir auf die Stigmatisierung der englischen Sprache [...]“ (Däßler 2001: 93). Die Begriffe haben sich $\mathrm{m}$.W. nicht durchgesetzt, ebenso wenig wie die meisten anderen. Am gebräuchlichsten ist wohl mittlerweile der Ausdruck „Denglisch“. ${ }^{4}$

\footnotetext{
${ }^{83}$ Kursivschreibung im Original.

${ }^{84}$ Spitzmüller weist darauf hin, dass der VDS den Ausdruck als Hauptstigmawort verwendet und so den Begriff verstärkt in die Medien gebracht hat. Dies sieht er als einen der Faktoren an, warum sich „Denglisch“ durchgesetzt hat (vgl. Spitzmüller 2005: 189). Der VDS definiert den Begriff „Denglisch“ folgendermaßen: „Wir verstehen darunter einen inhaltlich unklaren, regelarmen und deshalb ausdrucksschwachen Wortmischmasch aus deutschen und englischen Wörtern“ (VDS 2006i, 2008d).
} 


\subsubsection{Sprachreinigung - Purismus - Sprachpflege - Sprachkritik}

Eine der Schwierigkeiten der Diskussion über das Fremdwort und damit der Diskussion über Sprachkultur, Sprachpflege, Sprachkritik und Sprachreinigung oder Purismus zeigt sich darin, dass die Terminologie unterschiedlich verwendet wird: Laut Kolde sind die „zentralen Begriffe ,Sprachkritik und Sprachpflege' so vage und gleichzeitig so vieldeutig, daß ihre undifferenzierte Verwendung zu Missverständnissen geradezu herausfordert“ (Kolde 1986: 171). Aus diesem Grund sollen die Begrifflichkeiten, die in der Diskussion verwendet werden, aufgegriffen und definiert werden.

„Purismus“ ist als Terminus kein speziell sprachwissenschaftlicher, er kommt auch in der Kunstgeschichte und in der Alltagssprache vor (vgl. Sauter 2000: 11). Purismus (lateinisch purus, rein, klar, einfach, vgl. u.a. MLS 2005: 524) ist ein „Aspekt normativer Sprachkritik“ (Deubzer 1980: 11) und ein für die Wissenschaft nicht einfacher Terminus, impliziert er doch, dass etwas zuvor unrein gewesen sei (vgl. Sauter 2000: 11). Unter "Purismus“ werden „die Bestrebungen verstanden, eine Sprache von (vor allem lexikalischen) Einflüssen einer, mehrerer oder aller anderen Sprachen zu >reinigen< (MLS 2005: 524). Als derart definierter analytischer Begriff soll „Purismus“ in dieser Arbeit verstanden und verwendet werden, auch, wenn die vorherrschende Konnotation beim Begriff des "Sprachpurismus“ eindeutig negativ ist (vgl. Sauter 2000: 11). ${ }^{85}$ Die Begriffe „Purismus“, „Sprachreinigung“ und „Sprachpurismus“ werden im Folgenden synonym verwendet.

Larry Trask führt aus: "the belief that words (and other linguistic features) of foreign origin are a kind of contamination sullying the purity of a language" (Trask 1999: 254). In dieser Definition ist ein wichtiges Argument der Puristen angelegt, die Idee, dass die Reinheit der Sprache durch fremde Einflüsse kontaminiert wird. Dabei ist „,rein’ nicht nur mit ,fremdwortfrei' wiederzugeben, sondern entspricht eher

\footnotetext{
${ }^{85}$ Sauter führt des Weiteren aus, dass der Begriff als Spottname verwendet wurde, es sollte die Sprachreiniger besonders hart treffen, dass sie mit einem Fremdwort bedacht wurden (vgl. Sauter 2000: 11).
} 
,gesetzmäßig', ,normgerecht' o.ä.“ (Kirkness 1998: 407). Eine ähnliche Auffassung vertritt auch Thomas, der den Purismusbegriff ausdehnt:

\begin{abstract}
[purist activity is] a desire on the part of the speech community [...] to preserve a language from, or rid it of, putative foreign elements or elements held to be undesirable elements (including those originating in dialects, sociolects and styles of the same language). It may be directed at all linguistic levels but primarily the lexicon (Thomas 1991: 12).
\end{abstract}

Deubzer führt aus, dass die eigene Sprache durch bewusstes Vermeiden von Fremdwörtern gereinigt werden soll (vgl. Deubzer 1980: 11). Purismus steht synonym zum Begriff Sprachreinigung. Purismus in seiner schärfsten Form beinhaltet die Tilgung von nicht-nativem Wortgut (vgl. MLS 2005: 203), wobei mit den Wortbildungsmitteln der eigenen Sprache ein neues Wort geprägt wird, das das Fremdwort ersetzen soll (vgl. Deubzer 1980: 11). ${ }^{86}$ Kirkness bezeichnet dies als „puristische Reaktionen“ und versteht diese als „eine aktive (Abwehr-)Handlung in Form eines öffentlichen Kampfes gegen einzelne Fremdwörter bzw. gegen das Fremdwort schlechthin“ (Kirkness 1998: 407).

Nach Langer/Davies hat der Purismus einen weiteren Aspekt: Nicht nur die Tilgung von nicht gewollten Sprachelementen, sondern auch das Bewahren von gewollten Elementen gehört dazu (Langer/Davies 2005b: 3).

Mit dem Purismus häufig verknüpft wird eine nationalistische oder konservative Einstellung. Beispielsweise trat im 19. Jahrhundert neben die Verdeutschungsarbeit ein übersteigertes nationales Bewusstsein. In der Gegenwart existieren puristische Bestrebungen jenseits nationalistischer Ideologien (vgl. MLS 2005: 524).

Wann und warum es zu puristischen Bewegungen kommt, ist schwer $\mathrm{zu}$ beurteilen. Ausschlaggebend dafür ist nach Einschätzung einiger Wissenschaftler die Wahrnehmung der Menge der Fremdwörter bei den Menschen einer Sprachgemeinschaft (vgl. van der Sijs 1999: 23), doch diese ist selten einheitlich. Andere Sprachwissenschaftler, darunter Peter von Polenz, halten den Purismus für ein in bestimmten Wellenbewegungen wiederauflebendes Phänomen ist, das von politischen Fakto-

${ }^{86}$ Purismus wird von einigen Sprachwissenschaftlern sogar als linguistische Universalie (Thomas 1991) angesehen. 
ren eines Landes abhängig ist, Höhepunkte dieser Wellen sind in $\mathrm{Zu}$ sammenhang mit einer gesteigerten Aktivierung des Nationalgefühls zu sehen. Als Beispiel wäre die Zeit nach dem Dreißigjährigen Krieg, nach dem Niedergang der Napoleonischen Herrschaft, nach der Reichsgründung von 1871 und bei Ausbruch des Ersten Weltkriegs zu nennen (vgl. von Polenz 1967a: 79). Purismus wird als Anzeichen eines sich entwickelnden nationalen Selbstbewusstseins gesehen (vgl. Lewandowski 1990: 1048f.). Des Weiteren gehen einige Sprachwissenschaftler davon aus, dass dem Purismus ein Sprachbegriff zugrunde liegt, der von der Sprache als einer homogenen Einheit ausgeht (vgl. Spitzmüller 2007: 271).

\section{Sprachpflege bedeutet dagegen die}

Förderung des korrekten Sprachgebrauchs im Sinne der Beachtung der geltenden Sprachnormen und Erziehung zu einem reflektierten Umgang mit der Sprache. Sprachpflege läuft oft Gefahr, der Sprachentwicklung hinterherzulaufen und altertümliche oder elitäre Formen zu konservieren. Anstelle einer wiss. Fundierung ist Sprachpflege oft von subjektiven Urteilen ihrer Autoren geprägt, die mit Vorliebe > Ratgeber< verfassen (MLS 2005: 624).

Der Begriff Sprachpflege hatte und hat in Deutschland teilweise einen negativen Beigeschmack (vgl. Janich 1997: 76f., Förster 2000a: 9), doch wurde er durch Eingrenzung und wissenschaftliche Definition "gewissermaßen rehabilitiert“ (Wiechers 2004: 211, vgl. dazu auch Greule/Ahlvers-Liebel 1986: $72 \mathrm{ff}.) .{ }^{87}$

Der Begriff Sprachkritik ist schwer zu greifen: Er ist „zur Zeit noch unbestimmt und weit gefasst“" (Schiewe 2003: 328). Unter Sprachkritik wird im Allgemeinen die

Auseinandersetzung und Beurteilung herrschender Sprachnormen von Stilkritik über die Kritik von Sprachformen der Presse, des Rundfunks und Fernsehens, der Verwaltung und von Institutionen bis zur ideologiekritischen politischen Sprachkritik (MLS 2005: 620)

verstanden, sie hat „mit dem Sollen von Sprache zu tun“ (Schiewe 1998: 14).

Es gibt zahlreiche sprachkritische Arbeiten zur Sprache der Politik und der Öffentlichkeit, darunter zur Sprache der Frauenbewegung und der Ökobewegung (u.a. Pusch 1989, Brunner/Frank-Cyrus 1998). Nach 1945

${ }^{87}$ Zum Begriff der Sprachpflege siehe auch Greule (1986) und Greule/Lebsanft (1996). 
gab es auch Veröffentlichungen antifaschistischer Sprachkritik (u.a. Sternberger/Storz/Süskind 1957). ${ }^{88}$

Sprachkritik und Sprachpflege waren „vehementen Angriffen von Seiten der Sprachwissenschaft ausgesetzt, so dass es nötig erscheint, ihren Status deutlich und ihren Anspruch auf Existenz und Beachtung geltend zu machen“ (Schiewe 1998: 9, vgl. auch J. Bär 2002a: 240).

\subsection{Die Fremdwortdiskussion in Deutsch- land von 1989 bis zur Gegenwart}

Mit dem Begriff Fremdwortdiskussion

wird im weitesten Sinne der Diskurs um die Nützlichkeit, Angemessenheit und linguistische sowie sozio-politische Problematik von Fremdwörtern und Entlehnungen und ihrem Gebrauch im Deutschen bezeichnet (MLS 2005: 203).

Wobei sich die Frage stellt, ob es überhaupt möglich ist, von „der Fremdwortdiskussion“ zu sprechen, wie zum Beispiel Gardt einwirft: „Von Fremdwortdiskursen zu sprechen erscheint deshalb angemessen, da die Auseinandersetzung über Fremdwörter thematisch und formell sehr heterogen verläuft“89 (Gardt 2001a: 31). In diesem Kapitel soll die Fremdwortdiskussion in Deutschland von der Wiedervereinigung bis heute dargestellt werden, da die Wiedervereinigung für Deutschland ein einschneidendes geschichtliches Ereignis darstellt. Um die Diskussion zu gliedern, werden die Argumente und Einstellungen im Folgenden nach Akteuren aufgeführt, beginnend mit den Sprachwissenschaftlern über die Journalisten zu den Politikern. Sprachvereinigungen, die in der Diskussion ebenfalls aktiv sind, werden im darauffolgenden Kapitel dargestellt.

${ }^{88}$ Zum Thema Sprachkritik vgl. ausführlich unter anderem von Polenz (1999b: 294-338), Schwinn (1996), Deubzer (1980). Zur Geschichte der Sprachkritik vgl. unter anderem Schiewe (1998).

${ }^{89}$ Hervorhebungen im Original. 


\subsubsection{Die Fremdwortdiskussion in der Sprach- wissenschaft}

Die Fremdwortdiskussion wurde in der zweiten Hälfte des 20. Jahrhunderts als abgeschlossen angesehen (vgl. u.a. MLS 2005: 203), wurde als „unzeitgemäß und peinlich“ (Glück 2000b: X) gewertet. Doch es scheint, als ob sie immer wieder neu aufflackert. Von Polenz konstatierte 1999 noch, dass das Problem der „Fetischisierung von Sprache als zu ,hütendem' nationalem ,Schatz'“ endlich einige Pflöcke tiefer gehängt worden sei (von Polenz 1999a: 288), sprach von einer Verstärkung der „traditionelle[n] Distanzierung von fremdwortpuristischen Einstellungen“, die sich seit dem Zweiten Weltkrieg verstärkt hat (vgl. von Polenz 1999a: 288), und stellte zusammenfassend fest:

Auf vorübergehende Rückläufigkeiten durch puristische Haltung während des Ersten Weltkriegs und in der frühen Nazizeit folgten jedes mal neue Wellen der Aufnahmebereitschaft, teils als politische Reaktion gegen Nationalismus und Isolationismus, teils durch den starken wirtschaftlichen Einfluß Amerikas nach dem Ersten Weltkrieg, nach 1945 in Westdeutschland durch Besatzungszeit und amerikabezogene Bündnispolitik, die mit internationalen Organisationen im politischen, militärischen und wirtschaftlichen Bereich in allen westeuropäischen Ländern Internationalismen angloamerikanischer Herkunft und Englisch als internationale Verkehrssprache gefördert hat (von Polenz 1999b: 401).

Diese Aussagen haben bis zur Wiedervereinigung Gültigkeit gehabt. Doch Pfalzgraf merkt an, die Einschätzung von Polenz', dass sich seit der Wiedervereinigung „keine neue fremdwortpuristische Tendenz entwickeln [konnte]“ (von Polenz 1999a: 288), sei nicht zu halten (vgl. Pfalzgraf 2006: 12):

Tatsächlich haben sich seit der deutschen Vereinigung jedoch einige gravierende Neuentwicklungen in der Fremdwortdiskussion gezeigt, die Polenz Ende der 1990er Jahre aber nicht sieht - oder nicht sehen will (Pfalzgraf 2006: 12, vgl. auch Spitzmüller 2007: 268)..$^{90}$

\footnotetext{
${ }^{90}$ Nicht nur die Gründung des VDS und anderer Sprachvereine fällt in die Zeit relativ kurz nach der Wiedervereinigung, auch weist z.B. Kurt Gawlitta auf diese Koinzidenz hin: „Vielleicht werden spätere Generationen schärfer, als wir es heute vermögen, erkennen, wie dringend erforderlich die Gründung des Vereins 1997 war, und begrüßen, daß er im historisch genau passenden Moment, einige Jahre nach der Wiedervereinigung, auf der Bildfläche erschien“ (Gawlitta 2007: 82). Auf den Zusammenhang zwischen der deutschen Wiedervereinigung und dem Ansteigen des Diskurses um Sprache und Nation hat schon Uli Linke 2004 verwiesen:
} 
Aber nicht nur von Polenz, auch Annette Trabold hat die Lage noch im Jahr 1993 falsch eingeschätzt:

Inzwischen ist nun aber seit dem 3.10.1990 Deutschland vereint und daher auch ein Teil der irrationalen Angst vor Verfall oder Verlust $>$ der< deutschen Sprache etwas gewichen (Trabold 1993: 124).

Ebenso Ülkü noch im Jahr 2002:

Der national-völkische Fremdwortpurismus stellt in Deutschland kein öffentliches Anliegen mehr dar [...]. Die Deutschen haben eingesehen, Entlehnungen aus anderen Sprachen nicht mehr einseitig als Sprachverfall, -verderb, -zerstörung, Verwelschung, Verhunzung, Beschmutzung, Verunreinigung ... der Sprache zu betrachten, sondern als einen sprachkulturellen Gewinn [...]; eine Bereicherung des deutschen Wortschatzes [...] (Ülkü 2002: 435f.).

Trabolds ${ }^{91}$ und Ülküs Einschätzungen haben sich nicht bewahrheitet (vgl. auch Spitzmüller 2005: 110f.). Eisenberg stellt fest:

Über den Zustand des Deutschen wird in den vergangenen Jahren mehr und lauter geklagt. Auch scheint die Zahl der Stimmen, die das Klaglied anstimmen, zuzunehmen. Immer gibt es Sprachkritiker, die von Verfall und Bedrohtheit sprechen, aber inzwischen sehen fast sechzig Prozent der Deutschen die Entwicklung ihrer Sprache als bedenklich oder sogar als beunruhigend an. Wissenschaftler befürchten einen Verlust der universellen Ausdrucksmöglichkeiten, Politiker erinnern bei ihrer Meinung nach passender Gelegenheit an die marginale Rolle des Deutschen in internationalen Organisationen und einige Sprachwissenschaftler halten die Kraft des Deutschen zur Assimilation oder Integration fremden Sprachmaterials für nur noch gering. Meist wird dabei dem Englischen eine besondere Rolle zugeschrieben, und zwar sowohl was seine internationale Stellung als auch was seinen Einfluß auf die deutsche Sprache betrifft (Eisenberg 2004b: 121).

Bei der derzeitigen Diskussion handelt es sich also nicht mehr im eigentlichen Sinne um eine Fremdwortdiskussion, die Diskussion beschränkt sich weitestgehend auf Anglizismen (vgl. dazu z.B. Pfalzgraf 2006: 9, MLS 2005: 203, Wiechers 2004: 331), zeichnet sich dabei allerdings durch eine gewisse Verworrenheit aus. Diese hat verschiedene Gründe: Die „objektive wissenschaftliche Auseinandersetzung wird er-

\footnotetext{
"In a united Germany, national identity politics have become language politics, a terrain marked by a fear of linguistic estrangement and a public preoccupation with preserving an authentic national interior: the nation is configured as a speech community of ethnic Germans" (Linke 2004: 206).

${ }^{91}$ Trabold selbst hat diese Vermutung etwas relativiert: „Es bleibt abzuwarten, ob und wie sich der Zusammenschluß der BRD und der DDR auf die weitere Beurteilung sprachlicher Entwicklung auswirkt" (Trabold 1993: 125).
} 
schwert durch vielfach pseudo-wissenschaftliche Abhandlungen und eine ideologische Metaphorik“ (MLS 2005: 203). So handelt es sich um eine weltanschauliche und ideologisch-ideelle Diskussion (vgl. MLS 2005: 203). Laut Flamm befinden wir uns in einer „emotionale[n] Fremdwortfalle“ (Flamm 1994: 44).

Seit der Wiedervereinigung ist die deutsche Sprache häufig Gegenstand zahlreicher Untersuchungen, von Fachtagungen und Podiumsdiskussionen. ${ }^{92}$ Etliche der Untersuchungen haben dabei die Sprache der Presse zum Gegenstand (siehe Kapitel 1.4.2).

Inwiefern Anglizismen eine Gefahr für die deutsche Sprache und für einzelne Lexeme der deutschen Sprache darstellen könnten, sind die Wissenschaftler sich nicht einig. Im Jahr 1991 spricht Drosdowski von einer „Überflutung“93 des Deutschen mit Anglizismen:

Charakteristisch für die Entwicklung der deutschen Sprache nach 1945 ist auch die Überflutung mit Lehnwörtern angloamerikanischer Provenienz. Über die Bundesrepublik brandete mehr als vier Jahrzehnte eine Welle von Anglizismen und Amerikanismen hinweg, die an der Grenze zur DDR nicht haltmachte [...]. In den Bereichen Freizeit, Sport, Mode, Musik wimmelt es nur so von neueren Entlehnungen aus dem Englischen [...], und selbst in die Alltagssprache dringen immer mehr englische Lehnwörter ein (Drosdowski 1991: 25). ${ }^{94}$

Kettemann zum Beispiel stellt dagegen fest: „Die oft gehörte Befürchtung, dass Fremdwörter ursprünglich deutsche Wörter verdrängen, ist bisher am Sprachmaterial nicht belegbar“ (Kettemann 2002: 58). HansMartin Gauger erklärt: „[...] die Erregung über das Eindringen des Englischen teile ich weniger" (Gauger 1985: 50). Und Hoberg konstatiert:

\footnotetext{
${ }^{92}$ Als Beispiele sind hierfür die Herbsttagung der Deutschen Akademie für Sprache und Dichtung im Jahr 1998 (vgl. Meier 1999), die Herbsttagung der Deutschen Akademie für Sprache und Dichtung 2007 zum Thema „Zur Sprache kommen“ (vgl. Deutsche Akademie für Sprache und Dichtung 2008) und die IDS-Jahrestagung 1998 mit dem Thema: „Sprache - Sprachwissenschaft - Öffentlichkeit“ (vgl. Stickel 1999), anzuführen. Ebenso zu erwähnen ist die IDS-Tagung im Jahr 2000 mit dem Thema „Neues und Fremdes im deutschen Wortschatz", auf der die Teilnehmerinnen und Teilnehmer sich explizit mit der Thematik rund um Entlehnungen auseinandergesetzt haben (vgl. Stickel 2001). Für die IDS-Tagung 1998 und die Tagung der Deutschen Akademie für Sprache und Dichtung haben sich ungewöhnlich viele Medien interessiert und darüber berichtet (vgl. Spitzmüller 2005: 127).

${ }^{93}$ Diese Überschwemmungsmetaphorik wird im Diskurs noch häufig auftauchen. Vgl. z.B. Kapitel 2.4.2.

${ }^{94}$ Vgl. auch Drosdowski (1985 und 1988).
} 
Als Sprachwissenschaftler muss ich darauf hinweisen, dass hier eine Gefahr herbeigeredet wird, dass von den etwa 500000 Wörtern im Deutschen etwa 4000 englischen Ursprungs sind und ein großer Teil der Anglizismen relativ schnell wieder aus der deutschen Sprache verschwindet (Hoberg 2002a: 30). ${ }^{95}$

Einige Sprachwissenschaftler sehen eher eine Funktionsteilung als einen Verdrängungsprozess (vgl. Carstensen 1984, von Polenz 1994: 85). Dies wird in der jüngsten Forschung aufgegriffen (vgl. z.B. Spitzmüller 2005: 319).

Auch die Diskussion, den Begriff des Fremdworts abzuschaffen, gibt es nach wie vor. Dafür sprach sich beispielsweise Munske auf der IDSJahrestagung zum Thema Neues und Fremdes im deutschen Wortschatz aus:

Sind Fremdwörter die Gastarbeiter der deutschen Sprache? Angeworben in den Nachbarsprachen, weil der einheimische lexikalische Arbeitsmarkt neuen Benennungsaufgaben nicht mehr gewachsen war. Ihr fremdes Aussehen störte zunächst kaum, wurden sie doch nur für bestimmte Arbeiten (also fachsprachlich) eingesetzt, sollten ja auch bald wieder gehen, wie es Gästen ansteht. Wanderarbeiter der Sprache sollten sie sein, die keinerlei Bürgerrechte beanspruchen. Das hat sich als Irrtum erwiesen. Die Gastarbeiter blieben und die Fremdwörter auch. Die Menschen haben geheiratet oder Familienmitglieder nachgezogen, Kinder bekommen und Enkelkinder. [...] Ähnlich die Fremdwörter. Auch sie blieben nicht isoliert, sondern wurden durch Komposition oder Ableitung mit dem System des Gesamtwortschatzes verknüpft oder erhielten [...] durch Begründung der Lehnwortbildung, eine spezifische, eigene Nachkommenschaft: fremd im Aussehen, d.h. Fremdwörter nach dem ius sanguinis, aber hier geboren, d.h. Einheimische nach dem ius loci. [...] Fremdwort trägt die Stigmatisierung bereits in sich (Munske 2001: 7).

Munske äußert ergänzend Kritik am Purismus und dem Konzept „einer Sprache aufgedrungenen Wörter“. ${ }^{96}$ Er sieht Fremdwörter als das genaue Gegenteil an:

[...] sie sind aufgenommene, bereitwillig adaptierte. Es kommt zu Entlehnungen, wenn die lexikalischen Transferenzen der Zweisprachigen in einer Sprachgemeinschaft von den Einsprachigen akzeptiert werden. Wenn sich Puristen gegen fremdsprachigen Einfluss wenden, dann richtet sich dieser nur scheinbar nach außen, vielmehr nach innen gegen den Sprachgebrauch in der eigenen Sprachgemeinschaft (Munske 2001: 10).

95 Nicht expliziert wird, wie Hoberg zu diesen Zahlen kommt.

${ }^{96}$ Damit zitiert er Campe (1813). 
Aber nicht nur linguistische Faktoren werden seitens der Sprachwissenschaftler diskutiert, sondern auch politische: Von Polenz sieht den Purismus als problematisch an. Er führt die Verstrickung des Purismus in die deutsche Geschichte von der Bismarckzeit bis zur Zeit des Nationalsozialismus als Grund dafür an, dass

[...] kaum ein Germanist, Linguist oder Bildungspolitiker in deutschsprachigen Ländern es wagen kann, im Rahmen der Erörterung verschiedener Arten und Ziele von Sprachkritik und Sprachpflege auch nur gemäßigte Ziele der Fremdwortverdeutschung positiv zu nennen. (von Polenz 1999a: 264f.)

Kirkness fordert:

Der Wissenschaft obliegt es, nicht zuletzt angesichts des anhaltenden öffentlichen Interesses, die richtungsweisenden Ansätze zu einer konstruktiven Fremdwortkritik bei von Polenz (von Polenz 1967, zwei Arbeiten) systematisch aufzugreifen und weiterzuführen. [...] Denn der Purismus hat sich als keine geeignete Antwort auf die Fremdwortfrage erwiesen. (Kirkness 1998: 415).

Er wendet sich also gegen eine „Laienlinguistik“, in dem er die Wissenschaft auffordert, sich der Fremdwortkritik anzunehmen. Aufgrund ihrer eher ablehnenden Haltung gegenüber dem Purismus wird der Sprachwissenschaft seitens der Sprachvereine wie dem VDS ein „SichHeraushalten“ vorgeworfen (vgl. Kapitel 2.4.2). Doch die Wissenschaftler beziehen Stellung, nur eben oft nicht die Position, die den Sprachvereinen zupass käme (vgl. dazu auch Keller 2004: 2ff.). Denn eigentlich wünschen die Sprachvereine, dass die Wissenschaftler ihre Meinung gegenüber dem Purismus ändern (vgl. Spitzmüller 2007: 277). Glück sieht Gründe für die Zurückhaltung:

[...] niemand möchte den politischen Verdacht riskieren, den die Beschäftigung mit Fremdwörtern reflexhaft auslöst. Ich halte das für einen gefährlichen Anachronismus. [...] Dieser Verdacht hat in der Germanistik Folgen gehabt, denn er hat Tabus geschaffen. Er hat Untersuchungen $\mathrm{zu}$ heute offensichtlichen Sachverhalten wenn nicht verhindert, so doch zumindest nicht gefördert. [...] Es ist an der Zeit, sich mit diesen Fragen unvoreingenommen zu beschäftigen (Glück 2000b: XI).

Er äußert Verständnis für Anglizismengegner, beklagt wiederum eine mangelnde Sprachloyalität vieler Sprecher des Deutschen (vgl. Glück 
2000c: 124$)^{97}$ und bekräftigt die Forderung an die Wissenschaft, sich mit dem Thema auseinander zu setzen:

Die Leute, die sich an Anglizismen und ,Denglish' so stören, daß sie Bürgerinitiativen gründen, um gegen sie vorzugehen, sind keine dumpfen Deutschtümler. Es sind interessierte, engagierte Bürger, die sich um ihre Sprache und die ihrer Kinder und Enkel Sorgen machen. Das ist ihr gutes demokratisches Recht. Hier hat die Sprachwissenschaft eine Bringschuld: es gibt ein manifestes öffentliches Interesse an diesem Thema, dem sie sich zu stellen hat. Es ist politisch falsch und obendrein dumm, sich aufs hohe Roß zu setzen und vom Katheder herab zu verkünden, daß dieses Thema kein Thema sei, wie das nicht selten geschieht. Es ist übrigens ein Thema für die Wissenschaft (Glück 2006).

Mittlerweile wird Purismus von einigen Sprachwissenschaftlern auch differenzierter gesehen:

Dass Purismus nicht notwendigerweise nationalistisch fundiert sein muss, wird innerhalb der Linguistik mittlerweile kaum mehr bestritten. Man weiß, dass der nationalistische Purismus nur eine, wenngleich eine im 19. und 20. Jahrhundert recht verbreitete Kritik an Entlehnungen ist. (Spitzmüller 2005: 349, vgl. dazu auch Kirkness 1998, Gardt 2001b und Schiewe 2000, 2001)

Greule verweist auf den engen Zusammenhang zwischen Sprachloyalität und kultureller Behauptung und sieht - ähnlich wie viele Sprachvereine - in sprachlicher Illoyalität ein Symptom verloren gehender kultureller Identität (vgl. Greule 2002: 439). Dabei betrachtet er Anglizismen im Deutschen eher gelassen:

Aber schadet es der deutschen Sprache, und das heißt dem, der mit deutscher Sprache kommuniziert, wirklich, wenn in diese Sprache Internationalismen oder Europäismen als Folge internationaler Kommunikation und jahrhundertlangen kulturellen Austauschs in Europa aufgenommen wurden? (Greule 2002: 441).

Siegfried Grosse sieht die Fremdwortkritik als „interessante[s], leidvolle[s] Thema“, und verweist darauf, dass die Diskussion immer dann missverständlich und unerfreulich wird, wenn ideologische Argumente wie nationalpatriotische die sachlichen Argumente dominieren (vgl. Grosse 2000: 14). Und Friedhelm Debus argumentiert: „Dass die Gefahr

${ }^{97}$ Sprachloyalität wird als eine sozial-psychologische Bedingung für den Spracherhalt angesehen (vgl. MLS 2005: 613). Dieser Thematik der Sprachloyalität widmet sich ausführlich Wolf Peter Klein. Er führt an, dass diesbezüglich Aussagen von Personen, die wie Glück aus dem DaF-Bereich kommen, tief in der Sprachwirklichkeit verankert sind, gibt aber gleichzeitig zu bedenken, ob nicht die öffentliche Sprachthematisierung als Ausdruck einer gewissen Loyalität gesehen werden kann (vgl. Klein 2001). 
der verdrängenden Überfremdung des den Alltag bestimmenden Grundwortschatzes besteht, ist nicht zu leugnen“ (Debus 1999: 32). Es zeigt sich hier, dass die öffentliche Diskussion und die linguistische zum Thema Anglizismen sich in manchen Fällen kaum unterscheiden (vgl. Spitzmüller 2005: 355).

Interessant ist auch die Haltung von Harald Weinrich, der seine Einstellung gegenüber der Anglizismenkritik und dem Purismus deutlich gewandelt hat. 1969 sagte er, dass Puristen in der Regel keine Linguisten seien (vgl. Weinrich 1969: 380 sowie Kapitel 1.7.4), noch 1988 hielt er die Anglisierung der Sprache für nicht so bedrohlich. ${ }^{98}$ Mittlerweile ist er sogar dem VDS beigetreten (VDS 2006b). Gegenüber dem Focus äußerte er, dass er es als skandalös empfinde, wenn an den Universitäten Institute in Departments umbenannt würden, und die Chefetagen von Wirtschaft, Kultur und Wissenschaft immer sorgloser mit der deutschen Sprache umgingen (Klonovsky/Scherer 2005: 63ff.).

Das Verhältnis der Sprachwissenschaft zur Sprachpflege, auch in früheren Jahren hin und wieder diskutiert, wird zum wichtigen Diskussionsgegenstand. Wolf Schneider kritisierte 1994 die Sprachwissenschaft und fragte: „Und solchen modischen Unfug [gemeint sind die Anglizismen, Anm. d. Verf.] nur zu registrieren - das allein sollte Sprachwissenschaft heißen dürfen?"'99 (Schneider 1994: 21). Dieckmann bemerkt, dass es „für die Linguistik [...] von Interesse ist oder sein sollte, was außerhalb der Linguistik über Sprache gedacht und geschrieben wird, sei es, um

98 „In der heutigen Sprache ist, wie jeder täglich sehen und hören kann, die englischamerikanische Sprache der Hauptlieferant solcher Fremd- und Lehnwörter geworden. Müssen wir also heute wieder und vielleicht mehr denn je eine $>>$ Überfremdung $<<$ der deutschen Sprache befürchten? Ich glaube das nicht. Genauere Untersuchungen der englisch-amerikanischen Einflüsse auf die deutsche Gegenwartssprache zeigen nämlich, daß zwar ständig sehr viele lexikalische Elemente als englisch-amerikanische Kultur- und Subkulturwörter in die deutsche Gemeinsprache und des Weiteren recht viele wissenschaftliche und technische Begriffe aus dieser Fremdsprache auch in die deutschen Fachsprachen eindringen. Manches, ja das meiste von diesem lexikalischen Material ist jedoch schnellebiges Konsumgut, das ebenso rasch, wie es in die deutsche Sprache hineingerät, auch wieder aus ihr verschwindet [...]“ (Weinrich 1988: 214).

${ }^{99}$ Er wurde 1994 in Münster mit dem „Medienpreis für Sprachkultur“ der GfdS ausgezeichnet. Bei seiner Dankesrede griff er nicht nur die Sprachwissenschaft allgemein, sondern auch die GfdS im Besonderen an: „In der Satzung ihrer Gesellschaft aber kommt der Wunsch zu wirken nicht vor, sondern nur vorsichtigere Begriffe wie Pflege, Hilfe und Anregung" (vgl. Schneider 1994: 21). 
selbst daraus zu lernen, sei es, um durch linguistische Kritik die öffentliche Wirksamkeit eventuell fragwürdiger Auffassungen über Sprache zu mindern“ (Dieckmann 1992: 3).

Ulrich Knoop konstatiert:

Die Sprachwissenschaft hat zweifelsohne die humane Aufgabe, gerade im Sprachenstreit [...] und bei Sprachstreitigkeiten zu klären, zu reinigen, zu entgiften, zu entkrampfen [...] (Knoop 1985: 26).

Und Gauger fordert:

Der Sprachwissenschaftler sollte - als Sprachwissenschaftler - nicht werten. Im übrigen: nichts gegen Wertung! Es sollte nur der prinzipielle Unterschied zwischen Sprachwissenschaft und Sprachkritik nicht verwischt werden (Gauger 1985: 60f).

Als Ideal sieht Gauger ebenda eine durch Sprachwissenschaft beratene Sprachkritik, mit Sprachwissenschaft als Fundament der Sprachkritik, in der Wertung außerhalb der Sprachwissenschaft nicht nur nicht unerlaubt, sondern sogar gefordert ist. Er empfindet die Linguisten zwar als privilegiert für die Sprachkritik, wie er in einer Podiumsdiskussion zum Thema „Sprachkritik als angewandte Linguistik“ im Jahr 2002 nicht ganz schlüssig argumentiert, dennoch gibt es für ihn keinen Weg hin zu einer Wertung durch die Sprachwissenschaft:

Ich meine [...], dass eine gewisse Privilegierung des Sprachwissenschaftlers für die Linguistik schon dadurch gegeben ist, dass er sich doch als Linguist besser auskennt als andere, gewisse Fehler vermeidet, die von außerfachlichen Sprachkritikern, gegen die ich nichts habe, natürlich leicht gemacht werden. [...] aber - da kommt der Bruch - ich meine nach wie vor, dass von der Linguistik kein Weg zu dem, was die Sprachkritik unausweichlich macht und machen muss, führt: Bewerten (Gauger 2002 in Spitzmüller et al. 2002: 128). ${ }^{100}$

Eisenberg weist darauf hin, dass sprachwissenschaftliche Erkenntnisse über die Systematik und Produktivität der Bildung fremder Wörter die öffentliche Diskussion bisher kaum beeinflussen (Eisenberg 2002: 66). Außerdem stellt er fest:

${ }^{100}$ Gauger hatte 1999 ausgeführt, dass eine der Schwierigkeiten zwischen Laien und Linguisten in einer gewissen Hilflosigkeit der Linguisten den Fragestellungen der Laien gegenüber begründet ist, da diese Fragen stellen, die innerhalb der Sprachwissenschaft „nicht fragbar“ und nicht zu beantworten sind: „Man fragt uns, zum Beispiel, nach der Zukunft der deutschen Sprache. Da wäre nun zu sagen, daß wir von der Zukunft einer Sprache prinzipiell nicht reden. Wir vertreten eine empirische Disziplin, und im Blick auf die Zukunft fehlt Empirie“ (Gauger 1999: 91). 
German philology cannot simply ignore the public language debate, if only because a large majority of the Germans consider the development of their mother tongue to be alarming or disquieting („beunruhigend oder bedenklich”, [...]). We [gemeint sind die Sprachwissenschaftler, Anm. d. Verf.] have to be involved, but of course we have to insist in retaining the most important achievement of modern linguistics, that is its status as an empirical discipline. Descriptive linguists can contribute in an essential way to the language debate by clarifying what could be meant if one talks and worries about "endangeredness" with respect to a language such as German (Eisenberg 2004b: 122).

\section{Hinsichtlich der Anglizismenkritik und der Argumente von Puristen erläutert Eisenberg:}

Die härtesten Formulierungen sprechen von Zerstörung des Knochenbaus und des Tiefencodes. Zurück bleibe die leere Hülle einer Freizeitsprache. Tatsächlich ging der Einfluss des Lateinischen, des Griechischen und sogar des Französischen auf das Deutsche in der Vergangenheit wesentlich weiter, als der des Englischen gehen könnte (Eisenberg 2008b: 11). ${ }^{101}$

Nicht einverstanden ist Eisenberg auch mit den Aktivitäten der Sprachvereine in Deutschland, er spricht von der "privaten Fürsorge, derer sich die Sprache in Deutschland zu erwehren hat" (Eisenberg 2008b: 11) und führt aus:

Eine dreistellige Zahl von Vereinen, Stiftungen und Gesellschaften fühlt sich für ihren Schutz oder ihre Rettung verantwortlich. In den meisten Fällen wieder dadurch, dass man den Verfall beklagt. Das Unisono aus allen Richtungen wird unüberhörbar. Es dürfte wenige Sprachen auf der Erde geben, über die so schlecht geredet wird wie über die deutsche. Gut möglich, dass es gar keine gibt. Hören wir damit auf und wenden wir uns der Arbeit zur Verbesserung des Sprachgebrauchs zu (Eisenberg 2008b: 11).

Auch Jürgen Spitzmüller, Kersten Sven Roth, Beate Leweling und Dagmar Frohning widmen sich dem Verhältnis zwischen Linguistik und Sprachkritik:

Die Linguistik stellt sich heute als etabliertes akademisches Fach auch vor dem Hintergrund der Kontroversen der 60er Jahre - gleichzeitig als Instanz dar, an der sich wissenschaftlich fundierte Sprachkritik mit dem erklärten Ziel, Bestandteil eben dieses akademischen Faches zu werden, abarbeiten muss (und offensichtlich will) (Spitzmüller et al. 2002: 11). ${ }^{102}$

${ }^{101}$ Bei den „härtesten Formulierungen“ bezieht sich Eisenberg auf die Argumentation Dieter E. Zimmers (vgl. z.B.: Zimmer 1997).

102 Wie eine solche wissenschaftlich fundierte Kritik aussehen soll, wird nicht näher dargelegt. 
Die Sprachkritik wird als angewandte Linguistik verstanden (vgl. Spitzmüller et al. 2002: 7). Es wird argumentiert: „Die Verbindung von Linguistik und Sprachkritik ist nötig!“ (Spitzmüller et al. 2002: 9). ${ }^{103}$

Hoberg stellt zum Diskurs zwischen Öffentlichkeit und Sprachwissenschaft fest:

Das Interesse der Öffentlichkeit und besonders der Medien an Sprachfragen ist groß, sehr groß sogar, das Interesse der Sprachwissenschaftler am Interesse der Öffentlichkeit äußerst gering. Die Öffentlichkeit ist über dieses Desinteresse keineswegs betrübt oder verärgert, denn sie interessiert sich kaum für die Arbeit der Sprachwissenschaft. [...] Generell muss man sagen: Ein Diskurs zwischen Sprachwissenschaftlern und der Öffentlichkeit über Sprachnormen, Sprachkritik, Sprachethik, Sprachwandel findet kaum statt (Hoberg 2002a: 21ff.).

Jürgen Schiewe spricht von einem „Verlust des Kontakts der institutionalisierten universitären Linguistik zur Öffentlichkeit - ein Umstand, der inzwischen von beiden Seiten beklagt wird“ (Schiewe 2003: 327). Er macht die Linguistik dafür verantwortlich, „[...] daß es eine Kontinuität in der Verwendung und Inanspruchnahme jenes überkommenen Organismus-Begriffs der Sprache gibt“ und dass "die publizistische Sprachkritik noch immer einen Sprachbegriff aus dem 19. Jh. transportiert“ (vgl. Schiewe 2003: 330). ${ }^{104}$ In der Podiumsdiskussion „Sprachkritik als angewandte Linguistik?“ geht Schiewe noch einen Schritt weiter: „[...] ich bin der Meinung, dass sich die Linguistik mit Sprachkritik beschäftigen, dass sie Sprachkritik als Teil ihres Faches auch akzeptieren und ausbauen sollte“ (Spitzmüller et al. 2002: 127). ${ }^{105}$ Bei diesem Ausbau stehe nicht die

>Bekämpfung von Angloamerikanismen< im Vordergrund, sondern eine kritische Analyse der Diskurse, die gegenwärtig über das Fremde geführt werden [...] (Schiewe 2001: 288).

Des Weiteren erläutert er, dass eine Sprachkritik durch die Linguistik eine Erkenntnisform sei, deren Kultivierung sich die Linguistik nicht

\footnotetext{
${ }^{103}$ Gardt vertritt ebenfalls diese Tendenz. Er argumentiert: „Es gibt einen [gemeint ist der Unterschied zwischen Sprachwissenschaft und Sprachkritik, Anm. d. Verf.], doch er ist nicht prinzipieller, sondern gradueller Natur" (Gardt 2002: 49).

${ }^{104}$ Hierfür kritisiert er auch Helmut Glücks Veröffentlichung.

${ }^{105}$ Diese neue Linie der Sprachwissenschaft zeigt sich auch in der Etablierung eines Masterstudiengangs an der Universität Greifswald. Dort wird in Zukunft Sprachkritik als Teil des Faches (vgl. Spitzmüller et al. 2002: 127) verstanden.
} 
entgehen lassen sollte (vgl. Schiewe 2001: 294f.). Stukenbrock konstatiert bezüglich des Diskurses wiederkehrende Topoi wie die militarisierende Metaphorik, die Flut- und Überschwemmungsmetaphorik oder die Metaphorik von Krankheiten, die biologisch-pathologisierende Metaphorik (vgl. Stukenbrock 2005a: 225ff., Stukenbrock 2005b: 327ff.).

In Zusammenhang mit der kritischen Diskursanalyse steht die Gründung der Zeitschrift Aptum. Die Zeitschrift wurde 2005 gegründet und erscheint drei Mal jährlich, der Untertitel lautet „Zeitschrift für Sprachkritik und Sprachkultur“. Bereits im ersten Jahrgang haben namhafte Wissenschaftler wie Peter von Polenz und Georg Stötzel darin publiziert. In der Einführung der Herausgeber zum ersten Heft ist zu lesen:

Sprachkritik als Teil einer anwendungsbezogenen Sprachwissenschaft betreiben heißt, Sprachbewusstsein zu fördern mit dem Ziel, Sprachkultur $\mathrm{zu}$ pflegen, auszubauen und zu sichern (Schiewe/Wengeler 2005: 1).

Die Herausgeber schreiben im Vorwort:

Die Sprachwissenschaft hat in den vergangenen vierzig Jahre [sic] eine Fülle wertvoller Erkenntnisse über die Sprachstruktur und den Sprachgebrauch hervorgebracht. Sie hat sich aber zu wenig damit beschäftigt, diese Erkenntnisse konsequent und methodisch durchdacht anzuwenden [...] (Schiewe/Wengeler 2005: 1).

Schiewe und Wengeler argumentieren:

Die Linguistik hat in den letzten fünfzig Jahren die Berechtigung und Notwendigkeit von Sprachkritik unterschätzt, sie oft gar geleugnet. Grund hierfür war ein allzu enger deskriptiver und vom Prinzip der Wertfreiheit getragener Wissenschaftsbegriff (Schiewe/Wengeler 2005: 7f.).

Sie konstatieren Anzeichen für einen Positionswandel in der Sprachwissenschaft (Schiewe/Wengeler 2005: 8.) und sprechen sogar von einer „Neukonturierung ihres Faches“ (Schiewe/Wengeler 2005: 9). Die Zeitschrift versteht sich als Versuch des Brückenschlags (vgl. Schneider 2005: 155) und richtet sich ausdrücklich auch an „sprachinteressierte Nicht-Linguisten“ (Schneider 2005: 155). Diese möchte sie in Aufsätzen ebenfalls zu Wort kommen lassen (vgl. dazu Schiewe/Wengeler 2005: 9). Silke Wiechers fordert im Jahr 2001 sogar:

Es stünde m.E. an, dass sprachwissenschaftliche Institutionen handhabbare Bewertungskriterien für die Beurteilung von Anglizismen entwickelten. [...] Derart abgesichert sollten sich Sprachpflege, Sprachkritik und Sprachwissenschaft als Ressource auch für politische Entscheidungen verstehen und sich nicht davor scheuen, zur 
Meinungsbildung auf diesem wichtigen Gebiet beizutragen (Wiechers 2001: 161).

Anders sieht es Peter Auer. Er konstatiert in einer Podiumsdiskussion:

[...] denn ich gehöre zu jenen Linguisten, die die Meinung vertreten, dass die Sprachwissenschaft und die Sprachkritik essentiell eigentlich nichts miteinander zu tun haben, oder, anders gesagt, dass die Linguisten nicht in irgendeiner privilegierten Form Sprachkritik betreiben können (Spitzmüller et al. 2002: 125).

Dieser Meinung von Auer schließt sich die Verfasserin an. Eisenberg beschreibt eine der großen Schwierigkeiten der Diskussion. Viele Sprecherinnen und Sprecher glaubten, dass es das richtige Deutsch tatsächlich gebe:

Eine große Mehrheit der Sprachteilhaber ist sich sicher, dass es das gute und richtige Deutsch tatsächlich irgendwo gibt. Wo es sich in welcher Form aufhält, weiß man nicht genau. Aber es existiert. [...] $\mathrm{Da}$ viele an das gute Deutsch glauben, ist noch kein Grund, eine normative Grammatik zu schreiben. Die Linguistik ist eine empirische Wissenschaft, was sonst. Eine empirisch fundierte Grammatik ist deskriptiv, nicht präskriptiv. Sie beschreibt was ist und nicht was nach Meinung irgendwelcher Leute sein soll. Dennoch bleibt die Frage, woher das sichere Wissen von einer sprachlichen Norm kommt und worin diese bestehen könnte. Es kann ja nicht auf sich beruhen, wenn die Mehrheit der Sprecher die Existenz einer Sprachnorm unterstellt, die Mehrheit der Sprachwissenschaftler aber davon nichts wissen möchte (Eisenberg 2004a: 8f.).

Außerdem kritisiert Eisenberg die Art und Weise, in der argumentiert wird:

Im öffentlichen Sprachdiskurs greift man verbal bedenkenlos in eine der oberen Schubladen. Starke Worte kosten nichts, sie verpflichten zu wenig, sie begleiten uns auf Schritt und Tritt (Eisenberg 2008a: 4).

Es ist ein neues Konzept in der Sprachwissenschaft zu beobachten: Die Anglizismenkritik wird mehr und mehr im gesellschaftlichen Zusammenhang betrachtet. Barbour beispielsweise sieht eine Verbindung zwischen der deutschen Wiedervereinigung und dem erneuten Aufflammen der Kritik am Fremdwort. Er beschreibt den „concern about [...] the use of words of foreign origin“ als eine Ausprägung von Nationalismus (Barbour 2001: 362f., vgl. auch Thomas 1991: 135). Ülkü schreibt dazu:

Sprache ist überall und immer mehr gewesen als lediglich ein praktisches Kommunikationsmittel; sie ist seit jeher auch als ein Ausgangspunkt kultureller Eigenart und der nationalen Identität angesehen worden. [...] Nationalstaat und Sprachnationalismus, diese Erfin- 
dungen und Erzeugnisse der europäischen Kultur, sind eng miteinander verknüpft (Ülkü 2002: 419). ${ }^{106}$

Barbour weist auch auf den an der Sprache orientierten Nationalismus in Deutschland hin, mit dem Verweis auf die Zeit des Nationalsozialismus, da das sogenannte Dritte Reich als Staatsgebilde alle deutschsprachigen Regionen umfasst hat. ${ }^{107}$ Zudem sei es laut Barbour vor der Wiedervereinigung schwer gewesen, eine deutsche Identität zu gründen. Der Bundesrepublik vor 1990 habe eine Identität gefehlt, denn eine Identität begründet auf Sprache sei schon durch die DDR und damit verbunden die unterschiedlichen Staatsangehörigkeiten ${ }^{108}$ nicht möglich gewesen (Barbour 2000: 165ff.).

Law (2002: 83), Linke (2003: 150) und Pfalzgraf (2006: 311f.) sehen die Wiedervereinigung als einen Grund für die Stärkung der Fremdwortkritik und das Aufflammen des Purismus, ebenso Spitzmüller, der darauf hinweist, dass in der Zeit danach in der Politik sogar von einer deutschen „Leitkultur“ gesprochen wurde (2007: 266f.). ${ }^{109}$ Und Matthias Jung gibt zu bedenken:

Es mag sein, daß sich das deutsche Sprachbewußtsein im internationalen Vergleich allmählich „normalisiert“ - die Grenze zwischen nicht-xenophober Sprachloyalität einerseits, gefährlichem Sprachchauvinismus und arrogantem Kulturimperialismus bleibt, nach innen wie außen, immer wieder neu auszuhandeln (Jung 1995: 280).

Pörksen spricht vom „Ende des nationalen Krampfes“ (Pörksen 2000: 14). Die wissenschaftliche Diskussion macht aber nur einen Teil der Fremdwortdiskussion aus, Hoberg sieht die Anglizismen als „zur Zeit wichtigstes Sprachthema in der Öffentlichkeit“ (Hoberg 2002a: 30). Ähnlich Spitzmüller:

${ }^{106}$ Sprache wird als gesellschaftliches Phänomen verstanden, das Gruppenzugehörigkeit begründet (vgl. Saxer 1989: 82). Die Schweiz ist beispielsweise ein Sonderfall: Dort gibt es vier Nationalsprachen, ein Umstand, auf den viele Schweizer stolz sind. Damit ist die Schweiz nicht als ein Staat anzusehen, dem das Konzept einer Sprach- und Kulturgemeinschaftsnation zugrunde liegt (vgl. Koller 2000: 563ff.). Ulrich Ammon verweist des Weiteren auf die „Plurinationalität“ der deutschen Sprache (Ammon 2000: 509).

${ }^{107}$ Die Schweiz war jedoch kein Teil des sogenannten Dritten Reichs, damit umfasste es keinesfalls alle deutschsprachigen Regionen.

${ }^{108}$ Vgl. zur Staatsangehörigkeit u.a. Kirchhof (2008).

${ }^{109}$ Zur „Leitkultur“, u.a. angesprochen von Friedrich Merz (CDU), gab es eine breite Debatte in der Politik und in den Medien (vgl. ausführlich u.a. Schneider 2008: 126). Wolf Schneider schreibt im Zusammenhang mit den Anglizismen im Deutschen über die „leidige Leitkultur“ (Schneider 2008: 126). 
[...] der Teildiskurs zum $>>$ Einfluss $<<$ des Englischen auf das Deutsche [...] ist - neben dem Teildiskurs um die Rechtschreibreform der dominante metasprachliche Diskurs der 90er Jahre und bestimmt nach dem Rückgang des Rechtschreibdiskurses [...] nahezu ausschließlich die öffentliche, genauer mediale Reflexion des Deutschen (Spitzmüller 2002: 247).

In diesem Zusammenhang steht eine Aussage Jan Georg Schneiders, der sich aber nicht auf die Anglizismen beschränkt: „Der „Wunsch zu erfahren, was sprachlich korrekt ist und was unkorrekt, hat derzeit Hochkonjunktur“ (Schneider 2005: 154). Es herrscht „in der Öffentlichkeit starkes Interesse an einem sichereren Umgang mit Sprache“ (Schneider 2005: 154). Weiterhin stellt Schneider fest, dass das „Bedürfnis [...] derzeit vorwiegend von Autoren bedient [wird], die weniger zur Aufklärung beitragen, als vielmehr einen unangemessenen Sprachdogmatismus befördern“ (Schneider 2005: 154). Als Beispiel dafür führt er Bastian Sicks ${ }^{110}$ Buch: „Der Dativ ist dem Genitiv sein Tod“111 an. (Schneider hebt hervor, dass diese Publikation am 29. März 2005 in der

${ }^{110}$ Bastian Sick ist auch Ehrenmitglied des VDS und eines der Gesichter auf Anzeigen des VDS, (vgl. SN 2006b: 10).

${ }^{111}$ In Sicks Buch findet sich folgende Einteilung von Fremdwörtern: „willkommen“, „wenn sie unsere Sprache bereichern“; „unnötig“, „wenn sie gleichwertige deutsche Wörter ersetzen oder verdrängen“. Diese Einteilung erinnert stark an die Einteilungen des ADSV/DSV, die auch heute noch von sprachpflegenden Vereinigungen in ähnlicher Weise verwendet werden, und folgt keinen sprachwissenschaftlichen Kriterien (siehe auch Kapitel 1.4.1). Sick steht mittlerweile bei einigen Sprachwissenschaftlern stark in der Kritik: André Meinunger hat mit „Sick of Sick?“ sogar ein Buch veröffentlicht, das sich ausschließlich mit Sicks fachlichen Fehlern auseinandersetzt (Meinunger 2008). Zu Kritik an Sicks Veröffentlichungen siehe auch Eisenberg (2008a).

Insgesamt kritisiert auch Schneider: „Häufig verbindet sich diese Organismus-Vorstellung mit etymologischen Fehlschlüssen und einer Verkennung des metaphorischen Charakters von Sprache: So kritisiert zum Beispiel Sick den „Übersetzungsanglizismus“ Sinn machen (making sense) mit der Begründung, dass machen auf die indogermanische Wurzel magzurückgehe, die für kneten stehe. Etwas Abstraktes wie Sinn könne man jedoch nicht kneten oder formen; er sei „entweder da oder nicht“. Nimmt man diesen sickschen Buchstäblichkeitsgrundsatz beim Wort, so könnte etwas z.B. auch keine Schule machen; man könnte sich keine Sorgen machen und keinen schlechten Eindruck; ja streng genommen könnte man noch nicht einmal eine Frage stellen, eine Antwort geben oder Kritik üben." (J. G. Schneider 2006, Hervorhebungen im Original).

Ein weitere interessante Veröffentlichung über den vermeintlichen Untergang der deutschen Sprache ist „Du Jane, ich Goethe“ (Deutscher 2008). 
„Amazon“-Bestsellerliste auf Platz drei geführt wurde. Schneider 2005: 154). ${ }^{112}$ Er ergänzt:

An der Tatsache, dass Publikationen dieser Qualität derzeit den öffentlichen Diskurs über Sprache beherrschen, ist die Linguistik alles andere als unschuldig. In ihrem Selbstverständnis, eine ausschließlich deskriptive Wissenschaft zu sein, hat sie das Normativitätsproblem jahrzehntelang trivialisiert und muss sich nun nicht wundern, wenn sie zum Thema Sprachrichtigkeit kaum noch befragt wird. Dies ist umso bedauerlicher, als bei vielen Menschen offensichtlich ein Bedürfnis nach einem sicheren Umgang mit Sprache vorhanden ist; und hierzu gehört ohne Zweifel auch ein reflektierter Umgang mit Anglizismen (J. G. Schneider 2006).

Für Stickel ist der Erfolg Sicks „[s]ymptomatisch für die derzeitige Konjunktur sprachlicher Themen“ (Stickel 2007: 135). Zwar habe es Sprachbücher und -glossen auch früher schon gegeben, sie hätten aber nur ein begrenztes Publikum erreicht und „ihre Autoren wurden auch nicht wie Popsänger durch Sporthallen und Konzerthallen gereicht" (Stickel 2007: 135). In den letzten Jahren hat sich für diese Art der „Linguistik“ sogar ein Begriff gebildet, man spricht auch von „Laienlinguistik“113 (beispielsweise Antos 1996). ${ }^{114}$

Hier sei noch einmal auf die drei Typen der „ideology brokers“ verwiesen (Blommaert 1999: 9), die die Diskussion maßgeblich prägen. Linguisten, Puristen und Journalisten. Hinzuzufügen sind Politiker (vgl. auch Spitzmüller 2007: 262).

Die Anglizismendiskussion hat sich zu einer intensiven und emotional geführten Auseinandersetzung entwickelt (vgl. z.B. Keßler 2000: 51). Das IDS untersuchte im Jahr 1997 die Einstellung der erwachsenen Bevölkerung gegenüber sprachlichen Fragen und der Sprachentwicklung wie den Anglizismen. ${ }^{115}$ Befragt $\mathrm{zu}$ ihrem Interesse an sprachlichen

112 Mittlerweile ist von Sick in dieser Reihe bereits der vierte Band erschienen, (Sick 2004, 2005, 2006, 2009), ebenso die Publikation „Happy Aua“ (Sick 2007).

${ }^{113}$ Die „Volksetymologie“, die ja auch eine Laienlinguistik ist, gibt es schon länger.

${ }^{114}$ Antos schreibt „Laien-Linguistik“. Auch seit Anfang der 1990er Jahre sind immer wieder nicht-wissenschaftliche Publikationen zum Thema erschienen, wie Eckhard Henscheids „Dummdeutsch“ in zwei Bänden (Henscheid 1993), Rudolf Lubeleys „Sprechen Sie Engleutsch?“ (Lubeley 1993, Lubeley rief 1993 bereits zur Gründung einer „deutschen Sprachgemeinschaft“ auf (vgl. Spitzmüller 2005: 122) oder auch Walter Krämers „Modern Talking“ (Krämer 2000a), in denen die Verwendung von Anglizismen im Deutschen ins Lächerliche gezogen wird.

${ }^{115}$ Vgl. zu Einstellungen gegenüber Anglizismen auch schon Stickel (1984 und 1987). 
Fragen wurden im Zeitraum von Oktober bis Dezember 1997 insgesamt 2025 Personen, davon 1004 in den alten Bundesländern und 1021 in den neuen. Dabei bekundeten 43,5 Prozent der Probanden ein sehr starkes bis mittleres Interesse, gut die Hälfte der Befragten gab an, an sprachlichen Fragen nicht interessiert zu sein.

\begin{tabular}{|l|l|l|l|}
\hline $\begin{array}{l}\text { Interesse an Spra- } \\
\text { che (in \%) }\end{array}$ & Zusammen & Ost & West \\
\hline Sehr stark & 3,6 & 3,4 & 4,1 \\
\hline Stark & 9,2 & 9,9 & 6,5 \\
\hline Mittel & 30,7 & 31,8 & 27,0 \\
\hline Wenig & 31,5 & 29,9 & 37,3 \\
\hline Überhaupt nicht & 25,0 & 25,0 & 25,2 \\
\hline
\end{tabular}

Abbildung 2: Interesse an Sprache (Stickel 1999: 21)

Betrachtet man die Gruppe der Probanden, stellt man fest, dass mehr Frauen mittel bis sehr stark an Sprache interessiert (44,6 Prozent) sind als Männer (42,3 Prozent).

\begin{tabular}{|l|l|l|}
\hline $\begin{array}{l}\text { Interesse an Spra- } \\
\text { che (in \%) }\end{array}$ & Frauen & Männer \\
\hline Sehr stark & 3,7 & 3,4 \\
\hline Stark & 9,9 & 8,3 \\
\hline Mittel & 31,0 & 30,6 \\
\hline Wenig & 30,3 & 32,9 \\
\hline Überhaupt nicht & 25,2 & 24,7 \\
\hline
\end{tabular}

Abbildung 3: Interesse an Sprache nach Geschlecht der Gefragten (Stickel 1999: 21)

Gefragt wurde auch nach Sprachveränderungen. Die Frage nach auffälligen Sprachveränderungen in den letzten fünf bis zehn Jahren bejahten 46,6 Prozent der Befragten (45,2 Prozent Westdeutsche und 51,9 Prozent Ostdeutsche). Als Beispiele nannten 182 Personen Anglizismen 
oder Amerikanismen. Rund 26 Prozent empfanden die Sprachentwicklung als besorgniserregend (vgl. Stickel 1999: 20ff.).

\begin{tabular}{|l|l|}
\hline Sprachentwicklung ist: & $\%$ \\
\hline Eher erfreulich & 4,8 \\
\hline Eher besorgniserregend & 26,4 \\
\hline Teils/teils & 30,7 \\
\hline Weder noch & 26,4 \\
\hline Weiß nicht & 11,7 \\
\hline
\end{tabular}

\section{Abbildung 4: Sprachentwicklung (Stickel 1999: 25)}

Im Jahr 2001 veröffentlicht Glahn seine Untersuchung über Einstellungen gegenüber Anglizismen. ${ }^{116}$ Er kommt zu dem Ergebnis, dass das Verwenden von Anglizismen in der Gesellschaft mehrheitlich befürwortet wird. Dabei ist das Verwenden von Anglizismen nicht als eine Domäne der Jugend zu betrachten (vgl. Glahn 2001: 32), auch wenn Jugendliche das Verwenden von Anglizismen häufiger befürworten als Erwachsene (vgl. dazu Glahn 2002: 231). Außerdem kommt Glahn zu dem Ergebnis, „dass das Verwenden von Anglizismen die allgemeine Verständigung nicht nennenswert beeinträchtigt“ (Glahn 2002: 232). Dirk Hofmann untersucht ebenso die Einstellung gegenüber Anglizis-

${ }^{116}$ Er befragte dazu lediglich 67 weibliche und 63 männliche Personen aus verschiedenen Altersschichten (65 Jugendliche und 65 Erwachsene). Die Jugendlichen waren allesamt Gymnasiasten, bei den Erwachsenen hatten 20 der Probanden einen Hochschulabschluss. Diese befragte er anhand eines Fragebogens, der als wissenschaftliche Erhebung gekennzeichnet war. Insgesamt hatte der Fragebogen neun Fragen. Forschungsinteresse war, ob das Verwenden von Anglizismen in der Einstellung zur anglo-amerikanischen Kultur begründet liegt, welche sachlichen Gründe es für das Verwenden gibt, welche individuellen und sozialen Aspekte im Vordergrund stehen, ob soziale Faktoren eine Rolle spielen, ob das Verwenden abhängig ist von „Jugendlichkeit“ oder „Erwachsensein“, vom Geschlecht oder von der Bildung, und inwieweit Englischkenntnisse beim Gesprächspartner stillschweigend vorausgesetzt werden und ob das Verwenden von Anglizismen die Verständigung behindert. Dazu wurden vorwiegend geschlossene Fragen gestellt, zudem waren auf dem Fragebogen Argumente für und gegen die Verwendung von Anglizismen aufgeführt. Gefragt wurde beispielsweise auch nach Entlehnungen, die die Probanden nicht mögen, und Entlehnungen, von denen sie glauben, dass sie gerne verwendet werden (vgl. Glahn 2001: 25f.). 
men. ${ }^{117}$ Er hält fest, dass nur 40 Prozent der befragten Jugendlichen die Anglizismen, nach denen er fragte, „nützlich“ finden, wohingegen in der Altersgruppe der 31- bis 40-Jährigen 62,4 Prozent der Befragten mit Hochschulstudium und sogar 84,6 Prozent der Befragten ohne Hochschulstudium den Gebrauch von Anglizismen „nützlich“ finden. ${ }^{118}$ In der Altersgruppe der 41- bis 50-Jährigen nimmt diese Einstellung wieder ab. 36,2 Prozent beziehungsweise 26,4 Prozent finden Anglizismen nützlich. Hinsichtlich des Verständnisses von Anglizismen konstatiert Hofmann, dass rund 20 Prozent der Bevölkerung auch populäre Anglizismen nicht verstehen ${ }^{119}$ (vgl. Hofmann 2002: 241ff.). Eine neuere Untersuchung zur Einstellung zu Anglizismen ist die Analyse von Gerhard Stickel und Norbert Volz. ${ }^{120}$ Die beiden Wissenschaftler kommen zu

${ }^{117}$ Hofmann erhebt seine Daten anhand eines Fragebogens. Dieser Fragebogen enthält 16 Anglizismen, darunter „Streetworker“ oder „Date“, nach deren Bedeutung gefragt wird. Bei den ausgewählten Beispielen handelt es sich ausschließlich um Substantive, die mit Zitaten aus der Süddeutschen Zeitung belegt wurden, um ihren aktuellen Gebrauch darzustellen. Zudem fragt Hofmann danach, wie die Befragten das Verwenden dieser Wörter im Deutschen finden. Das Erhebungsgebiet war Nordrhein-Westfalen mit Schwerpunkt Köln, befragt wurden 620 Sprecher. Dabei variiert die Anzahl der Befragten in jeder Altersgruppe leicht. Eingeteilt wurden die Befragten in Gruppen, dabei bildeten jeweils die 15- bis 20 Jährigen, die 21- bis 30-Jährigen, die 31- bis 40-Jährigen, die 41- bis 50-Jährigen, die 51- bis 60-Jährigen und die Über-60-Jährigen eine Gruppe (vgl. Hofmann 2001: 237ff.)

118 Wie Hofmann zu diesem Ergebnis kommt, wird aus seiner Darstellung der Studie nicht ersichtlich. Anzunehmen ist, dass die Befragten das Schlagwort „nützlich“ bei der offenen Frage nach ihrer Einstellung zur Verwendung der Anglizismen im Deutschen eingetragen haben (vgl. Hofmann 2001: 236).

${ }^{119}$ Dies wurde anhand einer Liste von Anglizismen geprüft, in der die Befragten aufgefordert waren, die Bedeutung dieser Anglizismen anzugeben.

${ }^{120}$ Zweck dieser Untersuchung war die Erfassung von Meinungen, die in der Bevölkerung verbreitet sind, sowie von emotionalen Einstellungen. Die Stichprobe wurde aus 2025 Befragten gebildet, davon 969 Westdeutsche (Personen aus den alten Bundesländern und Westberlin, und 1056 Ostdeutsche (aus den neuen Bundesländern und Ostberlin). Dabei waren je 1000 Befragte für beide Gebiete angestrebt. Die tatsächlichen Zahlen ergaben sich durch die Aussortierung fehlerhaft oder unvollständig ausgefüllter Fragebögen. Bei der Auswertung der gesamtdeutschen Ergebnisse in Prozentanteilen wurden die Ergebnisse nach einem Verhältnis von 1:3,7 gewichtet. Die Auswahl der Probanden wurde nach dem ADM-Master-Sample durchgeführt, einem statistischen Modell des Arbeitskreises Deutscher Marktforschungsinstitute (vgl. Stickel/Volz 1999: 5ff.). Durchgeführt wurde die Erhebung anhand von Fragebögen, insgesamt waren es 54 Fragen, unterteilt in verschiedene Themengebiete: Sprachliche Selbsteinschätzung der Probanden, allgemeine Sprachentwicklung, dialektale Varianz des Deutschen, sprachliche Ost-West-Wahrnehmung in Deutschland, Mehrsprachigkeit in Deutschland und das Deutsche in der vielsprachigen Europäischen Union (vgl. Stickel/Volz 1999: 11ff.). 
dem Ergebnis, dass knapp die Hälfte der Befragten (46,6 Prozent) der Ansicht ist, dass sich die deutsche Sprache verändert hat.

\begin{tabular}{|l|l|l|l|}
\hline $\begin{array}{l}\text { Auffällige Sprach- } \\
\text { veränderungen (in \%) }\end{array}$ & Ost & West & $\begin{array}{l}\text { Zusammen } \\
\text { (gewichtet) }\end{array}$ \\
\hline Ja & 51,9 & 45,2 & 46,6 \\
\hline Nein & 48,1 & 54,8 & 53,4 \\
\hline
\end{tabular}

\section{Abbildung 5: Auffällige Sprachveränderungen Ost/West (Stickel/Volz} 1999: 18)

Von denjenigen Probanden, denen sprachliche Veränderungen aufgefallen sind, finden nur 8,4 Prozent diese Veränderungen gut. Die anderen bewerten sie als entweder ganz schlecht oder teilweise schlecht. Als sprachliche Veränderungen wurden meistens Anglizismen genannt. Stickel und Volz weisen ergänzend darauf hin, dass auch aus Kommentaren der Befragten deutlich wurde, dass Anglizismen häufig als negativ bewertet werden.

\begin{tabular}{|l|l|l|l|}
\hline $\begin{array}{l}\text { Bewertung der Verände- } \\
\text { rungen (in \%) }\end{array}$ & West & Ost & $\begin{array}{l}\text { Zusammen } \\
\text { (gewichtet) }\end{array}$ \\
\hline Gut & 9,4 & 4,6 & 8,4 \\
\hline Schlecht & 45,1 & 42,7 & 44,6 \\
\hline Teils/Teils & 45,5 & 52,7 & 47.0 \\
\hline
\end{tabular}

Abbildung 6: Bewertung der Veränderungen (Stickel/Volz 1999: 18)

Rund ein Viertel empfindet die Entwicklung der Sprache als „besorgniserregend“ (vgl. Stickel/Volz 1999: 47).

Im Jahr 2008 wurde von der GfdS in Zusammenarbeit mit dem Deutschen Sprachrat eine Umfrage in Auftrag gegeben, die das Institut für Demoskopie Allensbach durchführte. ${ }^{121}$ Die Umfrage kam zu dem Ergebnis, dass sich viele Deutsche inzwischen an die zunehmende Ver-

${ }^{121}$ Dazu wurden zwischen dem 4. und 17. April 2008 insgesamt 1820 bevölkerungsrepräsentativ ausgewählte Personen ab 16 Jahre befragt. Die Untersuchung zum Thema ,Deutsche Sprache' im weitesten Sinne wurde mündlich-persönlich durchgeführt (vgl. Schulz 2008: 1). 
wendung englischer Ausdrücke wie ,Kids', ,Event', ,Meeting' oder ,EMail' gewöhnt haben, aber insgesamt 39 Prozent gaben an - davon in einem überdurchschnittlichen Anteil Ältere ohne Englischkenntnisse dass sie sich an englischen Ausdrücken im Deutschen stören (vgl. Schulz 2008: 3). 65 Prozent waren der Ansicht, dass die deutsche Sprache immer mehr verkomme (Schulz 2008: 4).

Wenn jemand sagt: "Die meisten Menschen bei uns in Deutschland legen nur noch wenig Wert auf eine gute Ausdrucksweise. Die deutsche Sprache droht immer mehr zu verkommen."

Sehen Sie das auch so, oder sehen Sie das nicht so?

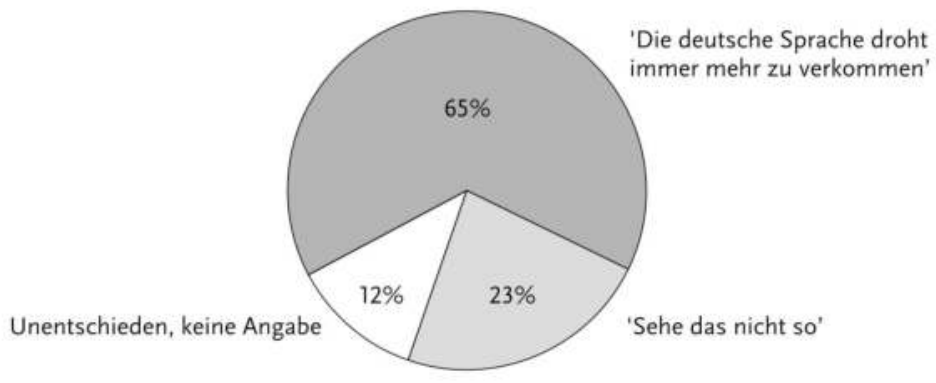

Abbildung 7: Erwartung, dass die deutsche Sprache immer mehr verkomme (Quelle: Schulz 2008: 4)

Die Studie ergab auch, dass sich die Menschen in den neuen Bundesländern stärker an englischen Ausdrücken stören als die in den alten Bundesländern (vgl. Schulz 2008: 9). 
Für viele Dinge des Alltags werden heutzutage immer häufiger englische Ausdrücke verwendet, wie zum Beispiel "Kids", “Event", "Meeting”, oder "E-Mail".

Wie ist Ihre Meinung dazu: Stört Sie das, oder stört Sie das nicht?

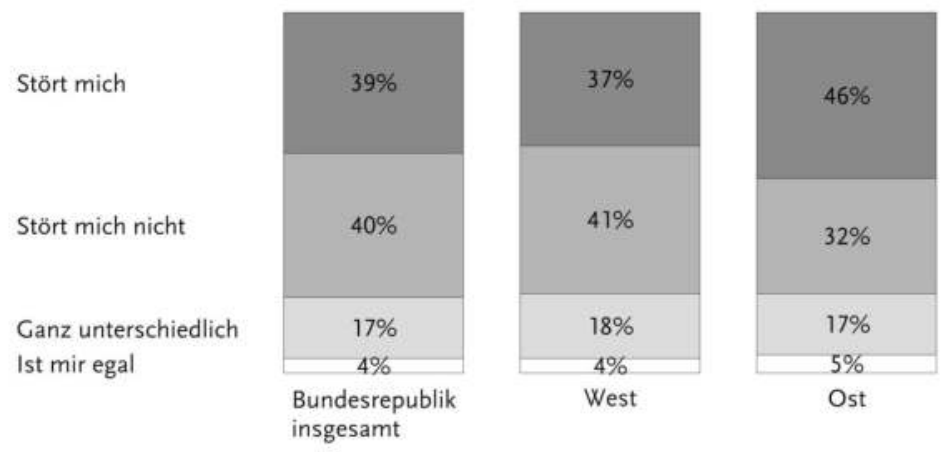

\section{Abbildung 8: Gewöhnung an englische Ausdrücke West/Ost (Quelle: Schulz 2008: 9)}

Zudem stören sich Ältere an den neuen Ausdrücken stärker als Jüngere. Menschen ohne Englischkenntnisse stören sich stärker als Menschen mit Englischkenntnissen. Insgesamt stören sich 39 Prozent der Bevölkerung an den englischen Ausdrücken. Dagegen sind 19 Prozent der Meinung, dass man mit englischen Wörtern besser ausdrücken könne, was man eigentlich sagen wolle (vgl. Schulz 2008: 1ff.).

Hobergs Ansicht nach handelt es sich bei der Anglizismendiskussion "vereinfacht gesagt, um einen Streit zwischen ,Laien' und Linguisten“ (Hoberg 2002a: 30). Denn ein großer Teil der Bevölkerung glaube, der englische Einfluss sei übermächtig, ihre Muttersprache verliere immer mehr an Boden, gehe bald unter, und man müsse etwas gegen die überflüssigen Anglizismen tun, da sonst die Verständigung nicht mehr möglich sei. Stickel befindet im Jahr 2007: „Das sprachliche Interesse in Deutschland nimmt zu [...]“ (Stickel 2007: 134). 


\subsubsection{Die Fremdwortdiskussion in den Medien}

Auch in den Medien werden Themen, die die deutsche Sprache betreffen, generell regelmäßig thematisiert, großen Raum nimmt dabei die Anglizismendebatte ein. Sie wird als eines der wichtigsten metalinguistischen Themen angesehen (vgl. Spitzmüller 2007: 261). Um auf die Anglizismen- bzw. Purismusdiskussionen in den Medien einzugehen, möchte ich mich auf die Analysen der Presse von Matthias Jung (1995) und Jürgen Spitzmüller (2005) stützen: Für das Jahr 1990 bemerkt Jung, dass ausgerechnet Der Spiegel, der traditionell als einer der Hauptsünder gilt, Stimmen Raum gibt, die von einer Anglisierung des Deutschen sprechen (vgl. Jung 1995: 268) ${ }^{122}$. Spitzmüller konstatiert verhaltene Anglizismenkritik und Kritik des Purismus für die Jahre 1990 bis 1993, er stellt kaum Veränderungen zum Diskurs der 1980er Jahre fest und hält fest, dass gemäßigte Anglizismenkritik sowie Purismuskritik relativ selten auftreten (vgl. Spitzmüller 2005: 115).

Dagegen sieht es in den Jahren 1994 bis 1996 schon anders aus. Die Anglizismenkritik nimmt im Vergleich zu den vorigen Jahren quantitativ zu. Zudem gewinnt die Diskussion an Schärfe (vgl. Spitzmüller 2005: 117). Neu ist auch der Diskurs über die französische Sprachpolitik (vgl. Spitzmüller 2005: 116) sowie eine Institutionalisierung der Anglizismenkritik von 1997 (dem Gründungsjahr nicht nur des VDS) bis 1999, die auch auf die neugegründeten Sprachvereine zurückzuführen ist. Die Schärfe der Diskussion, die Spitzmüller beschreibt, zeigt sich tatsächlich in den Medien. Glück schreibt beispielsweise in der Berliner Morgenpost: „Der Mangel an Sprachloyalität nach außen geht einher mit sprachlicher Wurstigkeit im Innern“ (Glück 1999: 4). Teilweise ist die Haltung der Journalisten gegenüber den Anglizismen schon im Titel zu erkennen, wie zum Beispiel in dem Focus-Artikel „Deutsch für Schimpansen“ (Bettermann 1999: 192ff.).

Ab dem Jahr 2000 stellt Spitzmüller eine Politisierung des Diskurses fest. Anglizismen werden von Journalisten, ${ }^{123}$ im Karneval und bei

${ }^{122}$ Hier verweist Jung u.a. auf den Spiegel vom 7. Mai 1990 (Der Spiegel 1990: 278ff.). Dort ist unter anderem von „Verbalimperialismus” die Rede (vgl. Jung 1995: 268f.).

${ }^{123}$ Auch Der Spiegel hat sich in den letzten Jahren des öfteren mit Anglizismen beschäftigt. Eine Eingabe der Stichwörter angl*, anglizismus und anglizismen im Archiv des Spiegels 
Kleinkünstlern häufig thematisiert. Außerdem verweist Spitzmüller auf Glücks Forderung nach einer Sprachakademie in der Welt (Glück 2000d: 31), darauf, dass der thüringische Ministerpräsident Bernhard Vogel im Sommerinterview des MDR die Verwendung von Anglizismen als Verhunzung der Sprache bezeichnete (MDR 2000), und darauf, dass der ehemalige Berliner Innensenator Eckart Werthebach (CDU) - wie später in diesem Kapitel noch dargestellt - eine intensive Debatte um Anglizismen initiierte. Diese Anregung wurde von der Presse aufgegriffen und ausgiebig diskutiert (vgl. dazu Spitzmüller 2005: 129). Bezüglich des VDS kristallisiert sich heraus, dass es immer wieder Themen gibt wie beispielsweise den Prozess von Peter Vogelgesang gegen Lufthansa (vgl. dazu Kapitel 2.5.2), oder die Verleihung des Deutschen Sprachpreises (u.a. edo 2000: 17), die von der Presse aufgegriffen werden. Innerhalb kurzer Zeit bestimmt der VDS den Diskurs maßgeblich mit (vgl.

am 6. Juli 2007 ergab 58 Treffer „Anglizismen“, einen Treffer „Anglizismenvermeidung“, fünf Treffer „Anglizismus“ und einen „Anglizismus-Kritiker“. Die Berichterstattung des Spiegels ist dabei bezüglich der Wertung von Anglizismen her unterschiedlich. 1998 berichtet Der Spiegel neutral über Peter Vogelgesang und seine Schwierigkeiten mit der Lufthansa. (Der Spiegel 1998b: 135, vgl. Kapitel 2.5.2). Anders ist dagegen der Tenor des Autors im Artikel: „Welcome in Blabylon“: „Alberne Anglizismen überspülen das Deutsche und erzeugen einen Mischmasch namens Denglisch“ ist dort zu lesen, Anglizismen werden auch als „sprachliche Heimsuchungen“ betitelt (Alexander et al. 2001: 160). Weiterhin heißt es: „Am ärgerlichsten sind die Ausdrücke, die den Bombast, den Zwangsoptimismus und die Gespreiztheit der in die Krise geratenen flotten Zeiten unironisch zur Schau tragen." (Alexander et al. 2001: 161). Dagegen wird einem Sprachgesetz kritisch gegenübergestanden: „Ein Blick nach Frankreich verstärkt die Skepsis gegen Gesetze zur Reinhaltung der deutschen Sprache.“ (Alexander et al. 2001: 162). In „Die Begriffswelt des Béla Anda“ steht: „Tatsächlich darf darüber nachgedacht werden, ob das, was der Kanzler und seine Minister für mitteilenswert halten, im Land auch ankommt." (Neubacher 2005: 164). Im Artikel „It's a trick“ ist zu lesen: „Mit englischen Werbesprüchen versuchen die Firmen dem Zeitgeist auf die Spur zu kommen. Sie wollen cool sein - und produzieren manchmal nur Quatsch.“ „Pidgin-Englisch am Rande der Verständlichkeit ist das“, schimpft Annette Trabold vom Institut für deutsche Sprache [...]. (Der Spiegel 1998a: 124). „Die Sprache lässt sich wesentlich besser verdichten als die deutsche“, sagt Holger Jung von der Hamburger Agentur Jung von Matt. (Der Spiegel 1998a: 125). So kommen auch durchaus Stimmen zu Wort, die nicht anglizismenkritisch sind: In einem Interview im Spiegel mit Walter Kempowski sagt dieser: „Lasst die Leute schnacken“, rät zu Gelassenheit und warnt vor neuer Deutschtümelei (Der Spiegel 2001: 92). In einem Interview unter dem Titel „Hohes Prestige“ sieht Christoph Schubert, Anglist an der Universität Würzburg keine Bedrohung der deutschen Sprache (Der Spiegel 2005: 183). Ab 1993 bis Mitte 2007 wurden zudem allein in der FAZ 549 Artikel zum Thema Anglizismen veröffentlicht, davon $210 \mathrm{ab}$ dem Jahr 2003. Dies ergab eine Stichwortsuche (angl*) im Archiv der FAZ auf CD-ROM am 6. Juli 2007. 
Spitzmüller 2005: 123). Anglizismenkritik äußert sich in dieser Zeit auch in zahlreichen Sprachglossen. Holger Appel schreibt beispielsweise in einer Glosse in der FAZ im Jahr 2000:

Vielleicht rufen Sie einfach mal bei Ihrem Call-Center an, die sagen Ihnen schon, was zur Zeit in ist. Ihrem Online-Broker mailen Sie dann, welche Orders er für Sie posten soll.[...] Das kommt Ihnen denglish vor? [...] Engagieren Sie doch einfach einen Communications Consultant (Appel 2000: 25).

Auch im "Streiflicht“ der Süddeutschen Zeitung wird das Thema aufgegriffen, beispielsweise, indem der Autor sich über das "Casino to go“ amüsiert (Süddeutsche Zeitung 2008a: 1) oder auch über die Verdeutschungen der Aktion „Lebendiges Deutsch“ (Süddeutsche Zeitung 2008b: 1). Ein andermal hat das Streiflicht den Anglizismengebrauch von Gerhard Mayer-Vorfelder (Sprachpanscher des Jahres 2003, vgl. Kapitel 2.5.4.1) im Blick und amüsiert sich über den Negativ-Preis des Vereins Deutsche Sprache an diesen (Süddeutsche Zeitung 2003: 1), oder der Autor rät Anglizismengegnern zur Gelassenheit (Süddeutsche Zeitung 2001: 1). In der Glosse "Sprach-Spiele“ in der Zeitung Die Welt wird ebenfalls immer wieder auf Anglizismen Bezug genommen, beispielsweise wenn der Begriff „Funeral Master“ kritisiert wird (Glück 2001c: 34, vgl. auch Kapitel 2.5.4.1), die Sprache der Post (Glück 2002b: 28) oder der Begriff "Wellness“ auf die Schippe genommen wird (Glück 2003b: 12). Die Kolumne „Wortgefecht“ der Welt am Sonntag setzt sich immer wieder mit „ärgerlichen Anglizismen“ auseinander (vgl. z.B. Krüger 2007: 78). Auch Ruprecht Skasa-Weiß hat sich in der Stuttgarter Zeitung in seinen Glossen mit Anglizismen beschäftigt. Beispielsweise mit der „Pauer“, wobei er sowohl den mangelnden Mut zur Integration von Anglizismen als auch die Verzagtheit der Deutschen beim Wörterbilden bemängelt (vgl. Skasa-Weiß 2006: 111ff.), oder auch mal die unterschiedlichsten Verwendungen von „Sinn machen“ aufs Korn nimmt (Skasa-Weiß 2007: 8).

Es ist davon auszugehen, dass sich der Diskurs in bestimmten Zeitungen konzentriert, wie in der Süddeutschen Zeitung oder der Frankfurter Allgemeinen Zeitung. ${ }^{124}$ Zahlreiche Artikel finden sich aber auch in der taz, wobei hier anders als in den anderen Zeitungen die anglizis-

${ }^{124}$ Diese gelten als Leitmedien der Bundesrepublik Deutschland (vgl. Meyn 2004). 
menfreundlichen überwiegen. Auf eine Entideologisierung des Diskurses, wie sie Jung noch 1995 verkündet hatte, kann daraus nicht geschlossen werden. Die Ergebnisse zeigen jedoch, dass Sprache und Nation als Themenkomplex durchaus wieder in den Medien auftauchen (vgl. Spitzmüller 2005: 145f.).

Anglizismen werden nicht nur in den Zeitungen, sondern auch im Hörfunk thematisiert. Die im Folgenden aufgeführten Sendungen sind Zufallsfunde, die exemplarisch die Situation skizzieren, ohne Anspruch auf Vollständigkeit. Beispielsweise hat Jakob Augstein unter dem Titel „Deutsch oder Denglish - das nationale Anliegen?" eine Hörfunksendung gemacht, die im DeutschlandRadio Berlin im Politischen Feuilleton am 26. Juli 2001 (Augstein 2001) ausgestrahlt wurde. Auch in weiteren Sendungen sind Anglizismen immer wieder Thema (vgl. Bayern2 Radio 2004, 2007).

Das Fernsehen widmet sich ebenfalls mitunter sprachpolitischen Themen. Im NDR wurde beispielsweise am 18. Januar 1999 ein Interview mit Gerd Schrammen ausgestrahlt (NDR 1999). Am 27. Januar 2002 wurde unter dem Titel „Fachchinesisch beim Gerätekauf. Und niemand versteht die Technik“ ein Beitrag von Gerd Cordes (Cordes 2002) über unverständliche Gebrauchsanleitungen gesendet. Dort heißt es:

Der deutsche Fernsehsender Premiere wirbt nicht nur mit englischen Begriffen, sondern auch mit Fantasiebezeichnungen wie „Dokutainment“. Hier sind dann auch Wörterbücher überfordert (Cordes 2002).

Am 13. November 2008 gab es einen 3Sat-Thementag mit dem Titel „Uns fehlen die Worte“, bei dem unter anderem die Zuschauer aufgerufen waren, Verdeutschungsvorschläge für Anglizismen einzureichen und der VDS im Mittelpunkt zweier Beiträge stand (vgl. Walter 2008, Billing 2008). Auch gibt es mittlerweile Fernsehshows, die sich mit dem Thema deutsche Sprache auseinandersetzen, wie „Frei von der Lippe“ mit Jürgen von der Lippe im MDR (von der Lippe 2008) sowie die Bastian-Sick-Schau mit Zwiebelfisch-Kolumnist und Autor Bastian Sick (Sick 2008).

Der Auslandssender Deutsche Welle hat dem Thema Anglizismen ein Symposium unter der Überschrift: „Passé und mega-out? Zur Zukunft der deutschen Sprache im Zeitalter der Globalisierung“ gewidmet. Stickel äußert sich bei dieser Diskussion: 
Ich glaube tatsächlich, dass die deutsche Sprache in ihrem Wortschatz durch die Aufnahme von Anglizismen bereichert wird, also durch Entlehnungen aus dem britischen und neuerdings auch aus dem amerikanischen Englisch. So wie das Deutsche einen wesentlichen Teil seines Ausdrucksreichtums aus dem Lateinischen, dem Französischen und auch aus dem Griechischen hat. Von daher sollten wir uns gar nicht vormachen, eine rein teutonisch-germanische Sprache zu sprechen, die verschmutzt wird durch Entlehnungen aus anderen Sprachen. Eine Menge wichtiger englischer Ausdrücke, die wir zusammen mit den neuen Sachen ins Deutsche übernehmen, sind ungemein praktisch. Die kann man auch verwenden.. [...] Das Werbe-Englisch ist eine andere Geschichte - und da hätte ich in vieler Hinsicht meine Zweifel, ob es sich dabei um Bereicherungen der deutschen Sprache handelt (Deutsche Welle 2002: 32).

\section{Thomas Steinfeld ${ }^{125}$ kritisiert die Bereitschaft der Deutschen, Fremd-} wörter zu benutzen:

Glaubt man den festen Redewendungen in den Diskussionen über die Zukunft der deutschen Sprache, fallen sie auf den Rücken, sobald sich die erste englische Vokabel im Tiefflug nähert. [...] Die deutsche Sprache, so heißt es immer wieder, sei durch den globalen Erfolg der englischen Sprache bedroht. Ganze Felder der Wissenschaft und des Geschäftslebens, und zwar ausgerechnet die volkswirtschaftlich und technisch entscheidenden, hätten sich kampflos dem Englischen oder besser: dem Jargon, der jeweils als das Englische ausgegeben werde - ergeben. Englische Vokabeln hätten den deutschen Wortschatz bis in seinen Kern durchsetzt. Da kommt sie, donnernd, die englische Sprache, und schon liegen wir strampelnd auf dem Rücken, wir tollpatschigen Tiere, wir Fanatiker der Beflissenheit, wir kurzbeinigen, breithüftigen Weltbürger. Merkwürdig, dass uns dieser Vergleich einzuleuchten scheint. Denn an diesem Vergleich ist so ziemlich alles falsch, was falsch sein kann. [...] Offenbar muss man Wörter wie „service center“ oder „mail“ nur leise brummen und die Arme wie Flügel spreizen, und die als Deutsche verkleideten kurzbeinigen Eierwärmer werfen sich vor Begeisterung selber um (Steinfeld 2002: 14ff.).

Dem fügt er hinzu: „[W]ir haben seit vielen Jahren eine hausinterne Liste, die vielleicht 400, 500 Einträge umfasst. Da ist auch das Wort ,Handy'126 eingetragen, aber da steht dann: ,zu ersetzen durch Mobiltelefon'. (Deutsche Welle 2002: 33). Dies zeigt, dass bei der FAZ durchaus auf Vermeidung von Anglizismen geachtet wird.

${ }^{125}$ Steinfeld war Leiter des Ressorts Literatur und literarisches Leben der Frankfurter Allgemeine Zeitung (vgl. Deutsche Welle 2002: 90), mittlerweile ist er bei der Süddeutschen Zeitung, Redaktion Feuilleton.

126 „Handy“ ist eine im Deutschen entstandene Bildung. 
An dieser Stelle darf der Germanist und Anglist Dieter E. Zimmer nicht fehlen, der als Redakteur für Die Zeit arbeitet, und seine Publikation "Deutsch und anders - die Sprache im Modernisierungsfieber" (erschienen 1997). ${ }^{127} \mathrm{Im}$ Kapitel „Neuanglodeutsch - über die Pidginisierung der Sprache“ stellt Zimmer fest, dass die die Anglisierung alle Bereiche der Sprache betreffe (vgl. Zimmer 1997: 20). Als Grund für das "Modernisierungsfieber“ wird unter anderem die „deutsche Identitätskrise“ (Zimmer 1997: 30) nach dem Zweiten Weltkrieg angeführt. ${ }^{128}$

Es bleibt festzuhalten, dass der öffentliche Diskurs zu Anglizismen seit den 1990er Jahren kontinuierlich und deutlich zugenommen hat und dass der VDS dabei eine nicht unwesentliche Rolle spielt (vgl. Klein 2001, Spitzmüller 2007: 268, Schneider 2008: 169).

\subsubsection{Die Fremdwortdiskussion in der Politik}

Auch in der Politik sind Anglizismen in der Bundesrepublik nach der Wiedervereinigung ein Thema: ${ }^{129}$

$\mathrm{Zu}$ Anfang des Jahres 2001 [...] kritisierten dann zahlreiche hochrangige deutsche Politiker aller Parteien den angeblich übermäßigen Gebrauch englischsprachiger Wörter und Wendungen im Deutschen [...] (Pfalzgraf 2006: 12f.).

Im Jahr 2001 sprach der damalige Bundestagspräsident Wolfgang Thierse von "Sprachverhunzung“ (vgl. Alexander et al. 2001: 162). Er hielt eine Rede vor dem deutschen Philologenverband, in der er sagte:

Ich erhalte immer wieder Einladungsschreiben, in denen es von angelsächsischen Modewörtern wimmelt: „Mega-Event“ mit „Performance“ bei hoher „Media-Präsenz“, „round-table-conference“ mit anschließendem „Presse-Briefing“ usw. Mitunter möchte ich solche Schreiben einfach an den bundestagseigenen Sprachendienst weiterleiten - mit der Bitte um Rückübersetzung in unsere Muttersprache (Deutscher Bundestag 2001).

${ }^{127}$ Jung verweist darauf, dass sich Zimmer 1981 noch durchaus wohlwollend gegenüber Anglizismen geäußert hat (vgl. Jung 1995: 249, Zimmer 1981: 59f.).

${ }^{128}$ An dieser Stelle ist anzumerken, dass Zimmer hier mit dem nicht zutreffenden Terminus der „Pidginisierung“ arbeitet. Zu einem ausführlichen Kommentar bezüglich der Rolle der Publikation in der Fremdwortdiskussion vergleiche Spitzmüller (2005: 117f.) und Pfalzgraf (2006: 202ff.), für weitere Kritik an Zimmer vgl. z.B. Peter Hohenhaus (2002).

${ }^{129}$ Bereits 1973 griff Bundespräsident Heinemann das Sprachproblem in einer Rede mit dem Titel „Verpflichtung zur Pflege der Deutschen Sprache“ auf (vgl. Heinemann 1973: 144ff.). 
In dieser Rede äußerte er sich auch negativ zu einem Sprachgesetz, begründet aus seiner eigenen Biographie:

Sprache kann man nicht verordnen. Der öffentliche und erst recht der private Sprachgebrauch lassen sich nicht vorschreiben. Jeder Versuch in diese Richtung ruft unweigerlich Verweigerung hervor. [...] Demokratie bedeutet nicht zuletzt Freiheit der Sprache (Deutscher Bundestag 2001).

Im Jahr 2000 hält der damalige Bundespräsident Johannes Rau anlässlich der Eröffnung des Kongresses „Gutenbergs Folgen. Von der ersten Medienrevolution zur Wissenschaft“ eine Rede (23. November 2000 in Mainz). Rau warnt davor, wenn Bürger sich um ihre Sprache sorgen, dies „pauschal als >>Deutschtümelei<< abzutun“:

Der inflationäre Gebrauch von Amerikanismen in der Werbung und in den Medien, aber auch in den Veröffentlichungen vieler Unternehmen und Behörden, soll Fortschrittlichkeit und Modernität signalisieren. Tatsächlich ist er oft ein Hinweis auf die Verarmung der Ausdrucksfähigkeit in der eigenen Sprache. Tatsächlich grenzt er all diejenigen aus, die Englisch und Amerikanisch nicht verstehen: viele Ältere, viele Jugendliche, die nicht die entsprechende Schulbildung haben, viele Menschen aus den neuen Ländern, und, das sollten wir auch nicht vergessen, viele der in unserem Land lebenden Ausländer (Rau 2002: 24f.).

Auch der ehemalige bayerische Innenminister Hans Zehetmair (CSU), Eberhard Diepgen (ehemaliger Bürgermeister von Berlin, CDU) und der ehemalige FDP-Chef Wolfgang Gerhard kritisierten den übermäßigen Gebrauch von Anglizismen im Deutschen (vgl. z.B. Pfalzgraf 2003b: 398, Pfalzgraf 2006: 13). Einen Schritt weiter ging der damalige Berliner Innensenator Eckart Werthebach (CDU). Er forderte ein Sprachgesetz ${ }^{130}$ und ordnete für Berliner Behörden an, Anglizismen zu vermeiden. Dies ist in der Bundesrepublik der erste Versuch einer gesetzlichen Maßnahme, um Einflüsse von Anglizismen auf das Deutsche einzudämmen (vgl. dazu u.a. Richter 2001: 18, Werthebach 2000: 6). ${ }^{131}$ Damit wurden seit 1930 in der deutschen Politik erstmals wieder Forderungen nach einem Sprachschutzgesetz laut (vgl. Pfalzgraf 2003b: 398, Spitzmüller 2005: 129 und Pfalzgraf 2006: 13).

${ }^{130}$ Auf die Vorreiterrolle von Werthebach weist Pfalzgraf besonders hin (Pfalzgraf 2006: 13). Der VDS hat den Vorstoß mehrheitlich begrüßt, dennoch war der Vorstand in dieser Frage gespalten (vgl. ausführlich Kapitel 2.3.2).

${ }^{131}$ Pfalzgraf sieht darin einen großen Erfolg für den VDS (vgl. Pfalzgraf 2008: 463). 
Bei einer Kleinen Anfrage wurde explizit nach der Auffassung der Regierung gegenüber dem VWDS gefragt:

Wie beurteilt die Bundesregierung die Auffassung sprachkritischer Initiativen, hier vor allem des Vereins zur Wahrung der deutschen Sprache (VWDS), der wachsende Gebrauch englischer Wörter und Wendungen gefährde die lebendige Entwicklung unserer Sprache (vgl. Focus Nr. 14 vom 3. April 1999, S. 192) und welchen Handlungsbedarf sieht sie ggf. in diesem Zusammenhang im Hinblick auf die Entwicklung der Amtssprache? (Koschyk 1999: 11).

Darauf hat die Bundesregierung bezüglich des VWDS ausweichend geantwortet:

Die Bundesrepublik hat im Bereich der Sprachbildung keine gesetzgeberischen Kompetenzen. [...] Im Hinblick auf den Gebrauch englischer Wörter in der Amtssprache sieht die Bundesregierung keinen Handlungsbedarf. Maßstab für den Gebrauch der Amtssprache ist eine bürgernahe Verwaltungssprache. Diesem Ziel dient auch die Arbeit der „Gesellschaft für deutsche Sprache“, die in vielfältiger Weise zur Sprachbildung beiträgt und deren Arbeit von der Bundesregierung gefördert wird. [...] (Bundesregierung 1999: 11).

Die Anglizismenfrage wird auch in einer Großen Anfrage, die die CDU im Jahr 2001 in den Bundestag einbringt, thematisiert (Lammert et al. 2001). In der Antwort heißt es: $:^{132}$

Die Bundesregierung hält [...] unabhängig von der Tatsache, dass dem Bund auch grundsätzlich keine Gesetzgebungskompetenz zur Regelung der deutschen Sprache zusteht, eine Schutzvorschrift für die deutsche Sprache [...] nicht für erforderlich. Eine lebendige Sprache unterliegt einem ständigen Wandel, der nicht durch staatliche Maßnahmen beeinflusst werden sollte (Bundesregierung 2001: 47f.).

Auf weitere Anfragen antwortete die Bundesregierung, dass es nicht nötig sei, ein „Sprachgesetzbuch“ zu verfassen (vgl. Bundesregierung 2001: 51). ${ }^{133}$ Die Frage 65 dieser Anfrage beschäftigte sich mit den verschiedenen Institutionen, wobei explizit auch nach dem VDS gefragt wurde:

Welche Rolle käme hierbei nach Ansicht der Bundesregierung der Deutschen Akademie für Sprache und Dichtung, dem Institut für deutsche Sprache, der Gesellschaft für deutsche Sprache und dem Verein Deutsche Sprache zu? (Bundesregierung 2002a: 16)

${ }^{132}$ An dem Text für die Große Anfrage haben u.a. Walter Krämer und Helmut Glück mitgewirkt (vgl. Protokoll der VDS-Vorstandssitzung vom 9. Februar 2000).

${ }^{133}$ Vgl. dazu auch die Antworten der Bundesregierung auf die Schriftlichen Fragen des Abgeordneten Jürgen Türk (Türk 2000a, Türk 2000b) im Jahr 2000 (Bundesregierung 2000a, 2000b). 


\section{$\mathrm{Zu}$ dieser Frage wurde nicht weiter Stellung bezogen:}

Die Bundesregierung legt großen Wert auf die Pflege der deutschen Sprache. Bei dieser wichtigen Aufgabe leisten nicht-staatliche Organisationen wesentliche Beiträge (Bundesregierung 2002a: 16). ${ }^{134}$

Auf die Große Anfrage der Abgeordneten Eckhardt Barthel (Berlin) und weiterer Abgeordneter (Barthel et al. 2001) aus dem Jahr 2001 antwortet die Bundesregierung:

[...] Zur Pflege und Förderung der deutschen Sprache unterstützt die Bundesregierung das Institut für deutsche Sprache (IDS), die Gesellschaft für deutsche Sprache (GfdS) und die Deutsche Akademie für Sprache und Dichtung (Bundesregierung 2002a: 4f.) ${ }^{135}$

Auch nach einer Beurteilung der Bundesregierung über die Auswirkungen der zunehmenden Zahl von Anglizismen auf die deutsche Sprache wird gefragt. In der Antwort heißt es:

Die Bundesregierung verfolgt die gegenwärtige Diskussion um Anglizismen in der deutschen Sprache mit großer Aufmerksamkeit. [...] Die Bundesregierung teilt auch nicht die Bedenken, dass das Vordringen von Wörtern aus dem angloamerikanischen Raum die deutsche Sprache gefährde. Der Anteil an so genannten Anglizismen in der deutschen Sprache ist keineswegs besorgniserregend. [...] Die Sprachwissenschaftlerinnen und Sprachwissenschaftler sehen in dem derzeitigen Gebrauch von Anglizismen keine Gefährdung der deutschen Sprache (Bundesregierung 2002a: 14f.).

In dieser Anfrage wird zudem die Frage nach einem Sprachgesetz gestellt, darauf wird geantwortet:

Die Bundesregierung hat im Bereich der Sprache aber auch grundsätzlich keine gesetzgeberischen Kompetenzen. [...] Die Bundesregierung hält aber unabhängig von der mangelnden Gesetzgebungskompetenz eine Schutzvorschrift für die deutsche Sprache - vergleichbar den Gesetzen in Frankreich und Polen - nicht für erforderlich. Nach unserer freiheitlichen demokratischen Grundordnung soll die Sprache des Menschen und damit sein Denken nicht reglementiert werden, sondern sich frei entfalten. [...] Von Seiten des Bundesministeriums des Innern sind daher auch keine Weisungen an Behörden der Bundesverwaltung geplant, Fremdwörter durch deutsche Begriffe zu ersetzen (Bundesregierung 2002a: 16).

\footnotetext{
${ }^{134}$ Anzuführen ist hier auch der Antrag der Abgeordneten Dr. Peter Gauweiler und anderer Abgeordneter und der Fraktion der CDU/CSU: Deutsch als dritte Arbeitssprache auf europäischer Ebene - Verstärkte Förderung von Deutsch als lernbare Sprache im Ausland (Gauweiler et al. 2003).

${ }^{135}$ Dies ist ein immer wieder thematisiertes Ärgernis für den VDS, und eines der Ziele der Vereinsarbeit ist auch, von der Bundesregierung ebenfalls gefördert zu werden (vgl. Kapitel 2.2.7).
} 
Der Forderung nach einem Sprachpflegegesetz wie in Frankreich, die auch in Deutschland in der Öffentlichkeit ab und an wieder laut wird, hatte Prof. Dr. Julian Nida-Rümelin auf einer Tagung der GfdS im Jahr 2002 bereits eine klare Absage erteilt. Er empfinde eine staatliche Kontrolle der Sprache als nicht sinnvoll. Denn eine gute Sprache lebe nur durch ihren lebendigen Gebrauch. Zudem sei dies in Deutschland aus historischen Gründen auch gar nicht durchsetzbar. Die sprachpflegerische Arbeit von Institutionen wie der GfdS fand Nida-Rümelin dagegen wichtig (vgl. auch J. Bär 2002b: 34). Auch Erika Steinbach (CDU) äußerte sich bei einer Aussprache im Bundestag ${ }^{136}$ negativ zu einem Sprachgesetz:

Ich glaube, wir brauchen kein neues Gesetz, und ein Sprachenschutzgesetz ist mit Sicherheit nicht der richtige Ansatz. Außerdem haben wir bereits ein Gesetz, das die Problematik [...] aufgreifen könnte. Das ist das Verbraucherschutzgesetz. Im Verbraucherschutzgesetz ist im Grunde genommen geregelt, dass Produkte in deutscher Sprache bezeichnet werden müssen (Steinbach in Bundesregierung 2002b). ${ }^{137}$

Doch sowohl Steinbach als auch Eckhard Barthel (SPD) äußerten in dieser Debatte Sorgen über das Übermaß der Anglizismen (vgl. Steinbach in Bundesregierung 2002b).

Im Jahr 2005 bat der FDP-Bundestagsabgeordnete Volker Wissing um Auskunft, warum die deutsche Bundesregierung in Gesetzen und Regierungsbroschüren nicht auf deutsche Ausdrücke zurückgreife, sondern Anglizismen verwende. In einem sieben Seiten langen Brief rechtfertigte der damalige Regierungssprecher Béla Anda die Verwendung der Anglizismen, ein Vorgehen, das auch in den Medien thematisiert wurde (vgl. Neubacher 2005: 164). Auch Wolfgang Thierse stellte fest:

Die Pflege unserer Muttersprache sollte eigentlich selbstverständlich sein: Sprache bedeutet Heimat. Pauschale Fremdwortablehnung und deutschtümelnder Purismus sind allerdings im Zeitalter der Globalisierung wenig sinnvoll. Sensibel verwendet, können Anglizismen unser Denken erweitern, unsere Sprache und Kultur bereichern (Thierse 2004: 187).

Im Jahr 2006 kam es zu einem Gesinnungswandel Erika Steinbachs (CDU). Sie forderte ein "Gesetz zum Schutz der deutschen Sprache“

${ }^{136}$ Bei der 212. Sitzung in Berlin, 24. Januar 2002 (Bundesregierung 2002b).

${ }^{137}$ Vgl. auch SN (2002a: 1). 
(vgl. u.a. Luck 2006). Relativ zeitgleich unternahm auch Markus Söder (CSU) einen erneuten Vorstoß für ein Sprachschutzgesetz (vgl. Spitzmüller 2007: 268). Im Jahr 2006 sagte Bundestagspräsident Norbert Lammert der Frankfurter Allgemeinen Zeitung, die Föderalismusreform sei der richtige Zeitpunkt, um im Grundgesetz festzulegen, dass Deutsch die Landessprache ist (FAZ 2006: 1). Im Jahr 2007 hat die Christdemokratin Julia Klöckner eine Initiative zum „sprachlichen Verbraucherschutz" ins Leben gerufen (J. G. Schneider 2007: 1). ${ }^{138}$ Und auf dem jüngsten Parteitag der CDU haben die Delegierten einem Antrag auf Aufnahme der deutschen Sprache ins Grundgesetz zugestimmt (Fried 2008: 5). ${ }^{139}$

Die Anglizismenfrage wird in der Politik also durchaus kontrovers gesehen, in jedem Fall spielen die Anglizismen in der Politik mittlerweile wieder eine Rolle.

Auch scheinen die Anglizismen seit der Wiedervereinigung die Bürger verstärkt zu beschäftigen. Neben dem Verein Deutsche Sprache im Jahr 1997, in dem kleinere Sprachvereine, die zeitgleich gegründet wurden, aufgingen, werden der Verein für Rechtschreibung und Sprachpflege fast zeitgleich gegründet. Diese Vereine bestimmen die Diskussion in den Medien maßgeblich mit. Darauf wird in den folgenden Kapiteln noch Bezug genommen. Insgesamt kann mit Schiewe festgestellt werden:

An dieser Situation [gemeint ist der beträchtliche öffentliche Einfluss von außerakademischen Institutionen wie Sprachgesellschaften und Sprachvereinen auf die öffentliche Meinung, Anm. d. Verf.] hat sich bis heute grundlegend kaum etwas geändert - außer daß die Medien als sprachkritische Institution zu den Vereinen hinzugekommen sind (Schiewe 2003: 329f.). ${ }^{140}$

Kirkness schreibt:

Die Auseinandersetzung mit den einzelnen Fremdwörtern und mit dem Fremdwort hielt und hält dennoch im ganzen deutschen Sprachraum unvermindert an, im Schulunterricht etwa, in der Stilund Sprachpflege, in der Sprachkritik und -kultur, und in der vorwis-

\footnotetext{
${ }^{138}$ Vgl. dazu ausführlich Pfalzgraf 2008.

${ }^{139}$ Damit kommt die CSU einer Forderung des VDS nach. Bereits Anfang 2009 waren kritische Stimmen in den Medien auszumachen (vgl. u.a. Droste in Mayerhöfer 2009). ${ }^{140}$ Auf die Beziehung zwischen dem VDS und den Medien wird in Kapitel 2.5.6 Bezug genommen.
} 
senschaftlichen öffentlichen Diskussion in der Presse (Kirkness 1998:

415).

Betrachtet man zusammenfassend die Zunahme der Anglizismendiskussion in Medien und Politik und das wachsende Interesse der Menschen in Deutschland an sprachpflegerischen Vereinigungen in der Zeit von 1989 bis heute, kann man sagen, dass die Themen Sprachpflege, Sprachrichtigkeit und Sprachidentität wieder Hochkonjunktur haben (vgl. auch J. G. Schneider 2006) und dass die Anglizismen klar als eines der wichtigsten metalinguistischen Themen, die in der Presse aufgegriffen werden, gesehen werden müssen. Des Weiteren ist $\mathrm{zu}$ bemerken, dass einige wenige Sprachwissenschaftler wie Schiewe und Wengeler sich von einem deskriptiven hin $\mathrm{zu}$ einem normativen Wissenschaftsbegriff wenden. ${ }^{141}$

Jung geht von einer „Renaissance nationaler Sprachargumentationen“ aus, also davon, dass die Argumente für eine Sprachreinigung im Zusammenhang mit Nationalgefühlen stehen (Jung 1995: 266, ähnlich auch Linke 2003: 150). Worin die Gründe für dieses Wiederaufkommen einer derartigen Sprachargumentation liegen, ist schwer festzustellen. Es hat in der deutschen Sprachgeschichte immer wieder weite Pendelausschläge zwischen einer großen Entlehnungsfreudigkeit und puristischer Abwehr gegeben (vgl. Munske 2001: 27). Wohl führt die zunehmende Entlehnung von Ausdrücken aus dem Englischen und deren Verwendung in Texten zu einem stärkeren Bewusstsein für die Sprache in der Öffentlichkeit (vgl. Busse/Görlach 2002).

Auch die deutsch-deutsche Wiedervereinigung ist als Grund in Betracht zu ziehen, schon allein weil der Diskurs um die Anglizismen im Deutschen nach der Wiedervereinigung deutlich stärker in die Medien gelangte. Dies kann wohl nicht als Zufall betrachtet werden, gerade nicht in dem Zusammenhang, dass Nationalismus- und Patriotismuskonzepte zeitgleich in den Diskussionen auftauchten (vgl. Spitzmüller 2007: 269). ${ }^{142}$ Zudem hat sich gezeigt, dass die Diskussion über das Fremd-

${ }^{141}$ Hier kann aber nicht von einem „Paradigmenwechsel“ ausgegangen werden. Dies wäre eine Übertreibung.

${ }^{142}$ Spitzmüller verweist auf die Debatte um die deutsche „Leitkultur“. Außerdem führt er an, dass auch umgekehrt gilt, dass das verstärkte Vorkommen der Anglizismendiskussion auch eine verstärkte Thematisierung von Nation und Nationalität bedingt (vgl. Spitzmüller 2007: 269f.). 
wort in Deutschland immer wieder in die jahrhundertealte Tradition des puristischen Diskurses gestellt ist und nicht losgelöst von den Ereignissen des Zweiten Weltkriegs betrachtet werden kann.

\subsection{Sprachpflegende Vereinigungen und Institutionen sowie Sprachinitiativen}

Im folgenden Abschnitt der Arbeit soll ein Überblick über die sprachpflegenden Vereinigungen und Institutionen sowie die Sprachvereine und Sprachinitiativen gegeben werden, die derzeit neben dem VDS existieren. Für eine ersten Darstellung der Einrichtungen, die die deutsche Sprache fördern, wie die Akademie der Bayerischen Presse, die Akademie für Publizistik, die Akademie für Rede und Sprache, die Arbeitsstelle für Erwachsenenbildung Diözese Rottenburg-Stuttgart, die Bertelsmann Stiftung, der Arbeitskreis selbstständiger Kultur-Institute, der Arbeitskreis für Jugendliteratur, die Arbeitsgemeinschaft Literarischer Gesellschaften, das Sprachservice-Telefon der Technischen Universität Dortmund, der Verein zur Förderung sprachwissenschaftlicher Studien, die Heinrich-Böll-Stiftung, die Hanns-Seidel-Stiftung, die HenriNannen-Schule, das Institut für Medienentwicklung, die Stiftung Lesen oder das Gemeinschaftswerk für Evangelische Publizistik, die sich ebenfalls der Sprachkultur widmen, sei auf das im Auftrag der Robert-BoschStiftung entstandene Handbuch von Bickes/Trabold und auf das im Auftrag des IDS entstandene Handbuch von Frank-Cyrus/Trabold et al. verwiesen. In den Handbüchern werden diese Einrichtungen kurz beschrieben, mit ihren Zielen und Aktivitäten, ihrem institutionellen Rahmen und ihren geplanten Maßnahmen (vgl. Bickes/Trabold 1994 und Frank-Cyrus/Trabold et al. 1999). ${ }^{143}$ Während das erste Handbuch einen Überblick über mehr als 90 Einrichtungen gibt, sind im Handbuch aus dem Jahr 1999 bereits insgesamt 135 Einrichtungen aufgeführt, die sich mit der Förderung der deutschen Sprache beschäftigen.

${ }^{143}$ Die Handbücher entstanden anhand einer Umfrage. Die Verfasserinnen schrieben 380 Einrichtungen an, und fragten diese nach ihren Aktivitäten, ihrem institutionellen Rahmen und auch danach, ob sie andere Einrichtungen kennen, die sich mit der Förderung der deutschen Sprache auseinandersetzen (vgl. Frank-Cyrus/Trabold et al. 1999: XI). 
Dieser Kurzüberblick auch über Einrichtungen, die sich mit Sprachkritik und Sprachpflege auseinandersetzen, bietet einen Einstieg in die Recherche. Einen ersten ausführlicheren Bericht über sprachpflegende Einrichtungen lieferte Hillen im Jahr 1982, Pfalzgraf ergänzte die Darstellung der Situation im Jahr 2006. Da jedoch ständig neue Organisationen und Publikationen hinzukommen, wie zuletzt die „Aktion Deutsche Sprache“ und die „Neue Fruchtbringende Gesellschaft“, sollen an dieser Stelle die derzeit aktiven sprachpflegenden Vereinigungen vorgestellt werden.

Unter denjenigen Vereinigungen, die sich gegen Anglizismen im Deutschen aussprechen, finden sich auch rechtsextreme Gruppierungen, auf diese wird nicht eingegangen. Hier sei auf Pfalzgraf (2003a, 2003b, 2006) verwiesen, ${ }^{144}$ ebenso auf dessen ausführliche Darstellung privater Internetseiten, die sich mit Anglizismen auseinandersetzen. ${ }^{145}$

${ }^{144}$ Im Folgenden wird unter Rechtsextremismus verstanden: „Rechtsextremismus ist eine Sammelbezeichnung für Ideologien und politischen Handlungsweisen, die die freiheitlich demokratische Grundordnung (FDGO) ablehnen und den demokratischen Verfassungsstaat durch eine autoritär geführte Volksgemeinschaft ersetzen wollen. Auch wenn der Rechtsextremismus nicht als einheitliche Ideologie zu verstehen ist, geht jede Ausprägung von ihm von einer naturgegebenen Ungleichheit der Menschen aus. Demzufolge wird das an den universalen Menschenrechten orientierte Gleichheitsprinzip abgelehnt. [...] Rechtsextremismus ist ein heterogenes Gemisch unterschiedlichster Begründungszu-

sammenhänge und Sichtweisen. Dies spiegelt sich in der organisatorischen Zersplitterung der extremen Rechten wieder. Eine allgemeingültige Definition von Rechtsextremismus ist demnach nicht möglich. Stattdessen gibt es eine Liste von ideologischen Bestandteilen, die grundsätzlich einer rechtsextremen Einstellung zugerechnet werden. Hierzu zählen: 1) Nationalismus 2) Rassismus, inkl. biologistischen und sozialdarwinistischen Theorien 3) Antisemitismus 4) völkisches Denken 5) Geschichtsrevisionismus 6) Militarismus, „Führertum“, Unterordnung unter Autoritäten. [...] Erst rechtsextremes Verhalten, Gewalt, Wahlverhalten, die Mitgliedschaft in Parteien oder Kameradschaften sowie der rechtsextreme Lifestyle (Kleidung, Musik, etc.) lassen sich erfassen. Polizei und Verfassungsschutz arbeiten deshalb mit der Definition: Bestrebungen gelten als extremistisch, die gegen die freiheitliche demokratische Grundordnung gerichtet sind und diese unter Akzeptanz von Gewalt ganz oder in Teilen abschaffen wollen." (Bundeszentrale für politische Bildung 2008). Für eine ausführliche Diskussion des Begriffs „Rechtsextremismus“ vgl. Klärner/Kohlstruck (2006).

${ }^{145}$ Die Internetautoren nutzen die Möglichkeit, ungefiltert, ohne redaktionelle Bearbeitung, ihre Meinung zu veröffentlichen. Pfalzgraf spricht von „Fremdwortkritik in unverfälschter Form“ (Pfalzgraf 2006: 223). Er hat eine ausführliche Untersuchung einiger Internetseiten vorgelegt, auf die ich mich hier beziehen möchte. Dafür hat er Begriffe wie Anglizismus, Anglizismen, Fremdwörter, Denglisch, Engleutsch usw. in die Suchmaschine Google eingegeben (ebenda). Eine Eingabe der Begriffe in die Suchmaschine Google 
Schon auf den ersten Blick zeigt sich, dass neben den Organisationen, die seit vielen Jahrzehnten bestehen, seit Mitte der 1990er Jahre zahlreiche Organisationen hinzugekommen sind. Klein spricht von einem "gewissen Boom in der Gründung von - meistens privaten - Sprachpflegeeinrichtungen“ (Klein 2001, vgl. zu diesem Thema auch Wiechers 2001). Eisenberg weist auf die „hilflosen Anwälte unserer Sprache“ hin, und darauf, dass es ständig Neugründungen von Organisationen gibt, die sich der deutschen Sprache annehmen (Eisenberg 2004c: 35). ${ }^{146}$ Diese Organisationen werden in diesem Kapitel vorgestellt.

Zunächst jedoch ein Blick zurück: Zu Beginn soll der Allgemeine Deutsche Sprachverein/Deutsche Sprachverein vorgestellt werden, den es nicht mehr gibt, auf dessen Arbeit die heutigen Sprachvereine aber immer wieder Bezug nehmen.

am 17. August 2006 ergab eine Trefferquote von mehreren Hundert. Zwar gibt es zahlreiche Seiten, Pfalzgraf stellte jedoch fest, dass auf vielen Auftritten nur wenige Sätze zum Thema Fremdwortdiskussion enthalten sind, und viele Seitenbetreiber lediglich eine Liste mit Verdeutschungsvorschlägen ins Netz stellen. Einige Seiten widmen oder widmeten sich ausführlich der Fremdwort- bzw. Anglizismendiskussion., beispielsweise „Die Kauderwelsch-Seite“ von Thomas Geist (Geist 2001). Thomas Geist prangert Anglizismenbenutzer unter dem Titel „Sprachpanscher“ an, Pfalzgraf verweist darauf, dass sich neben dem Verweis auf den VDS auch ein Verweis auf die Deutsche Sprachwelt findet (vgl. Pfalzgraf 2006: 255). Detlev Mahnert (Mahnert 2002a) zitiert unter anderem einen Artikel von Walter Krämer vom VDS und verlinkt auf die Seiten des VDS (Mahnert 2002b). Eigene Stellungnahmen zu Anglizismen gibt es nicht, dafür eine Textsammlung verschiedenster Stellungnahmen in Zusammenhang mit der Anglizismenkritik, wie „Jeder Vogel hält sein Nest für schön - nur die Deutschen scheißen hinein“, ebenso die Stellungnahme von Juri Novikov, der Denglisch „für eine Art geistiges AIDS“ hält (vgl. Mahnert 2002c). Unter den Internetseiten zu Anglizismen war auch „Die Seiten für gutes Deutsch“ von Robert Borsch (Borsch 2005). Auf seiner Internetseite befand sich die Rubrik „Sprachecke“. Diese verfasste Borsch zwischen 1996 und 1998, im gleichen Zeitraum, in dem sich zahlreiche private Sprachschutzvereine gegründet haben (vgl. Pfalzgraf 2006: 226f.). Diese Seiten sind seit April 2005 vom Netz (vgl. <http://web.archive.org/web/*/http:www.home.tonline.de/home/robert.borsch> 28. Juli 2008). Es kommen aber ständig neue Internetseiten zu Anglizismen im Deutschen hinzu, wie die von Oliver Baer (Baer 2008a, Baer ist VDS-Regionalvorsitzender und Vorstandsmitglied) oder Ruth Winklhofer (Winklhofer 2008), die beide auf den VDS verlinken.

${ }^{146}$ Eine der Organisationen, die Eisenberg hier aufführt, ist die Stiftung Deutsche Sprache (vgl. Kapitel 2.5.8). 


\subsubsection{Exkurs: Allgemeiner Deutscher Sprachver- ein/Deutscher Sprachverein}

Im Jahr 1885 kam es zur Gründung des Allgemeinen Deutschen Sprachvereins (ADSV), ${ }^{147}$ in dem sich Bürger zusammenschlossen, um gemeinsam ihre sprachpflegerischen Ziele zu verfolgen. Der Allgemeine Deutsche Sprachverein hatte zum Ziel:

a) die Reinigung der deutschen Sprache von unnöthigen fremden Bestandtheilen zu fördern -

b) die Erhaltung und Wiederherstellung des echten Geistes und eigenthümlichen Wesens der deutschen Sprache zu pflegen - und

c) auf diese Weise das allgemeine nationale Bewusstsein im deutschen Volke zu kräftigen (Riegel 1883: 53). ${ }^{148}$

Bereits im April 1886 erschien das erste Heft der monatlichen Zeitschrift des allgemeinen deutschen Sprachvereins. Herausgeber war Herman Riegel, ein Braunschweiger Kunsthistoriker und Museumsdirektor und der Gründer des Vereins (vgl. z.B. Korlén 1976: 332). Der Gründer eines Zweigvereins, der Sprachpurist und Gymnasiallehrer Hermann Dunger, wetterte im Jahr 1899 in seinem Vortrag „Wider die Engländerei in der deutschen Sprache“ gegen die Einflussnahme des Englischen auf das Deutsche:

Mit dem immer wachsenden Einfluß englischen Wesens mehrt sich neuerdings in bedenklicher Weise die Zahl der aus dem englischen stammenden entbehrlichen Fremdwörter. Auch in dieser Spracherscheinung treten die alten Erbfehler des deutschen Volkes wieder hervor: Überschätzung des Fremden, Mangel an Selbstgefühl, Missachtung der eigenen Sprache (Dunger 1899: 250).

Sein Text wurde als Erklärung auf der Hauptversammlung des ADSV einstimmig angenommen (vgl. u.a. Stickel 1994: 13). Zehn Jahre später brachte Dunger noch einmal eine stark überarbeitete und weitaus längere Druckversion des Vortrags mit dem Titel „Engländerei in der deutschen Sprache“ heraus. Dort heißt es „Englisch ist jetzt fein, Englisch ist Trumpf! [...] Wie der Deutsche früher der Affe des Franzosen war, so äfft er jetzt den Engländer nach“ (Dunger 1909: 3).

Dunger unterteilte damals die Fremdwörter in:

1) diejenigen Fremdwörter, für welche es an einem entsprechenden deutschen Ausdruck fehlt, die unentbehrlichen Fremdwörter, und 2) die

${ }^{147}$ Später: Deutscher Sprachverein (DSV).

${ }^{148}$ Vgl. hierzu ausführlich Kirkness (1975: 372). 
so genannten Lehnwörter, d.h. solche Ausdrücke, die sich im Laufe der Zeit bei uns eingebürgert und deutsche Gestalt angenommen haben (Dunger 1886: 5). ${ }^{149}$

Der Sprachverein widmete sich also unter anderem der Fremdwortfrage. Obwohl der Verein heute vor allem mit dieser in Zusammenhang gebracht wird, war sie nicht das Hauptanliegen des Vereins. Und auch der nationale Fanatismus in einigen der Zweigvereine war nicht in Riegels Sinn. 1893 kam es sogar zu einer Vereinskrise, denn viele Zweigvereine handelten gegen Riegels Absichten (vgl. Riegel 1883: 55). So ist das „Wörterbuch der Verdeutschungen“ nicht unter der Federführung Riegels entstanden, sondern in einem Zweigverein (vgl. Clay 1981: 56). ${ }^{150}$ Am raschen Wachstum des Vereins lässt sich ablesen, wie rege in der Bevölkerung, gerade bei Akademikern - unter den Vereinsmitgliedern waren vor allem Juristen, Beamte und Lehrer - das Interesse an der Sprachreinigung war (vgl. Sauter 2000: 178). Bereits 1891, also sechs Jahre nach der Gründung, bestand der ADSV aus 160 Zweigvereinen mit insgesamt 11000 Vereinsmitgliedern. Der Kampf gegen Fremdwörter wurde aus „moralischer und vaterländischer Entrüstung“ (Kirkness 1975: 377) geführt. Innerhalb des Sprachvereins gab es aber keine Auseinandersetzung über die Bestimmung des Fremdworts (vgl. Bernsmeier 1977: 395, Wiechers 2004: 25).

Deshalb kam es zu Protesten von Intellektuellen gegen den ADSV: 41 Gelehrte und Schriftsteller, darunter Theodor Fontane und Gustav Freytag, unterschrieben 1889 eine Erklärung. Diese ist in den Preußischen Jahrbüchern aufgeführt (vgl. Sauter 2000: 178). ${ }^{151}$ Sie wandten sich ge-

\footnotetext{
${ }^{149}$ Auch zu dieser Einteilung finden sich beim VDS Parallelen (siehe Kapitel 2.4.1).

${ }^{150}$ Eine ausführliche Darstellung dieser Zusammenhänge findet sich u.a. bei Wiechers (2004: 21f.)

${ }^{151}$ Während die Fremdwortjagd bei Fontane, Freytag und weiteren Schriftstellern und Gelehrten auf heftigen Widerstand stieß, war die Universitätsgermanistik damals geteilter Meinung. Sprachwissenschaftler wie Friedrich Kluge und Otto Behaghel unterstützten den Sprachverein, Literaturwissenschaftler wie Gustav Roethe und Erich Schmidt bekämpften ihn (vgl. von Polenz 1967: 81). Eine ausführliche Darstellung der Vorgänge um die „Erklärung der 41“ findet sich bei Sauter (2000: 178f., vgl. auch von Polenz 1967: 81). Im Jahr 1918 wandte sich auch ein Gutachten der Preußischen Akademie der Wissenschaften gegen die Fremdwortjagd: „ein Gewächs, das sich frei entfaltet wie die deutsche Eiche, aber nicht mit der Heckenschere durch irgendwelche behördlichen Eingriffe zurechtgeschnitten werden darf. [...] So darf wohl auch unsere Akademie, indem sie sich als einen Teil unseres Volkes fühlt, nicht stumm und still an den Reformbestrebungen des Tages vorübergehen. Sie darf nicht gleichgültig zuschauen, wenn gewisse vaterländisch
} 
gen den Versuch, die Regierung in die Sprachreinigung einzubeziehen, und forderten, dass die Sprache sich frei entwickeln müsse und nicht von Puristen beschädigt werden dürfe. Die Erklärung verursachte einigen Wirbel: Noch längere Zeit ist in den Preußischen Jahrbüchern die Rede und Gegenrede nachzulesen. Sie wurde sogar zum Trauma des Sprachvereins, dessen Folgen den Verein noch mindestens zwanzig Jahre beschäftigten (vgl. Sauter 2000: 178). Im Ersten Weltkrieg nutzte der ADSV die deutschnationale Stimmung für seine Zwecke: ${ }^{152}$

Eine so günstige Zeit, die vaterländischen Bestrebungen des Deutschen Sprachvereins zu Schutz und Stärkung des Deutschtums in den weitesten Kreisen unseres Volkes wirksam in die Tat umzusetzen, kehrt nie wieder (Sarrazin 1914: Sp. 338).

Sauter konstatiert:

Anstatt jedoch zur Versachlichung des Diskurses beizutragen, werden die Gefühle weiter aufgeheizt. Götze verherrlicht den Krieg als „Bildner“ der deutschen Sprache zu allen Zeiten (Sauter 2000: 180).

Insgesamt stand die Führung des Sprachvereins dem Krieg wohlwollend gegenüber:

Kennzeichnend für den Sprachverein ist jedoch, daß die Begeisterung nicht nachließ, daß niemals kritische Töne über den Krieg laut wurden, auch nicht in darauffolgenden Kriegszeiten (Sauter 2000: 180).

Ähnlich stellt sich die Situation im Zweiten Weltkrieg dar. Hierzu Korlén: „Es liegt auf der Hand, dass der deutschnationale Sprachverein mit der Machtübernahme Hitlers seine grosse [sic] Stunde gekommen sah.“ (Korlén 1976: 332).

Die Zahl der Mitglieder des Sprachvereins war rasch gewachsen, 1914 richtete sich ein Sprachaufruf bereits an 35000 Mitglieder (vgl. Wie-

gesinnte, aber doch sprachlich befangene und ungeschichtlich denkende Kreise das Leben der Sprache in allzu enge Bahnen zwingen und jene Heckenschere nicht nur selbst unermüdlich handhaben, um Kraut und Unkraut miteinander abzuschneiden, sondern auch die Hilfe der Staatsgewalt zur raschen Durchführung der Absichten herbeirufen“ (Diels 1918: 684).

${ }^{152}$ Im Zusammenhang mit dem ersten Weltkrieg wurde die Fremdwortbewegung zu einer Bürgerbewegung, an der beispielsweise auch Schulkinder teilnahmen - Else Ury hat das Phänomen der „Fremdwortkassen“ in ihrem Roman „Nesthäkchen und der Weltkrieg“ (Ury 1916: 51) beschrieben. 
chers 2004: 19). Im Jahr 1930 hatte der Deutsche Sprachverein (DSV), so nannte sich der Verein nach 1923, wohl an die 50000 Mitglieder. ${ }^{153}$

Der Sprachverein veröffentlichte Denkschriften, Empfehlungen und regelmäßige Mahnaufrufe. Darin forderte er, dass deutsche Waren nur noch mit deutschen Bezeichnungen angeboten werden sollten und „undeutsche“ Bezeichnungen auf Speisekarten und Ladenschildern zu verschwinden hätten (vgl. dazu von Polenz 1967a: 86). Zudem lieferte der DSV Verdeutschungsvorschläge, als Beispiel seien hier Vorschläge wie "Seelkunde“ (Psychologie) und "Gewerbsamung" (Industrialisierung) aufgeführt, mit denen eine rein deutsche wissenschaftliche Terminologie eingeführt werden sollte. ${ }^{154}$

Unter den Nationalsozialisten spielte der Sprachverein insgesamt eine unrühmliche Rolle. 1934 wurde Alwin Ruprecht Schriftleiter der Muttersprache $^{155}$. Tozo Hayakawa sieht mit diesem Wechsel eine deutliche Zäsur im Ton (vgl. Hayakawa 1995: 433). Ein Beispiel für den Tonfall Ruprechts ist ein Bericht über das Ende der „Comedian Harmonists“:

Damit wäre dann endlich ein Stück „Kulturschande“ beseitigt.

Noch ein Wort $\mathrm{zu}$ den Comedian Harmonists. Diese hatten geflissentlich verbreitet, sie seien alle sechs "gute Deutsche“. Nach Mitteilung der Reichsmusikkammer befinden sich aber unter den sechsen zwei Nichtarier preußischer Staatsangehörigkeit, ein Bulgare und ein aus Polen stammender Jude! Die Kammer hat der Vereinigung daher die Eingliederung und die Erlaubnis zum weiteren Auftreten versagt, weil ihnen die Eignung abgesprochen werden müsse, in dieser $\mathrm{Zu}$ sammensetzung deutsche Volkskunst darzubieten. Und diesen Leuten hat man noch bis ins Frühjahr 1934 hinein stürmisch zugejubelt und sein gutes Geld hingetragen. O Michel, Michel (Ruprecht d. J. 1934: 266f., zitiert nach Wiechers 2004: 45).

${ }^{153}$ Gudrun Fahrenkrog Clay spricht für das Jahr 1927 bereits von 50000 Mitgliedern (vgl. Clay 1981: 57), Ingrid Hillen in ihrer Untersuchung von fast 50000 Mitgliedern im Jahr 1930 (vgl. Hillen 1982: 55).

${ }^{154}$ Es gab viele Verdeutschungsbücher des ADSV/DSV, beispielsweise Dungers „Wörterbuch von Verdeutschungen entbehrlicher Fremdwörter“ (Dunger 1882) oder Sarrazins „Verdeutschungswörterbuch“ (Sarrazin 1896). Zudem sei hier auf zwei Bände in den Jahren 1933 und 1934 verwiesen, in denen obengenannte Vorschläge veröffentlicht wurden: Stoltenberg, H.L. (1933): Deutsche Weisheitssprache. Lahr. Und Stoltenberg, H.L. (1934): Der eigendeutsche Wortschatz der Weisheitslehre. Frankfurt. Hans L. Stoltenberg war im Sprachverein aktiv und wandte sich in der Muttersprache immer wieder an die deutschen Hochschullehrer (vgl. z.B. Polenz 1967a: 87).

${ }^{155}$ Unter diesem Namen wurde die Zeitschrift des Vereins mittlerweile herausgegeben. 
Wiechers konstatiert: „Mit solchen rassistischen Äußerungen hatte sich der Sprachverein eindeutig festgelegt“ (Wiechers 2004: 45), er verstand sich als „nationalistisch bis gut nationalsozialistisch“ (vgl. dazu Wiechers 2004: 45). ${ }^{156}$

Ruprecht wendete sich gegen alles vermeintlich Jüdische in der deutschen Sprache. In diesem Kontext steht ein Aufsatz über das Adjektiv „keß“ in der Muttersprache aus dem Jahr 1936 (Götze 1936: Sp. 7f.), den Polenz als „antisemitische[] sprachpolitische Schmähung“ wertete (von Polenz 1967a: 89). Noch rauere Töne wurden unter Rudolf Buttmann ${ }^{157}$ angeschlagen. 1933 stellte er sich den Vereinsmitgliedern vor:

Als langjähriges Mitglied des Deutschen Sprachvereins habe ich die Überzeugung, daß er berufen ist, in einer Zeit der Erneuerung des Deutschtumsgedankens in vorderster Reihe mitzukämpfen. Als alter Nationalsozialist habe ich das Bestreben, den Deutschen Sprachverein in dieser Kampffront an der richtigen Stelle einzuschalten (Buttmann 1933: Sp. 289f.). ${ }^{158}$

Weiter heißt es in dem Heft: „Der Gesamtverein und seine Zweigvereine [...] sind nun durch die Wahl des Vorsitzers nationalsozialistischer Führung unterstellt. Sie bedürfen deshalb keiner Gleichschaltung mit der NSDAP [...].“ (Ruprecht 1933: Sp. 307). ${ }^{159}$ Wiechers merkt hierzu an,

\footnotetext{
${ }^{156}$ Dies bedeutet nicht, dass sich alle Mitglieder des Sprachvereins als nationalsozialistisch verstanden. An dieser Stelle fehlt bisher auch eine ausführliche Untersuchung aller Publikationen in der Zeitschrift des Vereins. Aber in der Führung des Vereins trat diese Haltung deutlich zu Tage (vgl. auch Wiechers 2004: 42).

${ }^{157}$ Unter Buttmann kam es 1935 auch zur Schaffung eines Sprachpflegeamts als Dachverband für Organisationen, die sich mit Sprachpflege beschäftigen. Dessen Ziele wurden folgendermaßen dargestellt: „Die Überwachung der Sprache in ihren schriftlichen und mündlichen Äusserungen im persönlichen und öffentlichen Leben, besonders auch im Rundfunk und der Presse, mit Rügen, aber auch mit Lob. - Die Notwendigkeit der Pflege von Hochsprache und Mundarten soll der Öffentlichkeit immer wieder zu Bewusstsein gebracht werden. - Bekämpfung von Schäden im Wortschatz und Wortgebrauch, von Fremdwörtern, Modewörtern und Ankürzungswörtern. - Festigung der sprachlichen Verbindung mit dem Deutschtum jenseits der Grenzen“. (Fahrenkrog Clay 1981: 59). Die Schaffung des Sprachpflegeamts hatte aber nur wenig Folgen, de facto scheint es ein Amt ohne Befugnisse gewesen zu sein (vgl. Wiechers 2004: 51ff.).

${ }^{158}$ Wiechers verweist auf die Tatsache, dass Buttmann die Mitglieds-Nr. 4 der NSDAP hatte (vgl. Wiechers 2004: 35).

${ }^{159}$ Eine ausführlichere Darstellung dieser Zusammenhänge findet sich bei Peter von Polenz (1967a: 85). Bisher ist jedoch nicht erforscht, ob die Mitglieder des DSV mit dieser Aussage einer Gleichschaltung eventuell entgegenwirken wollten.
} 
dass der DSV als „freiwillig ,gleichgeschalteter' Verein“ zu sehen ist (Wiechers 2004: 329).

1934 positioniert sich der Verein mit folgendem Satz abermals deutlich: „Der Verein ist die SA unserer Muttersprache“ (Miebach 1934: Sp. 146). Von Polenz bemerkt zu den ersten Jahrgängen der Muttersprache nach 1933, sie stellten den chauvinistischen Höhepunkt in der Geschichte des Sprachpurismus dar. Außerdem stellt er fest, dass die Verknüpfung von Sprachreinigung und Rassenwahn sich dahingehend entwickelte, dass die gesamte Fremdwortfrage rassistisch behandelt wurde (von Polenz 1967a: 82ff.). Stukenbrock weist darauf hin, dass bis 1937 gemeinsame Veranstaltungen von NS-Organisationen und Zweigvereinen des DSV stattgefunden haben und bewertet die Haltung des DSV als einen „äußerst radikalisierte[n] Purismus“: „Die Sprachpflege tritt in den Dienst der Massenideologie, inkorporiert deren Antisemitismus und formt entsprechende antisemitische Sprachideologeme aus“ (Stukenbrock 2005b: 325). In diesem Zusammenhang steht auch die Distanzierung des Vereins vom einstigen Ehrenmitglied Eduard Engel. Im Umgang mit Engel - einem Juden - zeigt sich die linientreue Haltung des Vereins. ${ }^{160}$ In der Zeitschrift des Vereins wurde er im Jahr 1903 als „wackere[r] Mitkämpfer" begrüßt (Stoll 1903: Sp. 117), die verdeutschenden Überarbeitungen seiner Werke wurden gelobt:

Mit Freuden stellen wir fest, daß ein Schriftsteller von Bedeutung
seine Arbeiten bewußt im Sinne des Sprachvereins durchsieht: wenn
dies sogar auf Gebieten geschieht, deren Kunstsprache durch man-
chen bekannten Verfasser nicht eben zum Ruhme des Deutschtums
unliebsame Bereicherungen - besser schon Beeinträchtigungen - er-
fahren hat, so ist das erfolgreiche Auftreten Eduard Engels doppelt
und dreifach mit Dank zu begrüßen (Saalfeld 1904: Sp. 262f.).

Das Erscheinen von Engels „Deutscher Stilkunst“, insbesondere das Kapitel über die Fremdwortfrage, wurde im Sprachverein und in dessen Medien ausgiebig besprochen und über Jahre hinweg immer wieder zitiert (vgl. Sauter 2000: 287). Doch dann änderte sich der Ton: Viktor Rehtmeyer schrieb 1937 in einem Artikel in der Muttersprache: „So konnte Eduard Engel dem blinden deutschen Volke als guter Deutscher erscheinen, zumal da er sich durch seinen Kampf für die Sprachreini-

${ }^{160} \mathrm{Zu}$ Leben und Werk Eduard Engels und zu dessen Verhältnis zum ADSV vergleiche die ausführliche Darstellung von Anke Sauter (Sauter 2000). 
gung als guter Deutscher gebärdete“ (vgl. Rehtmeyer 1937: Sp. 142). Sauter stellt dazu fest:

Durch seine naive Kritik am Sprachgebrauch der Nationalsozialisten hatte sich der Sprachverein selbst in eine heikle Lage gebracht. Nun wollte man zeigen, daß man in der Rassenlehre den Standpunkt der Nationalsozialisten vertrat (Sauter 2000: 294). ${ }^{161}$

Der Linientreue gegenüber den Nationalsozialisten wurde das einstige Vorzeigemitglied geopfert. ${ }^{162}$ Generell kann festgestellt werden, dass die Bekämpfung der Fremdwörter im Deutschen von einer völkischen zu einer rassistischen und antisemitischen Angelegenheit wurde (vgl. Plümer 2000: 76, von Polenz 1967a: 89). ${ }^{163}$ Dennoch, der Sprachverein stieß bei den Nationalsozialisten auf wenig Gegenliebe (vgl. dazu Sauter 2000: 193). 1937 erfolgte eine Rüge von Goebbels (Stukenbrock 2005b: 326). ${ }^{164}$ Wiechers konstatiert:

Da man sich dort [gemeint ist der Sprachverein, Anmerkung d. Verf.] als nationalistisch bis gut nationalsozialistisch verstand, mußte die spätere Entwicklung, in der der Sprachverein bei der Regierung in Ungnade fiel, als eine Ernüchterung erscheinen (Wiechers 2004: 45f.).

Eine Anordnung des Reichsministers für Wissenschaft, Erziehung und Volksbildung ${ }^{165}$ erschwerte schließlich die Aktivitäten des Vereins. Das

${ }^{161}$ Vgl. zu diesem Thema auch Bernsmeier (1983: 42), von Polenz (1976a: 127ff.). und Stukenbrock (2005: 326).

${ }^{162}$ Sauter verweist auch auf die Rolle Georg Schmidt-Rohrs, der sich zuerst gegen eine „rassistische Sprachwissenschaft“ gewandt hatte, später jedoch ebenfalls auf die Parteilinie eingeschwenkt ist (vgl. Sauter 2000: 196). 1939 und 1940 hat Schmidt-Rohr seine Publikationen dem Verhältnis von Blut und Sprache gewidmet (vgl. ausführlich Hillen 1982: 59ff., vgl. zu Schmidt-Rohr auch Glück 1987: 119ff.).

${ }^{163}$ Von Polenz merkt hierzu an, dass sich die Entwicklung zum Antisemitischen erst ab dem Jahr 1936 vollzogen hat (vgl. von Polenz 1967a: 89).

${ }^{164}$ Im Jahr 1937 waren die Nationalsozialisten bereits mit den Aktivitäten des Sprachvereins nicht mehr einverstanden (vgl. Sauter 2000: 198 sowie die folgende Anmerkung). 165 „Nach einem Rundschreiben des Reichsministers und Chefs der Reichskanzlei ist dem Führer in letzter Zeit mehrfach aufgefallen, daß - auch von amtlichen Stellen - seit langem in die deutsche Sprache übernommene Fremdwörter durch Ausdrücke ersetzt werden, die meist im Wege der Übersetzung des Ursprungswortes gefunden und daher in der Regel unschön sind. Der Führer wünscht nicht derartige gewaltsame Eindeutschungen und billigt nicht die künstliche Ersetzung längst ins Deutsche eingebürgerter Fremdworte durch nicht aus dem Geist der deutschen Sprache geborene und den Sinn der Fremdworte meist nur unvollkommen wiedergebende Wörter.“ (Dt. Wissenschaft, Erziehung und Volksbildung, Amtsblatt 6, 1940: 534; zitiert nach von Polenz 1967: 96). Ein ähnlicher Wortlaut findet sich auch in einem Schreiben von Hans Heinrich Lammers, der diesen Erlass im November 1940 an die Obersten Reichsbehörden weitergegeben hat (vgl. Wie- 
genaue Ende des Sprachvereins ist noch nicht geklärt. Ab 1939 erschien die Zeitschrift unter einem neuen Herausgeber, 1943 wurde das Erscheinen der Zeitschrift eingestellt. Bernsmeier geht davon aus, dass der Verein zwar bis Kriegsende weiter existierte, eine geregelte Vereinsarbeit aber aufgrund der Kriegsereignisse nicht mehr stattfinden konnte (vgl. Bernsmeier 1983: 45, Stukenbrock 2005b: 326, vgl. zum Darmstädter Zweigverein Olt 1986 und 1991).

\subsubsection{Gesellschaft für deutsche Sprache}

Die Gesellschaft für deutsche Sprache (GfdS), die ihren Sitz seit 1965 in Wiesbaden hat, „ist eine politisch unabhängige Vereinigung zur Pflege und Erforschung der deutschen Sprache“ und möchte „das Bewusstsein für die deutsche Sprache [...] vertiefen und ihre Funktion im globalen Rahmen sichtbar [...] machen“ (GfdS 2001). Sie wurde am 10. Januar 1947 in Lüneburg gegründet (vgl. dazu auch Clay 1981: 66).

Sie will

allen helfen, die in sprachlichen Fragen Rat brauchen;

das Verständnis für Wesen, Bedeutung und Leistung der Sprache we-

cken und fördern;

die deutsche Sprachgemeinschaft anregen, sich mit der Sprache zu

beschäftigen und das Sprachgefühl zu vertiefen (zitiert nach Greu-

le/Ahlvers-Liebel 1986: 58).

Schwerpunkt der Arbeit der GfdS ist die Sprachberatung. Die Gesellschaft gibt zwei Zeitschriften heraus, die wissenschaftliche Muttersprache ${ }^{166}$ mit Aufsätzen und Besprechungen, und die eher sprachpraktische und populärwissenschaftliche Mitgliederzeitschrift Der Sprachfreund,

chers 2004: 45f.) Sauter weist jedoch darauf hin, dass dieser Erlass wohl keine so starke Zäsur darstellt, wie beispielsweise von Polenz annimmt (vgl. Sauter 2000: 198). Von Polenz legt ausführlich dar, „daß der Gebrauch bestimmter Fremdwörter im totalitären Staat oft absichtlich dazu dient, die Gedanken der Führer gerade nicht für alle erkennbar zu machen“ (von Polenz 1967: 83), und dass aus diesem Grund die Nationalsozialisten den DSV nicht unterstützten, auch wenn die Sprachreiniger dachten, durchaus im Sinne des Regimes zu handeln (vgl. für eine ausführliche Darstellung Olt 1991: 135ff., von Polenz 1967: 83 sowie Schiewe 2000: 56).

${ }^{166}$ Die Muttersprache gibt es bereits seit dem 1. April 1886, damals noch als Zeitschrift des ADSV unter dem Titel ZADS (Simon 1986: 83). Zur Auseinandersetzung der GfdS mit der Vergangenheit der Zeitschrift und der Kritik an der Vorgehensweise siehe ausführlich Simon (1986: 94ff.). 
später Der Sprachdienst, die sich mit sprachlichen Fragen im Alltag befasst (vgl. auch Clay 1981: 67f.). ${ }^{167}$ Seit 1971 wird durch die GfdS das "Wort des Jahres“ ermittelt (vgl. Hoberg 1996b: 90). Daneben stehen Symposien zu Sprachthemen, wie im Jahr 1998: „Sprachkultur oder Sprachverfall? Die deutsche Sprache vor der Jahrtausendwende“ in Bonn (vgl. Wieners-Horst 1998a: 36ff. sowie Wieners-Horst 1998b: 70ff.). ${ }^{168}$ Die Gesellschaft hat einen fünfköpfigen Vorstand als Leitung. Dieser wird aus dem 60-köpfigen Gesamtvorstand gewählt, der wiederum von der Mitgliederversammlung gewählt wurde. Die GfdS hat zahlreiche Zweigvereine im In- und Ausland, die von ihren jeweiligen Zweigvorsitzenden ehrenamtlich geleitet werden. Die Vorsitzenden organisieren beispielsweise Vorträge $\mathrm{zu}$ unterschiedlichen Sprachthemen. Die GfdS ist kein Verein mit Breitenwirkung, die Zahl der Mitglieder liegt derzeit ungefähr bei $2600 \mathrm{im}$ In- und Ausland (GfdS 2007).

In der Satzung von 1954 werden "Sprachhilfe“ und „Sprachauskunft“ als Aufgaben der Gesellschaft hervorgehoben:

Die Gesellschaft für deutsche Sprache ist eine gemeinnützige, unpolitische Vereinigung zur Pflege und Erforschung der deutschen Gegenwartssprache, die sie in all ihren Erscheinungen beobachten und weiterentwickeln will. Daher ist sie bemüht, das Sprachgefühl zu vertiefen, die Liebe zur Muttersprache und das Verständnis für ihr Wesen und ihre Leistung zu wecken, zu ihrer besseren Beherrschung hinzuführen und so den Weg zu bahnen zu rechtem Gebrauch ihrer geistigen Kräfte und Werte.

Hierzu gibt sie Zeitschriften und Einzelveröffentlichungen heraus, prüft die sprachliche Fassung von Entwürfen aller Art, besonders von amtlichen Schriftstücken (Gesetzen, Verordnungen, Dienstvorschriften usw.) - SPRACHHILFE -, erteilt Auskünfte über Fragen der Gegenwartssprache - Sprachauskunft - , erstattet Gutachten in sprachlichen Fragen und hält Lehrgänge ab (Satzung der GfdS 1954, zitiert nach Wiechers 2004: 95).

Die GfdS ist personell (zum Beispiel durch Personen wie Lutz Mackensen $^{169}$ ) und mit einem Teil ihrer Ziele der ersten Nachkriegsjahre als

167 Der Sprachdienst ist der Nachfolger der Zeitschrift Der Sprachfreund.

${ }^{168}$ Dieses Symposium veranstaltete die GfdS zusammen mit dem Arbeitskreis selbständiger Kultur-Institute (AsKI) (vgl. Wieners-Horst 1998a und 1998b).

${ }^{169}$ Lutz Mackensen war Vertreter einer rassistischen Sprachtheorie, unter anderem hat er 1935 in den Nationalsozialistischen Monatsheften einen Aufsatz veröffentlicht mit dem Titel „Sprache und Rasse“. Damit versuchte er, die Sprachwissenschaft auf einen neuen Kurs zu bringen (Mackensen 1935, vgl. u.a. Sauter 2000: 196). 
Nachfolgeorganisation des Allgemeinen Deutschen Sprachvereins anzusehen (vgl. Hillen 1982: 174). Auch in der Fremdwortfrage in den Nachkriegsjahren ist das Erbe des ADSV/DSV spürbar: In den 1950er Jahren wird der Grundsatz des Sprachvereins aus dem Jahr 1885 wieder zum sprachpflegerischen Leitbild. Im Jahr 1953 nimmt die GfdS ausführlich zur Fremdwortfrage Stellung:

Die Gesellschaft für deutsche Sprache beobachtet mit Sorge, daß die Überfremdung unserer Muttersprache auf fast allen Gebieten des staatlichen, wissenschaftlichen, gesellschaftlichen und häuslichen Lebens die Eigenständigkeit des deutschen Wortschatzes und Satzbaues ernstlich bedroht. Sie weiß wohl, dass unsere im Herzen Europas wachsende Sprache durch die Aufnahme fremden Wortgutes vielfach gefördert worden ist. Diese Kräfte, die uns in der Vergangenheit bereichert haben, sollen auch heute und in Zukunft beachtet bleiben. Wir kämpfen nicht gegen Fremdwörter, die eine Grundbedeutung gut und zweckmäßig abtönen, und nicht gegen Sachbezeichnungen, besonders wissenschaftlicher Art, für die deutsche Ausdrücke fehlen (17. Rundschreiben der GfdS, Februar 1953, zitiert nach Wiechers 2004: 217f.).

Wiechers verweist darauf, dass diese Argumentation als kluger Schachzug zu sehen sei, um auch konservative Vereinsmitglieder zu gewinnen. Weiter heißt es:

Wo sich aber fremdes Wortgut an die Stelle gleichwertiger deutscher Wörter setzt, wo gute, brauchbare Neubildungen mißachtet werden, wo sich undeutsche Ausdrucksformen in unseren Satzbau drängen, erhebt die Gesellschaft für deutsche Sprache Einspruch. Jede geistlose Fremdwörterjagd lehnt sie ab; nach wie vor aber bekennt sie sich zu ihrem alten Grundsatz: „Kein Fremdwort für das, was gut deutsch gesagt werden kann!“

Nach diesem Grundsatz wird sie neueindringende Fremdwörter beobachten, für sie, wo es möglich und sinnvoll erscheint, gute gleichwertige deutsche Wörter suchen und vorschlagen, und ferner die schon gebräuchlichen Fremdwörter prüfen und ihnen ebenso begegnen (17. Rundschreiben der GfdS, Februar 1953, zitiert nach Wiechers 2004: 217f.).

Der Sprachfreund und Der Sprachdienst liefern zahlreiche Belege zu einer Stellungnahme in der Fremdwortfrage:

Jeder weiß, daß ein Gartenweg, der nicht des öfteren gejätet wird, verkrautet. Mit unserer Sprache steht es ähnlich: wir müssen von Zeit zu Zeit Hacke und Spaten nehmen, um auszumerzen, was ungebeten und störend sich da breit machen möchte (MA. 1953: 2).

Diese Haltung spiegelt sich auch in zahlreichen Aufsätzen in der Muttersprache. Exemplarisch sei hier auf den Aufsatz „Die lieben Fremd- 
wörter" von Otto Brunner aus dem Jahr 1953 verwiesen, in dem Brunner bemerkt, dass das, was an Fremdwörtern ins Deutsche gelangt sei, „über alle Maße“ hinausgehe (Brunner 1953: 257). Zwei Jahre zuvor hatte er die GfdS aufgerufen, auf Zeitungen und Zeitschriften einzuwirken, weniger Fremdwörter zu verwenden. Außerdem hatte er gefragt, ob nicht von staatlicher Seite eingegriffen werden könne (vgl. Brunner 1951: 289). Der Ruf nach Überwachung der Sprache findet sich u.a. in der Muttersprache:

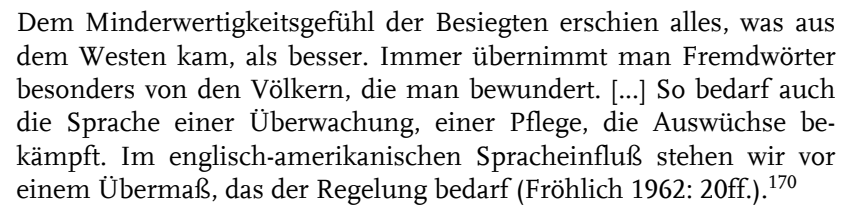

Der Sprachwissenschaftler Leo Weisgerber und seine Sprachauffassung prägen die Einstellung zum Fremdwort ${ }^{171}$ in der GfdS. ${ }^{172}$ Weisgerber sieht das Fremdwort als Störfaktor, lehnt aber die Fremdwortbekämpfung ab. Eine Bekämpfung der Fremdwörter würde die Annäherung der Völker erschweren und den Austausch zwischen den Sprachen beeinträchtigen. Später bezieht Weisgerber eine gemäßigte Position in der Fremdwortfrage. Dem Fremdwort wird nun mit einigen Vorbehalten ein Platz in der deutschen Sprache zugestanden. Er bewertet Fremdwörter als „schädlich“, „hinderlich“, „fragwürdig“, „überflüssig“, aber auch als „nützlich“ (Weisgerber 1960: 2f.). Dabei bezeichnet Weisgerber solche Fremdwörter als schädlich, die einem deutschen Wort den Platz wegnehmen. Fremdwörter, die einer deutschen Bildung im Wege stehen, sieht er als hinderlich. Als überflüssig bewertet er Fremdwörter, die nur eine fremde Atmosphäre imitieren. Als fragwürdig sieht er Fremdwörter, deren Verständnis besondere Schwierigkeiten bereitet. Entbehrliche Fremdwörter sind als neutral zu sehen, Notbehelfscharakter ge-

\footnotetext{
${ }^{170}$ Vgl. auch z.B. Holz (1953: 307ff.).

${ }^{171}$ Auch 1950 gab es in der GfdS schon Personen, die eine gemäßigte Position vertraten, wie z.B. Wilhelm M. Esser: „Der Kampf gegen das Fremdwort wurde zum Anliegen der volklichen Selbstdarstellung, ja, Selbstbehauptung und allenthalben durchlief man alle Stufen zwischen Fremdwortsucht und Fremdworthatz. [...] Nun - die Zeiten derartiger Überhitzung sind wohl vorbei“ (Esser 1950: 3). Aber diese Stimmen waren in der Minderheit (vgl. Wiechers 2004: 223).

${ }^{172}$ Weisgerber ist massiv kritisiert worden. Peter von Polenz spricht von einer „Mystifizierung von Begriffen wie Muttersprache“ (von Polenz 1999a: 289).
} 
steht er jenen Fremdwörtern zu, deren Verdeutschung sehr umständlich wäre, und schließlich sieht er solche Fremdwörter als notwendig an, deren geistiger Inhalt sich nicht völlig mit ihrer deutschen Entsprechung deckt (vgl. Weisgerber 1960: 2f.).

In den 60er Jahren kommt es also zu einem Wendepunkt in der Diskussion um das Fremdwort (vgl. Wiechers 2004: 202). In diesem Zusammenhang kam es auch es zu Streitigkeiten innerhalb der GfdS, diese führten schließlich zur Abspaltung ganzer Zweigvereine. Nüssler berichtet, die GfdS habe diese lieber geopfert, „als sich irgendwelchen politischen oder parapolitischen Ideen zu verschreiben“ (Nüssler 1979: 380).

Karlheinz Daniels forderte schon 1959 eine leidenschaftslose Sachlichkeit (vgl. Daniels 1959: 105ff.). ${ }^{173}$ Im Jahr 1967 wird ein Aufruf „zu einem maßvollen Gebrauch der Fremdwörter“ veröffentlicht (vgl. Förster 2000b: 330ff.). Durch das Verzichten auf „Schwarzweißkategorisierungen" wurde ein zunehmend sachliches Arbeiten ermöglicht (vgl. Wiechers 2004: 243). Insgesamt war die GfdS bemüht, ab den sechziger Jahren eine liberale Haltung gegenüber dem Fremdwort einzunehmen. Aus den aggressiv geführten Diskussionen um das Fremdwort hat sie sich zurückgezogen (vgl. Wiechers 2004: 252).

Clay schreibt dazu:

[...] die GfdS befasst sich sehr wohl mit der Fremdwortfrage, nur haben sich in fast 100 Jahren die Perspektiven geändert. Anstelle von nationalen Gefühlen und Argumenten kommen linguistische und stilistische; das Fremdwort wird nicht per se verbannt, sondern man fragt nach seiner Stellung innerhalb des Sprachzusammenhangs. Stellt das Fremdwort eine Bereicherung des deutschen Wortschatzes dar, dann hat es einen Platz darin gefunden. Es wird aber abgelehnt, wenn es der Denkfaulheit oder Protzsucht dient. Selbstverständlich wird es dort verbannt, wo es Missverständnisse hervorruft oder Verstehensschranken errichtet. Was bei der GfdS ganz verschwunden ist, ist die Polemik um das Fremdwort (Clay 1981: 70f.).

In den 1980er Jahren nimmt die GfdS wieder Stellung zum Fremdwort, sie rückt weiter ab von einem pauschalen Verbieten und berücksichtigt nunmehr den Kontext. Seitdem gilt das Fremdwort nur noch als bedenklich, wenn es das Verständnis erschwert oder manipulierend verwendet wird (vgl. u.a. Sauter 2000: 199). Uwe Förster stellt sogar fest,

${ }^{173}$ Dies ist zwar ein Fortschritt, aber selbst der Allgemeine Deutsche Sprachverein hatte dies schon hin und wieder beschwichtigend und defensiv getan. 
dass die Fremdwortfrage ängstlich umgangen wird (vgl. Förster 1989: 105).

Dabei sind Anglizismen durchaus Thema der GfdS. Zum Beispiel veranstaltete der Bamberger Zweigverein 1997 eine Podiumsdiskussion hierzu (Unger 1998: 24f.). Im Mai 1998 wurde auf der Mitgliederversammlung von Walter Krämer (damals Vorsitzender des VWDS und GfdS-Mitglied) ein Antrag gestellt, dass die GfdS sich an Aktionen des VWDS gegen die Anglisierung des Deutschen beteiligen solle. Dieser wurde abgelehnt (vgl. Pflug/Frank-Cyrus 1998: 148, u.a. auch Hensel 1999: 29 sowie Kapitel 2.8.).

Im Jahr 1999 erschien eine offizielle Stellungnahme der GfdS, in der sie sich gegen die Vorstellung von "lückenlos ererbtem Wortgut“ wendet. Dort heißt es weiter: Anglizismen werden „nicht nur ins Deutsche, sondern vermutlich in alle Sprachen der Erde übernommen“ (GfdS 1999: 218) und:

Anglizismen sind keine bösen Bazillen, die in die gute deutsche Sprache eindringen und sie krank machen oder gar zerstören, und die Deutschen werden nicht von Amerikanern sprachlich kolonisiert (GfdS 1999: 219).

2001 nimmt Hoberg auf einer Podiumsdiskussion Stellung. Es gebe verschiedene Möglichkeiten, sich angesichts des englischen Einflusses auf die deutsche Sprache zu verhalten und die GfdS wähle die folgende: Sie entwickele rational begründete Kriterien und diskutiere diese in der Öffentlichkeit und mit Institutionen, die Vorbildfunktion haben, unter anderem mit Schulen, Hochschulen und Medien (vgl. Hoberg 2001: 301). ${ }^{174}$ Auch in der jüngsten Zeit rückten die Anglizismen wieder in den Blickpunkt der GfdS: Die Gesellschaft gab zusammen mit dem Deutschen Sprachrat, dem sie angehört, eine repräsentative Umfrage über die Einstellung der Deutschen zu ihrer Muttersprache in Auftrag, in der auch die Einstellung gegenüber Anglizismen abgefragt wurde (vgl. Schulz 2008 sowie Kapitel 1.6).

\footnotetext{
${ }^{174}$ Als weitere Möglichkeiten, die die GfdS alle ablehnt, sieht Hoberg das Ignorieren der Anglizismen, eine Sprachgesetzgebung oder das Attackieren, Boykottieren und Diskriminieren von Personen oder Institutionen, deren Anglizismengebrauch keinen Gefallen findet (vgl. Hoberg 2001: 301). Die beiden letztgenannten Punkte kommen beim VDS in der Vereinsarbeit durchaus vor.
} 
Die GfdS stellt zunehmend die früher eher vernachlässigten weiteren Aufgaben von "Sprachpflege“ in den Vordergrund: Sprachberatung, Fachsprachen, Fachterminologie, Politiksprache, Mundarten, Sprachsoziologie, Sprachgeschichte, Sprachdidaktik. Dabei versteht sie Sprachpflege als „eine Beschäftigung mit Sprache, die auf der Basis wissenschaftlicher Erkenntnisse erfolgt und diese Erkenntnisse der interessierten Öffentlichkeit in allgemein verständlicher Form zugänglich macht“ (Stöckhardt 2000: 205). Im Sprachdienst heißt es weiter dazu:

Sprachpflege ist die Anleitung der Sprachteilhaber, die in der Sprache
angelegten, sich wandelnden Möglichkeiten situationsgerecht und
gut zu nutzen. Die wissenschaftlich begründete Sprachpflege nimmt
dabei die Kenntnisse der Sprachentwicklung zu Hilfe, berücksichtigt
also die Ergebnisse der Forschung (Beobachtung, Registrierung und
Analyse vergangener und gegenwärtiger Sprachzustände sowie Er-
mittlung künftiger Verhältnisse) bei ihrer informierenden und päda-
gogischen Tätigkeit (N. 1980: 121).

Der Begriff der Sprachpflege ist umstritten: Im Jahr 1992 kommt es innerhalb der GfdS zu einer Diskussion um eine Satzungsänderung, statt "Sprachpflege“ sollte „Sprachkultur“ in die Satzung aufgenommen werden. Dazu ist es aber nicht gekommen (vgl. Wiechers 2004: 210). Stattdessen wurde der Begriff Sprachpflege durch Eingrenzung und wissenschaftliche Definitionen "gewissermaßen rehabilitiert" (Wiechers 2004: 211).

Zum Thema Sprachreinigungsgesetz gibt es eine klare Linie. Die GfdS hat 1979 öffentlich dargelegt, dass sie ein Sprachreinigungsgesetz generell nicht befürwortet und diese Haltung im Jahr 2001 noch einmal öffentlich bekräftigt. In der Stellungnahme von Karin M. Eichhoff-Cyrus zur Diskussion über ein Sprachreinigungsgesetz im Sprachdienst heißt es:

Sprache ist ein wichtiges Element der Demokratie. Mündigen Bürgerinnen und Bürgern sollte es vorbehalten bleiben, Sprache in ihrem Sinne einzusetzen (Eichhoff-Cyrus 2001: 73).

Auch Hoberg äußert sich 2001 öffentlich gegen ein Sprachgesetz. ${ }^{175}$ Obwohl diese Stellungnahmen die antipuristische Haltung der GfdS zeigen (vgl. Pfalzgraf 2006: 182), hat die Gesellschaft dennoch die lange angekündigten Kriterien und Empfehlungen zur Beurteilung von Angli-

${ }^{175}$ Vgl. Hoberg (2001: 301, 1996a: 141, für weitere Aussagen Hobergs bezüglich des „Denglischen“ vgl. auch 2000a und 2000b). 
zismen nicht erarbeitet und vorgelegt (vgl. Wiechers 2004: 331). ${ }^{176}$ Die Gesellschaft, so wird weiter kritisiert, distanzierte sich jedoch bis heute nicht davon, dass die Arbeit des Sprachvereins in ihren extremen Auswirkungen bis hin zu Bücherverbrennungen geführt hatte (vgl. Simon 1986: 90f.). Simon weist darauf hin, dass eine Darstellung des Sprachvereins als unschuldige Organisation, die in die Hände der Nationalsozialisten fiel, nicht haltbar sei (Simon 1986: 96f.), ${ }^{177}$ Auch Wiechers erläutert, dass von einer Opferrolle keine Rede sein kann und kritisiert, dass die Auseinandersetzung der GfdS mit ihrer „faschistischen Hypothek" bis heute nicht wirklich erfolgt sei (Wiechers 2004: 329). An dieser Stelle ist anzumerken, dass sich die GfdS zumindest in der Diskussion um ihr Mitglied Mackensen mit der nationalsozialistischen Vergangenheit beschäftigt hat (Wiechers 2004: 85ff.). ${ }^{178}$

Insgesamt kann eine mittlerweile gemäßigte Haltung der GfdS gegenüber den Anglizismen in der deutschen Sprache konstatiert werden. Auf das Verhältnis GfdS - VDS wird in Kapitel 2.8 eingegangen.

\subsubsection{Institut für Deutsche Sprache}

Das Institut für Deutsche Sprache in Mannheim gibt es seit 1964. Es ist eine Stiftung des Bundes und des Landes Baden-Württemberg, und wird je zur Hälfte vom Bund und vom Land finanziert. Hinzu kommen Fördermittel aus verschiedenen Einrichtungen. Institutsdirektor ist Prof. Dr. Ludwig Eichinger. ${ }^{179}$

Die Aufgaben des Instituts sind folgendermaßen beschrieben:

Das Institut [...] ist die zentrale außeruniversitäre Einrichtung zur Erforschung und Dokumentation der deutschen Sprache in ihrem gegenwärtigen Gebrauch und in ihrer neueren Geschichte (IDS 2005a).

\footnotetext{
${ }^{176}$ Dies ist $\mathrm{m}$.W. bis heute nicht erfolgt.

${ }^{177}$ In diesem Zusammenhang kritisiert er scharf die Arbeiten von Helmut Bernsmeier. Er wirft ihm Schönfärberei und Verschweigen von Tatsachen vor (vgl. Simon 1986: 96).

${ }^{178}$ Zur Frage, ob es eine Alternative zu dieser freiwilligen Gleichschaltung gegeben hätte, vgl. Kapitel 1.7.1.

${ }^{179}$ Bis 2002 hatte der Sprachwissenschaftler Prof. Dr. Gerhard Stickel diesen Posten inne.
} 
Auf der Homepage des Instituts ${ }^{180}$ heißt es:

Mit seinen Vortragsveranstaltungen, Tagungen und Kolloquien ist das IDS auch ein Ort der wissenschaftlichen Begegnung und Kommunikation für in- und ausländische Germanisten und alle an Sprache Interessierten (IDS 2005a).

Gegründet wurde das IDS als Gegenstück zum Institut für Sprachwissenschaft der Akademie der Wissenschaften der DDR. Der Schwerpunkt der Arbeit des IDS liegt auf Fragen der Grammatik und der Lexik. Das IDS ist eine Schnittstelle zwischen Sprachpraxis und Sprachwissenschaft und veranstaltet u.a. Fachtagungen, deren Themen von der Kommission für Sprachberatung angesetzt und deren Ergebnisse in den IDS-Jahrbüchern publiziert werden. Beim IDS gab es auch eine „Kommission für wissenschaftlich begründete Sprachpflege“, diese wurde jedoch wieder aufgelöst, zudem ist es Sitz der „Kommission für deutsche Rechtschreibung“. Das IDS ist eines der beiden deutschen Mitglieder in der European Federation of National Institutions for Language (EFNIL). ${ }^{181} \mathrm{Im}$ Bereich der Sprachförderung ist das Handbuch zur „Förderung der Sprachkultur in Deutschland“ zu erwähnen; eine Aufstellung und Kurzvorstellung die Sprache fördernder Einrichtungen, die in Zusammenarbeit mit der GfdS und durch die Förderung der RobertBosch-Stiftung entstanden ist (Frank-Cyrus/Trabold et al. 1999, vgl. auch Kapitel 1.7). Auch das IDS beschäftigt sich mit der Fremdwortdiskussion und den Anglizismen:

Das Institut für Deutsche Sprache (IDS), das sich wiederholt an der generellen Fremdwortdiskussion beteiligt hat und in dem das [...] „Deutsche Fremdwörterbuch“ neu bearbeitet wird, will sich auch in der Diskussion über die Anglizismen im Deutschen nicht abstinent verhalten. Vor jeder generellen Wertung interessiert uns als Wissenschaftler zunächst die Frage, wie es zu der bemerkenswerten $\mathrm{Zu}$ nahme an Anglizismen überhaupt kommt [...] (Stickel 1994: 13). ${ }^{182}$

Im Jahr 2000 war die Fremdwortdiskussion sogar Thema der Jahrestagung, die unter dem Motto: „Neues und Fremdes im deutschen Wort-

\footnotetext{
${ }^{180}$ Auffällig ist am Webauftritt, dass im Titeltext im Browserfenster übrigens ausdrücklich: „Leitseite“ steht (vgl. z.B. „Leitseite, Aktuelles am/zum IDS“ (IDS 2005b).

${ }^{181}$ Dabei handelt es sich um eine 2004 in Stockholm gegründete Sprachorganisation, der Sprachakademien aus verschiedenen europäischen Ländern angehören und die zum Ziel hat, die Sprachen Europas zu erhalten und zu entwickeln. Mehr Informationen gibt es auf der Internetseite der EFNIL: http://www.efnil.org (vgl. dazu Stickel 2007: 142f.).

182 Diese Aussage ist insofern erstaunlich, dass er im Jahr 1985 konstatierte: „Das ,Fremdwort' hat ausgedient“ (Stickel 1985: 7).
} 
schatz - Aktueller lexikalischer Wandel“ stattfand. Teilnehmer waren unter anderem die Sprachwissenschaftler Peter Eisenberg und Peter Schlobinski sowie der VDS-Vorsitzende Walter Krämer. ${ }^{183}$

Mitarbeiter des IDS haben einige Beiträge zum Thema Anglizismen im Deutschen und zum Thema Sprachpolitik veröffentlicht: Ulrike Haß beschäftigt sich in „Zum Beispiel recykeln“ (Haß 1987) mit dem Problem der Integration von Anglizismen ins Deutsche, Klaus Heller mit Fremdwortschreibung und der Definition von Fremdwörtern (Heller 1966 und 2002), und Gisela Zifonun setzt sich in dem Artikel „Überfremdung des Deutschen: Panikmache oder echte Gefahr?" (Zifonun 2002) mit der Frage auseinander, ob die Angst vor der Überfremdung des Deutschen ernst genommen werden müsste. ${ }^{184}$ Daneben gibt es zahlreiche weitere Veröffentlichungen von Gerhard Stickel, die Einstellungen zu Anglizismen untersuchen, ohne sich gegen Anglizismen im Deutschen zu wenden. ${ }^{185}$ Doch nicht immer bleibt Stickel dieser Haltung treu: Über Stickels Einstellung gegenüber Anglizismen in Telefonrechnungen berichtet ein Spiegel-Artikel:

All denen, die das T-Englisch nicht verstehen, wird eine 36seitige Broschüre angeboten. In nur wenigen Stunden kann man damit die Telefonrechnung dechiffrieren.

Das geht zu weit, befand Institutsdirektor Professor Gerhard Stickel. In tadellosem Deutsch sandte er Telekom-Chef Ron Sommer einen Brief mit der Frage, ob das denn wirklich sein müsse (Der Spiegel 1998a: 124).

Stickel macht hier seine Position deutlich und verwendet sogar dieselben Mittel wie beispielsweise der VDS. Er benutzt die gleichen Ar-

${ }^{183}$ Hierauf werde ich in Kapitel 2.7. zurückkommen.

${ }^{184}$ Zifonun kommt zu dem Schluss, dass keine Gefahr der Überfremdung besteht (Zifonun 2002: 8).

${ }^{185}$ Vgl. Stickel, Gerhard (1987), Stickel, Gerhard (1999) sowie Stickel, Gerhard/Volz, Norbert 1999. Diese Untersuchungen wurden von Pfalzgraf auf puristische Bestrebungen analysiert. Pfalzgraf kommt zu dem Ergebnis, dass in Stickels Veröffentlichungen „keinerlei Kennzeichen der purismustypischen Diskurse“ auftreten (vgl. Pfalzgraf 2003: 178ff.). Interessant ist ein Hinweis von Pfalzgraf betreffend Stickels Artikel „Engleutsch“: Stickel fühlt sich, wie er selbst schreibt, durch Anglizismen „veralbert“. Außerdem geht er davon aus, dass Hemden mit anglo-amerikanischen Namen teurer seien (vgl. Stickel 1994: 13). Er bekennt sich zum Boykott dieser Hemden. Damit „bezieht Stickel eine ähnliche Position wie der Verein Deutsche Sprache (VDS), der immer wieder von Mitarbeitern des IDS wegen seines polemischen und undifferenzierten Verhaltens kritisiert wird“ (Pfalzgraf 2006: 168). 
gumente, indem er die Anglizismen in Zusammenhang mit Angeberei stellt und indirekt die Werbebranche angreift (vgl. Kapitel 2).

Die Anglizismenfrage ist also Gegenstand einiger Publikationen des IDS. Außerdem gibt das IDS ein Fremdwörterbuch (DFWB) heraus. ${ }^{186}$ Insgesamt steht das IDS dem Thema der Anglizismen im Deutschen wertneutral gegenüber. Diese Haltung erklärt das nicht immer einfache Verhältnis des IDS zum VDS, auf das in Kapitel 2.9 näher eingegangen wird.

\subsubsection{Deutsche Akademie für Sprache und Dichtung}

Die Deutsche Akademie für Sprache und Dichtung wurde am 28. August 1949 auf Anregung des Schriftstellers Oskar Jancke gegründet. Dabei war es das erste Anliegen der Autoren, einander näher kennen zu lernen und über ihr Schaffen zu diskutieren. Die Akademie, die ihren Sitz in Darmstadt hat, ist keine staatliche Institution. In der Rechtsform eines eingetragenen Vereins wird sie sowohl aus öffentlichen als auch privaten Mitteln finanziert, wobei der Anteil der öffentlichen Gelder mit etwa 90 Prozent klar überwiegt. Wie das IDS ist die Deutsche Akademie für Sprache und Dichtung Mitglied der EFNIL (Deutsche Akademie für Sprache und Dichtung 2005a). Mitglieder der Akademie sind

Persönlichkeiten [...], deren Arbeit und Interesse sich auf alle Gattungen und Gebiete der Literatur und Sprache beziehen: Schriftsteller, Übersetzer, Sprach- und Literaturwissenschaftler, Historiker, Kunsthistoriker, Pädagogen, Philosophen und andere. Die Aufnahme in die Akademie setzt ein Euvre voraus, das die deutsche Sprache und Literatur bereichert hat (Deutsche Akademie für Sprache und Dichtung 2005b).

Die Öffentlichkeit stellte über die Presse früh konkrete Forderungen an die Akademie, hauptsächlich die Forderung nach Sprachpflege (vgl. dazu Clay 1981: 79). „Sprachforschung, Sprachlehre, Sprachkritik“ lautete

${ }^{186}$ Das IDS ist auch Mitglied im Deutschen Sprachrat. Dabei handelt es sich um einen Zusammenschluss des IDS, der GfdS, des Deutschen Akademischen Auslandsdienstes (dieser kam erst später hinzu) und des GI zum Deutschen Sprachrat. Dieser widmet sich der Förderung und Vermittlung der deutschen Sprache (vgl. Deutscher Sprachrat 2006), zudem soll er die einzelnen Aktivitäten der Institutionen aufeinander abstimmen (vgl. Hoberg 2003: 182). 
dann auch das Thema der Frühjahrstagung in Köln im Jahr 1969. ${ }^{187}$ Ihren Aufgabenbereich umreißt die Akademie folgendermaßen:

Die Akademie sieht es als ihre Aufgabe an, die deutsche Literatur und Sprache zu pflegen und, wo es sein muß, zu vertreten, nicht zuletzt neue Entwicklungen aufmerksam und kritisch $\mathrm{zu}$ verfolgen, nach Möglichkeiten auch zu ermutigen und zu fördern (Deutsche Akademie für Sprache und Dichtung 2007).

Ihre Aufgaben nimmt sie wahr, indem sie Veranstaltungen zur Literatur, Sprache und zu kulturpolitischen Themen durchführt, Preise wie den Georg-Büchner-Preis vergibt, Publikationen herausgibt und sich in der Debatte um die Rechtschreibreform engagiert:

Die Akademie setzt sich zum Ziel, das deutsche Schrifttum vor dem In- und Ausland zu vertreten und auf die pflegliche Behandlung der deutschen Sprache in Kunst und Wissenschaft, im öffentlichen und privaten Gebrauch hinzuwirken (Deutsche Akademie für Sprache und Dichtung 2007).

In diesem Zusammenhang wird auch die Verwandtschaft mit der "großen Schwester", der Académie française, hervorgehoben.

Die Deutsche Akademie hat am 17. Januar 2002 eine ausführliche Stellungnahme zur Debatte über den zunehmenden Einfluss des Englischen auf die deutsche Sprache publiziert. In dem Schreiben von Christian Meier (damaliger Präsident) ${ }^{188}$ und Klaus Reichert (damaliger Vizepräsident, heutiger Präsident) heißt es:

Der zunehmende Anteil des Englischen an unserer öffentlichen Sprache erfüllt weite Teile der Sprachgemeinschaft mit Sorge. Nach der Diskussion um die Neuregelung der Rechtschreibung erleben wir eine zweite Debatte über die Zukunft der deutschen Sprache (Meier/Reichert 2002: 1).

${ }^{187}$ Auf dieser Tagung sprach sich der Linguist Harald Weinrich in einem Referat gegen eine puristische Haltung aus: „[Die Deutsche Akademie für Sprache und Dichtung] tut weiterhin gut daran, wenn sie sich jeglicher Werbung für die konservative Sondersprache des Purismus enthält. Die Sprache bedarf nämlich gar keiner globalen Eingriffe. Sie enthält als primäres Zeichensystem einen Rückkopplungs-Mechanismus, der unter wechselnden gesellschaftlichen Bedingungen die notwendige Anpassung der Sprache an neue Kommunikationsbedürfnisse von selber bewerkstelligt. Man kann sich auf diese Rückkopplung besser verlassen, als Puristen wahrhaben wollen. Puristen sind selten Linguisten“ (Weinrich 1969: 380).

188 Der damalige Präsident Christian Meier wird in den Sprachnachrichten vom 3. Oktober 2001 folgendermaßen zitiert: „Dadurch [gemeint ist der englische Spracheinfluss, Anm. d. Verf.], gehen viele Ausdrucksweisen und somit der Sprachreichtum verloren. [...] Gegen den Sprachverfall muss etwas getan werden. [...] Die Akademie hat keinen direkten Einfluß auf die Kultusminister und deren Bildungspolitik." (dpd 2001: 6) 


\section{Weiter gibt die Akademie bekannt:}

[...] Die Akademie [...] hält vielerlei Kritik im einzelnen für angebracht, rät aber insgesamt zur Gelassenheit. Ein Eingreifen durch staatlich verordnete Sprachregelungen wäre nicht nur unnötig, sondern schädlich. [...] Für eine Gefährdung ihrer Integrationskraft durch das vermehrte Eindringen von Anglizismen sehen wir keine Anzeichen [...]. Berührt ist vielmehr, was in Frankreich als ,usage' (Gebrauch) bezeichnet wird: der Sprachgebrauch in einer beachtlichen Anzahl gesellschaftlicher Bereiche. [...] Wo Imponiergehabe, Prestigeanleihe, modische Angepaßtheit vorherrschen, ist Kritik angebracht (Meier/Reichert 2002: 1ff.).

Das bedeutet, die Akademie bewertet Anglizismen im Deutschen nicht per se negativ, und sieht die Entwicklung nicht als Bedrohung der deutschen Sprache. ${ }^{189}$ Dennoch sieht auch sie die Verwendung von Anglizismen teils kritisch und stellt sie in Zusammenhang mit Imponiergehabe und modischer Angepasstheit. ${ }^{190}$

\section{Zur Frage der Gesetzgebung bezieht die Akademie klar Stellung:}

Die Akademie lehnt jede Form sprachlicher Zwangsregulierung und insbesondere staatliche Verordnungen oder Gesetze ab, die den Sprachgebrauch einschränken sollen (Meier/Reichert 2002: 5).

Auch Puristen oder Sprachreinigern steht sie skeptisch gegenüber:

Die Bemühungen der ,Puristen', der ,Sprachreiniger', etablierte Fremdwörter durch eigenes Wortgut zu ersetzen, hatten nur begrenzten Erfolg. Die Verdeutschungen wurden zumeist nicht angenommen, oder sie bereicherten die Sprache in einem anderen Sinn als beabsichtigt (Meier/Reichert 2002: 4).

Probleme sieht die Akademie allerdings beim Rückgang des Deutschen als Wissenschaftssprache: ${ }^{191}$

In verschiedenen Wissenschaften, in Technik, Ökonomie und anderen Bereichen verdrängt das Englische das Deutsche zunehmend. Dadurch entsteht die Gefahr, daß unsere Sprache nur mehr partiell abgebildet wird, daß sie einen den Dialekten ähnlichen Status erhält (Meier/Reichert 2002: 1).

\footnotetext{
${ }^{189}$ Abgesehen von der Kritik des Fremdwortgebrauchs aus Prestigegründen betreibt die Akademie keinerlei Anglizismenkritik. Anglizismengebrauch im Deutschen wird zwar kommentiert, jedoch nicht in negativ-ablehnender Weise (vgl. Pfalzgraf 2006: 212f.). ${ }^{190}$ Diese Stellungnahme in der Pressemitteilung veranlasste den VDS, in den Sprachnachrichten zu jubeln, der VDS und die Akademie zögen an einem Strang (vgl. Dieter et al 2002: 4). Doch m.W. kam es zu keiner weiteren Annäherung der beiden Organisationen. ${ }^{191}$ Für eine ausführliche Darstellung dieses Themas vgl. Ammon $(1998,2004)$ sowie Ammon/Mc Connel (2002).
} 
Die Akademie schlägt in ihrer Stellungnahme verschiedene Maßnahmen vor, die Förderung des Deutschen im gesamten Bildungswesen betreffend: Unter anderem sollte das Fach Deutsch als Fremdsprache im In- und Ausland fortentwickelt und ausgebaut werden. Sie vertritt die Auffassung, dass die Einführung des Englischen als alleinige Sprache in Studiengängen, in einigen Bereichen der Politik und des Rechts, als alleinige Kongresssprache und als alleinige Sprache der internationalen Wirtschaftskommunikation öffentlich diskutiert und im Einzelfall rational begründet werden sollte. Zudem schlägt die Akademie die Einrichtung einer öffentlich geförderten Arbeitsstelle in Sprachfragen vor, die mit Sprachwissenschaftlern, Übersetzern und Schriftstellern zu besetzen sei. Zu deren Aufgaben sollten Terminologiearbeit (in Kooperation mit den großen Wörterbuchverlagen), Textarbeit (für die Öffentlichkeit wichtige Texte sollen in einer verständlichen Sprache verfasst werden), Sprachberatung und Sprachaufklärung (Information über für die Öffentlichkeit relevante Sprachdiskurse und Erkenntnisse der Sprachwissenschaft) gehören (vgl. Meier/Reichert 2002: 6). An der Haltung der Akademie hat sich seither nichts verändert, sie hat sich nicht mehr offiziell zu Anglizismen geäußert. ${ }^{192}$

\subsubsection{Verein für Sprachpflege/ Deutsche Sprachwelt}

Der Verein für Sprachpflege (VfS) wurde 1963 als Verein für Sprachpflege Hamburg in der Hansestadt durch Heinrich Heeger, ${ }^{193}$ den ehemaligen Hamburger Zweigvereinsvorsitzenden der GfdS, gegründet. Zweck des Vereins war die „Pflege der deutschen Sprache“, seine Hauptaufgabe sah er in der Pflege des Wortschatzes. Der Verein mit

192 E-Mail von Corinna Blattmann, Deutsche Akademie für Sprache und Dichtung, an die Verfasserin, 16. Januar 2008.

${ }^{193}$ Matthias Jung bezeichnet Heeger in seinem Aufsatz „Amerikanismen, ausländische Wörter, Deutsch in der Welt. Sprachdiskussion als Bewältigung der Vergangenheit und Gegenwart“ überheblich als „lächerliche Witzfigur“ (Jung 1995: 257). Jung kommentiert einen Artikel aus der SZ (Kistenmacher 1976: 3) folgendermaßen: „Über den Vorsitzenden des obskuren „Vereins für Sprachpflege“ [...] berichtet man bezeichnenderweise unter der Überschrift ,Nur Sex lässt er gelten'“ (Jung 1995: 257). Den Eindruck, dass der Artikel Heeger tatsächlich dermaßen lächerlich macht, hatte die Verfasserin bei der Lektüre nicht. 
seinen rund 150 Mitgliedern (vgl. Kistenmacher 1976: 3) hatte das Ziel, „vorhandene Eigenwörter vor Verlust zu bewahren, vergessene der Vergessenheit zu entreißen, erforderliche zu schaffen, mitzuteilen, zu empfehlen, zu gebrauchen“ (vgl. Heeger 1966a: 14). Der Verein verstand sich als Nachfolgeverein des DSV (vgl. Kistenmacher 1976: 3) und vertrat einen konservativen Standpunkt sowie eine intolerante Haltung gegenüber Andersgesinnten. Dies kommt in Publikationen des Vereins klar zum Ausdruck (vgl. hierzu ausführlich Clay 1981: 72ff.). Im Sprachpfleger, der Zeitschrift des Vereins, seit 1963 vierteljährlich erschienen - in den 70er Jahren mit einer Auflage von rund 10000 (vgl. Kistenmacher 1976: 3) -, zeigt sich der „militante [...] Geist der Vereinsveröffentlichungen“ (vgl. Hillen 1982: 139) unter anderem in Parolen wie:

Leistet den Feinden unserer Muttersprache entschlossenen Widerstand! Unterstützt die verantwortungsvolle Arbeit der Vereine für Sprachpflege! Der Sprachverderber verrät und verhindert jede geistige Bildung (Heeger 1966a: 14).

Weiterhin heißt es im Sprachpfleger:

Seit dem letzten Weltkrieg ist unsere Muttersprache infolge der Überflutung durch fremdes, namentlich englisch-amerikanisches Wortgut ärger bedroht denn je. Unsere Zeitungen und Zeitschriften - so der "Spiegel“ nachgewiesener- und zugegebenermaßen - Rundfunk und Fernsehen sind die Haupteinfallstore; dazu kommt die Unmenge schlecht übersetzter Bücher mit ihrer Unzahl geistlos übernommener Fremdwörter. Daß man diesen Fremdwörterunsinn nicht mitmachen muß, wenn man nicht will, beweisen gelegentliche Ausnahmen auf allen Gebieten (Heeger 1966b: 15).

Zwischenzeitlich wurde es ruhig um den Verein für Sprachpflege. 1970 wurde er in „Muttersprache“ umbenannt (vgl. Wiechers 2004: 248). Erst im Jahr 2000 wurde er wiederbelebt.

Er fungiert seitdem wieder unter dem Namen Verein für Sprachpflege als Herausgeber der Sprachzeitung Deutsche Sprachwelt, einer Print- und Online-Zeitung, deren Internetausgabe mit „Weltnetzausgabe“ bezeichnet wird (Paulwitz 2003). Auf der Homepage der Deutschen Sprachwelt hieß es für eine gewisse Zeit:

Die Mehrheit der Initiatoren war der Ansicht, daß zwecks Wahrung der Unabhängigkeit ein Trägerverein existieren müsse. $\mathrm{Zu}$ diesem Zweck wurde der bereits existierende kleine „Verein für Sprachpflege“ (VfS) neu belebt. Sein Sitz wurde an den Sitz der DEUTSCHEN SPRACHWELT nach Erlangen verlegt (Riebe 2000b). 
Vereinsvorsitzender war zunächst Hans-Manfred Niedetzky, (ehemaliger VDS-Vorsitzender der Region Pforzheim, Nordschwarzwald und Professor für Betriebswirtschaftslehre und Handelsbetriebslehre an der FH Pforzheim (vgl. VDS 2006e). Jetzt ist Thomas Paulwitz ${ }^{194}$ erster Vorsitzender des Vereins. Auch steht er im Impressum der Deutschen Sprachwelt als Herausgeber und Schriftleiter. Mitglieder sind oder zumindest waren nach den Recherchen von Pfalzgraf zudem Stefan Micko und Stefan Wunner. ${ }^{195}$ In der Sprachwissenschaft wird die Deutsche Sprachwelt teilweise als politisch rechtsgerichtet kritisiert (vgl. Pfalzgraf 2006: 248).

Die Vereinsmitglieder agieren öffentlichkeitswirksam: Die Deutsche Sprachwelt schaffte es zum Beispiel im Zuge der FußballEuropameisterschaft mit einer Pressemitteilung über Anglizismen in der Fußball-Sprache in einige der führenden deutschen Medien, darunter das Magazin Quer des Bayerischen Rundfunks (Keienburg 2004). Ebenso verhielt es sich bei der Fußball-Europameisterschaft 2008, als die Deutsche Presseagentur (dpa) eine Meldung über Paulwitz und dessen Kritik an der Sprache Jogi Löws herausgab (Bellinger 2008).

Hauptaufgabe des Vereins ist die Herausgabe der Deutschen Sprachwelt ${ }^{196}$, dies beschreibt Wiechers: „Es handelt sich [...] um einen Zusammenschluss von Vertretern verschiedener Vereine mit dem Ziel,

\footnotetext{
${ }^{194}$ Paulwitz ist Journalist und Historiker. Er ist auf der Homepage der Gesellschaft für Freie Publizistik (GfP) als Magister Thomas Paulwitz bei den Referenten der Gesellschaft aufgeführt (Molau 2006). Das Bundesamt für Verfassungsschutz stuft die GfP als „rechtsextremistische Kulturvereinigung“ ein: „Die ,Gesellschaft für freie Publizistik e.V.' (GfP) unter Leitung von Andreas Molau [...] ist mit etwa 500 Mitgliedern die größte rechtsextremistische Kulturvereinigung. Ihr gehören vor allem Verleger, Buchhändler, Redakteure und Schriftsteller an“ (Bundesministerium des Innern 2007: 130). Im Jahr 2006 distanzierte sich Paulwitz von der NPD (Paulwitz 2006).

${ }^{195}$ Stefan Micko hat nach Pfalzgrafs Recherchen Verbindungen zum Arbeitskreis für Kultur und Geschichte der Österreichischen Landsmannschaft sowie zum Bund für Volksgesundheit (vgl. Pfalzgraf 2006: 103). Stefan Wunner soll nach Pfalzgrafs Recherchen Kontakte zu dem NPD-Anwalt Horst Mahler und zur Kameradschaft Schwerin haben (vgl. u.a. Pfalzgraf 2006: 104ff., vgl. auch SN 2005a: 19). Nach Angaben von Paulwitz hat Wunner nur für ein paar Monate bei der Deutschen Sprachwelt mitgeholfen, und hat für die Arbeit der Sprachwelt keine Bedeutung (E-Mail von Thomas Paulwitz an die Verfasserin, 4. Februar 2010).

${ }^{196}$ Pfalzgraf merkt an, dass er, als er eine Ausgabe der Deutschen Sprachwelt bestellte, auch gleich eine Ausgabe der Monatszeitschrift Eckartbote zugesandt bekam (Pfalzgraf 2003a: 109).
} 
gemeinsam erarbeitete Publikationen zu ermöglichen“ (Wiechers 2001: 157, vgl. Pfalzgraf 2006: 103). Die Deutsche Sprachwelt beschäftigt sich hauptsächlich mit der Anglizismenfrage. Das Lehngut wird gegliedert, dabei werden Lehnwörter (darunter „Keks“ und „Streik“), Lehnbildungen und Lehnschöpfungen in die Kategorie „Nicht zu Engleutsch gehören“ gerechnet. Dagegen wird „Pseudoenglisch“, also nachgeahmte englische Redewendungen als „klassisches Engleutsch“ klassifiziert:

Pseudoenglische Wörter sind im Englischen unbekannt. Deutsche
haben sie nach englischem Vorbild erfunden und damit die ärger-
lichsten engleutschen Wörter geschaffen [...] Je schneller diese Miß-
geburten verschwinden, desto besser (Deutsche Sprachwelt 2003b). ${ }^{197}$

„Nachgeahmte englische Redewendungen“ sind im Deutschen aus Sicht der Deutschen Sprachwelt nicht erwünscht, darunter werden wörtliche Übertragungen englischer Rede, die für den Nichtkundigen nur schwer zu erkennen sind, verstanden. ${ }^{198}$

Um die Vereinsziele umzusetzen, rufen Mitglieder unter anderem zur „Aktion Telephonstörung“, d.h. zu Protestanrufen bei „Sprachpanschern“ auf, mit dem Ziel: „Das schafft Panik und spricht sich in den Firmen, Behörden usw. herum“ (Deutsche Sprachwelt 2000a). Auch offene Briefe an Politikerinnen und Politiker gehören zur Vereinsarbeit (vgl. Deutsche Sprachwelt 2000a). Auf der Homepage findet sich eine Untersuchung von englischsprachiger Werbung in Deutschland der Firma Endmark sowie „Limbergs kleines irritierendes Wörterbuch der denglischen Sprache“, das auf ironisierende Art zeigen will, wie sich unbemerkt Wörter einschleichen, „die ein stabiles Sprachsystem aushöhlen“ (vgl. Limberg 2003). ${ }^{199}$

Der Verein führt jährlich die „Wahl zum Sprachwahrer des Jahres“ durch. Dabei werden jedes Jahr drei Preise vergeben: der Preis des

${ }^{197}$ Vgl. zur Lehngutgliederung Kapitel 1.4.1. Mit „Pseudoenglisch“ wird hier das bezeichnet, was in der Wissenschaft als Scheinentlehnung betrachtet wird (vgl. Kapitel 1.4.1). Der Begriff der „Mißgeburt“ zeigt wieder die Verwendung der Krankheitsmetaphorik. Diese Klassifizierung ist mittlerweile vom Netz, zu finden ist sie noch unter: $<$ web.archive.org/20030219094436/www.deutsche-

sprachwelt.de/engleutsch/wasistengleutsch.shtml> (13. September 2007).

${ }^{198}$ Darauf wird erst in neueren Ansätzen eingegangen, wie in der Gliederung, die Carstensen im Anglizismen-Wörterbuch vorstellt (AWb 1993: 7f., vgl. auch Keßler 2003).

${ }^{199}$ Auch Walter Krämers „Modern Talking auf Deutsch“ kann man über die Deutsche Sprachwelt beziehen (Deutsche Sprachwelt 2007a). 
Rechtschreibwahrers, der des Wortschatzwahrers und der des Sprachstilwahrers. Diese gehen auch an bekannte Persönlichkeiten. Beispielsweise wurde im Jahr 2002 Harald Schmidt der Sprachstilwahrer des Jahres, im Jahr 2000 kam dieser Preis der Frankfurter Allgemeinen Zeitung zu (vgl. Deutsche Sprachwelt 2000b, 2002), im Jahr 2004 bekam der Spiegel-Journalist Bastian Sick den zweiten Preis des Sprachwahrers, Deutsche Sprachwelt 2008). Auch der VDS wurde schon ausgezeichnet, im Jahr 2003 wurde die VDS-Regionalgruppe Stuttgart Wortschatzwahrer des Jahres. Den Sprachwahrer des Jahres 2007 erhielt die Porsche AG (vgl. Deutsche Sprachwelt 2008). ${ }^{200}$

Eine weitere Verbindung zum VDS ist Klaus Däßler. Er schreibt in der DSW Nr. 2 im Artikel „Am Ende führt Euch ein Narr“ über die „weltweite Sprachzerstörung“ (Däßler 2000). Hier klingen auch amerikakritische und amerikafeindliche Töne an:

\begin{abstract}
Was amerikanisch klingt, ruft angenehme, ,weltoffene' Assoziationen hervor. Amismen: Sie sollen in und außerhalb der USA, besonders bei der Jugend, das großartige Gefühl des ,American Way of Life' vermitteln, [...] ungeachtet dessen, daß es diesen ,Way' gar nicht gibt. [...] jeder möchte ein kleiner amistisch-multikultureller (also unkultureller) Disney McMorning sein [...] Damit beginnt dieser vielköpfige Moloch, mit Milliarden aus unserer Tasche gefüttert, die Nationalsprachen aufzufressen. Das ist plötzlich etwas anderes als Lehnwörter, Assimilation, Bereicherung, Sprachdemokratie. Das ist Sprachdiktatur, Unterwanderung, Strukturzerstörung durch eine Macht, die das Geld, das Papier, den Lautsprecher, den Fernsehschirm beherrscht (Däßler 2000).
\end{abstract}

Der Verein ist kein Mitglied im Netzwerk Deutsche Sprache. Als Begründung dafür ist bei Manfred Riebe vom Verein für Rechtschreibung und Sprachpflege zu lesen, dass die Vereine des Netzwerks durch ihr Ein-Punkt-Programm, das sich ausschließlich auf Anglizismen konzentriert, indirekt die Rechtschreibreform förderten (vgl. Riebe o.D.: 7).

Es bestehen aber Verbindungen zwischen dem VRS, dem Verein für Rechtschreibung und Sprachpflege, und dem VfS, zu denen Manfred Riebe, seinerzeit Vorsitzender des Nürnberger VRS, sich auch erklärte: „Wir] halfen [...] dabei, die neue Sprachzeitung die DEUTSCHE SPRACHWELT (DSW) aus der Taufe zu heben [...]“ (zitiert nach Pfalzgraf 2006: 102f.). Auf den VRS wird im folgenden Kapitel eingegangen.

${ }^{200}$ M.W. haben die Preisträger die Preise nicht abgelehnt. 


\title{
1.7.6 Verein für Rechtschreibung und Sprachpflege
}

Der Verein für deutsche Rechtschreibung und Sprachpflege (VRS) wurde am 31. Mai $1997^{201}$ gegründet. Er hat seinen Sitz in Schwaig bei Nürnberg.

In den Statuten des Vereins heißt es:

\begin{abstract}
Wir widmen uns der Sprachpflege, insbesondere dem Erhalt der bewährten deutschen Rechtschreibung. Unsere Anliegen sind vor allem die Kritik an der mißglückten ,Rechtschreibreform' und die Heilung der von ihr angerichteten Schäden, zudem die Kritik an übertriebenem Fremdwörter-Kauderwelsch. Wir treten für eine klare, reiche, bunte und gepflegte Muttersprache ein, so traditionsbewußt wie modern (VRS 2006).
\end{abstract}

Der Verein „widmet sich der Pflege der deutschen Sprache und insbesondere ihrer Rechtschreibung. Er wirkt darauf hin, daß die deutsche Sprache und ihre Rechtschreibung vor willkürlichen Eingriffen geschützt werden“ (VRS 2006).

Wichtigstes Thema der Vereinsarbeit ist die Rechtschreibung (vgl. u.a. Melsa 2003b). Auch der VRS wirbt mit Prominenten für seine Anliegen, ein prominentes Mitglied des Vereins ist beispielsweise der Schriftsteller Siegfried Lenz (VRS 2006).

Der Verein setzt sich für die Pflege der deutschen Sprache im weiteren Sinn ein, so für den sachgerechten Umgang mit Fremdwörtern (VRS 2003a). Eine Definition von Fremdwörtern, bzw. Anglizismen, findet sich jedoch nicht. Zurzeit hat der Verein etwa 200 Mitglieder. ${ }^{202}$ Vorsitzender des VRS ist derzeit Ulrich Brosinsky (vgl. Melsa 2006a). ${ }^{203}$ Manfred Riebe ist Pressesprecher und Schriftführer. Er war lange erster Vorsitzender, und publizierte in dieser Funktion unter anderem auch in der Deutschen Sprachwelt und in der Jungen Freiheit. ${ }^{204}$ Der VRS wird von einem siebenköpfigen Vorstand geleitet (Melsa 2006a). Ebenso wie der

\footnotetext{
${ }^{201}$ Der VRS wurde im gleichen Jahr wie der VDS gegründet.

202 Telefongespräch mit Manfred Riebe, 24. Juli 2008.

${ }^{203}$ Er löste Christian Melsa ab.

${ }^{204}$ Die Junge Freiheit gilt laut dem Verfassungsschutzbericht aus dem Jahr 2000 als Forum für rechte Intellektuelle (vgl. Pfalzgraf 2006: 93f. und Bundesministerium des Innern 2000: 101, vgl. auch ausführlich Pfeiffer, der auf die Nähe der Zeitung zu den Republikanern verweist (Pfeiffer 2000: 219).
} 
Verein für Sprachpflege ist der VRS kein Mitglied im Netzwerk Deutsche Sprache (vgl. Riebe o.D.: 7). Die Vereinsarbeit beschäftigt sich wenig mit dem Thema Anglizismen: Es gibt keine Pressemitteilungen dazu, ein Großteil der Pressemitteilungen hat die Rechtschreibreform zum Thema (Melsa 2006b), ebensowenig gibt es Aktionen zu Anglizismen im Deutschen (Melsa 2003a)205 oder Flugblätter (Melsa 2003c). Riebe äußert sich zu Anglizismen gegenüber der Jungen Freiheit sowie in einem Artikel, ebenfalls in der Jungen Freiheit. In dem Interview mit Riebe finden sich auch Seitenhiebe auf den VDS. ${ }^{206}$ Einer lautet folgendermaßen:

Im Gegensatz zum ,Sprachpanscher'-Negativ-Preis des VDS setzen wir auf einen ,Sprachwahrer'-Positiv-Preis für Leute, die sich um die Wahrung unserer Sprache besonders verdient gemacht haben. Wir wollen weder populistisch noch puristisch übertreiben und Sprachverhunzer nicht als ,Sprachpanscher' verunglimpfen, sondern weiterhin geduldige Aufklärungsarbeit leisten (Riebe 2000a: 4, vgl. auch Pfalzgraf 2003a: 108).

Trotz allem verlinkt die Homepage des VRS aber auf die des VDS (Melsa 2007). Wichtigstes Anliegen des Vereins ist es zu informieren, die Vereinsarbeit konzentriert sich auf das Internet. Dabei sind sowohl die Internetseiten des Vereins als auch Wikipedia und das Frankenwiki wichtige Medien für den Verein. ${ }^{207}$

Der VRS ist Herausgeber des Büchleins: „Engleutsch, Nein Danke! Wie sag ich's auf deutsch? Ein Volks-Wörterbuch“ von Micko und Paulwitz und ist auch finanziell an der Publikation beteiligt. ${ }^{208}$ Dabei handelt es sich um einen Leitfaden zur Verdeutschung englischer Ausdrücke. Die Autoren sind der Auffassung, englische Wörter sollten durch deutsche

205 Dies ist der Stand im November 2008, seit 2006 sind keine neuen Aktionen auf der Homepage verzeichnet.

${ }^{206}$ Details dazu sind im Forum des VDS und im Rechtschreibforum des VRS nachzulesen, und bei Pfalzgraf 2006: 95)

${ }^{207}$ Informationen von Manfred Riebe. Bei der deutschsprachigen Wikipedia ist Manfred Riebe mit seinem Klarnamen inzwischen gesperrt, er arbeitet aber unter Pseudonym weiter (Telefongespräch mit Manfred Riebe, 24. Juli 2008).

${ }^{208}$ Vgl. dazu Pfalzgraf (2003a: 112), auch zu den Hintergründen des Arbeitskreises für Kultur und Geschichte, in dessen Auftrag das Buch geschrieben wurde, und der sich zusammen mit der Österreichischen Landsmannschaft gebildet habe. „Engleutsch, Nein Danke!“ wurde allein in der ersten Auflage über 33000 mal verkauft (Klein 2001). 
ersetzt werden, wobei sie die jeweilige Kommunikationssituation außer acht lassen, wie Wiechers zu recht kritisiert (vgl. Wiechers 2001: 157). ${ }^{209}$

Pfalzgraf verweist hierbei auf Widersprüchlichkeiten in der Argumentation des VRS: Obwohl der VRS eine Eindeutschung von Anglizismen mehrfach ablehnt, unterstützt er die Publikation von Micko und Paulwitz, deren Hauptinhalt eine Wörterliste zur Verdeutschung von Anglizismen ist (vgl. Pfalzgraf 2003a: 112). Kritisiert wird am VRS eine "gewisse[ ] Affinität $\mathrm{zu}$ politisch rechtsgerichteten Gruppen“ (Pfalzgraf 2003a: 110).

\subsubsection{Bund für deutsche Schrift und Sprache}

Der Bund für deutsche Schrift und Sprache (BfdS) mit Sitz in Ahlhorn war 1918 unter dem Namen Bund für deutsche Schrift gegründet und 1941 aufgelöst worden. ${ }^{210}$ Im Jahr 1951 kam es zur Wiedergründung des Vereins. Derzeit ist Hanno Blohm 1. Vorsitzer des Bundes mit etwa 950 Mitgliedern im gesamten deutschen Sprachraum und einzelnen Mitgliedern im Ausland. Dazu kommen 400 Bezieher der Vereinszeitschrift Die deutsche Schrift. ${ }^{211}$ Der BfdS ist also nur eine kleine Organisation. ${ }^{212}$ Die Vereinszeitschrift erscheint vierteljährlich, sie hat den Untertitel „Blätter zur Förderung des Schriftwesens“. Zudem präsentiert sich der BfdS mit einer professionell gestalteten Internetpräsenz der Öffentlichkeit (vgl. auch Pfalzgraf 2006: 130). In den Statuten des BfdS ist festgehalten:

\footnotetext{
${ }^{209}$ Auf der Homepage findet sich noch der Hinweis, dass Stefan Micko und Thomas Paulwitz Mitglieder des VRS sind (vgl. Melsa 2007 und Kapitel 1.9.4). Dort findet sich auch ein Hinweis auf Hans-Manfred Niedetzky (vgl. VRS 2003b).

${ }^{210}$ Auffällig ist, dass es heißt: „1941 zur Auflösung gezwungen“, und damit auf die Nationalsozialisten verwiesen wird (vgl. Blohm 2007). Dies impliziert auch den Hinweis auf das im Januar 1941 erlassene Verbot der Fraktur durch Adolf Hitler (vgl. Hartmann 1999: 258, vgl. zur Fraktur u.a. Domke 1999 sowie die Arbeiten von Peter Rück 1993a und 1993b). Dennoch kann davon nicht auf die Haltung des BfdS zur Zeit des Nationalsozialismus geschlossen werden (vgl. zur Rolle des BfdS in der Zeit des Nationalsozialismus ausführlich Hartmann 1999: 193ff).

${ }^{211}$ Nach eigenen Angaben ist auch Thomas Paulwitz dem BdfS verbunden (E-Mail von Thomas Paulwitz an die Verfasserin, 8. Februar 2010).

${ }^{212}$ Clay verweist bereits 1981 darauf, dass der BfdS aufgrund seiner konservativen Haltung nur schwer junge Mitglieder findet (Clay 1981: 151f.).
} 
Der Bund für deutsche Schrift und Sprache tritt für die Pflege und Verbreitung der deutschen Druck- und Schreibschriften ein. [...] Der BfdS setzt sich für die Pflege und den Schutz der deutschen Sprache ein [...] (Blohm 2003a). ${ }^{213}$

Um die deutsche Schrift zu fördern, hat der Bund im Jahr 1993 auch die Stiftung Deutsche Schrift gegründet, diese ist seit 2001 unter www.deutscheschrift.de online zu erreichen (vgl. Blohm 2008). Die Mitglieder des BfdS sehen es als ihre Aufgabe an, „die Allgemeinbildung zu fördern und dadurch den Zugang $\mathrm{zu}$ geschichtlichem deutschen Kulturgut in Archiven und Büchereien zu erleichtern“. Dies geht aus einem Schreiben des Vorsitzenden an Silke Wiechers hervor (vgl. Wiechers 2001: 150). In der Zeitschrift des Bundes Die deutsche Schrift wird zu den Schwerpunkten der Vereinsarbeit Stellung bezogen:

Schwerpunkt unserer Vereinsarbeit und damit auch der Zeitschrift sind die beiden wesentlichen Grundpfeiler deutscher Kultur - Schrift und Sprache -, die angesichts unserer heutigen Schnellebigkeit und maßlosen Überbewertung zivilisatorischer Errungenschaften und der damit verbundenen Internationalisierung in Gefahr gekommen sind (Brunow 1990/1991: 2).

Die Fremdwortdiskussion beziehungsweise die Diskussion um die Anglizismen im Deutschen steht nicht unbedingt im Vordergrund der Vereinsarbeit. Die Organisation bemüht sich mehr, die Rechtschreibreform aufzuhalten. Es sei hierzu auf die Untersuchung von Silvia Hartmann verwiesen, die feststellt:

Hierbei mutet der Versuch der Vereinsleitung, eine direkte Verbindung zwischen der gegenwärtigen Rechtschreibreform und Reformplänen der Nationalsozialisten im Dritten Reich herzustellen, angesichts der Geschichte des Bundes für deutsche Schrift geradezu peinlich an (Hartmann 1999: 317).

Dennoch ist die Fremdwortarbeit ein wichtiger Punkt. ${ }^{214}$ Der BfdS schreibt beispielsweise:

In den letzten Jahrzehnten wurde unsere Muttersprache zunehmend mit neuen Fremdwörtern - vorwiegend englisch-amerikanischer Herkunft - überschwemmt. Wir wenden uns gegen diese offenbar

${ }^{213}$ Mittlerweile gibt der BfdS seine Satzung nicht mehr heraus (E-Mail von Elke Blohm, BfdS, an die Verfasserin, 5. Mai 2008).

${ }^{214}$ Auf der Homepage ist zu lesen: „Unter besonderem Einfluß des Anglo-

Amerikanischen wird die deutsche Sprache immer stärker durch Fremdwörter überlagert“. Dies führe zu „Sprachverwilderung“ (Blohm 2003a). In einem Werbeprospekt des Bundes heißt es: „Wie eine Seuche greift nun schon seit Jahrzehnten die Fremdwortsucht um sich“ (BfdS 2000). 
gezielte Entwicklung. Fremdwörter sind nur dann eine Bereicherung, wenn es dafür keinen deutschen Ausdruck gibt (BfdS 2000).

Es ist zu fragen, was der BfdS mit „offenbar gezielte[r] Entwicklung“ meint. Anscheinend wird von einer gezielten Steuerung der Sprache durch hier nicht weiter definierte Personen oder Personengruppen ausgegangen. An späterer Stelle nennt der BfdS die seiner Meinung nach Verantwortlichen:

Die Deutsche Bahn AG und die Deutsche Post führen laufend neue Fremd- und Dummwörter ein. Gesetz und Verordnungsgeber tragen ebenso zur Sprachverwilderung bei wie Funk, Fernsehen, Zeitungsverleger und verantwortungslose Pädagogen. Geradezu ein Tummelplatz des Sprachmißbrauchs ist die Werbung (BfdS 2000).

In Stellungnahmen zu Anglizismen wird immer wieder auf das nach Meinung der Verfasser fehlende Selbstbewusstsein der Deutschen hingewiesen. Unter anderem spricht Wolfgang Hendlmeier in seinem Beitrag: „Sprachpflege einst und heute“ von den Deutschen als schützenswerter „völkische[r] Einheit“ (Hendlmeier 1991: 14) und führt den Zweiten Weltkrieg als Ursache für die englischsprachigen Einflüsse auf die deutsche Sprache an. ${ }^{215}$

Der BfdS vertreibt auch Bücher: Eines trägt den Titel „Glanz und Elend der deutschen Sprache: Die englische Krankheit" und ist von Richard W. Eichler. ${ }^{216}$ Gedruckt ist es in Fraktur. Im Text heißt es unter anderem: „Das Übel der Fremdländerei und der Modetorheiten ist nicht neu“ (Eichler 1994: 8) oder:

Der Spott über $>>$ Sprachpuristen $<<$, den jene üben, die sich gern das Mäntelchen des Progressismus umhängen und noch nie begriffen haben, wo der Fortschritt wirklich liegen könnte, fällt neuerdings nicht mehr so leicht. Unsere selbstbewußten französischen Nachbarn scheuen sich nämlich nicht, der Flut oft gedankenloser angelsächsischer Neuwörter sogar mit gesetzlichen Mitteln entgegenzutreten (Eichler 1994: 9).

215 Dieser Artikel hat insgesamt einen „mehr oder minder offen nationalistischrassistischen Tenor in seiner Argumentation“ (Pfalzgraf 2006: 140f.). Neben Hendlmeiers Klage über „Liberalismus, Völker- und Rassenvermischung“, auf die Pfalzgraf verweist, konstatiert er in seiner Untersuchung eine „trotzig-naive Selbstaufwertung der Deutschen“ (vgl. Pfalzgraf 2006: 140).

${ }^{216}$ Prof. Richard W. Eichler wird in einer Liste der bekanntesten Namen des österreichischen und deutschen Rechtsextremismus und Neonazismus geführt (DÖW 2002, vgl. zu Eichler auch Mecklenburg 1996: 456). 
Der Autor spricht also von Fremdwörtern als „Flut“, die das Deutsche überschwemmt, und der man nur mit Mitteln der Gesetzgebung entgegentreten kann (vgl. Eichler 1994: 9). Weiter schreibt Eichler:

\begin{abstract}
Von den großen Völkern Westeuropas haben allein die Deutschen ein aus eigenem Stamm hergeleitetes, lückenlos vererbtes Wortgut. Das der Engländer besteht etwa zur Hälfte aus germanischen Wörtern (für den intimen Lebensbereich) und, von den Normannen vermittelt, solchen aus romanischer Quelle (für die kulturellen Begriffe). Die Franzosen und Spanier sind insgesamt Erben des römischen Weltreiches. [...Dass] im Einzelfall das Englische im Begriff window (Windauge) das schönere Wort besitzt im Vergleich zu Fenster (fenestra), bleibt die Ausnahme. Dieser Vorzug der Ursprünglichkeit bürdet uns die Verpflichtung zu ihrer Erhaltung auf (Eichler 1994: 1f.).
\end{abstract}

Hier wird die deutsche Sprache im Vergleich zu anderen Sprachen Westeuropas hervorgehoben, durch den „Vorzug der Ursprünglichkeit“. 217

Daneben existiert eine weitere Publikation: „Verlust der Sprache - Zur Überfremdung des Deutschen“, Autor ist Hartwig Wilde. Er beklagt unter anderem das „Sprachfieber“ (Wilde 2001: 7) und seine Folgen und äußert die Befürchtung, dass sich das deutsche Volk „als Kulturnation aufgibt“ (Wilde 2001: 12). Einem Sprachgesetz steht Wilde positiv gegenüber (vgl. Wilde 2001: 9), außerdem schlägt er die Gründung einer deutschen Sprachakademie vor (vgl. Wilde 2001: 12). Zudem beklagt er sich, dass jeder, der sich mit dem Thema beschäftigt, gleich als rechts gilt, und schreibt: „Manchmal denke ich schon resignierend, ob nicht diese lustvoll betriebene sprachliche Unterwürfigkeit der wahre Preis ist, den wir für diesen Krieg und Auschwitz zahlen müssen“ (Wilde 2001: 7). Im ersten Kapitel zitiert Wilde auch Walter Krämer und sympathisiert mit der Bissigkeit des Sprachkritikers und seinem Ausdruck „Schimpansendeutsch“ (vgl. Wilde 2001: 1, vgl. auch Kapitel 2.4.2). Die Publikation von Wilde ist auch in dem Band „Deutsche Annalen 1995.

217 Die „Ursprünglichkeit“ war von etwa 1550 bis etwa 1800 ein Gemeinplatz. Sie findet sich beispielsweise bei Harsdörffer und Schottelius, aber auch in Johann Gottlieb Fichtes „Reden an die deutsche Nation.“ (vgl. z. B. Siebente Rede. Noch tiefere Erfassung der Ursprünglichkeit und Deutschheit eines Volkes. Erstdruck 1808. In: Fichte 1978: $106 \mathrm{ff}$. vgl. auch Pfalzgraf 2006: 129). 
Jahrbuch des Nationalgeschehens" erschienen. Als Verlag fungiert der Druffel-Verlag. ${ }^{218}$

In dem 2002 veröffentlichten Buch „Sprache und Schriftpflege dienen der Kultur" von Wolfgang Hendlmeier stellt der Autor die Frage, ob es heute überhaupt eine wichtigere Aufgabe als die Sprachpflege geben könne (vgl. Hendlmeier 2002: 3), und beklagt sich über die „standpunktlosen Wissenschaftler" (Hendlmeier 2002: 6). Er bezeichnet die deutsche Sprache als eine „der ehrwürdigsten und ausdrucksstärksten Sprachen der Welt“ (Hendlmeier 2002: 5). Auch er macht den Zweiten Weltkrieg für den derzeitigen Zustand der deutschen Sprache verantwortlich (vgl. Hendlmeier 2002: 5). Interessant ist, dass Hendlmeier, der sich als Sprachpfleger versteht, sich abfällig über Puristen äußert und sie als „Sprachpfleger mit Scheuklappen“ bezeichnet (Hendlmeier 2002: 6). Ihnen wirft er vor, sich auf „Fremd- und Lehnwörter eingeschossen [zu haben]" und mit ihren Wortneuschöpfungen Schmunzeln zu erregen (vgl. Hendlmeier 2002: 6).

Der BfdS, der von Pfalzgraf als politisch rechtsgerichtet kritisiert wird, wendet sich nicht nur gegen Anglizismen, sondern bekämpft auch Fremdwörter aus anderen Sprachen (vgl. Pfalzgraf 2006: 252) ${ }^{219}$ und Wendungen, die dem Inneren Lehngut angehören (vgl. Pfalzgraf 2006: 135 sowie Blohm 2003c). Dies stellt innerhalb der puristischen Vereinigungen eine Ausnahme dar.

Auf seiner Homepage verweist der BfdS ausdrücklich auf andere sprachpflegerische Vereinigungen, allen voran auf den VDS (Blohm 2003d). Außerdem ist der BfdS Mitglied im Netzwerk Deutsche Sprache (Kapitel 1.7.14).

${ }^{218}$ Für diesen Hinweis sei Prof. Dr. Klaus H. Kiefer gedankt, Quelle: Schreiben an Walter Krämer, 26. Februar 1999, vgl. auch Dietzsch/Maegerle 1995. Der Druffel-Verlag, heute „Verlagsgesellschaft Berg“, wird vom Bundesamt für Verfassungsschutz unter „rechtsextremistische Verlage und Vertriebsdienste“ geführt (vgl. Bundesministerium des Innern 2007: 124ff.).

${ }^{219}$ In dieses Bild passt auch die Antwort im Internet auf die Frage (unter den FAQs), warum der Bund für deutsche Schrift und Sprache eine „Nazischrift“ verteidigt. Hier findet sich keinerlei Distanzierung (vgl. Blohm 2003b). Zu einer Darstellung des BfdS, dessen Arbeit und dessen Verhältnis zu den Machthabern in der Zeit des Nationalsozialismus vgl. ausführlich Hartmann (1999: 232ff.). 


\subsubsection{Arbeitskreis Unsere Sprache}

Der „Arbeitskreis Unsere Sprache“ (ARKUS) ist eine Unterabteilung von „Unser Land - Wissenschaftliche Stiftung für Deutschland e.V.“ mit Sitz in Starnberg. Vorstand der Stiftung ist Dr. Alfred Mechtersheimer. ${ }^{220}$ Thomas Paulwitz war kurzzeitig der "Koordinator“ von ARKUS $^{221}$ (vgl. dazu auch Pfalzgraf 2003a: 107).

Auf der Homepage des Vereins, Titel der Internetseite: „Die konservative Informationsbasis im Internet“222 wird zum Boykott von Waren mit nichtdeutscher Werbung aufgefordert:

Wir gehen von dem theoretischen Ansatz aus, wonach weniger gutgemeinte Appelle, als vielmehr ökonomische Zwänge die Verunstalter der deutschen Sprache zu einem Verzicht auf Anglizismen veranlassen werden. Mit einem neuen Sprachbewußtsein kann der Konsument eine Macht von unten entwickeln, die beispielsweise Unternehmen dazu anhält, aus Eigeninteresse ihre Produkte auf Deutsch zu bewerben (Mechtersheimer 2005a).

Es findet sich dort eine „Selbstverpflichtung zum Schutz der deutschen Sprache“ mit zehn Punkten, durch deren Unterschrift man sich unter anderem verpflichtet, „nach Möglichkeit in Wort und Schrift deutsche Bezeichnungen“ zu verwenden, auf Anglizismen zu verzichten, Rundfunkprogramme mit überwiegend englischsprachigen Liedern zu meiden oder „vornehmlich Filme deutscher und europäischer Herkunft“ zu sehen und „auf deutsch beworbene Waren und Dienstleistungen“ zu bevorzugen (vgl. Mechtersheimer 2005b). Die Unterzeichner der Selbstverpflichtung sollen auch bei der Einbürgerung in die Bundesrepublik die Beherrschung der deutschen Sprache einfordern. Des Weiteren sollen sie verlangen, dass Deutsch als gleichberechtigte Sprache sowohl in der EU als auch in der Wissenschaft erhalten wird. Deutsch wird vom Arbeitskreis auch als „Stiefkind in der EU“ bezeichnet (vgl. Mechters-

${ }^{220}$ Mechtersheimer ist nach Angaben des Verfassungsschutzes Bayern auch Vorsitzender der Deutschland-Bewegung, er wird vom Verfassungsschutz 2004 als Rechtsextremist eingestuft (vgl. dazu Bayerisches Staatsministerium des Innern 2004: 124, Pfalzgraf: 2006: 243; Mecklenburg 1996). Für ausführliche Informationen vgl. auch Pfalzgraf 2003a: 115). ${ }^{221}$ Nach Angaben von Paulwitz war dies in der Zeit von Anfang Februar bis zum 2. Mai 1998, er hob im Auftrag der Stiftung ARKUS „aus der Taufe“ (E-Mail von Thomas Paulwitz an die Verfasserin, 8. Februar 2010).

222 Über die Homepage von ARKUS vertreibt Mechtersheimer auch sein Buch mit dem Titel: Handbuch Deutsche Wirtschaft: 5000 Firmen und Heuschrecken?“ (vgl. Mechtersheimer 2007) 
heimer 2005a). Mit der Unterschrift versichert man, sich an Aktionen für die Erhaltung des Deutschen zu beteiligen (vgl. Mechtersheimer 2005b). ARKUS versteht den „Verfall der Sprache“ als „Folge der Globalisierung“.

Zu Anglizismen im Deutschen hat Heinz-Günter Schmitz ${ }^{223}$ im Jahr 1999 die Studie „Die Amerikanisierung und Internationalisierung der deutschen Sprache nach dem Zweiten Weltkrieg“ publiziert. Im Jahr 2006 wurde die überarbeitete Fassung unter dem Titel „Die Globalisierung der deutschen Sprache und der Verlust der Sprachloyalität“ veröffentlicht (vgl. Schmitz 1999, Mechtersheimer 2007). Im Mai 1998 hatte ARKUS zu einer eintägigen Tagung nach Frankfurt eingeladen, an der auch Vertreter des VDS teilnahmen. Darauf wird in Kapitel 1.7.14 eingegangen. Auch der ARKUS wird beispielsweise von Pfalzgraf als politisch rechtsgerichtet kritisiert (vgl. Pfalzgraf 2006: 252).

\subsubsection{Exkurs: Institutionen in Österreich}

\subsubsection{Verein Muttersprache}

Die größte in Österreich ansässige sprachpflegerische Organisation ist der Verein Muttersprache in Wien. 1886 als Verein zur Pflege der deutschen Sprache als Zweig des Allgemeinen Deutschen Sprachvereins gegründet erhielt er schnell Zuwachs. 1914 hatte er 600 Mitglieder, 1935 waren es bereits 3000. Während der Zeit des Zweiten Weltkriegs schränkte der DSV und damit auch der Vereins zur Pflege der deutschen Sprache seine Fremdwortjagd nach einer Rüge von Goebbels stark ein, schließlich wurde die Vereinstätigkeit eingestellt (vgl. Kapitel 1.7.1). Am 23. November 1949 kam es zur Neugründung als Verein Muttersprache. Der Verein versteht sich als eigentlicher Nachfolger des ADSV/DSV. Der GfdS, der offiziellen Nachfolgeorganisation, wirft er

\footnotetext{
${ }^{223}$ Heinz-Günter Schmitz ist emeritierter Professor für Deutsche Philologie am Germanistischen Seminar der Universität Kiel und Vorstandsmitglied der Henning-KaufmannStiftung. Ebenso hat er in Büchern des VDS publiziert und ist Mitglied des wissenschaftlichen Beirats des VDS. Zu dem Nachdruck dieses Aufsatzes kam es durch seine persönliche Bekanntschaft mit Alfred Mechtersheimer. (Telefongespräch mit Heinz-Günter Schmitz, 12. November 2008, vgl. auch Schmitz 2006).
} 
„Rückgratlosigkeit“ vor (vgl. Clay 1981: 101f.). Der Verein Muttersprache ist von einer puristisch-konservativen Einstellung geprägt. Dies spiegelt sich in der Vereinsarbeit wider. Sprachrohr des Vereins sind die seit 1951 erscheinenden Wiener Sprachblätter (seit 1959 erscheinen sie vierteljährlich). Der Verein war wie auch der ADSV/DSV von der Parole: „Kein Fremdwort für das, was deutsch gut ausgedrückt werden kann“ geprägt. Er hatte ein freundschaftliches Verhältnis zu Heinrich Heegers Verein für Sprachpflege (vgl. Clay 1981: 104).

Auf seiner Homepage wurde die Frage gestellt, warum man Fremdwörter „bekämpfen“224 sollte. Als Gründe für die Sprache der „Denglandgecken“ wurde unter anderem „Prahlsucht“ angeführt (vgl. Fischer 2007a). Diese ablehnende Haltung gegenüber Anglizismen wurde vom im Jahr 2000 gewählten Obmann Prof. Heinz Dieter Pohl ${ }^{225}$ etwas differenziert (vgl. Wiechers 2001: 153). Nach ihm hat der Verein zum Ziel, das sprachliche Bewusstsein der Menschen zu schärfen (vgl. Pohl 2000: 72). Es wird bedauert, dass die Rufe nach einer Sprachakademie „unverhört verhallen“ (Fischer 2007a). ${ }^{226}$ Zudem wendet sich der Verein gegen Regionalismen, besonders gegen norddeutsche (vgl. Wiechers 2001: 153). Mittlerweile ist Pohl stellvertretender Obmann, Obmann ist Dr. Franz Rader (Verein Muttersprache 2009). Auf der jetzigen Homepage sind weder Ziele noch Grundlagen des Vereins in irgendeiner Weise zu erkennen (vgl. Verein Muttersprache 2007), dafür werden aber Journalisten als „Sprachunbewusste“ oder „Sprachfeinde“ (Verein Muttersprache 2007) denunziert. Ziele und Aufgaben finden sich ausführlich auf den Seiten der Wiener Sprachblätter. Dort ist zu lesen, dass die Bekämpfung „überflüssiger Fremdwörter“227 ebenso Ziel des Vereins ist wie die Sprachkritik gegenüber Presse und Rundfunk, das Festhalten an der

${ }^{224}$ Diese Kriegsmetaphorik findet sich des öfteren: „[...] Univ-Prof. Dr. med. Ludwig Prokop schilderte Leben und Werk Mehls und rühmte,seinen geradezu fanatischen Kampf um die Reinhaltung und Erhaltung der deutschen Sprache' [...]“ (vgl. Verein Muttersprache 2007)

${ }^{225}$ Heinz Dieter Pohl war seit 1979 Professor für Allgemeine und Diachrone Sprachwissenschaft an der Universität Klagenfurt, seit Oktober 2007 ist er emeritiert (vgl. Pohl 2008). ${ }^{226}$ Gemeint ist „ungehört“. Für einen Sprachpflegeverein enthält die Homepage auffallend viele grammatische Fehler, außerdem ist sie für Nicht-Vereinsmitglieder völlig undurchsichtig. Einige Artikel sind nicht mehr online (Stand September 2007).

${ }^{227}$ Welche Fremdwörter als überflüssig zu sehen sind, ist nicht definiert, Wörter aus der Wissenschaftssprache aber sind erlaubt. 
alten Rechtschreibung sowie die Pflege der alten Schriften. Weiter heißt es:

Der Verein dient zur Pflege unserer deutschen Muttersprache. Er will Liebe und tieferes Verständnis für die in der Sprache schlummernden Schätze wecken und damit den Sinn für ihre Richtigkeit, Reinheit (Vermeidung entbehrlicher Fremdwörter) und Schönheit schärfen. Diese Pflege im weitesten Sinne umschliesst auch das gesprochene Wort (Sprecherziehung), die deutsche Schrift und die Rechtschreibung. Der Verein will die Sprachfreunde aus allen Lagern auf dem gemeinsamen Boden der Muttersprache sammeln und lässt daher alles Trennende unberührt, sofern es außerhalb der Sprachpflege liegt (z.B. parteipolitischer oder weltanschaulicher Art) (Fischer 2007b).

Interessant ist, dass Stefan Micko ${ }^{228}$ auch Mitglied dieses Vereins ist (und Obmann, also Vorsitzender war), und eine Zusammenarbeit mit dem Nürnberger Verein für deutsche Rechtschreibung und Sprachpflege angeregt hat (dies geht aus einem Rundschreiben an die Mitglieder des VRS vom September 1998 hervor, das auch an den VDS gegangen ist (vgl. VRS 1998)).

Der Verein Muttersprache ist der größte und aktivste sprachpflegerische Verein in Österreich. Daneben existieren noch einige kleinere Vereinigungen wie der Deutsche Sprachverein in der Steiermark, auf die jedoch in diesem Exkurs nicht weiter eingegangen wird. Nur die Interessengemeinschaft Muttersprache in Österreich Graz e.V. soll noch kurz vorgestellt werden.

\subsubsection{Interessengemeinschaft Muttersprache}

Die Interessengemeinschaft Muttersprache in Österreich Graz e.V. wurde 1998 gegründet und ist ein Verein, der laut Satzung folgendes Ziel hat:

Die Erhaltung und Pflege der deutschen Muttersprache und ihre Befreiung von jeglicher Neuerungssucht, von der die Betroffenen irrtümlich meinen, diese können eine Offenheit für internationale Verständigung beweisen (Pfannhauser 1998a).

Hier spricht der Verein von seiner Ansicht nach überflüssigen Anglizismen und führt als Beispiel auf: 
[Die] Benützung von - oft sogar falschen - Wortkonstruktionen, die zwar englisch klingen, aber im heutigen Englisch gar nicht vorkommen und [die] oft gedanken-, sinnlosen und nur vermeintliche[n] „Schmückung“ deutschen Textes mit englischen/amerikanischen Wörtern und/oder Texten - oder durch Ersatz deutschen Textes durch englische/amerikanische Wörter und/oder Texte (Pfannhauser 1998a).

In diesen kurzen Auszügen klingt schon durch die Krankheitsmetapher „Neuerungssucht“ an, welche Empörung die Verfasser gegenüber Anglizismen verspüren. Es handelt sich um eine reine Ablehnung von Anglizismen. Gräzismen oder Latinismen werden von der Interessengemeinschaft durchaus verwendet, wobei die Verfasser Wert darauf legen, dass sie die englische Sprache an sich nicht ablehnen (vgl. dazu Wiechers 2001: 152). Wiechers konstatiert zu Recht den missionarischen Eifer der sich kämpferisch äußernden Vereinsmitglieder, der sich auch auf die alte Argumentation des Allgemeinen Deutschen Sprachvereins stützt: „Als Richtschnur dient: Kein Fremdwort für das, was treffend deutsch ausgedrückt werden kann“ (Pfannhauser 1998a), und wirft dem Verein vor, dass es eine Definition dessen, was „treffend deutsch“ bedeutet, nicht gibt (Wiechers 2001: 152).

Das Vereinsziel soll erreicht werden durch „gezielte Förderungsmaßnahmen aller Aktivitäten, die dem Vereinszweck dienlich sind“ (Pfannhauser 1998a), durch öffentlichkeitswirksame Veranstaltungen und durch Publikationen. Unter anderem sollen Politiker, Ämter und Behörden und Institutionen vor allem aus dem kulturellen Bereich auf das Anliegen des Vereins aufmerksam gemacht werden. Das gleiche gilt für Unternehmen: Die IG Muttersprache zeichnet zum Beispiel immer wieder Firmen für Werbung und Kataloge in deutscher Sprache aus (Kartnig 2007: 6f.). Der Vereinsvorsitzende (Obmann des Vereins), Prof. Werner Pfannhauser ${ }^{229}$, stellt in seinen Ausführungen einen Zusammenhang zwischen der Verwendung von Anglizismen und politischer

\footnotetext{
${ }^{229}$ Werner Pfannhauser ist Ehrenobmann des Österreichischen Turnbundes, der gemeinsam mit der Österreichischen Landsmannschaft Sonnwendfeiern organisiert. Im Jahr 2003 war Werner Pfannhauser Festredner bei der Sonnwendfeier am 21. Juni auf dem Cobenzl (vgl. Wiener Nachrichten Online 2003, die Wiener Nachrichten Online werden vom DÖW als rechtsextrem eingestuft, vgl. DÖW 2006a). Auch ansonsten arbeiten der ÖTB und die Österreichische Landsmannschaft zusammen (vgl. ÖTB 2008). Aus dieser Kooperation gibt es auch eine Publikation von Pfannhauser (1976), zu Pfannhauser siehe auch Eckartbote (1999: 7).
} 
Unterordnung her, womit der Sprachpflege eine politische Dimension zugewiesen wird (vgl. Wiechers 2001: 153). Organ des Vereins ist die Zeitung Unsere Muttersprache, deren Ausgaben seit 2002 auch im Internet abrufbar sind (Pfannhauser 1998b). Diese wird alle drei Monate an rund 800 Personen verschickt. ${ }^{230}$

Die Interessengemeinschaft Muttersprache ist oder war Mitglied im Netzwerk Deutsche Sprache. ${ }^{231}$ Pfannhauser war bei Gründung des Netzwerks die treibende Kraft (VDS 2003b) und Gastgeber der ersten Tagung des Netzwerks in Graz im Jahr 1999 (Pfannhauser 1999). Die IG Muttersprache hat derzeit rund 600 Mitglieder. ${ }^{232}$

\subsubsection{Exkurs: Institutionen in der Schweiz}

In der Schweiz gibt es ebenfalls einige sprachpflegerische Vereinigungen. Nicht eingehen möchte ich auf die Deutsch-Freiburgische Arbeitsgemeinschaft, da Anglizismen in der Arbeit der Arbeitsgemeinschaft keine Rolle spielen. ${ }^{233}$ Auch in der Arbeit des Rottenbundes spielt die Fremdwortarbeit keine Rolle. ${ }^{234}$ So bleiben der Schweizerische Verein für die deutsche Sprache (SVDS) und der Sprachkreis Deutsch.

\subsubsection{Schweizerischer Verein für die deutsche Sprache}

Der SVDS, gegründet als Deutsch-Schweizerischer Sprachverein (DSSV), kann als schweizerischer Ableger des ADSV/DSV angesehen werden, wenn auch nicht im rechtlichen, so doch im geistigen Sinn (vgl.

\footnotetext{
230 Telefongespräch mit Helmut Heiter von der IG Muttersprache, 11. September 2007.

${ }^{231}$ Zumindest war sie Mitglied, wenn man davon ausgeht, dass das Netzwerk nicht mehr aktiv ist.

232 Telefongespräch mit Helmut Heiter von der IG Muttersprache, 11. September 2007. Die Differenz zeigt, dass die Vereinigung neben ihren 600 Mitgliedern noch rund 200 Interessenten hat.

${ }^{233}$ Dementsprechend gibt es auch keine Stellungnahme zu Anglizismen in der deutschen Sprache und keine Veröffentlichungen der Arbeitsgemeinschaft, die Anglizismen zum Thema haben. Ziele der Arbeitsgemeinschaft sind: „Die Pflege der deutschen Sprache (Hochsprache und Mundarten). Die Förderung der Kultur und des kulturellen Lebens in Deutschfreiburg. Die Wahrung der Rechte der deutschen Sprachgemeinschaft im Kanton Freiburg. Die Förderung der Verständigung zwischen den Sprachgemeinschaften und der Zweisprachigkeit [...]" (Deutsch-Freiburgische Arbeitsgemeinschaft 2002).

${ }^{234}$ Vgl. z.B. Rash (2006).
} 
Weber 1984: 8). Gerade in den frühen Schriften sind einige der Argumente des ADSV/DSV wiederzuerkennen (vgl. Rash 2002: 82). Der SVDS wurde im Jahr 1904 gegründet (Umbenennung 1994, vgl. Wyss 2005: 12), und hat Zweigstellen in Bern (Verein für Deutsche Sprache, gegründet 1912), Zürich (Züricher Sprachverein, gegründet 1943), Luzern (Gesellschaft für deutsche Sprache, gegründet 1956) und Basel (Basler Sprachverein, wiedergegründet 1959) (vgl. Rash 2001: 255). Ziel des SVDS ist „die Pflege der Muttersprache in ihren beiden Formen Hochdeutsch und Mundarten sowie die Wahrung des Sprachfriedens in der Schweiz“ (SVDS 2007a). Dabei will der SVDS „mit seinen Aktivitäten und Angeboten zu einem sorgfältigen und formfrohen Umgang mit der Sprache [...] beitragen“ (SVDS 2007a). ${ }^{235}$ Organ des Vereins ist der Sprachspiegel (von 1917 bis 1944 Mitteilungen des Deutschschweizerischen Sprachvereins, vgl. Rash 1998: 91, 2002: 81), eine Zeitschrift, die zweimonatlich erscheint. Er enthält nach Angaben des SVDS

Beiträge [...] zur Sprache, zur Entwicklung der deutschen Sprache, Informationen zur Sprachpolitik und einen beliebten $>$ Briefkasten $<$, in dem knifflige Fragen zu Grammatik und Orthographie kompetent beantwortet werden (SVDS 2007b).

Zudem ist der Sprachspiegel nach eigenen Angaben „strenger Wissenschaft verpflichtet“ (SVDS 2007b). Doch diese Wissenschaftlichkeit sieht beispielsweise Rash in ihrer Untersuchung des Sprachspiegels gerade nicht:

Der Sprachspiegel, the journal of the Deutschschweizerischer Sprachverein, regularly publishes articles describing English influences on Swiss Standard German. These are frequently impressionistic in nature and many display a marked puristic bias (Rash 2006).

Neben der Publikation von Büchern und der Zeitschrift Sprachspiegel erteilt der Verein kostenlos Sprachauskunft (SVDS 2007a) und rät, wenn man diese in Anspruch nimmt, zur Vermeidung von Fremdwörtern (vgl. Rash 1998: 93). Insgesamt konstatiert Rash, dass die Ziele des Vereins als sprachpuristisch verstanden werden können (vgl. Rash 1998: 91ff., 2002: 81). Auf den aktuellen Internetseiten des Vereins sind puris-

${ }^{235}$ Hier zeigt sich, dass sich die Ziele des Vereins verändert haben: Weber weist darauf hin, dass in der bis 1940 gültigen Satzung des damals noch DSSV „Reinheit, Eigenart und Schönheit der deutschen Sprache zu pflegen“ waren und dies durchaus als Sprachpurismus zu werten sei (vgl. Weber 1984: 6f.). 
tische Ansätze jedoch nicht auszumachen. Präsident des Vereins ist Johannes Wyss. Der Verein hat derzeit rund 1200 bis 1300 Mitglieder. ${ }^{236}$ Auch hat er einige Partnergesellschaften. In Deutschland ist dies die GfdS $^{237}$ (SVDS 2007c).

\subsubsection{Sprachkreis Deutsch}

Der Sprachkreis Deutsch (SKD), hervorgegangen aus der 1947 gegründeten Bubenberg-Gesellschaft - bis 1999 ist er unter diesem Namen in Erscheinung getreten (Zbinden 2007: 63) - hat seinen Vereinssitz in Bern. Zum Ziel der Vereinigung heißt es in den Statuten:

Für die Erhaltung der sprachlichen und kulturellen Vielfalt Europas.

Für die Landessprachen der Schweiz. Für gutes Deutsch und weniger Anglizismen (SKD 2006a). ${ }^{238}$

Dabei ist das Anliegen der Mitglieder des Sprachkreises Deutsch ein „überlegte[r] Umgang mit Anglizismen und Amerikanismen“ (SKD 2006b). Gegenwärtig hat der Sprachkreis rund 300 Mitglieder. ${ }^{239}$

Der Sprachkreis Deutsch ist ein politisch und konfessionell neutraler Verein „zur Pflege von Hochdeutsch und Mundart in der (deutschen) Schweiz“ (SKD 2006a), zu dessen Zielen es auch gehört, sich "gegen den übermässigen Gebrauch von Anglizismen und Amerikanismen [zu wehren]“ (vgl. SKD 2003a).

Im Leitbild findet sich eine Stellungnahme zu Anglizismen und Amerikanismen im Deutschen:

Sondersprachen und Übernahme fremden Wortgutes sollen möglich sein. Neues darf Platz finden, damit die Sprache mit uns lebt, jung bleibt und sich den Gegebenheiten der Zeit in vernünftiger Form anpasst. Der Wert des Beständigen muss jedoch erkannt und erhalten bleiben. Die Sprachgenerationen sollen miteinander und nicht gegeneinander antreten und für eine gepflegte und gewandte sprachliche Verständigung einstehen (SKD 2003a).

In der Anglizismenfrage wird also eine differenzierte Haltung angestrebt, dies zeigt zumindest ein Bemühen, Kommunikationszusam-

\footnotetext{
236 Telefongespräch mit Peter Heisch, Aktuar des SVDS, 11. September 2007.

${ }^{237}$ Bisher gibt es keine Zusammenarbeit mit dem VDS. Dafür gibt es nach Auskunft von Peter Heisch aber keinen besonderen Grund, dies habe sich einfach nicht ergeben (Telefongespräch mit Peter Heisch, Aktuar des SVDS, 11. September 2007).

${ }^{238}$ Vgl. auch SKD (2002).

${ }^{239}$ Telefongespräch mit Peter Zbinden am 17. April 2008.
} 
menhänge zu berücksichtigen und Anglizismen nicht pauschal abzulehnen (vgl. Wiechers 2001: 151). Der Präsident des Vereins Peter Zbinden beschreibt das Vorgehen des Sprachkreises nach 1999, das er als Jahr des Richtungswechsels ansieht, folgendermaßen: „Die kritische Beurteilung von Englisch trat an die Stelle derjenigen von Französisch, das ja auch gegen die Wogen des "global english“ kämpft" (Zbinden 2007: 63). ${ }^{240} \mathrm{Um}$ ihre Ziele $\mathrm{zu}$ erreichen, wollen die Mitglieder des Sprachkreises Deutsch „kämpfen“ (SKD 2003a), wobei dies wieder relativiert wird:

Allerdings soll der Kampf mit Argumenten, Fakten und Erklärungen so ausgefochten werden, dass die Meinungen und Ansichten anderer durchaus respektiert werden: im Sinne eines [...] mit Spass und Freude geführten Wettkampfes [...] (SKD 2003a).

Der Sprachkreis Deutsch organisiert unter anderem Podiumsdiskussionen, Vorträge und Diskussionsabende und veröffentlicht vier Mal jährlich die Vereinszeitschrift: „Mitteilungen“, in der Anglizismen immer wieder Thema sind.

Auch arbeitet der Sprachkreis Deutsch mit dem VDS im Netzwerk Deutsche Sprache zusammen, er war eines der Gründungsmitglieder des Netzwerks (vgl. SKD 2006b und Kapitel 1.7.10.2). Der VDS ist damit als Organisation ebenso wie alle anderen Organisationen des Netzwerks stimmberechtigtes Mitglied im Sprachkreis Deutsch. Der Sprachkreis Deutsch wirbt außerdem für den Anglizismen-Index des VDS auf seiner Homepage, und arbeitet im VDS-Arbeitskreis Wörterliste mit (vgl. Zbinden 2007: 68). Auf Aktionen der Stiftung deutsche Sprache weist er hin, zudem haben Vertreter des SKD auch am zweiten Köthener Sprachtag der Neuen Fruchtbringenden Gesellschaft teilgenommen (vgl. SKD 2008a sowie Kapitel 1.7.15). Partnervereine sind unter anderem die IG Muttersprache sowie der Verein Muttersprache (vgl. SKD 2008b).

${ }^{240}$ Zbinden beschreibt, dass im Jahr 1999 die damalige Bubenberg-Gesellschaft in einer Krise steckte, unter anderem wegen Überalterung und einer überholten Anti-FranzösischHaltung, und dass seine Korrespondenz mit Walter Krämer im SKD die Neuorientierung des Vereins bewirkte (vgl. Zbinden 2007: 64f.) 


\subsubsection{Stiftungen}

In Deutschland gibt es auch Stiftungen, die Arbeiten zum Thema Sprachpflege fördern beziehungsweise Preise für Sprachpflege vergeben. Diese sollen hier kurz vorgestellt werden. Nicht behandelt wird an dieser Stelle die Stiftung Deutsche Sprache. Diese wird als eine aus und mit dem Verein Deutsche Sprache entstandene Stiftung verstanden und deshalb unter dem Kapitel des Vereins Deutsche Sprache ausführlich vorgestellt.

\subsubsection{Theo-Münch-Stiftung}

Die Theo-Münch-Stiftung gibt es seit 2002, Stifter ist der Rechtsanwalt Theo Münch. Die Stiftung, die ihren Sitz in Düsseldorf hat, ,verfolgt das Ziel, die deutsche Sprache als eigenständige Kultursprache zu erhalten und weiterzuentwickeln“ (dsw 2005). Sie hat in Kooperation mit dem VDS und der Eberhard-Schöck-Stiftung bis 2005 den Kulturpreis Deutsche Sprache verliehen. Mittlerweile ist sie an dieser Preisverleihung nicht mehr beteiligt. ${ }^{241}$ Stattdessen wurde ein Theo-Münch-Sprachpreis eingerichtet. Vertreten wird die Stiftung durch den Vorsitzenden Prof. Dr. Hans-Manfred Niedetzky, durch Hans-Joachim Böhme als Stellvertreter sowie durch Dr. Bernd Fischer (vgl. Innenministerium NordrheinWestfalen 2008). Stiftungszwecke sind Wissenschaft und Forschung, Bildung, Erziehung und Ausbildung.

\subsubsection{Henning-Kaufmann-Stiftung}

Die Henning-Kaufmann-Stiftung zur Pflege der Reinheit der deutschen Sprache wurde im Jahr 1983 als Stiftung zur Pflege der deutschen Sprache im Stifterverband für die Deutsche Wissenschaft in Essen gegründet. Die Stiftung ist eine Nachlass-Stiftung des Gymnasiallehrers und Namensforschers Dr. Henning Kaufmann (1897 bis 1980). Sie will

\footnotetext{
${ }^{241}$ Seit dem Jahr 2005 besteht keinerlei Kooperation mehr zwischen der Theo-MünchStiftung und dem VDS. Diese Angabe stammt von Walter Krämer, aus einer E-Mail von Christiane Dahl, Mitarbeiterin der VDS-Geschäftsstelle, an die Verfasserin, 12. Oktober 2007. Grund dafür waren laut Holger Klatte „inhaltliche Unstimmigkeiten“ (E-Mail von Holger Klatte, VDS-Geschäftsführer, an die Verfasserin, 18. November 2009).
} 
an die lange Tradition deutscher Sprachpflege und Sprachkritik anknüpfen und im Geist der Treue zur eigenen Sprache auf einen sorgfältigen Sprachgebrauch, ein gutes und verständliches Deutsch hinwirken (Knoop 2007b: 43).

Purismus wird verstanden

nicht im Sinne eines strengen Purismus, der alle fremdsprachlichen Einflüsse unterschiedslos bekämpft, aber doch im Siunne [sic!] eines gemäßigten Purismus, der überhandnehmende fremdsprachliche Einflüsse einzuschränken sucht, wenn sie die Gemeinverständlichkeit der Sprache zu sehr beeinträchtigen und ihre historisch gewordene Eigenart bedrohen (Knoop/Schmitz 1985: 17f.). ${ }^{242}$

Seit 1984 verleiht die Stiftung jährlich den Deutschen Sprachpreis in Weimar, einen Preis in Höhe von damals 10000 DM, heute in Höhe von 5000 Euro, für „Verdienste um die Pflege der deutschen Sprache.“ Mögliche Preisträger sind Personen aus allen Bereichen des öffentlichen Lebens, insbesondere Wissenschaftler, die sich in irgendeiner Weise um die Pflege der deutschen Sprache verdient gemacht haben.

Bisherige Preisträger sind Hans-Martin Gauger (1984), Martin Wagenschein, die Arbeitsstellen für die Neubearbeitung des Grimmschen Wörterbuchs bei der Akademie der Wissenschaften der DDR (Berlin) und der Akademie der Wissenschaften zu Göttingen (1986), Will Quadflieg (1987), Hans Wollschläger (1988), eine Gruppe rumäniendeutscher Schriftsteller: Herta Müller, Gerhard Csejka, Klaus Hensel, Johann Lippet, Werner Söllner, William Totok, Richard Wagner, Helmuth Frauendorfer ${ }^{243}$ (1989), Uwe Pörksen (1990), Georges-Arthur Goldschmidt (1991). 1992 und 1993 wurde kein Sprachpreis vergeben. Das GoetheInstitut zur Pflege der deutschen Sprache im Ausland und zur Förderung der internationalen kulturellen Zusammenarbeit München (1994), Hans Hattenhauer (1995), Peter Eisenberg (1996), Wulf Kirsten (1997), Dorothea Kuhn (1998) Peter von Polenz (2000), Theodor Ickler (2001), Karl Heinz Bohrer (2002), das Streiflicht der Süddeutschen Zeitung (2003), Prof. Peter von Matt (2004), Heike Schmoll (2005), Dieter Henrich (2006), Charles Linsmayer (2007), Blanche Kommerell (2008) und Konrad Adam (2009) sind weitere Preisträger. Walter Krämer, Gründer

\footnotetext{
${ }^{242}$ M.W. gibt es keine neuere Darstellung der Purismusauffassung der Stiftung.

${ }^{243}$ Und ein Anerkennungspreis ging an Hans Beckmann, Bezirksvorsitzender der Gewerkschaft Deutscher Bundesbahnbeamten, Angestellten und Arbeiter.
} 
und Vorsitzender des VDS, bekam den Deutschen Sprachpreis im Jahr 1999 verliehen.

Teilweise vergibt die Stiftung den Sprachpreis in Zusammenarbeit mit anderen Organisationen, wie im Jahr 2007 mit dem Sprachkreis Deutsch (vgl. Kapitel 1.7.10.2, Knoop 2007b: 7). Die Stiftung gewährt Forschungsstipendien für Arbeiten, die der Sprachpflege und Sprachkritik gewidmet sind. Bisherige Veröffentlichungen, die durch Stipendien ermöglicht wurden, sind „Sprachpurismus und Emanzipation. Joachim Heinrich Campes Verdeutschungsprogramm als Voraussetzung für Gesellschaftsveränderungen“ von Jürgen Schiewe (Schiewe 1988), „Reinheit der Sprache des Herzens und des Leibes, zur Wirkungsgeschichte des rhetorischen Begriffs, puritas' in Deutschland von der Reformation bis zur Aufklärung" von Gerhard Härle (Härle 1996) sowie „Verstehenshilfe für die Klassikerlektüre und der Differenzwortschatz und seine Erklärung als Lesemotivation“ von Sarah Weiß (Weiß 2007). Dem Vorstand der Stiftung gehören Prof. Helmut Glück, Universität Bamberg, Dr. Michael Knoche, Direktor der Anna-Amalia-Bibliothek Weimar, Prof. Heinz-Günter Schmitz ${ }^{244}$ und Ulrike Johanning-De Abrew an. ${ }^{245}$ Außerdem publiziert die Stiftung jährlich die Begründung für den Deutschen Sprachpreis, die Laudatio auf den Preisträger und die Dankrede des Preisträgers in den Jahrbüchern der Stiftung (vgl. Knoop 1985, 1996, 2001, 2007a, 2007b).

\subsubsection{Lokale Gruppierungen}

Es sind nicht immer bundesweit oder international agierende Vereinigungen, die gegen die Zunahme der Anglizismen im Deutschen vorgehen wollen. Häufig sind es regionale Vereinigungen. Diese Auflistung erhebt keinen Anspruch auf Vollständigkeit, es kann durchaus sein, dass es kleinere lokale Gruppierungen gibt, deren Existenz sich meiner Kenntnis entzieht - obwohl für diese Arbeit über einen Zeitraum von vier Jahren in dieser Richtung recherchiert wurde. Die Aufzählung bietet jedenfalls einen guten Überblick. Der Verein zum Schutz der deut-

\footnotetext{
${ }^{244} \mathrm{Zu}$ Schmitz siehe Kapitel 1.7.8.

${ }^{245}$ Information aus Telefongespräch mit Ulrike Johanning-De Abrew, 28. September 2009.Ulrich Knoop war ebenfalls im Vorstand, gehört diesem aber nicht mehr an.
} 
schen Sprache e.V., im Mai 1997 von Wilfried Portzehl in Friedrichshafen gegründet, wird nicht aufgeführt, da er bereits 1999 vollständig im VDS aufgegangen ist. ${ }^{246}$ Der Sprachrettungsklub Bautzen wird dagegen vorgestellt, er war zwischendurch eine Regionalgruppe des VDS, ist aber wieder selbstständig.

\subsubsection{Senioreninitiative Nürnberg}

Die Senioren-Initiative Nürnberg (SIN) war die treibende Kraft bei der Gründung des Nürnberger Stadtseniorenrats und arbeitet seit dessen Gründung in diesem Gremium mit. Sie befasst sich vorrangig mit Fragen der Altenpolitik und mit Gesellschaftspolitik, von denen ältere Menschen besonders betroffen sind (vgl. Sprachbündnis Franken 2005b).

Die Senioreninitiative hat gemeinsam mit den Regionalgruppen Nürnberg und Erlangen des VDS im Jahr 2004 das Sprachbündnis Franken gegründet und die „Aktion Nein zu Denglisch“ mitinitiiert (Sprachbündnis Franken 2005c). Darauf wird in Kapitel 2.2.6 ausführlicher eingegangen werden.

\subsubsection{Sprachrettungsklub Bautzen/Oberlausitz}

Der Sprachrettungsklub Bautzen/Oberlausitz wurde am 17. Februar 1998 gegründet. Er war mit all seinen Mitgliedern dem VDS beigetreten und damit acht Jahre lang eine Regionalgruppe des VDS. Seit dem 29. November 2005 ist der Sprachrettungsklub Bautzen/Oberlausitz e.V. wieder ein eigener Verein, ${ }^{247}$ der „[m]it einer Strategie der fröhlichen

\footnotetext{
${ }^{246}$ Die Mitglieder von Portzehls Verein zum Schutz der deutschen Sprache haben auf der Mitgliederversammlung des Vereins im Mai 1999 den Beitritt zum damaligen VWDS beschlossen (vgl. u.a. VWDS-Nachrichten 1999c: 6).

${ }^{247}$ Der Grund für die Trennung dieser beiden Vereine liegt in Unstimmigkeiten zwischen Diethold Tietz und dem Vorstand des VDS. Diethold Tietz bemängelte die aus seiner Sicht mangelnde Demokratie des Vereins, und rief dann die Mitglieder der Regionalgruppe Bautzen auf einer Regionalversammlung zum Austritt auf. Daraufhin legte ihm der VDSVorstand den Austritt nahe. Tietz, der als Organisator der Delegiertenversammlungen und Vorstandsmitglied beim VDS sehr aktiv war, ist nicht mehr Mitglied des VDS, nach eigener Aussage wurde die Regionalgruppe „rausgeworfen“, Tietz selbst ist aus dem VDS ausgetreten (vgl. Protokoll eines Treffens der geschäftsführenden VDS-Vorstands vom 16. September 2005, Protokoll der VDS-Vorstandssitzung vom 12. November 2005, weitere Informationen aus Telefongespräch mit Diethold Tietz, 8. Januar 2009).
} 
Aggressivität“248 (vgl. Sprachrettungsklub 2005a) agiert und „gegen den Verfall der deutschen Sprache eintritt, gegen ,Fachjargon' in Politik, Behörden und im sonstigen öffentlichen Sprachraum und die Verwendung überflüssiger Begriffe aus dem anglo-amerikanischen Sprachraum“ (Sprachrettungsklub 2005b).

Der Sprachrettungsklub verfolgt seine Ziele beispielsweise mit Vorträgen und Teilnahmen an Stadtfesten sowie durch die Vergabe des Bautzener Sprachpreises. Dieser wurde im Jahr 2001 das erste Mal ausgeschrieben. Teilnahmeberechtigt sind Schüler des Landkreises Bautzen der Jahrgangsstufen 5 bis 12. Das Zertifikat „Wir sprechen die Sprache unserer Hörer" vergab der Verein an MDR 1 Radio Sachsen (vgl. SN 2005g: 25). Außerdem verfasst er Pressemitteilungen und bringt so Sprachthemen in die Medien (vgl. Sprachrettungsklub 2005b).

Vorsitzender des Sprachrettungsklubs ist Diethold Tietz, der auch im Vorstand des VDS war. Tietz tritt im Zuge der Vereinsarbeit häufiger in den Medien auf. ${ }^{249}$ Der Sprachrettungsklub Bautzen/Oberlausitz kooperiert zudem unter anderem mit der Deutschen Sprachwelt: Die Internetpräsenz des Sprachrettungsklubs führt unter der Rubrik „unsere Partner" die Deutsche Sprachwelt auf, ${ }^{250}$ ebenso die VDS Region Lübeck, die Neue Fruchtbringende Gesellschaft, die Aktion lebendiges Deutsch, das Haus der deutschen Sprache und die Aktion Deutsche Sprache (Sprachrettungsklub 2008). Heute ist der Sprachrettungsklub Bautzen/Oberlausitz auch Mitglied der Neuen Fruchtbringenden Gesellschaft.

\subsubsection{Aktion Deutsche Sprache}

Der Verein Aktion Deutsche Sprache (ADS) wurde am 31. März 2006 in Hannover gegründet. Die Aktion Deutsche Sprache ist als Abspaltung

\footnotetext{
${ }^{248}$ Diese fröhliche Aggressivität fordert Krämer immer wieder für den VDS (vgl. u.a. Protokoll der VDS-Vorstandssitzung vom 17. Juli 2002)

${ }^{249}$ Beispielsweise gab er auch der eher rechtskonservativen Jungen Freiheit ein ausführliches Interview im Jahr 2004 (Schwarz 2004). In dieser Tatsache spiegelt sich auch die Haltung des VDS gegenüber Zeitungen wie der Jungen Freiheit wider: Interviews geben ja, Artikel schreiben nein (Gespräch mit Walter Krämer, 25. März 2005).

${ }^{250}$ Auch umgekehrt verweist die Deutsche Sprachwelt auf den Sprachrettungsklub: „Die DEUTSCHE SPRACHWELT arbeitet dabei mit weiteren Sprachpflegeorganisationen wie dem Sprachrettungsklub Bautzen zusammen“ (dsw 2006).
} 
des VDS zu betrachten. Vorsitzender ist Dr. Hermann Neemann. Ziel des Vereins ist, „die deutsche Sprache als Amts-, Kultur-, Landes- und Wissenschaftssprache [zu] erhalten, pflegen, schützen und weiterentwickeln“. So will der Verein „mit allen Mitteln gegen die Verhunzung und Vermischung der deutschen Sprache mit Anglizismen und dem Sprachmischmasch ,Denglisch’ kämpfen“. Zusätzlich geht es den Mitgliedern „um gutes Deutsch durch Fragen der Rechtschreibung und Grammatik“ (Neemann 2008). Öffentlich in Erscheinung getreten ist die Aktion Deutsche Sprache noch nicht weiter, lediglich im Februar 2008 gab es eine „Sprachtreff-Veranstaltung“, bei der ein Vortrag zum Thema „Sprachen und Denken“ gehalten wurde (Neemann 2008).

Die 20 Gründungsmitglieder der Aktion Deutsche Sprache haben dabei zumeist zuvor im VDS mitgewirkt, wie es auf den „Internetz“-Seiten der Vereinigung heißt. Auch der Vorsitzende Neemann wirkte zuvor im VDS, er war lange Jahre Vorsitzender der Regionalgruppe 30 des VDS (Hannover) und im VDS-Bundesvorstand (vgl. z.B. Zick 2005a: 22). ${ }^{251}$ Auffällig ist: Anders als beim VDS ist im Vereinsziel der Aktion Deutsche Sprache auch die Auseinandersetzung mit der deutschen Rechtschreibung festgelegt. Womöglich liegt hier der Grund für die Abspaltung vom VDS. Es fällt auch auf, dass der VDS bei den Verweisen der ADS nicht gelistet ist. Aufgeführt sind hier die Deutsche Sprachwelt (vgl. Kapitel 1.7.5), die Neue Fruchtbringende Gesellschaft (siehe dazu Kapitel 1.7.15), die Schweizer Orthographische Konferenz, der Verein für Sprachpflege (vgl. Kapitel 1.7.5) sowie www.sprachpflege.info, ein Online-Nachschlagewerk über Sprachpflege der Deutschen Sprachwelt und des Vereins für Sprachpflege. Hinsichtlich der Neuen Fruchtbringenden Gesellschaft ist zu ergänzen, dass Neemann dort ebenfalls im Vorstand ist (vgl. NFG 2007g).

\subsubsection{Verein für Rechtschreibung und Sprachpflege}

Der Berliner Verein für Rechtschreibung und Sprachpflege (BVR) ist ein Schwesterverein des gleichnamigen Vereins aus Erlangen, beide Vereine koordinieren oder koordinierten sich bei ihren Aktionen (vgl. auch

${ }^{251}$ Sein Austritt aus dem VDS erfolgte im Jahr 2006 (Brief von Holger Klatte, VDSGeschäftsführer, an die Verfasserin, 7. Januar 2009). 
Pfalzgraf 2003a: 110). Er trat im Jahr 1999 mit einer Klage gegen die Rechtschreibreform in Erscheinung, ebenso war der Verein Träger eines Bürgerbegehrens gegen die Rechtschreibreform (Gizewski 1999). Dieses scheiterte, zog aber Beachtung in den Medien auf sich (vgl. u.a. Geschonneck 1999: 23, Asmuth 1999: 19). Sprecher des BVR ist wohl nach wie vor Gernot Holstein ${ }^{252}$, Vorsitzender Ernst Steppan. Steppan ist zugleich Gründungsmitglied des Erlanger Schwestervereins (vgl. VRS 2003a). Der Internetauftritt des Vereins, wohl bis ins Jahr 2000 unter http://www.rechtschreibvolk.de ${ }^{253} \mathrm{zu}$ erreichen, ist mittlerweile unter dieser Adresse nicht mehr zu finden. Da der Verein seit dem Jahr 1999 wie es scheint nicht mehr wirklich aktiv gewesen ist, soll diese Kurzdarstellung genügen.

\subsubsection{Der Deutsche Sprachrat}

Der Deutsche Sprachrat ist ein Zusammenschluss des IDS, der GfdS, des Deutschen Akademischen Austauschdiensts (dieser kam erst später hinzu) und des Goethe-Instituts. Er widmet sich der Förderung und Vermittlung der deutschen Sprache (vgl. Deutscher Sprachrat 2006), zudem soll er die einzelnen Aktivitäten der Institutionen aufeinander abstimmen (vgl. Hoberg 2003: 182).

Dabei sieht es der Deutsche Sprachrat als seine Aufgabe an,

durch Sensibilisierung des Sprachbewusstseins die Sprachkultur im
Inland sowie die Stellung der deutschen Sprache im Ausland zu för-
dern. Dies will er durch Sprachkultivierung im Sinne von Informati-
on und Aufklärung über Sprache und vermehrter Diskussion sprach-
licher Themen erreichen (Deutscher Sprachrat 2009).

Der Deutsche Sprachrat sucht nach eigenen Angaben „auf eine vermehrte öffentliche Sprachkritik und auf eine entwickelte Kritikfähigkeit vieler Menschen hinzuwirken“, und möchte gelungenen und kreativen Sprachgebrauch als vorbildlich herausstellen (vgl. Deutscher Sprachrat 2009). Um seine Ziele zu erreichen, arbeitet er auch mit Institutionen im Ausland zusammen. Außerdem unterstützt er die Forderung, dass

\footnotetext{
${ }^{252}$ Holstein war in politisch rechtsgerichteten Vereinigungen aktiv, wie unter anderem die taz recherchierte (vgl. Pfalzgraf 2003a: 110, Asmuth 1999: 19).

${ }^{253}$ Unter dieser Adresse ist er auf einer Internetseite mit einem öffentlichen Diskussionsforum der TU Berlin aufgeführt, Stand Februar 2000 (vgl. Aktionsbündnis 2000).
} 
Deutsch an allen Schularten als Hauptfach unterrichtet wird, und die Bemühungen, Fremdsprachenunterricht schon im Kindergarten einzuführen. Kernanliegen ist auch das Erlernen der deutschen Sprache im Ausland. Der Deutsche Sprachrat steht zudem der Bundesregierung bei ihren Bemühungen bei, Deutsch als Arbeitssprache der EU zu fördern. Einem Sprachgesetz steht der Deutsche Sprachrat kritisch gegenüber (Deutscher Sprachrat 2009).

$\mathrm{Zu}$ den Aktionen des Deutschen Sprachrats zählt unter anderem eine repräsentative Umfrage gemeinsam mit der GfdS über die Einstellung der Deutschen zu ihrer Muttersprache (vgl. Schulz 2008 sowie Kapitel 1.6 und Kapitel 1.7.2).

\subsubsection{Netzwerk Deutsche Sprache}

Das Netzwerk Deutsche Sprache war ein Zusammenschluss des VDS (anfangs noch VWDS), des BfdS, der Bubenberg-Gesellschaft, des Fördervereins für bairische Sprache und Dialekte ${ }^{254}$, und der Interessengemeinschaft Muttersprache in Graz. Im Jahr 2000 stießen die Association pour le Pluralisme linguistique et culturel en Europe (Nantes, Frankreich) ${ }^{255}$ und der Arbeitskreis Deutsche Muttersprache in Südtirol $^{256}$ hinzu. Gegründet wurde das Netzwerk im Jahr 1999 auf Initiative von Prof. Dr. Werner Pfannhauser, dem Vorsitzenden der Interessengemeinschaft Muttersprache (vgl. Kapitel 1.7.9.2).

Die Entstehung des Netzwerks funktionierte erst im zweiten Anlauf, bei einem ersten Versuch waren die ideologischen Differenzen zwischen den teilnehmenden Sprachvereinen zu groß (vgl. VDS 2003b) Im Mai 1998 hatte Mechtersheimer zu einer Tagung nach Frankfurt geladen. ${ }^{257}$ Dort hatte er sich für eine Unterstützung durch rechte Gruppierungen und Parteien ausgesprochen (vgl. Junker 2000: 2).

\footnotetext{
${ }^{254}$ Dieser Verein beschäftigt sich, wie der Name sagt, mit der Förderung der bairischen „Sprache“ und Dialekte, und wird daher in dieser Arbeit nicht näher vorgestellt.

${ }^{255}$ Da diese Vereinigung sich nicht um Anglizismen im Deutschen kümmert, sondern ihr Anliegen die Anglizismen im Französischen sind, soll hier nicht näher auf sie eingegangen werden.

${ }^{256}$ Dieser Verein wendet sich gegen Italianismen im Deutsch Südtirols.

$257 \mathrm{Zu}$ Mechtersheimer vgl. Kapitel 1.7.8.
} 
Ziel des Netzwerks war „ein Informationsaustausch und die Koordination von Aktionen“ der beteiligten Vereinigungen. Das Netzwerk sollte „Kontakte schaffen zwischen Menschen, denen die eigene Sprache kostbar und die Ausbildung darin wichtig ist, auch in einer oder mehreren Landes- und Fremdsprachen“ (vgl. VDS 2003c). Weiterhin hieß es:

Das Selbstbewusstsein der Völker Europas und damit Europas und damit Einheit in Vielfalt wird vor allem durch Medien und Werbeindustrie bedroht, die englische Wortfetzen in immer steigendem Ausmaß verwenden (vgl. VDS 2003c).

Die Vereine des Netzwerks forderten „zu allen vertretbaren Formen des zivilen Widerstandes gegen die übermässige und unnötige Verwendung englischer Bezeichnungen auf" (vgl. VDS 2003c) und wollten eine Bewusstseinsveränderung herbeiführen.

Die Arbeit des Netzwerks bestand in jährlichen gemeinsamen Tagungen. Zur ersten Tagung in Graz im Jahr 1999 wurde von Werner Pfannhauser bereits in der Einladung darauf hingewiesen, dass auf der Konferenz kein Raum für nationalistische und extrem puristische Positionen sei. ${ }^{258}$ Daraufhin erschienen einige der eingeladenen Gruppierungen nicht (vgl. Junker 2000: 2).

Im Anschluss an die Tagung wurde jeweils eine Entschließung veröffentlicht. Die erste Entschließung wurde anlässlich der Tagung in Graz vom 9. bis 11. September 1999 verfasst. Darin heißt es:

Die Vielfalt Europas, die sich in ihren Sprachen und Kulturen äußert, ist durch die Überflutung mit englischen Sprachbrocken bedroht. Es sind nicht einzelne Wörter, die als Lehnwörter aus vielen Sprachen in die eigenen Sprachen übernommen worden sind und werden, sondern es ist das Übermaß von englischen Brocken und Halbsätzen, die auch unsere deutsche Sprache - wie andere europäische Sprachen bedrohen. [...] Die unterzeichneten Sprachvereine aus Deutschland, der Schweiz, Südtirol und Österreich fordern daher Entscheidungsträger, aber auch Bürger ihrer Länder auf, dem Schutz der deutschen Sprache vor der Überflutung mit englischen Ausdrücken Aufmerksamkeit zu schenken, auch ihren Mitbürgern die unserer Muttersprache drohende Gefahr bewußt $\mathrm{zu}$ machen und damit Sprachpflege im besten Sinn zu unterstützen (VDS 2003c).

258 Dies ist aufgrund der Nähe Pfannhausers zum Österreichischen Turnbund und damit wohl auch zur Österreichischen Landsmannschaft bemerkenswert. Die Originaleinladung ist im Archiv des VDS trotz Suche durch die Mitarbeiter der Geschäftsstelle nicht mehr aufzufinden. 
Unterzeichner dieser Entschließung waren der Bund für deutsche Schrift und Sprache ${ }^{259}$, der Verein Deutsche Sprache, die BubenbergGesellschaft, der Arbeitskreis Deutsche Muttersprache in Südtirol, ${ }^{260}$ der Förderverein für bairische Sprache und Dialekt und die Interessengemeinschaft Muttersprache in Österreich/Graz. Pfalzgraf hat die Entschließung von 1999 inhaltlich untersucht, er konstatiert: „Die These von der Bedrohung der deutschen Sprache, und damit auch der deutschen Kultur, ist in der Entschließung nicht zu übersehen“ (Pfalzgraf 2006: 86). In diesem Sinne sind zumindest Begriffe wie „Überflutung“ und „drohende Gefahr“ zu verstehen, vor der die Bürger die Sprache „schützen“ sollen. Daher werden die Aktivitäten des Netzwerks von einigen Sprachwissenschaftlern auch als puristisch eingestuft (vgl. Janich/Greule 2002: 44). Und Wiechers konstatiert in ihrer Untersuchung:

Betrachtet man die Entwicklung des ,Netzwerk Deutsche Sprache', so wird deutlich, dass die Diskussion um die Zulässigkeit und die Verwendung von Anglizismen nur vordergründig sprachkritisch ist, dass vielmehr in der Frage nach der Stellung und dem Wert der deutschen Sprache vor dem Hintergrund des Phänomens Globalisierung eine politische Dimension erreicht wird (Wiechers 2001: 160).

Im Jahr 2000 wurde die Entschließung von Friedrichshafen veröffentlicht, als Ergebnis der sogenannten „Bodenseekonferenz“. Dieser Begriff wurde von Jürgen Spitzmüller aufgegriffen und kritisiert:

[S]prachkritisch [ist] anzumerken, daß der Terminus ,Bodenseekonferenz', der auf der Internetseite drei Mal als Verweis auf eine Tagung, die der VDS gemeinsam mit anderen sprachkritischen Vereinen abgehalten hat, nicht weniger problematisch ist (wegen Wannseekonferenz) (Spitzmüller 2002: 255).

Durch diese Kritik von Spitzmüller sahen sich einige VDS-Mitglieder verständlicherweise verunglimpft, da sie sich nicht in die Nähe des Nationalsozialismus gestellt sehen wollten und die Assoziation des Begriffs „Bodenseekonferenz“ mit „Wannseekonferenz“ nicht bedacht hatten (Gespräch mit Walter Krämer, 25. März 2005).

Die Friedrichshafener Entschließung beschäftigt sich nicht mit Anglizismen im Deutschen, sondern richtet sich gegen die Begünstigung des

${ }^{259}$ Den Bund für deutsche Schrift und Sprache, den Pfalzgraf als rechtsextrem einstuft, hat der Hinweis auf der Einladung, dass es keinen Raum gebe für nationalistische Positionen, nicht abgeschreckt.

${ }^{260}$ Als Landesangabe beim Verein Deutsche Muttersprache wird Südtirol genannt (vgl.

z.B. Pfannhauser 1999). 
Englischen als erste obligatorische Fremdsprache in Europa. Darauf soll hier aber nicht näher eingegangen werden. Es folgte die Berner Entschließung im Jahr 2001. Diese drehte sich um die Frage, welches die Arbeitssprachen sein sollen, in denen die Staaten der EU künftig miteinander verkehren.

Die Klosterneuburger Entschließung aus dem Jahr 2003 hat die Sprache der Wissenschaft zum Thema. Es wird gefordert, dass Wissenschaftler wieder vermehrt auf Deutsch publizieren sollten, und nicht mehr nur auf Englisch:

Das Argument, dann müsse man eben die Fremdsprache noch ausschliesslicher erlernen, führt letztlich zur Aufgabe unserer Muttersprache und Kultur und zwingt uns auf Jahrzehnte in politische und ökonomische Unterlegenheit (und auch Abhängigkeit) gegenüber dem englischsprachigen Raum. Zusammengefasst lautet unser Appell: Lasst uns unsere Muttersprache auch auf dem Gebiet der Wissenschaften bewahren und fördern! (SKD 2003b)

Unterzeichner waren der Arbeitskreis Deutsche Muttersprache in Südtirol (Italien), der Bund für Deutsche Sprache und Schrift (Deutschland und Österreich), der Förderverein für Bairische Sprache und Dialekte (Bayern und Österreich), die Interessengemeinschaft Muttersprache (Österreich), der Sprachkreis Deutsch/Bubenberg-Gesellschaft (Schweiz), der Verein Deutsche Sprache (Deutschland) und der Verein Muttersprache (Österreich) (vgl. SKD 2003b). Die Deutsche Sprachwelt ist nicht Teil des Netzwerks, veröffentlicht aber auf ihrer Internetpräsenz die Entschließungen ebenfalls, darüber steht: „Die DEUTSCHE SPRACHWELT unterstützt den Netzwerkgedanken“ (Deutsche Sprachwelt 2003a). Das Netzwerk sollte noch ausgeweitet werden zum „Europäischen Netz europäischer Sprachen“. In Zukunft sollten alle Vereine einen einheitlichen Namenszusatz tragen. Gedacht war der Zusatz: „Bürger für die Erhaltung der sprachlichen und kulturellen Vielfalt Europas“, den der VDS im Namen trägt (vgl. VDS 2003c). Dies ist aber offensichtlich nicht passiert. Das Netzwerk Deutsche Sprache hatte zudem für das Jahr 2005 eine Tagung in Weimar angekündigt (vgl. Deutsche Sprachwelt 2003a), die aber vom VDS abgesagt wurde (vgl. Zbinden 2007: 67). Das war das Ende des Netzwerks als aktiver Zusammenschluss, auch wenn es nie offiziell aufgelöst wurde. 
Insgesamt resümiert Zbinden: „Wesentliche Aktivitäten gelangen im Netzwerk nicht, sieht man von den Tagungen ab“. Gründe dafür waren unter anderem satzungsbedingt unterschiedliche öffentliche Auftritte der Vereine und Fragen der Mitgliedschaft. Trotzdem hegen die Mitgliedsvereine anscheinend wieder Hoffnung, das Netzwerk neu zu beleben. Im Jahr 2006 wurde auf einer Vorstandssitzung darüber berichtet, dass sich Walter Krämer (VDS) mit Peter Zbinden (Sprachkreis Deutsch) und Gottfried Fischer (Verein Muttersprache) getroffen habe und dass diese drei darin übereinkamen, das Netzwerk wiederzubeleben (vgl. Protokoll der VDS-Vorstandssitzung vom 21. Oktober 2006). ${ }^{261}$ Es gibt auch Überlegungen zu einem „VDS international“ (vgl. Zbinden 2007: 66f.). ${ }^{262}$ Auf der Tagung Idensen 2 wurde das Netzwerk Deutsche Sprache erneut diskutiert. Im Protokoll der Tagung ist zu lesen, dass das Netzwerk Deutsche Sprache reaktiviert werden soll, und zwar mit den Kernländern Deutschland, Österreich und der Schweiz. Dabei solle die Leitung nicht in Deutschland, sondern in einem kleineren deutschsprachigen Land liegen. In Zukunft sollen alle Länder, in denen es deutschsprachige Minderheiten gibt, diesem Netzwerk beitreten. Als Beispiel wird unter anderem Togo angeführt (vgl. Pogarell 2007c: 8). Doch bisher ist es $\mathrm{m}$.W. bei den Überlegungen geblieben.

\subsubsection{Neue Fruchtbringende Gesellschaft}

Seit Januar 2007 gibt es in Deutschland einen weiteren Zusammenschluss aus Sprachvereinen: Die Neue Fruchtbringende Gesellschaft (NFG). Mitglieder sind der Pegnesische Blumenorden, ${ }^{263}$ die Aktion Deutsche Sprache (vgl. Kapitel 1.7.12.3), der Sprachrettungsklub Bautzen/Oberlausitz (vgl. Kapitel 1.7.12.2) und der Verein für Sprachpflege (vgl. Kapitel 1.7.5) (NFG 2007d). Gründungsdokument der NFG ist die Köthener Erklärung. Darin heißt es, sie wurde gegründet:

${ }^{261}$ Auch Werner Pfannhauser (IG Muttersprache) war zu diesem Treffen geladen worden, zeigte aber offensichtlich kein Interesse.

${ }^{262}$ Im Kontrast dazu steht die Aussage des Geschäftsführers, dass das Netzwerk tot sei (Gespräch mit Holger Klatte, VDS-Geschäftsführer, 28. November 2008).

${ }^{263}$ Diese Zusammenarbeit kann über Thomas Paulwitz zustande gekommen sein. 
[...] mit dem Ziel, die deutsche Sprache als Amts-, Kultur-, Landesund Wissenschaftssprache zu erhalten, zu pflegen, zu schützen und weiterzuentwickeln $[\ldots]^{264}$

um mit der Neuen Fruchtbringenden Gesellschaft für die deutsche Sprache einen Ort zu schaffen, der für die Pflege der Sprache gute Kräfte anziehen, bündeln und ausstrahlen soll (NFG 2007a).

Schon in seinem Namen nimmt der Verein Bezug auf die „Fruchtbringende Gesellschaft“ des Barock (vgl. Kapitel 1.1), ebenso in der Gründungserklärung, so soll es:

wie den Gesellschaften von einst vor allen Dingen obliegen, die deutsche Sprache in ihrem grundlegenden Wesen und ihrer Bedeutung $\mathrm{zu}$ erhalten, auszuüben und zu pflegen, und sich für das Erreichen ebendieser Ziele in allen Bereichen unseres Lebens einzusetzen (NFG 2007a).

Vorsitzende ist Prof. Dr. Uta Seewald-Heeg, im Vorstand sind auch Dr. Hermann Neemann (stellvertretender Vorsitzender), Thomas Paulwitz und Diethold Tietz ${ }^{265}$ (NFG 2007g). Die NFG hat das „Köthener Haus der deutschen Sprache“ gegründet. Übergabe der ersten Räumlichkeiten war am 13. September 2008, dem Tag der deutschen Sprache (NFG 2007c). Die NFG sucht nach eigenen Angaben die Zusammenarbeit „mit allen an der Pflege der deutschen Sprache interessierten Einzelpersonen, Sprachvereinen und Institutionen“ (NFG 2007d). ${ }^{266}$ Ein weiteres Ziel der NFG ist: „Der Verein setzt sich insbesondere dafür ein, Köthen zur Stadt der deutschen Sprachkultur und Sprachpflege zu machen“ (NFG 2007e). ${ }^{267}$ Dabei sucht der Verein die enge Zusammenarbeit mit Ämtern der Stadt Köthen, mit allen kulturellen Institutionen und gesellschaftlichen Gruppen, den Kirchen, Schulen, Hochschulen,

\footnotetext{
${ }^{264}$ Vgl. hierzu auch die Ziele der Aktion Deutsche Sprache (Kapitel 1.7.12.3).

265 Tietz und Neemann sind ehemalige Vorstandmitglieder des VDS. Neemann ist im Jahr 2006, Tietz, im Jahr 2005 aus dem VDS ausgetreten.

${ }^{266}$ Seitens des VDS wird es keine Zusammenarbeit mit der NFG geben (Gespräch mit Holger Klatte, VDS-Geschäftsführer, 28. November 2008). Vgl. zum Verhältnis des VDS zur NFG auch Gerd Schrammen, der den Präsident der Deutschen Akademie für Sprache und Dichtung, Klaus Reichert, zitiert, welcher die NFG als „Leute, die von der Lebendigkeit einer Sprache keine Ahnung haben“ bezeichnete (Schrammen 2009: 111).

${ }^{267}$ Hier und beim Köthener Haus der deutschen Sprache zeigt sich auch deutlich die Konkurrenz zum VDS. Nicht nur sind ehemalige Mitglieder und Vorstandsmitglieder des VDS in der NFG versammelt, sondern es wird auch versucht, eine Idee des VDS zu verwirklichen. Während der VDS noch keine Räumlichkeiten hat und das Haus der deutschen Sprache der Stiftung deutsche Sprache nur virtuell existiert, haben die Köthener bereits die ersten Räumlichkeiten, dürfen diese aber nicht „Haus der deutschen Sprache“ nennen.
} 
Medien, Wirtschaft, Verbänden sowie allen demokratischen Parteien und Vereinen (NFG 2007e). Die Vereinsziele der NFG sollen unter anderem erreicht werden durch die Ausrichtung und Förderung von Fachtagungen, Vorträgen und Vereinstreffen (NFG 2007e). Bisherige Aktivitäten der NFG sind der Köthener Sprachtag und eine Tagung (Referenten waren bisher beispielsweise Thomas Paulwitz und Dietrich Voslam$\operatorname{ber}^{268}$ (NFG 2007b)). Eines der Hauptaufgabengebiete ist auch ein Schülerwettbewerb, denn die Gesellschaft will insbesondere junge Menschen ansprechen (NFG 2007f).

Parteipolitisch ist der Verein neutral, die NFG duldet keine Äußerungen und Handlungen in ihren Reihen, durch die andere Sprachen und Kulturen beleidigt, entwürdigt oder verunglimpft werden (NFG 2007e). Unterstützt wird die Arbeit der NFG von der Theo-Münch-Stiftung. Diese beteiligt sich z.B. an obengenanntem Schülerwettbewerb (Sprachpflege.info 2008a). Zentrales Informationsorgan ist die Internetpräsenz des Vereins, diese kann man auch auf alte Rechtschreibung umstellen (NFG 2007f).

${ }^{268}$ Wobei es Voslamber seitens des VDS nicht erlaubt war, dort als VDS-Abgeordneter aufzutreten, sondern als Privatperson (Gespräch mit Holger Klatte, Geschäftsführer des VDS, 28. November 2008). 



\section{Der Verein Deutsche Sprache}

Der Verein Deutsche Sprache wird heute als die „Speerspitze der Anglizismenkritik im deutschsprachigen Raum“ angesehen (vgl. J. G. Schneider 2006). Schon die Gründung des „Vereins zur Wahrung der deutschen Sprache“ zeige, dass der Gedanke zur Sprachreinigung durchaus noch nicht ad acta gelegt ist, schreibt Anke Sauter im Jahr 2000 (vgl. Sauter 2000: 200). Mit dieser Vermutung hat sie Recht behalten. Im folgenden Kapitel soll die Gründungsphase von der Idee über die Entstehung bis zu den ersten Jahren des heutigen Vereins Deutsche Sprache damals noch Verein zur Wahrung der deutschen Sprache - nachgezeichnet werden.

\subsection{Anfänge des Vereins Deutsche Sprache}

\subsubsection{Gründer und Vorsitzender Walter Krämer}

Ohne den Einsatz von Professor Dr. Walter Krämer ${ }^{269}$ gäbe es keinen Verein Deutsche Sprache. Gründung und Aufbau sind eng mit seiner Person verknüpft. Krämer wurde am 21. November 1948 in Ormont in der Eifel in eine Zollbeamtenfamilie bäuerlicher Herkunft hineingeboren. 1960 konnte er von der Volksschule in Winterscheid aufs ReginoGymnsium in Prüm und dann aufs Gymnasium am Kurfürstlichen Schloss in Mainz wechseln. Die Lieblingsfächer des Schülers waren Deutsch und Latein. Nach Abitur und Grundwehrdienst studierte er Mathematik und Volkswirtschaftslehre, dabei hatte er Spaß an Paradoxa aller Art, und erkannte, wie unausrottbar gewisse Irrtümer auf ewig bleiben. ${ }^{270} 1976$ schloss er sein Studium als Diplommathematiker ab, 1979 promovierte er. Es war keine mathematische, sondern eine staatswissenschaftliche Arbeit. Danach arbeitete er als Assistenzprofessor in

\footnotetext{
${ }^{269}$ Vgl. Dokument 22.

${ }^{270}$ Ein Beispiel hierfür sind Krämers Berechnungen der Kosten des Rauchens für das Gesundheitswesen und die häufige Annahme, dass Raucher das Gesundheitswesen verteuern.
} 
Wien, 1984 habilitierte er sich in Wien in Ökonometrie, der Titel seiner Habilitationsschrift lautete „Trend in ökonometrischen Modellen“. Er übernahm eine Professur für empirische Wirtschaftsforschung an der Universität Hannover, 1988 wechselte er an die Universität Dortmund auf den Lehrstuhl für Wirtschafts- und Sozialstatistik, forschte und lehrte an Universitäten in Österreich, England, Kanada, Australien, China und Frankreich. Krämer war unter anderem Fachgutachter für Statistik bei der Deutschen Forschungsgemeinschaft, und er ist Vorsitzender des Wissenschaftsrats des Rheinisch-Westfälischen Instituts für Wirtschaftsforschung und seit 2008 Mitglied der Nordrhein-Westfälischen Akademie der Wissenschaften. Zudem ist er Herausgeber der German Economic Review.

Neben seiner Tätigkeit als Professor veröffentlicht Krämer regelmäßig Artikel in Zeitungen und Zeitschriften, wie der Frankfurter Allgemeinen Zeitung, der Welt, dem Spiegel oder der Zeit. Außerdem hat der Wirtschaftswissenschaftler, Statistiker und Mathematiker zahlreiche Bücher veröffentlicht. Darunter finden sich Titel wie „Wie schreibe ich eine Seminar- oder Examensarbeit?“, „So lügt man mit Statistik“, „Denkste! Trugschlüsse aus der Welt der Zahlen“ oder das erfolgreiche „Lexikon der populären Irrtümer“, das Krämer gemeinsam mit Götz Trenkler verfasst hat. Neben diesen Publikationen finden sich auch einige, die sich mit Sprache auseinandersetzen: „Modern Talking auf deutsch. Ein populäres Lexikon“ (Krämer 2000a), zusammen mit Helmut Glück: „Die Zukunft der deutschen Sprache. Eine Streitschrift.“ (Glück/Krämer 2000) und „Die Ganzjahrestomate und anderes Plastikdeutsch“ (Krämer/Kaehlbrandt 2007), „Plastikdeutsch“ (Krämer/Kaehlbrandt 2009) sowie das „Lexikon der populären Sprachirrtümer. Missverständnisse, Denkfehler und Vorurteile von Altbier bis Zyniker“ (Krämer/Sauer 2009). Seine Veröffentlichungen und Abhandlungen haben Krämer bereits den Titel „Prof. Besserwisser“ eingebracht (Willmann 2003).

Politisch ist Krämer als liberal einzustufen. 1969 ist er der FDP beigetreten. Als Helmut Schmidt Kanzler wurde, trat er auch der SPD bei. Als dieser 1982 wieder gehen musste, trat Krämer wieder aus. In der FDP ist er noch immer. Seine politischen Gegner empfindet Krämer als Bedrohung, gegenüber der Zeit sagt er: „Sie kontrollieren große Teile der Medien, predigen auf unseren Kanzeln und dominieren die bundes- 
deutschen Lehrerzimmer“ (Willmann 2003). In seinem Dienstzimmer hängt eine Deutschlandfahne. Dazu hat er in den Sprachnachrichten, der Zeitschrift des VDS (vgl. Kapitel 2.5.1.4), Stellung genommen:

Manche Kollegen stören sich daran [gemeint ist die Fahne in seinem Dienstzimmer, Anm. d. Verf.]. Wer ist hier abnormal? In allen Ländern der Erde, Deutschland ausgenommen, würde das als Scherzfrage empfunden (Krämer 2005e: 2). ${ }^{271}$

Krämer ist eine auffällige Person. Ein Journalist beschrieb ihn als „seehundschnauzbärtig“ mit „üppiger, dunkler Haartracht“ (Willmann 2003), die Jungle World als „Mischung aus Waldemar Hartmann und einem ideellen Gesamthardrocker der frühen siebziger Jahre“ (Martens 2003), einen „latin lover“ nannte ihn die Süddeutsche Zeitung, aufgrund seines Betragens auf der Jahrestagung des IDS bezeichnete ihn die SZ auch als einen „Grobian“ (Unterstöger 2000: 10, vgl. zur Jahrestagung weiter unten in diesem Kapitel und Kapitel 1.7.3).

Nach den Motiven für die Gründung des Vereins befragt, antwortete Krämer der FAZ::

Immer wenn ich das mit englischen Brocken aufgeblasene Imponiergefasel mancher Kollegen lese, diese Schimpansensprache, werde ich krank vor Zorn. Da hab' ich mir gesagt: Bevor du mit Magengeschwüren zum Doktor musst, tust du etwas dagegen (Wermelskirchen 1999: 12).

Krämer achtet streng darauf, keine überflüssigen Anglizismen zu verwenden, dementsprechend nennt er sein Handy „Funktelefon“ oder spricht die Namen englischer Rockgruppen wie REM deutsch aus (vgl. Wermelskirchen 1999: 12). Auch Einladungen zu Gastvorträgen schlägt er hin und wieder aus, wenn die Einladenden seiner Meinung nach nicht $\mathrm{zu}$ tolerierende Anglizismen verwenden. ${ }^{272}$ Ebenso will er keine Zeitschriften zugesandt bekommen, wenn deren Sprachgebrauch ihm nicht zusagt. ${ }^{273}$ In der Zeitung Die Welt ist von Krämer zu lesen, dass

\footnotetext{
${ }^{271}$ Siehe dazu Anja Stukenbrock (Stukenbrock 2005a: 239).

${ }^{272}$ Vgl. dazu den Offenen Brief von Krämer an den damaligen Rektor der LudwigMaximilians-Universität München, Prof. Dr. Andreas Heldrich. Aus diesem geht hervor dass er seinen Vortrag im Rahmen einer Ringvorlesung absagt, weil die Universität ihre Fakultäten und Institute in „departments" umbenannt hat. (Offener Brief von Walter Krämer, 1. Vorsitzender des VDS, an den Rektor der Ludwig-Maximilian-Universität München, Prof. Dr. Andreas Heldrich" vom 25. April 2000).

${ }^{273}$ Vgl. dazu z.B. Brief von Walter Krämer an die McKinsey Company vom 11. März 2002, wo er die Firma bittet, von weiteren Zusendungen der Zeitschrift „Health“ abzusehen.
} 
die Verleugnung der eigenen Sprache eine Selbsttäuschung sei: „das dumme Imponiergehabe im Verein mit einer verbreiteten Illusion, sich durch das Abkoppeln von der deutschen Sprache auch von Deutschland selber und von der Geschichte abzukoppeln“ (Krämer 1998c: 4). Dies zeigt schon, dass Krämer kein Blatt vor den Mund nimmt und mit seinem mitunter polternden Auftreten auch des öfteren aneckt, so auf der obengenannten Tagung im Jahr 2000, wo er die Meinung vertrat, dass das Deutsche durch den Einfluss des Englischen zur "Schimpansensprache" verkomme (vgl. z.B. Steffens 2000). Dort beschimpfte er den Sprachwissenschaftsprofessor Peter Schlobinski als „Rotzlöffel“ - wobei er vorher nach eigenen Angaben provoziert worden war, dabei war laut Krämer auch ein NS-Vergleich geäußert worden (Gespräch mit Walter Krämer vom 25. März 2005, vgl. auch Rundschreiben eines VDSVorstandsmitglieds an die Vereinsmitglieder, 3. August 2000) ${ }^{274}$. Seine Bemühungen um die deutsche Sprache haben Walter Krämer im Jahr 1999 den Deutschen Sprachpreis der Henning-Kaufmann-Stiftung eingebracht (vgl. Kapitel 1.7.11.2).

\subsubsection{Von der Idee bis zur Entstehung}

Von der Idee bis zur Entstehung war es nur ein kleiner Schritt. Krämer hatte sich schon länger über die Anglizismen in der deutschen Sprache geärgert, und laut eigener Aussage das Gefühl, er müsse etwas tun (Gespräch mit Walter Krämer vom 25. März 2005). Am 30. Oktober 1997 versammelte er seine Assistenten, Mitarbeiter und seine Sekretärin um sich, erläuterte ihnen sein Anliegen und überzeugte sie von der Notwendigkeit einer Vereinsgründung. Keine 14 Tage später, am 12. November 1997, gründeten sie gemeinsam den „Verein zur Wahrung der deutschen Sprache“ (VWDS 1997, Dokument 2).

Die Gründungsmitglieder waren Krämer, Lars Tschiersch, Michael Lohre, Heide Aßhoff, Ulrich Heilemann (der nicht anwesend war, aber in Abwesenheit zum stellvertretenden Vorsitzenden gewählt wurde), Philipp Sibbertsen, Wolfgang Leininger, Jörg Bochow, Christian Kleiber, Michael Röhl und Thorsten Ziebach (vgl. Protokoll der VWDS-

${ }^{274}$ Hermann Unterstöger, ein Journalist, der die Tagung dokumentierte, hat „Rotzlümmel“ als Schimpfwort angegeben (vgl. Unterstöger 2000: 10). 
Gründungsversammlung vom 12. November 1997). ${ }^{275}$ Es kamen schnell einige weitere hinzu:

Ich habe einen Aushang gemacht, hier am Institut, darüber konnte ich gleich einige Mitglieder rekrutieren. Aber richtig groß geworden ist der VDS erst durch eine Anzeige in der Frankfurter Allgemeinen (Gespräch mit Walter Krämer vom 25. März 2005). ${ }^{276}$

Horst Hensel schreibt dazu: „Es scheint, als sei die Gründung des Vereins zur Wahrung der deutschen Sprache eine richtige Tat zum richtigen Zeitpunkt gewesen“ (Hensel 1999: 106). Interessant ist auch, dass Krämer nicht der einzige ist, der zu diesem Zeitpunkt anfängt, gegen Anglizismen vorzugehen. Die Vereinsgründung trifft wohl den Nerv der Zeit. Zur gleichen Zeit gruppieren sich private Sprachschützer um Gerhard Junker in Friedrichshafen, im Bodensee-VSDS (vgl. z.B. Krämer/Grobe/Petros 2007: 129). Gerhard Junker hat später wesentlich an der Erstellung der Vereinsrichtlinien des damaligen VWDS mitgearbeitet, außerdem gibt er den Anglizismen-Index heraus.

Ebenfalls ungefähr zur gleichen Zeit (17. Februar 1998) schart Diethold Tietz in Bautzen eine Gruppe von Anglizismengegnern um sich. Aus dieser wird der Sprachrettungsklub Bautzen (vgl. Kapitel 1.7.12.2), der dem VWDS beigetreten ist und bis 2005 eine Regionalgruppe bildete. Heute führt Tietz wieder einen eigenen Verein, den Sprachrettungsklub Bautzen/Oberlausitz.

Auch Dietmar Kinder gründete im September 1997 in Köln eine Vereinigung zur Pflege der deutschen Sprache, das Bürgerforum Deutsche Sprache. Das Bürgerforum wurde mit rund 170 Mitgliedern ebenfalls in den VDS eingegliedert (vgl. Protokoll der VWDS-Vorstandssitzung vom

${ }^{275}$ Der Verein ist im Dortmunder Vereinsregister unter der Nr. 4996 in das Vereinsregister eingetragen (vgl. u.a. Zabel 2001b: 244).

${ }^{276}$ In „Warum ich den VDS gegründet habe“ schreibt Walter Krämer: „Am 14. November 1997, kurz vor vier Uhr nachmittags, treffen sich zehn Menschen im zweiten Stock des Mathematikgebäudes der Dortmunder Universität. Einziger Zweck des Treffens: Gründung des Vereins." (Krämer 2007a: 9). Demnach wäre der Tag der Gründung der 14. November, so war es auch lange auf der Startseite des VDS im Internet zu lesen (VDS 2006f). Auf dem Gründungsprotokoll ist das Datum aber der 12. November. Entweder hat Krämer sich hier in seiner Erinnerung vertan, oder das Gründungsprotokoll trägt ein falsches Datum. Neben der Gründungsversammlung gab es außerdem noch eine Gründungsveranstaltung. Diese fand am 17. November statt. Seit diesem Tag ist der Verein auch im Vereinsregister angemeldet (vgl. Brief des Notars an Walter Krämer, 17. November 1997 und Liste mit Unterschriften der Gründungsmitglieder vom 17. November 1997). 
10. September 1998, Dokument 11; Krämer/Grobe/Petros 2007: 130), und zwar zum Jahresanfang 1999. Ebenso ist der im Mai 1997 von Wilfried Portzehl in Friedrichshafen gegründete „Verein zum Schutz der deutschen Sprache e.V.“ im Jahr 1999 vollständig dem VDS beigetreten, wohl, weil der VWDS schon zu dieser Zeit einigen Bekanntheitsgrad erreicht hatte. Denn nicht nur andere Sprachvereinigungen, auch die Medien werden schnell auf den neu gegründeten Verein aufmerksam. Darunter befinden sich namhafte Zeitungen und Zeitschriften wie die Frankfurter Rundschau, die Frankfurter Allgemeine Zeitung oder der Focus, der bereits am 5. Januar 1998 über den VWDS berichtet hat (Focus 1998: 138). Auch die Süddeutsche Zeitung berichtete bereits im Januar (Süddeutsche Zeitung 1998a: 12). Der öffentlich-rechtliche Rundfunk greift das Thema ebenfalls bald auf. Zum Beispiel widmet das Rhein-MainJournal am 29. Oktober 1998 dem VWDS fast eine ganze Stunde (HR4 1998). Der Spiegel berichtet im November 1998, und damit vergleichsweise spät (Der Spiegel 1998b: 135, vgl. dazu Spitzmüller 2005: 124). Auch namhafte Medien aus dem Ausland, wie der Guardian oder die New York Times thematisieren den VWDS bereits im ersten Jahr nach Vereinsgründung (VWDS 1998b).

Von Anfang an hat der Verein zahlreiche Reaktionen aus der Bevölkerung hervorgerufen. In der Vereinszentrale gehen fast täglich Briefe ein, von Mitgliedern und auch Nichtmitgliedern. Etlichen dieser Schreiben sind Kopien oder ausgeschnittene Originale von Anzeigen oder Zeitungsartikeln beigelegt, häufig auch Produktverpackungen (vgl. z.B. Brief eines VDS-Mitglieds an den VDS, 24. Januar 2001). So schreibt eine Frau: „Herr Professor, ich BITTE Sie, ich FLEHE Sie an, auch TEST muß verschwinden, so weit wie möglich“ (Brief eines VWDSMitglieds an Walter Krämer, 5. August 1999). Der Verein erfährt selbstverständlich nicht nur Zustimmung aus der Bevölkerung, auch wenn ein Großteil der Reaktionen, die in der Vereinszentrale des VDS schriftlich einlaufen, Sympathiebekundungen sind: Ein Mann hat beispielsweise ein Informationsblatt des VWDS an den Verein zurückgefaxt, versehen mit dem Zusatz: „Ist das Ihr einziges Problem? Weil es auch sonst keine Not in der Welt gibt“ (Fax eines Nicht-VWDS-Mitglieds an den VWDS, 5. Mai 1998). Im Vorstand wurde das Problem der Antipathie gerade in den Anfangsjahren des Vereins diskutiert, denn es zeigte 
sich, dass der Verein wiederholt Angriffen seitens der Werbeindustrie, der Wirtschaft, der Journalisten und der Sprachwissenschaft ausgesetzt war (Brief eines VDS-Vorstandsmitglieds an die Vorstandskollegen, 29. Oktober 2000). ${ }^{277}$

\subsubsection{Etablierung der Vereinsstruktur}

Sitz des Vereins war anfangs das Büro von Krämer am Institut für Wirtschafts- und Sozialstatistik der Universität Dortmund. ${ }^{278}$ Den Verwaltungsaufwand erledigte er mit Hilfe der anderen Mitglieder. Die Akten lagerten in den Regalen des Büros, ein Teil wanderte in einen kleinen Kellerraum des Instituts. Das Interesse der Menschen an dem Verein war von Anfang an groß, davon zeugen zahlreiche Ordner mit Korrespondenzen. Bald war das Büro zu klein, der Arbeitsaufwand nahm für Krämer überhand. Böse Zungen sprachen bereits vom „Institut zur Wahrung der deutschen Sprache“ (vgl. Aßhoff 1999: 5). Auf der Vorstandssitzung im Dezember 1999 wurde eine hauptamtliche Geschäftsführerin (Anke Breymann-Mbitse) berufen. Durch ihre Einstellung waren neue Räume nötig geworden (vgl. Protokoll der VWDSVorstandssitzung vom 16. Dezember 1999). Um die Arbeit in der Vereinszentrale zu bewältigen, wurden eine weitere hauptamtliche Mitarbeiterin sowie einige studentische Hilfskräfte beschäftigt (vgl. u.a. Protokoll der VDS-Vorstandssitzung vom 2./3. Februar 2001). BreymannMbitse hatte die Geschäftsführung inne bis Anfang 2008, abgelöst wurde sie von dem Germanisten Dr. Holger Klatte. Mittlerweile hat der Verein zehn Mitarbeiter (vgl. sn 2008: 28).

Der Verein hatte versucht, von der Kulturstiftung der Deutschen Bank eine halbe Stelle finanziert zu bekommen (vgl. Protokoll der VWDSVorstandssitzung vom 14. April 1998), was aber nicht gelungen ist (vgl. E-Mail von Christiane Dahl, Geschäftsstelle VDS, an die Verfasserin, 12. Oktober 2007). Seit 1999 hat der Verein seinen Sitz auf einem Gelände

\footnotetext{
${ }^{277}$ Auch in späteren Jahren wird der Verein noch hin und wieder kritisiert. Hier zeigt sich eine Offenheit im Umgang des Vereins mit Kritik. Beispielsweise werden in den Sprachnachrichten immer wieder kritische Stellungnahmen abgedruckt (vgl. Kapitel 2.5.1.4). ${ }^{278}$ Vogelpothsweg 78, in 44227 Dortmund.
} 
in unmittelbarer Nähe der Dortmunder Universität. ${ }^{279}$ Dort sind Teile des Archivs sowie das Büro des Geschäftsführers untergebracht.

Die Einführung der VWDS-Nachrichten, die seit 1999 regelmäßig erscheinen, war ein weiterer Schritt zur Etablierung der Vereinsstruktur. Dazu kommt der Entwurf eines Logos. Dieses beinhaltet die Farben Schwarz, Rot und Gelb, in Anlehnung an die deutsche Flagge. Die weißen Flächen sollen die Farben Österreichs und der Schweiz symbolisieren, als ganz oder teilweise deutschsprachige Länder (vgl. Junker 2000: 2, Dokument 23). Relativ rasch wuchs die Zahl der Mitglieder, was auch in der Presse nicht unbemerkt blieb. Beispielsweise schrieb die Süddeutsche Zeitung im März 1998:

So gründete erst vor einem Vierteljahr der Soziologie-Professor Walter Kramer [sic] eine Vereinigung zur Erhaltung der deutschen Sprache, der wöchentlich etwa hundert neue Mitglieder zuströmen (love 1998: 17).

Wegen der schnell steigenden Mitgliederzahlen machte sich der Vereinsvorstand schon bald Gedanken über eine Dezentralisierung der Strukturen, wie aus dem Protokoll einer Vorstandssitzung der Anfangszeit hervorgeht:

Es herrscht Konsens, daß wegen des unerwartet großen Zulaufs die Vereinsarbeit so wie in der letzten Vorstandssitzung beschlossen zu dezentralisieren ist. Alle Vorstandsmitglieder können ihnen geeignet erscheinende Personen zu Regionalbeauftragten ernennen (vgl. Protokoll der VWDS-Vorstandssitzung vom 4. Februar 1998).

Nach Erscheinen einer Anzeige in der FAZ am 7. Mai 1998, in der es heißt: „Die Telekom verabschiedet sich von der deutschen Sprache. Wir verabschieden uns von der Telekom" (VWDS 1998d: 19), ${ }^{280}$ verzeichnete der Verein abermals einen großen Zuwachs. Die erste bundesweite Mitgliederversammlung fand am 24. Oktober 1999 in Hannover statt, verbunden mit einem Symposium zum Thema „Die Zukunft der deutschen Sprache“ (Protokoll der ersten bundesweiten VWDS-Mitgliederversammlung vom 24. Oktober 1999). Dort wurde die neue Vereinssatzung gebilligt. ${ }^{281}$ Anfangs wurden sämtliche Beschlüsse in Mitglieder-

\footnotetext{
${ }^{279}$ Im Martin-Schmeißer-Weg 11, 44227 Dortmund.

${ }^{280}$ Diese Anzeige war gleichzeitig als Beitrittsformular zu verwenden.

${ }^{281}$ Vorher gab es noch einen Rechtsstreit vor dem Amtsgericht Dortmund, ob die in der Mitgliederzeitung erfolgte Einladung (Bullermann et al 1999: 6) als schriftliche Einladung zu werten ist (vgl. SN 2000a: 1).
} 
versammlungen gefasst. Dies war aufgrund der Vereinsgröße bald nicht mehr praktikabel. Seitdem gibt es eine Delegiertenversammlung. Diese findet einmal jährlich statt. Dazu entsendet jede zweistellige Postleitzahlenregion ${ }^{282}$ mindestens zwei Vertreter, i.d.R. den Regionalvorsitzenden und einen Vertreter des Regionalvorsitzenden (vgl. u.a. SN 2000e: 12). ${ }^{283}$ Diese Delegierten sind dann ebenfalls stimmberechtigt. Die erste bundesweite Delegiertenversammlung fand am 10. März 2001 in Berlin statt (vgl. SN 2000e: 12).

Wichtigster Punkt der neuen Satzung war die Änderung des Vereinsnamens, der identitätsstiftend wirkt (vgl. ausführlich Kapitel 2.1.4). In der neuen Satzung ist in Paragraph 1 dazu vermerkt: „Der Verein heißt „Verein Deutsche Sprache“ (VDS 2000c: 1, Dokument 3), ebenso ist der Begriff „Kolonisierung“ nicht mehr in der Neufassung der Satzung enthalten (vgl. Kapitel 2.3.2).

Von den Anfängen des Vereins bis heute gab es mehrere kleine Änderungen, wie die, dass das Stimmrecht nicht mehr übertragbar ist (vgl. Protokoll der ersten bundesweiten VWDS-Mitgliederversammlung vom 24. Oktober 1999). Auf den Mitgliederversammlungen finden auch allgemeine Strategiedebatten statt (vgl. Protokoll der ersten bundesweiten VWDS-Mitgliederversammlung vom 24. Oktober 1999) sowie Überlegungen zur Vereinsarbeit. Im Oktober 2002 kam es zu einer weiteren Satzungsänderung in der Wahlordnung (Anlage zum Protokoll der VDS-Vorstandssitzung vom 20. Oktober 2002). Am 15. Februar 2002 gab es einen Beschluss des Vorstands, dass Regionalvorsitzende eines Bundeslandes einen Landeskoordinator wählen können. Über diesen sollen Kontakte zur Landesregierung, deren nachgeordneten Behörden und anderen öffentlichen Einrichtungen laufen. Dabei gilt, dass der Landeskoordinator gleichzeitig Regionalvorsitzender sein muss, und kein Weisungsrecht gegenüber den Regionalvorsitzenden hat. (vgl. Brief eines VDS-Vorstandsmitglieds an Regionalvorsitzende, Ende März 2005). Im

\footnotetext{
${ }^{282}$ Dies bedeutet beispielsweise, die Region, in der die Postleitzahlen mit 96 anfangen, entsendet mindestens zwei Vertreter, ebenso die Region, in der die Postleitzahlen mit 97 anfangen u.s.w.

${ }^{283}$ Falls eine Region über 200 Mitglieder hat, wählen die Regionalgruppen je angefangene Zahl von 100 Mitgliedern einen weiteren Delegierten. Also bekommt eine Region ab dem 201. Mitglied einen weiteren Delegierten, den nächsten ab dem 301. Mitglied.
} 
Jahr 2004 hätte die Satzung ein weiteres Mal geändert werden sollen, dazu kam es aber nicht (für die Änderungen vgl. Dokument 4). Abermals geändert wurde die Satzung im Jahr 2007 (vgl. Protokoll der VDSDelegiertenversammlung vom 16. Juni 2007). Die Änderung betraf den Paragraphen 7, die Vorstandschaft besteht seitdem aus dem Vorstand, seinem Stellvertreter, dem Schatzmeister sowie acht weiteren Personen (vgl. VDS 2007e, Dokument 5). ${ }^{284}$

Eine weitere Satzungsänderung wurde 2008 beschlossen. Betrachtet man den veränderten Paragraphen 2, so stellt man fest, dass der Begriff „Überhäufung“ nicht mehr vorkommt. Außerdem wurden die Ziele des Vereins ergänzt. Der Paragraph lautet nun:

Der Verein verfolgt das Ziel, die deutsche Sprache als eigenständige Kultursprache zu erhalten und zu fördern. Er widersetzt sich insbesondere der fortschreitenden Anglisierung des Deutschen und der Verdrängung der deutschen Sprache aus immer mehr Bereichen des modernen Lebens. Er will bewirken, dass Deutsch als vollwertige Wissenschaftssprache erhalten bleibt und als Arbeitssprache in internationalen Organisationen den ihm gebührenden Rang erhält (vgl. VDS 2008o: 1, Dokument 6 und Kapitel 2.5.9).

Dies war die wichtigste inhaltliche Änderung, ebenfalls leicht angepasst wurde Paragraph 4 der Satzung. ${ }^{285}$

In den mehr als zehn Jahren seit Vereinsgründung, gab es immer wieder interne Querelen: Davon zeugen die „Berliner Verfahrensregeln“. Diese Regeln wurden am 4. August 2002 von Wolf Bock an die VDSRegionalleiter versandt, unterschrieben wurden sie von Kurt Gawlitta. ${ }^{286}$

\footnotetext{
${ }^{284}$ Vorher hatte es geheißen: „Der Vorstand besteht aus dem Vorsitzenden, seinem Stellvertreter sowie dem Schatzmeister (der geschäftsführende Vorstand) sowie sechs weiteren Personen“ (VDS 2000c: 1).

In den Sprachnachrichten ist dazu zu lesen, dass es zu heftigen Streitigkeiten kam, vgl. weiter unten in diesem Kapitel.

${ }^{285}$ Dort heißt es nun: „Der Verein ist selbstlos tätig und verfolgt ausschließlich und unmittelbar gemeinnützige Zwecke im Sinne des Abschnitts „Steuerbegünstigte Zwecke“ der Abgabenordnung. Seine Mittel sind nur entsprechend dieser Satzung zu verwenden. Insbesondere dürfen keine Personen durch satzungsfremde Ausgaben oder durch unverhältnismäßig hohe Vergütungen begünstigt werden“ (VDS 20080: 1).

${ }^{286}$ Es ging um „Versuche, einen anderen VDS zu bauen“ Kurt Gawlitta und Fritz Vilmar warfen den Vereinsmitgliedern „unkritische[n] Gefolgschaft“ vor (Brief von Walter Krämer an VDS-Mitglieder, 24. September 2002, vgl. Gawlitta 2002). Ein Streitpunkt war zudem die Frage, ob ein Sprachschutzgesetz gefordert wird. Mittlerweile gibt es laut Aussage der VDS-Geschäftsstelle zwischen Gawlitta, Vilmar und den anderen Mitgliedern des Bundes-
} 
In ihnen wurde zum Beispiel ein Generalsekretär für den Verein gefordert, doch dem wurde nicht nachgegeben. $\mathrm{Zu}$ den Verfahrensregeln heißt es in einer Stellungnahme des VDS-Bundesvorstands, man wolle "möglichen Spaltungstendenzen keinen Boden bereiten“ (VDSBundesvorstand o.D.). Dass es interne Schwierigkeiten beim VDS gegeben hat, zeigt auch ein Brief, unter anderem von Diethold Tietz, an den Vorstand. Darin wird beanstandet, dass zwar etwa 25 Anträge zur Delegiertenversammlung in die VDS-Geschäftsstelle eingesandt wurden, dies aber den Delegierten nicht mitgeteilt wurden. ${ }^{287}$ Die Unzufriedenheit einiger Mitglieder mit dem Vorstand wird ebenfalls deutlich im Antrag der Region 58 aus dem Jahr 2002:

Der Vorstand kehrt zu einer für alle transparenten, kooperativen, fairen Zusammenarbeit mit den Aktivisten und Regionen zurück und stellt die lang geforderte Vereinsdemokratie her (VDS Region Berlin/Potsdam 2002).

Weitere Hinweise auf Meinungsverschiedenheiten innerhalb des Vereins gibt die Publikation „,Deutsch nix wichtig?' Engagement für die deutsche Sprache“ von Kurt Gawlitta und Fritz Vilmar, 2002. Hier weist Gawlitta darauf hin, dass die Berliner Regionalgruppe Argumente für ein Sprachschutzgesetz erarbeitet habe, aber mit ihrer Forderung nach einem Sprachschutzgesetz beim VDS auf wenig Gegenliebe gestoßen sei. Es sei zu Streitigkeiten mit dem Vorsitzenden gekommen, weil in den Sprachnachrichten zwar Argumente gegen ein Sprachschutzgesetz erschienen sind, und die Gegenrede von Kurt Gawlitta und Fritz Vilmar dort ebenfalls erscheinen sollte, aber auf Einspruch von Krämer, dem sich der Vorstand weitestgehend anschloss, dann nicht veröffentlicht worden ist (vgl. Braun/Gawlitta/Vilmar 2002: 151ff.). Dennoch sind Gawlitta und Vilmar mit ihrer Forderung nach einem Sprachschutzgesetz an die Öffentlichkeit gegangen. ${ }^{288}$ Aus diesem Grund kam es wohl auch zu diesen Meinungsverschiedenheiten und zu einem Ausschlussverfahren gegen ein Vorstandsmitglied (der Ausschluss ist wegen Ver-

vorstands keine Querelen mehr (Gespräch mit Holger Klatte, Geschäftsführer des VDS, 28. November 2008).

287 Gespräch mit Diethold Tietz, 8. Januar 2008. Laut Tietz habe Krämer alle Vorschläge einfach „weggewischt“, die Meinung der Mitglieder spiele im Verein keine Rolle. Dies ist einer der Gründe, die später zu einem Zerwürfnis zwischen Tietz und Krämer führten. ${ }^{288}$ Zur Frage Sprachgesetz ja oder nein vgl. Kapitel 2.3.2. 
fahrensfehlern ungültig, siehe Brief eines VDS-Vorstandsmitglieds an den VDS vom 20. November 2000). Dieses Vorstandsmitglied hätte gerne eine härtere Linie vertreten, so forderte es ein Sprachschutzgesetz. Der Forderung wurde aber nicht stattgegeben. ${ }^{289}$

\begin{abstract}
Abermals Konflikte in dieser Hinsicht gab es im Jahr 2004. Tietz und zwei weitere Mitglieder haben auf der Delegiertenversammlung dazu aufgerufen, dem Vorstand das Misstrauen auszusprechen (vgl. spn 2004: 20 sowie Brief von Walter Krämer an die VDS-Vorstandsmitglieder, Juni 2005):
\end{abstract}

Wie sie ja in ihren Unterlagen sehen, gibt es auch bei uns im VDS Genossen, die ihre Zeit lieber damit zubringen, Sand in das Getriebe zu streuen als unserer Sache weiterzuhelfen. Fünf davon hatte der Vorstand zur Strafe für ein Jahr ausgeschlossen, sozusagen als Ermahnung [...]. Die haben dann geklagt und zu meiner großen Überraschung auch gewonnen. Der wesentliche Urteilstenor war, mit solchen Erscheinungen müsse ein Verein unserer Größe eben fertig werden. [...]. Ich sage auch schon jetzt, daß ich auf die neuerlichen Unterstellungen und Tatsachenverdrehungen, die in weiteren Rundbriefen oder in aktuellen und kommenden Ausgaben einer Zeitschrift namens "Sprachwelt“ schon gekommen sind oder noch kommen werden, weder hier noch sonstwo eingehen werde. Dazu ist mir meine - und auch Ihre - knappe Zeit zu schade. All denen, die andauernd an der Vorstandsarbeit herumzukritteln haben, ohne aber selber etwas zu unserer Sache beizutragen, sage ich hier ganz laut und deutlich: Dann kocht doch Eure eigene Suppe! Aber bitte nicht in unserer Küche! (Krämer 2004d: 24). ${ }^{290}$

${ }^{289}$ In diesen Querelen zeigt sich ein Problem, dass der VDS mit vielen anderen Vereinen teilt: Nicht immer sind die Aktionen, die einzelne Regionalgruppen starten und veranstalten, im Sinne des Bundesverbands. Das Problem zeigt sich ebenfalls an den regionalen Internetauftritten des VDS.

${ }^{290}$ In den Sprachnachrichten 2004, Nr. 2 ist zu lesen: „Nur bei der abschließend vorgesehenen Verabschiedung der neuen Satzung gelang es einigen Wichtigtuern - Dr. Horst Hensel, der diesen Teil der Sitzung leitete, gebrauchte kräftigere Ausdrücke - , mit überflüssigen Änderungs- und Geschäftsordnungsanträgen, den vorgegebenen Zeitrahmen zu sprengen bzw. die nötige Zweidrittel-Mehrheit für einige der von der Antragskommission vorgeschlagenen Änderungen nicht zustandekommen zu lassen.

Für die nächste Versammlung am 4. Juni 2005 in Dresden haben viele Regionalleiter, die schon diesmal eine Resolution zur entschiedenen Mißbilligung solcher Formaldebatten vorbereitet hatten, entschlossene Aktionen gegen dergleichen Verschleppungen angekündigt. Auch Vereinsvorsitzender Krämer konnte angesichts des destruktiven Verhaltens gewisser Teilnehmer einen seiner bekannten Zornesausbrüche nicht unterdrücken." (SN 2004: 20). Maercker verweist darauf, dass es sich bei den Querelen um eine inhaltliche Diskussion um Definitionen handelt (Maercker 2006: 229). In weiten Teilen ging es auch um Verbandsdemokratie. 
2006 wurde eine Schiedskommission unter Vorsitz von Dr. BerndHartwig Gravenhorst eingerichtet. ${ }^{291}$ Dass es immer wieder vereinsintern Meinungsverschiedenheiten gibt, wie die Ziele des Vereins am besten zu erreichen sind, davon zeugt auch die Einleitung der Schiedsordnung:

Im Verein Deutsche Sprache sind in den vergangenen Jahren erhebliche Meinungsunterschiede darüber aufgetreten, auf welchem Wege die Vereinsziele am besten $\mathrm{zu}$ erreichen sind und wie die innere Struktur des Vereins dafür auszugestalten ist. Die dadurch hervorgerufenen Spannungen haben das gemeinsame Bestreben [...] erheblich behindert und eine vertrauensvolle Zusammenarbeit auf allen Ebenen erschwert. Außerdem sind kostenträchtige gerichtliche Verfahren ausgelöst worden (VDS 2005g: 1). ${ }^{292}$

Die Struktur des überparteilichen und unabhängigen gemeinnützigen Vereins hat sich in den letzten Jahren kaum mehr verändert. Nur die Zahl der Mitglieder ist stetig gestiegen. Eine besondere Rolle spielt hierbei Krämers akademische Karriere. Er nutzt seinen Status als Professor gezielt, um andere Hochschullehrer, Akademiker, Politiker und Journalisten anzuwerben, die ihre Bekanntheit wiederum für die Vereinsarbeit nutzen können und so dem Verein als Multiplikatoren dienen. ${ }^{293}$ Der VDS mit seinem Vorsitzenden Krämer legt großen Wert darauf, viele Mitglieder zu bekommen. An den Verein gehen immer wieder Anfragen zwecks Kooperationen, die aber häufig abgelehnt werden. Die „Deutschen Konservativen“ haben beispielsweise eine solche Anfrage gestellt. Die Haltung von Krämer und dem VDS ist in diesem Falle: „Vorträge halten ja, Zusammenarbeit nein“ (Protokoll der VDS-Vorstandssitzung vom 17. Juli 2002, Brief eines VDS-Mitglieds an den VDS, 15. Juni 2002). Mit der kulturpolitischen Zeitschrift „Mut“ besteht eine Zusammenarbeit (vgl. Protokoll der VDS-Vorstandssitzung vom 2./3. Februar 2001). Diese hat sich aber in den Aktivitäten des Vereins bisher nicht

\footnotetext{
${ }^{291}$ Information aus E-Mail von Christiane Dahl an die Verfasserin, 12. Oktober 2007. Kurzzeitig angedacht war auch ein Ehrenrat (vgl. Protokoll der Ad-hoc-Vorstandssitzung vom 15. April 2000) Dieser wurde in einem Protokoll erwähnt, wurde aber mittlerweile als nie existent angegeben (vgl. auch die E-Mail von Christiane Dahl an die Verfasserin, 12. Oktober 2007).

${ }^{292}$ Hervorhebungen im Original.

${ }^{293}$ Dies ist ein bei Vereinen und eben auch bei Sprachvereinen übliches Vorgehen. Auch der ADSV hat schon Wert auf viele Juristen und Lehrer in seinen Reihen gelegt, letztere besonders wegen ihrer Multiplikatoren-Funktion (vgl. z.B. Sauter 2000: 178).
} 
weiter bemerkbar gemacht. ${ }^{294}$ Der VDS gehörte aber zum Netzwerk Deutsche Sprache (siehe Kapitel 1.7.14). Zudem ist er Partnerverein im Europäischen Forum für Mehrsprachigkeit, einer Organisation, die sich für die Förderung der Mehrsprachigkeit in der Europäischen Union einsetzt, wobei unter Mehrsprachigkeit sowohl verstanden wird, dass jeder Einzelne mehrere Sprachen beherrscht, als auch die Verwendung mehrerer Sprachen in einer übernationalen Einrichtung. Der VDS ist auch Mitglied im Europäischen Bürger-Netzwerk EUROPA JETZT!, dessen Ziel es ist, europäische Bürgergesellschaften im Internet $z u$ vernetzen und ihnen so mehr Gehör zu verschaffen (vgl. Grützke 2007). ${ }^{295}$

\subsubsection{Namensgebung: Vom Verein zur Rettung der deutschen Sprache zum Verein Deutsche Sprache}

Die Namensgebung des Vereins Deutsche Sprache war ein langwieriger Prozess: Angedacht war der Verein als „Verein zur Rettung der deutschen Sprache“. Doch schon bei der Gründungsversammlung am 12. November 1997 beschloss die Versammlung, den Zusammenschluss "Verein zur Wahrung der deutschen Sprache“ zu nennen (vgl. Protokoll der VWDS-Gründungsversammlung vom 12. November 1997) ${ }^{296} .1998$ wurde noch einmal kurzzeitig der Name „Verein zum Schutz der deutschen Sprache“ diskutiert (vgl. Protokoll der VWDS-Vorstandssitzung vom 14. April 1998). Anlässlich der Eingliederung des Bürgerforums Deutsche Sprache in den Verein wurde erwogen, den Namen „Bürgerforum Deutsche Sprache“ zu übernehmen, bzw. den Verein „Verein zur Wahrung der deutschen Sprache e.V. - Bürgerforum deutsche Sprache“ zu nennen (Protokoll der VWDS-Vorstandssitzung vom 8. Juli 1998,

\footnotetext{
${ }^{294}$ Der VDS hat versucht, mit dem Goethe-Institut zu kooperieren. Aus dieser Zusammenarbeit wurde nichts (vgl. Protokoll der VDS-Vorstandssitzung vom 2./3. Februar 2001). Angedacht war in den Anfangszeiten des Kulturpreises, diesen gemeinsam mit dem Goethe-Institut zu verleihen. Doch das Goethe-Institut zog sich wieder zurück (Brief von Walter Krämer an die Verfasserin, 7. Januar 2009).

${ }^{295}$ Der Internetauftritt des Bürger-Netzwerks ist höchst unübersichtlich (Grützke 2007).

${ }^{296}$ Krämer schreibt über den Vorschlag „Verein zur Rettung der deutschen Sprache“: „ein Kollege meint, das klingt übertrieben“, daraufhin habe man seinen Vorschlag „zur Wahrung“ angenommen (vgl. Krämer 2007a: 9).
} 
Dokument 10). Beide Alternativen wurden jedoch später wieder verworfen. So hieß der Verein bis zum Jahr 2000 Verein zur Wahrung der deutschen Sprache mit dem Zusatz „Bürger für die Wahrung der sprachlichen und kulturellen Vielfalt Europas (VWDS)“. Heute heißt er Verein Deutsche Sprache e.V.. Hin und wieder wird auch der Zusatz: „Bürger für die Erhaltung der sprachlichen und kulturellen Vielfalt Europas" angeführt.

Laut Krämer war die Namensgebung „Verein zur Wahrung der deutschen Sprache (VWDS)“ einer der größten Fehler, den er in der Vereinsarbeit begangen hat. „Das Wort „Wahrung“ in den Namen mit aufzunehmen, hat den Verein von der Assoziation sehr stark in die deutschtümelnde erzkonservative Ecke gerückt. Ich bin froh, dass wir dieses Wort im Namen wieder los sind“ (Gespräch mit Walter Krämer vom 17. März 2005). ${ }^{297}$ Als er bei den Mitgliedern um die Namensänderung warb, erläuterte er im Editorial der Vereinszeitschrift die Entscheidung:

Diesen Vorschlag haben wir uns nicht leicht gemacht. Aber es geht nicht anders, mit unserem alten Namen rennen wir republikweit gegen $\mathrm{zu}$ viele unnötige Wände (z.B. habe ich seit Gründung des Vereins mehr als 100 Bitt- und Bettelbriefe an Stiftungen, Ministerien und sonstige Mäzene geschrieben, in aller Regel ohne jeden Erfolg [...].) Der neue Namen dagegen ist kurz und knackig, weltanschaulich unanstößig, aber dennoch dem alten Namen äußerst ähnlich (Krämer 1999c: 2).

Auch in den Medien wurde der ursprüngliche Name des Vereins kritisiert. Im Stern stand zu lesen: „Ein schweres Manko des Vereins ist sein Name. >>Verein zur Wahrung der deutschen Sprache e.V. $<<$ klingt gefährlich nach Deutschtümelei und Sprachenpolizei“ (Steinhoff 1999: 60), ebenso äußerte Jörg Drews bei der Herbsttagung der Deutschen Akademie für Sprache und Dichtung Kritik:

Die Kehrseite dieses instabilen deutschen Selbstbewußtseins [gemeint ist das Selbstbewusstsein hinsichtlich der eigenen Sprache und Kultur, Anm. d. Verf.] ist der bisweilen ressentimenthafte Trotz, mit dem dann plötzlich wieder auf das Deutsche gepocht wird. Womit ich dem ,Verein zur Wahrung der deutschen Sprache' keinen Kultur-

${ }^{297}$ Vgl. dazu auch Rundschreiben von Walter Krämer an die VWDS-Mitglieder, August 1999. In diesem Brief warb er bei den Mitgliedern um die Zustimmung zur Namensänderung. 
chauvinismus unterstellen will, sondern nur meine Idiosynkrasien bei diesem Namen erläutern will (Drews 1999: 21).

Die Namensänderung erfolgte am 26. April 2000 (Brief von Walter Krämer an die VDS-Vorstandsmitglieder, 16. Mai 2000), verabschiedet worden war sie auf der ersten bundesweiten Mitgliederversammlung am 24. Oktober 1999 in Hannover. Im Protokoll dieser Versammlung heißt es zur Begründung, mit der Namensänderung sei keine Veränderung der Vereinsphilosophie verbunden, sondern man verspreche sich bessere Förderungsmöglichkeiten, da der alte Name viele Geldgeber abgeschreckt habe (vgl. Protokoll der ersten bundesweiten VWDS-Mitgliederversammlung vom 24. Oktober 1999, vgl. auch Krämer 1999c: 2). Weiter heißt es dort:

Zum anderen enge der Begriff „Wahrung“ das Arbeitsfeld des Vereins $\mathrm{zu}$ sehr ein, der ja auch eine Entwicklung vorantreiben wolle. Zudem sei das Wort „Wahrung“ nicht eindeutig positiv besetzt (Protokoll der ersten bundesweiten VWDS-Mitgliederversammlung vom 24. Oktober 1999).

Erste Bedenken bezüglich des Vereinsnamens seitens eines späteren Mitgliedes und ein Vorschlag zur Namensänderung finden sich zum Beispiel bereits in einer E-Mail vom 24. November 1998:

Wenn nur die Vereinsmeierei nicht wäre. Verein zur Wahrung der deutschen Sprache ist für meinen Geschmack allzu steif und offiziös. Falls es inzwischen einen Spitznamen (Deutschtümler?) für den VWDS gibt, könnte man überlegen, den Schmäh selbstironisch zu konterkarieren und kurzerhand als Vereinsnamen zu übernehmen, à la:

Die Deutschtümler

Verein für Wahrung der deutschen Sprache

Oder anglizistisch verbrämt:

Ässäsoziäschon für Krautspiik (E-Mail eines VWDS-Mitglieds an Walter Krämer, 24. November 1998).

Auch spätere Briefwechsel zwischen Krämer und anderen Mitgliedern zeigen, dass diese Frage die Mitglieder stark bewegt hat:

Umbenennung - unbedingt nötig! Vorschlag: „Bürgerforum Lebendiges Deutsch e.V. oder auch ... „Deutsche Sprache e.V.“ Bloß nichts mehr mit „Wahrung...", „Rettung...“ etc. (Brief eines VWDSVorstandsmitglieds an Walter Krämer, 22. Juni 1999). ${ }^{298}$

Nicht alle Mitglieder waren mit der Änderung des Namens einverstanden, teilweise regte sich heftiger Protest:

${ }^{298}$ Unterstreichungen im Original. 
[...]daß ich noch immer den alten Briefkopf verwende, mag Ihnen zeigen, wie sehr ich nicht einverstanden bin mit der ganzen Richtung, die der Verein genommen hat.

Mit der Umbenennung des Vereins, bzw. der Eliminierung des Wortes „Wahrung“ bin ich absolut nicht einverstanden! Was ist daran rechtsextrem, nationalistisch, dumpf-gestrig [...]? (Brief eines VDSMitglieds an Gerd Schrammen, 24. Februar 2000). ${ }^{299}$

Damit war dieses Mitglied nicht allein. Vereinzelte Mitglieder sahen sich zum Austritt veranlasst. Ein Mitglied des Vereins klagte sogar gegen die Änderung des Namens. In der Begründung für die Klage heißt es:

Gerade die Kombination der Begriffe „Wahrung“ und „deutsche Sprache ${ }^{a 300}$ im Namen des Beklagten (gemeint ist der VDS, Anmerkung der Verfasserin) ist prägend für dessen Ausrichtung. Unter diesem Vereinsnamen ist der Beklagte in den letzten zweieinhalb Jahren auf 10.000 Mitglieder angewachsen. Durch eine Änderung des ursprünglichen Vereinsnamens wird die Intention, nämlich Wahrung der deutschen Sprache abgeschwächt (Nähle/Boss 2000). ${ }^{301}$

Der Kläger verlor den Prozess, die Namensänderung wurde vom Gericht für gültig erklärt. Auch von anderer Seite wurde die Namensänderung nicht gern gesehen: Manfred Riebe vom Verein für Rechtschreibung und Sprachpflege in Nürnberg merkte an:

Das IDS und die GfdS haben eine gewisse Bedeutung in der sprachpolitischen Diskussion, die andere sprachpolitisch agierende Vereine durchaus motivieren kann, sich nicht nur nach deren Handbüchern, sondern auch nach ihrem Wohlwollen zu richten. [...]

Ein Fall eines solchen Einflusses ist auch bei der vor einem Jahr beschlossenen, wenn auch im Rechtsstreit befindlichen Änderung des Vereinsnamens des „Vereins zur Wahrung der deutschen Sprache“ (VWDS), Dortmund, zu vermuten. Er soll künftig unter Tilgung des Wortes ,Wahrung' zu einem ,Verein Deutsche Sprache' (VDS) werden.

,Wahrung'- auch hier scheint es zunächst um nichts weiter als um irgendein Wort zu gehen, das man auch weglassen oder gegen ein anderes, irgendwie ähnliches vertauschen kann. In Wirklichkeit geht es jedoch um politische Orientierung und Zielbestimmung bzw. um deren verdeckt vorgenommene wichtige Veränderung. [...] Zunächst ergibt sich daraus, daß der VWDS-Vorstand außerordentlich anpassungsbereit war und ist, was eine - vereinsrechtlich problematische -

${ }^{299}$ Auch wenn viele Mitglieder die Namensänderung begrüßten, dieses Schreiben ist kein Einzelfall (vgl. dazu z.B. Brief eines VWDS-Mitglieds an den VWDS, 25. Oktober 1999). ${ }^{300}$ Hervorhebungen im Original.

${ }^{301}$ In dieser Klage ging es nicht nur um die Namensänderung, sondern auch um eine weitere Satzungsänderung (siehe dazu 2.1.3) 
Umformulierung wesentlicher Vereinsziele mit Rücksicht auf verschiedentlich erfahrene ,öffentliche Resonanz' bzw. ,Kritik' an diesen betrifft (Riebe o.D.: 9f.).

Ein Großteil der Mitglieder aber war mit der Namensänderung einverstanden oder über diese erfreut. Auch seitens der Sprachwissenschaft wird die Namensänderung positiv bewertet: Stukenbrock verweist in ihrer Untersuchung über den VDS darauf, dass die Namensänderung als „Bemühen der populären Sprachpflege, ernster genommen zu werden“ (Stukenbrock 2005a: 224) zu sehen ist. Nussbaumer sieht die Umbenennung als symptomatisch dafür an, dass sich der VDS mehrheitlich um Mäßigung bemüht (vgl. Nussbaumer 2003: 111).

\subsection{Organisation}

\subsubsection{Vorstand}

Der Vereinsvorstand wurde in der Gründungsversammlung gewählt und durch Zuwahl erweitert und ergänzt. Er wird mittlerweile alle drei Jahre auf der Delegiertenversammlung neu gewählt. Der Vorstand besteht laut Paragraph 7 der Satzung aus dem ersten und zweiten Vorsitzenden sowie dem Schatzmeister und höchstens acht weiteren Personen $^{302}$ (VDS 2007e). Eine Wiederwahl der Vorstandsmitglieder ist zulässig. Jedes geschäftsführende Vorstandsmitglied vertritt den Verein nach außen (vgl. VDS 2000c: 1).

Die Aufgaben des Vorstands bestehen darin, die Vereinsziele in konkrete Maßnahmen umzusetzen, die Mitgliedsbeiträge festzusetzen, Mitglieder gegebenenfalls auszuschließen und einen wissenschaftlichen Beirat $\mathrm{zu}$ bestellen. Vorstandsvorsitzender des Vereins ist heute nach wie vor Vereinsgründer Krämer. Über die Befugnisse des Vorstands kam es zu Unstimmigkeiten. Einigen Mitgliedern war der Führungsstil Krämers zu wenig basisdemokratisch. Diese Querelen gehen aus einem

${ }^{302}$ Hier kam es in der Anfangszeit zu Unstimmigkeiten sowie zu einem Klagepunkt in der Klage eines Mitglieds: Der zweite Vorsitzende Horst Hensel war nicht durch die Mitgliederversammlung zum zweiten Vorsitzenden gewählt worden, sondern durch Kooptation (vgl. dazu u.a. Nähle/Boss). 
Protokoll der VDS-Vorstandssitzung vom 17. Juli 2002 hervor. Dort schreibt Krämer:

Hier scheint es im Vorstand und erst recht im weiteren Verein enorme Unterschiede in der Auffassung zu geben, was man unter Demokratie im allgemeinen und Vereinsdemokratie im besonderen verstehen soll. Insbesondere bin ich immer noch entsetzt über die von Schumacher in Bautzen unwidersprochen vertretene Meinung, der Vorstand sei das ausführende Organ der Delegiertenversammlung. Da kann ich nur auf gut Deutsch sagen: „over my dead body!“ (Protokoll der VDS-Vorstandssitzung vom 17. Juli 2002).

Daraufhin fragt er nach der Meinung des Vorstands:

Sind wir eher ausführendes Organ der Delegiertenversammlung oder eher unabhängige Entscheidungsträger? Etwas irritiert bin ich ferner immer noch von einem kleinen Satz in dem Rundbrief [...] von Anfang Juni: von einer starken Führung zur Diktatur sei es nur ein kleiner Schritt. [...] Diktatur und Führungsstärke haben miteinander nichts zu tun (Protokoll der VDS-Vorstandssitzung vom 17. Juli 2002).

Krämer hat an seinem Führungsstil nichts geändert. Im Jahr 2005 wurde infolge dessen ein Antrag auf Absetzung des Vorstands unter dem Vorsitzenden Krämer gestellt. Doch dazu kam es nicht (vgl. u.a. Brief eines VDS-Vorstandsmitglied an die Vorstandskollegen, 17. Juni 2005).

\subsubsection{Wissenschaftlicher Beirat}

Seit 1999 hat der Verein einen wissenschaftlichen Beirat, der mit der Aufgabe betraut ist, den Verein „in sprachwissenschaftlichen Angelegenheiten" fachlich zu beraten, "namentlich in Fragen der Sprachplanung". Dies besagt das Statut des Beirats (Wissenschaftlicher Beirat des Vereins Deutsche Sprache, o. D., Dokument 7). ${ }^{303}$ Außerdem zählen zu den Aufgaben unter anderem die „sprachwissenschaftlich begründete Bewertung und Kommentierung von Beschlußvorlagen und Beschlüssen des Vereins“, die „Beratung von Einrichtungen und Projekten des Vereins in sprachwissenschaftlichen Angelegenheiten“ sowie die „Beratung des Vereins bei Publikationsprojekten“ (Wissenschaftlicher Beirat des Vereins Deutsche Sprache, o. D.). Aufgabe des Beirats ist

${ }^{303}$ Vgl. auch VDS (2008c). 
auf Beschluß des Vereinsvorstands die Planung und Entwicklung einer Einrichtung, die der wissenschaftlich begründeten Sprachplanung dient und sich mit der Dokumentation der wissenschaftlichen Literatur und publizistischer Beiträge zur Entwicklung der deutschen Sprache und mit selbständigen Sprachplanungsaktivitäten befaßt (Wissenschaftlicher Beirat des Vereins Deutsche Sprache, o. D.). ${ }^{304}$

Diesem Beirat gehörten und gehören Wissenschaftler, darunter auch bekannte Linguisten wie Ulrich Knoop ${ }^{305}$, Helmut Glück ${ }^{306}$ oder Horst Haider Munske sowie einige wenige Journalisten an. Die Zusammensetzung des Gremiums ändert sich hin und wieder. Seit 2006 ist Roland Duhamel, Professor für deutschsprachige Literatur und für die Didaktik des Deutschen in Antwerpen, der auch Vorsitzender des belgischen Germanisten- und Deutschlehrerverbands ist, Vorsitzender des Beirats (Duhamel 2007: 21).

${ }^{304}$ Dies ist insofern interessant, als hier implizit die mögliche Gründung einer Sprachakademie festgehalten ist, eine „Sprachakademie“, wohl auch mit Blick auf die Darmstädter Akademie für Sprache und Dichtung, ausdrücklich nicht als solche bezeichnet wird, anders als beispielsweise in einem der Protokolle der Vorstandssitzungen (Protokoll der VDS-Vorstandssitzung vom 4. November 2001).

${ }^{305}$ Knoop war lange Zeit Vorsitzender des wissenschaftlichen Beirats. Diese Funktion hat er mittlerweile abgegeben: „Zunächst dachte ich, man könne mit klaren Gedanken etwas Nützliches bewirken. Leider nicht, denn die Anglizismendebatte ist kontaminiert mit der Identifikation von Anglizismus mit - vor allem - Amerika insgesamt (!), welches man dann nicht mag und mit dem Angehen gegen Anglizismen dieses Amerika stellvertretend kritisiert. ,Anglizismen' selbst rufen stilistische Probleme hervor - nicht sprachschädigende, da es bei Sprache immer um Sprechen geht (Humboldt: energeia = Sprache existiert nicht an sich sondern nur im Werden). Also ist der Einsatz von Anglizismen a) ein Angeber-Signal (leichter zu lösen mit Lächerlichmachen), aber b) auch ein semantisches Problem: Anglizismen sind ungenau bzw. unpräzise/verschleiernd, ihr Einsatz in Umgangssprache und Journalismus zeigt das: kids suggeriert Lockerheit, ähnlich job, obwohl es um gewichtige Dinge geht. So, das ist aber bei dem leider zusammengewürfelten Haufen von Leuten mit Professorentiteln im Beirat nicht so einfach zu präzisieren“ (vgl. E-Mail von Ulrich Knoop an die Verfasserin, 1. Mai 2008). Mittlerweile ist Knoop aus dem wissenschaftlichen Beirat ausgetreten.

${ }^{306}$ Auch Hermann Fink, der einige Bücher und Aufsätze über den Einfluss der Englischen Sprache auf das Deutsche verfasst hat, gehörte dem wissenschaftlichen Beirat (und dem VDS) an (vgl. Glück 2002a: 11). Er ist am 11. März 2002 verstorben. Er gehörte zu den Gründungsmitgliedern des Beirats, ebenso wie Manfred Fuhrmann, der am 12. Januar 2005 verstorben ist, Helmut Glück (Glück selbst beispielsweise ist nicht Mitglied des VDS, für eine Mitgliedschaft im wissenschaftlichen Beirat ist dies nicht nötig), Hans Haider, Wolfgang-Werner Sauer, Heinz-Günter Schmitz, Ferdinand Urbanek und Wolfram Wills. Diese Mitglieder haben auch die Thesen zur deutschen Sprache erstellt und unterzeichnet (vgl. Glück/Krämer 2000: 91, Spitzmüller 2005: 340). 
Eisenberg bemerkt zum Beirat: „Walter Krämer's Verein deutsche Sprache (VdS) [...] had no problem in constituting a highly reputable academic advisory board“ (Eisenberg 2004b: 122). Damit spricht Eisenberg einen wichtigen Punkt an: das Ansehen der Mitglieder im wissenschaftlichen Beirat, die dieses mit ihrer Mitgliedschaft in den Dienst der Ziele des VDS stellen (vgl. für diese Einstellung auch Protokoll der VDSVorstandssitzung vom 20. Oktober 2002).

Die Beiratsmitglieder sollen die „Verbindung mit wissenschaftlichen Standards und Entwicklungen garantier[en]“ (Brief von Ulrich Knoop an Walter Krämer, 18. September 2002). Hierbei kam es zu Unstimmigkeiten ${ }^{307}$ : Sie sind in den „Verfahrensregeln für eine kooperative Zusammenarbeit im VDS“ und im "Anhang der Verfahrensregeln“ von Kurt Gawlitta (Gawlitta 2002), nachzulesen. Es wurde gefordert, der wissenschaftliche Beirat benötige eine „verbandsdemokratische Grundlage“. Offensichtlich sollte die Delegiertenversammlung die Mitglieder des Beirats wählen, doch dies war nicht der Fall. Knoop begründete die Ablehnung dieser Forderung folgendermaßen:

Da Wissenschaftlichkeit (Wissenschaftlicher Beirat) nicht über Abstimmungen zu erreichen ist, sondern nur durch den Nachweis wissenschaftlicher Qualifikation, liegt hier ein gravierendes Mißverständnis über „Wissenschaft“ [...]. Die Legitimation der Beiratsmitglieder ergibt sich also aus ihrer wissenschaftlichen Qualifikation (Brief von Ulrich Knoop an Walter Krämer, 18. September 2002).

Nach Vorstellung Krämers sollte der wissenschaftliche Beirat sogar einmal „die Keimzelle eines deutschen Äquivalentes der Akademie Francaise [sic] werden [...], sozusagen die ,Academie Allemande’ [sic]“308 (Rundschreiben von Walter Krämer an die VWDS-Vorstandsmitglieder, 20. November 1998).

${ }^{307}$ Auch ein Mitglied äußert sich kritisch: „Es geht unehrlich zu!!! Dauernd wird über Geldmangel geklagt, aber gleichzeitig hält man sich einen zehnköpfigen!!! wissenschaftlichen Beirat! Oder machen die Herren das um Gotteslohn?“ (Brief eines VDS-Mitglieds an Gerd Schrammen, 24. Februar 2000). Dazu ist anzumerken, dass die Tätigkeit im wissenschaftlichen Beirat ehrenamtlich erfolgt.

${ }^{308}$ Aber Krämer selbst sieht gewisse Schwierigkeiten in dem Unterfangen, er schreibt: „[...] aber dazu müssten unsere öffentlichen Meinungsäußerungen weit professioneller und emotionsloser gestaltet werden“ (Rundschreiben von Walter Krämer an die VWDSVorstandsmitglieder, 20. November 1998). 
Das Statut des wissenschaftlichen Beirats beinhaltet unter anderem eine "Verpflichtung zu wissenschaftlicher Objektivität" sowie parteipolitische Neutralität und die Freiheit von Weisungen (vgl. Wissenschaftlicher Beirat des Vereins zur Wahrung der deutschen Sprache 1999). 1999 verfasste der wissenschaftliche Beirat die „Thesen zur Situation der deutschen Sprache“. Diese sollen die Positionen des Vereins wissenschaftlich stützen. Im Entwurf heißt es:

In der Sprachwissenschaft gilt die unbestrittene methodische Leitlinie, daß die zentrale Aufgabe die kontrollierbare Dokumentation, Beschreibung und Analyse der Sprache ist. Dieser Leitlinie widerspricht es nicht, wenn dokumentier-, beschreib- und analysierbare Sprachentwicklungen nach soziolinguistischen, sprachsoziologischen und sprachpolitischen Gesichtspunkten gewichtet und bewertet werden (Wissenschaftlicher Beirat des Vereins zur Wahrung der deutschen Sprache 1999).

Auf die Leitlinie wird anschließend Bezug genommen. Erwähnenswert ist insoweit, dass das Verhältnis zwischen dem VDS und seinem wissenschaftlichen Beirat offenbar nicht immer unproblematisch ist, der raue Umgangston zwischen VDS und Beirat wird beanstandet (vgl. Protokoll der VDS-Vorstandssitzung vom 26. Mai 2002). Außerdem kam es zu einem Gerichtsverfahren zwischen einem VDS-Vorstandsmitglied und einem Mitglied des Beirats (vgl. Protokoll der VDS-Vorstandssitzung vom 2. März 2005). Der wissenschaftliche Beirat betont zur Zusammenarbeit zwischen Verein und Beirat, „daß dieser keine Auftragsarbeiten für den VDS durchführt. Für Rat und Hilfe in wissenschaftlichen Dingen kann er aber jederzeit in Anspruch genommen werden“ (Protokoll der VDS-Vorstandssitzung vom 20. Oktober 2002). Ein Beispiel für die mitunter problematische Zusammenarbeit ist die Publikation „Wörter fallen nicht vom Himmel“ von Kurt Gawlitta und Fritz Vilmar. Diese wurde von Helmut Glück im Namen des wissenschaftlichen Beirats heftig kritisiert:

Ich halte diese Veröffentlichung für sehr problematisch. [...] Weiterhin ist die Veröffentlichung in einigen Teilen auf einem fachlich indiskutablen Niveau (Brief von Helmut Glück an Walter Krämer, 20. Januar 2002).

Glück beanstandet:

Schließlich ist der aufgeregte, abschnittsweise polemische, mitunter sektiererische Grundton der Broschüre nicht geeignet, für die Anliegen des VDS zu werben. [...] Sie ist politisch riskant und steht - meines Wissens - nicht im Einklang mit der offiziellen VDS-Politik. Der 
VDS hat bisher kein Sprachgesetz gefordert (Brief von Helmut Glück an Walter Krämer, 20. Januar 2002). ${ }^{309}$

Der Beirat wurde offenbar vor Erscheinen des Buches nicht angehört. Glück dazu weiter:

Der Wissenschaftliche Beirat wurde u.a. deshalb eingerichtet, daß VDS-Veröffentlichungen nicht der Lächerlichkeit anheimfallen. Er wurde von den Herausgebern nicht um seinen Rat gebeten. Auch deshalb distanziere ich mich von dieser Publikation in aller Form, und zwar im Namen des Wissenschaftlichen Beirats (Brief von Helmut Glück an Walter Krämer, 20. Januar 2002).

Das Buch (vgl. Kapitel 2.5.1.6) ist mittlerweile vergriffen.

Generell ist festzustellen, dass der wissenschaftliche Beirat sich stark im Hintergrund hält und sich nur äußert, wenn er explizit gefragt wird. Vielleicht kann man die Arbeit als eine Art „Einzelberatung hinter den Kulissen" charakterisieren.

Seitens der Sprachwissenschaft wurde die Gründung des Beirats weitgehend positiv aufgenommen. Wiechers konstatierte 2001: „im Hinblick auf den wissenschaftlichen Beirat wäre allerdings zu vermuten, dass in Zukunft die fachliche Auseinandersetzung stärker vorangetrieben wird“ (Wiechers 2001: 156). Im wissenschaftlichen Beirat sei auch das Bemühen des Vereins zu sehen, ernster genommen zu werden: „Der Wissenschaftliche Beirat ist als Bestreben des VDS zu sehen, sich auch aus sprachwissenschaftlicher Sicht mit dem Anliegen des Vereins auseinander zu setzen und von daher positiv zu bewerten“ (Stukenbrock 2005a: 224). Kritisch äußerte sich Nussbaumer, der konstatierte, dass der wissenschaftliche Beirat nicht ernst zu nehmen sei. Diese Aussage begründet er mit seiner Kritik an den Publikationen des Beirats (vgl. Nussbaumer 2003: 114). Spitzmüller, der den Beirat überkritisch als „sog. >>Wissenschaftlichen Beirat<<" (Spitzmüller 2005: 340, ebenso schon Nussbaumer 2003: 114) bezeichnet, sieht in der Einrichtung des Beirats aber einen wichtigen Schritt hin $\mathrm{zu}$ mehr Wissenschaftlichkeit (vgl. Spitzmüller 2005: 340ff.). M.E. ist dies nicht der Fall, da der VDS, der sich als Bürgerinitiative (vgl. Hensel 1999: 98, Krämer/Grobe/Petros 2007: 137) versteht, auf Wissenschaftlichkeit nicht unbedingt gesteiger-

${ }^{309}$ Mit „Sprachgesetz“ gemeint ist ein Sprachschutzgesetz vergleichbar mit der französischen Loi Toubon. Eine gesetzliche Regelung beispielsweise gegen englische Begriffe in Gebrauchsanleitungen ist durchaus Forderung des VDS. 
ten Wert legt. Eher ist der wissenschaftliche Beirat als ein Gremium anzusehen, das den Verein in der Öffentlichkeit als wissenschaftlich beraten darzustellen hat und dessen Tätigkeit das Ziel hat, den VDS in seinen Publikationen von Fehlern abzuhalten.

\subsubsection{Thesen des wissenschaftlichen Beirats}

In acht Thesen ${ }^{310}$ erläutert der wissenschaftliche Beirat die Gründe für eine Kritik der Anglizismen im Deutschen. Die Thesen sind Gegenstand der Forschung. Spitzmüller und Nussbaumer haben sich kritisch mit ihnen auseinandergesetzt.

These eins lautet:

Der äußere Einfluss auf Wortschatz und Struktur der deutschen Sprache war noch nie so groß wie am Ende des 2. Jahrtausends: Die Anglisierung des Deutschen betrifft mittlerweile alle sozialen Schichten der Sprachgemeinschaft (Finke et al. 2000: 88).

Nussbaumer kritisiert an der ersten These des Beirats, dass bezüglich des Terrainverlusts des Deutschen ein differenzierteres Bild gezeichnet werden müsste, unterschieden unter anderem nach Kommunikationsbereichen und Kommunikationssituationen. Ebenso vermisse er eine Reflexion über sprachpolitische Unterschiede und Gemeinsamkeiten zwischen Frankreich und Deutschland (vgl. Nussbaumer 2003: 111). Zudem führt er aus, dass ihn als deutschsprachigen Schweizer der Zusammenhang von Sprache, Volk und Nation irritiere, und verweist darauf, dass dies in der Manier des 19. Jahrhunderts geschehe (vgl. Nussbaumer 2003: 111). Spitzmüller kritisiert unter anderem die zweite These des Beirats, die lautet:

Die Anglisierung des Deutschen ist das Resultat der politischwirtschaftlichen Dominanz der USA, kommunikationstechnischer Entwicklungen und unserer mangelnden Sprachloyalität ${ }^{311}$ (Fink et al. 2000: 88).

Soweit in der zweiten These festgehalten ist, dass kommunikationstechnische Entwicklungen an der Verbreitung von Anglizismen beteiligt

\footnotetext{
${ }^{310}$ Im Entwurf waren zehn Thesen vorgesehen, aber bereits in der Gründungserklärung des Beirats wurden die Argumente in acht Thesen zusammengefasst. Veröffentlicht wurden die zehn Thesen nur einmal in einer Pressemitteilung. Inhaltlich sind sie mit den acht Thesen weitgehend identisch.

${ }^{311}$ Für eine Auseinandersetzung mit dem Begriff „Sprachloyalität“ vgl. Kapitel 1.6.
} 
sind, ist der These zuzustimmen (vgl. Schütte 2000: 77ff., Glück 2000c: 109f.). Schwieriger verhält es sich mit dem zweiten Aspekt der These. Spitzmüller merkt an, die These entwerfe ein nicht zutreffendes Bild eines einseitigen Sprachkontakts in Form eines fremdbestimmten Entlehnungsvorgangs ${ }^{312}$ (vgl. Spitzmüller 2005: 343). Doch diese Kritik ist nur teilweise berechtigt, beklagt die These ja gerade die „mangelnde Sprachloyalität" und sieht so die deutschsprachigen Sprecher, die Anglizismen verwenden, als Ursache.

In These drei wird festgestellt:

Die Sprachmacht ist heute in hohem Maß an Werbeagenturen, Journalismus und „Prominente“ gefallen. Dies ist zu beklagen. Sie muss der Sprachgemeinschaft zurückgegeben werden (Fink et al. 2000: 89).

An dieser These kritisiert Spitzmüller, dass nach wie vor die Entscheidung, welche Wörter man verwendet und welche eben nicht, bei jedem Einzelnen liege. Darauf, dass der Sprachteilhaber beispielsweise durch Zeitungen und audiovisuelle Medien beeinflusst wird, teilweise auch durch sprachpolitische Einrichtungen, ${ }^{313}$ nimmt er keinen Bezug.

These fünf lautet:

Das Deutsche ist in einigen Fachgebieten als Kommunikationsmittel ungebräuchlich geworden und droht unbrauchbar $\mathrm{zu}$ werden. Es ist in Gefahr, seinen Status als Wissenschafts- und Kultursprache zu verlieren (Fink et al. 2000: 90).

Spitzmüller argumentiert hier, dass die Verfasser mit dieser These einen anderen Teildiskurs betreten, der nicht mit dem Anglizismendiskurs vermischt werden sollte (vgl. Spitzmüller 2005: 349f.). Hierbei sei auf die Panik, ${ }^{314}$ die diese These hervorruft, aufmerksam gemacht (vgl. auch Kapitel 2.4.2).

In These sieben konstatieren die Beiratsmitglieder: „Es besteht dringender Bedarf an professioneller Planung der Entwicklung und Verwendung der Sprache (Sprachplanung)“ (Fink et al. 2000: 90). Diese Forderung nach Sprachplanung ist linguistisch durchaus legitim (vgl. auch Spitzmüller 2005: 349).

${ }^{312}$ Hier wählt Spitzmüller eine etwas unglückliche Ausdrucksweise, da ein Entlehnungsvorgang in der Regel nicht fremdbestimmt ist.

313 Beispielhaft sei hier auf Island oder Frankreich verwiesen.

${ }^{314}$ M.E. ist „Panik“ hier ein zu starkes Wort. 
Die achte These lautet: „Die Verteidigung einer guten, flexiblen, anspruchsvollen Sprache ist keine Deutschtümelei, sondern das Bekenntnis zu einem kulturellen Erbe, und sie dient der Erhaltung der Funktionsfähigkeit des Deutschen für spätere Generationen“ (Fink et al. 2000: 91). Hier werden zwei völlig unterschiedliche Aspekte miteinander vermischt: Einerseits, dass Gegner von Sprachreinigern diesen Deutschtümelei vorwerfen und sie in die rechte Ecke stellen. Dieser generelle Vorwurf der Deutschtümelei ist m.E. unberechtigt. Andererseits ist aber nicht abzusehen, dass das Deutsche seine Funktionsfähigkeit verliert. Dies ist als Übertreibung zu werten. In der Erklärung heißt es weiter: „Das Eintreten gegen die Anglisierung des Deutschen [...] wird oft [...] als undifferenzierter Purismus oder als wissenschaftsfremd denunziert" (Fink et al. 2000: 91). Damit verweist der wissenschaftliche Beirat darauf, dass sich die diesem Gremium angehörenden Mitglieder in ihren Publikationen durchaus mit der Thematik der Anglizismen im Deutschen auseinandergesetzt haben (vgl. u.a. Fink 1970, 1980, 1983, 2001, 1996, Glück/Sauer 1997, Schmitz 1999, Munske 2001). Die Vereinsarbeit basiert jedoch nicht auf einer wissenschaftlichen Fremdwortdefinition, und es handelt sich nicht um eine wissenschaftliche Vereinigung (z.B. Krämer 1998b: 5). ${ }^{315}$

Stukenbrock bemerkt insgesamt zur Kritik an den sprachpflegenden Institutionen:

Hier wird deutlich, dass es sich beim diskursiven Kampf des VDS nicht nur um [...] die Durchsetzung des eigenen präskriptiven Regulierungsbedürfnisses gegen den linguistischen Deskriptivismus, sondern auch um soziale, politische und materielle Macht und Ressourcenverteilung handelt (Stukenbrock 2005a: 234). ${ }^{316}$

Es zeigt sich, dass die Thesen durchaus wissenschafts- und sprachpolitische Punkte ansprechen, die innerhalb der Germanistik diskutiert werden und diskutiert werden sollten. Sie beinhalten substanzielle Fragen der Sprachpolitik (vgl. Spitzmüller 2005: 350). Für bedenklich hält Nussbaumer, dass sich hinter den Statements des Beirats die Vorstellung „einer statischen und reinen Sprache“ verbirgt, und damit „die

315 Damit teilt der Verein als Bürgerinitiative mit vielen anderen Bürgerinitiativen, dass die Argumente keine wissenschaftlichen Wesensmerkmale haben.

${ }^{316}$ Diese Anmerkung ist bezogen auf die GfdS, die nach Ansicht des VDS einen überproportionalen Anteil an staatlichen Ressourcen für die Sprachpflege bekommt. 
sattsam bekannte Ideologie des Eigenen und des Fremden“ (Nussbaumer 2003: 113). Er führt aus:

Als laienlinguistische Theorie - und nicht zuletzt mit ihren Bezügen zu politischen Einstellungen dem Eigenen und dem Fremden gegenüber [...] - ist diese Position ernst zu nehmen, als theoretisches Rüstzeug eines wissenschaftlichen Beirats ist sie einfach wertlos und gedankenlos (Nussbaumer 2003: 113).

Spitzmüller kritisiert insgesamt an den Thesen:

Eine Auseinandersetzung mit der Fachdiskussion findet leider kaum statt und der Eindruck, dass teilweise wissenschaftliche Befunde nur halb oder in falscher Korrelation wiedergegeben werden, um vorhandene Thesen zu stützen, drängt sich an einigen Stellen auf (Spitzmüller 2005: 350).

Ähnlich hatte sich Nussbaumer im Jahr 2003 geäußert:

Für alle Beiträge gilt jedoch, dass sie ihre Thematik nicht wirklich gründlich analytisch angehen, sondern sehr bruchstückhaft, essayistisch, polemisch [...] - eben nicht so, wie man es von einem „wissenschaftlichen Beirat" erwarten würde. Es fehlt in den Beiträgen [gemeint sind damit auch die weiteren Beiträge in Glück/Krämer 2000, nicht nur die Thesen des Wissenschaftlichen Beirats, Anm. d. Verf.] auch weitestgehend die Verweisung auf die ruhige, breit angelegte wissenschaftlichen [sic] Beschäftigung mit der Thematik, so als gäbe es diese nicht (Nussbaumer 2003: 111).

Insgesamt bin ich mit Spitzmüller der Meinung, dass die Thesen des Beirats „eher ein sprachpolitisches und wissenschaftspolitisches Dokument als eine wissenschaftliche Begründung von Anglizismenkritik“ (Spitzmüller 2005: 350) sind, da die Verfasser größtenteils Argumente des öffentlichen Diskurses verwenden, weitgehend aber auf eine wissenschaftliche Untermauerung verzichten (vgl. Spitzmüller 2005: 350, Nussbaumer 2003: 111). Hier rückt die Zielgruppe der Thesen in den Blick, denn die Thesen wenden sich nicht an ein Fachpublikum, sondern an eine breite Öffentlichkeit, und damit hauptsächlich an linguistische Laien.

\subsubsection{Arbeitsgruppen}

Der VDS hat zahlreiche Arbeitsgruppen, die sich mit verschiedenen Themen beschäftigen oder deren Mitglieder in unterschiedliche Gruppierungen, darunter auch Parteien, hinein wirken. An dieser Stelle sol- 
len die einzelnen Arbeitsgruppen vorgestellt werden, ihre Arbeit und deren Ergebnisse ${ }^{317}$ werden im Rahmen der Vereinsarbeit besprochen. Zum Beispiel gibt es die Arbeitsgruppe „Regionalleiter“, in der die Regionalleiter organisiert sind. Es gibt eine Arbeitsgruppe „Internationale Deutschlehrer-Initiative“, die fast 15000 Mitglieder hat (vgl. Pogarell 2007c: 8), größtenteils passive Mitglieder, verteilt auf etwa 70 Staaten (vgl. Kapitel 2.5.2).

Eine weitere Arbeitsgruppe nennt sich „Kontakt zu Schulen“. Vorsitzender ist Franz Aschenbrenner (ein Regionalvorsitzender), der als Englischlehrer an einer Berufsschule seine Schüler bei Menschen, die „Denglisch“ benutzt haben, auf Englisch anrufen ließ (Aschenbrenner 2006: 19) und die Schüler animierte, Anglizismen-Listen zu erstellen. ${ }^{318}$ Als erstes Arbeitsergebnis der Tagung Idensen 2 sind auf den Internetseiten des VDS nun auch Materialien und Unterrichtseinheiten zu finden, teilweise erstellt von Aschenbrenner. Vorgeschlagen wurde das Sammeln von „denglischen“ Ausdrücken. Es wurde hier explizit angemerkt, dass auch Lehrer, die „Denglisch“ nicht kritisch gegenüberstehen, diese Unterrichtseinheiten verwenden können. Dennoch bleibt festzuhalten, dass diese Vorschläge für eine Unterrichtseinheit letztendlich wieder darin endeten, dass Schüler Briefe an "Sprachsünder" verfassten (vgl. VDS 2008i).

Außerdem gibt es die Arbeitsgruppe „Wörterliste“. Ihre Aufgabe ist die Erstellung und Pflege der Anglizismenliste, die im Internet und als gedruckte Ausgabe erhältlich ist. In diesem Fall gibt es ein greifbares Ergebnis. $\mathrm{Zu}$ einer ausführlicheren Darstellung dieser Wörterliste, erschienen als Anglizismen-Index, siehe Kapitel 2.5.1.3.

Die Arbeitsgruppe „Tag der deutschen Sprache“ bereitet Aktionen für den Tag der deutschen Sprache vor (vgl. Kapitel 2.5.3). Etwas aus dem Rahmen fällt die Arbeitsgruppe "Gegen Abschaffung des Diploms“, da sie ein Ziel verfolgt, das nicht in direktem Zusammenhang mit den Anglizismen im Deutschen steht, sondern als wissenschaftspolitisch zu

${ }^{317}$ Hin und wieder drängt sich der Eindruck auf, dass es keinerlei Ergebnisse gibt, sondern die Aktionen einfach im Sande verlaufen.

${ }^{318}$ Mit diesem Fokus auf die Schule bewegt sich der VDS in der Tradition des ADSV/DSV, auf dessen Einwirken auf die Schulen verweist z.B. Clay (1981: 63). 
werten ist (vgl. Kapitel 2.5.9). Daneben gibt es die Arbeitsgruppen „Gegen bundesweiten Immersionsunterricht“, „Sprachlicher Verbraucherschutz“, „Stadtplanung und Stadtkultur“, „Bündnis 90/Die Grünen für klares Deutsch“, „CDU für klares Deutsch“, „SPD für klares Deutsch“, „Wörterliste (Anglizismen-INDEX)“, „Sprachenpolitik in Europa“, „Betriebswirte für klares Deutsch“, „Deutsche Sprache im Patentwesen“, "Informationstechnik und Informatik“, „Statistiker für klares Deutsch“, „Volkswirte für klares Deutsch“, „Mittelstand“, „Dialekte“, „Mathematiker für klares Deutsch“, „Studenten für klares Deutsch“, „Schulchöre“ (diese Arbeitsgruppe möchte Schulchöre dazu bewegen, deutsche Lieder zu singen, vgl. SN 2005b: 21), „Sprache und Marketing“, „Christen für klares Deutsch“ und „Für gutes Deutsch in Medizin und Biomedizin“.319

Die Gruppe „Demokratische Linke gegen politische Diffamierung des VDS“, die auf Betreiben des Berliner VDS gegründet wurde, sollte sich mit dem Problem beschäftigen, dass der VDS immer wieder in die rechte Ecke gerückt wird. Sie wurde aber nach kurzem Bestehen wieder aufgelöst, ohne in irgendeiner Weise aktiv zu werden (vgl. Rundschreiben zweier VDS-Vorstandsmitglieder an die Vorstandskollegen, 29. September 2002, vgl. ausführlich Kapitel 2.6). Seit dem Jahr 2005 wirbt die Arbeitsgruppe „Deutsch ins Grundgesetz“ bei Politikern darum, sich für die Verankerung des Deutschen im Grundgesetz einzusetzen (vgl. SN 2005b: 21, ausführlich Kapitel 2.3.2). Die meisten dieser Arbeitsgruppen treten außer auf der Homepage des VDS, auf der Ansprechpartner und Kontaktadressen aufgelistet sind, nicht in Erscheinung. Das weiß auch der Vorsitzende, der dies billigt:

Zur Funktion der Arbeitsgruppen: Viele sind nur reine Briefkastenadressen bzw. Anlaufstellen für Interessierte ohne eigene Aktionen. Bisher konnte jeder, der wollte, eine AG gründen. Meiner Meinung nach könnten wir das auch in Zukunft so halten. [...] Sollte sich herausstellen, daß AGs dem VDS mehr schaden als nützen, werden sie

${ }^{319}$ Außerdem gab es die Arbeitsgruppen „Klares Deutsch in der christlichen Arbeit“, „Frauen im VDS“, „AG-Werbung“, „FDP für klares Deutsch“, den „Weltverband Deutschsprachiger Journalisten (WDJ)“, „Klares Deutsch auf Hauptversammlungen“, „Esperantisten und Interlinguisten für klares Deutsch“, „Deutsche Sprache in europäischen Institutionen und Organisationen“, „Sprachenpolitik“, und die Arbeitsgruppen „Schüler für klares Deutsch“ sowie „Rhetorik für gutes Deutsch“. 
vom Vorstand [...] aufgelöst (Brief von Walter Krämer an die VDS-

Vorstandsmitglieder, 15. Juni 2001). ${ }^{320}$

Insofern hat der VDS zwar unzählige Arbeitsgruppen, viele haben aber keine wirkliche Funktion und auf die Erreichung der Vereinsziele somit keine Auswirkungen.

\subsubsection{Regionalgruppen}

Aufgrund der rapide wachsenden Mitgliederzahlen kam es zur Gründung von einzelnen Regionalgruppen. Mittlerweile hat der Verein 112, 75 im Inland und 37 im Ausland. ${ }^{321}$ Regionalgruppen im Ausland gibt es - meist auf Betreiben von Manfred Schroeder - in Ägypten, Algerien, Armenien, Aserbaidschan, Australien, Benin, Brasilien, Bulgarien, Elfenbeinküste, Estland, Finnland, Frankreich, Georgien, Ghana, Griechenland, Indonesien, Iran, Italien, Jemen, Jordanien, Kamerun, Kolumbien, Korea, Kroatien, Lettland, Litauen, Marokko, Mazedonien, Polen, Portugal, Rumänien, Russland, Senegal, Spanien, Südafrika, Togo, Türkei, Ukraine, Usbekistan und Weißrussland. Doch einige dieser Regionalgruppen im Ausland sind nicht aktiv. ${ }^{322}$ Keine Regionalgruppen gibt es dagegen in Österreich und der Schweiz. Auf Gründung einer Regionalgruppe in Österreich wurde bisher verzichtet auch auf Grund der politischen Positionen einiger bisher existierenden Sprachvereinigungen. Dagegen besteht eine enge Zusammenarbeit mit dem schweizerischen Sprachkreis Deutsch. Aus diesem Grund gibt es dort keine Regionalgruppe. ${ }^{323}$

Im Inland existieren Regionalgruppen mit vielen Mitgliedern, wie zum Beispiel die Regionalgruppen 30 und 50 mit fast 400 Mitgliedern, die Regionalgruppen $44^{324}$, 22 und 27 mit etwa 300 Mitgliedern, die Regionalgruppen 31, 45 und 51 mit etwa 250 Mitgliedern, die Regionalgrup-

\footnotetext{
${ }^{320}$ An dieser Politik hat sich nichts geändert.

${ }^{321}$ Die Regionalgruppen in Deutschland sind aufgeteilt nach zweistelligen Postleitzahlen, vgl. Kapitel 2.1.3.

${ }^{322}$ Auf Aktivität der Regionalgruppen kommt es Krämer erst in zweiter Linie an, wichtiger ist, dass überhaupt Regionalgruppen existieren. Dies geht aus einem Brief Krämers an einen potenziellen Regionalleiter in Portugal hervor (Brief von Walter Krämer an einen potentiellen Regionalleiter in Portugal, 20. Oktober 1998).

${ }^{323}$ Gespräch mit Holger Klatte, Geschäftsführer des VDS, 28. November 2008.

${ }^{324}$ Wobei die Nummerierung an die Postleitzahlen angelehnt ist.
} 
pen 21, 55, 59, 60, 61, 63, 76 und 79 mit rund 200 Mitgliedern. Dagegen gibt es auch Regionalgruppen, gerade im ländlichen Raum, die weniger als 20 Mitglieder haben, wie zum Beispiel die Regionalgruppen 98, 11, 19 und 16. Mitgliederstärkste Städte sind Berlin, Hamburg und Köln (vgl. Krämer/Grobe/Petros 2007: 158). Jede Regionalgruppe hat einen Regionalvorsitzenden und einen stellvertretenden Regionalvorsitzenden. Diese werden für eine Amtszeit von drei Jahren gewählt. Sie „unterstützen den Vereinsvorstand in der jeweiligen Region und vertreten die Mitglieder in der Delegiertenversammlung“ (VDS 2000c: 1). Bei der Aufgabenverteilung der Regionalvorsitzenden im Inland hat es Unstimmigkeiten gegeben: Einzelne Regionalvorsitzende haben nicht besetzte Nachbarregionen mit übernommen. Diese Übernahme der Verantwortung für Nachbarregionen soll nun nicht mehr erfolgen (VDS 2000c: 1).

\subsubsection{Mitglieder}

Die Mitglieder des VDS werden zentral in einer Mitgliederdatenbank erfasst. Für einen Beitrag von 30 Euro im Jahr kann jeder dem VDS beitreten. ${ }^{325}$ Wer will kann auch einen höheren Jahresbeitrag entrichten. Vor Vollendung des 27. Lebensjahres ist die Mitgliedschaft im VDS kostenlos. Ist bereits ein Familienmitglied im Verein, kostet die Mitgliedschaft für weitere Erwachsene 2,50 Euro im Jahr. Ausnahmen gibt es auch für ausländische Mitglieder. Während Mitglieder aus Europa und OECD-Staaten die gleichen Beitragssätze entrichten wie Mitglieder aus dem Inland, kostet eine Mitgliedschaft für Mitglieder aus Entwicklungsund Schwellenländern nichts (Schroeder 2008: 27).

Der Großteil der Mitglieder sind Männer ab 45 Jahren sind, häufig mit akademischer Ausbildung. ${ }^{326}$ Die Mitglieder arbeiten vornehmlich in

\footnotetext{
32535 Euro für Selbstüberweiser, Beitragssätze gelten seit dem Jahr 2007, vorher 20 Euro, vor der Euro-Einführung 40 DM, für Mitglieder, die überweisen 50 DM (vgl. u.a. Krämer 2007f: 2, SN 2001f: 16).

${ }^{326}$ Rund zehn Prozent der Mitglieder haben einen Doktortitel, etwa zwei Prozent sind Professorinnen und Professoren. Die Zahlen gehen aus der Mitgliederdatenbank des VDS hervor. Stand: 21. März 2005 sowie 24. April 2009. Ein ähnliches Bild zeichnet auch Baumert, der sich in einer Untersuchung mit den regionalen Führungen des VDS beschäftigt hat: „Auffällig sind das Durchschnittsalter und die soziale Stellung der Antwortenden. Das
} 
technischen, naturwissenschaftlichen und juristischen Berufen. Viele von ihnen haben jahrelang im Ausland gelebt.

Durch die kontinuierliche Steigerung der Mitgliederzahlen hatte der Verein bereits nach neun Monaten die GfdS, bis dahin die größte Vereinigung mit sprachpflegerischen Zielen, überholt, Anfang des Jahres 1999 war die 5000-Marke überschritten (vgl. Krämer 1999a: 2), das 10 000. Mitglied begrüßte der VDS im Jahr 2000 (vgl. SN 2000e: 5), Anfang des Jahres 2003 hatte der VDS 15261 Mitglieder (Stand Januar), davon ca. 1600 Ausländer (Protokoll der VDS-Vorstandssitzung vom 31. Januar 2003). Heute hat der VDS etwa 31000 Mitglieder in über 70 Ländern. ${ }^{327}$ Davon leben über die Hälfte in Deutschland (VDS 2008b).

Die meisten sind keine Mitglieder in politischen Parteien, und wenn doch, dann in demokratischen. ${ }^{328}$ Nach Angaben von Horst Hensel werden politisch rechtsgerichtete Personen im Verein nicht geduldet: „Manchmal melden sich aber auch seltsame Gestalten, frakturschriftschreibende Deutschtümler oder gar Nationalisten. Sie haben im Verein nichts zu suchen“ (Hensel 1999: 105). ${ }^{329}$

Es befinden sich viele Prominente unter den Mitgliedern, wie der Fußballtrainer Ottmar Hitzfeld, der Komiker Dieter Hallervorden, der Sänger Reinhard Mey, der Komiker Hape Kerkeling oder der Linguist Harald Weinrich. Der Kolumnist und Autor Bastian Sick ist Ehrenmitglied des VDS (vgl. Protokoll der VDS-Vorstandssitzung vom 2. März 2005). Viele dieser Prominenten werben für den VDS in Anzeigen. ${ }^{330}$ Auch Politikerinnen und Politiker sind Mitglied, darunter Walter Hirche, ehemaliger Minister für Wirtschaft, Arbeit und Verkehr des Landes Nie-

\footnotetext{
Alter reichte von 18 bis 96 Jahren, der Durchschnitt liegt mit etwas über 62 Jahren kurz vor dem Eintritt ins Rentenalter." Die am häufigsten genannten Berufe waren mit 15 Prozent Lehrer, über 33 Prozent der Befragten gaben an, einen Doktortitel zu haben, 20 Prozent waren habilitiert. (vgl. Baumert 2005: 41).

${ }^{327}$ Damit ist der VDS die größte Vereinigung in Deutschland dieser Art. Baumert spricht von „beeindruckender Größe“ (Baumert 2005: 32).

328 Gespräch mit Walter Krämer, 25. März 2005.

${ }^{329}$ In diesem Zusammenhang steht auch der Ausschluss von Mitgliedern, denen die Verbreitung rechtsextremen Gedankenguts oder die Mitgliedschaft in einer rechtsextremen Vereinigung nachgewiesen werden kann (siehe dazu Kapitel 2.6).

${ }^{330}$ Bastian Sick sagt zum Beispiel: „Wie ein Haus aus Steckbausteinen lässt sich unsere Sprache immer wieder neu zusammensetzen. Das macht sie so reich - und uns alle zu Architekten“ (SN 2006b: 10).
} 
dersachsen (vgl. u.a. SN 2005d: 3). Unter den Mitgliedern war auch die ehemalige stellvertretende SPD-Vorsitzende Renate Schmidt (vgl. u.a. Protokoll der VWDS-Vorstandssitzung vom 8. Juli 1998). Sie ist 1999 wieder ausgetreten, nachdem Vorwürfe bezüglich Rechtsradikalismus gegen den VDS aufgekommen waren (vgl. dazu u.a. Brief eines VWDSVorstandsmitglieds an einige Vorstandskollegen, 21. September 1999).

Der Verein hat durch Mitgliedschaften anderer Vereine zahlreiche Mitglieder gewonnen. Mitglieder sind der Heimatbund Niedersachsen e.V., der Verein Quelle (Lettland), der Verein der Deutschen in Klapeida/Memel (Litauen), der Verein der Dünaburger Deutschen (Lettland), der Verein der ehemaligen Thai-Studenten (Thailand), der Verein Deutscher Ingenieure (Argentinien), der Verein Ehemaliger Stipendiaten (Argentinien), der Verein ehemaliger V-Studenten (Argentinien), der Verein für ägyptische Übersetzer (Ägypten), der Verein Mutter Erde e.V., die Vereinigung der in Deutschland ausgebildeten Äthiopier (Äthiopien), die Vereinigung DACH-L (Indien), die Vereinigung der Deutschland-Rückkehrer (Ghana), die Vereinigung Deutsche Minderheit Arnswald (Polen), die Vereinigung Deutsche Minderheit in Starg (Polen), die Vereinigung Deutsche Minderheit Swinemünde (Polen) und die Vereinigung ehemaliger Ballester-Schüler (Argentinien). ${ }^{331}$ Als „korporatives Mitglied“ geführt sind in der Datenbank: Die Vereinigung Avenier de la Langue Francaise (Frankreich), Bund deutscher Nordschleswiger (Dänemark), der Bundesverband Mittelständischer Wirtschaft, der Deutsche Werkbund, der Deutsche Rock \& Popmusikerverband, der Förderverein „Schwäbischer Dialekt“ e.V., und die Theodor-Fontane-Gesellschaft e.V.. Ebenso ist die Senioren-Union der CDU korporatives Mitglied (vgl. VDS 2008g, sie taucht aber in der Datenbank als normales Mitglied auf). Die meisten dieser Mitglieder haben keine Beiträge zu leisten. ${ }^{332}$

Krämer versucht, gezielt Menschen, die in Deutschland in Zusammenhang mit Sprachpflege stehen, als Mitglieder anzuwerben. Darunter fallen beispielsweise Günther Drosdowski, der ehemalige Leiter der Dudenredaktion (verstorben im Jahr 2000) oder Horst Schlosser (GfdS). Letzterer hat eine Mitgliedschaft im VDS abgelehnt. Helmut Glück bei-

${ }^{331}$ Abfrage der elektronischen Mitgliederdatenbank des VDS, 28. November 2008.

${ }^{332}$ Abfrage der elektronischen Mitgliederdatenbank des VDS, 28. November 2008. 
spielsweise hält die Mitgliedschaft nicht für nötig, obwohl er einige Zeit lang Vorsitzender des wissenschaftlichen Beirats war. Seit dem 28. Oktober 2005 ist eine ganze Stadt Mitglied im VDS, das thüringische Mühlhausen (vgl. spn 2005: 28), und auch die Stadt Gotha ist seit 2005 Mitglied im VDS (vgl. Protokoll der VDS-Vorstandssitzung vom 12. November 2005), ebenso die Städte Rastatt, Landshut und Trossingen sowie die Landkreise Sömmerda und Harburg ${ }^{33}$. Die probonoFernsehproduktionsgesellschaft ist ebenfalls dem VDS beigetreten (vgl. medfux.de 2006: 13). Auch eine Universität, die Pomoren-Universität in Russland, ist Mitglied des VDS (Mindner 2008: 23).

Wie schon ausgeführt legt Krämer großen Wert auf viele Mitglieder. Dies zeigt sich immer wieder in Aktionen, so im Jahr 2002 mit der Aktion 26 000. Zu diesem Zeitpunkt hatte der Verein 13000 Mitglieder. Die Sprachnachrichten forderten diese auf, weitere $\mathrm{zu}$ werben, um die Mitgliederzahl zu verdoppeln. Krämers Argument: „Nur wenn wir viele sind, nimmt die Politik uns ernst!“ (SN 2002d: 8).

\subsubsection{Lokale Sprachbündnisse}

Die Arbeit des VDS wird auch durch lokale Sprachbündnisse unterstützt. Das Sprachbündnis Franken ist eine gemeinsame Initiative des VDS und der Senioren-Initiative Nürnberg e.V. (SIN) (siehe Kapitel 1.7.12.1). Es existiert seit dem 11. September 2004. Ziel des Sprachbündnisses ist es, „einen selbstbewußten und pfleglichen Umgang mit dem Kulturgut „Sprache” in allen Bereichen unserer Gesellschaft [zu] fördern“. Das Sprachbündnis befürchtet eine soziale Spaltung und kritisiert, „daß die deutsche Sprache vor allem in Wirtschaft, Medien und Wissenschaft, sogar im Inland, zunehmend durch Englisch ersetzt wird. Deutsch wird durch Englisch als Konferenzsprache, in vielen Konzernen sogar als Umgangssprache, abgelöst“ (Sprachbündnis Franken 2005a). Dieser Entwicklung möchte das Sprachbündnis entgegenwirken. In der Erklärung heißt es:

333 Information aus Abfrage der Mitgliederdatenbank, 2. Februar 2009. Ebenso wie Vereine als juristische Personen Vereinsmitglied sein können, gilt dies auch für Gemeinden oder Landkreise. 
Deutsch wird wieder eine Aufwertung erfahren, wenn es als dritte Amtsprache der EU neben Englisch und Französisch angewandt wird. Dieser einstimmige Beschluß des Bundestages (Deutsch als dritte Amtsprache) vom 1.4.2004 wird von uns unterstützt (Sprachbündnis Franken 2005a). ${ }^{334}$

Die Mitglieder des Sprachbündnisses nehmen regelmäßig mit eigenen Aktionen am Tag der deutschen Sprache teil. Das Sprachbündnis Franken hat auf Initiative der Senioreninitiative die „Aktion Nein zu Denglisch" ins Leben gerufen. Die Senioreninitiative hat ihren Ursprung in der Sorge vor einer Ausgrenzung der vielen Alten ohne Fremdsprachenkenntnisse (vgl. dazu Sprachbündnis Franken 2005b). Im Verlauf der Aktion wurden über 10000 Unterschriften gegen Anglizismen gesammelt. Die Senioreninitiative machte auch eine Eingabe an den Bayerischen Landtag, „Maßnahmen zur Eindämmung überflüssiger Anglizismen in der deutschen Sprache zu ergreifen" (Sprachbündnis Franken 2005c). Es wurden Vorträge zu Anglizismen gehalten, unter anderem von Prof. Dr. Helmut Glück und Staatssekretär Karl Freller am 18. März 2004 (vgl. Sprachbündnis Franken 2005c).

Das Sprachbündnis Franken sammelte etwa 1800 Unterschriften gegen die Umbenennung des Nürnberger Franken-Stadions in „easyCreditStadion“ (Sprachbündnis Franken 2005a). Diese Aktion war jedoch erfolglos, zum 14. März 2006 wurde das Stadion umbenannt. Unterstützt wird das Sprachbündnis Franken unter anderem von Renate Schmidt (SPD) ${ }^{335}$ (vgl. Sprachbündnis Franken 2005d).

Das Berliner Sprachbündnis wurde 2001 auf Initiative des Berliner VDS gegründet. Es wird von Personen des öffentlichen Lebens unterstützt, z.B. von Lothar de Maizière, Brigitte Grothum und Michael Degen. Ziel des Sprachbündnisses ist: „Gemeinsam gegen BSE (bad simple english)“336 (VDS 2001b). Das Berliner Sprachbündnis hat sieben Thesen zur deutschen Sprache erstellt, darin heißt es:

Wir stellen fest, dass die deutsche Sprache in allen Bereichen des modernen Lebens von einer Unmenge englischer Wörter durchsetzt

\footnotetext{
${ }^{334}$ Gemeint ist hier nicht Deutsch als Amtssprache, sondern als Arbeitssprache.

335 Renate Schmidt unterstützt das Sprachbündnis, obwohl sie aus dem VDS ausgetreten ist (vgl. Kapitel 2.5.5).

${ }^{336}$ BSE (auch „Rinderwahnsinn“ genannt) kommt aus der Sprache der Medizin und steht für Bovine Spongiforme Enzephalopathie.
} 
ist oder schon ganz durch die englische Sprache verdrängt wird (VDS 2003h).

Die Mitglieder des Sprachbündnisses befürchten:

Wenn es so weitergeht, werden unsere Enkel statt einer modernen deutschen Sprache nur noch einfaches Englisch erben. Das genügt weder für die Erfassung und Bewältigung der komplexen Wirklichkeit, noch für vertieften geistigen, wissenschaftlichen und künstlerischen Austausch (VDS 2003g).

Das Berliner Sprachbündnis hat am 3. Februar 2001 eine Pressemitteilung herausgegeben und sich am 6. Februar 2001 der Öffentlichkeit vorgestellt und ein beachtliches Medienecho hervorgerufen (vgl. Spitzmüller 2005: 137). Dies blieb aber die einzige nennenswerte Aktion des Bündnisses. Seit 2002 ist es nicht mehr aktiv. ${ }^{337}$

Das Sprachbündnis Rhein-Neckar wurde ebenfalls im Jahr 2001 gegründet, nach dem Vorbild des Berliner Sprachbündnisses, ebenso wie das Sprachbündnis Hannover und das Sprachbündnis Thüringen. Auch bei diesen Sprachbündnissen gibt es einige Personen des öffentlichen Lebens, die durch ihre Unterschrift die Arbeit des VDS unterstützen.

\subsubsection{Finanzierung des VDS}

Der VDS finanziert sich hauptsächlich durch den Mitgliederjahresbeitrag (vgl. Kapitel 2.2.5). Höhere Beitragszahlungen als der Mindestbeitrag sind erwünscht:

Wir denken, dass es eine Reihe von Mitgliedern gibt, deren Einkommensverhältnisse so sind, daß sie einen höheren Obulus für die Abwehr der Bedrohung unserer Muttersprache zu entrichten in der Lage und auch willens sind (Krämer 1999a: 2).

Der Verein finanziert sich auch durch Spenden, diese machen jedoch im Verhältnis zu den Beiträgen nur einen kleinen Teil der Finanzierung aus. $^{338}$ Die meisten Spenden kommen von Mitgliedern, ein Großteil

337 Telefongespräch mit Hermann Dieter, 9. Februar 2009.

${ }^{338}$ Im Geschäftsjahr 2001 zum Beispiel belief sich der Anteil der Mitgliederbeiträge auf 273 269,82 Euro, der Anteil der Spenden auf 48 038,53 Euro (vgl. Tschiersch 2002: 5). Ähnlich sah es in den anderen Geschäftsjahren aus: Im Jahr 2005 betrugen die Einnahmen 389415 Euro, davon waren 299908 Euro Mitgliederbeiträge und 82593 Euro Barspenden (vgl. Krämer 2006d: 15). Im Jahr 2007 hatte der Verein 385 862,80 Euro eingenommen, davon 284 430,33 Euro aus Mitgliederbeiträgen. Die Ausgaben beliefen sich auf 384 685,83 Euro (Schulz 2008: 1ff). 
sind Geldspenden, Sachspenden sind seltener. Außerdem nimmt der Verein noch ein wenig Geld durch den Verkauf von Büchern ein, ebenso bringen Bußgelder, außerordentliche Einnahmen und der Verkauf von Anstecknadeln Geld in die Kassen (vgl. die Berichte des Vereins über die Kassenlage). An die Regionalleiter schreibt Krämer 2001 unter der Überschrift „Schwerpunkte künftiger Arbeit“:

Einwerbung von öffentlichen Fördermitteln. Von unseren Mitglieds-
beiträgen können wir trotz Erhöhung nicht leben. Fernziel: ein Teil
der 1,5 Mio. DM jährlich, welche die Wiesbadener Gesellschaft für
Deutsche Sprache jedes Jahr kassiert, muß auf unser Konto fließen
(Rundschreiben von Walter Krämer an die VDS-Regionalleiter, Juni
2001).

$\mathrm{Zu}$ diesem Zweck hat Krämer mehrfach Kontakt zu Politikern aufgenommen (vgl. auch Protokoll der VDS-Vorstandssitzung vom 4. November 2001, Dokument 13), doch diese Bemühungen waren bisher vergeblich (vgl. vorheriges Kapitel). Es scheint, als ob die Finanzierung des Vereins nicht immer einfach ist.

\subsection{Selbstverständnis, Ziele und Leitlinien des Vereins}

\subsubsection{Selbstverständnis}

Uns vereint der Überdruß an der Vermanschung des Deutschen mit dem Englischen zu Denglisch; uns geht das pseudokosmopolitische Imponiergehabe vieler Zeitgenossen, wie es sich besonders im hemmungslosen Gebrauch von überflüssigen Anglizismen äußert, gewaltig auf die Nerven (vgl. VDS 2006f, auch in Baumert 2005: 32). ${ }^{339}$

In diesem Zitat zeigt sich ein wesentliches Charakteristikum des Vereins Deutsche Sprache. Der VDS versteht sich, wie bereits aufgeführt, nicht als akademischer Zirkel, sondern als Bürgerinitiative (vgl. Kapitel

${ }^{339}$ Mittlerweile ist dieser Text nicht mehr auf der Homepage des Vereins zu finden. Bei Baumerts Publikation handelt es sich um eine tendenziöse Veröffentlichung, beispielsweise bezeichnet er die Verwendung von Anglizismen im Deutschen als „Pestilenz“ (Baumert 2005: 39). 
2.2.2). ${ }^{340}$ Explizit stellt Krämer heraus, dass der Verein kein sprachwissenschaftlicher Verein ist:

Meinem Verein geht es nicht um Sprachwissenschaft, sondern um Sprachpolitik. [...] Von Sprachwissenschaft habe ich allenfalls rudimentäre Kenntnisse, bin auch gern bereit, dazuzulernen, überlasse aber dieses Feld ansonsten Ihnen [gemeint sind die Sprachwissenschaftler des IDS, Anm. d. Verf.] (Brief von Walter Krämer an das Institut für Deutsche Sprache, 16. Juni 1999).

Zabel ergänzt, dass dem Verein in Bezug auf den Fremdwortgebrauch im Deutschen nicht an einer akademischen oder wissenschaftlichen Diskussion gelegen ist, doch Zabel ist kein Funktionsträger im VDS, von daher kann diese Äußerung nicht als offizielle Vereinslinie gewertet werden (vgl. Zabel 2001b: 260). Der VDS sieht sich „auch als politische Bewegung, die konkrete sprachpolitische Ziele auch mit politischen Mitteln durchsetzen will“ (Protokoll der Zusammenfassung des Gedankenaustauschs VDS-GfdS vom 7. März 2002). Der Verein wird von seinen Mitgliedern als „echte und starke Lobby der deutschen Sprache“ (Pogarell 2007a: 33) empfunden. Immer wieder wird - unter anderem in den Sprachnachrichten - betont, dass die Mitglieder sich nicht als Puristen verstehen:

Wir sind aber keine Puristen, die sich gegen Fremdwörter als solche wehren, wir kämpfen nur gegen all die überflüssigen englischen Wörter und Redewendungen, die heute in den Medien, in der Werbung und bei den Bezeichnungen für Waren und Dienstleistungen immer mehr zur Mode werden (Krämer 1999a: 2).

An anderer Stelle heißt es: „Wir sind [...] keine sprachpolitischen Saubermänner [...]“ (VDS 2003k: 2). In den Thesen des wissenschaftlichen Beirats wird herausgestellt, dass man die Vereinsarbeit nicht als „undifferenzierte[n] Purismus“ (Fink et al. 2000: 91) versteht. Immer wieder distanziert sich der Verein explizit von den Begriffen „Purismus“ oder

${ }^{340}$ Dieses Selbstverständnis hat nicht Krämer vorgegeben. Er fragt die Vorstandskollegen in einem Rundbrief, „wo unsere Reise langfristig hingehen soll: In Richtung Massenbewegung [...] oder in Richtung „Ehrenwerte Gesellschaft“, die sich mehr auf wissenschaftliches Renommee und Expertenwissen stürzt.“ (Brief von Walter Krämer an die Zweigvorsitzenden der GfdS, 9. September 1998). In der folgenden Vorstandssitzung wurde diese Grundsatzfrage so beantwortet, dass der Verein „sowohl auf der Schiene „Massenbewegung“ als auch auf der Schiene „ehrenwerte Gesellschaft“ weiterfahren soll. Im Zusammenhang mit der Etablierung als „ehrenwerte Gesellschaft“ war sogar an eine eigene wissenschaftlich-kulturelle Halbjahresschrift gedacht (vgl. Rundschreiben von Walter Krämer an die VWDS-Vorstandsmitglieder, 25. Mai 1999). 
„puristisch“ - diese Wörter sind stigmatisiert, da sie nationalistischen Purismus implizieren (vgl. z.B. Pogarell 1998: 9f., vgl. auch Spitzmüller 2005: 241f.). Doch diese Haltung zieht sich nicht konsequent durch den Verein. Ihr wird beispielsweise in den Sprachnachrichten widersprochen: Dort berichtet Gerhard Junker, dass sich die Organisationen auf der Netzwerk-Tagung von Graz schnell auf eine Entschließung einigen konnten (vgl. Kapitel 1.7.14), „die dem Inhalt nach deckungsgleich mit dem VDS-Grundsatzdokument „Eckpunkte“ ist, in dem ein gemäßigter, sprich pragmatischer Purismus vorgegeben [...] wird“ (Junker 2000: 2). In der Entschließung heißt es:

Um richtig verstanden $\mathrm{zu}$ werden: wir vertreten weder einen Antiamerikanismus noch einen nationalistischen oder engstirnigen puristischen Standpunkt (VDS 2003c).

In der Frage, ob sich die Mitglieder des Vereins als Puristen verstehen, gibt es also keine klare Linie. Damit ist schon die Eigenwahrnehmung von Funktionären des Vereins, die in Publikationen ihren Ausdruck findet, nicht einheitlich, ebenso wenig die Fremdwahrnehmung. ${ }^{341}$ Dass über diese Frage immer wieder diskutiert wird, kann als Hinweis darauf gedeutet werden, dass viele Mitglieder des VDS sich der puristischen Tradition in Deutschland, in der sie sich mit ihrer Vereinigung bewegen, bewusst sind (vgl. Kapitel 1.7.1).

Obiges Zitat zeigt auch, dass sich die Organisationen des Netzwerks, und damit der VDS, nicht als „nationalistisch“ sehen. ${ }^{342}$ Dazu Hensel: „Der Nationalismusvorwurf ist nicht haltbar - und ein gefährlicher Unsinn dort, wo es um die Wissenschaftsfähigkeit der deutschen Sprache geht [...]“ (Hensel 2000: 49). Stukenbrock kritisiert: „Der Nationalismusvorwurf wird als "gefährlicher Unsinn“ dämonisiert [...]“ (Stukenbrock 2005a: 242). Damit wirft Stukenbrock dem VDS vor, er würde sich nicht ernsthaft mit diesem Problem auseinandersetzen. Dies stimmt aber nur bedingt (vgl. Kapitel 2.6). Auch gegen den Vorwurf der „Deutschtümelei“ wehrt sich der Verein immer wieder (vgl. z.B. Zabel 2001b: 254,

${ }^{341}$ Der VDS wird von einzelnen Wissenschaftlern durchaus als Puristenverein gesehen (u.a. Pfalzgraf 2006). Womöglich wird beim VDS der negativ konnotierte Begriff des Purismus auch dahingehend verwendet, um einen als „Kampfbegriff“ gehandelten Terminus aufzugreifen und diesen dadurch als Kampfbegriff unbrauchbar zu machen.

${ }^{342}$ Eine Organisation wie der BfdS scheint in manchen ihrer Publikationen jedoch durchaus auch nationalistische Töne anzuschlagen (vgl. Kapitel 1.7.7). 
Schroeder 2005a: 28). Dabei gehört ein „gesunder Sprach- und Kulturpatriotismus“ durchaus zum Selbstverständnis (VDS o.D.b.: 1, Dokument 9).

Großen Wert legt der Vorstand auf das Image des Vereins. Zum Beispiel sollten laut Vorstand Regionaltreffen nicht in Hinterzimmern von Kneipen stattfinden und keinesfalls politische Themen diskutiert werden (vgl. Empfehlungen zur Durchführung von VDS Regionalversammlungen, ohne Datumsangabe). Am Image des Vereins wird viel gearbeitet, der Verein soll jugendlich und frisch erscheinen. Dies geht zum Beispiel aus einer Bitte Krämers anlässlich der Preisverleihung des „Kulturpreises deutsche Sprache“ in Kassel hervor:

Bitte Kinder und Enkel mitbringen. In den Medien darf auf keinen Fall der Eindruck entstehen, der VDS wäre ein Verein verbiesterter alter Rentner (VDS 2001f: 1).

Das Erscheinungsbild des Vereins wurde durch die Firma „Internationale Medienhilfe“343 analysiert. Dabei stellte diese fest:

Bild in der Öffentlichkeit: altmodisch, unmodern, humorlos, nörglerisch, national, weltfremd, anti-amerikanisch, keine linguistischen Fachkenntnisse, keine Ahnung von internationalen Entwicklungen, keine einheitliche Werbung, Öffentlichkeitsarbeit (Analyse des VDSErscheinungsbildes - Kurzfassung der IMH Service - Internationale Medienhilfe, ohne Datumsangabe).

Dies entspricht nicht dem Bild, das der VDS in der Öffentlichkeit abgeben möchte:

angestrebtes Ziel: mehr junge Mitglieder, anderes Bild in der Öffentlichkeit - jung, modern, humorvoll, kritisch, international, weltoffen, völkerverbindend, kompetent, einheitliches Erscheinungsbild (Analyse des VDS-Erscheinungsbildes - Kurzfassung der IMH Service - Internationale Medienhilfe, ohne Datumsangabe).

Inwieweit sich das Bild des VDS in der Öffentlichkeit in Zukunft wandeln wird, bleibt abzuwarten.

\subsubsection{Ziele und Leitlinien}

Wurde im vorangegangen Kapitel das Selbstverständnis des Vereins dargestellt, so werden hier die Ziele und Leitlinien der Vereinsarbeit be-

${ }^{343}$ Gründer der Internationalen Medienhilfe ist Björn Akstinat, ehemaliges VDS-

Vorstandsmitglied (Internationale Medienhilfe 2009). 
schrieben. Das Ziel des Vereins ist in Paragraph 2 der Satzung niedergelegt. Dort heißt es:

Der Verein verfolgt das Ziel, die deutsche Sprache als eigenständige Kultursprache zu erhalten und zu fördern. Insbesondere tritt er dafür ein, daß sich die deutsche Sprache gegen die Überhäufung mit Wörtern aus dem Englischen behauptet (VDS 2000c: 1). ${ }^{344}$

Dies ist nicht die ursprüngliche Satzung. Seit Gründung des Vereins sind einige Punkte geändert worden. Dort hieß es unter anderem in Paragraph 2:

Der Verein soll dazu beitragen, daß die deutsche Sprache als selbständige Kultursprache erhalten bleibt. Insbesondere soll er die Kolonisierung ${ }^{345}$ des Deutschen durch das Englische bekämpfen (VWDS 1997: 1).

Wiechers konstatiert:

Hier wird ein sprachpolitischer Akt suggeriert, eine von außen gelenkte Kampagne gegen die deutsche Sprache, der man sich widersetzen müsse. Dieser Zusatz fehlt in den späteren Satzungen (Wiechers 2001: 155).

Es wird hinzugefügt, dass die deutsche Sprache nicht nur zu erhalten, sondern auch zu fördern ist. Mit dieser Entwicklung waren nicht alle Mitglieder einverstanden, es kam zu Austritten. ${ }^{346}$

In einem anderen Text geht der VDS noch einen Schritt weiter - unter dem Punkt „VDS vorgestellt“ heißt es:

Wir wollen der Anglisierung der deutschen Sprache entgegentreten und die Menschen in Deutschland an den Wert und die Schönheit ihrer Muttersprache erinnern. Wir wollen unsere Sprache bewahren

\footnotetext{
${ }^{344}$ Maercker merkt diesbezüglich an, dass die „nur vage definierte Normenbasis“ dazu dient, den Zusammenhalt im Sprachverein zu garantieren (Maercker 2006: 229). 345 Über zehn Jahre später distanziert sich der Verein deutlich von diesem Begriff: „Dass trotzdem immer wieder Zeitgenossen mit begrenztem Wahrnehmungs- und Urteilsvermögen von Sprachkolonisierung reden, wo es sich nur um eigene Gedankenlosigkeit handelt, ist bedauerlich“ (Behland 2008b: 1).

${ }^{346}$ Das damalige Mitglied Siegfried Piotrowski klagte. In der Klageschrift heißt es: „In dieser veränderten Fassung soll der Beklagte (der VDS, Anm. d. Verf.) lediglich noch dafür eintreten, daß sich die deutsche Sprache gegen die Überhäufung mit Wörtern aus dem englischen [sic] behauptet.“ (Nähle/Boss 2000). Dies sei eine wesentliche Abschwächung des ursprünglichen Vereinszwecks, „nämlich Bekämpfung der Kolonisierung des deutschen [sic] durch das englische [sic]“ (Nähle/Boss 2000). Weiter steht in der Klageschrift: „Wenn man in der veränderten Fassung der Satzung bloß zum Ausdruck bringt, daß man der Überhäufung mit Wörtern aus dem englischen [sic] Einhalt gebieten will, so ist die Grenzziehung insoweit im Vergleich zur ursprünglichen Satzung des Vereinszwecks bis zur Unkenntlichkeit verwässert“ (Nähle/Boss 2000).
} 
und weiter entwickeln. Die Fähigkeit, neue Wörter zu erfinden, um sich auf neue Dinge zu beziehen, darf nicht verloren gehen (VWDS 1999d: 1).

Es soll nicht nur verhindert werden, dass englische Wörter ins Deutsche gelangen und dort verwendet werden, sondern es sollen auch neue deutsche Wörter gebildet werden. Das Zitat ist insofern interessant, als hier konkret Sprachplanung als Ziel des Vereins aufgeführt wird. In den Statuten des Vereins steht außerdem:

Wir kämpfen für mehr Selbstachtung und Würde aller Menschen, die Deutsch als Muttersprache haben [...] und versuchen, die Vermanschung des Deutschen mit Englisch zu Denglisch aufzuhalten (VDS 2003k: 1). ${ }^{347}$

Hier wird die „Vermanschung des Deutschen mit Englisch“ konkret in den Zusammenhang der "Selbstachtung und Würde“ aller DeutschMuttersprachler gesetzt. Zudem zielte der Verein in seinen Leitlinien auf eine „Wahrung der nationalen Eigenarten durch Förderung der Landessprachen“ (Zabel 2003: 225).

Aber nicht nur der „Kampf“ gegen die „Vermanschung des Deutschen mit Englisch“ sondern auch eine gesetzliche Regelung der Sprache im Zuge des Verbraucherschutzes sind Ziel des Vereins:

Dazu gehört auch die Forderung nach einer gesetzlichen Regelung der Verwendung von Anglizismen, zumindest was den Gebrauch von englischen Begriffen in Gebrauchsanweisungen etc. angeht (vgl. VDS 2003e, 2005c). ${ }^{348}$

In der Anfangszeit nach der Vereinsgründung wurde über die Forderung nach einem Sprachschutzgesetz diskutiert. Bei der Vorstandssitzung am 14. April 1998 ist bereits ein Gesetzentwurf verteilt worden, da die „Überflutung der deutschen Sprache durch das dadurch entstehende Kommunikationsproblem konträr zum Grundgesetz steht“, doch wurde dieser als verfrüht abgelehnt (vgl. Protokoll der VWDS-Vorstandssitzung vom 14. April 1998). 1999 war beispielsweise in der FAZ und in der Süddeutschen Zeitung eine Meldung erschienen (vgl. Spitzmüller 2005: 189), dass der Verein ein Sprachgesetz fordere, und zwar für die Berei-

${ }^{347}$ Dieser Text ist mittlerweile von der Homepage des Vereins verschwunden.

${ }^{348}$ Zur Thematik der Spezialgesetzgebungen in Deutschland, die sich mit der deutschen Sprache auseinandersetzen vgl. u.a. die Publikation zu Staats- und Verwaltungsrecht von Paul Kirchhof und Charlotte Kreuter-Kirchhof (2008) sowie Glück (2001). 
che Werbung und Medien sowie für Behörden. ${ }^{349}$ Die Regionalgruppe des VDS Berlin/Brandenburg unter Vorsitz von Kurt Gawlitta war auch mit einem Gesetzentwurf an die Öffentlichkeit gegangen, was zu Unstimmigkeiten innerhalb des Vereins führte (vgl. u.a. Dieter et al. 2001, Kapitel 2.1.3), da der Bundesvorstand des VDS ausdrücklich keine Sprachschutzgesetzgebung forderte:

Die in langen Diskussionen auf mehreren Sitzungen hergestellte Vorstandsmeinung ist, daß der VDS derzeit kein Sprachgesetz fordert. $\mathrm{Ob}$ nur aus taktischen Überlegungen oder aus Überzeugung spielt keine Rolle. [...] Ein Eintreten für ein „Sprachgesetz“ riskiert die für uns lebenswichtige Unterstützung durch die Medien (Rundschreiben von Walter Krämer an die VDS-Regionalleiter, März 2002).

Und an anderer Stelle:

Und da müssen wir aufpassen, daß wir unseren enormen Rückenwind in den Medien nicht leichtfertig durch überzogene Forderungen verspielen (Rundschreiben von Walter Krämer an die VDS-Regionalund Arbeitsgruppenleiter, ohne Datumsangabe).

Davon unabhängig besteht die Forderung nach Verbesserung des Verbraucherschutzes bezüglich Gebrauchsanweisungen und Inhaltsangaben. Die „Erarbeitung eines Sprachgesetzes im Sinne eines Verbraucherschutzes" (Rundschreiben von Walter Krämer an die VDSRegionalleiter, Juni 2001, vgl. auch Protokoll der VDS-Vorstandssitzung vom 4. November 2001) ist als Ziel der Vereinsarbeit zu sehen. Die Vereinslinie insgesamt $\mathrm{zu}$ diesem Thema wird deutlich in diesem Rundschreiben:

Konsensfähig ist auf jeden Fall ein Sprachgesetz im Sinn des Verbraucherschutzes: Bedienungsanleitungen, Inhaltsangaben usw. müssen auch auf Deutsch erfolgen (Rundschreiben von Walter Krämer an die VDS-Regional- und Arbeitsgruppenleiter, ohne Datumsangabe).

Es scheint also, als wären die Mitglieder des VDS und Krämer zwar durchaus nicht gegen ein Sprachschutzgesetz an sich, hätten aber Angst, mit einer solchen Forderung die Medien gegen sich aufzubringen (vgl. Kapitel 2.3.2).

Anstatt der Forderung einer Sprachschutzgesetzgebung weiter nachzugehen, hat der VDS seit dem Jahr 2005 eine andere Forderung erhoben. Seit diesem Zeitpunkt existiert die Arbeitsgruppe „Deutsch ins Grund-

${ }^{349}$ Die Junge Freiheit griff das Thema ebenfalls auf (Junge Freiheit 1999: 12). 
gesetz“ (vgl. ausführlich Krämer 2005b: 1), mit dem Ziel, die deutsche Sprache im Grundgesetz zu verankern. Dies sieht der VDS als zukünftigen Artikel 22 a mit Wortlaut „Die Sprache der Bundesrepublik Deutschland ist Deutsch“ als „[g]eistige Grundlage für ökonomischen Erfolg“ (vgl. Krämer 2005b: 1, VDS 2005a). Bis jetzt zeigen diese Bemühungen wenig Erfolg: Der Petitionsausschuss des Deutschen Bundestags hat am 21. November 2006 einen entsprechenden Antrag abgelehnt (vgl. u.a. VDS 2007a). ${ }^{350}$ Inwiefern diese Arbeitsgruppe in Zukunft Einfluss auf die Politik und auf die Gesetzgebung nehmen kann, bleibt abzuwarten. Für einen weiteren Vorstoß des VDS nach einem Sprachgesetz, das mit dem französischen Gesetz vergleichbar wäre, gibt es m.W. keine Anzeichen. ${ }^{351}$ Hier zeigt sich also eine Änderung der Vereinslinie, weg von der Forderung nach einem Gesetz, das die Verwendung von Anglizismen im Deutschen verbieten soll, hin zu einem Vorstoß, die deutsche Sprache im Grundgesetz zu verankern.

Im Jahr 2000 forderte ein Vorstandsmitglied in dem Schreiben „Quo vadis VDS“ eine Anpassung der Vereinsarbeit an die Strategie der neuen Arbeitswelt (Brief eines VDS-Vorstandsmitglieds an die Vorstandskollegen, 29. Oktober 2000), in dem es Toleranz bei „lässlichen Sündern“ und die Belobigung derjenigen anmahnt, die Sprachdisziplin aufbringen. ${ }^{352}$ Dies ist insofern interessant, als er damit auch der Forderung von Kritikern des VDS entspricht, von der Diffamierung der „Sprachsünder" Abstand zu nehmen. Ein Schritt in diese Richtung ist auch die Einrichtung des Kulturpreises Deutsche Sprache.

${ }^{350}$ Die CDU hat wie bereits ausgeführt auf ihrem Parteitag einem Antrag für eine Aufnahme der deutschen Sprache ins Grundgesetz zugestimmt (vgl. Fried 2008: 5 sowie Kapitel 1.6.3). Außerdem vermeldete der VDS im Jahr 2009, dass sich Union und FDP in ihren Koalitionsverhandlungen darauf geeinigt hätten, die deutsche Sprache im Grundgesetz zu verankern (VDS 2009c). Dies ist aber nicht der Fall.

${ }^{351}$ Der Ruf nach einem Sprachgesetz wird von außen immer wieder kritisiert (vgl. z.B. Hoberg 2001: 301).

${ }^{352}$ M.E. ist bisher nur wenig Veränderung in der Vereinsarbeit erkennbar. Nach wie vor werden mit den Sprachpanschern und dem Sprachhunzer Firmen und Personen angeprangert (vgl. dazu die Kapitel 2.5.4.1 und 2.5.4.2). 
Ziel des VDS war zudem die „Einrichtung einer Deutschen Sprachakademie (vgl. Rundschreiben von Walter Krämer an die VDSRegionalleiter, Juni 2001). ${ }^{353}$ Auch in These 7 des Beirats steht geschrieben:

Notwendig ist eine Institution, die Gegenentwürfe für bereits anglisierte Terminologien erarbeitet und die weiteren Entwicklungen aktiv mit durchdachten Übersetzungen und Neuprägungen begleitet“ (Fink et al. 2000: 91).

Spitzmüller bemerkt hierzu: „Dies ist insofern interessant, als dass das Gremium hier eindeutig Position bezieht hinsichtlich der Frage nach Verdeutschungen“ (Spitzmüller 2005: 350). Darauf kommt der VDS in seiner Festschrift zum zehnjährigen Bestehen, zurück: In „Das Wörtermachen nimmt den Deutschen keiner ab!“ fordert Kurt Gawlitta, „dass wir eine kontinuierliche Wortbildung in Gang bringen“ (Gawlitta 2007: 87). Hierfür liefert er verschiedene Vorschläge, unter anderem auch eine Kooperation zwischen der Stiftung Deutsche Sprache, die in enger Verbindung mit dem VDS steht, und der Kultusministerkonferenz, einem Kultusministerium oder der Bundesregierung (vgl. Gawlitta 2007: 90).

Ein weiteres Ziel der Vereinsarbeit ist die Einwerbung von öffentlichen Fördermitteln (vgl. Kapitel 2.2.7). ${ }^{354}$ Erklärtes Ziel ist auch, dass in Zukunft die Anglizismenarbeit nicht sofort in den Kontext von Sprache und Nation gestellt wird..$^{355}$

${ }^{353}$ Vgl. ebenso Protokoll der VDS-Vorstandssitzung vom 4. November 2001 und Kapitel 2.5.8 zur Stiftung Deutsche Sprache, die diese Akademie für den VDS einrichten soll.

${ }^{354}$ Bisher hat dies aber nicht funktioniert. Information von der Geschäftsstelle des VDS, Telefongespräch mit Sabine Riga, VDS-Geschäftsstelle, 10. Oktober 2007.

${ }^{355}$ Gespräch mit Holger Klatte, Geschäftsführer des VDS, 28. November 2008. 


\title{
2.4 Fremdwort und Anglizismus in der Arbeit des VDS und der Sprachgebrauch des Vereins
}

\subsubsection{Fremdwort und Anglizismus}

Beim Fremdwortkonzept wird in der Regel die einfache Unterscheidung zwischen fremdem und deutschem Wort getroffen. Bereits 2001 verweist Barbour auf die fälschliche Annahme des VDS, dass das Fremde in einer Sprache leicht auszumachen sei (Barbour 2001: 360). Gegenstand der Vereinsarbeit ist nicht das Fremdwort, sondern der Anglizismus im speziellen. Fremdwörter griechischen, lateinischen oder französischen Ursprungs etwa spielen in der Vereinsarbeit keine Rolle (vgl. dazu auch Law 2002: 79). Es wurde auch vereinsintern diskutiert, auf die Differenzierung zwischen Anglizismen und Fremdwörtern griechischer oder lateinischer Herkunft deutlicher hinzuweisen (vgl. z.B. Protokoll der VWDS-Vorstandssitzung am 10. September 1998). Trotz des wissenschaftlichen Beirats gibt es keine klaren Vorgaben für die Definition des Fremdworts und für die des Anglizismus. Weder auf der Homepage noch in den Sprachnachrichten oder in anderen Publikationen des Vereins findet sich eine sprachwissenschaftliche Definition. Dies kritisiert beispielsweise Pfalzgraf in seiner Untersuchung (vgl. Pfalzgraf 2006: 90). Der VDS verurteilt nicht alle Anglizismen. ${ }^{356}$ In den strategischen Leitlinien, die aber m.E. nicht zur offiziellen Vereinslinie wurden, hieß es:

\begin{abstract}
Wir streben an, dass die deutsche Sprache [...] sich in ihrem Sprachraum gegen die Ersetzung oder die Vermengung mit Wörtern und Wendungen aus dem Amerikanischen dadurch behauptet, dass sie Amerikanismen hinnimmt, sofern sie sprachlich-funktionell notwendig sind, anstatt sie vor allem als Mittel zur uneingeschränkten Etablierung einer globalisierten Waren- und Kulturwelt zu missbrauchen (VDS o.D.c: 1 ).
\end{abstract}

Die Anglizismen werden an dieser Stelle also in zwei Gruppen unterteilt, in diejenigen, die „sprachlich-funktionell notwendig sind“, und in

${ }^{356}$ Dies hat auch der ADSV immer behauptet, die Realität hat aber anders ausgesehen (vgl. Pfalzgraf 2006: 74). 
diejenigen, die „vor allem als Mittel zur uneingeschränkten Etablierung einer globalisierten Waren- und Kulturwelt missbrauch[t]“ werden. Welche Anglizismen welcher Kategorie zuzuordnen sind, geht hieraus nicht hervor, ebenso wenig, was es genau bedeutet, dass ein Wort „sprachlichfunktionell notwendig“ ist. ${ }^{357}$ An anderer Stelle heißt es: „[wir] akzeptieren fremde Wörter - auch englische - als Bestandteile der deutschen Sprache, wenn sie die Verständigung erleichtern“ (VDS 2003k: 3).

In einer Pressemitteilung aus dem Jahr 1998, also kurz nach Vereinsgründung, hatte der VWDS einen Kriterienkatalog veröffentlicht, mit dessen Hilfe „überflüssige“ Anglizismen zu erkennen seien:

1. Der englische Ausdruck muß hinreichend weit (nicht nur in der Werbung oder in Fachsprachen) verbreitet sein. Damit entfallen Werbe-Eintagsfliegen wie „wellness“"358 oder „airconditioning“ statt Klimaanlage in der Autowerbung [...]

2. Es muß für den englischen Ausdruck mindestens zwei treffendere deutsche Wörter geben. [...]

3. Der englische Ausdruck muß die zwischenmenschliche Verständigung behindern. [...]

4. Der englische Ausdruck muß die deutsche Sprache ärmer machen (VWDS 1998c).

Diese Kriterien, die auf den ersten Blick plausibel erscheinen, wurden bereits 2000 von Thomas Niehr kritisiert: Niehr führt aus, dass das „scheinbar objektiv messbare Kriterium ,Verbreitung'“ sich als nicht operationalisierbar erweist, denn eine Verbreitung eines Wortes ließe sich zwar mutmaßen, aber nicht wirklich umfassend feststellen, auch nicht durch quantifizierende Untersuchungen des Sprachgebrauchs. Zudem erweise sich die Antwort auf die Frage nach „zwei treffenderen Ausdrücken“ als schwierig, aus dem Grund der Nichtbeachtung der Unterscheidung zwischen langue und parole und dahingehend, dass diese Frage nur in der jeweiligen Situation entschieden werden kann. Bezüglich der Verständlichkeit bemängelt Niehr, dass es nicht möglich sei, einzelnen Wörtern ohne Kontext die Verständlichkeit abzusprechen, und dass die Verständlichkeit nicht immer alleinige Intention eines

${ }^{357}$ Im Anglizismen-Index wird eine ähnliche Einteilung dagegen ausführlich diskutiert und dargelegt, welche Wörter beispielsweise als „ergänzend“ zu klassifizieren sind (vgl. ausführlich Kapitel 2.5.1.3).

${ }^{358}$ Hier irrte der VDS, „Wellness“ ist wohl kaum mehr als Eintagsfliege anzusehen, dies stellte auch schon Niehr bei einer quantitativen Analyse in Tageszeitungen im Jahr 1998 fest (vgl. Niehr 2002b: 5). 
Sprechers sei. Hinsichtlich der Verarmung führt er an, dass dies in einer diachronen Studie erst noch erforscht werden müsste, dass es aber durchaus so sei, dass Altes und Neues nebeneinander existiere (vgl. Niehr 2002b: 5ff.). Dieser Kriterienkatalog ist in neueren Veröffentlichungen $\mathrm{m}$.W. nicht wieder aufgetaucht.

Zabel veröffentlichte zur Frage, welche Anglizismen im Deutschen nicht verwendet werden sollten, folgende Einteilung:

Im Sinne einer vorläufigen Arbeitshypothese schlagen wir vor, sich bei der Übernahme von Anglizismen an folgenden Kriterien zu orientieren:

Begriffe und Redewendungen aus dem angloamerikanischen Kulturkreis sollten in der deutschen Alltagssprache nur dann benutzt werden, wenn sie mindestens zwei der folgenden drei Voraussetzungen genügen:

a) Eine treffende, selbst etwas längere Übertragung lässt sich in der deutschen Sprache weder bilden noch finden.

b) Es handelt sich um einen „Internationalismus“ im Sinne der Definition im letzten Absatz von ,Worum es geht'359

c) Das Wort oder die Redewendung lässt sich ohne größere lautliche oder grammatische Veränderungen in deutschsprachige Sätze und Wortfelder einbauen (Zabel et al. 2001: 226 sowie VDS Region Leipzig 2005).

Um die Einteilung zu veranschaulichen, gibt es eine kleine Liste mit Wörtern, die entweder mindestens zwei Voraussetzungen erfüllen und damit verwendet werden sollten (hier in Auszügen): „Disco (a, b, c), dopen $(a, b)$, Fairness $(a, b, c)$, Fan $(a, c)$, Hostess $(a, c)$ ” “ oder aber weniger als zwei Voraussetzungen erfüllen und damit nicht verwendet werden sollten. Zu diesen werden Verdeutschungsvorschläge mitgeliefert: airbag (Prallkissen), bodyguard (Leibwächter), call center (Anrufzentrale), copyright (Urheberrecht), display (Sichtfeld, Anzeigefeld), editorial (Leitartikel), joint venture (Firmenverbund), lobby (Interessengruppe)“ (Zabel 2001 et al.: 226 sowie VDS Region Leipzig 2005)

\footnotetext{
${ }^{359}$ Dort ist zu lesen: „Die Fachsprachen und ihre Begriffssysteme nehmen insoweit eine Sonderstellung ein, als es dort unsinnig wäre, englische oder andere fremdsprachige Fachwörter, deren Bedeutung weltweit festliegt, im internationalen Austausch ständig neu zu übersetzen. Für die außer- und zwischenfachliche Kommunikation, die nur in einer entsprechend ausgebauten Alltagssprache möglich ist, müssen jedoch deutsche Übersetzungen bereitgehalten und genutzt werden. Falls sich für einen solchen Begriff eine treffende Übersetzung weder bilden noch finden lässt, wird er als „Internationalismus“ in die deutsche Sprache aufzunehmen und nach Möglichkeit ihrem Regelsystem anzupassen sein“ (Zabel et al. 2001: 224).
} 
Zabel weist weiterhin darauf hin, dass der VDS die Fachsprachen mit ihrer jeweiligen Terminologie von der Kritik und damit von der Zielsetzung eines reduzierten Fremdwortgebrauchs ausschließt. Ebenso sollen Internationalismen von dieser Zielsetzung ausgeschlossen bleiben (vgl. Zabel 2001b: 257). ${ }^{360}$ Doch auch diese Kriterien zur Einteilung überzeugen nicht, denn die Entscheidung, ob ein Kriterium zutrifft oder nicht, ist subjektiv (vgl. zur Kritik an der Einteilung auch die Ausführungen über den Anglizismen-Index, Kapitel 2.5.1.3).

Die Äußerungen des VDS zum Umgang mit Fremdwörtern waren und sind nicht einheitlich, so fand sich beispielsweise folgende Unterteilung von Anglizismen auf der Homepage des VDS Dresden:

Unentbehrliche Fremdwörter

Viele Fremdwörter sind fest eingebürgert: z.B. Kultur, Religion, Alkohol, sozial, Technik, Minister, Kapitel, Fabrik, Klima, Kritik, Maschine, Phantasie, Stil, Tragik, Charakter, Theater, Diplomat, Dogma, um nur einige von hunderten $\mathrm{zu}$ nennen. Unser Verstand sagt uns auch ganz genau, wo der Unterschied zwischen einem eingebürgerten Fremdwort und den übrigen überflüssigen und daher schädlichen Fremdwörtern liegt. Für demolieren, frequentieren, dekorieren, lädieren, für interessant, pikant, vakant und amüsant, für Negligé, Prinzip, Detail, Attraktion und Motiv haben wir genug deutsche Wörter und wir empfinden sie als fremd. Aber selbst wenn das Wort Religion ein fester Bestandteil der deutschen Sprache darstellt, so hat Luther doch bei der Bibelübersetzung das aus dem Lateinischen stammende Wort Religion durch das anschaulichere deutsche Wort Glauben ersetzt (VDS Region Dresden 2005).

Der VDS Dresden wandte sich nicht nur gegen Anglizismen, sondern auch gegen Gallizismen und Latinismen. Damit nahm er aber eine Sonderstellung innerhalb des VDS ein. An anderer Stelle wurden die Anglizismen eingeteilt in „überflüssig“ und „bereichernd“, wobei Anglizismen dann als bereichernd gelten, „wenn sie die Verständigung erleichtern“ (VDS Region Dresden 2005). Es tauchte dort außerdem der Begriff „Pseudo-Anglizismen“ auf, der für Scheinentlehnungen stehen kann. Damit zeigt sich ansatzweise eine sprachwissenschaftliche Lehngutgliederung. Insgesamt sind die Kriterien, nach denen die Anglizismen unterteilt sind, jedoch wenig wissenschaftlich (vgl. auch Law 2002: 79f., zur Gliederung lexikalischen Lehnguts nach sprachwissen-

${ }^{360}$ Die Publikation von Zabel wurde im Auftrag des VDS herausgegeben. 
schaftlichen Kriterien vgl. Kapitel 1.4.1). ${ }^{361}$ Mittlerweile sind sie völlig von den Internetseiten des VDS Dresden verschwunden (VDS Region Dresden 2008).

VDS-Mitglieder selbst fordern mitunter klare Kriterien für die Einteilung der Anglizismen:

Bevor noch mehr Mitglieder Bauchschmerzen bekommen und austreten, sollten wir klarstellen, dass wir ausschließlich gegen neuere überflüssige Anglizismen kämpfen, aber nicht gegen lateinische, französische und italienische Fremdwörter, nicht gegen die Rechtschreibreform, die Popmusik oder für die deutsche Schrift!

Das alte DIN A4-Blatt „Leitlinien“ hatte klare Vorschläge, unter welchen zwei Voraussetzungen ein Anglizismus akzeptiert wird. Diese wären eine echte Hilfe für Aktive und zur Information anhand von konkreten Beispielen. Das neue enthält wieder nur Allgemeinplät$\mathrm{ze}^{362}$ (Brief einer VDS-Regionalvorsitzenden an den VDS, ohne Datumsangabe).

Insgesamt gibt es also keine klare Vereinslinie, welche Anglizismen „erlaubt" sind und welche nicht. Zudem wird nicht angegeben, ab wann ein Fremdwort als eingedeutscht gilt. Dies zeigt sich unter anderem auch in Schreiben des Vereins an Mitglieder:

In der Tat können wir auch keine befriedigende Antwort auf die Frage geben, ab wann ein Wort als „eingedeutscht“ gilt. [...] In der gegenwärtigen Situation, die ja in allen Bereichen sehr schnelllebig ist, sind vielleicht viele Wörter einfach Modewörter, die schnell wieder verschwinden werden, oder die verschwinden, weil das Bezeichnete auch verschwindet. Deshalb meine ich, dass es sehr schwierig ist, eine klare Abgrenzung vorzunehmen, ab wann ein Wort zu einer Sprache gehört (Brief der VDS-Geschäftsstelle an ein VDS-Mitglied, August 2001).

Es gibt aber eine vom Vorstand verabschiedete Liste der fünf ärgerlichsten Anglizismen, auch wenn dies wohl eine einmalige Aktion aus dem Jahr 1998, also aus der Anfangszeit des Vereins, war: „Event, Statement, Highlight, Kids und Service-Point“ (vgl. Protokoll der VWDS-

${ }^{361}$ Diese Unterteilungen erinnern stark an Dungers Unterteilung aus dem 19. Jh. (vgl. dazu Kapitel 1.7.1, verwendet vom ADSV/DSV). Sie wurden in abgewandelter Form auch von Weisgerber verwendet (vgl. Weisgerber 1960) und sind in der Wissenschaft kritisiert worden, unter anderem durch von Polenz: „seine [gemeint ist Leo Weisgerber, Anm. d. Verf.] von soziopragmatischen Bedingungen des Sprachgebrauchs weit entfernte Bewertung von Fremdwörtern als ,schädlich', ,hinderlich', ,fragwürdig', ,überflüssig', ,nützlich' usw. (Weisgerber 1960) hatten in der fachlichen Diskussion keine anhaltende Wirkung “ (von Polenz 1999a: 289). Hervorhebungen im Original.

362 Unterstreichung im Original. 
Vorstandssitzung vom 10. September 1998). Außerdem heißt es seitens des VDS immer wieder, man wende sich gegen „überflüssige“ Anglizismen. Interessanterweise wird aber diese Haltung, die lange Zeit das maßgebliche Ziel der Vereinsarbeit war, in neueren Publikationen des Vereins angegriffen (vgl. z.B. Gawlitta 2007: 81). ${ }^{363}$ Insgesamt ist festzustellen, dass die wissenschaftliche Auseinandersetzung mit dem Fremdwort oder dem Anglizismus im VDS eine untergeordnete Rolle spielt. Es geht mehr um Empfindungen, wie das Beispiel „ärgerlichste“ Anglizismen verdeutlicht. Auch die Unterteilung in „unnötige“ und „nicht-unnötige“ Anglizismen folgt keiner wissenschaftlichen Gliederung, sie wird vielmehr nach der Sprecherintuition der Vereinsmitglieder vorgenommen.

Als Grund für die Einstellung gegen Anglizismen werden funktionale Gründe aufgeführt, so, dass ältere Menschen sie nicht verstehen. Auch dass beispielsweise Wissenschaftler gar nicht verstanden werden wollen, ${ }^{364}$ wird als weitere Funktion der Anglizismen genannt. Weitere Gründe sind Imponiergehabe, Anbiederung, Würdelosigkeit sowie fehlender Selbstrespekt und Effekthascherei (vgl. z.B. VDS 2001d, Krämer 2007a: 16ff.).

Es zeigt sich insgesamt eine Beliebigkeit und Widersprüchlichkeit in der Fremdwortdefinition, -auffassung und -kategorisierung (vgl. Law 2002: 79), ausgehend von der Annahme, dass das Fremde leicht zu identifizieren sei, wie Barbour schon 2001 in Bezug auf den VDS kritisiert hat (Barbour 2001: 362). Dabei ist es keinesfalls so, dass der VDS sich nicht mit Argumenten von Linguisten auseinandersetzte. Spitzmüller verweist dazu auf die Bibliothek des VDS als „eine beeindruckende [...] Sammlung kontaktlinguistischer Forschungsliteratur" (vgl. Spitzmüller 2005: 22). In der Tat befindet sich in den Räumen der Geschäftsstelle eine Bibliothek mit rund 180 Werken, darunter viele sprachwissen-

\footnotetext{
${ }^{363}$ Dort schreibt Gawlitta weiter: „Ein schwächeres Argument gibt es kaum. Ein allgemeingültiger Maßstab, wann fremde Anleihen überflüssig sind, existiert nämlich nicht, sondern wird von jedem anhand der eigenen Interessen anders beurteilt" (Gawlitta 2007: 81).

${ }^{364}$ Diese Annahme ist in der Wissenschaft umstritten: vgl. z.B. Glahn: „[...] ist anzunehmen, dass das Verwenden von Anglizismen die allgemeine Verständigung nicht nennenswert beeinträchtigt“ (Glahn 2000: 232).
} 
schaftliche, aber auch Materialien von sprachpflegenden Vereinigungen (VDS 2003d). Die Bibliothek wird derzeit hauptsächlich vom Geschäftsführer des VDS genutzt. Etwa dreimal im Jahr sucht ein VDSFunktionär die Bibliothek auf, um sich dort $\mathrm{zu}$ informieren. ${ }^{365}$ Insgesamt scheint es, als ob sich der VDS auch nach über zehn Jahren Vereinsgeschichte nach wie vor schwer tut mit der Definition und dem Verständnis von Anglizismen. Denn beispielsweise im Protokoll der Tagung Idensen 2 tauchte dieses Thema wieder auf: Hier wurde von Max Behland die Frage aufgeworfen, was denn ein Anglizismus sei, und ob es nicht erforderlich sei, um den Vorwurf, ein „Puristenverein“ zu sein, zu vermeiden, die abzulehnenden Anglizismen besser zu definieren. Denn man wolle nicht als Fremdwortjagdverein verstanden werden (vgl. Aden 2007: 11).

\subsubsection{Diskurs, Metaphorik und Argumentation des VDS}

Um den VDS und seine Arbeit besser verstehen zu können, ist es hilfreich, den Diskurs, die Metaphorik und die Argumentation des Vereins näher zu betrachten. Als Quellen für den Diskurs des VDS über den Anglizismus im Deutschen wurden für dieses Kapitel hauptsächlich die Sprachnachrichten, aber auch der Internetauftritt des Vereins sowie Bücher herangezogen, die entweder im Auftrag des VDS herausgegeben wurden oder von VDS-Funktionären oder dem Vorsitzenden veröffentlicht wurden.

Diskursstiftendes Thema ist die „von den Akteuren behauptete Identitätsgefährdung der deutschen Sprache durch Fremdwörter" (Stukenbrock 2005a: 225). Betrachtet man die Sprache des VDS genauer, so stellt man fest, dass in Publikationen des Vereins von „Überschwemmung“ (Stemmler 1999: 6) gesprochen wird, vom „Kampf“ gegen Anglizismen oder von „Sprachblödsinn“ (Tietz 2000: 6), „BSE (Bad Simple English)“ (Krämer 2005e: 2), „Dampfplaudergewerkschaft“ (Krämer 2000f: 7), „Sprachschlamperei“ (Krämer 2000f: 7), „Schimpansenspra-

${ }^{365}$ Information aus Gespräch mit Holger Klatte, Geschäftsführer des VDS, 28. November 2008. 
che“ (Krämer 2005e: 2), „Bastard“, (Stilkenboom 2000: 4). Menschen, die Anglizismen verwenden, werden als „Sprachsünder“ (SN 2000d: 3) tituliert, die Anglizismen werden mit den Urwaldmenschen Tarzan und Jane assoziiert (Krämer 1998a: 418).

Die „Flut- und Überschwemmungsmetaphorik ${ }^{366}$ (vgl. auch Stukenbrock 2005a: 226, Spitzmüller 2005: 244ff.) ${ }^{367}$ findet sich in vielen Publikationen des Vereins, am häufigsten in den Sprachnachrichten. ${ }^{368}$ Ein Beispiel für die Verwendung der Wassermetaphorik ist der „Untergang der deutschen Sprache“ oder „Untergang“ (Kreimeier 1999: 5). Diese Metaphorik beinhaltet, dass das Deutsche stark in Gefahr ist. So kommt ein Element der Panikmache in den Diskurs (vgl. dazu auch Spitzmüller 2005: 350). ${ }^{369}$ Das sind Techniken des Populismus. Eisenberg kritisiert:

Within linguistics the term [gemeint ist „endangeredness“, Anm. d. Verf.] is used for such, and only such, languages which are in danger of becoming extinct by the loss of native speakers. Some years ago the Society of Endangered Languages (Gesellschaft für bedrohte Sprachen) was founded. [...] When talking about a language with nearly 100 million speakers and more than 20 million learners one should carefully avoid even the slightest associative links in this direction (Eisenberg 2004b: 122f.).

${ }^{366}$ Diese Metaphorik spielt auch im Einwanderungsdiskurs eine Schlüsselrolle (vgl. u.a. Böke 1996: 438), aber beispielsweise auch in der Sozial- oder Schulpolitik.

${ }^{367}$ Spitzmüller ordnet die Wassermetaphorik dem Bereich „Sprache als Container“ zu, mit der Begründung, in dieser Metaphorik könne man von einem Konzept eines Behälters ausgehen, in den Entlehnungen einflössen (vgl. Spitzmüller 2005: 244). In dieser Metaphorik spiegeln sich die Organismuskonzepte des 19. Jahrhunderts, von Grimm über Schleicher zu Steinthal. Diese besagen, dass die Sprache ebenso wie die organische Welt eine bestimmte Lebensspanne hat, von einer Geburt bis zu ihrem Tod. Im frühen 19. Jahrhundert waren diese Modelle vor allem auf von Humboldt gegründet, der von einem Sprachgeist ausging, der eine Sprachgemeinschaft prägt. Aus diesen Annahmen heraus resultiert die Vorstellung, dass es wenig entwickelte, voll entwickelte und eben auch „verfallende“ Sprachen gibt, dieses „Verfallen“ wird von Sprachvereinen dann auch regelmäßig heraufbeschworen. Auch im 20. Jahrhundert haben sich Sprachwissenschaftler, u.a. Noam Chomsky, wieder auf die Humboldtschen Vorstellungen bezogen. Und auch wenn viele Vorstellungen als veraltet gelten, die Fragen und Forschungsprobleme sind es nicht (vgl. ausführlich MLS 2005: 460f.).

368 Diese Metaphorik verwendete schon der ADSV/DSV (vgl. u.a. Pfalzgraf 2006: 79f.).

${ }^{369}$ Stukenbrock geht sogar so weit, dieser Metaphorik durch die Visualisierung der Tsunami-Katastrophe und der Überflutung von New Orleans in den Medien einen im öffentlichen Bewusstsein besonderen, existenzielle Grundängste hervorrufenden Raum einzuräumen (vgl. Stukenbrock 2005a: 226). 
Die Sprache wird auch in weiteren Metaphern mit Zerstörung in $\mathrm{Zu}$ sammenhang gebracht, „sprachliche Entgleisungen“ (Hanke 2001: 4), ist hierfür ein gutes Beispiel. Auch Kriegsmetaphorik, ${ }^{370}$ also Begriffe wie „Kampf“ (Krämer 2002c: 2), „Verteidigung“ (Fink et al. 2000: 91) oder „Mitstreiter“ (u.a. SN 2002g: 13), findet sich regelmäßig. Stukenbrock bezeichnet dies als „bellum verbale“ (Stukenbrock 2005a: 227). In diesem Kontext stehen Äußerungen wie „[w]ir kämpfen nicht gegen das Englische, wir verteidigen das Deutsche“ (SN 2001h: 7), ${ }^{371}$ „Widerstand gegen sprachliche Konzepte der Globalisierer“ (SN 2001g: 4) oder der Begriff „anglizistische Sprachinvasion“ (Hanke 2001: 4). ${ }^{372}$ Dies geht so weit, dass ein Artikel in den Sprachnachrichten überschrieben ist mit „Dolchstoß ${ }^{373}$ aus Deutschland“ (Ho 2006: 29). ${ }^{374}$

Die Anglizismenverwendung im Deutschen wird beim VDS als Verfall der Sprache bezeichnet. Begriffe wie "Sprachblödsinn“ (Tietz 2000: 6), "Sprachschlamperei“ (Krämer 2000f: 7) oder „Schimpansensprache“ (Krämer 2005d: 2) zielen in diese Richtung. In den Publikationen findet sich zudem der Begriff „Sprachmüll“ (Krämer 2000f: 7), den es zu beseitigen gilt. Ebenfalls hier einzustufen ist der Begriff „Denglisch“, der auf die Vermischung des Deutschen mit dem Englischen abzielt (u.a. SN 2002a: 1, vgl. Kapitel 1.5.3). Dadurch wird die angestrebte „Reinheit“ der

\footnotetext{
${ }^{370}$ Kriegsmetaphorik ist ein häufig angewandtes rhetorisches Element. Auch beispielsweise in der Sprache der Wirtschaft, der Politik oder des Sports wird diese Metaphorik verwendet.

${ }^{371}$ Vgl. zur Geschichte dieses Diskurses die Kurzdarstellung von Stukenbrock (2005: 227ff.).

${ }^{372}$ Der Begriff taucht über die Jahre hinweg immer wieder in leicht abgewandelter Form auf, in den Sprachnachrichten aus dem Jahr 2005 steht er sogar in einer Überschrift: „Die amerikanische Sprachinvasion nach 1945 und ihre Ideologen“. In diesem Artikel von Schmitz wird die „Sprachinvasion“ in einen direkten Zusammenhang mit dem Ende des Zweiten Weltkriegs gestellt (vgl. Schmitz 2005b: 10).

${ }^{373}$ Damit wird auf die Verschwörungstheorie der Obersten Heeresleitung und rechter Kreise nach Ende des Ersten Weltkriegs angespielt.

${ }^{374}$ Die Kriegsrhetorik des Vereins wird in der Presse negativ bewertet. Die Märkische Allgemeine Zeitung beispielsweise berichtet unter der Überschrift: „Zuwanderungsgesetz für Fremdwörter gefordert. Der Verein Deutsche Sprache will mit harter, beharrlicher Arbeit und strammer Kriegsrhetorik das Deutsche von den Anglizismen reinigen“. Weiter heißt es in dem Artikel: „Wenn Gawlitta mit säuselnder Stimme sagt, dass die Sprache „wie sauberes Wasser und klare Luft“ rein zu halten sei, dann muss man sich fragen, was für ein Begriff von ,Fremdheit' in der Sprache hier eigentlich projiziert wird“ (Zugaro-Merim 2002: V8).
} 
Sprache zwar nicht als solche benannt, jedoch implizit gefordert. ${ }^{375}$ In diesen Zusammenhang fällt auch die Bezeichnung „BSE (Bad Simple English)“, die Krämer häufig verwendet (Krämer 2005d: 2).

Die Anglizismen im Deutschen werden vom VDS weiterhin immer wieder mit Krankheiten in Zusammenhang gebracht. ${ }^{376}$ Es ist die Rede von „Sprachauswurf“ (SN 2000c: 1), von „ungehemmtem Anglizismenwahn“ (Hanke 2001: 4), von „Anglizismus-Epidemie“ (Brinkmann 2001: 8). Ein Autor in den Sprachnachrichten spricht von „[k]ollektive[r] Psychopathologie“ (Baumann 2000: 1). Die Sprache wird als Organismus dargestellt, eine Sprachauffassung, die heute weitestgehend nicht mehr geteilt wird (vgl. u.a. J. G. Schneider 2006). In den Sprachnachrichten ist zu lesen, dass die „innere Form der Sprache negativ beeinfluss[t]“ wird:

Dem Verein Deutsche Sprache ist seit seiner Gründung im November 1997 bewußt, dass Anglizismen und Amerikanismen nicht nur zur Veränderung des Wortschatzes der deutschen Sprache führen, sondern auch die ,innere Form' ${ }^{377}$ unserer Muttersprache negativ beeinflussen (Burkert 2005: 12).

${ }^{375}$ Spitzmüller spricht hier von einem „verbalem Ausweichmanöver“ (vgl. Spitzmüller 2005: 242).

${ }^{376}$ Einige Sprachwissenschaftler sprechen in dem Zusammenhang von biologisch-pathologisierender Metaphorik.

377 Hiermit verweist Burkert u.a. auf Humboldt und dessen Sprachauffassung. In der Publikation „Die Zukunft der deutschen Sprache“ heißt es: „Solche Lehnvorgänge dauern länger, und sie haben strukturelle Folgen, denn sie berühren den Kern des Sprachsystems, während Wortentlehnungen zunächst einmal nur die Oberfläche der Sprache betreffen und für sich genommen undramatisch sind“ (Glück 2000a: 66). Hierzu merkt Stukenbrock kritisch an, diese Aussage verweise auf Weisgerbers veraltetes Sprachkonzept eines muttersprachlichen Weltbilds, das durch innere Sprachform vermittelt wird (vgl. Stukenbrock 2005a: 225). Nussbaumer kritisiert diese Schrift unter anderem aus dem gleichen Grund (vgl. Nussbauer 2003: 110). Ebenso Schneider: „Betrachtet man diese Protagonisten des öffentlichen Sprachdiskurses aus linguistischer Perspektive, so stellt man fest, dass sich die von ihnen propagierte Sprachauffassung in der Regel an einer alten Metapher orientiert - der biologistischen Metapher von Sprache als einem Organismus: Ein Organismus kann geboren werden und sterben; er kann krank werden und verfallen, er ist - um es mit einem Ausdruck von Jürgen Spitzmüller zu sagen - eine klar ,abgrenzbare Einheit'. Ein Sprachsystem erscheint somit als ein abgeschlossenes organisches Gebilde, welches es zu erhalten gilt und das durch schädliche Einflüsse von außen in seiner Identität gefährdet ist.“ (J.G. Schneider 2006). Sprachen als Organismen zu verstehen, diese Auffassung war im 19. Jahrhundert modern und erlebte in der „inhaltsbezogenen Sprachwissenschaft" Leo Weisgerbers eine Renaissance. In der modernen Linguistik wird diese Auffassung nicht geteilt. Zur „Verdinglichung der Sprache“ und die damit einhergehende Oganismus-Argumentation vgl. auch Keller (2003: 24ff., 2006: 193ff.). 
In anderen Publikationen wendet sich der VDS dann explizit dagegen, die Sprache als Organismus aufzufassen (vgl. z.B. Schrammen 2003: 538). ${ }^{378}$

In älteren Publikationen des Vereins fällt noch der Begriff „Pidgin“379, beispielsweise in einer Anzeige in der FAZ „Wir fühlen uns durch dieses Pidgin [gemeint ist die Sprache der Telekom, Anm. d. Verf.] angepöbelt (VWDS 1998d: 19). Das „Pidginisierungsargument“, wie Schneider es nennt, taucht immer wieder auf. Mit diesem Argument soll suggeriert werden, dass die deutsche Sprache als eigenständige Kultursprache bedroht ist (vgl. J. G. Schneider 2006). ${ }^{380}$ Die Verwendung des negativ konnotierten Begriffs „Pidgin“ ist schwierig (vgl. Kapitel 1.6 und u.a. Schneider 2008: 102f.). ${ }^{381}$ Durch den Begriff „Pidgin“ wird eine Situation benannt, die im Deutschen aus sprachwissenschaftlicher Sicht nicht gegeben ist. Damit wird ein Bedrohungsszenario aufgebaut. Diese Übertreibungen werden laut Stukenbrock „nicht nur mit Nachsicht behandelt, sondern von den Akteuren sogar zum methodischen Prinzip erhoben“ (Stukenbrock 2005a: 226), indem sie als rhetorisches Element im Diskurs des Vereins immer wieder auftauchen. Ein weiterer interessanter Aspekt: Der Anzeigentext zeigt durch das Wort „angepöbelt“, wie stark die Debatte emotionalisiert ist. Die Mitglieder fühlen sich persönlich angegriffen.

\footnotetext{
${ }^{378}$ Inkonsistenz in den Aussagen ist immer wieder ein Problem des VDS, das liegt auch an seiner Struktur.

${ }^{379}$ Pidginsprache wird definiert als: „Wortgeschichtlich wahrscheinlich auf englisch business $>$ Handel< zurückgehend. Was auf die Funktion als Behelfssprache, als Handelshilfssprache hinweist. Pidginsprachen sind charakterisiert durch eine im Vergleich zur jeweiligen Muttersprache der Sprecher deutlich reduzierte grammatische Struktur (Flexionsverlust, syntaktische Vereinfachungen, Reduktion des Tempus- und Modussystems), ein stark eingeschränktes Lexikon, eingeschränkten Stilumfang (Tendenz zu Umschreibungen und Metaphern) und ein verändertes, i.d.R. vereinfachtes phonologisches System [...]. Ihr Gebrauch ist meist sozial negativ konnotiert. [...] P. entstehen, wenn zwei oder mehr Sprachgemeinschaften kommunizieren möchten/müssen und sich dabei der offensichtlicheren Merkmale der Sprache des anderen bedienen, diese aber, um sich dem Gegenüber verständlich zu machen, reduzieren“ (MLS 2005: 494f.).

${ }^{380}$ Dies besagt der Begriff „Pidgin“ nicht, ist aber die Botschaft, die durch diesen Begriff transportiert wird. Das Argument sieht beispielsweise Schneider als teilweise berechtigt an.

${ }^{381}$ Von diesem sachlich falschen Begriff hat sich der Verein mittlerweile weitgehend verabschiedet.
} 
Mitglieder und Funktionäre des VDS ziehen immer wieder englische Begriffe und deren Verwendung ins Lächerliche. Ein Beispiel ist der „body bag“, der im Deutschen als Begriff für eine Tasche mit einem breiten Gurt verwendet wird. VDS-Akteure beteuern immer wieder, dass dieser Begriff im Englischen für einen „Leichensack“ verwendet wird. Die Argumentationsweise hat einige Sprachwissenschaftler dazu bewogen, sich in einem Blog mit fachlichen Fehlern des Vereins auseinanderzusetzen. Denn auch im Englischen kann mit „body bag“ durchaus eine Tasche bezeichnet werden (vgl. Stefanowitsch 2007a).

Regelmäßig werden mit der Verwendung von Anglizismen Gefühle verbunden, darunter Begriffe wie „Stolz“, „Scham“, „Angst“, aber auch "Neid“ und „Bedrückung“ (vgl. Stukenbrock 2005a: 221). Krämer schreibt hierzu: „Deutsch zu sprechen ist vielen Deutschen offensichtlich lästig oder peinlich“ (Krämer 2000a: 254, vgl. Stukenbrock 2005a: 237). ${ }^{382}$ Gawlitta sieht in den Anglizismen eine "Selbstaufgabe” der Deutschen (Gawlitta 2001b: 3). Die Verwendung von Anglizismen drückt nach Ansicht des VDS einen Minderwertigkeitskomplex der Deutschen aus (vgl. Krämer 2000e: 3). ${ }^{383}$ Es wird auch immer wieder die „linguistic submissiveness“ angeführt, die die Londoner Times beschrieb. Ein Begriff, der sehr häufig in Publikationen des VDS auftaucht, ist "pseudokosmopolitische[s] Imponiergehabe vieler Zeitgenossen“ (vgl. u.a. VWDS 1998a). Der Gebrauch von Anglizismen im Deutschen wird mit Angeberei in Verbindung gebracht, ebenso mit Effekthascherei (vgl. z.B. Krämer 2004c: 2) oder mit „pseudokosmopolitische[r], auf Denglisch daherkommende[r] Weltoffenheit“ (SN 2003h: 6, vgl. auch Pfalzgraf 2006: 72). Der Begriff „Dampfplaudergewerkschaft“ (Krämer 2000f: 7) ist hierfür ein weiteres Beispiel. Wer Anglizismen benutzt, dem wird vom VDS also Imponiergehabe und Wichtigtuerei

\footnotetext{
${ }^{382}$ Mit Gefühlen in Verbindung gebracht wird die Verwendung beispielsweise auch Pfitzner (1978), der von „Prestige“ als einem Motivationsgrund ausgeht. Vgl. zu Funktionen der Anglizismen, den Einstellungen gegenüber Anglizismen und deren Verwendung u.a. Galinsky (1975) und (Stickel/Volz 1999). In diesen Publikationen beziehen sich alle Argumente oder Befragungen auf die Motivation der Verwendung eines Anglizismus. Die Aussage, dass das Deutschsprechen als „lästig“ oder „peinlich“ empfunden wird, lässt sich dadurch weder verifizieren noch falsifizieren.

${ }^{383}$ Die Sprache wird hier als „Kristallisationspunkt kollektiver Identität“ verwendet (vgl. Stukenbrock 2003: 325).
} 
unterstellt, eine typisches Argumentation von Anglizismengegnern (vgl. Hoberg 2001: 300). ${ }^{384}$ Auf Aufklebern ist zu lesen: „Ich bin der Größte! Ich kann Denglisch!“ Der Zusammenhang zwischen Imponiergehabe und der Verwendung von Anglizismen wird in sprachwissenschaftlichen Untersuchungen nicht hergestellt. ${ }^{385}$ Nussbaumer führt hierzu aus, dass sich hinter dem Vorwurf der Wichtigtuerei gerade der Ungebildeten eine elitäre Haltung des VDS zeige, und dass es sich um ein vorgeschobenes Argument handele (vgl. Nussbaumer 2003: 116). Anzumerken ist aber, dass sich die Vorwürfe des VDS in aller Regel nicht gegen die Ungebildeten wenden, sondern gegen Journalisten, Werbemacher, Leute aus der Wirtschaft u.s.w..

Immer wieder wird auch eines der typischen Argumente von Anglizismengegnern angeführt, die Anglizismen werden als „überflüssig“ kategorisiert (vgl. u.a. Pogarell/Schröder 1999). Seitens des VDS argumentiert man weiter gegen Anglizismen, diese verdrängten deutsche Wörter und seien durch diese ersetzbar. Einige Anglizismen werden vom VDS daher als „schädlich“ angesehen. Schneider kritisiert dies. Nach seiner Ansicht werden viele der deutschen Begriffe, die vom VDS als Synonyme (beispielsweise im Anglizismen-Index) für Anglizismen angegeben werden, im konkreten Sprachgebrauch anders verwendet (vgl. J.G. Schneider 2006 sowie Kapitel 2.5.1.3).

Ein wichtiges Argument gegen die Anglizismen ist auch das Argument der Kommunikationsbarriere. Dieses taucht im Diskurs regelmäßig auf. Es wird beispielsweise darauf hingewiesen, dass diejenigen, die die Kommunikationsbarrieren aufbauen, nicht als gute Demokraten verstanden werden (vgl. Spitzmüller 2007: 275). Hoberg erläutert zynisch:

Allerdings wird dieses Argument fast nie von den angeblich betroffenen Menschen vorgebracht, sondern von solchen, die selbst keine Schwierigkeiten mit dem Englischen haben. In einer rührendfürsorglichen, caritativen Haltung tritt man für die armen Menschen

\footnotetext{
${ }^{384}$ Hier hat Hoberg Verständnis: „Sie behaupten, Anglizismengebrauch sei häufig nichts weiter als Angeberei oder Imponiergehabe, was man kaum bestreiten kann“ (Hoberg 2001: 300).

${ }^{385}$ Eisenberg und Baurmann weisen beispielsweise darauf hin, man könne zwar mit fremden Wörtern imponieren, einschüchtern und Sachverhalte verschleiern (vgl. Eisenberg/Baurmann 1984: 20), aber: „All dies sind Funktionen, die dem fremden Wort in seinem Gebrauch aufgebürdet werden, die es aber von sich aus und notwendigerweise nicht hat" (Eisenberg/Baurmann 1984: 20).
} 
ein, die leider wenig oder gar kein Englisch gelernt haben und daher ihr alltägliches Leben kaum zu meistern imstande sind (Hoberg 2001: 300).

Diese Beobachtung Hobergs trifft nur teilweise $\mathrm{zu}$, denn VDSFunktionäre argumentieren nicht nur damit, dass andere das „englische Kauderwelsch“ nicht verstehen würden, sondern auch damit, dass sie selbst sich „plötzlich [...] fühlen wie ein Analphabet“ (Hensel 2000: 43).

Diskursstiftend ist auch die sich wiederholende Debatte um den Patriotismus. Dies zeigt sich in folgender Äußerung Eberhard Schöcks, Stifter des Kulturpreises Deutsche Sprache: „Für mich ist die Anglisierung unserer Sprache nur ein Symptom - die Krankheit ist das fehlende Nationalbewusstsein“ (Schöck 2005: 4, ähnlich Muschg 2005: 2, und SN 2006a: 5). ${ }^{386}$ Hier wird die Gefährdung der Sprache zur Gefahr der Integrität und Identität auf politischer, kultureller und ethnischer Ebene (zu diesem Konzept vgl. Gardt 2004: 197). Die Zeit des Nationalsozialismus wird immer wieder thematisiert, unter anderem werden „Die Schatten des Dritten Reiches“ angesprochen (Wolffsohn 2005: 5). An anderer Stelle heißt es „Wegen der historischen Last des Dritten Reichs ist Deutschland hier [gemeint ist für Sprachanleihen aus Amerika, Anm. d. Verf.] besonders anfällig. Es hat immer noch kein normales und gelassenes Selbstbewußtsein“ (Gawlitta 2001d: 8).

Im Jahr 2005 schreibt Krämer:

Lieber ein halber Ami als ein ganzer Nazi. [...] Solange wir weiter unsere über tausendjährige glorreiche Geschichte, mit Helden wie Karl dem Großen, Luther, Leibniz, Bach und Beethoven, Einstein, Gauß und Dürer [...], auf 12 Jahre Naziherrschaft reduzieren lassen, wird auch die deutsche Sprache nicht komplett genesen (Krämer 2005c: 2).

Hierbei rückt die Geschichte des Purismus in den Fokus des Diskurses. Krämer argumentiert damit indirekt dafür, dass der Purismus destigmatisiert wird (vgl. Spitzmüller 2007: 270).

In diesem Zitat verknüpft Krämer die Anglizismen mit der Reduzierung der deutschen Geschichte auf die NS-Zeit. Pfalzgraf merkt hierzu an, dass Krämer die Anglizismen als eine Folge des Zweiten Weltkriegs darstellt und damit den verlorenen Weltkrieg verantwortlich macht für

${ }^{386}$ Hierzu äußert ein Mitglied in einem Leserbrief der Ausgabe heftige Kritik: „Schon den ausländischen Mitgliedern des Vereins gegenüber ist es geboten, Patriotismusdebatten nicht im VDS zu führen“ (Esser 2006: 21). 
den Einfluss des Englischen auf das Deutsche (vgl. Pfalzgraf 2006: 75f.). Die Sprache wird beim VDS also häufig in Verbindung zu kulturellen und politischen Größen wie Nation, Zweiter Weltkrieg oder Amerikanisierung Europas gesetzt (vgl. auch Pfalzgraf 2006: 74). In der Abhandlung „Wer wir sind“ fällt der Begriff „Kulturimperialismus“, in den Publikationen wird dieser Aspekt aufgeführt, zum Beispiel, wenn es heißt „Hallo Coca-Cola!“387 (Krämer 2000e: 3) oder wenn Deutschland als „51. Bundesstaat" bezeichnet wird. ${ }^{388}$ In den Sprachnachrichten wird auch sehr direkte Kritik an Amerika laut:

Die Wiege der abendländischen Kultur steht immer noch in Europa, und auch in sonstiger Hinsicht haben wir keinen Anlaß, vor den selbsternannten Hütern von Freiheit und Gerechtigkeit jenseits des Atlantiks irgendeine Demutshaltung einzunehmen. Liebe Amerikaner, arbeitet erst einmal Eure eigene Vergangenheit auf, den Sklavenhandel und den Völkermord an den Indianern, den Bombenterror auf Hiroshima und Dresden, statt als selbstgerechte Moralapostel den Rest des Universums zu belehren, dann lassen wir uns gern von Euch etwas über Kultur und Moral erzählen (Krämer 2003a: 2).

Vorstand und Funktionäre des Vereins betonen häufig, nicht amerikafeindlich zu sein. Der Text mit Bemerkungen wie „selbstgerechte Moralapostel“ muss vor diesem Hintergrund gelesen werden und kann durchaus als antiamerikanisch verstanden werden. Die Anglizismen, die ins Deutsche kommen, wurden gerade zu den Anfangszeiten des Vereins als Kolonialisierung der Sprache verstanden. Davon zeugen Aussagen wie: „Die schleichende Verwandlung des Deutschen zur Spielwiese sprachkolonialer Dürftigkeiten“ (Michel 1999: 5). Krämer verweist darauf, durch die Verwendung von Anglizismen werde man „zu blinden Nachahmern einer angelsächsischen Denkweise und Weltansicht" und gebe „unsere eigenen komparativen Vorteile, die wir in Deutschland immer noch besitzen, ohne Gegenleistung [auf]“ (Krämer 2005d: 2). Auch der Begriff „Kulturnation“ wird immer wieder in den Zusammenhang mit der Sprache gestellt:

Diese [gemeint ist die Sprachentwicklung, Anm. d. Verf.] wird fast ausschließlich bestimmt von dem werbe- und mediengetragenen Diktat einer kleinen Kaste von blinden Nachbetern und unkritischen

\footnotetext{
${ }^{387}$ Hervorhebung im Original.

${ }^{388}$ Walter Krämer publizierte seine Dankesrede anlässlich der Verleihung des Deutschen Sprachpreises an ihn in überarbeiteter Form unter dem Titel: „Der 51. Bundesstaat: Die deutsche Sprache als Opfer deutscher Selbstverleugnung“ (Krämer 2000b).
} 
Missionaren der amerikanischen ,Leitkultur'. Damit ist Deutschland wohl das erstaunlichste Beispiel von Selbstkolonisierung einer ehemaligen europäischen Kulturnation (Föhr 1999: 2). ${ }^{389}$

Anglizismen werden also nicht als Bereicherung, sondern als Bedrohung der Identität der Deutschen angesehen (vgl. Pfalzgraf 2006: 76f.). Schiewe konstatiert, Veränderung werde als „Verfremdung“ oder gar als "Aufgabe der nationalen Identität“ (vgl. Schiewe 2003: 330) verstanden: „Diese Form der Sprachkritik nahm in ihrer Extremform nationalistische Züge an“ (vgl. Schiewe 2003: 330): Damit verweist Schiewe auf die Geschichte des DSV (vgl. Kapitel 1.7.1 und weiter unten in diesem Kapitel). Die Aussage, die deutsche Sprache und Kultur werde misshandelt (vgl. SN 2000d: 3) ist als Beispiel anzuführen, ebenso der Ausdruck „Kultureintopf“ (Frank 2000: 3). Anglizismen werden als eine „Vermischung der Sprache“ bezeichnet, ein weiterer Begriff, der ebenfalls auf Vermischung hinweist, ist „Sprachgulasch“ (Mai 1999: 1). ${ }^{390}$

Pfalzgraf verweist auf den engen Zusammenhang zwischen Sprache und Ideologie (Pfalzgraf 2006: 74ff.). Spitzmüller setzt den Diskurs über Anglizismen im Deutschen in Zusammenhang mit „Identitätsfindung, Selbstfindung und Ausgrenzung“ (Spitzmüller 2002: 259):

Der aktuelle Diskurs über den „Einfluß“ des Englischen auf das Deutsche ist [...] in einen gesamtgesellschaftlichen Diskurs über Nation, Identität und Alterität eingebettet. Er ist (auch) Ausdruck eines tief greifenden Mentalitätswandels und der Unsicherheit, die dieser Wandel hervorruft, einer Unsicherheit, der mit einer in dieser Form neuartigen Identitätsfindung, einer (auch) sprachlichen „Selbstfin-

${ }^{389}$ Pfalzgraf wertet diese Diskussion nach Gardt als sprachideologischen Diskurs (vgl. Pfalzgraf 2006: 74, vgl. Kapitel 1.4.3). Entscheidende Impulse zu einer Kulturnation, auf die in Deutschland in Gegenwart und Vergangenheit immer wieder Bezug genommen wird und wurde, hat bereits Johann Gottfried Herder gegeben, in dem er die Nation als Gemeinschaft auffasste, die durch eine Sprache und eine auf dieser Sprache beruhenden Kultur konstituiert ist. Anhand dieser Vorstellung konnte die Rückständigkeit gegenüber Frankreich und England in eine bedeutende Zukunft umgedeutet werden. Schon bei Herder war mit dem Gedanken der Kulturnation die Vorstellung verbunden, dass die Entstehung einer deutschen Nation nicht neu, sondern eine Wiedergeburt einer ruhmreichen Nation sei, davon ausgehend, dass die deutsche Nation nach dem Dreißigjährigen Krieg in eine Art zweihundertjährige Totenstarre verfallen gewesen war (vgl. Strock 2001: 14). Für eine ausführliche Darstellung des Zusammenhangs zwischen Sprache und Nation vgl. von Polenz 1967). Vom Begriff „Selbstkolonisierung distanziert sich der Verein mittlerweile, vgl. Kapitel 2.3.2

${ }^{390}$ Auch der bekannte Informatiker Weizenbaum verwendete diesen Begriff. 
dung“ und mithin der Abgrenzung von „anderen“ begegnet wird

(Spitzmüller 2002: 262). ${ }^{391}$

Siehe dazu auch das folgende Zitat:

Wollt Ihr, so müssen wir unsere Mitbürgerinnen und Mitbürger fragen, wollt Ihr diese Sprache auf ein Küchen- und Alltagsidiom herunterbringen, während ihr zugleich versucht, eine vom American way of life dominierte englischsprachige Kultur zu imitieren? In dieser Kultur werdet Ihr immer nur Untermieter und Bürger zweiter Klasse sein. Denn Sprache und Denken, Sprache und Kultur, Sprache und Lebensweise gehören zusammen, und nur in dieser Einheit sind sie kreativ (Meyer 2002: 3). ${ }^{392}$

Diese Aussage wird auch als Ethnisierung ${ }^{393}$ der Sprache verstanden.

Von der politischen Dimension zeugt auch die folgende Aussage:

Am Anfang des dritten Jahrtausends ist die vielgepriesene deutsche Freiheit somit zu einer fremdbestimmten geworden. Die Selbstverständlichkeit, mit der die Deutschen ihre Kultur aufgeben und sich die nordatlantische Kultur bis in das Kleinste hinein zu eigen machen, das stimmt doch eher bedenklich. Anderen nachzueifern ist einfach zu wenig für die zweitgrößte Volksgruppe in Europa, egal wie man zu ihrer Vergangenheit stehen mag. Die Deutschen sind wieder dort angekommen, wo sie an ihrem Anfang waren: ohne Geschlossenheit. Diesmal aber ohne Bewußtsein ihrer Freiheit (VDS Region Dresden 2005). ${ }^{394}$

Nussbaumer sieht einige Argumente des VDS als vorgeschoben an. Dahinter verberge sich „ein Unbehagen an der Gegenwart und ihren neuen Formen sprachlicher Wirklichkeitsbewältigung und damit eben auch Unbehagen an neuen Konstrukten sozialer Wirklichkeit“ (Nussbaumer 2003: 116). Er bewertet den Diskurs als sprachpolitischen Populismus,

${ }^{391}$ Nicht ganz verständlich ist, warum Spitzmüller diesen Begriff in Anführungszeichen setzt. Dass die englische Sprache die deutsche Sprache beeinflusst, ist Konsens. Auch stellt sich die Frage, ob es sich bei dieser Form der Identitätsfindung tatsächlich um eine neuartige Form handelt.

${ }^{392}$ Hans Joachim Meyer ist Historiker und Anglist. Er war Universitätsprofessor und Staatsminister für Wissenschaft und Kunst des Freistaates Sachsen.

${ }^{393}$ Unter Ethnisierung wird dabei verstanden: „[E]twas unter dem Gesichtspunkt des Ethnischen betrachten, mit ethnischen Belangen in Verbindung bringen “ verstanden (DFWB 2004: 291). Den Begriff „ethnicization“ verwendet beispielsweise Linke (2004). Sie sieht den VDS als den wichtigsten Akteur in Deutschland in diesem Themenfeld und die Arbeit des VDS als „linguistic fabrication of an ethnic Germanness“ und als „lingusitic nationalism“ (Linke 2004: 213f.).

${ }^{394}$ Auch Hoberg, der unter anderem Briefe von VWDS-Mitgliedern durchgesehen hat, verweist auf diesen Zusammenhang als einen Beweggrund der Anglizismengegner: „Sie behaupten, die Deutschen hätten Probleme mit ihrer Identität, sie besäßen ein zu geringes nationales Selbstbewusstsein, sie flüchteten aus ihrem Deutschsein.“ (Hoberg 2001: 300). 
der mit populistischen Strömungen westeuropäischer Länder, etwa in Asyl- und Migrationsfragen, verwandt ist (vgl. Nussbaumer 2003: 117) und erläutert weiter:

Und es ist auch die Nostalgie, das Heimweh nach der Größe, als die Deutschen noch etwas galten in der Welt. Diese Größe meint der VDS damit wiedererlangen zu können, dass er die Sprachgrenzen dicht macht. (Nussbaumer 2003: 116). ${ }^{395}$

Weiter geht noch Uli Linke, die die Argumentation des VDS unter der Kategorie „ethnolinguistischer Rassismus [Übersetzung der Verf.]“ subsumiert (vgl. Linke 2004: 205). ${ }^{396}$

Auch auf die Tradition des ADSV/DSV wird Bezug genommen (vgl. Dey 2003, zu dieser Einschätzung auch Pfalzgraf 2006: 80, Baumert 2005: 32). In den Sprachnachrichten taucht ebenfalls ein Element aus dem Diskurs des ADSV/DSV, nämlich der Slogan „Gedenke, daß Du ein Deutscher bist" wieder auf (Aden 2005: 4). Und auf den Seiten des VDS Dresden hieß es lange: „Kein fremdes Wort für das, was sich mit einem deutschen Wort ausdrücken läßt“ (VDS Region Dresden 2005). ${ }^{397}$ Pfalzgraf konstatiert:

Dies [gemeint ist, dass sich der VDS auf den ADSV bezieht, (Anm. d. Verf.) ist insofern bemerkenswert, als daß der ADSV in der Sprachwissenschaft als vorzügliches Beispiel einer puristischen Vereinigung angesehen wird, der VDS jedoch jegliche Purismusvorwürfe weit von sich weist (Pfalzgraf 2006: 80). ${ }^{398}$

Stukenbrock wertet die Verweise auf die Tradition der Sprachvereine in ihrer Untersuchung als "Selbstaufwertungsstrategie“ des Vereins (Stukenbrock 2005a: 231). ${ }^{399}$ Der alte Slogan des Sprachvereins, auf dessen

\footnotetext{
395 Davon zeugen die Publikationen des VDS m.E. nicht.

${ }^{396}$ Insgesamt bewertet sie die sprachpuristischen Bewegungen als „ethnolinguistic racism“, sieht den VDS aber als wichtigsten deutschen Vertreter (Linke 2004: 205ff.). Doch m.E. nach ist der Begriff „Rassismus“ in diesem Zusammenhang zu stark und von daher nicht glücklich gewählt.

${ }^{397}$ Als Quelle ist Mackensen (1980: 70) genannt. Mackensen, Lutz (1980) (Hg.): Gutes Deutsch in Schrift und Rede. Reinbek. (Nachdruck, die Erstauflage stammt aus dem Jahr 1964).

${ }^{398}$ Zum gespaltenen Verhältnis des VDS zum „Purismus“ vgl. Kapitel 2.4.2.

${ }^{399}$ Zur sachlichen Tradition vgl. u.a. Kapitel 1.7.1. Stukenbrock verweist auch auf die Untersuchungen von Hobsbawm und Ranger, die von „invented tradition“ sprechen (Hobsbawm/Ranger 1983). Der Verweis auf andere Sprachpatrioten ist nicht eine Erfindung des VDS, schon Schottelius beispielsweise hat sich auf Karl den Großen und auf Martin Luther bezogen (vgl. Stukenbrock 2006: 229).
} 
Tradition zurückgegriffen wird, ist von den Seiten des VDS Dresden verschwunden. Es scheint, als ob ein Umdenken stattfindet und man sich nicht mehr in der Tradition des ADSV/DSV sehen möchte, oder zumindest ein schärferes Bewusstsein für die Sprache hat, mit der man sich an die Öffentlichkeit wendet.

Despektierliche Äußerungen über diejenigen, die nach Ansicht des VDS schuld an den Anglizismen im Deutschen sind, tauchen im Diskurs des VDS immer wieder auf. Der VDS greift regelmäßig verschiedene Gruppen an, ganze Berufsgruppen werden diffamiert: Dazu gehören die Werbeindustrie, die „Werbefuzzis“ und „Werbefritzen“, die Medien, die Wirtschaft oder diejenigen, die viel mit dem Internet arbeiten, die „Cyber-Kretins“ (vgl. SN 2000c: 1, Stukenbrock 2005a: 229). An anderer Stelle heißt es:

Wollen wir uns in unserer Sprache nach dem Modediktat von Werbefuzzis, journalistischen Schnöseln, sich aufblähenden Wirtschaftskapitänen, akademischen Wichtigtuern, Möchtegern-Intellektuellen und opportunistischen Politikern richten, die meinen, wenn sie etwas auf Englisch sagen oder in Englisch benennen, sie hätten damit das Gütesiegel des Neuen und Kreativen sicher? Und die auf diese Weise das Ansehen der deutschen Sprache immer mehr auf den Hund bringen? (Meyer 2002: 3).

Auch die Wissenschaft wird gescholten, der der VDS mangelnde Sprachloyalität ${ }^{400}$ anlastet:

Die liberale Feierabendruhe, der Dämmerschlaf vieler Sprachwissenschaftler angesichts der öffentlichen Anglisierung, der fachsprachlichen Ausdrucksverarmung und Entwertung unseres Alltagsdeutsch wirken gespenstisch. Sie sind nicht nur ein Vorspiel, sondern die wichtigste Ursache für die in Wissenschaft und Wirtschaft jetzt bereits einsetzende Sprachnacht (VDS 2006g).

Dieses Zitat hebt Stukenbrock in ihrer Untersuchung des Diskurses des VDS hervor, zeigt es doch, dass der VDS der Wissenschaft mangelnde Aktivität bezüglich der Anglizismen im Deutschen vorwirft. ${ }^{401}$ Nuss-

\footnotetext{
${ }^{400}$ Vgl. Kapitel 1.6.

${ }^{401}$ Es wird der Mehrheit der Nicht-Wissenschaftler eine Minderheit der Wissenschaftler (und der Menschen aus der Wirtschaft) gegenübergestellt. Dies werde an anderer Stelle ganz anders dargestellt, wie Stukenbrock kritisiert. Sie führt aus, dass es bei Glück heißt „Wir Linguisten“ auf der einen, die „kleinen Leute“ mit ihrem „Kantinenenglisch“ (Glück 2000a: 65f. u. 69) auf der anderen Seite (vgl. Stukenbrock 2000: 233). Hierbei ist anzumerken, dass Glück vielmehr das „Kantinenenglisch der kleinen Leute“ neben das „Airport
} 
baumer sieht in der Wissenschaftsschelte eine zentrale Argumentation des VDS. Er führt aus, der Vorstand des Vereins möchte die Erkenntnisse der Wissenschaft nicht zur Kenntnis nehmen, da „das genauere Hinsehen das schnelle Werten unmöglich machen würde“ (Nussbaumer 2003: 115). Weiter weist er darauf hin, dass seitens des VDS die Wissenschaft als staatlich bestellt angesehen wird und laut VDS weder das Geld noch das Ansehen, das sie hat, verdienen würde (vgl. Nussbaumer 2003: 117). ${ }^{402}$ Nussbaumer verweist auch darauf, dass dies mit einer „antiwissenschaftlichen, antiakademischen Haltung [einhergeht] “ (Nussbaumer 2003: 115, vgl. auch Stukenbrock 2005a: 232).

Auch die Politiker werden angegriffen, wenn beispielsweise Krämer schreibt:

,a real challenge', das ist für Stoibers Wahlkampfleiter Michael Spreng die Wachablösung in Berlin. Diese ,challenge' kann er haben! Und mit ihm alle anderen, die mit dummen englischen Werbesprüchen nach unsren Wählerstimmen schielen (Krämer 2002a: 2).

An anderer Stelle fordert Krämer, „einer dieser Personen per Stimmzettel eins auszuwischen“ (Krämer 2002b: 2). Er wendet sich also mit deutlichen Worten gegen Anglizismenbefürworter oder direkt gegen Politiker. Kurz eingegangen werden soll noch auf den von ihm gern benutzen Begriff „Schimpansensprache“, ein Schimpfwort, mit dem Krämer Menschen, die Anglizismen benutzen, herabwürdigt (vgl. Spitzmüller 2007: 275). Verallgemeinernd bezeichnet der VDS diejenigen, die Anglizismen verwenden, als „Sprachsünder“ (SN 2000d: 3).

In solchen Begrifflichkeiten spiegelt sich ein Problem des VDS wider: Die Sprache der Publikationen des Vereins und die Äußerungen von Funktionären sind teilweise als polemisch $\mathrm{zu}$ charakterisieren (vgl. Niehr 2002a: 30f.).

Andererseits wird gerade das Polemisieren des Vereins positiv hervorgehoben, so im Spiegel:

[...] Polemik, wie sie Verein und Stiftung Deutsche Sprache lieben, wenn sie etwa gegen den Wort-Import „recyclen“ anwitzeln, indem sie dessen deutsche Aussprache nahe legen: „rezützeln“- „rezützeln

English der Schickeria“ stellt, also weite Teile der Gesamtbevölkerung kritisiert und nicht explizit nur die „kleinen Leute“ (vgl. Glück 2000a: 69).

${ }^{402}$ Die besagte Kritik des VDS bezieht sich jedoch nicht auf die Wissenschaft an sich, sondern auf die GfdS (vgl. Kapitel 2.2.7). 
wir also unsere Muttersprache!" Solcher Mut zum Polemisieren tut not (Schreiber 2006: 182). ${ }^{403}$

In den Medien wird aber auch kritisch über den Sprachgebrauch des VDS berichtet, so zum Beispiel durch den Politiker Manfred Büttner:

Die Texte des VDS sind wenig intellektuell. Briefe von Funktionären strotzen von falschem Deutsch, schwülstigen und aufgeblasenen Parolen, unverständlichen Formulierungen, Fremdwörtern, Rechtscheib- und Grammatikfehlern [sic] ${ }^{404}$ (Büttner 2001).

Der VDS betont immer wieder, dass ihm von Ausländern viel Sympathie und Verständnis für seine Anliegen entgegengebracht wird, beispielsweise in den Sprachnachrichten in dem Artikel „Denglish mindert Lust auf Deutsch - Befremden in der Slowakei über Verhunzung der Muttersprache in Deutschland“ (Herrmann 2005: 31, vgl. auch Grobe 2001: 1f.).

Ansonsten fällt auf, dass die meisten Argumente, mit denen der VDS für seine Anliegen eintritt, als Erwiderungen auf Angriffe von Seiten der Kritiker der Anglizismengegner formuliert sind (vgl. u.a. Dieter/Schrammen 2005).

Die Sprache des VDS wird von einigen Wissenschaftlern, u.a. Schneider, als eine dogmatische Sprachkritik - dogmatisch beispielsweise in der Hinsicht, dass Wörter einseitig mit Richtig-Falsch-Kriterien bewertet werden - gesehen, die ungeeignet ist, um Menschen für den Sprachgebrauch zu sensibilisieren (vgl. J.G. Schneider 2006).

Nussbaumer kritisiert, dass der VDS den öffentlichen sprachkritischen Diskurs vergifte, dazu trage der „Bierernst, ja Todernst“ der Sprachkritik des Vereins bei. Zudem inszeniere der Verein eine „ungeheure Aufgeregtheit" (vgl. Nussbaumer 2003: 117f.). Diese Kritik ist nicht von der Hand $\mathrm{zu}$ weisen, die Aussagen sind teilweise als verbissen zu sehen. (vgl. Kapitel 2.5.1.6). Dies wird auch vereinsintern so gesehen: „Die Sprache des VDS klingt manchmal ein wenig verbissen, zugegeben“ (Klatte 2008a: 104).

In Briefen an die VDS-Zentrale wird die Sprache und die Metaphorik des VDS auch von Mitgliedern kritisiert (Brief eines VDS-Mitglieds an

\footnotetext{
${ }^{403}$ Für eine ausführliche Besprechung und Kritik dieses Artikels vgl. Jan Georg Schneider (2007: 1ff.).

${ }^{404}$ Dies ist auch Walter Krämer bekannt, intern hat er einen Ausdruck des Artikels mit der Bemerkung versehen: „Dieser Vorwurf stimmt \& ist ernst zu nehmen.“
} 
die VDS-Geschäftsstelle, 7. März 2001). ${ }^{405}$ Dies geschieht, wie in diesem Kapitel dargelegt, aus nachvollziehbaren Gründen. Anzumerken bleibt außerdem, dass die Sprache des VDS oft grob und umgangssprachlich (vgl. auch Law 2002: 81), teilweise sehr aggressiv ist (vgl. z.B. Zifonun, die von „Aggressionsvokabular“ spricht, Zifonun 2002: 7) und dass insgesamt häufig negativ konnotierte Begriffe verwendet werden. In diesen Punkten wird die Sprache des VDS m.E. häufig zurecht kritisiert.

Festzuhalten bleibt auch, dass in Publikationen des VDS immer wieder bestimmte Gruppen - beispielsweise Politiker oder Wissenschaftler für ihren Sprachgebrauch diffamiert werden. Auch der Feststellung, dass der Verein stark polemisiere, ist zuzustimmen. Bezüglich antiamerikanischer Äußerungen des Vereins kann gesagt werden, dass sich in einigen Metaphoriken des Vereins durchaus Antiamerikanismus äußert, die Frage, ob der Verein generell in seiner Sprache Antiamerikanismus zum Ausdruck bringt, aber nicht zu bejahen ist.

\subsection{Vereinsarbeit}

Bereits 1999 wird der Verein hin und wieder in eine Reihe mit Institutionen wie der GfdS und dem IDS gestellt, als weithin akzeptierte Sprachautorität gehandelt, und Krämer wird in Zeitungen als „SprachExperte“ tituliert (vgl. Spitzmüller 2005: 126). Und schon im Jahr 2000 wurde auf die regen Aktivitäten des Vereins hingewiesen:

Ein rühriger $>>$ Verein Deutsche Sprache $<<$ hat die althergebrachten Sprachgesellschaften im Nu überflügelt und die allgemeine Gedankenlosigkeit im Reden und Schreiben beherzt durch viele öffentliche Aktionen angeprangert (Strocka 2000: 2).

Die Arbeit des Vereins soll im Folgenden ausführlich dargestellt werden. Wichtiger Bestandteil der Vereinsarbeit ist die Pflege von Kontakten zu Politikern, zu Journalisten und zu Kulturvereinigungen. Das Schreiben von Briefen an Institutionen und Firmen, die nach Meinung der VDS-Mitglieder unnötige Anglizismen verwenden sowie das Schrei-

\footnotetext{
${ }^{405}$ Dieses Mitglied hatte auch zu denen gehört, die das Wort „Wahrung“ im ursprünglichen Vereinsnamen kritisiert hatten, und weist erneut darauf hin (Brief eines VDSMitglieds an die VDS-Geschäftsstelle, 7. März 2001). In dem Schreiben wird kritisiert, dass Publikationen des VDS dem Verfasser sprachlich schlampig erscheinen.
} 
ben von Leserbriefen sind ebenfalls essenzieller Teil der Arbeit. ${ }^{406}$ Tagungen, Vorträge und Pressekontakte sowie Pressearbeit zählen genauso zur Vereinsarbeit wie Aktionen zum Tag der deutschen Sprache, Einzelaktionen oder die Publikationen, die der Verein herausgibt, darunter Bücher, die Sprachnachrichten sowie der Internetauftritt des Vereins. Ebenfalls wesentlicher Bestandteil sind die Verleihung des „Sprachpanschers“, des "Sprachhunzers“ und des „Kulturpreises Deutsche Sprache“ (diesen vergibt der VDS nicht allein, vgl. Kapitel 2.5.4.3). In jüngster Zeit ist mit der Stiftung Deutsche Sprache ein weiteres wichtiges Aktionsfeld hinzugekommen. Alle diese Themen drehen sich um Anglizismen und Sprachpflege. Daneben engagiert sich der Verein aber auch auf anderen Gebieten, wie das Engagement zur Erhaltung von Diplomstudiengängen zeigt.

Die Schwerpunkte der Arbeit sind in den Leitlinien des VDS vorgeschrieben. Dort sind verschiedene Gruppen und Einrichtungen festgelegt, mit denen zusammengearbeitet werden soll, darunter Politiker, Behörden, Lehrer, Firmen, Journalisten, Schriftsteller und die entsprechenden Berufsverbände, die Konferenz der Innenminister, die Bundesbeauftragten für Fragen der Kultur und der Medien, die Bundeskulturstiftung sowie weitere sprach- und kulturpolitische Einrichtungen (vgl. Zabel et al. 2003: 350f., vgl. auch VDS 2008m).

\subsubsection{Publikationen}

Der VDS hat bisher zahlreiche Publikationen verschiedener Art veröffentlicht. Dazu zählen der zentrale Internetauftritt des Vereins mit dem Forum, regionale Internetauftritte sowie die Sprachnachrichten als Zeitung des Vereins. Daneben gibt es Bücher (vom Vorsitzenden, von VDSFunktionären oder aber herausgegeben im Auftrag des Vereins), den

\footnotetext{
${ }^{406}$ Nicht immer sind Aktionen des VDS gewünscht, z.B. lehnte die Niedersächsische Landesbibliothek 2001 eine Fotodokumentation des VDS, die dieser dort ausstellen wollte, ab. Vgl. Brief von der Niedersächsischen Landesbibliothek an ein VDS-Vorstandsmitglied, 6. November 2001).
} 
Anglizismen-Index, das VDS-Tagebuch sowie den Erfolgskalender. ${ }^{407}$ Im Folgenden werden diese Publikationen des Vereins vorgestellt.

\subsubsection{Internetauftritte}

Der VDS hat einen zentralen Internetauftritt, dieser ist unter www.vdsev.de seit $1998^{408}$ zugänglich. Der Auftritt enthält ausführliche Informationen zur Struktur des Vereins, zu seinen Zielen und Aktivitäten und zu den Regionalgruppen des Vereins. Der Vorstand und die Leiter einzelner Arbeitskreise sind dort genannt, die Satzung ist abrufbar, ebenso sind prominente Mitglieder aufgeführt. ${ }^{409}$ Neuigkeiten und Veranstaltungen rund um den Verein stehen dort, der Tag der deutschen Sprache wird ausführlich dokumentiert, ebenso ausführlich wird die Aktion „Deutsch ins Grundgesetz“ vorgestellt. Darüber hinaus sind die Sprachnachrichten ab Ausgabe 2002, Nr. 1 abrufbar. Daneben gibt es ausgewählte Beiträge aus den Sprachnachrichten als mp3 zum Download. Alle Pressemitteilungen, die der Verein bisher herausgegeben hat, sind abrufbar. Des Weiteren gibt es ein Forum, das allen Interessierten die Möglichkeit bietet, ihre Meinung zu äußern (Kapitel 2.5.1.2), den Anglizismen-Index (Kapitel 2.5.1.3) und den Erfolgskalender „Lichtblicke“ in elektronischer Fassung (Kapitel 2.5.1.5). Hingewiesen wird auf die Mitgliedschaft des VDS im Netzwerk Deutsche Sprache sowie auf die Sprachbündnisse des Vereins (Kapitel 2.2.6). Zudem befinden sich Unterrichtsmaterialien, der Pressespiegel und die Deutschlehrerbörse des VDS (vgl. Kapitel 2.5.9) auf der Homepage. Die Sprachpanscher und Sprachhunzer werden aufgeführt, daneben gibt es Argumente für Deutsch, eine Dokumentation der „Aktion Sprachtest“ sowie eine Kurzdarstellung des Kulturpreises Deutsche Sprache. Unter der Rubrik „Literatur" finden sich ausgewählte Texte und Literaturhinweise, aber auch

\footnotetext{
${ }^{407}$ Dabei gab es eine Zeitlang keine Regel, ob Publikationen in alter oder neuer Rechtschreibung verfasst werden, Verfasser von Vereinsdokumenten sind für deren Rechtschreibung verantwortlich, der Verfasser eines Dokumentes bestimmt auch dessen Rechtschreibung (vgl. Protokoll der VWDS-Vorstandssitzung vom 11. April 1999). Zur aktuellen Regelung vgl. Kapitel 2.5.9.

${ }^{408}$ Information von Walter Krämer, geht hervor aus E-Mail von Christiane Dahl an die Verfasserin, 12. Oktober 2007.

${ }^{409}$ Vgl. VDS (2008a).
} 
Stellungnahmen aus der Politik zum Thema deutsche Sprache. Neben der Möglichkeit der Kontaktaufnahme und einem Beitrittsformular bietet die Homepage auch noch den Versand von Büchern aus dem IFBVerlag an. Der Internetauftritt ist neben den Sprachnachrichten das zentrale Informationsorgan des Vereins, Pfalzgraf spricht von einem „hoch organisierten Internetauftritt“ (Pfalzgraf 2006: 13). Dieser zeichnet sich durch eine grafisch und strukturell professionelle Aufmachung aus. Der Internetauftritt hat nach Angaben des VDS täglich etwa 1000 Besucher. ${ }^{410}$

Neben dem zentralen Internetauftritt des VDS existieren weitere Internetauftritte von Regionalgruppen: ${ }^{411}$ Diese unterscheiden sich zum Teil inhaltlich und gestalterisch wenig vom zentralen Internetauftritt des VDS, wie beispielsweise der Auftritt des VDS Leipzig. Es sind jedoch teilweise starke Unterschiede erkennbar. Einige Auftritte sind in Design und Aufmachung weit weniger professionell und in sprachlicher Hinsicht weniger gelungen, einige regionale Auftritte, wie der der Region Lübeck, sind völlig unprofessionell. ${ }^{412}$ Zudem lässt sich feststellen, dass es manchmal an Absprachen oder an Aktualisierungen mangelt. ${ }^{413}$ Die

\footnotetext{
${ }^{410}$ Brief von Holger Klatte, VDS-Geschäftsführer, an die Verfasserin, 7. Januar 2009.

${ }^{411}$ So sind die Regionalgruppen von Leipzig, Dresden, Potsdam, Lübeck/Wismar, Kiel/Flensburg, Bremen/Bremerhaven/Umland, Kassel, Münster/Umland, Siegen/Wittgenstein/Olpe/Altenkirchen, Rhein-Neckar, Ortenau, München/Umgebung, Bodensee/Oberschwaben, Regensburg Stadt und Land und Mainfranken mit einem eigenen Auftritt vertreten und von der zentralen Internetseite verlinkt. Stellungnahmen der Regionalgruppen hinsichtlich der Unterteilungen von Anglizismen wurden unter 2.4 diskutiert, ebenso wie der Verweis auf die Tradition des ADSV/DSV auf der Homepage des VDS Dresden.

${ }^{412}$ Auf der Startseite der VDS Region Lübeck ist beispielsweise zu lesen: „Wenn sie es leid sind, ihren Kindern kids [sic], Ihrem Friseur Head-Cut, Ihrem Bäcker Backfactory oder Back shop zu sagen [...]“ (VDS Region Lübeck 2008). Außerdem sind die Seiten grafisch wie auch strukturell wenig ansprechend. Andere regionalen Internetseiten weisen ebenso deutliche sprachliche Schwächen auf, wie die Seiten des VDS Berlin, wo unter Kontakt zu lesen ist: „Kontaktmöglichkeiten mit uns“ (VDS Region Berlin/Potsdam 2008a), auch dieser Internetauftritt ist optisch wenig ansprechend.

${ }^{413}$ So findet man beispielsweise unterschiedliche Mitgliederzahlen auf den Seiten des Kulturpreises Deutsche Sprache (14 000, Stand November 2008) (Jury des Kulturpreises Deutsche Sprache 2008c), den Seiten der VDS Region Kassel (18000, Stand Dezember 2008) (VDS Region Kassel 2008) oder den Seiten des Bundesverbands (mittlerweile 31000 , VDS 2008b) oder unterschiedliche Informationen über Kooperationen auf den Seiten der VDS Region Kassel, hier wird die Theo-Münch-Stiftung noch als Kooperationspartner geführt (vgl. VDS Region Kassel 2008).
} 
Regionen Lübeck und Siegen/Wittgestein, Olpe, Altenkirchen ${ }^{414}$ verweisen auf auch Paulwitz und die Deutsche Sprachwelt (vgl. Kapitel 1.7.5), von denen sich der Bundesverband distanziert. Offensichtlich werden die regionalen Internetauftritte vom Bundesvorstand des Vereins nicht kontrolliert.

In jüngster Zeit wurden jedoch die Seiten des VDS Dresden sowohl sprachlich als auch optisch stark überarbeitet und verbessert, was zeigt, welche große Bedeutung den Internetauftritten auch im VDS beigemessen wird. Positiv hervorzuheben sind die regionalen Seiten der VDS Region Münsterland. Dort wird auf der Startseite bereits Wert auf die Kulturarbeit der VDS-Region gelegt, beispielsweise lobt man pfiffiges Deutsch, organisiert Kulturveranstaltungen und verleiht PositivSprachpreise an junge Leute (VDS Region Münsterland 2008). Es ist davon auszugehen, dass die Internetseiten einer der wichtigsten Faktoren sind, um neue Mitglieder und damit Unterstützung $\mathrm{zu}$ gewinnen (vgl. auch Pfalzgraf 2006: 13). ${ }^{415}$

\subsubsection{Forum}

Das Forum in der heutigen Form gibt es seit 2001. Es besteht aus derzeit sechs einzelnen Diskussionsforen zu den Themen Sprachenpolitik, Medien und Freizeit, Klartext (hinter dieser Rubrik stecken: allgemeine Diskussionen über Deutsch und Englisch), Produkte und Unternehmen, Vereinsaktivitäten und Kniffe, Tricks und Tests (Fragen, Hilfestellungen und Anregungen zum Forum). Derzeit hat das Forum über 1000 registrierte Mitglieder und umfasst etwa 50000 Beiträge. Diese Beiträge gliedern sich in rund 3000 Diskussionsstränge (VDS 2008j). Schon in der Anfangszeit wurde beschlossen, das Forum zu moderieren. ${ }^{416}$

\footnotetext{
${ }^{414}$ Vgl. dazu den Internetauftritt (VDS Region Wortreich, Siegen/Wittgenstein, Olpe, Altenkirchen 2008).

${ }^{415}$ Wohl aus diesem Grund ist seit 2007 auch das Anlegen eines Wikis des VDS angedacht (vgl. Baer 2007a: 23). Dieses Wiki gibt es aber (Stand 2009) bisher nicht.

416 „Um keinen nationalistischen und fremdenfeindlichen Beiträgen eine Plattform zu bieten, haben wir uns dazu entschlossen, dieses Forum zu moderieren“ (Brief eines VDSFunktionärs an Walter Krämer, 29. Januar 2001). Das Problem mit rechtsextremen Beiträgen hat sich seiner Erfahrung nach mittlerweile erledigt. „Seit wir im Prinzip klar ankündigen, rechtsextreme Beiträge zu löschen, kommen auch keine mehr. Falls doch, so werden sie von uns aber gelöscht. Aber meistens antworten die anderen Gesprächsteilnehmer
} 
Über diese Entscheidung wurde intern diskutiert, auch über den Wortlaut des Vorspanns: Ein VDS-Funktionär war der Ansicht, dass man in einem Sprachwahrverein höchstens von „Grundgesetztreue“ sprechen sollte (Brief eines VDS-Funktionärs an Walter Krämer vom 29. Januar 2001). Doch diese Meinung setzte sich nicht durch. Jetzt ist im Vorspann zu lesen: „Wir möchten nationalistischen und fremdenfeindlichen Beiträgen keine Plattform bieten." (vgl. VDS 2008j). Weiterhin wird darauf hingewiesen, dass das Forum kein Rechtschreibforum ist und dass sachfremde Beiträge, politische Pamphlete und Werbung entfernt werden (vgl. VDS 2008j).

Thilo Machotta war der erste Moderator des Forums. ${ }^{417}$ Er sagt: „Die meisten Diskussionsteilnehmer im Forum sind Interessierte, keine Vereinsmitglieder." Auch hat er die Erfahrung gemacht, dass viele erst über das Forum zum Verein kommen.

Die Themen, die mit großer Emotion kontrovers diskutiert werden, sind vielfältig: Sie reichen von der Interpretation des Terminus Sprachpflege (Thread "Sprachpflege“) ${ }^{418}$ über grammatische Fragen ${ }^{419}$ bis hin zur Anglizismenfrage. ${ }^{420}$ Einige Diskussionen werden wenig sachlich geführt, beziehungsweise wird schnell vom Thema abgeschweift (vgl. den Thread: „Die Geschlechtsneutralität“). ${ }^{421}$ Es kommt auch immer wieder $\mathrm{zu}$ einem relativ heftigen Austausch (z.B. Thread „Denglischtümler preist Abkehr von unserer Muttersprache“. ${ }^{422} \mathrm{Zu}$ finden ist auch ein Angriff auf eine kritische Berichterstattung über den VDS (vgl. Thread:

auf rechtsextreme Äußerungen schon dementsprechend, so dass ich als Moderator gar nicht eingreifen muss." Aber der Moderator des VDS scheut sich auch nicht, einzugreifen. Denn dies wurde ihm vom Vorstand des VDS aufgetragen: „Es gab eine Zeitlang Versuche von eher rechten Vereinigungen, wie der Deutschen Sprachwelt, massiv in unserem Forum aufzutauchen, da mussten wir dann auch durchgreifen und die rauswerfen." Diese Praxis des VDS, das Forum zu moderieren und gegebenenfalls auch Einträge zu löschen, wird in anderen Foren teilweise heftig diskutiert.“ (Gespräch mit Thilo Machotta am 21. März 2005).

${ }^{417}$ Derzeit moderieren das Forum Joseph Braun und Martin Hahn (vgl. VDS 2008j).

${ }^{418}<$ http://vds-ev.de/forum/viewtopic.php?TopicID=3249> (13. Januar 2008).

${ }^{419}<$ http://vds-ev.de/forum/viewtopic.php?TopicID=3249> (13. Januar 2008).

${ }^{420}<$ http://vds-ev.de/forum/viewtopic.php?TopicID=3092, (13. Januar 2008).

$421<\mathrm{http} / / /$ vds-ev.de/forum/viewtopic.php?TopicID=80> (13. Januar 2008).

$422<$ http://vds-ev.de/forum/viewtopic.php?TopicID=21238\&page=0> (13. Januar 2008). 
„Sinnentstelltes Zitat des VDS“). ${ }^{423}$ Es scheint, dass das Forum zunehmend als Medium für Sprachberatung angesehen wird (vgl. z.B. Threads „waehren und knipsen“424 und "bis zu dem Punkt“, ${ }^{425}$ was als Zeichen dafür gesehen werden kann, dass der VDS zunehmend als Autorität in Fragen der Sprachkritik angesehen wird.

\subsubsection{Anglizismenliste/Anglizismen-Index}

Den Anglizismen-Index (vorher: Anglizismenliste) des VDS gibt es seit dem Jahr 2002. Er enthält derzeit rund 6800 Einträge. Den Index gibt es sowohl online unter http://vds-ev.de/anglizismenindex, als auch in Buchform unter dem Titel „Der Anglizismen-Index. Anglizismen. Gewinn oder Zumutung?" (der Anglizismen-Index ist jährlich neu erschienen, neueste Ausgabe 2008). ${ }^{426}$

In den frühen gedruckten Versionen sind dem Anglizismen-Index zwei Aufsätze hinzugefügt: Heinz-Günter Schmitz „Über die Sprachloyalität der Deutschen“ und Hermann Zabel „Überwindung der Ausgrenzung“. In der Ausgabe von 2008 sind hinzugekommen: ,'Blockbuster' und andere Zumutungen“ von Gerhard H. Junker, „Über Deutsch für Inländer und Englisch für Dummschwätzer“ von Peter Hahne und „Wie wir es sehen, Sprache zwischen Pflege und Wissenschaft" von Heinz-Dieter Dey (vgl. Junker et al. 2008: 263ff.). Zabels Aufsatz ist dagegen nicht mehr enthalten.

Den Index will man nicht als puristisch verstanden wissen: „Der Anglizismen-Index ist nicht das Werk von Puristen, sondern von Menschen, die sich konstruktiv und tolerant mit der deutschen Sprache auseinandersetzen“ (vgl. Junker et al. 2008). Mit der Liste will der VDS diesen Menschen ein Werkzeug an die Hand geben, das Hilfe anbietet, „Alternativen zu der um sich greifenden Unsitte“ der Anglizismen $z u$ finden. Zudem soll die Liste in ihrer Endfassung „den politisch verantwortli-

\footnotetext{
${ }^{423}<$ http://vds-ev.de/forum/viewtopic.php?TopicID=3276> (13. Januar 2008). Bei dem angegriffenen Artikel handelt es sich um „Wenn die Sorre in Gilbhart durch die Zeugemutter fährt... Kleine Geschichte der sprachpflegerischen Eindeutschungen - von erfolgreich bis skurril“" (Klemm 2005).

${ }^{424}<$ http://vds-ev.de/forum/viewtopic.php?TopicID=3356> (13. Januar 2008).

$425<$ http://vds-ev.de/forum/viewtopic.php?TopicID=3355> (13. Januar 2008).

${ }^{426}$ Den Index gibt es auch online (VDS 2008e).
} 
chen Stellen als Beratungs- und Entscheidungsvorlage dienen“ (vgl. Zabel 2001b: 267).

Der Index ist offen für Eingaben, jeder, der einen Vorschlag für einen Anglizismus einbringen möchte, der seiner Meinung nach in der Liste fehlt, kann diesen über ein Formular an den VDS schicken. Dann wird im Arbeitskreis über die Aufnahme dieses Wortes in den Index diskutiert. ${ }^{427}$ Basis des Anglizismen-Indizes ist das „Wörterbuch überflüssiger Anglizismen“ von Rainer Pogarell und Markus Schröder, erstmals erschienen 1999. Dem Index zugrunde gelegt wurde die überarbeitete Version aus dem Jahr 2001 (siehe auch Kapitel 2.5.1.6). Zur Erstellung der Liste haben die Autoren englische Wörter im Deutschen „gesammelt“. Zu ihrer Vorgehensweise schreiben sie:

Wir haben die Wörter aus allen gesellschaftlichen Bereichen gesammelt, mit denen ein normaler Mensch in Berührung kommen kann. Es geht also nicht nur um die Werbung. Wo immer uns überflüssige Anglizismen auffielen, haben wir sie aufgenommen. Sehr vorsichtig verhalten haben wir uns bei Fachwortschätzen und bei bestimmten Modesportarten, die nur von einem kleinen Bevölkerungsteil ausgeübt werden. Ganz die Finger gelassen haben wir von typischen englischen oder amerikanischen Erscheinungen [...] (Pogarell/Schröder 2001: 10).

Im Unterschied zum „Wörterbuch überflüssiger Anglizismen“ haben in den Anglizismen-Index auch Anglizismen, die nicht als „überflüssig“ angesehen werden, Eingang gefunden. Im Verhältnis sind dies aber nur wenige (vgl. später in diesem Kapitel).

Zusätzlich wurden andere Quellen mit berücksichtigt. Dies waren Beiträge von Vereinsmitgliedern und Funde aus dem Internet. ${ }^{428}$ In dieser Herangehensweise unterscheidet sich die Version 2008 von den frühen Versionen, bei denen das Internet als Quelle nicht verwendet wurde. ${ }^{429}$ Insgesamt liegt dem Anglizismen-Index kein definiertes Korpus

\footnotetext{
${ }^{427}$ Gespräch mit Holger Klatte, Geschäftsführer des VDS, 28. November 2008.

${ }^{428}$ Dort wurden als Quellen herangezogen: Google, Die Wortwarte (ein Projekt der Uni Tübingen), LEO, Link Everything Online, Langenscheidts Fremdwörterbuch, das Marketing-Lexikon-online, Webster's unabridged dictionary, The Jargon Lexic Terms, Wikipedia - das fruchtbringende Wörterbuch, die Suchmaschine Yahoo sowie The American Heritage Dictionary (Junker et al. 2008: 12).

${ }^{429}$ Die Belege für den Anglizismen-Index werden gesammelt und dann mit englischen Wörterbüchern abgeglichen, ein Wörterbuch, das verwendet wurde, ist das MerriamWebster (vgl. Tätigkeitsbericht des AK-Wörterliste von Gerhard Junker, 3. Juni 2002).
} 
zugrunde. Die Autoren erheben bei ihrer Wörterliste keinen Anspruch auf Vollständigkeit oder Perfektion, der Anglizismen-Index ist ein „Buch zum Bessermachen“ (Junker et al. 2008).

Schon beim Anlegen der Liste kämpfte die Arbeitsgruppe mit Schwierigkeiten bezüglich der Einteilung. Hierzu erläutert Junker:

Es wurde schließlich ein Gruppierungssystem erarbeitet, das sich jedweder Bewertung von Anglizismen enthält und neben ihrer unstrittigen Einordnung in eine oder mehrere Domänen nur die Bennennung des Status der Einführung des betreffenden Anglizismus in die Umgangssprache vorsieht - die Bewertung der Nützlichkeit wird dem Anwender überlassen. Dies ermöglicht, auch Anglizismen aufzunehmen, die schon lange heimisch sind (z.B. Pullover, stoppen) und auch solche, die gerade eingeschleppt werden und deren Vordringen noch gestoppt werden kann (Tätigkeitsbericht des AKWörterliste von Gerhard Junker, 3. Juni 2002).

Die Anglizismen wurden unterteilt in „Ärgerliche Angloamerikanismen, das deutsche Wort ist besser oder war früher da“, „Grenzfälle“, „ins Deutsche übernommen“ und „Pseudo-Anglizismen“. ${ }^{430}$ Zudem wird unterschieden nach „ergänzend“431, „differenzierend“, „verdrängend“, „Eigennamen, Abkürzungen“. Die Druckversion Ausgabe 2008, auf die an dieser Stelle näher eingegangen werden soll, ist ein wenig anders aufgebaut: Hier wird in erster Linie unterschieden nach „ergänzend“, „differenzierend“, „verdrängend“, „Eigennamen“, „Abkürzungen“. 432

${ }^{430}$ Dieses Vorgehen wird auch vom wissenschaftlichen Beirat des VDS kritisiert. Es findet sich die Problematik der „überflüssigen“ Anglizismen, ohne dass Kriterien ausreichend diskutiert werden (vgl. Glück 2005: 203).

${ }^{431}$ Zunächst hieß diese Statusgruppe „Integriert“, nach Kritik von Zifonun wurde sie umbenannt in „Bewährt“ (vgl. Zabel 2003: 327), in den jüngsten Auflagen heißt diese Statusgruppe „Ergänzend“. Ausführlich werden die Statusgruppen folgendermaßen beschrieben:

„Integriert: Es handelt sich um ein schon vor längerer Zeit aus dem Englischen ins Deutsche übernommenes Wort, das ins Flexionsspektrum des Deutschen integriert und in seiner Aussprache ans Deutsche angepasst ist“ (Zabel 2003: 326, Hervorhebung im Original).

„Bewährt: Es handelt sich um einen Anglizismus, der bereits in der deutschen Sprache heimisch geworden ist, obwohl er die deutschen Sprachregeln in Lautung und Flexion bricht. Für ihn ist es meist wenig sinnvoll, eine akzeptable deutsche Entsprechung zu suchen“ (Zabel 2003: 328).

${ }^{432}$ Wobei mit „Ergänzend“ diejenigen Anglizismen bezeichnet werden, für die nicht vorrangig Verdeutschungen gefunden werden müssen. „Differenzierend“ bezeichnet Anglizismen, deren Bedeutung mit einem deutschen Wort noch nicht in dieser Differenzierung ausgedrückt werden kann, und die von den Autoren bis zur Bildung eines geeigneten 
Dabei sind von den im Index aufgenommenen Anglizismen insgesamt zwei Prozent als „ergänzend“ und 80 Prozent als „verdrängend“ kategorisiert worden. Die Autoren haben sich entschieden, das „Muster der Mengenlehre“ zugrunde zu legen und nur solche Fachausdrücke aufzunehmen, die eine Schnittmenge mit der Allgemeinsprache bilden:

Der INDEX enthält Anglizismen, die nachweislich und wiederholt in der deutschen Allgemeinsprache verwendet werden. Fachausdrücke sind nur dann aufgenommen worden, wenn sie eine Schnittmenge mit der „Allgemeinsprache“ bilden [...] (Junker et al. 2008: 6). ${ }^{433}$

Das Schnittmengenmodell beinhaltet die verschiedenen Sprachdomänen „Eigenname, Abkürzung“, „Gesellschaft, Kultur, Politik“, „Informatik im Alltag, Konsuminformatik“, „Popkultur und Szene“, „Reklame, Werbung“, „Sport“, „Technik, Wissenschaft“ sowie „Wirtschaft“ (Junker et al. 2008: 6) und die „(All)-Gemeinsprache“. Um herauszufinden, welche Anglizismen in der Allgemeinsprache verwendet werden, wurden vermutlich die Internetquellen herangezogen, ansonsten folgten sie wohl ihrer Sprachintuition. Genauer erläutert wird das im AnglizismenIndex vom Autorenkollektiv jedoch nicht (vgl. Junker et al. 2008: 6ff.). ${ }^{43}$

Expliziert wird dagegen, welche Wörter nicht in die Liste aufgenommen wurden: Einerseits Wörter, die in

jedem englisch-deutschen Taschenwörterbuch zu finden sind, es sei denn, sie sind im Begriff, deutsche Wörter zu verdrängen [...] sie haben in deutschen Texten einen Bedeutungswandel erfahren [...] sie sind das Grundwort für Wortverbindungen [...] (Junker et al. 2008: 7).

Außerdem nicht enthalten sind pornografische und vulgärsprachliche Wörter sowie Lehnwörter, „die längst eingeführt sind und deren Herkunft aus dem Englischen nicht oder kaum noch erkennbar ist“" (Junker et al. 2008: 7).

Die Autoren erläutern auch, dass Verdeutschungsvorschläge der „Aktion ,Lebendiges Deutsch'“ (vgl. Kapitel 2.5.8) aufgenommen wurden, wenn

deutschen Wortes als „Übergangslösung“ akzeptiert werden. Mit „verdrängend“ werden diejenigen Anglizismen bezeichnet, die nach Ansicht der Autoren ein gleichbedeutendes deutsches Wort verdrängen. Sie seien selbst teilweise als „überflüssig“ zu sehen (Junker et al. 2008: 7ff.).

${ }^{433}$ Hervorhebungen im Original.

${ }^{434}$ Dies entspricht nicht den lexikographischen Standards. Das Anglizismen-Wörterbuch löst dieses Problem, indem es auf Korpora der deutschen Sprache wie das Paderborner und das Mannheimer Korpus zurückgreift (vgl. AWb 1993: 47ff.). 
sie den Autoren als vertretbar erschienen. Nicht angenommen wurden die Vorschläge, die die Autoren als sachlich oder sprachlich falsch werten, wie zum Beispiel „Sportwandern“ für „Nordic Walking“, hier plädieren die Autoren für „Stockwandern“ (vgl. Junker et al. 2008: 7).

Der Anglizismen-Index ist ein textbelegtes, alphabetisch geordnetes, einsprachiges Wörterbuch, ${ }^{435}$ das nach dem Lexemmodell auch Einheiten unterhalb der Wortbildungsebene berücksichtigt ebenso wie Einheiten oberhalb der Wortebene. ${ }^{436}$ Die einzelnen Artikel sind in vier Spalten unterteilt, die folgendermaßen aufgebaut sind: Spalte 1 enthält das jeweilige Wort in Originalschreibweise. Dabei werden aus dem Englischen stammende Wörter und Scheinentlehnungen klein geschrieben, Mischkomposita mit großem Anfangsbuchstaben. ${ }^{437}$ Spalte zwei enthält die Kennziffer für den Status, den die Autoren des Anglizismen-Index dem jeweiligen Anglizismus zuordnen, ${ }^{438}$ Spalte drei eine deutsche Entsprechung für den Anglizismus, außerdem teilweise "gewagte oder spöttische Übertragungen“. Diese sind in kursiv gesetzt (vgl. Junker et al. 2008: 10). Zusätzlich werden die Anglizismen in Spalte drei teilweise weiter beschrieben: (AE) steht für amerikanisches Englisch, (BE) für Britisches Englisch, (d.A.) für deutsche Aussprache und (PA) für Pseudoanglizismus (Scheinentlehnung) (vgl. Junker et al. 2008: 10). Spalte vier schließlich gibt an, in welchen Kommunikationsbereich der Anglizismus nach Meinung der Autoren einzuordnen ist (vgl. Junker et al. 2008: 11).

Der Anglizismen-Index enthält auch einige witzig gemeinte Karikaturen (beispielsweise unterhalten sich unter dem Stichwort „After-WorkParty“ zwei nackte Hintern miteinander, vgl. Junker et al. 2008: 17).

${ }^{435}$ Vgl. zur Methodik und Klassifizierung einsprachiger Wörterbücher u.a. Rettig (1989), zum Aufbau und zur Strukturierung von Lemmata Wolski (1989).

${ }^{436}$ Damit ist gemeint, dass auch beispielsweise Prä- oder Suffixe mit berücksichtigt werden.

${ }^{437}$ Wenn ein Wort mehrere Bedeutungen im Deutschen hat, so wird es mehrmals - jeweils mit einer Bedeutung - aufgeführt (hochstehende Zahlen zeigen auch an, wie oft das Wort bereits aufgeführt wurde). Komposita und Ableitungen werden eingerückt, darüber steht jeweils die Basis beziehungsweise der Bestandteil des Kompositums.

${ }^{438}$ Die Kennziffern lauten 0 für „Eigennamen und Abkürzungen“, 1 für „ergänzend“, 2 für „differenzierend“ und „3“ für „verdrängend“. 
Die Einträge in den Index werden hier exemplarisch anhand des Buchstaben „M“ vorgestellt. Insgesamt sind zum Buchstaben „M“ im Anglizismen-Index 334 Einträge verzeichnet. Davon ordnen die Autoren 19 der Kategorie 0, also den Eigennamen zu. Sechs Einträge werden als „ergänzend“ angesehen, 50 als „differenzierend“. Der weitaus größte Teil gilt als „verdrängend“. Von den Einträgen sind 16 Verben, 277 Substantive, 12 Phraseologismen, 20 Adjektive/Adverbien, 6 Prä- und Suffixe, zwei Pronomina. Die Artikel enthalten keine phonologischen Angaben, keine Angaben über Genus oder Aussprache, keine zeitlichen oder geographischen Markierungen.

Zum Teil sind die Einträge mit „Allgemeinsprache“ gekennzeichnet. Dies wäre laut Einteilung der Autoren eigentlich nicht nötig, denn die Autoren geben an, nur Begriffe in die Liste aufzunehmen, die ihrer Meinung nach in der Allgemeinsprache enthalten sind. ${ }^{439}$ Betrachtet man die Einträge zum Buchstaben „M“ im „Wörterbuch überflüssiger Anglizismen“, ist festzustellen, dass diese mit den Eintragungen im Anglizismen-Index beinahe identisch sind. Lediglich diejenigen Anglizismen, die im Index mit „ergänzend“ und mit „Eigennamen, Abkürzungen“ gekennzeichnet sind, finden sich nicht im „Wörterbuch überflüssiger Anglizismen“.

Vergleicht man die Einträge im Anglizismen-Wörterbuch (AWb ${ }^{440}$ von Carstensen/Busse zum Buchstaben „M“, so stellt man fest, dass hier

\footnotetext{
${ }^{439}$ Hier zeigt sich, dass die Wörter, die im Anglizismen-Wörterbuch nicht verzeichnet sind, auch in der Allgemeinsprache nicht häufig verwendet werden. Dies kann jedoch in dieser stichprobenartigen Analyse des Indexes nicht mit Sicherheit gesagt werden.

${ }^{440}$ In den einzelnen Artikeln wird jeweils das Lemma mit Angabe der Silbentrennung, aufgeführt, und zwar in der Form, die im Paderborner Korpus am häufigsten belegt ist. Zudem werden alle im Korpus vorkommenden Schreibvarianten des Lemmas aufgeführt. Das AWb versucht auch anzugeben, wie die Anglizismen von der Mehrzahl der Sprecher in der Standardsprache ausgesprochen werden. Zudem ist das Genus angegeben (bei mehreren Möglichkeiten das am häufigsten im Korpus verwendete). Folgen zwei Genusangaben, werden diese in etwa gleich häufig verwendet. Auch Flexionsformen der Anglizismen werden angegeben. Bei Verben liefert der AWb-Artikel Informationen über die Verbklassen, ob es sich um transitive oder intransitive Verben handelt, um reflexive oder reziproke, und Informationen darüber, wie die zusammengesetzten Perfektformen gebildet werden. Bei Adjektiven werden Angaben über Beschränkungen der grammatischen Möglichkeiten oder auch die Steigerung des Adjektivs gemacht. Geographische Markierungen werden für die Anglizismen ebenfalls mit angeführt, ebenso zeitliche, pragmatische oder Häufigkeitsmarkierungen, lexikographische Definitionen, der Erstbeleg im
} 
insgesamt 133 Einträge verzeichnet sind, davon zwei Verben, 104 Substantive, 10 Phraseologismen, 11 Prä- oder Suffixe sowie 5 Adjektive. Die große Differenz ergibt sich teilweise daraus, dass der Anglizismen-Index verschiedene Komposita mit einem Anglizismus als Bestandteil einzeln aufführt, das AWb jedoch den Bestandteil des Anglizismus nur einmal. Zudem werden im Anglizismen-Index Anglizismen, die im Deutschen mehrere Bedeutungen haben, anders als im AWb jeweils als einzelne Artikel geführt. Auffallend ist, dass beinahe alle Substantive im AWb in Großschreibung, also in dieser Hinsicht an das Deutsche angepasster Schreibung verzeichnet sind. Beim Anglizismen-Index ist dies meist nicht der Fall. Ebenso wenig wird im Anglizismen-Index die integrierte k-Schreibung verwendet, oder die im Deutschen häufige Zusammenschreibung von Komposita. Dabei wird im AWb jeweils die am häufigsten im Korpus belegte Schreibung verwendet. Während im AWb beispielsweise als übliche Schreibweise „Musikbox“ aufgeführt ist, ist dieses Wort im Anglizismen-Index als „music box“ aufgeführt. Schneider erläutert hierzu:

Durchgehend erfolgt die Schreibung nach dem American Heritage Dictionary: Hardliner z.B. wird zu hard-liner - eine Schreibung, für die z.B. weder in der FAZ, noch in der SZ (Grundlage: alle Ausgaben von 1999 bis 2005) auch nur ein einziger Treffer angezeigt wird (J.G. Schneider 2006). ${ }^{441}$

Der Anglizismen-Index ist ein Verzeichnis von Anglizismen mit einer Geschmackswertung der Autoren:

Ein Sprachwissenschaftler könnte an dieser Stelle einwenden, dass die Zuordnung von Anglizismen zu diesen Begriffen [gemeint sind die Statusgruppen, Anm. der Verf.] auf subjektiven Einschätzungen

Korpus, die Erstbuchung in deutschen Wörterbüchern, der Entlehnungsweg, die englische Aussprache sowie weitere Informationen zum Lemma, wie die englische Aussprache des Wortes oder ein sprachhistorischer Kommentar zum Entlehnungsprozess mit aufgeführt. Außerdem werden Synonyme, eventuell Vergleiche und der Beleg aufgeführt. Außerdem werden im sogenannten „Nest“ eines Artikels Komposita, Ableitungen und motivierte Formen aufgeführt (vgl. AWb 1993: 79ff.) Die Belege stammen aus dem Paderborner Korpus und dem Mannheimer Korpus sowie aus Zeitungen. Etwa 100000 Belege liegen dem AWb zugrunde.

${ }^{441}$ Vgl. auch Jan Georg Schneider (2007: 9). 
und nicht auf einem wissenschaftlichen rational überprüfbaren Verfahren beruht (Zabel 2003: 327, vgl. auch Junker et al. 2008: 7).442

In Zusammenhang mit der subjektiven Wertung der Autoren steht auch der Untertitel „Gewinn oder Zumutung“: Durch die vielen Wertungen der Statusgruppe 3 entsteht beim Leser der Eindruck, die Anglizismen seien in der Mehrheit als „Zumutung“ zu verstehen.

Der Anglizismen-Index war seit seiner Entstehung Gegenstand von Kritik seitens der Sprachwissenschaft. So kritisiert Zifonun die Wortwahl des VDS als „Aggressionsvokabular“ und dass einige der Wörter längst eingebürgert seien (vgl. Zifonun 2002: 7, ebenso Pfalzgraf 2006: 85). Die Ersteller der Liste haben nach der Kritik von Zifonun in der Anglizismenliste des Jahres 2003 gegenüber der Erstauflage 146 Begriffe gestrichen, da diese schon lange eingebürgert waren (vgl. Zabel 2003: 327). Law merkt an, dass sich Wörter in der Liste befinden, die sich problemlos an das deutsche Deklinations- und Konjugationssystem anpassen sowie keine Schwierigkeiten bei der Aussprache bereiten - dabei sind dies Kriterien dafür, dass ein Wort verdeutscht werden soll (vgl. Law 2002: 80).

Schneider kritisiert an der Einteilung der Anglizismen die fehlende empirische Grundlage:

Es lässt sich leicht zeigen, dass sehr viele der Anglizismen, die im Anglizismen-Index als „verdrängend“ eingestuft werden, im konkreten Sprachgebrauch deutlich anders verwendet werden als die angebotenen „Ersetzungen“ und den Sprechern somit Bedeutungsdifferenzierungen ermöglichen. Für das Wort Hardliner z.B. bietet der Index Dickkopf, Sturkopf, Betonkopf und (seit neuestem) Prinzipienreiter an. Betrachtet man konkrete Verwendungsweisen in konkreten Äußerungskontexten, so zeigt sich, dass keine der angebotenen Alternativen den Bedeutungsumfang von Hardliner auch nur annähernd abdeckt (J.G. Schneider 2006).

Einige Wissenschaftler kritisieren, dass die Liste verschiedene Funktionen von Fremdwörtern, wie das Ermöglichen von Nuancierungen, einfach ignoriert: „Danach soll chatten mit plaudern oder schwatzen ersetzt werden, obwohl es ein Wort für eine neue Aktivität geworden ist, für

\footnotetext{
${ }^{442}$ An dieser Stelle wird zudem darauf verwiesen, dass der VDS beim Anglizismen-Index keinen Anspruch auf Wissenschaftlichkeit erhebt, außerdem habe kein Kritiker der Anglizismenliste je ein plausibles Alternativverfahren vorgeschlagen (vgl. Zabel 2003: 327).
} 
spontane Gespräche im Internet“ (Law 2002: 80). Und Schneider stellt fest:

Die Tendenz, den Anglizismen den Aufenthalt zu erschweren und die Assimilation $\mathrm{zu}$ verweigern, anstatt sie $\mathrm{zu}$ integrieren, zeigt sich auch daran, dass im Anglizismen-Index und im ,Wörterbuch überflüssiger Anglizismen' die ,englischen' Substantive grundsätzlich kleingeschrieben werden und eine Orthographie verwendet wird, die bei der Verwendung der Anglizismen in der deutschen Sprache gar nicht vorkommt (J.G. Schneider 2006). ${ }^{443}$

Auch werden keinerlei Angaben über Zusammenhänge, in denen Anglizismen verwendet werden, gemacht (vgl. Law 2002: 80). Michael Klemm kritisiert: „Warum der Aperitif besser sein soll als (der als Wortbildung transparentere) Before-dinner-drink, oder was best practice mit der ,Eindeutschung' Synergieeffekt zu tun hat, bleibt das Geheimnis der Verfasser der Liste“ (Klemm 2005). ${ }^{444}$ Während man die erste Anmerkung noch als Geschmacksfrage sehen könnte, ist die zweite nicht von der Hand zu weisen. Die Kritik kam auch bei den Wortlisten-Erstellern an:

Unsere Wortlisten werden angegriffen [...] m.E. zum Teil zu recht. Deshalb meine ich, wir müssten unsere Generallinie eines ,gemäßigten Purismus' genauer definieren, müssten unsere vereinsoffiziellen Schriften und Wörterlisten darauf abklopfen, ob sie mit den drei Kriterien der neuen Leitlinien übereinstimmen (Brief des Arbeitskreises an die VDS-Vorstandsmitglieder, 29. Oktober 2000),

schreibt Junker an den Vorstand. Er fordert ebenda eine Entscheidung, wie mit dem Ersatz eines englischen durch ein anderes Fremdwort umgegangen werden soll. Diese Entscheidung ist nicht erfolgt.

Pfalzgraf weist darauf hin, dass bei den Verdeutschungsvorschlägen des Anglizismen-Index semantische Differenzen zwischen den Anglizismen und den vom VDS vorgeschlagenen Verdeutschungen nicht erkannt werden. Als Beispiel hierfür wird „Einsatz/Großgewinn/Hauptgewinn“ für „Jackpot“ angeführt. Rudolph Muhr fasst seine Kritik folgendermaßen zusammen:

Diese Vorgehensweise zeigt, dass es auch diesen Autoren weniger um Hilfe in der Sprachpraxis ging, sondern eher darum, möglichst alle Wörter englischer Herkunft auszumerzen. Das lässt trotz des prominent besetzten wissenschaftlichen Beirats Zweifel aufkommen: ${ }^{445}$

\footnotetext{
${ }^{443}$ Hervorhebungen im Original.

${ }^{444}$ Hervorhebungen im Original.

${ }^{445}$ Es ist davon auszugehen, dass der wissenschaftliche Beirat bei dieser Publikation nicht um Rat gefragt wurde.
} 
Sind nicht auch hier puristisch-sprachreinigende Zielsetzungen am

Werk...? (Muhr 2004: 45).

Die Anglizismenliste ist somit als sprachreinigende Maßnahme zu betrachten.

\subsubsection{Sprachnachrichten}

Seit 1999 publiziert der Verein die Mitgliederzeitschrift Sprachnachrichten wobei die Ausgabe 1999, Nr. 1 noch unter dem Titel VWDSNachrichten erschien, also den Vereinsnamen „Verein zur Wahrung der deutschen Sprache“ im Namen trug. Ab der zweiten Ausgabe hieß die Zeitschrift Sprach-Nachrichten, hatte aber noch den gleichen Aufbau und das gleiche Layout wie die VWDS-Nachrichten. Diese lösten die davor existierenden „Informationen für neue Mitglieder" ab (vgl. Zabel 2001b: 246). Ab Ausgabe 2001, Nr. 3, heißt die Mitgliederzeitung Sprachnachrichten, im Titel geschrieben als sprach nachrichten, in den Kopfzeilen ist ebenfalls der Bindestrich weggefallen. Die Sprachnachrichten erscheinen seit 2000 vier Mal jährlich, davor gab es sie drei Mal im Jahr. Eine Ausnahme bildet hier das Jahr 2004, in dem wiederum nur drei Ausgaben erschienen sind. 2002 wurde festgelegt: „(i) Die Zeitung erscheint viermal jährlich, spätestens in der letzten Woche des jeweiligen Quartals“ (Protokoll der VDS-Vorstandssitzung vom 26. Mai 2002). Dabei wurde bis in das Jahr 2007 die alte Rechtschreibung benutzt. ${ }^{446}$ Seit 2008 wird die neue Rechtschreibung verwendet. ${ }^{447}$ Herausgeber ist der VDS, Verantwortlicher im Sinne des Presserechts (V.i.S.d.P.) war Heiner Schäferhoff, ab Ausgabe 2007, Nr. 4 hat Max Behland die Redaktionsleitung übernommen, seit Ausgabe 2009, Nr. 1 zeichnet wieder Heiner Schäferhoff verantwortlich. ${ }^{448}$

\footnotetext{
${ }^{446}$ Dies war im Jahr 2002 in einer Vorstandssitzung festgelegt worden. „Es wird grundsätzlich die alte Rechtschreibung genutzt“ (Protokoll der VDS-Vorstandssitzung vom 26. Mai 2002) und wird auch im Impressum angemerkt: „Wir verwenden die traditionelle Rechtschreibung“ (z.B. SN 2005c: 28).

${ }^{447}$ So lange, bis die Hausschreibung des VDS ausgearbeitet ist, vgl. auch Kapitel 2.5.9. ${ }^{448}$ Ab Jahrgang 2002 sind die Ausgaben online (VDS 2007c).
} 
Angefangen mit einer Auflage von $5000^{449}$ erreichten sie in der Ausgabe 2000, Nr. 3 bereits eine Auflage von 15 000. Die Ausgabe 2003, Nr. 3 brachte es auf eine Auflage von 20 000, die erste Ausgabe 2005 erreichte eine Auflage von 27 000, die Ausgabe 2005, Nr. 4 bereits 30 000. Innerhalb von drei Jahren hat sich die Auflage also verdoppelt, Ausgabe 2007, Nr. 3 erschien in einer Auflage von 35 000, ebenso die Ausgaben im Jahr 2008, die Ausgaben von 2009 wurden in einer Auflage von 50000 gedruckt.

Schon im Impressum wurde von Ausgabe 2000, Nr. 4 bis Ausgabe 2001, Nr. 3 Wert darauf gelegt, keine Anglizismen zu verwenden, dort hieß es "Internetz“ und „E-Post“ (vgl. z.B. SN 2001c: 2), in neueren Ausgaben werden diese Begriffe nicht mehr verwendet.

Die Ausgaben des ersten Jahrgangs gleichen sich optisch weitestgehend, im Jahr 2000 wurde der Kopf der Mitgliederzeitschrift moderner gestaltet, die große Farbfläche, die noch die ersten Jahrgänge geziert hatte, gibt es ab diesem Zeitpunkt nicht mehr, aufgrund der Namensänderung wird auch das Logo des Vereins im Kopf der Zeitung ausgetauscht. Noch einmal verändert wird das Layout in Ausgabe 2000, Nr. 3. Hier steht auch einmalig „Europa ist unser Haus und Deutsch unsere Sprache“ im Kopf der Zeitung. Danach erscheinen die Sprachnachrichten nicht mehr großformatig. Ab Ausgabe 2001, Nr. 4 wird das Erscheinungsbild der Sprachnachrichten professionalisiert. Die Layouter folgen seitdem den Layoutgesichtspunkten professioneller Zeitschriften. Beispielsweise wird die erste Seite mit einem großen Bild aufgemacht. Bei den Umbrüchen wird seitdem auch auf Layoutregeln der Zeitungen geachtet. ${ }^{450}$ Dies war in den ersten beiden Jahrgängen noch nicht der Fall (vgl. Titelblatt SN 2000, Nr. 3, Titelblatt SN 2000, Nr. 4). Zudem erhält die Titelseite ab diesem Zeitpunkt eine sogenannte Promo am Kopf der Seite, einen mit Bild- und Grafikelementen gestalteten Kasten, in dem auf einen besonders bemerkenswerten Artikel in der jeweiligen Ausgabe hingewiesen wird. Auch freigestellte Bilder gibt es seitdem in

\footnotetext{
${ }^{449}$ Diese Angabe war der ersten Ausgabe der VWDS-Nachrichten nicht zu entnehmen, sie stammt von Walter Krämer (aus einer E-Mail von Christiane Dahl, VDS-Geschäftsstelle, an die Verfasserin, 12. Oktober 2007).

${ }^{450}$ Z.B. auf den sogenannten Blockumbruch, das bedeutet, dass alle Beine eines oben auf einer Seite platzierten Artikels gleich lang sind.
} 
den Sprachnachrichten. An dieser Professionalisierung des Layouts waren nur junge Menschen beteiligt, keiner der Gestalter war zum Zeitpunkt des Relaunchs über 18 Jahre alt (vgl. VDS 2001e: 1). Hin und wieder wurden in späteren Ausgaben kleine layouttechnische Veränderungen vorgenommen, beispielsweise wurde in Ausgabe 2002, Nr. 3 der Kopf der Sprachnachrichten mit dem VDS-Logo hinterlegt. Dies war jedoch einmalig im Layout der Vereinszeitschrift. Ab Ausgabe 2003, Nr. 1 taucht das Vereinslogo im Kopf der Zeitschrift wieder auf. Geändert wird noch einmal die Gestaltung des Kopfs, es kommen ein Inhaltsverzeichnis sowie vier Teaser (davon zwei bebildert) mit in den Kopf der Publikation. Ab Ausgabe 2004, Nr. 1 wird das Layout der Seitenköpfe innerhalb der Zeitung verändert. Durch einen auffällig gestalteten Seitenkopf auf der jeweils ersten Seite einer Rubrik erhält die Zeitung eine stärkere Gliederung. In Ausgabe 2005, Nr. 2 wird der Titel noch einmal leicht modifiziert, es tritt ein großes Bild-Grafik-Element in Gestalt eines Teasers auf die Seite, und auch in den folgenden Ausgaben wird der Kopf der Zeitung immer wieder leicht variiert (vgl. Ausgabe 2005, Nr. 4). In Ausgabe 2007, Nr. 1 steht einmalig im Kopf der Slogan: „Der Klügere spricht deutsch!“

Ab Ausgabe 2007, Nr. 2 wurde das Layout nochmals modernisiert. Ab dieser Ausgabe ist das Layout durchgehend vierfarbig gehalten. Auch der Umfang der Zeitung ist seit den ersten Jahrgängen wesentlich gestiegen, und zwar ab Ausgabe 2001, Nr. 1. Hatte die erste Ausgabe der Nachrichten noch sechs Seiten, so hatte die Ausgabe 2005, Nr. 4 bereits 36 Seiten. Diese relativ hohe Seitenzahl haben die darauf folgenden Ausgaben beibehalten. Der Jahrgang 2009 ist dann mit einer Seitenzahl von 32 erschienen. Die Zeitung verwendet ab 2001, Nr. 4 journalistische Darstellungsformen wie Interviews oder Kommentare und Glossen. Kommentare sind im Gegensatz zu den früheren Ausgaben mit dem Hinweis „Meinung“ gekennzeichnet. (vgl. z.B. Dey 2005: 2). Die Professionalisierung der Sprachnachrichten hat sich positiv auf das Erscheinungsbild der Publikation ausgewirkt. ${ }^{451}$

${ }^{451}$ Seit 1999 sind die Sprachnachrichten regelmäßig erschienen, im April 2002 wurde aber lediglich eine schnelle Notausgabe gedruckt, als ein Vorstandsmitglied die Materialien für die Publikation mehrere Wochen lang nicht bearbeitete (vgl. Rundschreiben 
Die ersten Ausgaben der Vereinszeitschrift aus dem Jahr 1999 waren noch nicht gegliedert. Ab Ausgabe 2000, Nr. 1 sind dann erste Rubriken angeführt, die Ausgabe ist unterteilt in eine erste Seite und die Rubriken „Information/Aktuelles“, „Aktionen“, „aus den Regionen“, „Vermischtes“ und "Seite für den Leser“. In den nächsten Ausgaben kommen noch die Rubriken „VDS intern“, „aus den Arbeitsgruppen“, „Tagungsberichte“, „Aufgelesen“, „Impulse“ und „Sprachhunzer des Monats“ hinzu (vgl. SN 2000, Nr. 3 und Nr. 4).

Ab Ausgabe 2001, Nr. 4 ändert sich die Gliederung der Sprachnachrichten. Rubriken sind ab dieser Ausgabe „sprache und politik“, „aus den regionen“, „aktionen“, ${ }^{452}$ „leserbriefe“, „pressespiegel“, „bücher“. In der Dezemberausgabe des Jahres 2001 und auch in den folgenden Jahrgängen gibt es in den Dezemberausgaben zusätzlich die Rubrik „frohe weihnachten“. In den Ausgaben des Jahres 2001 tauchen die Rubriken "jahreshauptversammlung“, „blick ins ausland“ und „meinung“ auf. In Ausgabe 2002, Nr. 2 gibt es erstmals die Rubriktitel „do you speak denglisch?“ und „blick zurück“. Ab Ausgabe 2002, Nr. 3, wird der erstgenannte Rubriktitel leicht abgewandelt in "sprechen sie denglisch?“. Zudem ändern sich die Titel in „aus den arbeitsgruppen“, „aus dem verein“, „meldungen“, „Vereinsleben“, „Leserbriefe“, „deutsche Sprache“, „zu guter letzt“453 und, „deutsch in aller Welt“. Letzterer wird in Ausgabe 2001, Nr. 1 noch einmal modifiziert, in „deutsch und andere sprachen in der welt" (ab Ausgabe 2003, Nr. 1) und einmalig in Ausgabe 2003, Nr. 3: „in aller Welt“.

Die Kleinschreibung der Rubriken wird ab Ausgabe 2003 wieder aufgehoben, in Ausgabe 2003, Nr. 4 tauchen neue Rubriken auf: „Sprachkritik“ und „VDS von innen“. Auch gibt es wieder Seiten ohne Rubriktitel. Mit der Ausgabe 2004, Nr. 1 gibt es eine grundlegende neue Gliederung der Zeitung (siehe weiter oben in diesem Kapitel), die Rubriken an sich bleiben jedoch gleich, hinzu kommt nur die Rubrik „Deutschland und

von Walter Krämer an die Regionalleiter und Delegierten des VDS vom 29. April 2002, ebenso Gespräch mit Walter Krämer, 20. April 2005).

${ }^{452}$ Man mag sich an dieser Stelle fragen, wie die Kleinschreibung der Rubriktitel mit dem sprachpflegerischen Anspruch der Sprachnachrichten übereinstimmt.

${ }^{453}$ Wohl in Anlehnung an den gleichnamigen Titel der Zeitung Die Welt. 
die Welt ${ }^{\star 454}$. Ab Ausgabe 2005, Nr. 1 ändern sich wiederum einige Rubriktitel: Aus „Sprechen Sie Denglisch“ wird schlicht „Denglisch“. Die Rubrik „VDS von innen“ heißt ab dieser Ausgabe „Vereinsleben“. Hinzu kommt „Der VDS im Ausland“, und auch Leserbriefe kommen ins Blatt. Ab Ausgabe 2005, Nr. 3 gibt es dazu eine eigene Rubrik „Briefe/Leserbriefe“, die neben Leserbriefen auch Briefe an den Verein abdruckt. Ab Ausgabe 2006, Nr. 3 verschwindet die Rubrik „zu guter Letzt“. Ab Ausgabe 2007, Nr. 1 gibt es wiederum neue Rubriken: Die Seiten werden unter anderem gegliedert in „Aktuell“, „Interview“, und „Meinung“, wobei es diese Unterteilung auch in früheren Ausgaben schon gegeben hatte. Und mit der Ausgabe 2007, Nr. 4 kommt die Rubrik „Streifschuß“ hinzu.

Ab Jahrgang 2001 sind einige Artikel wesentlich länger und ausführlicher geworden. Hatten die ersten Ausgaben noch das Aussehen einer Tageszeitung, die aber fast ausschließlich Meinungen zum Besten gab, gleichen die neueren Ausgaben eher einem Magazin. Generell kann gesagt werden, dass sich wie in einem Magazin oder einer Zeitung auch einige Elemente wiederholen. So gehört z.B. das Vorstellen von Mitgliedern (jeweils ein sehr junges und ein älteres Mitglied) in den früheren Ausgaben zu den festen Rubriken, ebenso finden sich immer wieder Leserbriefe an den VWDS/VDS, Karikaturen, Zitate sowie zahlreiche Artikel von Mitgliedern, in denen Beispiele angeführt werden, welchen Anglizismen sie im täglichen Leben begegnen.

Im Folgenden sollen die Inhalte der Sprachnachrichten näher betrachtet werden. Dabei geht es darum, einen Überblick über die Zeitschrift, deren Inhalte und Themen zu geben. In jeder Ausgabe findet sich ein Editorial des Vereinsvorsitzenden. Betrachtet man alle Editorials der Jahre 1999 bis einschließlich 2009, so stellt man fest, dass sich die meisten Editorials thematisch ähneln, und dass sich gewisse Themen ständig wiederholen. ${ }^{45}$ Die ersten Editorials drehen sich hauptsächlich um organisatorische Fragen und um die Etablierung der Vereinsstruktur, z.B. ruft Walter Krämer im ersten Editorial vermögende Mitglieder zu einem

\footnotetext{
${ }^{454}$ Damit zitieren die Sprachnachrichten die gleichnamige Rubrik der Frankfurter Allgemeinen Zeitung.

${ }^{455}$ An dieser Stelle ist darauf hinzuweisen, dass die Ausgaben 2000, Nr. 3; 2000, Nr. 4;

2001, Nr. 1; 2001, Nr. 2 und 2001, Nr. 3 kein Editorial enthalten.
} 
höheren Beitrag auf, um eine hauptamtliche Kraft und Räume finanzieren zu können (Krämer 1999a: 2), dies gilt auch für das zweite Editorial (Krämer 1999b: 2). Die Aufforderung, Geld für Vereinszwecke bereitzustellen, sei es für den Verein oder die Stiftung Deutsche Sprache (bisweilen auch die Aufforderung zur Berücksichtigung der Stiftung im Testament) oder höhere Beiträge zu zahlen, ist eines der dominierenden Themen der Editorials (vgl. Krämer 1999a: 2, 1999b: 2, 2001: 2, 2003d: 2, 2004c: 2, 2005a: 2, 2005e: 2, 2006a: 2, 2006c: 2, 2007b: 2, 2008a: 2).

Das Editorial wird gerade in den Anfangsjahren auch genutzt, um Mitglieder zu informieren oder einzuladen. Beispielsweise lud Krämer über das Editorial die Mitglieder zur ersten Mitgliederversammlung des VWDS ein, er lud zu einem Symposium ein und informierte über die neue Satzung und die Namensänderung des Vereins (vgl. Krämer 1999b: 2, vgl. auch Krämer 1999a: 2, 1999d: 2, 2000d: 2, 2007f: 2). In einem Leitartikel wurde in der Zeit der Etablierung der Vereinsstruktur zur Gründung von Arbeitsgruppen aufgerufen, es wurde die Vereinsarbeit vorgestellt, außerdem wurden Neuerungen in der Vereinsstruktur dargestellt (vgl. Krämer 2000c: 2).

In den ersten Ausgaben ruft Krämer immer wieder zur Kritik an den Sprach-Nachrichten auf, die ersten Ausgaben bezeichnet er als „Experiment“ (Krämer 1999a: 2). Aufruf zur Kritik an den Sprach-Nachrichten (Krämer 1999c: 2).

Im Editorial wird die Meinung des Vorsitzenden transportiert. Hier spricht Krämer immer wieder von der „Verteidigung unserer schönen deutschen Sprache“ (z.B. Krämer 2000d: 2), er stellt einen Bezug zwischen Sprache und Nation her und setzt sich auch mit der Geschichte NS-Deutschlands und deren Auswirkung auf den Sprachpurismus auseinander (vgl. Kapitel 2.4.2). Manche Editorials sind in einem eher lockeren Ton gehalten, zum Beispiel heißt es: „Denglisch-Schwätzer laufen wie mit einem großen Pickel auf der Nase durch die Gegend“ (Krämer 2005e: 2).

Weiteres wiederkehrendes Thema ist der Hinweis auf die erfolgreiche Vereinsarbeit: Einen positiven Ton schlägt Krämer 2002 an, wenn er von einem Stimmungsumschwung im Land bezüglich der Anglizismen, weg von einer toleranten Haltung hin zu einer kritischen schreibt (Krä- 
mer 2002c: 2). In Ausgabe 2004, Nr. 1 verweist er ebenfalls auf die Erfolge für die deutsche Sprache und abermals auf einen Stimmungsumschwung (vgl. Krämer 2004a: 2, ebenso 2004c: 2, 2005a: 2, 2007b: 2, 2007f: 2). Sich stets wiederholendes Thema ist Krämers Hinweis auf die steigende Zahl der Mitglieder, verbunden mit einem Aufruf an die Vereinsmitglieder zur Werbung weiterer Mitglieder (vgl. Krämer 1999d: 2, 2000c: 2, 2002a: 2, 2002b: 2, 2002d: 2, 2004a: 2, 2005a: 2, 2005e: 2, 2006a: 2, 2007b: 2, 2007f: 2, 2008a: 2).

Ein weiteres wiederkehrendes Thema ist das Vorstellen von Aktionen oder Veranstaltungen und damit in der Regel verbunden die Aufforderung, sich an diesen Aktionen oder Veranstaltungen $\mathrm{zu}$ beteiligen. So ruft Krämer zur Beteiligung an der Wahl des Sprachpanschers auf (Krämer 1999d: 2, 2000c: 2, 2000d: 2, 2002b: 2, 2003b: 2, 2004b: 2, 2006c: 2, 2006e: 2, 2007d: 2, 2008c: 2, 2008d: 2, 2009a: 2). Ebenfalls ruft er zur Teilnahme an der Preisverleihung des Kulturpreises Deutsche Sprache auf (Krämer 2003b: 2, 2003c: 2, 2006e: 2, 2007d: 2, 2008c: 2), zur Teilnahme an Aktionen zum Tag der deutschen Sprache (vgl. Krämer 2006e: 2), an Arbeitsgruppen (Krämer 2000d: 2, 2003b: 2, 2003c: 2) oder an Einzelaktionen wie Unterschriftensammlungen oder einer Aufkleberaktion (Krämer 2002a: 2, Krämer 2003a: 2).

Die Leitartikel werden zusätzlich genutzt, um Aktionen, an denen der Verein beteiligt ist oder gerade arbeitet, vorzustellen, wie den Prozess, den Peter Vogelgesang gegen die Lufthansa führte (vgl. Krämer 2000c: 2, vgl. Kapitel 2.5.2) oder die Wahlprüfsteine (vgl. Krämer 2002b: 2, 2002c: 2). Ebenso wurde der Startschuss zur Aktion „Lebendiges Deutsch“ behandelt, (vgl. Krämer 2006b: 2) und dort zur Beteiligung aufgerufen (Krämer 2006c: 2). Wiederkehrendes Thema der Editorials ist die Kritik am Sprachgebrauch bestimmter Personengruppen. So greift Krämer die Politik (Krämer 2002a: 2) und die Werbewelt an (Krämer 2002d: 2, 2004b: 2). Er wendet sich auch gegen die englische Sprache im deutschen Wissenschaftsbetrieb (Krämer 2005d: 2, 2009b: 2) und kritisiert englische Film- und Serientitel im Fernsehen (Krämer 2005e: 2) oder die Verwendung von Englisch in der Industrie (Krämer 2006a: 2). Thematisch aus der Reihe fallen nur wenige Editorials: Zum einen aufzuführen ist der Leitartikel der Ausgabe 2005, Nr. 2. Hier fordert Krämer die Mitglieder des Vereins zu mehr Nationalstolz und Patriotismus auf 
(Krämer 2005c: 2). Im Leitartikel der Ausgabe 2003, Nr. 1 kritisiert Krämer den Umgang Amerikas mit seiner Geschichte (Krämer 2003a: 2). Auch in einem der jüngsten Editorials greift er wieder die Beziehung Deutschlands zu Amerika auf (Krämer 2008d: 2).

In den jüngeren Editorials zeigt sich ein neuer, positiver Tenor, beispielsweise in den Editorials der Ausgaben 2008, Nr. 1 und Nr. 4, die sich thematisch mit der Entwicklung des VDS und dessen strategischer Neuausrichtung beschäftigen: „Warum erzähle ich das alles? Weil immer noch zu viele VDS-Mitglieder zu viel jammern und zu wenig die schönen Seiten der aktuellen Sprachentwicklung sehen“ (Krämer 2008e: 2).

Nicht nur die Leitartikel, sondern auch die anderen Beiträge der Vereinszeitschrift sollen im Folgenden betrachtet werden. Krämer verweist deutlich auf den Forumscharakter des Blattes, und darauf, dass die Artikel in den Sprachnachrichten die Meinung der Verfasser und nicht die des Vereinsvorstands widerspiegeln. ${ }^{456}$ Ein Beispiel dafür sind die wiederkehrenden Diskussionen über ein Sprachenschutzgesetz (Korthuis 1999: 4, Hanke 2000: 7, SN 2001d: 8, Aden 2006: 6f., ${ }^{457}$ vgl. Kapitel 2.3.2).

Regelmäßiger Inhalt der Sprachnachrichten sind Briefe von Mitgliedern an Firmen (vgl. u.a. Ambros 1999: 4) oder an Politiker (z.B. an den damaligen Bundespräsidenten Johannes Rau im März 2000, Dieter 2000a: 2). Die Sprachnachrichten werden häufig - und nicht nur in den Editorials (siehe weiter oben in diesem Kapitel) - auch dazu genutzt, die Vereinsmitglieder zu mobilisieren: So wurden schon Aufrufe zum Boykott von Geschäften, die englische Begriffe verwenden, in den Vereinsnachrichten des VDS veröffentlicht. Unter der Überschrift: „Bevorzugen Sie Anbieter, die Deutsch mit Ihnen sprechen“, zum Beispiel wird in der Ausgabe 1999, Nr. 1, zum Boykott der Karstadt AG aufgerufen (vgl. VWDS-Nachrichten 1999a: 3, vgl. auch SN 1999b: 4).

${ }^{456}$ Gespräch mit Walter Krämer, 17. März 2005.

${ }^{457}$ Aden legt ausführlich da, warum ein Sprachgesetz in Deutschland nicht nötig sei, da einerseits Deutsch sowohl die Verwaltungs- als auch die Gerichtssprache ist, andererseits auch das Gewohnheitsrecht anzuwenden ist (vgl. Aden 2006: 6f.). Dazu gibt es auch eine breite juristische Literatur, vgl. z.B. Kirchhof/Kreuter-Kirchhof (2008). 
Ebenso regelmäßig finden sich Vorschläge von sogenannten Sprachhunzern in den Sprachnachrichten, unter der Rubrik „Sprachhunzer aufgespiesst“ (z.B. Schrammen 2005c: 11). Diese werden mit der dienstlichen Postadresse und Faxnummer veröffentlicht (vgl. Kapitel 2.5.4.2).

Auch Musterbriefe, die Mitglieder an Sprachhunzer oder an Firmen, die ihnen Werbeprospekte in englischer Sprache zusenden, schicken können, finden sich immer wieder in den Sprachnachrichten (vgl. z.B. Schrammen 2000: 3). Daneben gibt es Musterbriefe für alle „Anglizismenfreunde“ in Deutsch und Englisch (Dengler 2001: 12).

Zudem enthalten die Sprachnachrichten alle vereinsintern wichtigen Mitteilungen, wie 1999 den Entwurf für eine neue Satzung (VWDSNachrichten 1999b: 6) oder Protokolle der Mitglieder- und Delegiertenversammlungen (z.B. Brandner 2000: 2). Zu diesen Mitteilungen ist auch der Abdruck der Entschließungen des Netzwerks Deutsche Sprache, wie der Berner Entschließung (Netzwerk Deutsche Sprache 2001: 4) zu zählen (vgl. Kapitel 1.7.14 und 2.12).

Regelmäßiges Element ist der Abdruck von Leserbriefen. Nur selten finden sich kritische Töne, wie der Leserbrief von Rolf Dennes, der den Aufruf Franz Starks ${ }^{458}$ - an die Deutschen, die Sprache wieder als „Herrschaftsinstrument“ zu gebrauchen, missbilligt (Dennes 2007: 21). Zahlreiche Leserreaktionen auf einen Artikel gibt es eher selten. Der Abdruck des Artikels „Weltsprache mit Harry-Potter-Syndrom“ hat aber einige Reaktionen hervorgerufen. In diesem Artikel heißt es:

Von allen Seiten gleichsam mit Federkiel und Dreschflegel durch die Höhen und Tiefen der Gelehrsamkeit gejagt, wuchs die Sprache [gemeint ist die deutsche Sprache, Anm. d. Verf.], wurde reifer und vollkommener, und bekam dabei soviel von der Wirklichkeit eingebleut, daß ihr diese wohl niemals wieder zu nehmen war.

Ganz anders lief es in der Kinderstube des Englischen (Mey 2005: 1).

Mit diesem Tenor waren zahlreiche Leser der Sprachnachrichten nicht einverstanden. Ein Leser schreibt:

\footnotetext{
${ }^{458}$ Dieser Aufruf wurde im Artikel „Sprache als Herrschaftsinstrument“ veröffentlicht (Stark 2007b: 1f). Dr. Franz Stark (Promotion über ein sprachpolitisches Thema) war Chefkorrespondent beim Bayerischen Rundfunk und seit 1993 Lehrbeauftragter für "Deutsch als Fremdsprache“ an den Universitäten Passau und München. Er ist zudem Mitglied des wissenschaftlichen Beirats und Autor (vgl. Kapitel 2.2.2).
} 
Der Leitartikel ,Weltsprache mit Harry-Potter-Syndrom' [...] ist meines Erachtens schon fast ein Hetzartikel gegen alles Englische, auch wegen des populistisch-tendenziösen Aufmachers. Den Beitrag könnte man bewusst Agitation nennen [...] (Andersen 2006: 20). ${ }^{459}$

In Artikeln wird immer wieder der Zusammenhang mit der deutschen Geschichte hergestellt:

Hitler hat mit seiner Volk-ohne-Raum-Politik, die in der Praxis zur klaustrophobischen Abschottungspolitik geriet, unsere Sprache zum bürokratischen Dorfdialekt verhunzt. Gleichzeitig aber bauten die Briten ihr Kolonialreich zum Commonwealth weiter aus; und nicht nur sie, auch Franzosen, Spanier und Portugiesen haben den anderen Kontinenten nicht nur ihre koloniale Blutspur, sondern auch ihre Kultur, ihren Esprit, ihre Sprache eingraviert (Kreimeier 1999: 5).

An dieser Stelle ist der Artikel „Deutscher Patriotismus heute“ zu diskutieren. In diesem legt der Autor Menno Aden $^{460}$ ausführlich blutige Konflikte in anderen Ländern dar und lässt den Eindruck entstehen, dass Deutschland eine besonders ruhige und gewaltfreie Geschichte hat. Aden verweist nur in Zusammenhang mit den Vertreibungen auf den Zweiten Weltkrieg:

Wir Deutschen leben seit unvordenklichen Zeiten in geographischer und völkischer Kontinuität dort, wo wir heute noch wohnen. Wir sind dafür nicht besonders dankbar, denn erst durch die Vertreibungen nach dem Zweiten Weltkrieg haben wir gemerkt, daß eine solche Kontinuität nicht selbstverständlich ist (Aden 2005: 5).

Weiter heißt es:

Das Volk Israel hatte seine von den meisten Juden längst aus den Augen verlorene Urheimat nie vergessen: es meinte, in die Heimat zurückzukehren, als es ab 1900 die vor Urzeiten verlassenen Wohnstätten wieder einnahm (Aden 2005: 4).

Nach Aden findet man die Begründung der völkischen Rassenlehre in Frankreich (vgl. Aden 2005: 4). Er stellt fest:

${ }^{459}$ Dieser Artikel veranlasste ein Ehepaar sogar zum Austritt (vgl. Rübenkamp 2006: 21), rief aber auch viel Zustimmung hervor: „Großartig, daß dieser Artikel endlich mutig aus dem politisch korrekten Mauseloch hervorkommt, in dem sich der VDS lange genug verkrochen hatte“ (Däßler 2006: 21, ähnlich Günther 2006: 21). In der Unterschiedlichkeit der Reaktionen zeigt sich auch das breite politische Spektrum der Mitglieder.

${ }^{460}$ Menno Aden ist Jurist und Mitglied des VDS-Vorstands. Außerdem ist er Vorsitzender der Staats- und Wirtschaftspolitischen Gesellschaft e.V. (SWG). Diese Vereinigung wird in Medienberichten beispielsweise des NDR und des Hamburger Abendblatts und in der Anfrage von der Abgeordneten Christiane Schneider mit rechtsextremen Personen in Verbindung gebracht und veröffentlichte nach Angabe von Schneider im Jahr 1998 eine Festschrift für den als „Holocaust-Leugner“ bekannten und rechtskräftig verurteilten Historiker David Irving (C. Schneider 2008: 1f.). 
Deutsche Geschichte ist daher, gemessen an der Größe des deutschen Volkes und der früheren Ausdehnung des Deutschen Reiches, ein Beispiel für die ruhige Entwicklung eines Volkes, für die es in Europa bei einem gleich großen Volk keine Parallele gibt (Aden 2005: 5). ${ }^{461}$

Auch dieser Artikel hat m.E. zurecht Widerspruch hervorgerufen. Ein Leser schrieb:

,Wir Deutsche leben' so schreibt er [gemeint ist Menno Aden, der Autor des Artikels, Anm. d. Verf.], seit unvordenklichen Zeiten in ,völkischer Kontinuität dort, wo wir heute wohnen'. Das ist platteste NSIdeologie und weit von der historischen Wahrheit entfernt (Eylmann 2006: 21).

Dieser Artikel, dessen Tenor durchaus als deutschnational zu werten ist, zeigt ein Problem der Sprachnachrichten auf, das bis in die neuesten Ausgaben besteht. Immer wieder werden Bilder oder Wörter verwendet, die „völkisches Gedankengut" transportieren und damit bei vielen Menschen Assoziationen zum Nationalsozialismus wecken. Der Artikel ist ebenso wie "Sprache als Herrschaftsinstrument" von Franz Stark (vgl. Stark 2007b: 1f.) als antiamerikanisch zu verstehen. Die beiden Artikel sind nicht die einzigen Veröffentlichungen in den Sprachnachrichten, die als amerikafeindlich gelesen werden können.

In den Sprachnachrichten findet auch Sprachberatung statt: Leser können in den Rubriken „Sprachgebrauch“ und „Guter Rat“ Fragen stellen, diese beantworten Vorstandsmitglied Gerd Schrammen und der Lektor Dieter Burkert (vgl. Schrammen 2006b: 16, Burkert 2006a: 16, 2006b: 16). In diesem Punkt ähnelt die Vereinsarbeit beispielsweise der Arbeit der GfdS.

Regelmäßig finden sich Besprechungen von Büchern des IFB-Verlags, mit dem der VDS eine enge Zusammenarbeit pflegt und in dem zahlreiche Publikationen des VDS verlegt werden, oder von Büchern, die

\footnotetext{
${ }^{461}$ Angesichts der Zahl der Toten in den beiden Weltkriegen (allein im Zweiten Weltkrieg kämpften 60 Millionen Soldaten, beispielsweise lag bei den sowjetischen Soldaten die Todesrate bei rund 50 Prozent, bei den Deutschen bei rund 30 Prozent, Overmanns 2002: 363) und dem systematischen Mord von Millionen von Juden (die Forschung spricht derzeit von 5,2 bis 6,2 Millionen Menschen, Salewski 2005: 235) in der Zeit des Nationalsozialismus kann von einer ruhigen Entwicklung des deutschen Volkes m.E. keine Rede sein.
} 
Krämer geschrieben hat (z.B. Braunshausen 1999: 2, Zabel 2000: 5, vgl. Kapitel 2.5.1.6). ${ }^{462}$

Karikaturen finden sich ebenfalls regelmäßig. Themen sind die deutsche Sprache der Zukunft, so ist zum Beispiel ein Jugendlicher abgebildet, der auf einem Computer seine „Deutsch-Homework“ macht. Darüber steht: „Ich downloadete, du downloadetest ......" und der Jugendliche sagt: „Ei leik aua lengwitsch“ (Barthold 2002: 4, vgl. auch Haitzinger 1999: 1).

Häufig werden auch Gedichte abgedruckt, wie „Ein Wintermärchen“ von Heinrich Heine, ${ }^{463}$ oder "Stufen“ von Hermann Hesse ${ }^{464}$ und Gedichte von Mitgliedern. In den Sprachnachrichten wurden zudem die Gedichte der Gewinner des VDS-Wettbewerbs „Deutschland sucht den Superdichter“ publiziert (Schrammen 2006a: 14f.), bei dem der VDS, nach dem Vorbild der Fernsehshow „Deutschland sucht den Superstar“, die vier schönsten Gedichte der Teilnehmer prämierte. ${ }^{465}$

\footnotetext{
${ }^{462}$ Hier wird unter anderem auch der Kommentar über das Buch „Sternstunden der deutschen Sprache“ in der Publikation „Die deutsche Schrift“ des Bundes für deutsche Schrift und Sprache angeführt: „[...] Man wird dieses Buch immer wieder gerne in die Hand nehmen, um darin zu schmökern und sich an der Vielfalt unserer Muttersprache zu erfreuen" (SN 2005f: 16).

${ }^{463}$ In: SN 2000, Nr. 3, S. 6.

${ }^{464}$ In: SN 2001, Nr. 3, S. 5.

${ }^{465}$ Dieser Wettbewerb hat m.E. weitgehend VDS-intern stattgefunden. Die schönsten Gedichte des Wettbewerbs gibt es auch als Buch (Mindner 2003a). Eines der ausgezeichneten Gedichte ist folgendes von Rudolf Schwarz:

„Ich glaube dir nicht: Auch wenn du sagst / der Himmel sei voller Delfine / die unsere Gedanken lesen / und im Wasser / da seien Engel nie gewesen / auf dem Land hätten sie auch nichts zu suchen / sollten nur unseren Herzen /Liebe bringen und Licht - / Ich glaube dir nicht

Auch wenn du sagst / Rosen sind roter Frauenschlaf / der verliebten Männer Träume / schenkt für reichlich Geld / Wo sind die weiten Räume / wo diese Rosen blühen / du scheinst sie / dir auszudenken und / zu füllen mit künstlichem Licht - / Ich glaube dir nicht

Auch wenn du sagst / die Erde küßt den fernen Mond / und der Mond die verliebte Erde / daraus machten sie / einen Trick - daß Nacht und Tag werde und daß die Sonne / ihr Feuerrad nur dann entzünde / wenn zwei Menschen sich liebten / genau dann entstünde das Licht - / Ich glaube dir nicht." (Schwarz in Schrammen 2006a: 14).

Ausgezeichnet wurde auch die folgende Adaption von Goethes Erlkönig von Silvia Triebel: „Herr König: Wer radelt so früh schon durch den Wind? / Es ist die Mutter mit ihrem Kind. / Sie hat das Mädchen gut angeschnallt, / so ist es sicher auf dem Asphalt.
} 
Die Artikel befassen sich thematisch gerade in den früheren Jahrgängen zumeist in irgendeiner Weise mit Anglizismen, zum Beispiel finden sich Interviews zum Thema Anglisierung mit Musikern (vgl. Mindner 2003b: 10, Hellebronth 2005: 4), oder Schriftstellern (vgl. z.B. SN 2003b: 3). Weitere Themen sind grammatikalische Phänomene des Deutschen wie „Schrumpfungen des Konjunktivs“ oder „zunehmender Verfall von Deklinations- und Modusformen“ (hierfür macht der Autor teilweise das Englische verantwortlich (vgl. Urbanek 2000: 9). Auch der Genitiv im Deutschen (vgl. Fischer 2005: 18) und die Rechtschreibreform (vgl. z.B. Spörr 2002: 14) werden diskutiert. Aber es findet sich auch einmal ein Artikel über die Bedeutung der Bibel (Glück 2003a: 5). Dennoch sind in den ersten Jahrgängen Abweichungen vom Anglizismen-Thema eher selten.

In den Sprachnachrichten schreiben Gastautoren wie Joachim Sartorius, einst Generalsekretär des Goethe-Instituts, (Sartorius 2000: 1), Dr. Franz Baumann, Leiter der UNO-Verwaltung New York (Baumann 2000: 1), oder Politiker wie Hans Zehetmair in seiner Eigenschaft als Bayerischer Staatsminister für Wissenschaft, Forschung und Kunst (vgl. Zehetmair 2000: 1). Auch die Mitglieder des wissenschaftlichen Beirats wie HeinzGünter Schmitz oder Ferdinand Urbanek ${ }^{466}$ (Urbanek 2000: 9) veröffentlichen immer wieder.

„Mein Schatz, was zappelst Du hin und her?“ / „Zur Tagesmutter mag ich nicht mehr! / Denn der Herr König ist oft dabei.“ / „Mein Kind, das ist doch einerlei.“

„Du liebes Kind, komm doch mit mir! / Gar schöne Dinge zeig ich Dir; / Dann gehen wir zwei noch an den Strand / und drei Kugeln Eis kriegst Du in die Hand.“

„Ach Mama, ach Mama, Du ahnst es ja nicht, / was der Herr König mir leise verspricht.“ / "Sei ruhig, bleibe ruhig, mein Kind; / Du weißt, wie manche Leute so sind.“

„Willst, kleines Mädchen, Du mit mir geh'n? / Da vorn auf dem Spielplatz spielen wir schön. / Und anschließend gehen wir wieder hinein / und schließen uns heimlich im Zimmerlein ein.“

„Ach Mama, ach Mama, und sag ich ein Wort, / bringt mich der Herr König sicherlich fort!“ / „Mein Kind, mein Kind, ich höre Dich nicht, / der Wind weht von vorn, direkt ins Gesicht."

„Ich liebe Dich, mich reizt Deine schöne Gestalt, / und bist Du nicht willig, so brauch ich Gewalt./ „Ach Mama, ach Mama, er faßte mich an! / Er hat's auch unter dem Kleid ge$\tan . . . !$

Die Mutter ahnt nichts, sie radelt geschwind, / sie küßt zum Abschied ihr zitterndes Kind, / bevor sie wieder aufs Stahlroß steigt - /in Ihren Armen das Kind, es schweigt.“ (Triebel in Schrammen 2006: 15).

${ }^{466}$ Urbanek ist Mediävist und nicht „Midiävist“, wie in den Sprachnachrichten geschrieben. 
Des Weiteren fällt in Ausgabe 2006, Nr. 2 auf, dass junge Leute und deren Interessen Gegenstand der Artikel sind. Berichtet wird beispielsweise über Stefan Raab (Akstinat 2006: 13), über eine studentische WG, die Anglizismen verbannt hat (Mindner 2006a: 3), und über allgemeine studentische Themen (z.B. SN 2006d: 11). So soll gezeigt werden, dass der VDS keine Altherrengruppe ist, sondern ein Verein, der Themen, die für junge Erwachsene interessant sind, aufgreift. Ab der Ausgabe 2003, Nr. 2 haben die Sprachnachrichten auch eine Jugendredaktion. Diese gibt es zwar nicht mehr seit Ausgabe 2008, Nr. 1. Aber auch in den nachfolgenden Ausgaben beschäftigen sich zahlreiche Artikel mit Themen, die junge Leute ansprechen, wie Musik für Jugendliche und junge Erwachsene (vgl. SN 2008c: 20, Klatte 2008b: $20^{467}$ ).

Noch einmal verstärkt ab Ausgabe 2007, Nr. 3, ab welcher die Redaktionsleitung an Max Behland überging, zeigt sich eine deutliche Ausweitung des Themenspektrums. Die Auseinandersetzung mit Klischees unter dem Titel „Typisch Deutsch“ wird Thema der Sprachnachrichten (SN 2008b: 18), ebenso die Themen "Sprache in der Schule“ (Hildebrandt 2008: 6f.) und Englischunterricht im Kindergarten, dem der VDS kritisch gegenübersteht (Baer 2008b: 9). Die Themenvielfalt zeigt sich auch in der Vorstellung von deutschsprachigen Radiosendern im Ausland (Akstinat 2008: 19) oder einem Bericht über die Berliner Philharmoniker (Krämer 2008b: 18). Interessant sind die Auseinandersetzungen von Wissenschaftlern mit der Rechtschreibreform. Beispielsweise legt Weinrich dar, dass ein sprachliches Regelwerk immer nur eine Momentaufnahme ist und eine pluralistische Gesellschaft auch in der Lage sein muss, mit „Torheiten“ zu leben (vgl. Weinrich 2008: 6f.). In diese Reihe der wissenschaftsnahen Artikel sind auch die Betrachtungen und Erklärungen zu Piktogrammen zu stellen (Hinrichsen 2008: 8f.), ebenso ein Artikel zu Vornamen im Deutschen. Dabei werden sowohl historische Aspekte aufgezeigt als auch die beliebtesten Vornamen genannt (vgl. Götz 2008: 5).

Nicht mehr regelmäßiges Thema sind ab Jahrgang 2008 in den Sprachnachrichten die Sprachhunzer. Dies wird auch in Leserbriefen themati-

${ }^{467}$ In diesem Bericht wendet sich Klatte, der als Geschäftsführer und Pressesprecher eine offizielle Funktion innehat, gegen die Einführung einer gesetzlichen Quote für deutschsprachige Musik, eines der deklarierten Ziele des VDS (vgl. Klatte 2008b: 20). 
siert: „Die Nominierung zum Sprachhunzer vermisse ich sehr. Sie ist bereits zwei Mal in letzter Zeit ausgefallen“ (Skornig 2008: 25).

Die Themenerweiterung der Sprachnachrichten fällt einigen Lesern positiv auf, so schreibt beispielsweise Friedrich Kellner in einem Leserbrief: „Sie haben aus einer lesenswerten Anti-Anglizismen-Kampfschrift eine liebenswerte Zeitschrift für das Wohl der deutschen Sprache gemacht“ (Kellner 2008: 25).

Positiv fällt auch auf, dass der Verein in den Sprachnachrichten einen durchaus offenen Umgang mit Kritik pflegt. Folgender Brief an den Verein wurde abgedruckt:

Es ist eine Sache, deutsche Begriffe für Dinge zu verwenden, für die es von Beginn an deutsche Wörter gab. Es ist aber völlig über das Ziel hinausgeschossen, künstlich pseudo-deutsche Wörter für Entwicklungen einzuführen, die von vorneherein weltweit unter einem einzigen Namen bekannt geworden sind. Sollten wir doch froh sein, daß globale Entwicklungen auch globale Namen bekommen. Sucht euch ein sinnvolleres Betätigungsfeld [...] (Peter 2005: 25).

Und auch dieser Brief wurde veröffentlicht:

Gibt es eigentlich auch einen Preis für Ignoranz, Engstirnigkeit und Selbstüberschätzung? Wenn ja, dann möchte ich Ihren Verein gern nominieren. Ich schätze den ausländischen Einfluß auf unsere Sprache sehr und begreife es als Bereicherung für die deutsche Sprache. Wenn unsere Vorfahren genauso ignorant gegenüber fremden Einflüssen gewesen wären wie Sie, dann könnten wir nur auf einen Bruchteil unseres heutigen Wortschatzes zurückgreifen. Wie würde Literatur aussehen, wenn Autoren nicht die Möglichkeit hätten, ein und dieselbe Sache mit verschiedenen Worten auszudrücken? (Lehmann 2005: 25).

Kritik, auch am VDS selbst und dessen Vorgehen, findet eher selten statt. Zum Beispiel wird das „Wörterbuch überflüssiger Anglizismen“ angegriffen:

Auch im VWDS stößt man auf Sprachfanatiker, die um der rechten Lehre willen im Grunde alle englischen Wörter [...] aus unserer Sprache verbannen wollen, auf Biegen und Brechen (Grobe 1999: 1).

Negativ fällt bei der Lektüre auf, dass sich gerade in den älteren Ausgaben verhältnismäßig häufig Tipp- und Rechtschreibfehler finden (vgl. SN 2000b: 3), etwas befremdend wirkt, dass Anführungszeichen teilweise englisch gesetzt werden (vgl. Liefländer 2000: 5).

Insgesamt ist festzustellen, dass „Sprachnachrichten“ eigentlich ein irreführender Titel ist, denn die Zeitschrift des VDS enthält, für eine Vereinszeitschrift nicht unüblich, wenig Nachrichten und viele Meinungs- 
elemente. Die Texte sind zweckgerichtet, teilweise aggressiv, zumindest jedoch offensiv. Patricia Maercker merkt an, dass die Texte teilweise sehr emotional seien und dass eine größere Genauigkeit, beispielsweise durch das Erbringen von Nachweisen, zu wünschen wäre. (vgl. Maercker 2006: 229ff.).

Die Sprachnachrichten wurden vom Erscheinungsbild in den letzten Jahren immer professioneller. Auch redaktionell wurden die Sprachnachrichten im Lauf der Jahre wesentlich besser bearbeitet, die sprachliche Qualität der Artikel hat sich deutlich gewandelt.

Kritisch anzumerken bleibt, dass sich trotz der Beteuerungen des Vorsitzenden, mit nationalistischem Gedankengut nichts $\mathrm{zu}$ tun zu haben, in manchen Artikeln nationalistische Tendenzen finden. Einige Sprachwissenschaftler kritisieren zudem, dass immer wieder die gleichen Appelle ausgesprochen werden, in denen die Leser „zur Pflege der Sprache und zur Besinnung auf das Nationalgefühl“ angehalten werden (vgl. Maercker 2006: 229). Neben allen Vereinsmitgliedern erhalten seit einigen Jahren auch einige Interessierte die Sprachnachrichten. Dies und der hohe Grad der Professionalisierung, vor allem was das Layout der Zeitschrift angeht, weisen darauf hin, dass sich die Sprachnachrichten seit 1999 bis heute vom vereinsinternen Mitteilungsblatt zu einem PRMagazin des Vereins gewandelt haben.

\subsubsection{Lichtblicke - VDS-Tagebuch}

Beim VDS-Tagebuch handelt es sich um eine vereinsinterne Publikation, die jeden Monat erscheint. Das Tagebuch wird an die Regionalbeauftragten und Arbeitsgruppenleiter sowie an weitere Interessenten geschickt. Es dient der vereinsinternen Verständigung und beinhaltet Mitteilungen über alle Veranstaltungen und Aktionen des VDS und seiner Regionalgruppen. Über die aus Vereinssicht wichtigsten Veranstaltungen wird zusätzlich in den Sprachnachrichten berichtet. Außerdem werden die Erfolge dieser Veranstaltungen in den Rundbrief „Lichtblicke Ein Erfolgskalender" aufgenommen. Diesen gibt Eva-Maria Kieselbach halbjährlich heraus. Darüber hinaus erscheint eine Auswahl der Erfolge aus den Rundbriefen in gedruckter Form, ebenfalls herausgegeben von Kieselbach. 
Auf die vierte Auflage soll in dieser Arbeit Bezug genommen werden: „Lichtblicke. Ein Kalender sprachlicher Erfolge. 1997 bis 2008.“ (Kieselbach 2008), in dem „Erfolge für die deutsche Sprache“ aufgelistet sind. Im Vorwort schreibt Kieselbach: „Diese Erfolge sind zum guten Teil auf Initiative von VDS-Mitgliedern zustande gekommen. Sie zeigen, wie langsam aber stetig steigendes Selbstbewusstsein dazu führt, auf die Kraft der deutschen Sprache zu setzen. (Kieselbach 2008: 1). Sie fordert des Weiteren die Leser der "Lichtblicke“ auf, ihr alles zu melden, was diesen lobenswert erscheint, wie beispielsweise das örtliche Schuhgeschäft, das mit „Schlussverkauf“ anstatt „Sale“ wirbt, aber auch, dass der „Reading Room“ des Internetauftritts der Frankfurter Allgemeinen Zeitung nach Protesten in "Lesesaal“ umbenannt wurde (vgl. Kieselbach 2008: 1). Dies zeigt schon die Bandbreite der dargestellten Erfolge für die deutsche Sprache. Exemplarisch sollen hier einige der Einträge aus „Lichtblicke“ vorgestellt werden:

Für das Jahr 1997 verzeichnet „Lichtblicke“ nur einen einzigen Eintrag: die Gründung des VDS (vgl. Kieselbach 2008: 36). Im Jahr 1998 meldet der Erfolgskalender des VDS unter anderem die Umbenennung der Bezeichnungen der Deutschen Telekom (vgl. dazu Kapitel 2.5.2), aber auch, dass eine Buchhandlung in Freiburg ihren Werbespruch zum Semesterbeginn von „Let's start again“ in „Auf geht's!“ geändert hat. Die Regionalgruppe Bautzen meldet für das Jahr 1998, dass, nachdem gegen eine Anzeige der Deutschen Verkehrswacht, die nach Angaben des Vereins „sehr viel Denglisch enthielt“, protestiert worden war, diese in $\mathrm{Zu}$ kunft „in gutem Deutsch“ erscheint (vgl. Kieselbach 2008: 36).

1999 ist unter anderem verzeichnet, dass es statt „Müll-Sheriffs“ bei der städtischen Müllabfuhr in Hannover jetzt „Abfallfahnder“ heißt und dass die Barmer Ersatzkasse in einer Anzeige statt „No Sports“ „Sport? Nein danke!“ schreibt. Außerdem wird der geplante „Nightliner“ in Regensburg nach Protesten „Nachtbus“ genannt. Im August meldet die Region Köln, aus dem von der Stadt geplanten „Security Point“ werde ein „Sicherheitsmobil“. Außerdem wird der „Container Coach“ ab diesem Zeitpunkt als „Öko-Lotse“ bezeichnet. Bundesweit vermeldet der 
Verein die erneuten Änderungen der Telekom-Bezeichnungen als Erfolg ${ }^{468}$ (vgl. Kieselbach 2008: 35).

Im Jahr 2000 ist zunächst verzeichnet, dass die geplante neue Autorennstrecke nach vielen Protesten nun doch „Lausitzring“ heißt, anstatt, wie vorgesehen "EuroSpeedway“ (vgl. Kieselbach 2008: 35). Für den Juli 2000 gibt es zwei Einträge, beide aus der Region 24, Kiel: Zum einen hatte eine Fotofirma, die 1999 nach den Kids von Kiel gesucht hatte, die gleiche Aktion mit ,...vielleicht wird Ihr Fratz der süßeste Schatz von Kiel" bezeichnet. Zum anderen tauschte die Firma Coop das Wort „Highlights“ in ihren Werbeprospekten gegen die Bezeichnung „Extra Tipp“ aus ${ }^{469}$ (vgl. Kieselbach 2008: 35).

2001 verzichtet der Sender SAT.1 laut Eintrag im „Erfolgskalender“ auf das Motto „Powered by Emotion“" ${ }^{470}$ auch wird vermeldet, dass das Tiefbauamt der Stadt Braunschweig ein Verkehrsschild mit der Aufschrift „Kiss \& Ride“ nach Protesten wieder entfernte. Im Jahr 2001 meldet die Region Hannover noch die Änderung des Begriffs „family card“ in „Familienkarte" durch das niedersächsische Sozialministerium. Im März verzichtet die Telekom-Auskunft auf den Begriff Operator, dieser heißt ab diesem Zeitpunkt Mitarbeiter.

Im April streicht das Modehaus H\&M ersatzlos englische Werbesprüche auf Plakaten und aus Broschüren. Im Juni verlautet die Region Bautzen, dass der Kreistag des Niederschlesischen Oberlausitzkreises eine Regelung zum Schutz der deutschen Sprache im Sprachgebrauch der Kreisverwaltung beschließt.

Für das Jahr 2002 meldet das Erfolgstagebuch: Ab Januar heißt der Sender „Premiere World“ nur noch „Premiere“. Die Sparten des Senders wurden ebenfalls neu betitelt: Anstelle von „Premiere Movie“ heißt es

${ }^{468}$ Warum der Verein allerdings eine Namensänderung von Orts- und Nahverbindung in Cityverbindung in seinem Erfolgstagebuch aufführt, ist nicht ersichtlich.

${ }^{469}$ Inwiefern das ein Erfolg im Kampf gegen die Anglizismen sein soll, ist nicht unbedingt nachvollziehbar, da „Tipp“ ebenso aus dem Englischen stammt wie das Wort „Highlight“. Die einzige Erklärung für die Aufnahme dieser Änderung in die Erfolgsmeldung liegt meiner Meinung nach in den unterschiedlichen Zeiträumen, in denen die Entlehnungen ins Deutsche gekommen sind und evtl. daran, dass „Highlight“ phonetisch und graphematisch fremder anmutet als „Tipp“.)

${ }^{470}$ Dieser Verzicht auf einen englischen Slogan war nur von kurzer Dauer, mittlerweile heißt es bei Sat1 "Colour your life“. 
jetzt „Premiere Film“, anstelle von „Premiere Sunset“, „-Comedy“ und „SciFi“ heißt es jetzt „Premiere Serie“ und anstelle von „Premiere Select“ heißt es jetzt „Premiere Direct“. ${ }^{471}$ Aber nicht nur im Bereich der Medien, auch in der Politik verzeichnet „Lichtblicke“ einen Erfolg: Ab März nennt die CDU ihr Wahlkampfquartier nicht mehr Headquarter (vgl. Kieselbach 2008: 34). Seit Mai 2002 erscheint in der Fachzeitschrift für Chemiker Angewandte Chemie in jedem dritten Heft ein Abschnitt zur Terminologie in der Chemie anstatt wie bisher in englischer in deutscher Sprache.

Für Juni meldet die VDS-Region Herford, dass der Haupt- und Finanzausschuss der Stadt einem Bürgerantrag stattgegeben hat, aufgrund dessen die Stadt ab sofort Anglizismen meiden wird. Die Region Bremen-Umland vermeldet für September die Verabschiedung einer Empfehlung der Stadtverwaltung Delmenhorst, keine „denglischen Modewörter" zu verwenden. Aus Hannover wird im September berichtet, dass anstatt der Bezeichnung Service-Point im niedersächsischen Justizministerium ein „i“ für Information angebracht wird. Für November ist der Beitritt des vom VDS kritisierten Vorstandsmitglied der DAK - diese war Sprachhunzer des Monats November 2002 - vermerkt. Im Dezember gibt es eine Meldung über Österreich: Der Sender Österreich 1 legt nach Kritik des VDS über „zuviel Denglisch“ am Klassik- und Kulturprogramm ein Schulungsprogramm für alle Mitarbeiter auf. Im gleichen Monat wird, diesmal wiederum aus Deutschland, berichtet, dass die Fernsehzeitschrift Hörzu anstatt „Editorial“ wieder den Begriff „Leitartikel“ verwendet (vgl. Kieselbach 2008: 33).

Für das Jahr 2003 ist zu lesen, dass das medizinische Journal German Medical Science nicht nur, wie geplant, in englischer, sondern in deutscher und englischer Sprache erscheinen wird. Es wird vermeldet, dass die Schnellimbisskette McDonalds ihren Werbespruch von „Every time a good time“ in "Ich liebe es“ geändert und dass die GEWRheinEnergy ihre "Colon-Tarife“ in "Regio-Tarife“ umbenannt hat. Außerdem wurde der Firmenname geändert in „GEWRheinEnergie“. Laut Erfolgskalender gab es in der Stadt Köln noch einen Ratsbeschluss, Anglizismen und Amerikanismen $\mathrm{zu}$ vermeiden. Im Dezember wird mitgeteilt, dass die

${ }^{471}$ Mittlerweile wurde Premiere umbenannt in „Sky“. 
Interessengemeinschaft Wilhelmshöhe den bisherigen Werbespruch „Kassel Best Side“ in „Kassels schönste Seite“ umbenannt hat (vgl. Kieselbach 2008: 32).

Für das Jahr 2004 wird aus der Region Hannover berichtet, dass das Landeskriminalamt die Arbeitsgruppe „Task Force BOK“ (Bekämpfung Organisierter Kriminalität) in „Konzeption BOK“ geändert hat. In der Gemeinde Kirchham in der Nähe von Passau fahren die Gäste nach Protesten anstatt mit dem "Shuttle“ mit dem "Gästebus“. Im Februar wird beim Preis des Verbands der Hochschullehrer für Betriebswirtschaft e.V. aus dem „Best Textword Award“ der „Lehrbuchpreis“, aus „Best Book Award“ der „Monographiepreis“. Die Stadt Pforzheim nennt seit März die Hundekotentsorgungsstellen anstelle von „Dog Station“ „Hundekot-Entsorgung“. Ebenfalls im März werden auf der Frühjahrstagung der Deutschen Physikalischen Gesellschaft von zehn Plenarvorträgen, von denen fünf auf Englisch angekündigt waren, nur drei auf Englisch gehalten. Auch die meisten Hauptvorträge wurden nach Protesten vor Ort auf Deutsch gehalten. Der letzte Eintrag im Erfolgstagebuch für den März 2004 meldet, dass die Messe „Family \& Home“ in „Familie und Heim“ umgetauft wurde.

Aus Freiburg wird gemeldet, dass aus der „First responder group“ des Deutschen Roten Kreuzes in Emmendingen die „Schnelle Eingreiftruppe“ wird. In Kassel wird aus dem Damenmodegeschäft für große Größen „Big \& Chic“ „Mehr Mode“. Und die Zeitschrift Jagdmarkt verzichtet auf die Ausdrücke „Download, Newsletter und FAQ (Frequently Answerde [sic] Question“, zugunsten von „Herunterladen“, „Rundschreiben“ etc. Ab Mai verwendet der Radiosender Deutschlandfunk nicht mehr das Wort Hotline, er nennt diese Einrichtung jetzt Hörertelefon.

Im Jahr 2004 sind unter den Erfolgen zahlreiche Änderungen von Werbeslogans gelistet: Neben einem neuen Motto für Sat.1 „Sat.1 zeigt's allen“ hat die Lufthansa ihren Spruch in „Alles für diesen Moment“ gewandelt. Douglas verwendet anstatt "Come in and find out” den Slogan "Macht das Leben schöner”, Siemens verwendet anstatt „Be inspired” "Die Zukunft zieht ein.“ und RWE anstatt „One Group. Multi Utilities.“ „Alles aus einer Hand” (vgl. Kieselbach 2008: 29). 
2005 wird das Motto der Karnevalssession 2005 von „Kölle und de Kids der Welt fiere nit nur Fasteleer...“ in „Kölle und de Pänz us aller Welt“ geändert, und gemeldet, dass die Bergsträßer Winzer e.G. ihren Weißen Burgunder von „Springtime“ in „Frühlingswein“ umgetauft haben. Zudem hat die Zeitung Magdeburger Volksstimme nach Beschwerden ihrer Leser gelobt, Anglizismen zu vermeiden und die Stadt Mühlhausen ist als erste Stadt dem VDS beigetreten (Kieselbach 2008: 25) ${ }^{472}$

Für 2006 vermeldet Kieselbach, dass der Internetreiseveranstalter Opodo nach nur einer VDS-Nachfrage den Werbespruch auf seiner Internetseite von "travel your way“ in „...und die Reise beginnt“ geändert hat. Auch im Bereich der Politik werden Erfolge gemeldet: Der NRWVerbraucherminister Eckhard Uhlenberg hat laut Kieselbach eine Aktion für Grundschüler über den Umgang mit Geld von "Money \& Kids“ in „Alles im Griff!“ umbenannt, außerdem hat der nordrheinwestfälische Ministerpräsident Jürgen Rüttgers seine Minister zum Verzicht auf Anglizismen in öffentlichen Verlautbarungen aufgerufen. Das Jugendmagazin Spießer verzichtet auf Anglizismen, ebenso ruft Werner Kieser (Kieser-Training) seine Mitarbeiter dazu auf, „Denglisch und nichtssagende Modewörter“ zu vermeiden. Auch die Jugendzeitschrift $B R A V O$ GIRL! gibt an, in Zukunft bewusst auf Anglizismen zu verzichten. ${ }^{473}$ Ebenso wird aufgeführt, dass die Bezeichnung „Funeralmaster“ verschwunden ist (vgl. Kapitel 2.5.4.1). Auch Erfolge auf regionaler Ebene werden wieder gelistet, beispielsweise nennt der CVJM Tönisheide seine Stunde zum Besinnen nicht wie geplant "Timeout“, sondern „Auszeit“. Bei McDonald's in Dresden-Gompitz wurde auf Anregung eines VDS-Mitglieds unter dem Schild mit der Aufschrift „McDrive“ ein zweites mit der Aufschrift „Autoschalter“ angebracht (Kieselbach 2008: 17ff.).

2007 wird gemeldet, dass für den Bürgerfunk der 46 privaten Radiosender in Nordrhein-Westfalen neue Regeln gelten und die Programme nur

\footnotetext{
${ }^{472}$ Aufgelistet ist aber beispielsweise im halbjährlichen Rundbrief für 2005 auch, dass das Lied „Schnappi, das kleine Krokodil“ im Februar 2005 in der deutschen Version unter anderem in der Schweiz, in Holland und in Japan erfolgreich war, dieser Eintrag fehlt in der gedruckten Version.

${ }^{473}$ Für die Verwendung von Anglizismen in BRAVO GIRL! und Mädchen vgl. Keßler (2003).
} 
noch in deutscher Sprache ausgestrahlt werden dürfen. ${ }^{474}$ Billigfluganbieter Easyjet nennt seine neue Dienstleistung nach Protest eines VDSMitglieds statt „Speedy Boarding“ nun „Schneller an Bord“. Auch die Medien sind wieder vertreten: Die Westdeutsche Allgemeine verzichtet eine Woche auf Anglizismen und ein Verlag versieht seine Bücher nun anstatt mit „Made in Germany“ mit „Gedruckt in Deutschland““ ${ }^{475}$ Weiterhin hat die Landesregierung in Nordrhein-Westfalen die „NRW Graduate Schools“ in „NRW-Forschungsschulen“ umbenannt (vgl. Kieselbach 2008: 10ff.).

2008 ist verzeichnet, in immer mehr Bundesgesetze werde der Zusatz aufgenommen, dass Kenntnisse der deutschen Sprache erforderlich seien. Außerdem wurden die Inhaber eines Ladens darauf aufmerksam gemacht, dass „Kids sale inside“ im Deutschen „drinnen KinderAusverkauf“ hieße. Daraufhin wurde die Aufschrift entfernt. Nach Protesten von VDS-Mitgliedern wurden die Geschäftsleute in Emmendingen davon überzeugt, ihre Gewerbeschau nicht „Emmendingen by night and day“ sondern „Emmendinger Leistungsschau“ zu nennen. Zudem spricht der Deutschlandfunk in Zukunft nicht mehr vom „Airport Orly“, sondern vom „Flughafen Orly“. Porsche setzt intern ganz auf die deutsche Sprache zur besseren Verständigung der Mitarbeiter untereinander. ${ }^{476}$ Die Begriffsänderung bei der Frankfurter Allgemeine Zeitung, die ebenfalls 2008 erfolgte, wurde in diesem Kapitel bereits aufgeführt (vgl. Kieselbach 2008: 2ff.).

War es 1997 noch ein Eintrag und waren es 1998 gerade fünf, so sind für das Jahr 2005 schon 86 Einträge, für 200687 Einträge, 2007 dann 90 Einträge (für 2008 sind es in der vierten Auflage 46 Einträge, das liegt daran, dass nur das erste Halbjahr des Jahres 2008 verzeichnet ist). Die Einträge spiegeln die Bandbreite der Vereinsarbeit wider, angefangen von den Medien über die Politik bis zum Einzelhändler vor Ort. Laut

\footnotetext{
${ }^{474}$ Dies mag ein Erfolg für die deutsche Sprache sein, für Mitbürger mit Migrationshintergrund, die sich bisher in ihrer Muttersprache beim Bürgerfunk engagiert haben, ist dies als Rückschlag zu werten.

475 Der Anglizismen-Index des VDS zählt „made in Germany“ nicht zu den englischen Ausdrücken, die nicht verwendet werden sollten (vgl. Kapitel 2.5.1.3).

${ }^{476}$ Dieser Eintrag ist mit dem Zusatz versehen, dass die Firma 2007 einen Zulassungsrekord in Deutschland hatte. Dies als eine Folge der Nicht-Verwendung von Anglizismen auszugeben greift jedoch ein wenig kurz.
} 
diesem Erfolgstagebuch hat der Verein vieles bewirkt, auch wenn die Herausgeberin selbst einschränkt, dass nicht alle aufgelisteten Erfolge auf die Arbeit von VDS-Mitgliedern zurückgehen. Ob und wie die Arbeit des VDS tatsächlich wirkt, ist nur schwer messbar. An einigen Entscheidungen, wie beispielsweise der Namensänderung des Lausitzrings oder der Umbenennung der Berufsbezeichnung „Funeralmaster“, war der VDS aufgrund seiner Aktionen sicherlich beteiligt oder ursächlich. Dies gilt auch für Umbenennungen im regionalen Umfeld, wie beispielsweise bei McDonald's in Dresden oder beim CVJM Tönisheide. Inwieweit die Vereinsarbeit aber an Entscheidungen wie der von McDonald's, den Deutschland-Werbespruch zu ändern, beteiligt war, ist im Einzelnen hier nicht nachzuvollziehen. Anzunehmen ist, dass selbst wenn die Arbeit des VDS die Anregung gab, sie wohl nicht der einzige Grund für eine Namensänderung eines Unternehmens war, zumal auch andere Stellen dies als ihren Erfolg deklarieren. Anzunehmen ist also, dass die „Erfolge“ viele Väter haben. Es sei auf die Studie der Werbeund Trendforschungsagentur Endmark aus Köln hingewiesen, in der untersucht worden ist, wie viele Deutsche englische Werbesprüche überhaupt richtig verstehen. Auf diese Studie verweist der VDS auch immer wieder. Befragt wurden 1104 repräsentativ ausgewählte 14- bis 49-Jährige, deren Muttersprache Deutsch ist. Selbst den McDonald'sSlogan „Every time a good time“ konnten nur 50 Prozent korrekt übersetzen, die meisten der untersuchten Werbebotschaften, darunter auch der Douglas-Spruch „Come in and find out“ wurden gar nicht oder falsch verstanden. (vgl. Thuma 2003: 87). ${ }^{477}$

Das VDS-Tagebuch und der Erfolgskalender erfüllen m.E. aber eine weitere Funktion: Sie dienen mit ihren Meldungen über die Tätigkeiten und Veranstaltungen sowie über die „Erfolge“ der Sicherung des inneren Zusammenhalts, in dem sie nach innen den Eindruck vermitteln, dass der VDS sehr erfolgreich sei. Wahrscheinlich dienen sie auch der Motivation der einzelnen Regionalgruppen.

${ }^{477}$ Mittlerweile sind eine zweite und dritte Auflage dieser Studie mit ähnlichen Ergebnissen erschienen. 


\subsubsection{Bücher}

Der Verein als Organisation, Funktionäre des Vereins und sein Vorsitzender haben eine Reihe von Büchern veröffentlicht. Im Folgenden werden zum einen Bücher vorgestellt, die Walter Krämer zu den Themen Anglizismen, Sprachpflege und Sprachkritik oder über den VDS publiziert hat. Ebenso werden Bücher vorgestellt, die Vorstandsmitglieder des VDS zu den Themen Anglizismen, Sprachpflege und Sprachkritik und VDS veröffentlicht haben, und Bücher, in denen eine Zusammenarbeit bei der Entstehung des Buchs mit dem VDS aufgeführt wird. ${ }^{478}$ Bei den Publikationen besteht des öfteren eine enge Zusammenarbeit des VDS mit dem IFB-Verlag. ${ }^{479}$ Einige Bücher des VDS erlangten in der Öffentlichkeit Aufmerksamkeit. Klein beispielsweise stellt fest:

Zur Einschätzung dieser Publikationen ist nicht nur allein die Tatsache ihres Erscheinens, sondern auch ihre Aufnahme in der (kaufenden) Öffentlichkeit mit zu berücksichtigen. Derlei Traktate und Sammlungen stoßen nämlich auf eine große Resonanz. [...] Dieser Erfolg wiederum wird in der Presse gelegentlich anerkennend und zustimmend notiert (Klein 2001).

Im Jahr 2000 erschien im Piper-Verlag Walter Krämers „Modern Talking auf deutsch. Ein populäres Lexikon.“. In diesem satirischen Buch nimmt Krämer 1000 englische Begriffe, die im Deutschen verwendet werden, aufs Korn, übersetzt sie entweder wortwörtlich oder interpretiert sie auf seine eigene Weise. Ein Beispiel: Unter dem Eintrag „blind date“ ist zu lesen: „Verabredung mit einer sehbehinderten Person (im Gegensatz zu ,deaf date' = Verabredung mit einer hörbehinderten Person [...]“. Auch das Vorwort zu diesem Büchlein ist satirisch, es spielt auf Asterix und Obelix und deren Kampf gegen die Römer an (vgl. Krämer 2000a: 5). Des Weiteren enthält das Buch einige Karikaturen. Zu sehen ist beispielsweise ein Eskimo vor seinem Iglu, versehen mit der Unterzeile „pole position“ (vgl. Krämer 2000a: 174).

\footnotetext{
${ }^{478}$ Nicht besprochen wird wegen dieser Auswahlkriterien in diesem Kapitel Wolf Schneiders „Speak German“ (Schneider 2008), obwohl die Aktion „Lebendiges Deutsch“ der Stiftung Deutsche Sprache in diesem Buch ausführlich dargestellt wird. Ebenfalls nicht näher vorgestellt wird daher auch „Sternstunden der deutschen Sprache“, herausgegeben von Walter Krämer und Reiner Pogarell (2003).

${ }^{479}$ Vgl. dazu auch Protokoll der Zusammenarbeit VDS-IFB-Verlag, ohne Datumsangabe.
} 
Die Publikation „Die Zukunft der deutschen Sprache. Eine Streitschrift“ aus dem Jahr 2000, herausgegeben von Helmut Glück und Walter Krämer, erschienen bei Klett, beinhaltet unter anderem Konferenzbeiträge der VDS-Konferenz im Jahr 1999 in Hannover unter dem Motto: „Die Zukunft der deutschen Sprache“ (Glück/Krämer 2000). Jacques Toubon ${ }^{480}$ stellt in seinem Beitrag die Frage: „Wozu dient künftig eine Nationalsprache?" und argumentiert für eine Sprachschutzgesetzgebung (Toubon 2000: 11ff.). Der Beitrag Franz Starks befasst sich mit „Sprache als Instrument der Außenpolitik“. Stark kritisiert, dass sich Wissenschaftler zu selten mit Sprache und Sprachverwendung im internationalen Kontakt befassen, und stellt ausführlich die Situation der deutschen Sprache in außenpolitischen Zusammenhängen der Bundesrepublik Deutschland dar (Stark 2000: 19ff.).

Horst Hensels Beitrag „Sprachverfall und kulturelle Selbstaufgabe“ setzt sich mit der Anglisierung der deutschen Sprache mit im Diskurs häufig auftauchenden Argumenten und Kommentaren, wie der beinahe schon obligatorischen (Lokal-)Journalistenschelte, auseinander. ${ }^{481}$ Hensel stellt die Frage, ob Englisch wirklich im Vergleich zu Deutsch die „bessere“ Sprache sei, und führt Gegenbeispiele an, wie die freiere Wortstellung im Deutschen (Hensel 2000: 45). Auch die Werbeindustrie steht - wie so häufig - im Mittelpunkt der Kritik (Hensel 2000: 47). Hensel spricht sich für eine Stärkung des Deutschen als Wissenschaftssprache aus (Hensel 2000: 49f.). Enthalten ist auch eine Untersuchung von Wolfgang-Werner Sauer: „Berufsbezeichnung zwischen Customer Service Spezialist und Kundenberater - Ergebnisse einer empirischen Untersuchung“. Ausgewertet wurden rund 7400 Stellenanzeigen aus der FAZ, der SZ und der Welt. Dabei kommt Sauer zu dem Ergebnis, dass etwa jede dritte Stellenanzeige englische Sprachanteile enthält (Sauer 2000: 52ff.). Helmut Glück befasst sich in seinem Beitrag mit der Frage „Dürfen Linguisten werten?" und kommt zu dem Schluss, dass diese es nicht

\footnotetext{
${ }^{480}$ Jacques Toubon ist ehemaliger französischer Justizminister und Minister für Kultur und Frankophonie. In seiner Amtszeit wurde das französische Sprachschutzgesetz verabschiedet, die „Loi Toubon“.

${ }^{481}$ Bezeichnenderweise führt Hensel an dieser Stelle keine echte Referenz auf. Stattdessen spitzt er die Sprache der von ihm kritisierten Volontäre in Lokalausgaben der Regionalzeitungen zu: „Standing Ovations für Kids zum großen Event“ (Hensel 2000: 43).
} 
nur dürfen, sondern auch sollten (Glück 2000a: 62ff.). Zudem beinhaltet die Publikation eine Mitschrift der Podiumsdiskussion dieser Konferenz und die Gründungserklärung des wissenschaftlichen Beirats, die „Thesen zur Situation der deutschen Sprache“ (vgl. Kapitel 2.2.2.1).

Eine weitere Veröffentlichung in Zusammenhang mit dem VDS ist Horst Hensels „Sprachverfall und kulturelle Selbstaufgabe“ aus dem Jahr 1999, erschienen im DruckVerlag Kettler. ${ }^{482}$ In dieser Publikation beschreibt Hensel die Verwendung von Anglizismen in der deutschen Sprache als „Sprachverfall“ und „sprachliche Unterwürfigkeit“, zu der die Deutschen niemand zwinge, sondern die sie freiwillig betrieben und damit ihre Kultur aufgäben (vgl. Hensel 1999: 28). Außerdem ist das dritte Kapitel des Buchs eine der ersten Veröffentlichungen zum VWDS (Hensel 1999: 97ff.), in der Hensel den Verein, seine Mitglieder, seinen Vorsitzenden sowie seine Arbeit vorstellt. Er kritisiert Organisationen wie die GfdS und die Deutsche Akademie für Sprache und Dichtung, sie täten zuwenig gegen Anglizismen in deutschen Medien, und greift Medien an, die sich kritisch über Sprachwahrer äußern, wie die Süddeutsche Zeitung (vgl. Hensel 1999: 30f). Er prangert an, das Deutsche werde durch die Verwendung von Anglizismen verhunzt und es komme zur „Pidginisierung“483 (Hensel 1999: 20ff.). Besprochen wurde das Buch in der als rechtskonservativ geltenden Wochenzeitschrift Junge Freiheit. Dort wird es als „provokante Schrift“ bezeichnet, die „einen weiten Bogen zieht vom Verfall der deutschen Sprache aufgrund unseres speziellen Minderwertigkeitskomplexes bis hin zur drohenden weltweiten kulturellen Vereinheitlichung und Nivellierung“ (Pickert 1999: 14). Das Buch wurde zu einem Bestseller (vgl. u.a. Nussbaumer 2003: 118). ${ }^{484}$

$\mathrm{Zu}$ den Publikationen des Vereins zählt auch der Sammelband „Denglish, nein danke! Zur inflationären Verwendung von Anglizismen und Amerikanismen in der deutschen Gegenwartssprache“, herausge-

\footnotetext{
${ }^{482}$ Horst Hensel war stellvertretender Vorsitzender des V(W)DS.

${ }^{483}$ Dass dieser Begriff in Verwendung mit Anglizismen im Deutschen fachlich falsch ist, wurde schon in Kapitel 1.6 dargelegt.

${ }^{484}$ Nussbaumer führt aus, dass sich hinter den Büchern wohl auch einer der Gründe für die Vereinsarbeit jedenfalls bestimmter Menschen im VDS verbirgt: „Es ist ein pekuniärer Beweggrund, denn die Bücher eines Walter Krämer oder Horst Hensel dürften sich recht gut verkaufen“ (Nussbaumer 2003: 117). Dem entgegen stehen aber viele Stunden Vereinsarbeit, die sich finanziell nicht auswirken.
} 
geben von Hermann Zabel im Auftrag des VDS. ${ }^{485}$ In diesem Sammelband sind Aufsätze verschiedener Sprachwissenschaftler wie HeinzGünter Schmitz oder Hermann Fink zu finden, die sich mit Anglizismen und Amerikanismen im Deutschen befassen. Darüber hinaus sind Aufsätze von VDS-Mitgliedern zum Thema „Denglisch als Sprache der Verschleierung und der Täuschung“ zusammengefasst. Ein Kapitel ist dem Thema „Sprache und Kultur“ gewidmet, hier publiziert u.a. Reiner Pogarell. Ein weiteres Kapitel behandelt den VDS. Hier finden sich u.a. die Leitlinien, die Thesen des wissenschaftlichen Beirats sowie Informationen zum Berliner Sprachbündnis und zu Zielen und Aktivitäten des Vereins. Dies soll an dieser Stelle genügen, da die Inhalte dieses Sammelbandes schon an verschiedenen Stellen in dieser Arbeit diskutiert wurden (vgl. die Kapitel 2.2.2.1, 2.3.2, 2.2.6).

Die VDS-Publikation war auch Gegenstand von Rezensionen. Einige davon finden sich abgedruckt in der zweiten Auflage von „Denglisch, nein danke" aus dem Jahr 2003. Gerhard Schoebe beispielsweise schrieb über den Sammelband:

Die Kritik ist nicht Teil einer Fremdwortjagd, vielleicht sogar aus sachfremden Motiven, sondern vielmehr ein Stück verantwortungsbewusster Sprachpflege, die einen aktuellen Übelstand sichtbar macht, damit abgeholfen werden kann. Mehrere Beiträge breiten mit überzeugendem Material Befunde über Beschaffenheit und Auftreten jenes oben charakterisierten "Denglisch“ aus (Schoebe 2003: 296). ${ }^{486}$

Schoebe verweist auch darauf, dass sich der VDS mit dieser Publikation erstmals mit seinem Werk und seinen Zielen vorstellt. Thomas Niehr schreibt, er habe sich nach den Erfahrungen der Jahrestagung des IDS 2000 in Mannheim und nach seinen Erfahrungen mit Regionalvertretern und deren Argumentation mit „einem gewissen Unbehagen“ an die Lektüre des Sammelbands gemacht. Jedoch kommt er zu dem Schluss, dass in den meisten der Aufsätze „das Bemühen um Sachlichkeit“ im Vordergrund stehe, und dass die „eindeutigen Absagen an wenig hilfreiche Polemisierungen wie ,Schimpansendeutsch' [...]“ den Vereinszielen besser dienen (Niehr 2002a: 30). Als linguistisches Missverständnis kri-

\footnotetext{
${ }^{485}$ Hinweis in der Einführung: „Der vorliegende Sammelband wird im Auftrage des Vereins Deutsche Sprache herausgegeben.“, Zabel 2001a: 11).

${ }^{486}$ Diese Rezension hätte auch in einer Zeitschrift der GfdS erscheinen sollen, der Text wurde aber abgelehnt (vgl. Zabel 2001a: 298)
} 
tisiert Niehr die Argumentation bezüglich sog. wörtlicher Übersetzungen. Niehr führt an, auch für einen Amerikaner sei ein „laptop“ ein tragbarer Computer und nicht etwa eine „Schoßspitze“ (vgl. Niehr 2002a: 31) ${ }^{487}$ Insgesamt kommt er zu dem Schluss, dass man über viele Behauptungen, die in dem Sammelband enthalten sind, lange streiten könne, das Buch jedoch viel interessanten Diskussionsstoff biete (vgl. Niehr 2002a: 31).

Das „Wörterbuch überflüssiger Anglizismen“ von Reiner Pogarell und Markus Schröder „entstand auf direkten Wunsch des Vereinsvorsitzenden Walter Krämer“ (SN 2006c: 29). Dies ist ein Wörterbuch, das nach Meinung der Verfasser und ihrer Mitarbeiter überflüssige Anglizismen im Deutschen aufführt und ihnen Verdeutschungsvorschläge gegenüberstellt. Klein weist darauf hin, dass es sich um ein Verdeutschungswörterbuch nach altem Vorbild handle (vgl. Klein 2001). Gemeint sind damit u.a. die Verdeutschungswörterbücher des ADSV/DSV (vgl. Kapitel 1.7.1). Ziel ist: „[...] denjenigen Menschen helfen, die sich um gutes Deutsch bemühen und deutschsprachige Texte auch aus deutschen Wörtern bauen möchten“ (Pogarell/Schröder 2001: 9). Die Autoren finden nicht die aufgeführten Einzelbeispiele, sondern die Gesamtmenge besorgniserregend (vgl. Pogarell/Schröder 2001: 8). Die erste Auflage erschien im Jahr 1999 im IFB-Verlag, weitere Auflagen folgten. In der vierten Auflage setzen sich die Verfasser auch mit Kritik an ihrem Buch auseinander, beispielsweise damit, dass Anglizismen, die sie in ihre Liste aufgenommen haben, im Deutschen nicht verwendet werden. ${ }^{488}$ In ihrer Wortliste kennzeichnen die Autoren zahlreiche Wörter mit Denglisch, bewerten sie also negativ. Corinna Peschel kritisiert, dass die Autoren „relativ unverhohlen nationalpolitisch“ argumentieren (Peschel

${ }^{487}$ Diese Rezension ist auch abgedruckt in der Neuauflage von „Denglisch, nein danke! (Niehr 2003). Zwischen Zabel und Niehr entstand ein regelrechter Disput (vgl. Niehr 2006: 186ff.).

${ }^{488}$ Diese Kritik ist m.E berechtigt, denn schon unter dem Buchstaben $a$ sind beispielsweise „abandon“ oder „abduction“ aufgeführt, die m.W. nach - wenn überhaupt - dann nur äußerst selten oder in Fachsprachen verwendet werden. Da das „Wörterbuch überflüssiger Anglizismen“ in weiten Teilen identisch ist mit dem Anglizismen-Index, vgl. für eine ausführliche Darstellung der Kritik Kapitel 2.6.1.6. 
2000: 63). ${ }^{489}$ Politische Töne kommen in der Tat bei der sehr verkürzten Version des Endes des DSV ins Spiel (vgl. Pogarell/Schröder 2001: 9, ebenso Pogarell/Schröder/Bartzsch 2008: 9). 2007 ist die 7. Auflage erschienen, die wie alle vorher in der Öffentlichkeit auf Resonanz stieß (vgl. Klein 2001).

Die Publikation „Wörter fallen nicht vom Himmel. Plädoyer für eine selbstbewusste Sprachpolitik. Textsammlung." haben Hermann H. Dieter, Kurt Gawlitta, Gernot Meißner und Fritz Vilmar im Namen des VDS Berlin/Potsdam im Jahr 2001 gemeinsam veröffentlicht. Thema dieser Textsammlung ist vor allem die Diskussion darüber, ob es wegen der Anglizismen im Deutschen notwendig sei, einen gesetzlichen Schutz für die Sprache zu erlangen (vgl. Gawlitta 2001a: 1). In „Days for Kids. Zwischen Überwältigung und Selbstaufgabe. Ein Plädoyer für eine aktive Schutzpolitik für die deutsche Sprache.“, einem Gastkommentar von Kurt Gawlitta, der am 29. April 2000 im Tagesspiegel erschienen ist, plädiert der Autor dafür, dass die Regierung eine „nationale Verantwortung für die Zukunft unserer Landessprache“ übernehmen solle (vgl. Gawlitta 2001b: 4). Ebenfalls abgedruckt ist ein Artikel von Eckart Werthebach aus der Berliner Morgenpost vom 31. Dezember 2000 mit dem Titel „Die deutsche Sprache braucht gesetzlichen Schutz“ (vgl. auch Kapitel 2.3.2). In diesem fordert er ein Sprachschutzgesetz nach dem Vorbild Frankreichs oder Polens und gibt an, dass er „als Verfassungssenator der deutschen Hauptstadt prüfen [werde], welche Möglichkeiten es gibt, eine weitere Zurückdrängung und Verarmung der deutschen Sprache auch gesetzgeberisch zu verhindern“ (Werthebach 2001: 6f.). Auch Helmut Glück wird mit einem Beitrag aus der Welt vom 10. Februar 2001 mit dem Titel „Es gibt längst ein Sprachenrecht“ zitiert. Darin führt er anhand verschiedener Beispiele wie den Regelungen über die Amtssprache der Behörden oder Notare sowie über die Sprache der Bildungseinrichtungen aus, dass es längst ein Sprachenrecht im Deutschen gebe, dieses aber über die Spezialgesetzgebung verstreut sei (vgl. Glück 2001a: 9). Hermann H. Dieter stellt in „Die Deutschen haben ein Sprachproblem“ die Frage, ob es etwas deutscheres gebe als die deut-

${ }^{489}$ Die Verwendung des Adjektivs „nationalpolitisch“ ist in diesem Zusammenhang nicht korrekt, es ist jedoch klar, was damit gemeint ist. 
sche Sprache und spricht im Zusammenhang mit den Anglizismen im Deutschen vom „Albtraum der deutschen Sprache“ (Dieter 2001: 11). Zudem enthält das Buch unter anderem einen offenen Brief an Wissenschaftler mit der Forderung nach Sicherung und Ausbau von Deutsch als nationale Wissenschaftssprache (vgl. Dieter et al. 2001: 26ff.) sowie einen kurzen historischen Abriss über sprachpflegende Vereinigungen (vgl. Meißner 2001: 81ff.). Das Interessante an „Wörter fallen nicht vom Himmel“ ist aber, dass neben der Forderung nach einem Sprachgesetz auch ein Gesetzesentwurf für ein solches abgedruckt ist, vorgelegt von Kurt Gawlitta, und das, obwohl die Vereinslinie zu diesem Zeitpunkt war, dass man kein Sprachschutzgesetz fordere (vgl. Gawlitta 2001c: 39ff., vgl. Kapitel 2.3.2). Des Weiteren sind Wörterlisten mit Eindeutschungen aus der Barockzeit und der Zeit des Deutschen Reichs enthalten, ebenso wie deutsche Übersetzungen der Loi Toubon und des polnischen Sprachgesetzes (vgl. Dieter et al. 2001: 101ff.). ${ }^{490}$ Die Publikation wurde vom stellvertretenden Vorsitzenden des wissenschaftlichen Beirats als polemisierend eingestuft (vgl. zu diesem Beispiel der Arbeit des Beirats Kapitel 2.2.2) und ist auf den Internetseiten des VDS Berlin/Potsdam unter den Publikationen von Kurt Gawlitta nicht mehr aufgeführt (vgl. VDS Region Berlin/Potsdam 2008b).

Reiner Pogarells „,Sitzung' oder ,Meeting'? Historische und aktuelle Fragestellungen zur Sprachreinigung in Deutschland“ aus dem Jahr 1998 ist ebenfalls eine Publikation im IFB-Verlag. Das Vorwort hat Walter Krämer verfasst. Er ruft darin zum Bürgerprotest gegen die Anglizismen auf (vgl. Krämer 1998b: 5). Pogarell gibt einen kurzen Überblick über die Geschichte des Purismus und die Geschichte der deutschen Sprache, widmet sich sprachwissenschaftlichen Vorbehalten gegenüber dem Purismus und erstellt Kriterien für erfolgreiche Verdeutschungen. Insgesamt ist die Publikation eine populärwissenschaftliche Zusammenstellung zum Thema Purismus, da sie sprachwissenschaftliche und politische Zusammenhänge - wie die Wortbildung als Beispiel für sprachwissenschaftliche Inhalte (vgl. Pogarell 1998: 66) - stark verkürzt und vereinfacht darstellt.

${ }^{490}$ In „Wörter fallen nicht vom Himmel“ sitzen bemerkenswerterweise alle Anführungszeichen, wie im Englischen üblich, oben. 
Ludger Gawlittas Untersuchung über die Akzeptanz englischsprachiger Werbeslogans „Let's make things better“ erschien 2001 im IFB-Verlag und wird hier aufgeführt, da sie vom VDS unterstützt wurde und daher als Publikation des VDS gelten kann. ${ }^{491}$ Dabei handelt es sich um die Präsentation der Ergebnisse einer Befragung von 240 Personen aus verschiedenen deutschen Städten. Diese wurden in einer Umfrage anhand eines ausführlichen Fragebogens nach ihren Eindrücken hinsichtlich des Vorhandenseins, der Zunahme englischer Werbeslogans und ihrer Einstellung dazu befragt. Dabei sagten 95 Prozent der Befragten aus, dass Werbeslogans oft englische Begriffe enthalten, rund 41 Prozent der Befragten finden englische Werbeslogans moderner als deutsche. Bei der Gruppe der 50- bis 65-Jährigen war die Akzeptanz gegenüber englischsprachigen Werbeslogans jedoch gering (vgl. L. Gawlitta 2001: 52ff.). Diese Publikation ist anders als andere Publikationen im IFBVerlag deutlich wertneutraler gegenüber Anglizismen, was damit zusammenhängen mag, dass sie als Fachhochschul-Abschlussarbeit erstellt wurde (vgl. L. Gawlitta 2001: 85).

Der von Hermann Zabel herausgegebene Sammelband: „Ein See - Drei Länder - Eine Sprache“ ist der Tagungsbericht vom Internationalen Bodenseetreffen der Sprachvereine im Netzwerk Deutsche Sprache vom 5. bis 8. Oktober 2000 zum Thema Amerikanismen und Anglizismen in der deutschen Sprache, erschienen im IFB-Verlag im Jahr 2001. Inhalt des Bandes ist u.a. die „Friedrichshafener Entschließung“ (vgl. Kapitel 1.7.14). Darin wirft Heinz-Günter Schmitz ${ }^{492}$, der selbst Sprachwissenschaftler ist, der Sprachwissenschaft eine „bewußt ahistorischsynchronistische Sprachauffassung“ vor (Schmitz 2001: 27). Weiter beklagt er das fehlende Verständnis für „sprachreinigende, ,puristische” Bestrebungen und Bewegungen, auch der der Vergangenheit (die das Deutsche ja wirklich wesentlich mitgeprägt haben)“ (Schmitz 2001: 27). ${ }^{493}$ Hermann Zabel legt unter dem Titel „Die gebrannten Kinder“ mögliche Gründe der Sprachwissenschaftler dar, sich von Fremdwortjagd zu distanzieren, wobei er das Ende des DSV sehr einseitig darstellt,

\footnotetext{
${ }^{491}$ Vgl. dazu Vilmar (2002a: 32).

492 Unter „Autoren“ wird Schmitz fälschlicherweise als „Hans-Günter“ aufgeführt, im Inhaltsverzeichnis dagegen mit „Heinz-Günter“ (vgl. Zabel 2001).

${ }^{493}$ Zur Haltung der Sprachwissenschaft vgl. Kapitel 1.6.
} 
indem er nur auf das Verbot durch die Nationalsozialisten verweist, aber auf die unrühmliche Rolle des DSV zur Zeit des Nationalsozialismus keinen Bezug nimmt (Zabel 2001c: 34). Neben diesen beiden Aufsätzen enthält der Tagungsband Zusammenfassungen der Tagungsvorträge. Bemerkenswert, weil klar antiamerikanische Töne anklingen, ist Klaus Däßlers Vortrag „Die Wurzeln der Internationalen Sprachzerstörung“. Er hebt hervor, dass „unser Problem eindeutig amerikanische Wurzeln hat" (Däßler 2001: 93) und ruft deshalb zum Boykott amerikanischer Produkte und Filme auf (Däßler 2001: 130).

Eine interessante Veröffentlichung ist „,Deutsch nix wichtig’?“ (2002a) von Kurt Gawlitta und Fritz Vilmar. ${ }^{494}$ Der Titel bezieht sich auf ein Graffito, das Demonstranten aus Protest gegen ein Seminar von Vilmar an eine Mauer gesprüht hatten (vgl. Kapitel 2.5.7). Im ersten Teil dieser Publikation steht eine Analyse des „Sprachimperialismus“, wobei Vilmar die Sprache als „Herrschaftsinstrument“ versteht, im Vordergrund. Des Weiteren führt der Autor aus, dass es sich bei der Amerikanisierung unserer Sprache und Gesellschaft um eine „Selbstaufgabe“ handelt. Zudem enthält dieser Abschnitt einen kurzen Überblick über die Aktivitäten und Ziele des VDS. Gernot Meißner schreibt über „Wortschöpferisches Engagement in der deutschen Sprachgeschichte seit dem Barock“, wobei er angefangen mit den Sprachakademien des 17. Jahrhunderts über Einzelpersonen wie Campe bis hin zu den Aktivitäten des ADSV/DSV die Situation der Sprachreinigung im Deutschen darlegt. Im Abschnitt „Bürger gegen Denglisch“ werden die Ergebnisse von Untersuchungen und Umfragen zur Einstellung gegenüber Anglizismen vorgestellt. Neben einer Zusammenfassung von Ludger Gawlittas Untersuchung (siehe oben in diesem Kapitel) steht die Zusammenfassung einer Befragung des Kölner Boulevardblattes Express. In dieser Umfrage antworteten 87 Prozent der Befragten auf die Frage: „Brauchen wir ein Anti-Denglisch-Gesetz?“ mit Ja (vgl. Gawlitta/Vilmar 2002b: 65). Weiterer Themenschwerpunkt von „,Deutsch nix wichtig’?“ ist die Bewahrung des Deutschen als Wissenschaftssprache. Hier geht Vilmar ausführlich auf wissenschaftliche Erkenntnisse ein. Weiterhin wirft er der Politik

${ }^{494}$ Diese Publikation enthält verhältnismäßig viele Fehler, zudem sitzen die Anführungszeichen oben. 
"Defätismus und Nonchalance“ in diesem Bereich vor (vgl. Vilmar 2002b: 78).

Hermann H. Dieter legt die politischen Reaktionen auf einen Offenen Brief an die Kultusminister dar (vgl. Dieter 2002a: 86ff. sowie Kapitel 2.5.9). Er beschäftigt sich mit der „Unersetzlichkeit der Muttersprache auch für wissenschaftliche Kommunikation und Erkenntnis" (vgl. Dieter 2002b: 97ff.). Gegenstand der Publikation sind die Ergebnisse einer Befragung von Ärzten zu deren Einstellung gegenüber der „Anglisierung ihrer Fachsprache“ (Haße 2002: 108ff.) sowie die Darlegung von Axel Flessner zum Thema „Wissenschaftliche Selbstbeschränkung durch Englisch“ (Flessner 2002: 117ff.). Zweiter Themenschwerpunkt der Publikation ist die Diskussion um ein Sprachschutzgesetz im Deutschen. Hier legen die Autoren einen neuen Gesetzentwurf vor (Gawlitta/Flessner 2002: 124ff.). Aufschlussreich ist das Buch auch deswegen, weil es in einer detaillierten Dokumentation interne Querelen des VDS darlegt, vor allem hinsichtlich der Frage nach einem Sprachschutzgesetz (vgl. Braun/Gawlitta/Vilmar 2002: 151ff. sowie ausführlich Kapitel 2.3.2). Die im Anhang des Buchs enthaltenen Dokumentationen, beispielsweise über das Seminar an der Freien Universität Berlin, geben interessante Hinweise auf die Vereinsgeschichte (Vilmar 2002c: 206f., vgl. Kapitel 2.5.7).

Zum zehnjährigen Bestehen des Vereins ist ebenfalls im IFB-Verlag die Festschrift „Eine Stimme für unsere Sprache. 10 Jahre Verein Deutsche Sprache" erschienen, herausgegeben von Walter Krämer, Myriam Grobe und Dawit Petros. Darin erläutert Krämer seine Motivation für die Gründung des VDS, Peter Zbinden vom Sprachkreis Deutsch in Bern beschreibt die Zusammenarbeit der beiden Vereine, Eva Maria Kieselbach stellt die Vereinsarbeit und ihre Auswirkungen vor, Reiner Pogarell diskutiert das Verhältnis der Sprachreiniger zur Sprachwissenschaft. Hier stellt er die Geschehnisse, die schließlich zum Ende des DSV geführt haben, genau wie Zabel sehr einseitig dar, wenn er schreibt:

Dieser Text [gemeint ist der Erlass des „Reichsministers für Wissenschaft, Erziehung und Volksbildung“ vom 19. November 1940, Anm. der Verf.] kann als das Ende der für ihre Sprache engagierten Sprachwissenschaft in Deutschland gelesen werden. Er wäscht nicht die deutschen Linguisten von ihren Naziberührungen rein, aber er zeigt auch den Irrsinn auf, den Einsatz für die deutsche Sprache als Naziangelegenheit zu bezeichnen. Purismusgegner können sich sehr 
wohl auf Hitler berufen, nicht aber die „Wahrer“ der deutschen Sprache (Pogarell 2007a: 28, vgl. dazu Kapitel 1.7.1).

Interessant an dieser Festschrift ist, dass sie einen Überblick über die Vereinsarbeit und die Entstehung aus einem internen Blickwinkel bietet, und auch, dass sie aktuelle Stellungnahmen zur Vereinslinie enthält, weswegen wiederholt auf Aussagen aus der Festschrift Bezug genommen wird (u.a. Kapitel 1.7.14).

Menno Aden veröffentlicht im Jahr 2007 im IFB-Verlag den Titel „Deutsch und Englisch. Zum deutschen sprachlichen und kulturellen Selbstbewußtsein“. Darin setzt er sich mit dem „Bedeutungsverlust“ der deutschen Sprache auseinander und argumentiert, dass dies eine Folge von politischen Versäumnissen zu Beginn der Neuzeit sei: „Wäre es uns gelungen, etwa Australien, Brasilien oder auch nur Südafrika zu kolonisieren, stünde die deutsche Sprache anders da" (Aden 2007: 15). Er befürchtet: „Es ist nicht undenkbar, daß der deutsche Sprachraum in den nächsten fünfzig Jahren seine Sprache als Kultursprache verloren haben wird“ (Aden 2007: 17). ${ }^{495}$ Aden erläutert weiter, dass Kinder zu einem „ausgesprochenen Sprachpurismus“ neigen. Dies habe er an seinen eigenen Kindern beobachtet (vgl. Aden 2007: 22). ${ }^{496}$ Es folgt ein kurzer Überblick über den Beginn der Sprachpflege und über das Verhältnis von Sprache und Demokratie (vgl. Aden 2007: 25ff.). Sprachen sieht Aden als „lebende Gebilde“497, die wachsen und das Fremde „gleichsam als Speise zu sich [nehmen]“ (Aden 2007: 34). Ein Kapitel ist dem „deutschen Minderwertigkeitskomplex“ gewidmet. Hier führt der Autor aus, dass das Verhältnis der Deutschen zu ihrer Sprache sich auch aus einer "gefühlten politischen Machtlosigkeit“ ergebe (Aden 2007: 52). Zudem sei „mit der Ausschaltung Deutschlands 1918 und 1945 [...] die im Grunde einzige lateinische Hochkultur Europas weggefallen“ (Aden 2007: 120). ${ }^{498}$ Deutsch wird als „Ursprache“ angesehen, die „ihr Wortgut zwar nicht ausschließlich, aber doch zum überwiegenden Teil aus der

\footnotetext{
${ }^{495}$ Aden weist auch darauf hin, dass wir Deutsche soweit gehen, dass wir mittlerweile von "George Frederick Handel“ sprechen, anstatt von "Georg Friedrich Händel“ (vgl. Aden 2007: 20). Dass diese Aussage allgemeingültig ist, möchte ich bezweifeln.

${ }^{496}$ Dabei handelt es sich lediglich um eine Einzelbeobachtung Adens.

${ }^{497}$ Damit nimmt er auf Organismusmodelle Bezug.

${ }^{498}$ Die näheren Erläuterungen auf der folgenden Seite konnte die Verfasserin nicht nachlesen, diese Seite ist nicht bedruckt (vgl. Aden 2007: 121).
} 
eigenen, letztlich ursprachlichen, also (indo-)germanischen Quelle [schöpft]“" ${ }^{499}$ das Englische oder Französische dagegen als "hybride Sprachen“, und zwar „im gärtnerischen Sinne“ (Aden 2007: 127). Schließlich setzt sich Aden mit dem Zusammenhang von Sprache und wirtschaftlichem Erfolg auseinander und führt aus, dass es in Deutschland zwar "keine allgemeine gesetzliche Regelung, die den Gebrauch der deutschen Sprache im öffentlichen und privaten Rechtsverkehr erzwingt," gibt, wohl aber ein Gewohnheitsrecht (vgl. Aden 2007: 141f.). In einer in den Sprachnachrichten auf Intervention von Krämer hin nicht veröffentlichten Rezension ${ }^{500}$ greift Helmut Glück diese Publikation an. Er kritisiert, wenn eine Veröffentlichung zum Thema Sprache mit einem wissenschaftlichen Anspruch versehen wird, muss sich diese Veröffentlichung an wissenschaftlichen Standards messen lassen. Aden aber kenne den Forschungsstand weder in methodischer noch in sachlicher Hinsicht (vgl. Glück 2008:b 2), er verwende zwar die Fachterminologie, beherrsche sie aber nicht. Zudem verweist Glück darauf, dass Aden argumentierte, der deutsche Sprachraum werde eventuell seine Sprache als Kultursprache verlieren (siehe oben in diesem Kapitel). Glück legt an dieser Stelle dar, dass dies unwahrscheinlich sei, „denn das Deutsche ist eine der am besten ausgebauten und erforschten Sprachen überhaupt“ (Glück 2008b: 3). Zudem verlieren nicht Sprachräume Sprachen, allenfalls wechseln die Sprecher einer Sprache zu einer anderen Sprache. Adens Theorie, dass Kinder zu Sprachpurismus neigen, kontert Glück ebenfalls. ${ }^{501}$ Das Buch sei "voller sachlicher Fehler“ (Glück 2008b: 3), der Ton sei „oft anmaßend und dröhnend deutschnational“ (Glück 2008b: 5). Insgesamt sieht Glück die Publikation als „untaugliche[n] Versuch“ (Glück 2008b: 1), das sprachliche und kulturelle Selbstbewusstsein der Deutschen zu beschreiben. Thomas Paulwitz hat Adens Buch, bezugnehmend auf die Rezension von Glück, in der Jungen

\footnotetext{
${ }^{499}$ Dies ist insofern erstaunlich, als sich das Buch vorher ausführlich damit auseinandersetzt, dass die deutsche Sprache aufgrund fremder Einflüsse bedroht sei.

${ }^{500}$ Nachzulesen ist diese jedoch auf der Homepage von Menno Aden (Glück 2008b). Aden hat die Rezension von Glück wiederum mit Anmerkungen versehen.

${ }^{501}$ In einer Replik führt Aden an, dass Glück wohl selbst keine Kinder habe. Hier irrt Aden.
} 
Freiheit besprochen und es als „Streitschrift“, die zum „Nachdenken anregt" bezeichnet (Paulwitz 2008: 32). ${ }^{502}$

In „Sprache - ,Sanftes' Machtinstrument in der globalen Konkurrenz. Wo, wie und wieweit wir Deutsch verteidigen sollten. Zehn Thesen für eine deutsche Sprachenpolitik.“, erschienen im Jahr 2007 im IFBVerlag, führt der Autor Franz Stark in zehn Thesen aus, warum und wie die deutsche Sprache verteidigt werden sollte. Dabei verweist er in These eins auf den Charakter einer Sprache als Instrument, mit dem man sich Vorteile verschaffen und Macht ausüben kann (vgl. Stark 2007a: 11ff.). In These zwei setzt er sich damit auseinander, dass besondere historische Konstellationen zur weiten Verbreitung einer Sprache führen (Stark 2007a: 16). In These drei wird dargelegt, dass es unangebracht sei, das Englische „für eine den anderen generell überlegene Sprache zu halten“, da „jede ,voll ausgebaute' Sprache für die muttersprachlichen Sprecher die gleiche Leistungsfähigkeit besitzt“ (Stark 2007a: 21). Um darzulegen, dass auch das Englische sprachliche Nachteile hat, vergleicht Stark das Deutsche mit dem Englischen. Als Beispiel führt er an, dass durch die freiere Wortstellung im Deutschen diese Sprache variantenreicher ist (vgl. Stark 2007a: 25). These vier zielt auf den Instrumentalcharakter der Sprache (These eins) ab, der den politischen Klassen der USA, Großbritanniens und Frankreichs viel bewusster sei als den deutschen (Stark 2007a: 26ff.). These fünf besagt, dass die Nationen, die „nicht auch der ,kulturellen Konvergenz' erliegen wollen, die die Globalisierung begleitet, [...] sich verstärkt um die Bewahrung ihrer Sprache in Domänen außerhalb des Globalisierungsprozesses kümmern [müssen] " (Stark 2007a: 32). These sechs und sieben legen den Anspruch der deutschen Sprache dar, als eine der führenden europäischen Sprachen wahrgenommen zu werden (vgl. Stark 2007a: 37ff.). These acht besagt, dass das Deutsche diskriminiert werde, da der Status, neben Englisch und Französisch gleichberechtigte dritte Amtssprache $e^{503}$ der EU zu sein, nur auf dem Papier bestehe (vgl. Stark 2007a: 48ff.). In These neun führt Stark aus, dass Deutschland an der Diskriminierung

${ }^{502}$ Die Kritik Glücks an der Publikation wertet er als politisch motiviert. Glück selbst sieht er dabei als „linksliberal“ (Paulwitz 2008: 32). Der Autor Menno Aden schreibt genau wie Paulwitz für die Junge Freiheit (vgl. u.a. Aden 2008: 13).

${ }^{503}$ Hier geht es um den Status von Deutsch als dritter Arbeitssprache der EU. 
der deutschen Sprache Mitschuld habe, da 1973 die deutschen Beamten der EG selbst auf Deutsch verzichteten (vgl. Stark 2007a: 53). These zehn schließlich legt die "hartnäckige ,deutsche Krankheit"“ dar, nach der die Deutschen ihre Sprache freiwillig mit englischen Ausdrücken durchsetzten und stellt die Frage, inwieweit Sprachpolitik helfen könne. Dabei kommt Stark zu dem Schluss, dass Deutschland „dringend“ eine „Zentralstelle für die Entwicklung von Konzepten und Maßnahmen der Sprachstatusplanung“504 brauche (vgl. Stark 2007a: 66ff.).

Gemeinsam mit Roland Kaehlbrandt veröffentlichte Walter Krämer bei Piper im Jahr 2007 „Die Ganzjahrestomate und anderes Plastikdeutsch“, ein satirisches Lexikon, das sich unter anderem bissig mit Anglizismen, mit der Sprache der Politik und mit der Sprache der Wirtschaft auseinandersetzt (Krämer/Kaehlbrandt 2007). Im Jahr 2009 ist dazu bei Piper der Fortsetzungsband „Plastikdeutsch“ erschienen, ebenfalls von Walter Krämer und Roland Kaehlbrandt (Krämer/Kaehlbrandt 2009).

Ebenso im Piper-Verlag ist 2009 das „Lexikon der populären Sprachirrtümer „Missverständnisse, Denkfehler und Vorurteile von Altbier bis Zyniker“, eine gemeinsame Veröffentlichung von Walter Krämer und dem Sprachwissenschaftler Wolfgang Sauer, veröffentlicht worden (Krämer/Sauer 2009). In dieser durchaus lehrreichen Publikation werden gängige irrige Annahmen zu Worten oder Redewendungen aufgegriffen und richtig gestellt. Ein Beispiel: „Die Hängematte kommt von >>hängende Matte<<. " Hierzu wird erläutert, dass sich die Hängematte vom indianischen "hamaca“ ableitet, so nannten die Indianer ihr Schlafnetz, die sie zwischen Bäumen aufspannten (vgl. Krämer/Sauer 2009: 136).

Im Jahr 2009 wiederum im IFB-Verlag erschienen ist Gerd Schrammens „Ich spreche gerne Deutsch. Über die mißhandelte Muttersprache." In dieser Textsammlung, deren Hauptanliegen das Aufzeigen der „Verunstaltung der Muttersprache“ (Schrammen 2009: 10) ist, finden sich wieder aufgelegte Artikel aus den Sprachnachrichten von Schrammen, aber auch von weiteren Autoren, unter anderem Aden und Krämer. Des Weiteren wird auf die "giving-story“ von Jil Sander einmal mehr Bezug genommen, aber auch auf den „Bodybag“ und das „Han-

${ }^{504}$ Hervorhebungen im Original. 
dy“, ebenso werden die Texte wieder aufgelegt, die zu den jeweiligen Sprachpanschern des Jahres erschienen sind. Episoden über Ereignisse, die Sprachvereine als Erfolge für die deutsche Sprache ansehen, werden aufgelistet. Journalisten und Sprachwissenschaftler werden massiv kritisiert, allen voran Jan Georg Schneider, der aufgrund seiner Kritik der Argumentation des VDS in den Fokus gerückt ist. Diesem wird „Gelehrte Anglizismenblindheit“ vorgeworfen (vgl. Schrammen 2009: 86ff.). Auch Briefwechsel zwischen Firmen und dem Verein finden sich in dieser Textsammlung. ${ }^{505}$

Bei den Publikationen handelt es sich größtenteils um laienlinguistische Darstellungen. Einige davon, so beispielsweise Krämers „Modern Talking“ haben einen gewissen Unterhaltungswert, andere, so Adens „Deutsch und Englisch“, fallen vor allem durch fachliche Fehler auf. Generell ist, wie in allen Publikationen des VDS, der Ton oft polemisch, vereinzelt sogar deutschnational. Diese Bücher, davon zeugen schon zahlreiche Neuauflagen, erzielen zum Teil sehr gute Verkaufserfolge. Sie treffen wohl genau die Stimmung der Zeit, bringen den VDS in die Diskussion und sind so als ein nicht unwesentlicher Teil der Öffentlichkeitsarbeit des Vereins zu werten (vgl. auch Spitzmüller 2005: 123).

\subsubsection{Aktionen}

Der VDS schaltet mitunter Anzeigen in Tageszeitungen, z.B. in der FAZ, erstmals am 7. Januar $1998^{506}$, oder im Schlesier im Jahr $1997^{507}$. Die Anzeige in der FAZ bewirkte viele Reaktionen aus der Bevölkerung und einen ersten größeren Mitgliederzuwachs. Am 7. Mai 1998 erschien

\footnotetext{
${ }^{505}$ Erstaunlicherweise ist auch abermals ein Text des brasilianischen Schriftstellers Zé do Rock abgedruckt, der mit seinem speziellen und vereinfachten Deutsch beim VDS offensichtlich nicht aneckt (vgl. Rock 2009: 91ff.).

${ }^{506}$ Aus einem Schreiben von Walter Krämer an einen Journalisten des Bayerischen Rundfunks geht hervor: „Vor allem die beiliegende Annonce aus der FAZ hat einen RiesenWirbel ausgelöst (seit zwei Tagen werden wir von Post überschwemmt). Ganz offensichtlich hat diese Aktion einen Nerv getroffen [...]. (Brief von Walter Krämer an einen BRJournalisten, 9. Januar 1998)

${ }^{507}$ Dies geht u.a. hervor aus einem Schreiben von einem Mitglied des Bundes für deutsche Schrift und Sprache, das den VWDS fragt, ob es nicht sinnvoller wäre, den BfdS zu unterstützen anstatt die Kräfte zu zersplittern (Brief eines BfdS-Mitglieds an den VWDS, 22. Januar 1997).
} 
noch einmal eine Anzeige in der FAZ (VWDS 1998f: 19), in der der VDS die Telekom für ihre neuen Begriffe angreift, daraufhin treten zahlreiche Bürger dem Verein bei (vgl. Kapitel 2.4.2). Auch in Zeitschriften schaltet der VDS Anzeigen, vor allem in der Anfangszeit waren diese zahlreich. ${ }^{508}$

Im August 2002 erstellte der VDS einen Fragebogen an Parteien zur Bundestagswahl 2002, Thema: „Sprache im 3. Jahrtausend“. Dieser enthält sechs Fragen, zur Einstellung gegenüber der Sprachkompetenz, zum Deutschen als Wissenschaftssprache, zum sprachlichen Verbraucherschutz, zu einem Deutschen Sprachrat, zur deutschen Sprache als Amtssprache der EU und zur Sprachloyalität. ${ }^{509}$ Ersteller des Fragebogens war Hermann H. Dieter. 255 der 570 angeschriebenen Bundestagskandidatinnen und -kandidaten beantworteten die Fragen zur Bundestagswahl, 82 antworteten im Sinne des VDS, einige dieser Befragten waren SPD-Abgeordnete, am meisten Zustimmung erfuhr der VDS bei der CDU. Die Politiker der Grünen reagierten nicht, nur Politiker der FDP und der Statt-Partei können sich eine Akademie zur Sprachpflege

\footnotetext{
${ }^{508}$ Beispielsweise wird im Protokoll der VWDS-Vorstandssitzung vom 10. September 1998 über Anzeigen in der Deutschen Apotheker Zeitung, in der Ärzte-Zeitung, in der Süddeutschen Zeitung, in der Frankfurter Allgemeinen Zeitung, in den Ruhr-Nachrichten, in der Frankenpost, in der Schlaraffenzeitung, im Prümer Landboten, im Darmstädter Echo, in der Zeitschrift Der Monat, im Münchner Merkur und in der Zeitung Fach und Führung berichtet. Einige dieser Anzeigen waren kostenlos, bei Anzeigen in Tageszeitungen bekam der Verein immer wieder Rabatte (vgl. u.a. Protokoll der VWDS-Vorstandssitzung vom 8. Juli 1998). Wie viele Anzeigen es genau waren, ist nicht mehr feststellbar, in Tageszeitungen waren es nach Angaben der Geschäftsstelle ungefähr zehn Anzeigen im Laufe der Jahre (Brief von Holger Klatte, VDS-Geschäftsführer, an die Verfasserin, 7. Januar 2009).

${ }^{509}$ Darunter unter anderem:

„1. Wie würden Sie den Deutschunterricht an den Schulen in Zukunft gewichten?“ Die Antwortmöglichkeiten sind folgende: „Die mangelhafte Sprachkompetenz im Deutschen stellt ein nur nebensächliches Bildungsdefizit unserer Schüler dar. Viel wichtiger wäre es, ihre Sprachkompetenz im Englischen zu stärken.“

„Von der Stärkung des Deutschunterrichts erwarte ich keine Verbesserung, denn die Ursachen für die mangelhafte Sprachkompetenz unserer Schüler im Deutschen liegen woanders."

„Ich werde mich in meinem Bundesland dafür einsetzen, daß Deutsch bis zum Abitur Pflichtfach bleibt und nach landes- oder bundesweit einheitlichen Kriterien geprüft wird.“ Schon bei der ersten Frage zeigt sich die Problematik des Fragebogens. Durch die beschränkte Anzahl von Antwortmöglichkeiten und deren Formulierung wird der Befragte in seiner Antwort stark eingeschränkt und beeinflusst, die Antwortmöglichkeiten sind suggestiv (vgl. zu dieser Einschätzung auch Pfalzgraf 2008: 457).
} 
vorstellen (vgl. u.a. Dieter 2000b: 6). Die gleiche Aktion führte der VDS noch einmal zur Wahl des 15. Niedersächsischen Landtags durch, hier beantworteten Politiker aus allen Parteien im Landtag die Fragen, Zustimmung fanden die Positionen des VDS bei Politikerinnen und Politikern der CDU und der FDP, am meisten Ablehnung bei der SPD und Bündnis90/Die Grünen. Die Fragebögen hatten eine Rücklaufquote von 19,11 Prozent, insgesamt ergab sich eine Ablehnung von Maßnahmen wie der Zubilligung einer sprachlichen Leitkompetenz an den Staat durch einen Sprachrat. Der VDS wertet dies „als fehlenden politischen Mut, einer kleinen Schar von Sprachpanschern in Wirtschaft und Werbung, in Gesellschaft und Medien beherzt entgegenzutreten“510 (Auswertung der Fragen zur Wahl des 15. Niedersächsischen Landtags, Januar 2003, veröffentlicht auch in den Sprachnachrichten, Ambros/Neemann 2003: 2). Zu Politikern, die sich zustimmend geäußert haben, möchten die Mitglieder des VDS in Zukunft den Kontakt besonders pflegen (vgl. Ambros/Neemann 2003: 2). Wahlprüfsteine wurden auch vor der Bundestagswahl 2006 durchgeführt, diesmal war jedoch die Beteiligung der angeschriebenen Kandidaten wesentlich geringer als vor der Wahl im Jahr 2002 (Dieter 2005: 7). Zwischenzeitlich gab es Überlegungen im VDS, von den Wahlprüfsteinen wieder abzukommen, denn man fürchtete, die politische Neutralität des Vereins in Frage zu stellen (Pogarell 2007d: 19). Im Jahr 2008 wurde die Aktion Wahlprüfsteine abermals durchgeführt, und zwar in Hamburg (vgl. SN 2008a: 11). Ob und inwieweit der VDS damit in der Politik etwas bewegt hat, ist in Frage zu stellen, in jedem Fall hat er sich mit diesen Aktionen aber in die Medien gebracht (vgl. VDS 2002a sowie Spitzmüller 2005: 137).

Der VDS führt in unregelmäßigen Abständen auch „Sprachtests“ durch. Dabei werden Publikationen verschiedener Branchen untersucht, beispielsweise Versandhauskataloge nach dem Vorkommen von englischen Begriffen analysiert. Es wurden fünf Bewertungskriterien festgelegt: Das erste ist die „Begrüßung“, darunter werden der Name des Katalogs, das Deckblatt und die Umschlagseiten verstanden. Zweites Kriterium ist der Bereich „Produkte“, hierunter sind die Bezeichnungen für Produktli-

${ }^{510}$ Dies ist eine der möglichen Interpretationen. Eventuell sehen die Abgeordneten aber auch einfach keine Notwendigkeit einer Zubilligung einer sprachpolitischen Leitkompetenz an den Staat. 
nien und -kategorien einzuordnen. Drittes Kriterium ist die „Anpreisung“, also Werbesprüche und ähnliches. Vierte Kategorie ist „Sonstiges“, ein Auffangbecken für auffällige Anglizismen, und fünfte Kategorie „Aktionen“, sofern welche stattfanden. Für die Aktion „Happy Preis“ zum Beispiel bekommt der Otto-Katalog zwei Minuszeichen in der Tabelle. Er ist das Schlusslicht des Sprachtests, mit Begriffen wie „Highlights“ und „Fashion Hits“ in der Kategorie „Begrüßung“. Spitzenreiter der Auswertung ist der Katalog von „Manufactum“, in dem zwar Begriffe wie „E-Mail“ und „Homepage“ vorkommen, der aber gleichzeitig das „Anschwellen der idiotischen Apostrophenflut“ anprangert (vgl. Hahn/Dieter 2001: 10). Diese Sprachtests folgen keinerlei empirischen Vorgehensweisen, sie liefern keine repräsentativen Ergebnisse, sondern stellen nur eine Momentaufnahme dar. Dabei verfolgt der Verein mit den Sprachtests keinerlei wissenschaftlichen Anspruch:

Auch der Verein will Sprachtests unternehmen, natürlich nicht in Form wissenschaftlicher Untersuchungen - er will sich lediglich darum bemühen, beispielsweise die außer Rand und Band geratene Sprache der Sportreporter, die Sprache der Fernsehzeitschriften oder der Krankenkassen und ihrer Mitgliederzeitschriften zu kennzeichnen und zu kritisieren, und zwar nach dem Vorbild der Stiftung Warentest (Hensel 1999: 101).

Diese stichprobenartigen Sprachtests ${ }^{511}$ führt der VDS gerne zur Bestätigung seiner Thesen an. Publiziert werden die Ergebnisse unter anderem in den Sprachnachrichten (vgl. u.a. Hahn/Dieter 2001: 10, Pfützner 2002: 8) und auf der Homepage des Vereins unter Aktion Sprachtest (VDS 2008n).

VDS-Mitglieder, allen voran Vorstandsmitglied Manfred Schroeder, unternehmen immer wieder Reisen ins Ausland, um dort Mitglieder zu werben, teils mit großem Erfolg. Um neue Mitglieder anzuwerben hat sich Schroeder in seiner Eigenschaft als "Außenminister" des Vereins bisher auf zahlreiche Vortragsreisen, unter anderem nach Russland ${ }^{512}$ (vgl. Schrammen 2002: 14), Bulgarien, Georgien, Polen, Tschechien,

511 Ein andermal wurden im „Sprachtest Büromöbel“, 18 Büromöbelgeschäfte hinsichtlich ihrer Werbesprache untersucht. Dabei wurden die Geschäfte, je nach Anzahl der Anglizismen auf ihrer Homepage und in den Werbeprospekten, in unterschiedliche Gruppen eingeteilt, darunter „Vorbildliche Sprachfreunde“ und „Aktive Sprachhunzer“.

512 Dort warb er beispielsweise im Jahr 2002228 Mitglieder. 
Indien oder Kolumbien, begeben (vgl. u. a. Protokoll der VDSVorstandssitzung vom 10. Juni 2005).

Die Arbeitsgruppe „Internationale Deutschlehrer-Initiative“ unter Leitung von Manfred Schroeder hat unter anderem eine Aktion „Offener Brief“ gestartet, dies ist m.E. die einzige größere Aktion dieser Arbeitsgruppe gewesen. Im Bericht des Vorsitzenden heißt es:

Zahlreiche Deutschlehrerverbände und -gruppen haben sich - über die jeweiligen deutschen und österreichischen Botschaften - an die Bundesregierungen, -präsidenten und Landesregierungen gewandt [...]. Stimmen aus dem Ausland haben in Deutschland und Österreich immer eine besondere Wirkung (Schroeder 2002, vgl. auch Grobe 2001: 2$).{ }^{513}$

Wichtiger für den VDS ist aber die Mitgliedschaft im Verein, „sei sie auch nur passiv, den [sic] auch ,Zahlen zählen'“ (Schroeder 2002). Für seine Aktivitäten wird Schröder immer wieder angegriffen, das zeigt die Verteidigung von Krämer aus dem Jahr 2004:

Das ist ein großes Verdienst meines Vorstandskollegen Manfred Schroeder, der letztes Jahr allein in Osteuropa und Zentralasien über 2000 neue Mitglieder für den VDS gewonnen hat. Und ich muß all denen, die darüber die Nase rümpfen, weil die meisten dieser Neumitglieder keinen Beitrag zahlen, hier mal ganz deutlich ins Stammbuch schreiben: Erstens zahlen sehr viele dieser Ausländer, wie etwa unsere ständig wachsende Anhängerschaft in Südkorea, sehr wohl Beitrag, und zweitens ist mir ein Deutschlehrer in Kasachstan, der im Jahr 300 Euro verdient und seinen Landsleuten unter großem Einsatz von Herzblut, Arbeit und Geduld die Werke von Goethe und Schiller näherbringt, erheblich lieber als ein beitragzahlender bundesdeutscher Bedenkenträger, der nur herumnörgelt und sich hauptsächlich damit beschäftigt, andere im Verein von ihrer Arbeit abzuhalten (Krämer 2004d: 24).

Auch Schroeder selbst verteidigt seine Aktivitäten. So gibt er an, dass er die Reisen zu großen Teilen privat finanziere:

Vortragsreisen ins Ausland kosten viel Geld, aber sie belasten den VDS-Haushalt nicht. Sie werden zum Teil durch eine zweckgebundene Spende finanziert, zum größten Teil aber von mir selbst [...]. (Schroeder 2008: 27).

Insgesamt kommen mittlerweile etwa 15000 Mitglieder des VDS aus dem Ausland, das ist etwas weniger als die Hälfte (Pogarell 2007c: 8).

${ }^{513}$ Inwieweit es beispielsweise Reaktionen auf diesen Offenen Brief gegeben hat, geht aus Veröffentlichungen des Vereins m.E. nicht weiter hervor. 
Es gibt regelmäßig Kampagnen der einzelnen Regionalgruppen des VDS, wie die Verleihung von eigenen Sprachpreisen. So gibt es einige Regionalgruppen, die den Preis des regionalen Sprachhunzers verleihen (vgl. Kapitel 2.5.4.4). Eine Aktion einer Regionalgruppe war auch die Versteigerung der deutschen Sprache im Internet bei eBay, bei welcher der VDS die Deutsche Sprache mit folgendem Vermerk zum Verkauf anbot:

\begin{abstract}
Erstklassiges, hoch entwickeltes Sprachsystem mit dem Markennamen Deutsch. Rund 1500 Jahre alt, mit ungefähr 450.000 Wörtern. Sehr nützlich vor allem durch seine weite Verbreitung, hauptsächlich in Europa. Aber das Teil hat durch fahrlässigen Gebrauch vor allem in letzter Zeit einigermaßen gelitten, weist ziemlich viele Anglizismen auf und ist im Ausland wahrscheinlich beliebter als im deutschsprachigen Raum (SN 2003a: 1).
\end{abstract}

Dabei hatte der VDS für den Höchstbietenden eine Urkunde über den symbolischen Besitz der deutschen Sprache ausgelobt. Die Versteigerung hatte mit einem Euro begonnen, der VWL-Student York M. Schneider-May aus St. Gallen hatte zehn Millionen Euro geboten, als eBay die Auktion stoppte (vgl. SN 2003a: 1). Der VDS hatte dadurch große Resonanz in den Medien, beispielsweise berichtete Der Spiegel (Schreiber 2006: 182, vgl. auch den Pressespiegel des Vereins: VDS 2003i).

Die Regionalgruppen starten häufig Kampagnen gegen Anglizismen, so zum Beispiel verschiedene Unterschriftenaktionen. Diese haben teilweise einen konkreten Anlass. Die Unterschriftenaktion des Sprachbündnisses Franken ist als ein Beispiel zu nennen (vgl. Kapitel 1.7.12.1 sowie 2.2.6), ebenso die Unterschriften des gesamten Vereins gegen „Denglisch“. Hier waren erst eine Million (vgl. SN 2001b: 14), dann 200000 Unterschriften geplant (SN 2002b: 2), die in den einzelnen Regionalgruppen gesammelt werden sollten. Letzten Endes waren es zumindest knapp 150000 Unterschriften (genau: 149 631), die in Berlin an die damalige Bundestagsvizepräsidentin Antje Vollmer übergeben wurden. Die Aktion wurden als Massenpetition deklariert und dem Petitionsausschuss des Deutschen Bundestags übersandt. In dem Ausschuss wurde der Antrag „Deutsch als Arbeitssprache auf europäischer Ebene festigen - Verstärkte Förderung von Deutsch als erlernbare Sprache im Ausland“ angenommen, außerdem wurde über eine Musikquote diskutiert. Letzten Endes sah der Petitionsausschuss aber keine Veranlassung, 
ein Gesetz zum Schutz der deutschen Sprache, ${ }^{514}$ eine Verankerung der deutschen Sprache im Grundgesetz oder eine Musikquote vorzuschlagen. Beim VDS war man über das „[magere] Ergebnis“ der wohl bisher größten Unterschriftenaktion der Vereinsgeschichte enttäuscht (vgl. u.a. SN 2003i: 20, Tietz 2003: 15, Kieselbach 2004a: 10, Kieselbach 2007b: 8). Ein weiteres Beispiel: Die Region Wiesbaden sammelte im Jahr 2002 eine Reihe von Unterschriften gegen die Anglizismen in Wiesbadener Tageszeitungen und übergab sie an die Zeitungshäuser (vgl. Rundschreiben eines VDS-Vorstandsmitglieds an die VDS-Regionalvorsitzenden, Ende März 2002).

Unterschriftenaktionen des VDS haben nicht immer etwas mit Anglizismen zu tun: Zum Beispiel wurden die Mitglieder der Regionen auch aufgefordert, für die Verankerung des Deutschen im Grundgesetz Unterschriften zu sammeln. Die Unterschriftenlisten wurden an Abgeordnete vor Ort übergeben (vgl. Kieselbach 2005a: 28). Insgesamt 4544 Unterschriften wurden 2007 beispielsweise von Kurt Gawlitta, Region Berlin/Potsdam, an die Berliner Bundestagsabgeordnete und Kulturexpertin der CDU, Monika Grütters, übergeben (vgl. Schomaker 2007: 34, vgl. auch Kapitel 2.3.2). Unterstützt hatten diese Aktion beispielsweise der niedersächsische Wirtschaftsminister Walter Hirche (vgl. Zick 2005b: 23), ebenso Markus Söder (CSU) und Norbert Lammert (CDU) (vgl. SN 2006e: 6). Mittlerweile hat die CDU diesen Vorschlag des VDS aufgegriffen (vgl. Fried 2008: 5, vgl. dazu auch Kapitel 1.6.3), was der VDS mit den Worten „CDU folgt dem VDS“ kommentiert (VDS 20081). ${ }^{515}$ Ebenso gab es zahlreiche Unterschriftenaktionen für mehr Deutsch in der EU, also für eine Stärkung von Deutsch als Arbeitssprache (vgl. u.a. Zick 2005a: 22). ${ }^{516}$ Auch Schüler wurden vom VDS schon zum Mitmachen

\footnotetext{
${ }^{514}$ Dies ist ein Beispiel dafür, dass es beim VDS lange keine einheitliche Linie gab, ob ein Sprachschutzgesetz gefordert wird oder nicht.

515 Es gab zudem eine weitere Unterschriftenaktion des VDS zum Thema „Deutsch ins Grundgesetz“, gemeinsam mit dem Verband für deutsche Kulturbeziehungen im Ausland (vgl. SN 2008d: 2), bisher jedoch ohne großen Erfolg.

${ }^{516}$ Die Unterschriftenliste für eine Musikquote in deutschen Radiosendern unterschrieben 600 deutsche Musiker, neben Reinhard Mey beispielsweise auch Xavier Naidoo und 2RAUMWOHNUNG (vgl. Akstinat 2004: 2). Diese hat bisher nicht den vom VDS erhofften Erfolg gebracht.
} 
bei Unterschriftenaktionen animiert, ${ }^{517}$ beispielsweise wurden in Delbrück Elfjährige während ihres Unterrichts auf die Straße geschickt, die 802 Unterschriften für den VDS sammelten (vgl. SN 2002f: 6). ${ }^{518}$

Ein Zeichen reger Vereinsarbeit war auch der Aufruhr, den der VDS veranstaltete, als die Stadt Frankfurt im Jahr 1999 überlegte, sich „The city of the Euro" zu nennen. ${ }^{519}$ Der öffentliche Protest des VDS stieß in den Medien auf große Resonanz. Darüber berichtete unter anderem Der Spiegel unter der Überschrift „The City of the Äppelwoi“, wobei die Überschrift die Sympathie mit dem Verein deutlich macht (Der Spiegel 1999: 20). ${ }^{520}$ Auch in der Überschrift einer dpa-Meldung in der $S Z$ vom 27. Januar 1999 zeigt sich dies: „Se sitty of se juro“ (dpa 1999: 12). Nicht immer wurde das Ansinnen des VDS in der Berichterstattung ernst genommen, so in dem Artikel "Jeanne d Arc kam in den Römer“ [gemeint ist Ilona Waldera, zu der Zeit die Pressesprecherin des VDS] in der Frankfurter Neuen Presse (mhs 1999: 14). Und FAZ-Autor Peter Badenhop kommentiert: „solch provinzielles Spektakel und mehr oder weniger politisches Gerangel und Gezanke“ [gemeint ist der Streit um „City of the Euro“, Anm. d. Verf.) (Badenhop 1999: 58). ${ }^{521}$ Doch trotz aller Protestaktionen wird die Stadt Frankfurt häufig als "City of the Euro“ aufgeführt, so zum Beispiel auf Internetseiten des hessischen Wirtschaftsministeriums über den Finanzplatz Frankfurt (vgl. z.B. Hessisches Ministerium für Wirtschaft, Verkehr und Landesentwicklung 2008). Im Rahmen dieser Image-Kampagne gab es sogar Poststempel mit der Aufschrift „City of the Euro“ (vgl. Hutter 2002: 16). Dies zeigt,

\footnotetext{
${ }^{517}$ In der Regel durch Lehrer, die VDS-Mitglieder sind.

${ }^{518}$ Dies ist kritisch zu sehen, da es fraglich ist, ob man Minderjährige so instrumentalisieren sollte.

${ }^{519}$ Krämer hatte sich auch an ein Mitglied des Bundestags gewandt, dieses sah aber „keinen aktuellen Ansatzpunkt, um die Anliegen Ihres Vereins im Kulturausschuß des Deutschen Bundestags zu behandeln“ (Brief eines Mitglieds des Bundestags an Walter Krämer, 5. März 1999).

${ }^{520}$ Eine Stichwortsuche im CD-Rom-Archiv des Spiegels ergab für die Jahre 1994 bis 2005, dass Walter Krämer zwar des öfteren im Spiegel auftauchte, aber fast immer als Statistiker und nur einmal in seiner Eigenschaft als Vorsitzender des VDS, in: „The City of the Äppelwoi“ (Der Spiegel 1999: 20).

${ }^{521}$ Kritisch äußerte sich auch der Autor Martin Zips in der Süddeutschen Zeitung (Zips 1999: 12).
} 
dass es zwar zu massiven Protesten kam, diese aber nichts geändert haben.

Die Mitglieder von VDS-Regionalgruppen starten hin und wieder auch Protestaktionen: Im Jahr 2003 haben VDS-Mitglieder bei der Frühjahrstagung der Deutschen Physikalischen Gesellschaft in Kiel protestiert. Daraufhin wurden auf der Tagung von zehn Plenarvorträgen, von denen fünf auf Englisch angekündigt waren, nur drei auf Englisch und die meisten Hauptvorträge auf Deutsch gehalten (vgl. dazu Voslamber 2004: 13). Diese rege Vereinsarbeit der Regionalgruppen bringt den VDS immer wieder in die regionalen Medien.

VDS-Mitglieder werden regelmäßig aufgerufen, Geschäfte und Produkte, die „witzige, spritzige, treffende deutsche Namen“ tragen, zu fotografieren (vgl. Däßler 2005: 27). Die Fotos werden in den Sprachnachrichten und einige zudem in einem kleinen Buch veröffentlicht (vgl. Däßler/Tietz 2005). Aber nicht nur dem VDS in ihrer Sprachwahl positiv auffallende Geschäfte werden vom Verein bedacht: Der VDS hat Aufkleber produzieren lassen, die normalerweise an Infoständen verteilt oder an Mitglieder verschickt werden, diese kleben die Aufkleber beispielsweise auf Plakate, auf denen auf „Denglisch“ geworben wird (vgl. Vilmar 2002a: 31). Auf diesen Aufklebern steht: „Der Klügere spricht Deutsch“, 522 „Europa ist unser Haus - Deutsch ist unsere Sprache“, „Ich bin der Größte! Ich kann Denglisch“ und „Die USA-Massenverblödung, die in Deutschland immer mehr um sich greift, ist eine der schlimmsten Kriegsfolgen. Albert Schweitzer“, „...wir sprechen auch deutsch.“ und „Stoppt die Amerikanisierung unserer Sprache und Kultur“" 523

Der letztgenannte Aufkleber wurde bereits intern heftig diskutiert: „Ebenso UNfröhlich ist der „Stoppt...“-Aufkleber, der ist doch NUR aggressiv!!“524 (E-Mail eines VDS-Vorstandsmitglieds an die Vorstandskol-

\footnotetext{
${ }^{522}$ An einem Infostand auf der Leipziger Buchmesse im Jahr 2005 verteilte der VDS davon ungefähr 600 Stück (vgl. Mindner 2005: 20).

${ }^{523}$ Vgl. dazu auch Maercker (2006: 229).

${ }^{524}$ Hervorhebungen im Original. Die Aufkleber hat die Verfasserin im Jahr 2004 aus verschiedenen Kisten im Archiv des VDS zusammengesammelt, es wurden also soweit möglich in einer Vollerhebung alle Aufkleber, die der Verfasserin zugänglich waren, betrachtet. Aus den Sprach-Nachrichten geht hervor, dass es zudem einen Aufkleber zum Europäischen Jahr der Sprachen gegeben hat (vgl. SN 2001e: 9). Dieser war aber nicht mehr vor-
} 
legen, 4. Februar 2003), dennoch wurden sie, wohl auf Wunsch Krämers, der die Kritik auch in den Sprachnachrichten abschmetterte, produziert und verteilt:

Einige Mitstreiter meinen, dieser Aufkleber wäre antiamerikanisch. Wenn sie damit meinen, daß wir uns mit diesem Aufkleber gegen die zwangsweise Einführung des „American Way of Life“ im Rest der Erde wehren wollen, dann haben sie recht. (Krämer 2003a: 2).

Krämers Kommentar in den Sprachnachrichten und der Aufkleber an sich haben eine heftige Debatte im VDS ausgelöst, beides erfuhr viel Zustimmung, ${ }^{525}$ aber auch sehr viel Ablehnung, einige Mitglieder traten in Folge aus dem VDS aus, da sie den Aufkleber und/oder Krämers Editorial als amerikafeindlich auffassten (vgl. SN 2003k: 13)

In Erfurt fand eine heftig kritisierte Aufkleberaktion statt. Mitglieder des VDS klebten die roten Aufkleber mit der schwarzen Schrift: „...wir sprechen auch deutsch." auf Geschäfte:

Das fällt auch bei der Erfurter Aktion (Anbringung roter Klebestreifen: Wir sprechen auch Deutsch durch VDS-Mitglieder, J.S.) auf. Sowohl die Inszenierung als auch die Botschaft [...] erinnern in frappierender Weise an ein prekäres Ereignis aus der jüngeren Geschichte: den nationalsozialistischen Boykott vom 1.- 3. April 1933. Diese Kombination, die [...] wohl auch intendiert ist, impliziert diese Stigmatisierung der betreffenden Sprachbenutzer und die daraus zu interpretierende Aufforderung, entsprechende Geschäfte zu boykottieren. [...] (Spitzmüller 2002: 254f.)

Spitzmüller hebt hervor, die Aktion zeige „mangelnde Sensibilität eines Vereins, der kulturelles Bewusstsein fördern will, gegenüber der Geschichte dieser Kultur" (Spitzmüller 2002: 261). ${ }^{526}$

Für seine Kritik wurde Spitzmüller selbst angegriffen:

Um die Dringlichkeit eines Problems zu unterstreichen, werden die rhetorischen Mittel der Übertreibung sowie der Zuspitzung im Sinne der Provokation eingesetzt. Dabei besteht erfahrungsgemäß die Gefahr, dass Übertreibungen und Zuspitzungen nicht als Provokation verstanden werden. Auch sind Kränkungen und Verletzungen der angegriffenen Personen und Institutionen nicht ausgeschlossen. In

handen. Mittlerweile sind fast alle Aufkleber verteilt, in der Geschäftsstelle gibt es nur noch wenige Exemplare des Aufklebers „...wir sprechen auch deutsch.“.

${ }^{525}$ Laut einer E-Mail eines Vorstandsmitglieds an die Kollegen war dies der Aufkleber, der bei der Bevölkerung, beispielsweise bei Infoständen, den größten Erfolg hatte (vgl. E-Mail eines Vorstandsmitglieds an die Vorstandskollegen, im Anhang der E-Mail vom 4. Februar 2003).

${ }^{526}$ Gemeint ist die Geschichte des Landes. 
diesen Fällen heiligt der Zweck die Mittel, die natürlich fortfallen, wenn der Zweck erreicht ist (Zabel 2001b: 279f.).

M.E. hat Zabel mit dieser Einschätzung nicht recht. ${ }^{527}$ Sobald Personen beleidigt werden oder sich massiv angegriffen fühlen, sind der Verein oder dessen einzelne Mitstreiter zu weit gegangen. Aber nicht nur Spitzmüller kritisierte das Vorhaben, auch VDS-Mitglieder waren mit der Aktion nicht einverstanden, wie eine Stimme aus dem VDS-Forum zeigt:

Ja, das ist ja wohl das allerletzte [...]. Da könnte auch >Kauft nicht bei Sprachpanschern< draufstehen und es würd' noch keinem auffallen. Wirklich, ich bin der letzte, der dauernd mit Nazianalogien um die Ecke kommt, aber irgendwo ist auch meine Grenze erreicht (zitiert nach Spitzmüller 2002: 259).

Ebenso ist man in der Bundeszentrale des VDS nicht glücklich über solche Aktionen. Zwar könne man jedes Mitglied verstehen, das sich über das Sprachgebaren von Geschäften ärgert, und begrüße, wenn dieser Sprachgebrauch kritisiert wird, doch müsse dies im Rahmen der Gesetze getan werden, der Ton solle höflich bleiben und es solle sachlich argumentiert werden. Mittlerweile wurde die Produktion dieser Aufkleber eingestellt, die Aufkleber, die noch vorhanden sind, werden aber noch verteilt. ${ }^{528}$

In den Vereinsnachrichten des VDS wurden gerade in den Anfangsjahren immer wieder Boykott-Aufrufe veröffentlicht (vgl. Kapitel 2.5.1.4) und der VDS Leipzig rief auf seinen Internetseiten zum Boykott von Waren mit englischen Begriffen auf:

Wir werden bevorzugt solche Waren kaufen, die in deutscher Sprache ausgezeichnet sind und für die in deutscher Sprache geworben wird [und] wirken auf unsere Umgebung ein, sich im gleichen Sinne zu verhalten (VDS Region Leipzig 2005).

Mittlerweile ist dieser Aufruf von den Internetseiten verschwunden, auch in den Sprachnachrichten ist in jüngerer Zeit kein Boykott-Aufruf mehr aufgetaucht, was darauf hindeutet, dass man seitens des Vereins mit solchen Aufrufen vorsichtiger geworden ist (VDS Region Leipzig 2008).

${ }^{527}$ Auch wenn Zabel kein Funktionär des VDS war, bleibt zu bedenken, dass diese Publikation im Auftrag des VDS entstanden ist.

${ }^{528}$ Gespräch mit Holger Klatte, VDS-Geschäftsführer, 28. November 2008. 
Der VDS hat zudem zahlreiche Plakate drucken lassen, unter anderem eines mit einem Abdruck der Rede des damaligen Bundespräsidenten Johannes Rau (vgl. Kapitel 1.6.3), oder eines mit dem Informatiker Josef Weizenbaum, der darauf hinwies, dass man in seiner Muttersprache am besten denken könne (vgl. SN 2001e: 9).

Der VDS ist auch auf der Frankfurter Buchmesse vertreten, um dort auf seine Belange aufmerksam zu machen. Immer wieder wirbt er in Fußgängerzonen für sein Anliegen. Weiteres Engagement des VDS sind Projekte an Schulen: So erstellte der Leistungskurs Deutsch der Gesamtschule Horn eine Liste von Anglizismen unter dem Motto: „Deutsch-englische und andere Bastarde nötigen zu einem ständigen Codewechsel“ (vgl. Stilkenboom 2000: 4, vgl. auch Kapitel 2.2.3). Im Kreis Steinfurt in Nordrhein-Westfalen beispielsweise veranstalteten Landkreis und VDS einen Sprachwettbewerb für die 5. und 6. Klassen der Hauptschulen im Kreis. Die Schüler waren aufgerufen, sich als "Sprachdetektive“ zu betätigen, eine Aktion, die von den regionalen Medien begleitet wurde (vgl. z.B. Bischof 2005: 1f.). Ähnliche Aktionen gab es auch in anderen Landkreisen. Dennoch haben die Mitglieder des VDS Schwierigkeiten, ihr Anliegen in den Schulen so darzustellen, dass sich Schüler und Lehrer dafür interessieren (vgl. z.B. Hornhardt 2003: 14).

Ein weiteres Beispiel einer Aktion des VDS ist der satirisch gemeinte Antrag an die Stadt Köln, diese in "Cologne“ umzubenennen. Im Anschreiben heißt es: „da neben immer mehr Unternehmen und Veranstaltern mittlerweile auch offizielle städtische Stellen - bzw. der Stadt nahestehende Einrichtungen - vermehrt dazu übergehen, den ,zeitgemäßen' Namen Cologne anstatt des alten für ihre Stadt zu verwenden, finden wir, daß es nun an der Zeit ist, daraus die nötigen Konsequenzen zu ziehen“ (Kinder 2002: 1, Dokument 21). ${ }^{529}$ Denn, so heißt es weiter: „Zeugt es nicht von einer geradezu einmaliger [sic] Weltläufigkeit, nicht länger der eigenen Bevölkerung kölntümelnd nach dem Mund zu reden und nun endlich so zu heißen, wie die Angloamerikaner einen heißen?“ (Kinder 2002: 1). Auch diese Aktion brachte den VDS in die Schlagzeilen

${ }^{529}$ Dieser Antrag ging auch an den Kölner Stadtanzeiger, an die Kölnische Rundschau, den Kölner Express sowie Bild Köln. 
(vgl. VDS 2002a), ebenso wie die Aufregung, die der VDS um eine Werbekampagne der Berliner Stadtreinigung im Jahr 1999 und gegen deren Slogans wie "We kehr for you“530 und "Come to where the Eimer is" verursachte. Spitzmüller verweist darauf, dass die Werbeagentur mit der Kritik sehr gut leben konnte, da sie schnell einen hohen Bekanntheitsgrad erlangte, und dass dieser Effekt wohl auch beabsichtigt war. Er sieht darin, dass die Werbebranche den Diskurs aufgreift und imitiert, eine neue Dimension der Anglizismendebatte (vgl. Spitzmüller 2005: 125).

In Prozessen hat der VDS in der Vergangenheit Mitglieder unterstützt, so Peter Vogelgesang bei seiner Klage gegen die Lufthansa Technik AG. ${ }^{531}$ Der Kläger hatte sich geweigert, während seiner Arbeitszeit die im Unternehmen üblichen englischen Ausdrücke zu verwenden. Ein Beispiel: anstatt „engine“ verwendete er konsequent „Triebwerk“. Daraufhin wurde er von der Lufthansa Technik AG erst ermahnt und schließlich abgemahnt. ${ }^{532}$ Den anschließenden Rechtsstreit vor dem Arbeitsgericht Frankfurt um Entfernung der Ermahnung und der Abmahnung aus seiner Personalakte hat Vogelgesang verloren. Der Fall ging in die Berufung, Vogelgesang verlor abermals. ${ }^{533}$ Der VDS brachte den Fall in die Berichterstattung, wie der Blick in den Pressespiegel in den Jahren 1998 und 1999 zeigt (vgl. VWDS 1998b, VWDS 1999c, vgl. auch Spitzmüller 2005: 125). In den Medien stieß der Fall auf unterschiedliche Reaktionen. Die meisten Berichte waren neutral (vgl. u.a. Der Spiegel 1998b: 135, Süddeutsche Zeitung 1999: 12, Bettermann 1999: 192ff.). Vogelgesang wurde aber auch kritisiert (vgl. Geissler 1998: $9^{534}$ ), so in Leserbriefen (vgl. u.a. Leserbrief von Winfried Gaumitz in

\footnotetext{
${ }^{530}$ Anstatt „we care for you“ und „come to where the flavour is“, dem bekannten Spruch der Marlboro-Kampagnen.

${ }^{531}$ Vgl. dazu unter anderem die Sprachnachrichten: „Der Vorstand des Vereins zur Wahrung der deutschen Sprache wird Herrn Vogelgesang in seinem berechtigten Arbeitskampf gegen seinen Arbeitgeber, die Lufthansa Technik AG, unterstützen“ (Schäferhoff 1999: 6).

${ }^{532}$ Vgl. z.B. den Brief von Peter Vogelgesang an den VDS vom 29. September 1998.

${ }^{533}$ Vgl. die Berufungsbegründung der Anwälte des Klägers an das Landesarbeitsgericht Frankfurt, 5. August 1999.

${ }^{534}$ Wobei Geissler stets fälschlicherweise von der „Gesellschaft zur Wahrung der deutschen Sprache“ schreibt (vgl. Geissler 1998: 9).
} 
der FAZ vom 14. November 1998, in dem das Unverständnis über Vogelgesangs Verhalten deutlich zur Sprache kommt).

Ein anderes Beispiel ist die Unterstützung eines Mannes, der sich mit der Telekom vor Gericht traf: Er hatte die Rechnungen von der Telekom, in der Begriffe wie "CityCall“ auftauchen, in englischer Währung bezahlt (vgl. dazu Hensel 1999: 98f.). Auch dies war in den Medien eine vielbeachtete Aktion (vgl. VWDS 1999c). Spitzmüller verweist darauf, dass die Tarifreform der Deutschen Telekom vehemente Proteste und einiges Echo in den Medien hervorrief, unter anderem in der Süddeutschen Zeitung (Süddeutsche Zeitung 1998b: 12) und in Die Welt (Die Welt 1998: 12) (vgl. Spitzmüller 2005: 124). Fälle dieser Art kommen aber in der Vereinsarbeit nur selten vor.

Seit 2005 gibt es eine weitere Aktion des VDS, die Wortpatenschaften. Im Internet ${ }^{535}$ kann jeder die Patenschaft für ein bestimmtes deutsches Wort übernehmen:

Die Öffentlichkeit ist aufgerufen, einzelne Wörter per Mausklick in Patenschaft zu nehmen, und sich dann für den gepflegten Umgang mit dem Wort einzusetzen, es vor Verdrängung zu behüten, es häufig zu benutzen (VDS 2005f: 6).

Im Jahr 2006 wurde zunächst die 2000. Wortpatenschaft, dann die 4000. Wortpatenschaft vergeben (vgl. VDS 2006c, VDS 2006d). Dies zeigt, wie schnell diese Aktion einen gewissen Bekanntheitsgrad erlangte. Wortpatenschaften kann man aber auch gewinnen, wenn man bei Rätseln des VDS mitmacht (vgl. SN 2006f: 27). Prominente befinden sich ebenfalls unter den Wortpaten, so ist beispielsweise Ulrich Wickert Pate für das Wort „Freiheit“. Auch Iris Berben oder der CDU-Europaabgeordnete Thomas Mann sind Wortpaten (vgl. Mindner 2006b: 8). Kritisiert wurden die Wortpatenschaften beispielsweise von der taz, die schrieb, dass damit „aus Scheiße Geld“ gemacht würde (vgl. Rosenkranz 2006: 4). Bei den Wortpatenschaften handelt es sich um eine kommerzielle Aktion, von der der VDS sich mittlerweile distanziert. Die Einnahmen (in der Regel 10 Euro pro Wortpatenschaft) gehen an die Agentur medfux des ehemaligen Pressesprechers des VDS, Tobias Mindner. ${ }^{536}$

535 Unter www.wortpatenschaften.de, www.wortpatenschaften.at oder www.wortpatenschaften.ch.

${ }^{536}$ Gespräch mit Holger Klatte, Geschäftsführer des VDS, 28. November 2008. 


\subsubsection{Tag der deutschen Sprache}

Die im vorangehenden Abschnitt vorgestellten Aktionen waren meist Einzelaktionen. Hier soll ein Ereignis vorgestellt werden, das jährlich stattfindet und aus vielen Aktionen in den Regionen besteht: 2001 hat der Verein den Tag der deutschen Sprache eingeführt. Dieser findet jährlich am zweiten Septembersamstag statt und:

soll bewirken, daß die deutschsprachige Gemeinschaft der derzeitigen Anglomanie und dem Fremdwortgebrauch im weitesten Sinn entgegentritt.

soll den Sinn für die Schönheit und Ausdruckskraft der deutschen Sprache bei allen Bürgern unseres Landes aufbauen und festigen.

soll verhindern, daß sich die kulturellen Schwächephasen aus Vergangenheit und Gegenwart künftig wiederholen.

soll die Bedeutung guter muttersprachlicher Kenntnisse für die internationale Wettbewerbsfähigkeit hervorheben [...].

soll den Willen zur Verständlichkeit in Schrift und Sprache, d.h. den sprachlichen Gemeinsinn, bei den deutschen Bürgern dauerhaft verankern.

soll erreichen, daß wir unsere eigene Sprache schätzen. Nur so wird sie im Ausland, besonders in der EU, ernstgenommen.

soll an die Gleichwertigkeit der deutschen Sprache mit anderen Kultursprachen erinnern (Dey 2004: 46).

Mit verschiedenen Aktionen wie zum Beispiel Dichterlesungen, einem Sprachquiz und der Verleihung von Urkunden für besonders guten Sprachgebrauch auf regionaler Ebene soll der Tag der deutschen Sprache die Bevölkerung auf den derzeitigen Zustand der deutschen Sprache aufmerksam machen. So hat die Stuttgarter Zeitung am 14. September 2002 eine Ausgabe völlig ohne Anglizismen veröffentlicht. ${ }^{537}$ Ein Mitglied aus Weimar hat über Weimar, Erfurt und Arnstadt Postkarten aus einem Ultra-Leicht-Flugzeug abgeworfen, auf denen auf die „Gefahr durch Anglizismen“ hingewiesen wurde (vgl. Dey 2002: 7). Diese Aktionen sind typisch, denn am Tag der deutschen Sprache soll das Anliegen auf sympathische Art und Weise transportiert werden. Krämer fordert: „Hier dürfen wir der Öffentlichkeit auf keinen Fall ein Bild von Eiferern und Sektierern bieten. Stattdessen [...]: fröhliche Aggressivität!“ (Proto-

${ }^{537}$ Dafür wiederum wurde die Stuttgarter Zeitung mit dem Institutionenpreis des Kulturpreises Deutsche Sprache ausgezeichnet (Schrammen 2004: 28), ebenso mit dem Stuttgarter Sprachpreis, einem regionalen Positivpreis der VDS Region Stuttgart (SN 2003d: 15). 
koll der VDS-Vorstandssitzung vom 17. Juli 2002, ebenso beispielsweise Krämer 2004a: 3 sowie Krämer 2007d: 2).

Langfristig wünscht der Verein für den Tag der deutschen Sprache einen Kalendereintrag. Die Medien nehmen regen Anteil am Tag der deutschen Sprache, sowohl die regionalen als auch die überregionalen, viele Reaktionen sind positiv (vgl. z.B. Heringlehner 2004: D1, Natter 2004: 1). Im Jahr 2005 haben erstmals die öffentlich-rechtlichen Rundfunkanstalten eigene Beiträge zum Tag der deutschen Sprache verfasst, so der SWR und der WDR (vgl. VDS 2005d). Diese Tendenz hat sich auch 2006 und 2007 fortgesetzt (VDS 2006h, VDS 2007e). Zudem gibt es seitens des VDS jährlich eine Dokumentation zum Tag der deutschen Sprache, in der die verschiedenen Aktionen der einzelnen Regionalgruppen festgehalten werden (z.B. Dey 2004).

\subsubsection{Preise des VDS}

\subsubsection{Sprachschuster und Sprachpanscher}

Der Preis des Sprachpanschers (vorher: Sprachschuster) ${ }^{538}$ ist ein Negativpreis, der diejenigen „auszeichnet“, die nach Ansicht des VDS ein mit besonders vielen Anglizismen durchsetztes Deutsch verwenden. Die Kandidaten, die für diesen Sprachpreis in Frage kommen, werden in den Sprachnachrichten veröffentlicht, unter der Rubrik „Am Pranger“ (vgl. z.B. SN 2002c: 7). Dabei spricht der VDS selbst von einem "Schmähpreis“ (SN 2003e: 7). Ursprünglich geplant als „Sprachgimpel des Jahres“ (SN 1999a: 3) stieß der Preis des Sprachschusters bzw. Sprachpanschers bald auf öffentliches Interesse, Krämer selbst bezeichnete schon 2002 den Sprachpreis als „einen[n] unserer besten Werbeträger" (Krämer 2002b: 2). Benachrichtigt wird der jeweilige Preisträger durch eine Urkunde, die er per Post zugestellt bekommt (vgl. z.B. VDS 2003a). Vor Einführung des Preises wurde vereinsintern viel über die Variante diskutiert, statt eines Negativpreises einen Positivpreis zu vergeben (vgl. z.B. Protokoll der ersten bundesweiten VWDS-

${ }^{538}$ Zur Umbenennung kam es, da sich die Zunft der Schuhmacher verunglimpft sah (vgl. z.B. Keeve 1998, Spitzmüller 2005: 124). 
Mitgliederversammlung, 24. Oktober 1999). Diese Vorgehensweise hat sich vereinsweit nicht durchgesetzt, ${ }^{539}$ dafür werden aber regional teilweise Positivpreise vergeben (siehe Kapitel 2.5.4.4). Im Jahr 1997 wurde der bundesweite Preis unter dem Namen Sprachschuster verliehen. Bereits im Jahr 1998 erhielt er den Namen Sprachpanscher, (vgl. dazu u.a. Protokoll der VWDS-Vorstandssitzung, 10. September 1998).

1997 erhielt Jil Sander den Sprachschuster, wegen ihrer Zitate in einem Artikel im FAZ-Magazin vom 22. März 1996. Dort wurde die Modeschöpferin folgendermaßen zitiert: „Mein Leben ist eine giving-story. Ich habe verstanden, daß man contemporary sein muß [...]“ (Mosebach 1996: 21ff., Dokument 1). ${ }^{540}$ Die Verleihung des Sprachpanschers an Jil Sander wurde von der regionalen Presse und den überregionalen Zeitungen aufgegriffen und rief ein geteiltes Echo hervor, verschaffte dem Verein aber auch relativ schnell Bekanntheit (vgl. Spitzmüller 2005: 124). Jil Sander wurde später vom VDS sogar für ihre sorgfältige Sprachwahl, beispielsweise in einem Spiegel-Interview und einem Interview mit der Zeitung Die Welt, gelobt (vgl. Klawitta/Tuma 2003: 94ff., Goy/von Taube 2003: 30, SN 2003f: 7).

1998 erhielt Ron Sommer in seiner Eigenschaft als Telekom-Chef den Sprachpanscher, u.a. wegen Ausdrücken wie „Short-Distance-Call“. In der Begründung ist zu lesen: „Durch die unkritische Anpassung an das moderne pseudokosmopolitische Imponiergehabe, mit dem viele Deutsche sich heutzutage den Anschein von Weltläufigkeit zu geben suchen, hat die Deutsche Telekom eine Spitzenstellung an Illoyalität gegenüber unserer Sprache eingenommen“ (VDS 1998a). 1999 war Johannes Ludewig, damaliger Vorstandsvorsitzender der Deutschen Bahn, Sprachpanscher des Jahres. Begriffe wie „service points“ und „ticket counters“ und „db-lounges“ waren ausschlaggebend. Der Verein kritisierte

pseudokosmopolitisches Imponiergehabe der Deutschen Bahn AG als unhöflich und anmaßend gegenüber inländischen und ausländischen Kunden gleichermaßen, die in der Mehrzahl des Englischen

${ }^{539}$ Inzwischen vergibt die Deutsche Sprachwelt einen Positivpreis.

${ }^{540}$ Pfalzgraf schreibt, dass dieses Interview nicht zu bekommen war. Bei der Publikation handelt es sich nicht um ein abgedrucktes Interview, sondern um ein Zitat von Jil Sander, das in einem Artikel über sie verwendet wurde. Erschienen ist der Artikel im FAZ-

Magazin vom 22. März 1996, S. 21ff., im Archiv der FAZ unter dem Schlagwort Jil Sander abzurufen, der Artikel heißt „Jil Sander“, Autor ist Martin Mosebach). 
nicht mächtig sind und sich von dieser fremden Sprache überrumpelt und entmündigt fühlen (vgl. VWDS 1999a). ${ }^{541}$

Professor Andreas Heldrich, der damalige Rektor der LudwigMaximilian-Universität München, war der Sprachpanscher 2000. Ausschlaggebend war die Umgestaltung der Fakultäten, Fachbereiche und Institute zu „departments“542 (VDS 2000a). Im Jahr 2001 wurde Wolfgang $\mathrm{H}$. Zocher, der damalige Vorsitzende des Bundesverbands Deutscher Bestatter e.V., zum Sprachpanscher. Der Grund war die Einführung der Ausbildung zum „funeral master“ (vgl. VDS 2001c).

Sprachpanscher 2002 wurde Dr. Klaus Zumwinkel, der damalige Vorstandsvorsitzende der Deutschen Post. Der VDS kritisiert bei Zumwinkel das „gedankenlose Anbiedern an den amerikanischen Kulturkreis, wie es sich in den postalischen Bezeichnungen [...] Global mail, Mailing Factory, Fulfilment, Stampit, Postage point, Freeway [...] äußert”. Solchen Anglizismengebrauch bewertet der Verein als „einen peinlichen Beweis des Misstrauens gegen unsere eigene Sprache und Kultur" (vgl. VDS 2002b). Hinsichtlich der Reaktion Zumwinkels war in der Zeitung Die Welt zu lesen, dass dieser "schwer beleidigt“ reagiert habe (Glück 2002b: 28).

Sprachpanscher 2003 wurde Gerhard Mayer-Vorfelder, Präsident des Deutschen Fußballbunds. Er wurde nominiert wegen der Anglizismen in der Zeitschrift des DFB, wie „Home \& Away Shirts“ oder "Signature Shirts“ (vgl. VDS 2003a). Dieser bezeichnete die Preisverleihung an ihn als „Witz“ und „reinen Populismus“ (Süddeutsche Zeitung 2003: 1).

Der Sprachpanscher 2004 ging an Markus Schächter in seiner Eigenschaft als Intendant für englische Ausdrücke in Sendungen des ZDF wie „Kiddie Contest“ oder „History“, und „Nightdream“ (vgl. VDS 2004a). Den Sprachpanscher 2005 erhielt Museumsdirektor Professor Herbert Beck, Leiter des Frankfurter Städel-Museums, dafür, dass im Museum Ausdrücke wie „Art after work“ oder „Art Talk for Families“ verwendet werden (vgl. VDS 2005b). 2006 wurde Günther Oettinger, der Ministerpräsident von Baden-Württemberg zum Sprachpanscher ge-

\footnotetext{
${ }^{541}$ Hier urteilt der VDS über die Englischkenntnisse der in- und ausländischen Kunden der Bahn. Eine Studie, die diese Einschätzung untermauert, hat er nicht vorgelegt.

${ }^{542}$ Vgl. den offenen Brief von Walter Krämer an Andreas Heldrich mit der Absage eines Vortrags (25. April 2000).
} 
wählt. Er hatte in einer SWR-Reportage gesagt: „Englisch wird die Arbeitssprache, Deutsch bleibt die Sprache der Familie und der Freizeit, die Sprache, in der man Privates liest" (vgl. VDS 2006a). Oettinger hat nach der Verleihung des Preises an ihn ein Umdenken angekündigt und laut VDS seine Aussage relativiert (vgl. Krämer 2007d: 2) $\cdot{ }^{543}$ Des Weiteren engagiert er sich dafür, Deutsch als Arbeitssprache in der EU $\mathrm{zu}$ stärken (vgl. u.a. Billing 2008, Staatsministerium BadenWürttemberg 2007: 1ff.).

Sprachpanscher 2007 wurde Hartmut Mehdorn, Vorstandsvorsitzender der Deutschen Bahn AG, und damit zum zweiten Mal ein BahnVorstandsvorsitzender. Anstoß genommen wurde an "counter“ statt Schalter, den „service-points“ und „McClean“ (vgl. VDS 2007b).

Zum Sprachpanscher des Jahres 2008 nominiert wurde Klaus Wowereit, Regierender Bürgermeister von Berlin. Dieser hatte zum Tag der Deutschen Einheit Fahnen über dem Brandenburger Tor flattern lassen mit der Aufschrift „Power for peace - Power for unity - Power for understanding“ (VDS 2008k). ${ }^{544}$ Der Sprachpanscher 2009 ging an den Deutschen Turner-Bund für Ausdrücke wie „Feel Well Woman in motion“, „Rent a Star“ und "Champions Trophy“ (VDS 2009b).

Da es sich bei dem Preis um einen Negativpreis handelt, wird dem VDS vorgeworfen, sein Sprachpatriotismus drücke sich „durch öffentliche Verunglimpfung der <Sprachverderber>“545 (Law 2002: 81) aus. Hoberg kritisierte das Attackieren und Diskriminieren von Personen und Institutionen, deren Anglizismengebrauch nicht gefällt, bereits im Jahr 2001 öffentlich (vgl. Hoberg 2001: 301). Stukenbrock verweist darauf, dass die Negativauszeichnungen der Stigmatisierung dienen und denunziatorischen Charakter haben (vgl. Stukenbrock 2005a: 229). Auch in der Presse findet sich diese Kritik zumindest vereinzelt:

\footnotetext{
${ }^{543}$ Eine Presseerklärung und damit eine offizielle Stellungnahme Oettingers gab es zu diesem Thema nicht, dies ergab eine telefonische Anfrage in der Pressestelle der Staatskanzlei am 7. November 2008. In einem Protokoll des VDS-Vorstands ist diesbezüglich verzeichnet, dass Oettinger gegenüber einem VDS-Vorstandsmitglied ein Umdenken angekündigt hatte (Protokoll der VDS-Vorstandssitzung vom 21. Oktober 2006).

${ }^{544}$ Wowereit zeigte sich von dem Preis unbeeindruckt (Gespräch mit Holger Klatte, 28. November 2008).

${ }^{545}$ Hervorhebung im Original.
} 
Durch die Wahl des ,Sprachpanschers des Jahres', bei dem verdienstvolle Persönlichkeiten aufs widerlichste beleidigt werden, stellt sich der VDS zudem außerhalb der sogenannten, guten Sitten' (Büttner 2001).

Ein weiteres Beispiel liefert die Leipziger Volkszeitung:

Sprachschützer wollen Nacht-Bus fahren und nicht ,Night-Liner', Selbsternannte Anwälte des Deutschen vergeben ,Panscher-Preis' für Unternehmen [...] Vor allem, da von der Spitze des 1997 gegründeten Vereins nicht nur unumstrittene Aktionen ausgehen. So hieß der „Sprachpanscher“ im ersten Jahr noch „Sprachschuster“. Da sah sich das Schuhmacherhandwerk verunglimpft. Vereinspräsident Walter Krämer verwendet in seinen Briefen gern Ausdrücke wie „Werbefuzzies“ oder „Imponiergefasel“ (Heckmann 1999: 4).

Und die Süddeutsche Zeitung beschreibt in ihrem Streiflicht nach der Verleihung des Preises an Gerhard Mayer-Vorfelder den VDS als „fast manisch" und empfiehlt, die ganze Angelegenheit in einen Rucksack zu packen, der in DFB-Fanshops angeboten wird und „Funset“ heißt (Süddeutsche Zeitung 2003: 1).

Der Preis stößt von Anfang an auf reges Interesse in den Medien. Vom Stern, der den frühen Erfolg des Preises wohl richtigerweise der Bekanntheit Jil Sanders zuschrieb (vgl. Steinhoff 1999: 58), über das Handelsblatt (vgl. u.a. Sprothen 2004: 70) berichten die großen deutschen Medien jedes Jahr über den Negativ-Sprachpreis (vgl. dazu den Pressespiegel des Vereins, u.a. VDS 2006h, VDS 2007e). Auch in den SprachSpielen in der Tageszeitung Die Welt werden die Negativ-Sprachpreise thematisiert. So wird zum Beispiel in der Kolumne im Jahr 2001 aus dem Begriff „Funeralmaster“ der Kurzbegriff „funster“. Damit passe der Begriff gut in „unsere Fun-Gesellschaft“, es heißt spöttisch weiter, dass die Beerdigung zum „Event“ werde, mit einer „cold meat party“ anstelle eines kalten Büfetts (Glück 2001c: 34).

\subsubsection{Sprachhunzer}

Jeden Monat wählt der Verein nach Vorschlägen von Vereinsmitgliedern einen ,Sprachhunzer des Monats'“. Kandidaten für den Sprachhunzer des Monats sind „Institutionen oder Firmen, deren Werbung negativ bei der Verhunzung der deutschen Sprache aufgefallen ist (SN 1999a: 3). Im Gegensatz zu den Sprachpanschern werden diese nicht in Pressemitteilungen veröffentlicht und dadurch in den Medien lanciert: 
$\mathrm{Zu}$ Beginn wurden sie gar nicht veröffentlicht:

Dies ist eine interne Vereinsangelegenheit und nicht für die Öffentlichkeit bestimmt - anders als der Sprachpanscher des Jahres sollen die Sprachhunzer des Monats nur Vereinsmitgliedern bekannt gegeben werden, um deren Proteste auf ein- und dasselbe Ziel zu konzentrieren (SN 1999a: 3).

Dies geschah aber von Anfang an in den Sprachnachrichten, und diese sind seit Ausgabe 2002, Nr. 2, im Internet zugänglich (vgl. Kapitel 2.5.1.4). Mittlerweile werden damit die Sprachhunzer auch veröffentlicht. Nur einige Sprachhunzer sollen exemplarisch genannt werden: ${ }^{546}$ Die Karstadt AG, die Deutsche Bank AG und die Illustrierte Bunte gehörten dazu (vgl. SN 1999a: 3), ebenso wie Premiere World und der FC Bayern München (vgl. SN 2000b: 3). Die Reaktionen der so geschmähten Personen und Firmen sind sehr unterschiedlich. Davon zeugen u.a. Briefwechsel zwischen Betroffenen und Vereinsmitgliedern. So wehrte sich eine Politikerin im Jahr 2003 gegen den Vorwurf, ein Sprachhunzer zu sein. Aus ihrem Antwortschreiben wird deutlich, dass der Ton der Briefe, die sie von VDS-Mitgliedern erhalten hatte, sie persönlich getroffen hat und sie in ihrem Misstrauen gegen eine „mit missionarischem Eifer betrieben Sprachreinigungspolitik“ bestärkt (vgl. Brief einer Politikerin an den VDS, 18. Juli 2003). ${ }^{547}$ Im Jahr 2002 gehört dann die DAK zu den Sprachhunzern. Hierzu ist im November 2002 in den „Lichtblicken“ vermerkt, dass ein kritisiertes Vorstandsmitglied der DAK, nachdem dieses Sprachhunzer des Monats war, dem VDS beitritt (Kieselbach 2008: 33).

Auch hier ist zu kritisieren, dass es sich bei der Auslobung des Sprachhunzers des Monats und der verfassten Briefe an die veröffentlichten Adressen um eine regelrechte Kampagne seitens der Anglizismengegner auf die geschmähten Institutionen oder Personen handelt, die von einigen der geschmähten Personen auch durchaus als Angriff empfunden wird (vgl. z.B. Brief einer Politikerin an den VDS, 18. Juli 2003). Außerdem ist anzumerken, dass der Name „Sprachhunzer“ als schlech-

${ }^{546}$ Interessant ist, dass Walter Krämer die Vereinsmitglieder auffordert, nicht im Namen des Vereins zu protestieren, sondern privat: „sonst riecht das ganze nach konzentrierter Aktion." (Rundschreiben von Walter Krämer an Regionalbeauftragte und Arbeitsgruppenleiter, Juni 1999)

${ }^{547}$ Auch die Politikerin macht in ihrem Schreiben darauf aufmerksam, dass es den Begriff „Sprachhunzer" nicht gibt (vgl. Brief einer Politikerin an den VDS, 18. Juli 2003). 
tes Deutsch empfunden wird. Darauf wird immer wieder hingewiesen, sei es von solcherart Geschmähten, von Mitgliedern oder in den Medien, und es wird kritisiert, es müsste eigentlich „Sprachverhunzer“ heißen. Darum weiß man beim VDS:

Zugegeben, das Wort ,Sprachhunzer' klingt fremd. In einem ehrwürdigen Etymologischen Wörterbuch lesen wir jedoch: hunzen ist von Hund abgeleitet, wird mundartlich gebraucht und bedeutet: ,wie einen Hund behandeln', ,schinden', ,plagen' oder ,verderben' (Schrammen 2009: 34),

erläutert der zweite Vorsitzende des Vereins, Gerd Schrammen, zu diesen Vorwürfen.

\subsubsection{Kulturpreis Deutsche Sprache}

Der Kulturpreis Deutsche Sprache wird von der Eberhard-SchöckStiftung und dem Verein Deutsche Sprache ${ }^{548}$ gemeinsam verliehen, von 2003 bis 2005 war auch die Theo-Münch-Stiftung beteiligt, doch mittlerweile besteht keinerlei Zusammenarbeit mehr mit dieser Stiftung. ${ }^{549}$ Nach Beendigung der Zusammenarbeit mit der Theo-MünchStiftung steuerte die Stiftung Deutsche Sprache einmalig einen Teil des Preisgelds bei. Erstmals wurde der Kulturpreis Deutsche Sprache im Herbst 2001 vergeben, im Zusammenwirken mit der Brüder Grimm Gesellschaft e.V. und im Einvernehmen mit der Henning-KaufmannStiftung. Seitdem erfolgt die Preisverleihung jährlich. Ort der Preisverleihung ist Kassel. Der Verein hatte auch in Dortmund und München angefragt, hier kam jedoch keine Zusammenarbeit zustande (vgl. Riedel 2001: 30, Forster 2000: 43). ${ }^{550}$

So wurde Kassel Ort der Preisverleihung. Der Kulturpreis Deutsche Sprache ,ist kein Literaturpreis, sondern eine Auszeichnung, die hervor-

${ }^{548}$ Vgl. Kapitel 2.5.8.

${ }^{549} \mathrm{Zu}$ den Gründen wollte sich der VDS nicht äußern. Hier zeigt sich wieder eine Schwäche der regionalen Internetauftritte: Beispielsweise auf den Seiten der Region Kassel ist die Theo-Münch-Stiftung noch genannt (vgl. Kapitel 2.5.1.1).

${ }^{550}$ Der Oberbürgermeister der Stadt München, Christian Ude, hatte dem VDS zugesagt, die Preisverleihung logistisch zu unterstützen, wurde jedoch mit folgendem Brief an Krämer in der Süddeutschen Zeitung zitiert: „[...] als High-Tech-Metropole (wissen Sie dafür einen guten deutschen Ausdruck?) ist unsere Stadt international und weltoffen orientiert. Ich möchte da, bei allem Verständnis für die Ziele Ihres Vereins, als Oberbürgermeister keine falschen Signale setzen“ (Brief zitiert nach Forster 2000: 43). 
ragenden Einsatz für die deutsche Sprache und zukunftsweisende, kreative sprachliche Leistungen in deutscher Sprache anerkennt“ (Jury des Kulturpreises Deutsche Sprache 2008a). Die Gründe für die Verleihung des Preises werden folgendermaßen angegeben:

In der Gegenwart verursacht ein Übermaß an englischen Elementen in vielen Bereichen vergleichbare Probleme. Ganze Gruppen der Bevölkerung sind von der Kommunikation in einigen wichtigen Bereichen bereits ausgeschlossen, ganze Handlungszusammenhänge gehen der deutschen Sprache verloren. Das ist für eine Kulturnation in einem demokratischen Staat nicht hinnehmbar. [...]

Er möchte anderen Nationen zeigen, daß die deutsche Sprache in Deutschland geschätzt und geliebt wird, daß sie nicht abgeschrieben ist, daß niemand auf dem Weg zum Deutschen den Umweg über das Englische nehmen muß und daß wir uns für die Zukunft unserer Sprache auch in den internationalen Beziehungen einsetzen werden (Jury des Kulturpreises Deutsche Sprache 2008a).

Über die deutsche Sprache heißt es weiter:

Sie wurde geliebt, gepflegt, geachtet, aber auch durch Gleichgültigkeit, Überheblichkeit und Dummheit entwürdigt. Immer wieder wurde deshalb aufgerufen zu ihrem Schutz vor Verwahrlosung und ihrer Verteidigung gegen Geringschätzigkeit: Martin Luther, Gottfried Wilhelm Leibniz, Gotthold Ephraim Lessing, Christoph Martin Wieland, Johann Wolfgang von Goethe, Jacob Grimm, Arthur Schopenhauer und Karl Kraus gehören zu den Vorkämpfern für ein klares und schönes Deutsch.

Der Kulturpreis Deutsche Sprache stellt sich in diese Tradition, namentlich in die Tradition der Aufklärung (Jury des Kulturpreises Deutsche Sprache 2008a).

Er besteht aus drei einzelnen Preisen. Der wichtigste ist der mittlerweile mit 30000 Euro (bis 2007: 35000 Euro) dotierte Jacob-Grimm-Preis (Jury des Kulturpreises Deutsche Sprache 2008d). Mit diesem Preis werden „beispielhafte Verdienste bei der kreativen Weiterentwicklung unserer Sprache und phantasievolle Beiträge zur Erweiterung ihres Funktionsspektrums [ausgezeichnet]“ (Jury des Kulturpreises Deutsche Sprache 2008a). Der Jacob-Grimm-Preis wird Personen verliehen, die sich entweder

besondere Verdienste um Anerkennung, Weiterentwicklung, Erhalt und Pflege der deutschen Sprache als Kultursprache erworben haben - sei es in literarischen Werken, sei es in wissenschaftlichen Essays oder Abhandlungen, sei es in der politischen Rede oder Publizistik (Jury des Kulturpreises Deutsche Sprache 2008d),

oder er wird Persönlichkeiten verliehen, die 
das Ansehen der deutschen Sprache als Kultursprache vermehrt und ihre Bedeutung und Verbreitung als Fremdsprache gefördert haben (Jury des Kulturpreises Deutsche Sprache 2008d).

Bisherige Preisträger des Jacob-Grimm-Preises sind Rolf Hochhuth $(2001)^{551}$, Ludmilla Putina (2002), Christian Meier, zu dem Zeitpunkt Präsident der Deutschen Akademie für Sprache und Dichtung, (2003), Loriot (2004), Paul Kirchhof (2005), der Schriftsteller Günter de Bruyn (2006) und Frank Schirrmacher (2007). ${ }^{552}$ Im Jahr 2008 wurde der Preis nicht vergeben (Jury des Kulturpreises Deutsche Sprache 2008b). ${ }^{553} \mathrm{Im}$ Jahr 2009 erhielt den Preis die Schriftstellerin Cornelia Funke (Jury des Kulturpreises Deutsche Sprache 2009). Neben dem Jacob-Grimm-Preis stehen der Initiativpreis Deutsche Sprache und der Institutionenpreis Deutsche Sprache. Der Initiativpreis ist mit 5000 Euro dotiert und wird Personen, Gruppen oder Einrichtungen verliehen,

die Ideen für die Förderung und Weiterentwicklung der deutschen Sprache umgesetzt oder Vorbilder für gutes, klares und elegantes Deutsch in literarischen Texten, in wissenschaftlichen Abhandlungen, in der politischen Rede, in Texten zu Musikstücken oder in der Publizistik gegeben haben (Jury des Kulturpreises Deutsche Sprache 2008a).

\footnotetext{
${ }^{551}$ Rolf Hochhuth als Preisträger war nicht unumstritten: Eine extrem kritische Stimme war Manfred Büttner (SPD): „Der VDS ist ebenso wie andere Vereinigungen dieser Grauzone [...] eine Plattform für Personen, die offenbar sonst kaum Ansehen geniessen. Man blieb weitgehend unter sich, als man in Rolf Hochhuth den Preisträger fand. Ist er doch ebenso wie Krämer und Jebens Autor bzw. Interviewpartner der vom Verfassungsschutz als rechtsextrem eingestuften „Jungen Freiheit“, für die Hochhuth (JF 10/98 27.2.1998) den Nachruf auf Ernst Jünger schrieb.“ (Büttner 2001). Helmut Glück hat aufgrund dessen eine Entschuldigung der SPD gefordert, da Büttner SPD-Mitglied ist. Dies geht aus einem Brief von Helmut Glück an Eckhardt Barthel und Michael Müller, 8. Mai 2001, hervor. Im Antwortschreiben heißt es: „Ich teile Ihre Auffassung, dass die Beschimpfung nicht hinnehmbar ist. [...] Ich kann nicht nachvollziehen, in welcher Eigenschaft Büttner gesprochen hat. Im Namen der SPD-Bundestagsfraktion sicherlich nicht" (Brief von Michael Müller an Helmut Glück, 30. Mai 2001).

${ }^{552}$ Schirrmacher verärgerte später jedoch den VDS zwischenzeitlich, da er als Mitherausgeber der FAZ an der Entscheidung, im Internetangebot der FAZ einen „Reading Room“ einzurichten, beteiligt war. Ein VDS-Mitglied schrieb an die Redaktion und erhielt folgende Antwort: „[...] unter mehreren Namensvorschlägen für unser Internetforum hat sich Herr Dr. Schirrmacher für „Reading Room“ entschieden. Der Name erinnert an den zerstörten Reading Room der alten British Library, auch war unserem Herausgeber wichtig, daß Englisch die Leitsprache des Internets ist" (vgl. Behland 2008a: 16). Mittlerweile ist das Internetangebot wieder umbenannt (vgl. Kapitel 2.5.1.5).

${ }^{553}$ Dies nahm Sprachpflege.info zum Anlass, zu veröffentlichen, der Preis sei nur noch mit 5000 Euro dotiert (Sprachpflege.info 2008b).
} 
Dieser Preis „wird auch jüngeren Menschen verliehen, die souverän sprachliche Leistungen vorgelegt haben, denn er soll die junge Generation anregen, ein zeitgemäßes, zukunftsgerichtetes Deutsch zu schreiben und zu sprechen“ (Jury des Kulturpreises Deutsche Sprache 2008a). Bisherige Preisträger sind der Verein für pädagogische Arbeit mit $\mathrm{Zu}$ wandererkindern in Osnabrück (2002), die deutsch-französische Arbeitsgruppe DeutschMobil die Sprachlektoren in französische Schulen schickt (2003), Peter Schlenter und Deville Schober, Gründer des Netzwerks für deutschsprachige Musik, Literatur und deutschen Film „Irgendwo in Deutschland“ (2004), Landrat Axel Gedaschko, für seine Bemühungen um eine verständliche Verwaltungssprache (2005), 2006 wurde der Preis nicht verliehen. Im Jahr 2007 ging er an die Deutsche Bibliothek Helsinki, 2008 wurde der Initiativpreis abermals nicht verliehen, 2009 ging er an den Mensch zuerst e.V. Kassel (Jury des Kulturpreises Deutsche Sprache 2009).

Der Institutionenpreis Deutsche Sprache ist im Gegensatz zu den beiden anderen Preisen undotiert. Er wird Einrichtungen oder Firmen verliehen, „die sich im Alltag von Wirtschaft, Politik oder Verwaltung um ein klares und verständliches Deutsch bemüht und gezeigt haben, daß man die deutsche Sprache auch dort flexibel, klar und ohne Verrenkungen verwenden kann“ (vgl. Jury des Kulturpreises Deutsche Sprache 2008b).

Bisherige Preisträger des Institutionenpreises Deutsche Sprache sind ComputerBild (2001), die Hertie-Stiftung (für den Wettbewerb „Jugend debattiert“) (2002), das Versandhaus Manufactum (2003), die Redaktion der Stuttgarter Zeitung (unter anderem für Ausgaben ohne Anglizismen, 2004), der SWR-Sender Das Ding (2005), die Firma Weleda (2006), die Zeitschrift Angewandte Chemie (2007), die Schweizer Post (2008) und die Deutschsprachige Gemeinschaft Belgien (2009) (Jury des Kulturpreises Deutsche Sprache 2009).

Vorschläge für Preisträger kann jeder einreichen, eine unabhängige Jury entscheidet über die eingereichten Vorschläge. Mitglieder der Jury sind: Helmut Glück, Sprachwissenschaftler und ehemaliger (stellvertretender) Vorsitzender des wissenschaftlichen Beirats des VDS, Walter Krämer, 
Vorsitzender des VDS, Eberhard Schöck, Gründer der Eberhard-SchöckStiftung, sowie Peter Klein ${ }^{554}$ (Jury des Kulturpreises Deutsche Sprache 2008a). Laudatoren waren bisher unter anderem Robert Gernhardt, Walter Krämer, Helmut Glück, Thomas Roth (Journalist), Wolfgang Thierse, Norbert Lammert und Konrad Schily (vgl. Jury des Kulturpreises Deutsche Sprache 2008c).

Mit der Verleihung des Kulturpreises Deutsche Sprache engagiert sich der VDS in Kooperation mit sprachpflegenden Stiftungen in einer publikums- und medienwirksamen Aktion. ${ }^{555}$

Vor allem so berühmte und beliebte Preisträger wie Loriot dienen hier als positive Imageträger. Die Ansprachen und Dankesreden erscheinen jährlich im IFB-Verlag, herausgegeben von Helmut Glück, Walter Krämer und Eberhard Schöck (vgl. z.B. Glück/Krämer/Schöck 2002).

\subsubsection{Weitere Preise}

Es gibt einige weitere regionale und überregionale Preise des VDS: Ein regionaler Positivpreis ist der Sprachpreis der Region Würzburg, den unter anderem der Main-Post-Redakteur Herbert Scheuring für seine Glossen erhielt (vgl. Natter 2008: 9). Seit 2005 verleiht der VDS auch den "Schleswig-Holsteinischen Sprachpreis“, der im Wechsel von den schleswig-holsteinischen Regionen vergeben wird. Mit dem nichtdotierten Preis sollen „beispielhafte Nutzungen der deutschen Sprache in Kultur, Wissenschaft, Wirtschaft und Politik gewürdigt werden“ (Jipp 2005: 26)..$^{556}$

Die Kölner VDS-Region verleiht ebenfalls einen regionalen Sprachpreis, den nach dem Lehrer Heinrich Welsch, dem Dichter des Lieds „Dreimol

\footnotetext{
${ }^{554}$ Ulrich Knoop, Sprachwissenschaftler und ehemaliger Vorsitzender des wissenschaftlichen Beirats des VDS, ist aus der Jury ausgetreten, ebenso der Journalist Thomas Steinfeld. Nicht mehr Mitglied der Jury ist auch Wolfgang Windfuhr. Dipl.-Volkswirt Hanns M. Hock gehörte bis zu seinem Tod der Jury an.

${ }^{555}$ Ein professioneller Internetauftritt des Kulturpreises Deutsche Sprache unter www.kulturpreisdeutschesprache.de trägt zur Bekanntheit des Preises bei.

${ }^{556}$ Auch die Region Bautzen verleiht einen Positivpreis, den Bautzener Sprachpreis. Dieser wurde unter anderem bereits an eine Sparkasse verliehen für ihre Aktion „Wir sprechen die Sprache unserer Kunden“ (vgl. SN 2002e: 5). Dieser war in der Zeit, in der der Sprachrettungsklub eine Regionalgruppe des VDS war, auch ein regionaler Preis des VDS.
} 
Null es Null bliev Null“, benannten Lehrer-Welsch-Preis. Der Preis ist ein Positivpreis (vgl. Kinder 2005: 20). Die Kölner Region verleiht aber auch einen Schmähpreis, den "Sprachtünnes“ (vgl. Kinder 2005: 20). Die Region Oldenburg vergibt einen regionalen Schmähpreis, den „Sprachschrott-Preis“ (vgl. spn 2007: 24f.), ebenso die Region Münsterland (VDS Region Münsterland 2008). Außerdem wurde vom VDS und dem Deutschen Musik-Exportbüro einmalig der Internationale Musikpreis 2004 verliehen, den eine Gruppe aus Rumänien gewann (vgl. z.B. SN 2004b: 2).

\subsubsection{Kontakte und Briefe}

Eines der wichtigsten Mittel um Einfluss zu nehmen ist für den VDS das Schreiben von Briefen an Firmen, Politiker, Journalisten oder Einzelpersonen. Waren es anfangs nur einzelne Mitglieder, die Briefe verfassten, so werden Briefaktionen seit spätestens 2001 von der Vereinszentrale gesteuert:

Gerade deshalb ist es eben unsere Taktik, die Proteste zu bündeln.

Wenn ein Konzern drei perfekt formulierte Proteste bekommt schert ihn das wenig. Wenn aber 300 oder 700 kommen, dürfte das zumindest zu internen Diskussionen führen (Bomba 2000: 8). ${ }^{557}$

In der Vorstandssitzung vom 15. Februar 2002 wurde festgelegt, dass Briefe mit Vereinskopf, die an Personen des öffentlichen Lebens gehen, als Kopie an den VDS-Vorstand ${ }^{558}$ geschickt werden müssen. In der Begründung heißt es: „Damit sollen widersprüchliche Aussagen von VDSFunktionsträgern, die uns in der Vergangenheit sehr geschadet haben, frühzeitig erkannt und zurechtgebogen werden" (Brief des Vorstands an die Regionalvorsitzenden, Ende März 2002).

Krämer hat des Weiteren erklärt:

Es schadet unserem Anliegen ganz enorm, wenn ein- und derselbe [sic] Person verschiedene Schreiben zum gleichen Thema erhält und nicht weiß, wer im VDS für was eigentlich zuständig ist, oder wenn VDS-Briefe Rechtschreibfehler enthalten und in schlechtem Deutsch geschrieben sind (Brief von Walter Krämer an alle Regional- und Arbeitsgruppenleiter, o.D.).

${ }^{557}$ Dies ist auch das Prinzip von anderen Nichtregierungsorganisationen, wie Amnesty International.

558 Zunächst war dies Horst Hensel, später Gerd Schrammen. 
Auf der Homepage des VDS wird aber immer wieder zu Protestbriefen aufgerufen:

Die rohen Sprachverderber in Deutschland sollen mit Protesten überhäuft werden. Machen Sie mit! Schreiben Sie ein paar kritische Zeilen an die hier vorgestellten Sprachsünder! Wir müssen ihnen zeigen, wie sehr sie sich lächerlich machen und mit ihrem albernen Denglisch die schöne deutsche Sprache verunstalten. Auf ihren Schreibtischen soll sich viel Papier türmen. Deshalb sind Briefe oder Faxe besser geeignet als elektronische Mitteilungen oder Telephonanrufe (VDS 2005e).

Auch in den Sprachnachrichten werden Firmen oder Personen veröffentlicht, die von möglichst vielen Mitgliedern angeschrieben werden sollen (vgl. Kapitel 2.5.1.4 und 2.5.4.2), zudem veröffentlichen die Regionalgruppen sogenannte Sprachverderber auf ihren Internetseiten. Zu den Protestbriefen gibt es einen Leitfaden des Vereins, der regelmäßig in den Sprachnachrichten abgedruckt ist:

Beachten Sie bitte die folgenden Faustregeln: 1. In der Kürze liegt die Würze. 2. Gute Argumente, Witz und Spott wirken besser als Wut und wüste Beschimpfungen. 3. Verzichten Sie auf Witzchen mit Hilfe von Englisch oder Denglisch. Das verwenden die Empfänger gegen uns, wie bereits geschehen. (z.B. Schrammen 2005a: 10).

Dass Krämer darum bittet, von „wüste[n] Beschimpfungen“ Abstand zu nehmen, weist darauf hin, dass es Briefe gab, in denen sich VDSMitglieder im Ton vergriffen hatten. So wurden Menschen, die Anglizismen benutzen, als „Sesselpupser“ bezeichnet, oder die Obstplantagen Krämer in Meckenheim erhielten eine Werbekarte, die sie vorher verteilt hatten, mit einem VDS-Aufkleber und einem Brief mit folgender Passage zurück:

Ihr tickt wohl nicht richtig. Wo sind wir denn hier? Verkauft Euer Grünzeug an Engländer oder Amerikaner, wenn Ihr kein Deutsch könnt (vgl. Bier in SN 2007: 17).

Die Empfängerin des Briefes, Michaela Bier von den Obstplantagen Krämer, fühlte sich angegriffen und brachte dies auch zum Ausdruck:

Ungeachtet unserer Einstellung zum Phänomen der Amerikanisierung betrachten wir diese Aktion als beleidigend und feige (Bier in SN 2007: 17).

Die Redaktion der Sprachnachrichten, in denen ihr Schreiben abgedruckt wurde, überschrieben es mit „Feige Tat“ (vgl. SN 2007: 17). Zwar ist nicht festzustellen, ob der beleidigende Brief tatsächlich von einem VDS-Mitglied verfasst wurde, der Absender unterzeichnete lediglich mit 
S. Ch.. Doch durch den Aufkleber wurde eine Verbindung zum VDS geschaffen, solche Aktionen schaden dem Image des Vereins massiv.

Um die Mitglieder zum Schreiben von Protestbriefen zu veranlassen, werden auch hier VDS-intern Preise vergeben, es gibt immer wieder Briefwettbewerbe (vgl. Schrammen 2005c: 11). Stukenbrock bewertet dies kritisch als eine „zur Denunziation aufrufende Aktion [...]“ (Stukenbrock 2005a: 229).

Dass der VDS-Vorstand mit seinen Aufrufen zu Protestbriefen bei seinen Mitgliedern Erfolg hat, davon zeugen eine ganze Reihe voller LeitzOrdner in den Räumen der VDS-Zentrale. Wie viele Briefe es genau sind, lässt sich nicht mehr feststellen, weil nicht alle Protestbriefe in Kopie an den Verein geschickt wurden und werden. ${ }^{559}$ Krämer schätzt das Gesamtaufkommen aller Briefe einschließlich der von Vereinsmitgliedern verfassten E-Mails und der Leserbriefe auf mit „Sicherheit mehrere Hunderttausend“ (E-Mail von Christiane Dahl an die Verfasserin, 12. Oktober 2007).

Er verfasst selbst jedes Jahr zahlreiche Briefe, Protestbriefe und Briefe, in denen er um finanzielle und ideelle Unterstützung für den Verein wirbt: Bereits im August 1999 hatte er über 100 Bettelbriefe verfasst (vgl. Rundschreiben von Walter Krämer an die VWDS-Vereinsmitglieder, August 1999), wie z.B. an Joachim Neubauer, Vorsitzender des Deutschen Musikverlegerverbandes (Brief von Walter Krämer an Joachim Neubauer, 14. April 1999). Er nutzt dabei bewusst sein Ansehen als Hochschullehrer für die Vereinszwecke und fordert die anderen Hochschullehrer im VDS auf, ihren Status zu nutzen: Neue Mitglieder

[1]assen sich gern von Hochschullehrern überzeugen. Werfen Sie also Ihr Ansehen in die Waagschale, und überzeugen Sie möglichst viele Menschen in Ihrer Umgebung, unserer Bürgerinitiative beizutreten [...] (Brief von Walter Krämer an Hochschullehrerinnen und Hochschullehrer vom Juni 2003).

${ }^{559}$ Einen kleinen Eindruck der Beteiligung an den Briefwettbewerben des VDS geben folgende Zahlen: „Wir erhielten insgesamt 755 Belege über Protestbriefe, d.h. 92 veröffentlichte Leserbriefe, 178 Briefe an Sprachhunzer und 485 kritische Schreiben und Beschwerden an Denglisch-Schwätzer jeglicher Art. Für 2004 waren 420 Belege für Protestbriefe bei uns eingegangen, im einzelnen 83 Leserbriefe, 157 Briefe an Sprachhunzer und 180 Briefe und Beschwerden an andere Denglisch-Benutzer. [...] Ohne Zweifel wurde uns nur ein Teil der Briefe zugeschickt, die VDS-Mitglieder geschrieben haben“ (Schrammen 2006c: 20). 


\subsubsection{Briefwechsel mit Firmen und Organisationen}

Immer wieder stehen Firmen und Einrichtungen im Visier der VDSMitglieder: Die Deutsche Telekom hat 1998 sehr viele Briefe von VDSMitgliedern bekommen. Da Korrespondenzen oft in Kopie an die Vereinszentrale gehen und dort archiviert werden, ist der Briefwechsel zwischen der Telekom und VDS-Mitgliedern gut dokumentiert. Mitglieder baten um „Zusendung einer Rechnung in der die einzelnen Rechnungsposten in deutscher Sprache ausgewiesen sind [sic]" (Brief eines Ehepaars (VDS-Mitglieder) an die Deutsche Telekom, 9. Mai 1998), sie empfanden die Rechnungen als „Zumutung“ (vgl. Brief eines VDSMitglieds an die Deutsche Telekom, 13. März 1998, Dokument 15, vgl. auch Ambros 1999: 4). ${ }^{560}$ Grund für die Beschwerden waren die Bezeichnungen CityCall-Verbindung, RegioCall-Verbindung und GermanCall-Verbindung, die die Telekom im Juli 1998 in Orts- und Nahverbindung für CityCall-Verbindung, Nationale Fernverbindung für GermanCall und Internationale Fernverbindung für GlobalCall geändert hat (dafür wurde sie auch zum "Sprachpanscher“ gekürt, vgl. Kapitel 2.5.4.1). Dieser Änderung vorausgegangen war neben den Briefen an die Telekom ein Musterprozess, den ein VWDS-Mitglied gegen die Telekom geführt hatte (vgl. Hensel 1999: 99). ${ }^{561}$

Auch der Axa Colonia Konzern hat zahlreiche Briefe vom VDS nach Einführung des Werbespruchs „The future.Together.Now.“ erhalten. Im Oktober 1999 änderte die Axa Colonia ihren Werbespruch in „Für Ihre Sicherheit. Für Ihr Vermögen“. Aus einem Schreiben des Konzerns geht hervor, dass man im Konzern eine Mail eines VDS-Mitglieds „zum Anlaß [nimmt], nochmals gründlich über die Problematik zu diskutieren“ (vgl. Brief eines VWDS-Mitglieds an Axa Colonia, 7. November 1999). Dies ist ein deutliches Zeichen, dass die Vereinsarbeit des VDS wirkungsvoll war.

\footnotetext{
${ }^{560}$ Wie viele es genau sind, lässt sich trotzdem nicht feststellen, da einerseits nicht alle Mitglieder eine Kopie an die Zentrale geschickt haben, andererseits diese Briefe auch nur bedingt sortiert wurden.

${ }^{561}$ (Vgl. Kapitel 2.5.1.5) Auch das IDS hatte die Bezeichnungen kritisiert. Spitzmüller verweist kritisch darauf, dass Kunden durch solche Bezeichnungen Telefonrechnungen nicht verstehen könnten, diese jedoch als Information für Kunden dienen sollten. Er führt weiter aus, dass ein Nichtverstehen aber kein Grund gegen die Verwendung in einer Werbebroschüre sei (Spitzmüller 2005: 354).
} 
Manche Briefwechsel, wie der mit der Barmer Ersatzkasse, zeigen die vom Verein beabsichtigte Wirkung:

\begin{abstract}
Mit Schreiben vom 20.11.1998 hatten wir Ihnen unsere Gedanken zu dem von Ihnen zu recht kritisierten Einsatz von Anglizismen dargestellt.

Mit den heutigen Zeilen will ich die damaligen Aussagen unterstreichen. So kann ich Ihnen mitteilen, daß inzwischen die für den Umdenkungsprozeß erforderlichen Gespräche mit den Vertretern der Fachverlage stattgefunden haben. Auch hausintern haben wir erfolgreich gekämpft und, wo wir dies unmittelbar beeinflussen können, die Weichen in die neue Richtung gestellt. Unser jüngstes Produkt der 'neuen Linie`: Der wieder aufzulegende Jugendkalender der BARMER. Die ursprünglich vorgeschlagene Bezeichnung 'fine timer` wurde ausgetauscht gegen den neuen Titel „Gute Zeit (Brief der Barmer Ersatzkasse an Walter Krämer, 14. Januar 1999. Dokument 16).
\end{abstract}

Ein weiteres Beispiel ist der Antwortbrief, den der damalige Geschäftsleiter von Nordsee, Heiner Kamps, an Walter Krämer schickte. In diesem kündigte er eine neue Kommunikationsrichtlinie für die Firma an, sie beinhaltet, dass die Firma ohne Anglizismen auskommen soll (vgl. Schrammen 2009: 143f.).

Andere Schriftwechsel, wie der bezüglich des Slogans „Enercity, positive energie“ der Stadtwerke Hannover, hatten dagegen weniger Erfolg:

Wir haben uns die Entscheidung für diesen Namen nicht leicht gemacht und sind uns auch der Nachteile, die englische Begriffe mit sich bringen, durchaus bewusst (Brief der Stadtwerke Hannover an Walter Krämer, 17. Juli 2001, Dokument 18).

Sogar mit gerichtlichen Konsequenzen drohte offensichtlich die Firma Mey (vgl. Protokoll der VDS-Vorstandssitzung vom 19. Juli 2000).

Protestbriefe gehen nicht nur an große Firmen, sondern auch an mittelständische und kleine Unternehmen. Davon zeugen zahlreiche Beispiele im Archiv der Vereinszentrale, so der E-Mail-Verkehr zwischen einem Vereinsmitglied und der Firma earsandeyes GmbH. Das Vereinsmitglied kritisierte englische Ausdrücke in der deutschen Version des Internetauftrittes der Firma (Brief eines VDS-Mitglieds an earsandeyes $\mathrm{GmbH}$, Mai 2001), und erhielt prompt ein Antwortschreiben der Firma mit der Zusage der Überarbeitung der Internetseite (Brief der earsandeyes $\mathrm{GmbH}$ an ein VDS-Mitglied, Mai 2001).

Auch Wissenschaftler oder Kultureinrichtungen stehen teilweise im Fokus: Eine Protestbriefaktion des VDS fand zur Unterstützung des 
Belgischen Germanisten- und Deutschlehrerverbandes statt. Mitglieder protestierten im Jahr 2000 mit Briefen an das Goethe-Institut gegen die Entscheidung, Gastredner Vorträge auf Englisch halten zu lassen (vgl. u.a. Brief eines VDS-Vorstandsmitglieds an Regionalbeauftragte und Aktivisten, 27. Mai 2000). Die Region 91, Erlangen, berichtet über die Umbenennung der Medizinischen Fakultät Erlangen in Medizinstadt Erlangen $\mathrm{GmbH}$, die Medical Valley Center Erlangen heißen sollte. Die Medizin AG des VDS beansprucht für sich, durch ihre schriftlichen Proteste an dieser Namensänderung beteiligt gewesen zu sein.

\subsubsection{Kontakte und Briefwechsel mit Journalisten und Politikern}

Ein Teil der Vereinsarbeit funktioniert über gute Kontakte zu Politikerinnen und Politikern:

Die Politik vor unseren Karren spannen. Auch das wird ein Schwerpunkt der künftigen Vereinsarbeit sein. Erste Vorgespräche mit Berliner Spitzenpolitikern haben bereits stattgefunden (Krämer 2000c: 2).

Es zeugen etliche Briefwechsel mit Politikern im Archiv des VDS von dem regen, aber oft erfolglosen Bemühen, Politiker als Mitglieder für den Verein zu gewinnen (vgl. z.B. Brief von Walter Krämer an Peter Müller, Ministerpräsident des Saarlands, 9. Dezember 2008). Müller lehnte die Mitgliedschaft $\mathrm{ab}^{562}$. Auch einen Briefwechsel zwischen Walter Krämer und Angela Merkel hat es gegeben, diese lehnte eine VDSMitgliedschaft ebenfalls ab. ${ }^{563}$ Vergeblich war auch das Treffen von Mitgliedern des VDS-Bundesvorstands und des wissenschaftlichen Beirats mit dem damaligen Staatsminister Michael Naumann, dem die Texte des VDS nicht gefielen. ${ }^{564}$ Renate Schmidt, Vorsitzende des Landesverbands der Bayern SPD, war kurzzeitig Mitglied des VDS, ist aber wieder aus dem Verein ausgetreten (vgl. auch Kapitel 2.2.5). ${ }^{565}$

\footnotetext{
${ }^{562}$ Information aus Abfrage der Mitgliederdatenbank, 2. Februar 2009.

563 Gespräch mit Walter Krämer, 25. März 2005.

${ }^{564}$ In der Folge kam es auch zu einem Zerwürfnis zwischen den für dieses Treffen maßgeblichen Vorstandsmitgliedern des VDS aus Berlin, und dem Vertreter des wissenschaftlichen Beirats, Helmut Glück. Dieser war nicht über alle Textänderungen und neuen Texte informiert gewesen (Telefongespräch mit Hermann Dieter, 9. Februar 2009).

${ }^{565}$ Grund für den Austritt war, dass sich der Verein aus Sicht von Renate Schmidt nicht ausreichend gegen rechte Gruppierungen abgrenzt, und unter anderem, dass Krämer der
} 
Auch Hartwig Fischer, CDU-Generalsekretär in Niedersachsen, ist vom VDS angeschrieben worden, er wurde wegen eines englischen Wahlkampflieds für Christian Wulff kritisiert (Brief eines VDS-Mitglieds an Hartwig Fischer, CDU-Generalsekretär in Niedersachsen, ohne Datum). Dies hat keine Wirkung erzielt:

Aber selbst, wenn man die Aspekte Europa und Modernität außer Acht lässt, hat die englische Sprache bzw. die Verbundenheit zur angelsächsischen Kultur eine historische Tradition, besonders hier in Niedersachsen, wie Ihnen sicher bekannt sein dürfte (Brief von Hartwig Fischer, CDU-Generalsekretär in Niedersachsen, an den VDS, 20. August 1998).

Kurz eingehen möchte ich an dieser Stelle noch auf ein Schreiben eines VDS-Vorstandsmitglieds an Prof. Dr. Julian Nida-Rümelin, damals Staatsminister für Kultur:

Wir [gemeint sind die Mitglieder des Vereins Deutsche Sprache, Anm. d. Verf.] sind der Überzeugung, daß sie mit einer derartig skurillen [sic] Ansicht als Kulturminister nicht mehr tragbar sind, denn Sie begehen Verrat an unserer Sprache [...]. Deshalb fordern wir Sie auf, sofort zurückzutreten (Brief eines VDS-Vorstandsmitglieds an Prof. Dr. Julian Nida-Rümelin, 31. Dezember 2001).

Vorausgegangen war die Aussage Nida-Rümelins, dass Deutsch als Wissenschaftssprache „tot“ sei, bei der Auftaktveranstaltung zum „Europäischen Jahr der Sprachen“ in München (vgl. u.a. Offener Brief an Prof. Dr. Julian Nida-Rümelin vom Bundesvorstand des VDS, 5. Februar 2001). Der Vorwurf des VDS schadete dem Politiker nicht.

In einem Brief an Wolfgang Gerhardt, FDP, kritisierte Krämer den Slogan „vote yellow“ (Brief von Walter Krämer an Wolfgang Gerhardt, FDP, 23. März 2000). In der Antwort steht:

Ich darf Sie also beruhigen, dass die Bundespartei keinesfalls vorhat, mit o.g. Motto zukünftig Wahlkämpfe zu bestreiten. Bei ,vote yellow' handelt es sich nach meiner Kenntnis um eine Kampagne, die im nordrhein-westfälischen Kommunalwahlkampf initiiert wurde (Brief von Wolfgang Gerhardt, FDP, an Walter Krämer, 17. April 2000).

Von guten Kontakten zur Politik zeugt, dass Krämer und Glück bei dem Text für die Große Anfrage an die Bundesregierung zum Thema Sprache und Globalisierung beratend tätig waren (vgl. Kapitel 1.6 und Protokoll der VDS-Vorstandssitzung vom 9. Februar 2000). Eine Basis zur

Jungen Freiheit ein Interview gegeben hatte (vgl. Brief vom Büro Renate Schmidts an ein VDS-Vorstandsmitglied, 21. September 1999). 
Zusammenarbeit gab es offensichtlich auch mit dem damaligen Berliner Innensenator Eckart Werthebach (CDU) (vgl. z.B. Protokoll der VDS-Vorstandssitzung vom 2./3. Februar 2001, Dokument 12). Der Verein erfährt Zustimmung von Seiten der Politik, zahlreiche Politiker bedienen sich in ihrer Argumentation der des VDS (vgl. auch Pfalzgraf 2008: 468), auch wenn man sich in manchen Parteien nicht einig ist, z.B. hieß es in einer Presseerklärung des FDP-Kreisverbands Bremen: „Endlich ein Verein, der den Mut hat, gegen die Verwässerung unserer deutschen Sprache anzugehen und auch etwas dagegen zu unternehmen bereit ist. [...]" (Presseerklärung der stellvertretenden Kreisverbandsvorsitzenden der FDP, Agnes Müller-Lang, in Bremen, 2. Juli 2002). Dagegen schrieb man aus der Parteizentrale der FDP im Jahr 2000 an den Vereinsvorsitzenden:

Wir bedauern, dass wir mit Ihnen in diesem Punkt [gemeint ist die Verwendung von Anglizismen im Deutschen, Anm. d. Verf.] nicht einer Meinung sind, weil es im Kontakt mit speziellen Zielgruppen [...] durchaus üblich ist, sich auch im deutschsprachigen Austausch englischer Fachbegriffe zu bedienen. [...] (Brief der FDP an Walter Krämer, 13. Dezember 2000).

Pfalzgraf verweist darauf, dass der VDS in der Lage wäre, einen stärkeren Einfluss auf Gesellschaft und Politik auszuüben, als dies bisher angenommen wird. Außerdem sei davon auszugehen, dass die Bereitschaft deutscher Politiker, sich für einen gesetzlichen Schutz der deutschen Sprache zu engagieren, auf die Vereinsarbeit des VDS zurückzuführen ist. Dies gelte insbesondere für Politiker der CSU/CDU (vgl. Pfalzgraf 2008: 469 sowie Kapitel 1.6.3).

Auch die deutschen Bundespräsidenten sind Ansprechpartner: Ein VWDS-Vorstandsmitglied schrieb an Roman Herzog, den ehemaligen Bundespräsidenten. Darin wird kritisiert, dass Herzog sich während seiner Amtszeit nie zum Thema Anglizismen im Deutschen geäußert habe (Brief eines VWDS-Vorstandsmitglieds an Roman Herzog, 6. Mai 1999). Im Antwortschreiben heißt es: „Herzog sähe sich nicht als „Oberlehrer der Nation“ (Brief des Büros Roman Herzogs an den VDS, 22. Juni 1999). Die gleiche Aussage trifft auch Johannes Rau ein halbes Jahr später, fügt aber hinzu, dass er in seinen Reden versucht, Vorbild zu 
sein, und damit seinen Beitrag für die Pflege der deutschen Sprache zu leisten (Brief von Johannes Rau an den VWDS, 7. Dezember 1999). ${ }^{566}$

Journalisten sind ebenfalls wichtige Ansprechpartner des Vereins. Krämer hat unter anderem 1999 dem damaligen Chefredakteur des ZDF geschrieben und ihn auf fehlerhafte Sprache der Mitarbeiter hingewiesen. Im Antwortschreiben des ZDF-Pressesprechers heißt es:

Unsere Reporter und Moderatoren sind zur richtigen Verwendung der deutschen Sprache verpflichtet. [...] Daß dabei in der Öffentlichkeit allgemein gebräuchliche englische Begriffe wie ,job' oder ,team' nicht nur, aber auch benutzt werden, halte ich für vertretbar (Brief des ZDF an Walter Krämer, 13. Mai 1999).

Die ARD wird ebenfalls häufig von Vereinsmitgliedern angeschrieben (vgl. u.a. Brief eines VDS-Mitglieds an die ARD, 6. Februar 2001). Die VDS-Mitglieder erhalten jeweils standardisierte Antwortschreiben, in denen es heißt:

Jede Sprache nimmt Lehnworte aus anderen Sprachen auf. [...] Das äußerst korrekte Deutsch von Sprachwissenschaftlern oder Bürokratendeutsch wären den Zuschauern nicht zuzumuten." (Brief der ARD-Zuschauerredaktion an ein VDS-Mitglied, 8. Februar 2001, die gleiche Aussage findet sich auch in zahlreichen anderen Antwortschreiben der ARD, z.B. Brief der ARD-Zuschauerredaktion an ein VDS-Mitglied, 6. Dezember 2002).

Journalisten stehen aber nicht nur in der Kritik, sie sind gleichzeitig wichtige Multiplikatoren für den VDS. Auch bei den Journalisten wird um Sympathie für den Verein geworben und versucht, möglichst viele Journalisten als Mitglieder oder wenigstens für die Ziele des Vereins gewinnen zu können. Die Mitglieder, vor allem aber die Regionalvorsitzenden, werden immer wieder aufgefordert, persönlichen Kontakt zu Journalisten zu pflegen. So soll eine positive Darstellung des Vereins in der Öffentlichkeit gewährleistet werden (vgl. u.a. Protokoll der VDSVorstandssitzung am 11. März 2001). ${ }^{567}$ Es zeigt sich über die Jahre, dass der Verein gute Kontakte zu den Medien hat. Nicht zuletzt zeugt davon die Berichterstattung über Aktionen des Vereins (vgl. das folgende Kapitel).

${ }^{566}$ Johannes Rau wurde vom VWDS/VDS mehrmals angeschrieben (vgl. Dieter 2000a: 2).

567 Wobei davon abgeraten wird, Journalisten zu Regionalversammlungen einzuladen (vgl. VDS o.D.a: 1). 


\subsubsection{Medienauftritte und Pressearbeit}

Einer der wichtigen Faktoren der Arbeit des VDS ist die Öffentlichkeitsarbeit. Mitglieder des VDS und besonders ihr Vorsitzender waren und sind in allen wichtigen Medien der Bundesrepublik vertreten. Beim Fernsehen hatten sie unter anderem Auftritte im ZDF, in der ARD und bei 3Sat, ${ }^{568}$ mittlerweile gibt es sogar einen Film über den VDS mit dem Titel „Wer rettet die deutsche Sprache?“, der im SWR ausgestrahlt wurde, Autor ist der Journalist Harold Woetzel (Woetzel 2005). Durch Pressemitteilungen macht der VDS häufig auf sich aufmerksam und versucht, seine Ziele in den Medien zu platzieren. Wiechers weist schon 2001 auf die „von Anfang an [...] professionell organisierte Presse- und Öffentlichkeitsarbeit“ hin (Wiechers 2001: 155f.). Der Grad der Professionalisierung hat sich seitdem noch verstärkt. Der Verein veröffentlicht Pressemitteilungen zu den verschiedensten aktuellen Sprachthemen. So hat er beispielsweise am 31. Dezember 2001, am Tag vor der Einführung des Euro, eine Pressemitteilung veröffentlicht, in der er „die Nachrichtensprecher des deutschen Rundfunks und Fernsehens auffordert, die neuen Zehntel-Euro-Münzen auf deutsche Weise auszusprechen“ (VDS 2001d). Insgesamt gibt die Zentrale des VDS mittlerweile rund 20 Pressemitteilungen im Jahr heraus, von denen die meisten Eingang in die deutschen, aber auch internationalen Medien finden (vgl. z.B. VDS 2007d). Auch der Pressespiegel des Vereins, der online zugänglich ist, zeugt davon, dass der Verein es immer wieder schafft, seine Themen in den Medien zu platzieren. ${ }^{569}$

\footnotetext{
${ }^{568}$ Unter anderem im ZDF: „Modern Talking - wer rettet die deutsche Sprache?“ Berlin Mitte vom 15. Februar 2001, ARD: „Man spricht Deutsch - aber wie?“ Sabine Christiansen, Sendung vom 29. Juli 2001 (Hier war Gerd Schrammen als Vertreter des VDS in der Sendung, 3Sat: „[tsent] oder [sent]?“ Kulturzeit vom 7. Januar 2002. Klein führt zur ARDSendung aus: „Man mag von solchen Veranstaltungen halten, was man will, als eine Art Bekundung von öffentlichem Interesse an der deutschen Sprache kann die Talkshow sicherlich gewertet werden. Dass bei der Ansetzung der Sendung das vielbeschworene Presse-Sommerloch eine Rolle gespielt haben könnte, muss nicht gegen diese Einschätzung sprechen“ (Klein 2001, vgl. zu den Sendungen auch Pfalzgraf 2006: 13).

${ }^{569}$ An der Entstehung des Pressespiegels maßgeblich beteiligt ist Joseph Braun, ein finnisches Mitglied des VDS, der im Internet mit einem speziellen Suchmechanismus nach Zeitungsartikeln sucht. Die Zeitungsartikel liegen in Papierform in der Zentrale des Vereins Deutsche Sprache vor.
} 
Wichtiger Faktor der Öffentlichkeitsarbeit sind die Leserbriefe: Die Aktion „Wer schreibt die meisten Leserbriefe“ soll hier Anreize schaffen (vgl. z.B. Protokoll der VDS-Vorstandssitzung am 2./3. Februar 2001). Das Mitglied, das die meisten Briefe schreibt, bekommt eine Prämie. Wie viele Leserbriefe VDS-Mitglieder seit 1997 an Zeitungen geschrieben haben, ist nicht mehr festzustellen, da nicht alle Mitglieder Kopien an die Vereinszentrale schicken und dort Leserbriefe an verschiedenen Stellen aufbewahrt werden. Dennoch kann davon ausgegangen werden, dass es mehrere zehntausend Leserbriefe waren. ${ }^{570} \mathrm{Al}$ leine die gesammelten abgedruckten und aus den Zeitungen kopierten Exemplare in der Vereinszentrale belaufen sich auf mehrere Tausend (vgl. auch oben in diesem Kapitel). Auch die Preise für die fleißigsten Leserbriefschreiber zeigen, wie viel Wert seitens des Vorstands auf dieses Mittel gelegt wird, öffentlich Druck und Aufmerksamkeit zu erzeugen.

Schon im ersten Jahr der Vereinsgründung wurde die Presse auf den Verein aufmerksam, und im Laufe der Jahre ist eine stetig steigende Medienpräsenz des VDS zu konstatieren. Spitzmüller weist darauf hin, dass Krämer als Vorsitzender des VDS „recht schnell die Position einer weithin akzeptierten Sprachautorität errungen hatte“ (Spitzmüller 2005: 126) und dass der Verein hin und wieder in eine Reihe mit Institutionen wie der GfdS und dem IDS gestellt werde (vgl. Spitzmüller 2005: 126). ${ }^{571}$ Die Medien gelten als der „Ort, der die populäre, publizistische Sprachkritik der Vereine verbreiten hilft“ (Schiewe 2003: 330). Dies gilt in besonderem Maße für den VDS. Waren die Medienberichte in den Anfangsjahren des VDS dem Verein gegenüber teilweise kritisch, so sind die meisten Berichte in den letzten Jahren ganz im Sinne des Vereins. Gerade die Verleihung der Preise des VDS (beispielsweise wurde im Jahr 2001 eine dpa-Pressemitteilung über die Verleihung des Kulturpreises an Rolf Hochhuth in über 40 Tageszeitungen veröffentlicht) aber auch einzelne Aktionen wie bei der geplanten Benennung Frankfurts in "City of the Euro" oder die Versteigerung der deutschen Sprache auf eBay bringen den VD in die Schlagzeilen (vgl. VWDS 1999c, VDS

${ }^{570}$ Vgl. Kapitel 2.5.

${ }^{571}$ Wobei es auch zu Verwechslungen der Institutionen kam (vgl. Spitzmüller 2005: 126). 
2003i). ${ }^{572}$ Zudem wenden sich in den letzten Jahren immer häufiger Journalisten von sich aus an den Verein (vgl. Protokoll der VDSVorstandssitzung vom 10. Juni 2005). Wiechers konstatiert:

Verglichen mit den anderen Sprachvereinen nimmt der VDS durch seine Medienpräsenz und die hohe Mitgliederzahl eine herausragende Stellung in der sich entwickelnden (politischen) Diskussion um die Bedeutung der deutschen Sprache ein (Wiechers 2001: 156).

Der VDS ist nicht nur der erste dieser Vereine, der eine breite Öffentlichkeit erreicht, er hat von Anfang an auch eine sehr gute Publicity (vgl. auch Spitzmüller 2005: 123ff.) - selbst wenn es hin und wieder Veröffentlichungen gibt, in denen der VDS lächerlich gemacht wird, wie folgendes Beispiel aus der Süddeutschen Zeitung zeigt:

Demnächst werden sich Krämers Mannen versammeln, und ein Ruck wird durchs Land gehen: Dann werden aus Teenagern Backfische und flotte Bienen, aus Jeans Nietenhosen, aus Hot Dogs heiße Hunde, und Dieter Bohlen dann Kapellmeister der Gruppe Modernes Reden, wird Verona Feldbusch zur Reinheitskönigin der neuen Mitte küren. [...] Schnell einen Preis her für den schönsten Anglizismus des Jahres! (nma 1999: 17)

Zudem gibt es zahlreiche Berichte in regionalen Tageszeitungen über Regionalvorsitzende, beispielsweise in der Main-Post (Heringlehner 2004: D1). Der VDS bestimmt den Diskurs über die Anglizismen maßgeblich mit und wird auch weiterhin aktiv am Diskurs teilnehmen. Die wenn auch in weiten Teilen neutrale - Berichterstattung über Aktionen des Vereins in Form von Meldungen und Berichten hat dazu geführt, den Diskurs zu katalysieren und somit die Purismuskritik stimuliert (vgl. Spitzmüller 2005: 123ff., 2007: 268ff.).

\subsubsection{Tagungen und Vorträge}

Tagungen und Vorträge sind ebenfalls wesentlicher Bestandteil der Vereinsarbeit. Dies wird in den Protokollen der Vorstandssitzungen regelmäßig betont. Hier sollen beispielhaft einige Veranstaltungen aufgeführt werden, bei denen Mitglieder des VDS beteiligt waren. Der VDS beteiligte sich an der Tagung "Sprache und Gesellschaft“ der evangelischen Akademie in Mülheim vom 16. bis 18. November 2001, ebenso an einer Sprachtagung in New York (Dieter 2002c: 4). Krämer sprach

${ }^{572}$ Vgl. auch Spitzmüller (2005: 125f.). 
auf einer unter anderem von der Robert-Bosch-Stiftung initiierten Sprachtagung zum Thema Mehrsprachigkeit in Europa vom 23. und 24 Januar 2004 in Berlin (SN 2004a: 1). Auch an einer Tagung am 9. Juni 2005 mit der Sächsischen Landeszentrale für politische Bildung nahmen Vertreter des VDS teil (vgl. Baer 2005: 7). Manfred Schroeder hielt 2005 auf einer Tagung in Polen einen Vortrag (Schroeder 2005b: 29). Im Jahr 2007 sprach er auf einer Tagung in Griechenland (Schroeder 2007: 22), 2008 in Tschechien (Schroeder 2008: 27). Max Behland vertrat 2007 den VDS auf der Tagung der Schweizer Orthographischen Konferenz (sda/spn 2007: 2). ${ }^{573} 2009$ veranstaltete der VDS gemeinsam mit der Evangelischen Akademie eine Tagung zum Thema „Deutsch der ,Jeckes' in Israel (spn 2008: 35). Eigene Tagungen veranstaltete der VDS bis zum Jahr 2004 in Zusammenarbeit mit dem Netzwerk Deutsche Sprache (vgl. Kapitel 1.7.14).

Prof. Fritz Vilmar, ${ }^{574}$ Emeritus der Freien Universität Berlin und VDSMitglied, hielt 2001 ein Seminar an der FU mit dem Thema „Die Amerikanisierung der deutschen Sprache als politisches Problem“. Dagegen protestierte das „Bündnis kritischer Studenten“. Die Demonstranten befürchteten laut Spiegel „impliziten Antiamerikanismus und beschmierten zum Beispiel eine Mauer mit der Inschrift ,Fuck deutsche Sprache' (vgl. Alexander et al. 2001: 160). Weiter wurde berichtet:

Mit Flugblättern, Boykottaufrufen und gesprühten Parolen störte nun im Sommersemester ein kleiner Trupp von Studenten das Blockseminar von Professor Fritz Vilmar, 71, Emeritus der Freien Universität. Die letzte Veranstaltung musste nach Lankwitz ausweichen. [...] Dabei ist Vilmar alles andere als ein Rechter (Alexander et al. 2001: 160). ${ }^{575}$

${ }^{573}$ Es ist in dieser Arbeit nicht möglich und auch nicht sinnvoll, auf alle Tagungen einzugehen, an denen Vertreter des VDS teilnahmen. Als Auswahlkriterium dient an dieser Stelle die Veröffentlichung über den Vortrag in den Sprachnachrichten.

${ }^{574}$ Fritz Vilmar war lange Jahre in der IG Metall tätig und SPD-Mitglied. Die SPD verließ er jedoch, unter anderem wegen deren sozialen Substanzverlustes. Im Jahr 1976 gründete Vilmar die „Hochschulinitiative Demokratischer Sozialismus“. Er ist politisch dem linken Spektrum zuzuordnen. Auch der Spiegel verweist auf die Tatsache, dass Vilmar keinesfalls als „Rechter“ angesehen werden kann (siehe oben in diesem Kapitel).

${ }^{575}$ Im Spiegel heißt es weiter: [Diese Vorkommnisse] „spiegeln die zunehmende Gereiztheit beim Thema sprachliche Überfremdung. Noch vor Jahren war auf diesem Feld mit Humor gestritten worden“ (Alexander et al. 2001: 160). Es findet also in diesem Artikel durchaus eine Auseinandersetzung mit dem Thema Anglizismen und den Reaktionen der Bevölkerung statt. 
Auch die Sprach-Nachrichten verweisen darauf, dass es nicht mehr möglich war, die Veranstaltung in den Räumen des Instituts abzuhalten, ein Wachdienst musste eingesetzt werden (vgl. SN 2001a: 12). In ihren Flugblättern bezeichneten die Demonstranten die Kritik der Amerikanisierung der Sprache als "antidemokratischen Anti-Amerikanismus“ (Vilmar 2002c: 206). ${ }^{576}$ Das Seminar rief großes Medieninteresse hervor, dabei zeigte beispielsweise der Spiegel Sympathien für die Seminarleiter. Über diesen Artikel freute man sich beim VDS, da er "ganz im Sinne des VDS argumentiert“ (vgl. SN 2001a: 12). Das Ereignis belebte die Debatte, zeigt aber auch, wie eng Ideologie und Sprache miteinander verwoben sein können und welche ideologischen Muster den Diskurs häufig prägen (vgl. Spitzmüller 2005: 137f.).

Ein weiterer Punkt der Vereinsarbeit sind Vorträge von VDSMitgliedern: Die Vorträge finden in Schulen, ${ }^{577}$ in Volkshochschulen ${ }^{578}$ oder bei Burschenschaften statt, ${ }^{579}$ auch vor Vereinen von Kriegshinterbliebenen $^{580}$, vor Mitgliedern von Kommunalvereinen ${ }^{581}$ und bei ande-

\footnotetext{
${ }^{576}$ Noch kritischer äußern sich Henry Morgenthau und Arthur Harris auf der „Zuhauseseite des Allgemeinen Studierendenausschusses (AstA) an der Freien Universität Berlin“: Am 6. Juli 2001 schrieben sie dort, hinter dem Seminar verbergen sich „nationale Erweckungsphantasien“ und „ein Antiamerikanismus, der sich symbolisch und psychologisch in die Nähe des europäischen Judenhasses schreibt" (Morgenthau/Harris 2001). Damit verkennen die beiden Autoren m.E. die Absichten Vilmars, der, wie auch der Spiegel feststellt, keinesfalls als Rechter gelten kann.

577 Zum Beispiel: „Der Mißbrauch von Amerikanismen in der deutschen Sprache“ Vortrag im Beruflichen Schulzentrum für Wirtschaft in Dresden vor dem Leistungskurs Deutsch (vgl. VDS Region Dresden 2005).

${ }^{578}$ Beispielsweise Walter Krämer am 13. November 2001: „Deutsch oder Denglisch?“ Vortrag in der Volkshochschule Krefeld.

${ }^{579}$ Peter Jaensch, Mitglied des VDS Dresden (kein Funktionär), hat am 18. Juni 2003 unter dem Titel: „Ist Deutsch ein Auslaufmodell?“ einen Vortrag vor der Darmstädter Burschenschaft Rheno-Markomannia (VDS Region Dresden 2005) gehalten, in dem er unter anderem sagte:

„Gerade in unserer antinational eingestellten Zeit fällt deshalb den deutschen Burschenschaften und dem Verein Deutsche Sprache bei der Bewahrung jahrhundertealter Traditionen eine besondere Aufgabe zu. Die deutschen Burschenschaften haben Metternich, Hitler, Ulbricht und Honecker überstanden, da werden sie auch noch die 68er und die Atlantiker überstehen. Genauso wie der Verein Deutsche Sprache der Flut der Anglizismen widerstehen wird“. Abgesehen davon, dass der Vergleich zwischen den Burschenschaften und dem VDS hinkt, und die 68er und die Atlantiker als Übel in einer Reihe mit Hitler genannt werden, fällt auf, dass Jaensch sich stark an die Burschenschaft anbiedert. ${ }^{580}$ Zum Beispiel: „Warum Deutsch, wenn es auch auf Englisch geht ?“ Vortrag von Peter Jaensch vor Mitgliedern des Verbandes der Kriegshinterbliebenen Siegen und der Regio-
} 
ren sprachpflegerischen Vereinigungen ${ }^{582}$. Krämer selbst hält Vorträge, die in der Bevölkerung auf reges Interesse stoßen. ${ }^{583}$

Im zehnten Jahr seiner Vereinsgründung veranstaltete der VDS die Tagung Idensen $2^{584}$. Anhand der Dokumentation dieser Tagung ist zu erkennen, dass der VDS seine Vereinsarbeit optimieren möchte. Daher soll im Folgenden kurz auf die Inhalte eingegangen werden: Im Verein wachse das Bedürfnis, ernst genommen zu werden und Kompetenzen $\mathrm{zu}$ beweisen. Eine „Akzentverschiebung im Markenkern“ sei erforderlich, und es sei zu fragen, wo der VDS Kompetenzen bieten könne (vgl. Baer 2007b: 3, Dokument 14). An gleicher Stelle ist vermerkt, dass man in Zukunft „[a]uf Augenhöhe mit Gesprächspartnern umgehen [wolle]“ und diese „nicht immer gleich beschimpfen“ wolle, sondern statt dessen „Brücken bauen zum Einverständnis“ (vgl. Baer 2007b: 4), ein deutlicher Schritt in eine neue Richtung der Vereinskultur. Hervorgehoben wird an anderer Stelle des Protokolls, dass man Wert auf „unideologisches, undogmatisches Auftreten“ legen wolle (Baer 2007c: 6). Ebenso wird gefordert, neben den Sprachnachrichten eine weitere Zeitschrift zu gründen, die von den Germanisten des Vereins gefördert und meinungsführendes Organ zum Thema „Lebendige deutsche Sprache“ werden soll. Auch steht der Vorschlag im Raum, mit einem großen wissenschaftlichen Kongress ein deutliches Signal $\mathrm{zu}$ setzen, indem man einen Schwerpunkt auf sprachwissenschaftliche Kompetenzen legt (vgl. Pogarell 2007d: 18). Damit deutet sich ein Wandel im Bewusstsein des VDSFührungszirkels an, weg von einer aggressiven Haltung gegenüber Menschen und Institutionen, die Anglizismen verwenden, hin zu einer auf den sprachpflegerischen Kompetenzen aufbauenden und stärker auf

nalgruppe Siegen des Vereins Deutscher Sprache, 6. Oktober 2003 (VDS Region Dresden 2005).

${ }^{581}$ Hier sei als Beispiel auf den Vortrag „Welchen Weg nimmt die deutsche Sprache?“ von Friedhelm Debus auf der Jubiläumsveranstaltung des Kommunalvereins Molfsee im Jahr 1998 verwiesen (vgl. Jahresblätter des Kommunalvereins Molfsee 1998: 10ff.).

${ }^{582}$ Beispielsweise bei Zweigvereinen der GfdS (Protokoll der VWDS-Vorstandssitzung vom 10. September 1998) oder beim Verein Muttersprache in Österreich.

${ }^{583}$ Beispielsweise mussten bei einem Vortrag in Westerstede im Jahr 2005 zusätzliche Stühle organisiert werden, der Reporter beschreibt den ganzen Vortrag und seine Reaktionen auf das Publikum ein wenig spöttisch als „Event“ (Tschapke 2005a: 12).

${ }^{584}$ Bereits im Januar 2006 hatte die Tagung Idensen 1 stattgefunden, Ergebnisse wurden aber erst nach Idensen 2 protokolliert (Pogarell 2007b: 18). 
den Kompetenzen des wissenschaftlichen Beirats und damit auf wissenschaftlicher Basis beruhenden konstruktiven Vereinsarbeit (vgl. Klatte 2007: 16f).

\subsubsection{Stiftung Deutsche Sprache}

Die Stiftung Deutsche Sprache wurde im Jahr 2001 gegründet, mit dem Ziel,

die deutsche Sprache für die heutigen und kommenden Generationen als ein Kulturgut von höchstem Wert, als Ausdruck ihrer Identität, als vollwertiges Mittel der Verständigung im Alltag, als Medium der Forschung, des Denkens, des gesellschaftlichen Diskurses unbeschädigt zu erhalten, zu stärken und für neue Aufgaben tauglich zu machen (Stiftung Deutsche Sprache 2005a, Dokument 8).

Sprecher des Stiftungsvorstands ist Walter Krämer, weitere Vorstandsmitglieder sind Helmut Glück und Axel Flessner. ${ }^{55} \mathrm{Zu}$ den Zielen der Stiftung gehört auch zu verhindern, dass sich Anglizismen im Deutschen weiter ausbreiten:

Sie möchte vermeiden, daß noch mehr Bereiche der wissenschaftlichen und fachlichen Verständigung an das Englische verlorengehen, da sich solche Verluste kaum rückgängig machen lassen. Sie möchte verhindern, daß sich das englisch-deutsche Kauderwelsch (,Denglisch'), das sich im sprachlichen Alltag eingenistet hat und für viele Menschen nicht mehr verständlich ist, noch weiter ausbreitet (Stiftung Deutsche Sprache 2006a).

$\mathrm{Zu}$ ihrem Selbstverständnis in bezug auf Anglizismen nehmen die Vorstandsmitglieder wie folgt Stellung:

Wir sind keine Puristen, keine Fremdwort-Jäger, keine Bilderstürmer.

Wir bejahen die Bereicherung des Deutschen durch fremde Sprachen; und manche Importe gerade aus dem Englischen begrüßen wir. Unsere Initiative richtet sich allein gegen die schiere Anglomanie, gegen das Übermaß (Stiftung Deutsche Sprache 2005b).

Zweck der Stiftung ist „die Förderung, Bildung und Erziehung durch die Weiterentwicklung und Pflege der deutschen Sprache“, beispielsweise durch „die Durchführung oder Förderung von wissenschaftlichen

585 Die Stiftung hat auch einen Beirat. Vorsitzender ist Cornelius Sommer, weiterhin gehören ihm an Stephan Brandner, Horst Hensel, Norbert Lammert, Christian Meier, Reinhard Mey, Rüdiger Rothkamm, Helmut Schäfer, Wolfgang Schneider und Walter Terschüren an (vgl. Stiftung Deutsche Sprache 2009). Zum Beirat der Stiftung gehörte auch Ulrich Knoop als Vorsitzender. 
Veranstaltungen [...] und wissenschaftlichen Untersuchungen zum Thema „Deutsche Sprache“, die „Herausgabe und Förderung von dem Stiftungszweck dienenden Publikationen“ sowie „die Unterstützung des gemeinnützigen ,Vereins Deutsche Sprache e.V.“, zum Beispiel „durch gemeinsame Veranstaltungen, Publikationen oder durch die finanzielle Förderung von Vorhaben des Vereins“ (vgl. Stiftung Deutsche Sprache 2006a). In Informationsmaterialien des VDS ist zu lesen, dass die Stiftung Deutsche Sprache auf die Einrichtung einer Deutschen Sprachakademie hinwirken und andere Aufgaben übernehmen soll, die der Verein nicht selbst durchführen kann (VDS 2004d: 7). Die Stiftung wird vom VDS als "geistliche[r] Arm unserer Bürgerinitiative gegen sprachliche Umweltverschmutzung“ verstanden (VDS 2004d: 7). Der Vorsitzende des VDS ruft die Vereinsmitglieder auf, die Stiftung in ihrem Testament $\mathrm{zu}$ berücksichtigen, da Verein und Stiftung die gleichen Ziele verfolgen (vgl. Krämer 2007c: 2).

Die Stiftung ist also sowohl personell als auch inhaltlich stark mit dem VDS verbunden. Dies zeigt sich auch darin, dass 50000 DM des Startkapitals vom VDS kamen (vgl. Protokoll der VDS-Vorstandssitzung vom 11. März 2001). ${ }^{586}$ Stickel verweist ebenfalls auf diesen Zusammenhang. Er sieht die Stiftung als eine Sprachorganisation, die aus und mit dem VDS entstanden ist (Stickel 2007: 135). Wolf Schneider bezeichnet die Stiftung als dem VDS nahe stehend (vgl. Schneider 2008: 146). ${ }^{587}$

Sie bietet Sprachberatung an, der Schwerpunkt der Arbeit liegt auf der Beratung zu Fragen, die den sprachlichen Alltag betreffen, „vor allem bei der Frage nach plausiblen deutschen Äquivalenten für fremdsprachige Begriffe“ (Stiftung Deutsche Sprache 2006b). Die Sprachberatung ist noch an der Universität Freiburg angesiedelt und per Mail zu erreichen unter der Adresse sprachberatung@stiftungds.de (Krämer 2006c: 2). Ziel und Aufgabe der Sprachberatung beschreibt der Sprachwissenschaftler Ulrich Knoop, bei dem die Beratungsstelle derzeit ansässig ist, folgendermaßen:

${ }^{586}$ Fast 30000 DM der 100000 DM Startkapital der Stiftung sind durch Spenden infolge von Anzeigen in der FAZ zustande gekommen (vgl. Protokoll der VDS-Vorstandssitzung vom 11. März 2001).

${ }^{587}$ Aus diesem Grund wird die Stiftung auch an dieser Stelle der Arbeit vorgestellt. 
Wer kennt alle Übersetzungsvorschläge und wer kann welche machen? Dafür gibt es nun seit neuestem eine Arbeitsstelle, die eine Sprachberatung anbietet. Sie sammelt alles, was es an Problemen mit den Anglizismen gibt, und macht Vorschläge für den angemessenen Umgang oder zu deren Übersetzung (Knoop 2006: 21).

Dabei beantwortet die Sprachberatungsstelle ausschließlich Fragen zu Anglizismen, für weitere Sprachberatung würden die Kapazitäten nicht ausreichen. Sie arbeitet mit der Aktion „Lebendiges Deutsch“ und mit der Arbeitsgruppe zum Anglizismen-Index zusammen (vgl. Knoop 2006: 21).

Mittelfristiges Ziel der Stiftung ist die Einrichtung eines „Hauses der deutschen Sprache“ in Berlin, in dem Vortragsreihen, Informationsveranstaltungen und Ausstellungen stattfinden sollen. Dabei besteht seitens des Stiftungsvorstands des "Hauses der deutschen Sprache“ nicht der Anspruch, dass das Haus eine Akademie ist. Beauftragter ist Dr. Cornelius Sommer (vgl. Schneider 2008: 163). Das „Haus der deutschen Sprache“ existiert bereits virtuell, so wird beispielsweise über den Online-Auftritt eine Sprachberatung angeboten (Haus der deutschen Sprache 2008a). Auch der VDS stellt sich dort vor (Haus der deutschen Sprache 2008c). Veranstaltungen, beispielsweise Lesungen junger Autoren, wurden schon organisiert (Haus der deutschen Sprache 2008b).

Seit 2005 wird im Internetauftritt der Stiftung unter dem Motto „Aktion ,Lebendiges Deutsch'“ jeden Monat ein Anglizismus vorgestellt, für den Übersetzungsvorschläge gesucht werden. Für einen anderen Anglizismus wird ein Übersetzungsvorschlag geboten. Die Aktion kam auf Anregung von VDS-Mitglied und Sprachkritiker Wolf Schneider zustande, der den „Kampf gegen solche Missgeburten [gemeint sind die Anglizismen, Anm. der Verfasserin] systematisieren“ und die Öffentlichkeit mobilisieren will (Schneider 2008: 148). Die Aktion wird als Aktion des VDS angesehen (vgl. Krämer 2007e: 27). ${ }^{588}$

Neu an unserer Arbeit ist die Systematik, mit der wir zu Werke gehen. Reden, Artikel, Forderungen und Anprangerungen gibt es ja reichlich, und gern begegnen wir dort unseren Verbündeten. Aber, fragten wir uns 2005: Wie wäre es, wenn wir unsere Landsleute allmonatlich auf dumme Anglizismen stießen und ihnen deutsche Alternativen dazu anböten? (Schneider 2008: 149).

${ }^{588}$ Dennoch an dieser Stelle und nicht bei den Aktionen des VDS vorgestellt wird die Aktion, da sie in der Öffentlichkeitsarbeit in der Regel als Aktion der Stiftung geführt wird. 
Wichtig für das Anliegen der Aktion „Lebendiges Deutsch“ ist die Veröffentlichung der Verdeutschungsvorschläge in den Medien. Dafür konnte Wolf Schneider die Deutsche Presseagentur (dpa) gewinnen, die seit Februar 2006 jeweils am ersten Sonntag des Monats „Drei Wörter des Monats“ der Aktion „Lebendiges Deutsch“ an die Redaktionen in Presse und Rundfunk vermittelt. Laut Wolf Schneider „machen Dutzende dieser Redaktionen davon Gebrauch, oft über fünfzig, manche mit Würdigungen, Hintergrundberichten oder Interviews" (Schneider 2008: 149f.). 589

Ausgewählt werden die Anglizismen nach folgenden Kriterien: Sie müssen zum einen „ziemlich bekannt“ sein, also beispielsweise häufig in den Medien verwendet werden. Weiterhin müssen die „vier in höchstem Grade sprachinteressierte[n] Männer“ der Aktion „Lebendiges Deutsch“, Wolf Schneider (unter anderem ehemaliger Chefredakteur der Welt und Leiter der Henri-Nannen-Schule), Josef Kraus (Präsident des Deutschen Lehrerverbandes und Autor), Walter Krämer (vgl. Kapitel 2.1.1) und Dr. Cornelius Sommer (früher Diplomatischer Dienst, jetzt betraut mit der Einrichtung des „Hauses der deutschen Sprache“, siehe oben), die drei Anglizismen als „ärgerlich empfinden - weil sie hässlich, sperrig, aufgeblasen sind oder weil sie vermutlich von vielen, dies es angeht, nicht verstanden werden“. In fünf Fällen verzichtet die Jury auf Verdeutschungen: Für Wörter, die im Deutschen völlig zu Hause sind, wie „Baby“ oder "Cowboy“ werden keine Vorschläge angeboten, ebenso wenig für Wörter, bei denen „der Zug abgefahren“ ist, wie „Mailen“, das einem „E-Post-Versenden“ nach Ansicht der Jury immer überlegen sein würde, für Wörter, die viele verschiedene Bedeutungen im Deutschen haben (beispielsweise „Cluster“) für Wörter, die sich möglicherweise als „verbale Eintagsfliegen“ erweisen, um diese nicht zu verewigen (beispielsweise „Rail Marshall“), und schließlich für Wörter, bei denen die Jury beim Versuch der Eindeutschung merkt, „dass sie aus lauwarmer Watte“ sind. ${ }^{590}$ Als Beispiel liefert Schneider den Begriff „Anti-Aging“. Einsender hatten den Vorschlag gemacht, statt des Modeworts lieber eines

589 Zustimmung erfährt die Aktion auch von Seiten einiger Politiker. So unterstützt beispielsweise Bundestagspräsident Norbert Lammert diese Aktion (vgl. W. Schneider 2006: 2).

${ }^{590}$ Hier zeigt sich wieder, wie subjektiv diese Kriterien sind. 
der Wörter für den jeweiligen Einzelfall zu verwenden (Schneider 2008: 150ff). ${ }^{51}$ Am Beispiel von „Blackout“ erläutert Schneider den Prozess: Per E-Mail verständigen sich Kraus, Schneider, Krämer und Sommer darauf, welche Übersetzung sie anbieten, für welches Wort sie eine deutsche Entsprechung suchen und für welche Vorschläge zum Suchwort des Vormonats sie sich entscheiden. Im Falle von „Blackout“ gingen 1758 Vorschläge ein. ${ }^{592}$ Daraus wurden Grüße, Lob und Beleidigungen aussortiert, danach werden die Wörter alphabetisch im Computer erfasst, gleichlautende Wörter addiert und den Juroren übermittelt, sortiert nach der Häufigkeit. Bei „Blackout“ waren die häufigsten Vorschläge „Aussetzer“ (368), „Filmriss“ (124), „Ausfall“ (36), „Denkblockade“ (36), „Denkloch“ (32), „Gedächtnislücke“ (32), „Erinnerungslücke“ (25) und „Totalausfall“ (25). Dabei werden von der Jury sechssilbige Wörter wie „Erinnerungslücke“ automatisch ausgeschieden. ${ }^{593}$ Das Fremdwort ist lediglich zweisilbig, da sind für die Juroren auch beim Verdeutschungsvorschlag zwei Silben „erstrebenswert, mehr als drei kaum erträglich“ (Schneider 2008: 151). Gegen „Totalausfall“ entscheidet sich die Jury, weil er zu nah an einer Ohnmacht liegt. Daraufhin bildet sich jedes Jurymitglied eine Meinung, ob ein Vorschlag darunter ist, den es für perfekt hält (4 Punkte), für sehr gut (3 Punkte), oder für gut (2 Punkte), passabel (1 Punkt) oder indiskutabel (0 Punkte). Dabei ist ein Wort, das auf 13 Punkte kommt, automatisch ausgesucht. Dies war aber bisher noch nie der Fall. Im vorliegenden Beispiel erhielt „Aussetzer“ 10 Punkte, „Denkloch“ 9, Filmriss 5, Hirnblock 4 und Hirnriss 3. Daraufhin argumentierte ein Jurymitglied per Mail gegen „Denkloch“, er bezeichnete das als „brutales Wort“, ebenso wurde gegen "Hirnblock“ und „Hirnriss“ argumentiert. Dadurch kam in einem zweiten Durchlauf eine Mehrheit für „Aussetzer“, der auch der Favorit der Einsendungen war, zustande (vgl. Schneider 2008: 152). ${ }^{594}$

\footnotetext{
${ }^{591}$ Dieses Beispiel macht deutlich, dass es für einige der Anglizismen keine deutsche Entsprechung gibt und diese die Sprache bereichern.

${ }^{592}$ Im nächsten Absatz schreibt Schneider, dass es 1759 Einsendungen waren (vgl. Schneider 2008: 151).

${ }^{593}$ Auch dies ist ein willkürlich festgelegtes Kriterium.

${ }^{594}$ Dieser Umstand hatte jedoch keinen Einfluss auf die Jury (ebenda).
} 
Mittlerweile bekommt die Aktion „Lebendiges Deutsch“ auf jede Publikumsfrage zwischen 500 und 5000 Zuschriften. Beispielsweise waren es bereits im Februar 2006507 Zuschriften mit Verdeutschungsvorschlägen für das Wort „Countdown“ (das erste Wort, das über die dpa verbreitet wurde). Man einigte sich in der Jury auf den Vorschlag "Startuhr“ (vgl. W. Schneider 2006: 2). ${ }^{595}$ Insgesamt kamen bereits über 50000 Zuschriften (vgl. VDS 2008b), eine Rekordbeteiligung mit 4426 Einsendungen mit insgesamt 10380 Verdeutschungen erzielte das Wort „Brainstorming“ (Verdeutschungsvorschlag: Denkrunde), viel Widerspruch rief der Verdeutschungsvorschlag „Hingeher“ für „Event“ hervor. Auch wurde "Rechner" für "Computer" vorgeschlagen, ein Wort, das gerade Informatiker gerne verwenden. ${ }^{596}$ Einige der Vorschläge wurden bereits in Buchform veröffentlicht (Pretscher/Hoppe 2008). Die Aktion „Lebendiges Deutsch“ ruft einiges Echo hervor. Scharfe Kritik erfuhr sie von Georg Ringsgwandl:

Das ist kein Witz, sondern eine Initiative aus dem ,Haus der deutschen Sprache' (HDS), erbaut von einem Fähnlein sprachbesorgter Käuze, die unerschrocken der Anglizismenflut entgegengehen. Noch ist das HDS nur eine Homepage, aber wenn sich genügend Sprachschuhplattler finden, und das steht beim nächsten Anstieg der Arbeitslosenzahlen $\mathrm{zu}$ befürchten, so wird daraus bald ein richtiges Haus mit Schild außen und Ausstellungen innen drin, wo zeigen wie fuckin inglisch [sic] unsere Sprach fertig macht (Ringsgwandl 2009: I).

Auch Sprachwissenschaftler Anatol Stefanowitsch kritisiert die Aktion: Zwar hebt er hervor, dass sie „etwas weniger aufgeregt“ daherkomme als andere Aktionen zur Sprachbewahrung, dennoch störe ihn die „Inkompetenz" der Jury (vgl. Stefanowitsch 2007c). Diese Behauptung erläutert er anhand des Verdeutschungsvorschlags der Jury für „Happy Hour“. Die Jury wählte den Begriff aus, den auch die meisten Teilnehmer vorschlugen: „Blaue Stunde“. Damit werde laut Stefanowitsch der Begriff für die ruhigen Stunden vor Sonnenuntergang oder Sonnenaufgang auf Billigpreisaktionen, die nichts mit der Ruhe und Melancholie der „Blauen Stunde“ zu tun haben, ausgedehnt, womit man der deutschen Sprache keinen Gefallen tue (Stefanowitsch 2007c).

595 Dieser Begriff ist m.E. nach nicht unbedingt treffend.

${ }^{596}$ Schneider selbst verwendet „Computer“ aber durchaus (Schneider 2008: 151). 
Außerdem wurden bereits mehrere hundert Zeitungsartikel über die Aktion „Lebendiges Deutsch“ veröffentlicht. Viele Autoren dieser Artikel standen der Aktion positiv gegenüber (vgl. Kieselbach 2007a: 78, Krämer 2007e: 27). In der Glosse „Wortgefecht“ in der Zeitung Die Welt beispielsweise ist zu lesen: „Ist die Empfehlung Mist, wird sie verworfen. Ist sie gut, wird sie sich durchsetzen. Das ist - anders als in Frankreich mit seinen verordneten Ersatzwörtern - gesprochene Demokratie“ (Krüger 2008a: 77). Der Autor der Glosse verweist aber auch darauf, dass die Reaktionen auf die Aktion „Lebendiges Deutsch“ nicht durchweg positiv gewesen seien. Auch sei in einigen Artikeln von „Deutschtümelei“ und "Hexenjagd auf Anglizismen“ die Rede, zudem werde die Aktion von Kritikern als „Aktion scheintotes Deutsch“ abgetan (vgl. Krüger 2008a: 77). Krüger kritisiert die Aktion: „Manche Anglizismen haben [sic] sind besser als ihr Ruf. Zumindest, wenn man die Alternativen der Aktion ,Lebendiges Deutsch' liest“. Als Beispiel führt er „Eilmampf“ für „Fastfood" an“ (Krüger 2008b). ${ }^{597}$

\subsubsection{Weiteres Engagement des VDS}

Im Vordergrund der vorliegenden Arbeit steht das Engagement des VDS bezüglich des Anglizismengebrauchs im Deutschen, denn dieses ist eindeutig Mittelpunkt der Vereinsarbeit. Schon 2001 stellte Klein bezüglich des VDS fest: „Sein öffentliches Wirken richtet sich so gut wie ausschließlich gegen Anglizismen“ (Klein 2001). So heißt es im Jahr 2000 dann auch in den Sprachnachrichten:

Es werden vielerlei Vorschläge gemacht, worum wir uns kümmern sollen. Man vergißt dabei, daß der Verein gegründet wurde, um gegen die Anglizismen zu kämpfen. Darüber hinaus können wir uns vorerst nicht auch noch um Fragen des guten Stils im Deutschen, andere Fremdwörter, grammatikalische Fehler und Feinheiten im Ausdruck kümmern. Wir können nicht alle Probleme gleichzeitig anpacken (Bomba 2000: 8).

Daran hat sich in den ersten Jahren der Vereinsgeschichte wenig geändert. Erst in jüngster Zeit deutet sich an, dass die Anglizismenkritik zu einem Punkt der Vereinsarbeit unter mehreren wird. An dieser Stelle

597 Über diesen Verdeutschungsvorschlag spotteten auch beispielsweise die Autoren des Streiflichts der Süddeutschen Zeitung (Süddeutsche Zeitung 2008a: 1). 
soll daher auf das weitere Engagement eingegangen werden: Ein Anliegen des VDS ist auch, Deutsch als dritte Arbeitssprache in der EU zu stärken. Hensel verweist darauf, dass dieses Ziel vor Einführung des Arbeitskreises „Stärkung der deutschen Sprache in europäischen Institutionen und Organisationen“ heftig diskutiert wurde (Hensel 1999: 101). Dennoch ist es eines der Ziele, die im VDS immer wieder verfolgt werden (vgl. u.a. Gawlitta/Vilmar 2002b: 198). Es scheint, als ob es in jüngster Zeit mehr Bedeutung in der Vereinsarbeit erlangt hat: Das Ziel wurde 2008 auch in die neue Satzung des VDS aufgenommen (vgl. VDS 2008o: 1), zudem wandte sich die Arbeitsgruppe, die mittlerweile „Sprachenpolitik in Europa" heißt, an die holländische und luxemburgische Regierung, um zu erreichen, dass die deutsche Sprache in der Zeit deren Ratspräsidentschaften in deren Internetauftritten auch angemessen berücksichtigt werde. Zumindest die finnische Regierung veröffentlichte daraufhin in der Zeit ihrer EU-Ratspräsidentschaft auf ihrer Internetseite eine Rubrik „Aktuelles“ in deutscher Sprache. Mittlerweile hat das Europaparlament eine Entschließung verabschiedet, in der es heißt, den Ländern mit der Ratspräsidentschaft werde empfohlen, ihre Internetseiten in möglichst vielen Sprachen zu veröffentlichen, sollte dies nicht möglich sein, dann zumindest in den meistgesprochenen Amtssprachen (vgl. z.B. Voslamber 2006: 5, vgl. zum Thema Deutsch als Arbeitssprache in der EU auch Voslamber 2008a: 10 sowie Voslamber 2008b: 3).

Der VDS setzt sich des Weiteren für den Erhalt von Deutsch als Wissenschaftssprache ein: „Unsere Forderungen an die Wissenschaft: Erhaltung und weiterer Ausbau der deutschen Sprache in Forschung und Lehre. Deutsch als gleichberechtigte Konferenzsprache auf Kongressen“ (vgl. VDS 2003f). ${ }^{598}$ Diese Forderung ist mittlerweile in den Fokus der Vereinsarbeit gerückt. 2008 wurde die Erhaltung des Deutschen als Wissenschaftssprache als Vereinsziel in die Satzung des Vereins aufgenommen (vgl. VDS 2008o: 1).

Eine der Hauptaktivitäten in diesem Zusammenhang war ein Offener Brief einer Wissenschaftlergruppe an alle 29 Kultus-, Bildungs- und

${ }^{598}$ Auch zu diesem Thema gibt es Briefwechsel und Schreiben (vgl. z.B. Brief eines VDSVorstandsmitglieds im Auftrag des Bundesvorstands des VDS an die Deutsche Forschungsgemeinschaft, 6. April 2001). 
Wissenschaftsministerinnen und -minister im Jahr 2001, mit der Forderung der Sicherung des Ausbaus von Deutsch als Wissenschaftssprache. So solle die deutsche Sprache neben der englischen Sprache zweite Tagungssprache auf internationalen Tagungen in Deutschland sein (vgl. Dieter et al. 2001: 1f.). Dieser Brief wurde über dpa verbreitet und dadurch in zahlreichen Medien abgedruckt (Dieter 2002a: 93). Über die Reaktionen der Angeschriebenen war man beim VDS enttäuscht:
Entweder wurde die Verantwortung für die deutsche Sprache der Wissenschaft und ihre Zukunft in unserem Staat vollständig auf die Wissenschaftler und die Autonomiebefugnisse ihrer Organisationen abgeschoben oder es wurde bedauernd festgestellt, dass man ,da nichts machen könne' (Dieter 2002a: 93). ${ }^{599}$

Eine Forderung des VDS an die Kultusminister lautet, den Deutschunterricht an den Schulen verbindlich bis zum Abitur beizubehalten (vgl. VDS 2003f). ${ }^{600}$ Ebenso fordert der VDS von der Sprachwissenschaft die Erarbeitung eines Wörterbuchs, das Respekt vor der deutschen Sprache hat (vgl. SN 2000c: 1). ${ }^{601}$

Die alte oder neue Rechtschreibung ist dagegen kein Thema des VDS (vgl. dazu u.a. Bomba 2000: 8). Über die Jahre hinweg betont der Verein immer wieder, dass er sich zur Frage der Rechtschreibung neutral verhalte (vgl. Zabel 2003 sowie Meyer 2008: 16). Dafür wird die Vereinsführung von einigen Mitgliedern stark kritisiert. Die Publikationen des Vereins sind größtenteils in neuer Rechtschreibung verfasst, die Sprachnachrichten waren lange Zeit in alter Rechtschreibung, derzeit werden die Ausgaben in der aktuellen Rechtschreibung publiziert. Dies wird sich aber wieder ändern. Der VDS arbeitet, nach dem Vorbild der Frank-

\footnotetext{
${ }^{599}$ Anführungszeichen im Original wie im Englischen oben. Enttäuschung wurde auch darüber geäußert, dass die Reaktionen nur langsam eintrafen und viele der Angeschriebenen überhaupt nicht geantwortet hatten (vgl. Dieter 2002a: 93).

${ }^{600}$ Dieser Forderung waren die Kultusminister bereits im Jahr 2000 nachgekommen: „Aufgrund der aktuellen Oberstufenvereinbarung der KMK der Länder der Bundesrepublik Deutschland vom 16. Juni 2000 ist Deutsch für alle Schülerinnen und Schüler ein bis zum Abitur durchgehendes Pflichtfach, ebenso wie Mathematik und eine Fremdsprache. In diesen Fächern müssen alle Kurse der Kurs- bzw. Qualifikationsphase der Oberstufe in die Gesamtqualifikation eingebracht werden.“ (Bundesregierung 2002a: 18). ${ }^{601}$ Wie dies genau aussehen soll, wird jedoch nicht näher erläutert (vgl. SN 2000b: 1).
} 
furter Allgemeinen Zeitung, an einer Hausschreibung. ${ }^{602}$ Durchaus kritische Artikel zur Rechtschreibreform finden sich aber in den Sprachnachrichten, so dass bei der Lektüre der Mitgliederzeitschrift der Eindruck entsteht, tendenziell sei man beim VDS von der Rechtschreibreform und auch von deren Reform nicht begeistert (vgl. u.a. Minder 2006a: 4).

Interessiert ist der Verein an der Einführung einer Deutschquote im Bereich Pop-Musik (vgl. u.a. Krämer 2007c: 2). Außerdem spricht er sich gegen die Einführung von Bachelor- und Masterstudiengängen an deutschen Universitäten aus (vgl. u.a. SN 2003c: 6, Schrammen 2005b: 7). ${ }^{603}$

Zudem beschäftigt er sich mit der Frage, ab welchem Alter Kinder in Schulen Englisch lernen sollten. Fremdsprachunterricht in Kindergärten und Grundschulen lehnt er ab (vgl. Baer 2008b: 9).

Regionalgruppen des VDS engagieren sich im Bereich Deutschunterricht für Migrantenkinder. Die Förderung der deutschen Sprache, beispielsweise in Form von Lesepatenschaften, soll eine zunehmende Rolle spielen, ebenso das Heranführen von Kindern an das Dichten, u.a. durch Lesungen oder Wettbewerbe. ${ }^{604}$

Basismitglieder fordern immer wieder, sich auch anderer Tätigkeitsfelder anzunehmen:

Wir sollten die Sprache ganzheitlich behandeln und schützen. Allein, in der Hauptsache, nur gegen die Fremdwörter aus dem Englischen oder Amerikanischen vorzugehen, halte ich für zu wenig. Da dürfte sich der Verein nicht „Verein Deutsche Sprache“ nennen, sondern „Verein gegen Anglizismen“ (Brief eines VDS-Mitglieds an den VDS, 6. Juni 2002).

Gefordert wurde auch die Abschaffung von <sch> zugunsten des <宛 (vgl. Brief eines VDS-Mitglieds an Walter Krämer, 16. Februar 2001). Auf solche Vorschläge wird beim VDS jedoch nicht eingegangen.

Das Engagement in Bereichen, die nichts mit dem Anglizismus im Deutschen zu tun haben, beschränkte sich in der Regel auf wenige Aktionen oder Briefe. Erst in der jüngsten Zeit sind neue Aktionsfelder zur

${ }^{602}$ Gespräch mit Holger Klatte, Geschäftsführer des VDS, 28. November 2008. Beispielsweise sollen für die Getrennt- und Zusammenschreibung eigene Regeln erarbeitet werden.

${ }^{603}$ Um diese Forderung durchzusetzen, gibt es auch eine Arbeitsgruppe „Gegen das Diplomverbot“ (vgl. Schrammen 2005b: 7 und Kapitel 2.2.3).

${ }^{604}$ Gespräch mit Holger Klatte, VDS-Geschäftsführer, 28. November 2008. 
Vereinsarbeit des VDS dazugekommen. Es findet sich auf den Internetseiten des Vereins auch eine Deutschlehrer-Börse, über die online Deutsch-als-Fremdsprache-Lehrer an Institutionen und Firmen in aller Welt vermittelt werden können, wo sich sowohl Lehrkräfte als auch Institutionen/Anbieter registrieren lassen können (vgl. VDS 2008h). Doch bisher hat diese Deutschlehrerbörse nur wenig Erfolg. Aus diesem Grund gibt es seitens des Vereins Überlegungen, sie wieder einzustellen. ${ }^{605}$

Ein weiteres neues Geschäftsfeld ist das Sprachsiegel, das der VDS gegen eine Summe von 800 bis 9000 Euro an Firmen ${ }^{606}$, die besonders gutes Deutsch verwenden („klar, treffend, logisch“), verkauft (vgl. Mindner/Pogarell 2008a, Mindner/Pogarell 2008b). Als Träger des Sprachsiegels aufgelistet sind bisher Kieser-Training, tegut und www.projektdeutschland.de (Mindner/Pogarell 2008c). ${ }^{607}$ Daneben gib es laut Werbematerial des VDS mittlerweile eine Stellenbörse unter der Adresse www.kultur-nuetzt.de. Diese ist aber noch nicht aktiv (vgl. VDS 2009a). ${ }^{608}$

Vereinzelt wird gegen den Wandel in den Schwerpunkten der Vereinsarbeit auch Kritik von Mitgliedern laut, die das Gefühl haben, der VDS habe ohne basisdemokratische Entscheidung sein Tätigkeitsfeld ausgeweitet:

Ich bemerkte beim letzten Lesen der Sprachnachrichten, daß der Verein für Dinge eintritt, die ich gar nicht mittragen möchte. Ich bin [...] gegen eine Quote für deutsche Musik. Ursprünglich trat ich dem Verein bei, weil ich gegen die zunehmenden überflüssigen Anglizismen in der deutschen Sprache etwas tun wollte. Jetzt aber fällt mir

${ }^{605}$ Gespräch mit Holger Klatte, VDS-Geschäftsführer, 28. November 2008. Die Einnahmen aus der Deutschlehrerbörse gehen an die Agentur medfux.

${ }^{606}$ Der Preis hängt vom Umfang des geprüften Produkts ab. Die Auffrischung kostet dann noch ein Fünftel des Erstbetrags (Mindner/Pogarell 2008b). Bisher hat das Sprachsiegel aber nach Angaben von Holger Klatte keine Einnahmen gebracht (Information aus E-Mail von Holger Klatte an die Verfasserin, 12. Oktober 2009).

${ }^{607}$ Hiermit hat der VDS den Unmut der DSW auf sich gezogen. Diese prangert an, dass der VDS damit ein altes Geschäftsmodell aufgegriffen habe und dass andere Anbieter ein solches Siegel bereits ab 20 Euro vergeben würden, der Bautzener Sprachrettungsklub sogar kostenlos (vgl. Deutsche Sprachwelt 2007b).

${ }^{608}$ Die Einnahmen aus dem Verkauf des Sprachsiegels gehen an die Agentur medfux. Nach welchen Kriterien das Sprachsiegel vergeben wird, ist aus den Informationen zum Sprachsiegel nicht ersichtlich. 
auf, daß der Verein seine Interessen ausgeweitet hat. Vielleicht bin ich nicht auf dem laufenden, aber wurde diese Ausweitung der ,Einsatzgebiete' denn eigentlich mehrheitlich beschlossen? (Leopold 2005: 22).

Es deutet sich also ein Wandel hinsichtlich der Arbeit des VDS und der Schwerpunkte der Vereinsarbeit an. Dahingehend ist auch die Aussage des Geschäftsführers des VDS zu werten, der die Arbeit des Vereins als eine kulturpolitische sieht. Für die Zukunft wolle man weg von einer reinen Anglizismenkritik und weg vom Protest hin zu einer konstruktiven Vereinsarbeit zur Förderung der deutschen Sprache, basierend auf wissenschaftlichen Grundfesten, bestehend aus Kulturveranstaltungen und der Förderung von Projekten in diesem Rahmen. ${ }^{609}$ Nicht zu vernachlässigen ist an dieser Stelle auch die Arbeit der Stiftung Deutsche Sprache, die mittlerweile zu einem Schwerpunkt der Arbeit des VDS geworden ist (vgl. voriges Kapitel). Insgesamt zeichnet sich der Verein, wie in diesem Kapitel dargestellt wurde, durch eine von Anfang an rege Vereinsarbeit aus, die sich von Jahr zu Jahr weiter steigert, und die dem VDS zunehmend Ansehen in der Öffentlichkeit bringt.

\subsection{Der Verein Deutsche Sprache und Rechtsextremismus}

Rechtsextremismus war schon früh ein Problem für den VDS, denn die Thematik zieht Menschen aus dem rechten Lager an. So läuft der VDS immer noch Gefahr, dem rechten Lager zugeordnet $\mathrm{zu}$ werden. ${ }^{610}$ Schon für das Jahr 1998 ist festzuhalten, dass sich immer wieder Menschen, die zu den Informationsständen des Vereins kamen und dort angesprochen wurden, als DVU-Anhänger zu erkennen gaben (Protokoll der VWDS-Vorstandssitzung vom 8. Juli 1998).

In den Medien fällt das Urteil unterschiedlich aus. Der Bonner Generalanzeiger zum Beispiel schreibt am 19. März 1998, es sei darauf zu ach-

${ }^{609}$ Gespräch mit Holger Klatte, Geschäftsführer des VDS, 28. November 2008.

${ }^{610}$ Es wird immer wieder vermutet, dass diese Gruppierungen eventuell als Agitationskader benutzt werden, die nach außen wirken sollen, um das Themenfeld zu besetzen und dort neue Anhänger zu rekrutieren. Inwieweit eine solche Vermutung zutreffen könnte oder reine Spekulation ist, müsste aber eine eigene Untersuchung klären. 
ten, „die Ziele seiner Gruppierung [des VWDS, Anm. der Verf.] nicht mit Fremdenfeindlichkeit in einen Topf zu werfen" (Walledorf 1998: 13). Dagegen berichtet die Süddeutsche Zeitung, der VDS stünde im Verdacht „Hort für übereifrige Deutschtümelisten zu sein“ (Forster 2000: 43). Anne Riedel berichtete am 22. März 2001 in der Frankfurter Rundschau über Hinweise, dass Kassel als Ort der Preisverleihung des Kulturpreises Deutsche Sprache (vgl. Kapitel 2.5.4.3) mit dem VDS einen "Verein aus der Grauzone zwischen dem rechten Rand demokratischer Parteien und extremster Rechten" nach Kassel geholt hat (Riedel 2001: 30). Doch in den letzten Jahren ist diese Diskussion weitestgehend aus den Medien verschwunden - die Berichterstattung über den Verein ist zumeist neutral oder positiv. ${ }^{611}$ Einige Mitglieder befürchten dennoch, mit Rechtsextremismus in Verbindung gebracht zu werden:

Nach den Erfahrungen der Mannheimer Tagung [gemeint ist die Tagung des IDS im Jahr 2000, Anm. d. Verf.] des „VDA - Verband der Abwiegler Deutschlands“ (für die dort versammelte Elite der deutschen Sprachwissenschaft) [sic] muß mit solchen Versuchen durchaus gerechnet werden, denn dort haben sich gleich zwei der versammelten Elitemenschen $\mathrm{zu}$ der Äußerung verstiegen, unsere Grundsatzschrift „Leitlinien“ sei „das Gebetbuch des Untermenschen“. Ähnliches ist auch den grau gewordenen Apologeten der „political correctness“ zuzutrauen - denn wir werden diesen Leuten offenbar langsam unbequem (Rundschreiben eines VDSVorstandsmitglieds an die Vereinsmitglieder, 3. August 2000).

Dass dies geschieht, zeigt beispielsweise ein Blick auf die Internetseiten von Horst Hensel, der zu seiner Verteidigung gegen den Vorwurf, durch sein Engagement beim VDS lasse er sich mit Rechtsextremen ein, einen Auszug eines Kommentars aus der Westfälischen Rundschau vom 12. Mai 2001 abgedruckt hat. Dort heißt es:

Die Anschuldigungen [...] gegen den Kamener Schriftsteller und Lehrer Horst Hensel sind ungerechtfertigt und ungeheuerlich. Sowohl die Biografie Hensels als auch sein neuer Roman (Stauffenbergs Asche) weisen ihn als Gegner rechtsradikaler Strömungen aus. [...] Die jetzt erfolgten linken Attacken sind in keiner Weise zu rechtfertigen (Hensel 2001).

Hensel berichtet auch von Verdächtigungen, denen er auf Tagungen des Schriftstellerverbands ausgesetzt sei (Protokoll der VWDSVorstandssitzung vom 8. Juli 1998).

${ }^{611}$ Positive und neutrale Berichterstattungen über den VDS waren schon an anderer Stelle Thema dieser Arbeit, vgl. Kapitel 2.5. 
Schon in den Sprachnachrichten vom März 1999 ist Rechtsextremismus in einem Artikel des Vorstands des Vereins thematisiert:

Neuerdings werden wir ganz besonders dem Vorwurf ausgesetzt, unser Verein gäbe Rechtsradikalen ein Forum. [...] Hierbei geht es in der Sache darum, dass sich wohl einige wenige Menschen in unseren Verein [...] eingeschlichen haben, deren demokratische Haltung zu bezweifeln ist. Sie haben bei uns aber nichts zu suchen! Menschen, die einer rechtsradikalen oder nationalistischen Vereinigung angehören, bei ihnen mitarbeiten, bei ihnen auftreten, an ihren Veranstaltungen teilnehmen oder in ihren Publikationsorganen veröffentlichen, gehören nicht in unseren Verein, sondern werden ausgeschlossen [...] Bei Licht betrachte [sic] zeigt es sich, dass es im Missverstehens [sic] unseres Vereins, seiner Ziele und Tätigkeiten liegt, dass einige Rechtsradikale ihn benutzen und funktionalisieren möchten (Bullermann et al. 1999: 6).

Intern wird über das Thema Rechtsextremismus viel diskutiert:

Ich schlage vor, daß sich unsere Netz-Intelligentia auch dieses Themas annimmt und insbesondere Strategien entwickelt, wie wir möglichen Versuchen begegnen, die uns böswilligerweise in Verbindung mit diesen widerwärtigen Glatzköpfen bringen wollen. [...] Ich halte es aus VDS-spezifischen Gründen für erforderlich, daß wir uns auf solche möglichen Unterstellungen vorbereiten [...] (Rundschreiben eines VDS-Vorstandsmitglieds an die Vereinsmitglieder, 3. August 2000).

Der VDS wendet sich entschieden gegen jegliche Vorwürfe des Rechtsextremismus:

Wir [...] lehnen es aber ab, daß ein Einsatz für die Sprache zur Verfol-

gung nationalistischer Ziele mißbraucht wird (VDS 2004b).

Auch thematisieren Vereinsmitglieder und der Vorsitzende die Problematik in den Medien (vgl. u.a. Tschapke 2005b). Gerade in den Anfangsjahren grenzte sich der Verein auf seiner Internetseite expressis verbis von nationalistischen Zielen ab: „Wir [...] arbeiten mit anderen europäischen Organisationen [...] zusammen, sofern diese [...] keine nationalistischen Zwecke verfolgen“ (VDS 2003f). Er war auch dem Netzwerk gegen Rechtsradikalismus ${ }^{612}$ beigetreten, wie aus der Pressemitteilung des Vereins vom 15. Mai 2001 hervorgeht (VDS 2001a). Dies war wohl als „Akt von Symbolkraft“ zu verstehen (Pfalzgraf 2003a: 106), kam aber bei

612 (www.netzgegenrechts.de). 
einigen Mitgliedern überhaupt nicht gut an. ${ }^{613}$ Wegen der Vorbehalte seitens der Mitglieder ist der VDS wieder ausgetreten:

Um einige davon ist es nicht besonders schade, um andere dagegen schon. Deshalb versteht es sich von selbst, daß ich als Vereinsvorstand zunächst einmal die Notbremse ziehen musste, um weiteren Schaden vom Verein abzuwenden (Protokoll der VDSVorstandssitzung vom 17. Juli 2002).

Damit zusammen hängt auch die Gründung der AG „Demokratische Linke gegen politische Diffamierung des VDS“ durch Fritz Vilmar im Jahr 2000. Diese wurde 2002 wieder aufgelöst, da sie nicht tätig geworden war (vgl. Protokoll der VDS-Vorstandssitzung vom 20. September 2002).

Rechtsextremismus ist auch immer wieder Thema von Vorstandssitzungen, so wird beispielsweise 2002 beschlossen:

[...] ein Verweis im Impressum soll verhindern, daß der VDS für Verbindungen $\mathrm{zu}$ rechtsextremen Seiten verantwortlich ist ${ }^{614}$ (Protokoll der VDS-Vorstandssitzung vom 20. September 2002).

In späteren Sitzungen steht die Problematik ebenfalls immer wieder auf der Tagesordnung. Ein weiterer Vorwurf gegenüber dem VDS ist, dass er rechtsextremes Gedankengut in die Mitte der Gesellschaft trage. Auch dagegen wehrt sich der Verein, indem er argumentiert, dass Menschen aus allen politischen Lagern die Forderungen des VDS unterstützen und dass diese nicht allein deshalb falsch sein können, weil Leute aus dem rechten Lager sie befürworten (vgl. Dieter/Schrammen 2005: 94).

Auch die tendenziell rechte Presse hat Interesse am Verein: Die Junge Freiheit hat beispielsweise 2004 einen Artikel mit Titel „Der Klügere spricht Deutsch“ (Schwarz 2004: 3) veröffentlicht und ein Interview mit Diethold Tietz geführt (zu dem Zeitpunkt Vorstandsmitglied). In diesem Interview sind auch die Aufkleber des VDS abgedruckt. Unter den Aufkleber mit der Aufschrift „Der Klügere spricht Deutsch.“ hat der Autor der Jungen Freiheit „Nationale Würde“ geschrieben (vgl. Schwarz 2004:

${ }^{613}$ Diese behaupteten, das Netz gegen Rechts wäre eigentlich eine „TAZ gegen Rechts“, denn andere Quellen würden wenig vorkommen. Einige Mitglieder sind wegen des einschlägigen Internet-Verweises auf das Netz gegen Rechtsextremismus auch ausgetreten, haben mit Austritt gedroht oder Nicht-Mitglieder begründeten es mit der Kooperation, dass sie nicht dem VDS beitreten möchten (vgl. Protokoll der VDS-Vorstandssitzung vom 17. Juli 2002, vgl. u.a. Brief eines VDS-Mitglieds an Walter Krämer, 29. Mai 2002).

${ }^{614}$ Siehe weiter unten in diesem Kapitel. 
3). ${ }^{615}$ Insgesamt gibt es zum Umgang mit Zeitungen mit nationalistischen Tendenzen eine allgemeine Vereinslinie: Interviews geben ja, Artikel schreiben nein. ${ }^{616}$ Unverlangte Zusendungen von Publikationen von politisch rechtsgerichteten Gruppierungen verzeichnet der VDS immer wieder, wie zum Beispiel die Zusendung der „Huttenbriefe für Volkstum, Kultur, Wahrheit und Recht“. ${ }^{617}$ Diese wurde auch an Mitglieder des VDS verschickt. Die Deutsche Gesellschaft zur Bewahrung der Deutschen Kultur in Düsseldorf sandte ebenfalls Informationsmaterialien in die Vereinszentrale (vgl. u.a. Protokoll der VWDSVorstandssitzung vom 8. Juli 1998), die Post wurde vom Verein nicht beantwortet, ${ }^{618}$ sondern in gesonderten Ordnern im Archiv in der Vereinszentrale aufbewahrt.

Auch wurde der VDS von Internetseiten rechter Gruppierungen aus verlinkt. Eine davon, der Deutsche Sprachkampf (DSK), führte unter der Überschrift: „Hier finden Sie die Verweise zu den Unterstützern des D.S.K.“ zuoberst den VDS auf, der dort ebenfalls verlinkt ist (DSK 2003). Pfalzgraf weist darauf hin, dass ein Link auf der Seite des DSK zu den Rundbriefen des Vereins führte. Er kritisierte, dass sich das Logo des VDS auf externen Homepages rechtsgerichteter Gruppierungen befand (vgl. Pfalzgraf 2003a: 106f.) und bemerkt: „Inwiefern der VDS dies, wie auch die Nutzung des VDS-Logos billigt, ist unbekannt.“ (Pfalzgraf 2006: 243). Dass solche Homepages auf den Verein verlinken und das

${ }^{615}$ Der VDS führt in seinem Pressespiegel auch einen Artikel aus dem Eckartboten aus dem Jahr 1999 (vgl. Eckartbote 1999: 7). Dabei handelt es laut DÖW sich um eine politisch rechtsgerichtete Monatszeitschrift (vgl. z.B. DÖW 2006b). Dass der VDS auch diese Zeitschrift in seinem Pressespiegel aufführt, zeigt, dass man hier anscheinend um Vollständigkeit bemüht ist. Dabei ist der VWDS in diesem Artikel gar nicht erwähnt, vielmehr geht es um die IG Muttersprache.

${ }^{616}$ Walter Krämer im Gespräch vom 25. März 2005. Auch Krämer hat der Jungen Freiheit ein Interview gegeben (vgl. Schwarz 2000: 3). Diese Vereinslinie hat aber wohl keine Gültigkeit, die Junge Freiheit führt unter ihren Autoren die VDS-Funktionäre Menno Aden, Eva-Maria Kieselbach, Klaus Däßler und Gerd Schrammen (vgl. Junge Freiheit 2008). ${ }^{617}$ Vgl. Huttenbriefe 2006.Vgl. zu den „Huttenbriefen“ Mecklenburg (1996: 263f.) Die „Huttenbriefe“ werden publiziert vom Deutschen Kulturwerk Europäischen Geistes (vgl. u.a. DÖW 2006a, Mecklenburg 1996: 263f.). Der Freundeskreis Ulrich von Hutten, der die Hutten-Briefe verlegt, wird auch vom Verfassungsschutz beobachtet und ist Gegenstand des Berichts des Verfassungsschutzes (Bayerisches Staatsministerium des Innern 2007: 117).

${ }^{618}$ Gespräch mit Walter Krämer, 17. März 2005. 
Logo des VDS benutzen, stört aber auch die Mitglieder und Vorstandsmitglieder des VDS massiv:

Schlimm, daß der Verein mit Logo zitiert wird [gemeint ist die Homepage des Deutschen Sprachkampfs]. [...] Ich bin der Meinung, daß wir hier nicht tatenlos bleiben dürfen, sondern sofort etwas unternehmen sollten, um nicht in den braunen Sumpf hineingezogen zu werden (vgl. Brief eines VDS-Vorstandsmitglieds an Walter Krämer, 23. Juli 2002). ${ }^{619}$

Dazu ist anzumerken, dass der Vorstand des VDS und der wissenschaftliche Beirat sich gemäß der Aussage von Walter Krämer nach rechtlichen Mitteln, dagegen vorzugehen, erkundigt hätten. Nach dessen Angaben sei es nicht möglich, juristisch dagegen vorzugehen. ${ }^{620}$

In Pfalzgrafs Untersuchung wird auch darauf verwiesen, dass die Verdeutschungsliste, die auf der Homepage als „Unser Wörterbuch“ tituliert wird, weitestgehend mit der Liste des VDS übereinstimmt. Pfalzgraf wirft hier die Frage auf, inwieweit der VDS dem DSK eine Genehmigung für die Nutzung der Anglizismenliste erteilt hat. Krämer versichert, dies sei nie der Fall gewesen. ${ }^{621}$ Der Internetauftritt ist mittlerweile vom Netz, ${ }^{622}$ zeigte aber deutlich die Problematik auf, mit der der VDS zu kämpfen hat.

Pfalzgraf weist auch auf die Anzeigenpolitik des Vereins hin: Dieser hat im Huginn und Muninn, Organ der Arbeitsgemeinschaft Neureligiöser Stammesverbände Europas (ANSE), Anzeigen geschaltet. Diese Schrift charakterisiert er als „Neuheidnisches Neonazipamphlet“ (Pfalzgraf 2003a: 106). Er geht aber davon aus, „dass inzwischen in solchen Schriften nicht mehr inseriert wird“ (Pfalzgraf 2003a: 106).

${ }^{619}$ Vgl. auch Brief eines VDS-Vorstandsmitglieds an Walter Krämer, 24. Juli 2007.

${ }^{620}$ Dies ist in der Tat für den VDS problematisch: Auf einigen Internetseiten rechtsextremer Vereinigungen finden oder fanden sich Hinweise auf den VDS, wie zum Beispiel auf den Seiten des „Deutschen Sprachkampfs“ (vgl. Kapitel 1.4.3). „Dagegen sind wir juristisch leider machtlos“ Gespräch mit Walter Krämer, 25. März 2005.

${ }^{621}$ Gespräch mit Walter Krämer, 25. März 2005.

${ }^{622}$ Er ist aber im Internet-Archiv unter http://www.archive.org in der Version vom 28. Mai 2002 noch größtenteils zu finden

(http://web.archive.org./web20020528034429/http://despka.piranho.de, 8. Dezember 2006). Die Startseite fehlt zwar, aber viele andere Seiten sind archiviert. Unter http://web.archive.org/web/de/*/http://despka.piranho.de, 8. Dezember 2006, wird ersichtlich, dass die Seiten des Deutschen Sprachkampfes ein letztes Mal am 19. April 2005 geändert wurden. Dies bedeutet, dass sie seitdem nicht mehr online verfügbar sind. 
Unter Bezugnahme auf den Verein wurde ein Flugblatt „Aktion Klartext - Forum zur Wahrung der deutschen Sprache e.V." verteilt, das presserechtlich von den damaligen Mitgliedern Karl Mosler, Thomas Paulwitz, Hartmut Pilch und Siegfried Piotrowski verantwortet wurde. Dieses Flugblatt wurde vom Vorstand nicht gerade mit Wohlwollen zur Kenntnis genommen, da der Text nationalistisch ausgelegt hätte werden können und die Verteiler damit laut Vorstand gegen „ihre Treuepflicht“ gegenüber dem Verein verstoßen hatten (vgl. Protokoll der Ad-hoc-VDSVorstandssitzung vom 15. April 2000). ${ }^{623}$ Auch Vorträge von VDSMitgliedern sind nicht immer im Sinne des Vereins, so rückte ein Mitglied bei einem Vortrag vor den Rotariern in Celle den Verein in die rechte Ecke (vgl. u.a. Brief eines VDS-Vorstandsmitglieds an Walter Krämer, 23. Juli 2002, Brief eines VDS-Vorstandsmitglieds an Walter Krämer, 24. Juli 2007). Dem Vorsitzenden ist es nach eigener Aussage extrem wichtig, nicht in die Nähe rechtsextremer Vereinigungen gestellt zu werden. Dies ist glaubhaft, auch für Kritiker des Vereins:

\begin{abstract}
Es geht nicht darum, dem VDS vorzuwerfen, er sei rechtsextrem. Dies trifft sicher nicht zu. Wie in allen anderen Vereinigungen der Grauzone herrschen jedoch ein Denken und eine Atmosphäre vor, von der sich Rechtsextreme angezogen fühlen und wo sie sich bewegen, wie die Fische im Wasser. Die offenbar der sozialen Demokratie fernstehenden Grundpositionen vieler ihrer Anhänger machen es Rechtsextremen leicht, über diese Vereine ihr Gedankengut bis weit in die Mitte der Gesellschaft zu tragen (Büttner 2001).
\end{abstract}

$\mathrm{Zu}$ diesem Ergebnis kommt auch Spitzmüller: Er wertet die „vehementen Beteuerungen“ des VDS, nicht nationalistisch zu sein, folgendermaßen:

Das ist auch gut so und sollte durchaus ernst genommen werden; eine nationalistische oder gar nationalsozialistische Motivation muss man dem Verein nicht attestieren. Allerdings bewegt er sich mitten in dem [...] Diskurs um Nation [und] Nationalität [...] (Spitzmüller 2002: 255).

Pfalzgraf konstatiert ebenfalls die Bemühungen des Vereins, Abstand vom rechten Lager zu bekommen (Pfalzgraf 2003: 106). Der VDS kann

${ }^{623}$ In dieser Sache wurde laut Protokoll einstimmig beschlossen, den „Ehrenrat“ des Vereins (bestehend aus Kurt Gawlitta, Wolfgang Haße und Hermann Neemann) zu bitten, Ausschlussgründe gegen die Verteiler des Flugblatts zu prüfen. Im Oktober 2007 hieß es auf Nachfrage der Verfasserin aus der Vereinszentrale, einen Ehrenrat habe es nie gegeben (Angabe von Walter Krämer aus E-Mail von Christiane Dahl an die Verfasserin, 12. Oktober 2007). 
und darf auf keinen Fall als rechtsextreme Vereinigung angesehen werden, auch wenn er sich noch ausdrücklicher von Vereinigungen, deren Mitglieder teilweise der rechten Szene nahe stehen, distanzieren könnte oder den Hinweis auf das Netzwerk Deutsche Sprache von seinen Internetseiten entfernen könnte (Stand Juli 2008, vgl. VDS 2008f).

Beim VWDS/VDS kam und kommt es immer wieder zu Ausschlussverfahren gegen Personen, die Beziehungen in die rechtsextreme Szene unterhalten oder durch ihre Äußerungen auffallen. Diese Mitglieder stehen zunächst unter Beobachtung: „Die Problemmitglieder werden beobachtet, um rechtzeitig Gegenmaßnahmen ergreifen zu können“ (Protokoll der VWDS-Vorstandssitzung vom 16. Dezember 1999). Bereits 1998 wurde intern diskutiert, ob die Mitgliedschaft in Parteien wie der NPD oder der DVU als Ausschlussgrund genügen. Im Vorstand herrschte jedoch zunächst Konsens darüber, dass „in erster Linie ein vereinsschädigendes Verhalten, egal aus welcher Gesinnung heraus, zum Ausschluß führen sollte“ (Protokoll der VWDS-Vorstandssitzung vom 10. September 1998). Es wurde diskutiert, die Satzung zu ändern. In der geänderten Satzung hätte es dann geheißen:

Dies tun sie, wenn sie einer rechtsradikalen oder nationalistischen Vereinigung angehören oder sich zu den Zielen solcher Vereinigungen bekennen, wenn sie in ihnen mitarbeiten, bei ihnen auftreten, an ihren Veranstaltungen teilnehmen, in ihren Publikationsorganen veröffentlichen (Satzungsentwurf, vgl. Protokoll der VWDSVorstandssitzung vom 16. Dezember 1999).

Doch diese Satzung ist nicht in Kraft getreten. In einer späteren Pressemitteilung des Vereins heißt es:

Er [der VDS, Anm. der Verf.] wendet sich gegen Rassismus, Fremdenfeindlichkeit und Rechtsradikalismus (auch Linksradikalismus) in jeder Form. Entsprechende Äußerungen oder gar Handlungen von Mitgliedern sind ein Ausschlussgrund (VDS 2001a).

Mittlerweile wurden einige Mitglieder ausgeschlossen. ${ }^{624}$ Exemplarisch möchte ich hier auf das Ausschlussverfahren gegen den ehemaligen

\footnotetext{
${ }^{624}$ Die Frankfurter Rundschau verweist beispielsweise auf einen VDS-Regionalbeauftragten im Raum Essen mit einer rechtsextremen Biographie (Riedel 2001: 30). Hierbei handelt es sich, wie Pfalzgraf aufführt, um Michael Frank. Von diesem Mitglied hat sich der VDS getrennt. Zudem war laut Pfalzgraf der „ehemalige SS-Mann“ Hugo Roggendorf Regionalbeauftragter für Chile (vgl. Pfalzgraf 2003a: 105), Hugo Roggendorf war auch im Jahr 1998 bei einer Vorstandssitzung des Vereins persönlich anwesend (vgl. Protokoll der VWDS-Vorstandssitzung vom 10. September 1998) und ist nach wie vor Mitglied des VDS
} 
NPD-Vorsitzenden Günter Deckert eingehen. Nachdem die Mitgliedschaft von Deckert dem Vorstand im Dezember 2000 bekannt geworden war, schrieb Krämer an Deckert folgenden Brief:

Sie sind ehemaliger Vorsitzender der NPD. Die NPD und das Gedankengut ihrer Mitglieder werden von uns nicht toleriert. Nichts davon gehört in den ,Verein Deutsche Sprache'. Wir sind dem Grundgesetz verpflichtet und treten weltoffen und fremdenfreundlich auf. Ich fordere Sie auf, unverzüglich aus dem ,Verein Deutsche Sprache' auszutreten. Andernfalls werden wir ein Ausschlussverfahren gegen Sie einleiten (Brief von Walter Krämer an Günter Deckert, 24. Januar 2001).

Dieser Aufforderung ist Deckert nicht nachgekommen. Auf Antrag von Krämer wurde im Februar 2001 das Ausschlussverfahren gegen Deckert eingeleitet, das mit dem einstimmigen Ausschlussbeschluss endete (vgl. Protokoll der VDS-Vorstandssitzung 2./3. Februar 2001, Dokument 12). Deckert wurde dies schriftlich mitgeteilt:

[D]urch ihren Brief vom 27.01.2001 haben Sie kundgetan, daß Sie Ihren früheren radikalen Überzeugungen weiterhin anhängen. Außerdem stellen Sie in Aussicht, den VDS mit einem rechtsextremen Verein in Verbindung zu bringen (Brief von Walter Krämer an Günter Deckert, 8. Februar 2001. Dokument 20). ${ }^{625}$

Oft sah sich der Verein dem Vorwurf ausgesetzt, deutschtümelnd zu sein beziehungsweise deutschtümelnde Mitglieder zu haben. Von diesem Vorwurf grenzten sich der Verein und dessen wissenschaftlicher Beirat in der Vergangenheit immer wieder ab (vgl. z.B. Fink et al. 2000: 91). Krämer ergänzt aber, dass er bei einem Verein mit über 30000 Mitgliedern nicht ausschließen könne, dass auch solche Mitglieder darunter seien. Diese seien aber auf keinen Fall die Mehrheit (vgl. Spörri 2008). Das Problem teilt der VDS mit vielen anderen Vereinen in Deutschland, man kann es dem Verein und seinem Vorstand nicht zum Vorwurf machen.

(Abfrage der elektronischen Mitgliederdatenbank des VDS, 20. Januar 2009). Auch Dr. Albrecht Jebens, Funktionär der GfP, den das ARD-Magazin Panorama als „Rechtsradikalen“ bezeichnet (vgl. u.a. Steinhoff 2002), war Regionalbeauftragter des VDS. Hier muss dem VDS vorgeworfen werden, nicht gründlich genug zu sein bei der Auswahl seiner Funktionäre (vgl. auch Pfalzgraf 2003a: 107). Mittlerweile ist Jebens nicht mehr Mitglied des Vereins (Abfrage der elektronischen Mitgliederdatenbank des VDS, 20. Januar 2009).

${ }^{625}$ Günter Deckert ist ehemaliger Bundesvorsitzender der NPD, zu weiteren Informationen über Deckert vgl. Mecklenburg 1996: 282f. und 452f. u. sowie unter anderem Ernst 2000: 6, Leffers 2001). 


\subsection{Der Verein Deutsche Sprache und sein Verhältnis zur Sprachwissenschaft}

Das Verhältnis des VDS zur Sprachwissenschaft ist nicht einfach. Einerseits erhebt der VDS massive Vorwürfe gegen „die Sprachwissenschaft“: Der Verein kritisierte beispielsweise im Jahr 2003 noch in seinen „Argumenten zur deutschen Sprache“ die „nur akribisch beobachtenden Sprachwissenschaftler[ ]“ (Schrammen et al. 2003) sowie deren „Selbstüberhebung, mit der die Sprachwissenschaft auf die kulturpolitische Arbeit des VDS reagiert“ (Schrammen et al. 2003). Weiter wirft er der Sprachwissenschaft vor:

Die Sprachwissenschaft und die sprachpflegenden Institutionen haben ein viel zu enges Forschungsfeld, um aus eigener Kraft die Zusammenhänge von Sprache und Gesellschaft zu erhellen (Schrammen et al. 2003). ${ }^{626}$

Insgesamt wird seitens des VDS die Situation dahingehend bewertet, dass die Linguistik „sich aus ihrer Verantwortung gestohlen [habe]“ (Glück/Krämer 2000: 90). ${ }^{627}$ Pogarell meinte, dass sich die Sprachwissenschaft nicht für die deutsche Sprache einsetze, weswegen die deutsche Sprache eine andere Lobby benötige (Pogarell 2007a: 23ff.).

Ein Thema, weswegen die Sprachwissenschaft den VDS kritisiert, ist der Anglizismen-Index (vgl. Kapitel 2.5.1.3). Krämer reagiert darauf:

Zwar meinen immer wieder Leute aus dem Elfenbeinturm der etablierten Sprachwissenschaften, uns wegen dieser Liste kritisieren $\mathrm{zu}$ müssen, weil wir angeblich gegen irgendwelche Regeln der Germanistik verstoßen, aber da sage ich nur: Liebe Sprachwissenschaftler, Ihr habt über 50 Jahre mit den Händen in den Taschen zugesehen, wie unsere schöne deutsche Sprache den Bach hinuntergeht, greift Euch erstmal an die eigene Nase! (Krämer in Pohl 2005: 34)

Vielleicht um diesem Vorwurf entgegenzuwirken sind einige Sprachwissenschaftler Mitglied im VDS und an Publikationen des Vereins beteiligt. Zudem setzt sich der wissenschaftliche Beirat teilweise aus Sprachwissenschaftlern zusammen (vgl. Kapitel 2.2.2).

${ }^{626}$ Diese Behauptung ist nicht haltbar. Das Forschungsfeld der Sprachwissenschaft, das von der Morphologie über die Syntax bis hin zur Phonologie, Pragmatik, Semantik oder Lexikographie reicht, ist keinesfalls als eng zu sehen.

${ }^{627}$ Vgl. zu dieser Diskussion auch Pfalzgraf (2006: 77f). 
Der VDS ist mittlerweile verstärkt Gegenstand der Forschung geworden (vgl. auch Kapitel 1.4.3). Wohl angeregt durch Wiechers' Aufsatz aus dem Jahr 2001 beschäftigten sich auch Stukenbrock (2005), Spitzmüller (2003 und 2005) und Pfalzgraf (2006) ausführlich mit dem Verein, dessen Veröffentlichungen und Aktionen. In diesen Analysen wird der VDS teilweise massiv kritisiert. Spitzmüller beispielsweise bemängelt eine mangelnde Sensibilität bei Vereinsaktionen im Umgang mit der deutschen Geschichte und der puristischen Tradition, in der sich der Diskurs heute bewegt. Er wirft dem VDS „sprachgeschichtliche Naivität“ vor:

Diese sprachgeschichtliche Naivität drückt sich auch und gerade in der naiven Wiederverwendung von Begriffen und Strategien aus, die durch historische Konnotationen massiv aufgeladen sind und deshalb lange Zeit tabuisiert waren (Spitzmüller 2003: 254). ${ }^{628}$

Law kommt zu dem Schluss, der VDS zeichne sich teilweise durch „unwissenschaftliche[ ] und unreflektierte[ ] Vorgehens- und Ausdrucksweise“ (Law 2002: 81) aus. Sie ordnet den VDS „der negativ behafteten Bewegung des Fremdwortpurismus“ (Law 2002: 81) zu. Nussbaumer sieht in dem „sprachpolitische[n] Populismus“ des Vereins „eine materielle Verwandtschaft zu neueren populistischen Strömungen [...] in Migrations- und Asylfragen“ (Nussbaumer 2003: 117). Für ihn ist der VDS „wissenschaftlich nicht ernst zu nehmen - politisch dagegen umso ernster: Da wollen uns bestimmte Leute doch tatsächlich ein bestimmtes Reden aus- und ein anderes einreden“ (Nussbaumer 2003: 117). Außerdem kritisiert er, dass der Verein Ressentiments schüre und den öffentlichen sprachkritischen Diskurs vergifte. Er empfiehlt der Wissenschaft als Gegenrezept, sich der öffentlichen Sprachdebatte zu stellen (vgl. Nussbaumer 2003: 117f.).

Der VDS tritt nach Ansicht von Stukenbrock mit einem „Verbindlichkeitsanspruch [...] in der Anglizismenfrage“ (Stukenbrock 2005a: 243) auf. Sie stellt fest: „Es findet [beim VDS, Anm. d. Verf.] eine interdisziplinäre Vernetzung des sprachkritischen Anglizismen-Diskurses mit

${ }^{628}$ Vgl. auch die Einschätzung der Erfurter Aufkleberaktion durch Spitzmüller in Kapitel 2.5.2. 
dem Schuld- und Vergangenheitsbewältigungsdiskurs statt [...]“ (Stukenbrock 2005a: 238). ${ }^{629}$

Pfalzgraf sieht in dem Verein eine klar zu den sprachpuristischen $z u$ zählende Vereinigung, auch wenn das Selbstverständnis des Vereins ein anderes ist. Er bemängelt, dass der Verein keine Fremdwortdefinition gibt und ordnet ihn einer neopuristischen Strömung zu, die in Deutschland in der Zeit nach der Wiedervereinigung entstanden sei. Zudem hebt er die Ähnlichkeit mit früheren Sprachschutzvereinen, vor allem mit dem ADSV/DSV hervor (vgl. Pfalzgraf 2006: 90f. und Pfalzgraf 2006: 311).

Insgesamt neigen einige Sprachwissenschaftler bisher dazu, die Aktivitäten des Vereins eher kritisch zu beobachten. Dessen ist man sich beim VDS bewusst:

Der VDS hat in Wissenschaftskreisen keinen guten Ruf. Insbesondere die Philologien beachten den VDS kaum. [...] Der VDS gilt als ,Laienverein' in sprachlichen Fragen (Klatte 2007: 16).

Interessant ist auch, dass der VDS immer wieder den Duden kritisiert, z.B. weil in den Duden Wörter wie „downloaden“ oder "chatten“ aufgenommen wurden:

Auch wenn die Duden-Leute sich zehnmal nur als Beobachter und nicht als Richter sehen: Ihr Lexikon setzt Normen, und damit hat die Duden-Redaktion eine Verantwortung für die Entwicklung unserer Sprache, der sie sich nicht entziehen kann. Durch ihre bequeme Beobachter-Haltung geben die Duden-Mitarbeiter diese Fortentwicklung irgendwelchen Werbefuzzis und Cyber-Kretins (Der Spiegel) in die Hände, deren sprachlichen Auswurf sie getreulich kommentieren (SN 2000c: 1). ${ }^{630}$

Mittlerweile beschäftigen sich zwei Blogs von Sprachwissenschaftlern, der „Bremer Sprachblog“ und der Blog „Nörgeln, immer nur nörgeln“, mit dem VDS und weisen diesem manche Fehler nach. In „Nörgeln, immer nur nörgeln" setzen sich Autoren mit Publikationen des VDS auseinander, beispielsweise werden Heinz-Günter Schmitz’ Thesen von einer „Überflutung“ des Deutschen mit Anglizismen (vgl. Schmitz 2008: 5) angegriffen (Falk 2008). Und der Sprachwissenschaftler und Autor des Bremer Sprachblogs Anatol Stefanowitsch kritisiert in seinen Veröffentlichungen unter anderem die Verurteilung des Begriffs „body bag“

${ }^{629}$ Beim Anglizismendiskurs handelt es sich nicht um eine „Disziplin“.

${ }^{630}$ Hervorhebung im Original. 
(vgl. Stefanowitsch 2007a und Kapitel 2.4.2). Er berichtet auch von einer unangenehmen Begegnung mit VDS-Mitgliedern, die im Gespräch mit ihm Antiamerikanismus durchklingen ließen: „Er hat keine Minute gebraucht, um die sprachpflegerische Maske fallen zu lassen und durch dumpfen Antiamerikanismus zu ersetzen“ (Stefanowitsch 2007b). Nicht alle Blog-Einträge Stefanowitschs über den VDS sind jedoch kritisch, so weist er darauf hin, dass der VDS die fälschliche Herleitung des finnischen Worts „Kaffepaussi“ durch den Deutschen Sprachrat kritisierte (vgl. Stefanowitsch 2008).

\subsection{Der Verein Deutsche Sprache und die Gesellschaft für deutsche Sprache}

Das Verhältnis zwischen dem VDS und der GfdS ist nicht einfach. Seitens des VDS vermisst man in der Arbeit der GfdS das Vorgehen gegen Anglizismen im Deutschen. ${ }^{631}$ Im ersten Jahr nach Vereinsgründung hat Krämer versucht, die Zusammenarbeit der beiden Vereine zu aktivieren. Als Mitglied der GfdS hat er auf der Mitgliederversammlung der GfdS vom 10. Mai 1998 einen ausführlichen Antrag gestellt, dass die GfdS unter anderem eine Arbeitsgruppe zum Studium der Probleme durch Anglizismen einrichten, und sich an den Aktionen des VWDS, wie den Protestbriefen an die Deutsche Telekom, beteiligen möge. Dieser Antrag wurde mit 20 gegen 13 Stimmen (7 Enthaltungen) abgelehnt (vgl. Pflug/Frank-Cyrus 1998: 148, Zabel 2001b: 271). Dafür wurde Krämer aber eingeladen, in der Fremdwort-Kommission der GfdS mitzuwirken (vgl. Pflug/Frank-Cyrus 1998: 148). In einem Rundbrief Krämers an die Zweigvorsitzenden der GfdS heißt es: „Ich würde mich freuen, wenn Sie [...] vielleicht sogar einen unserer Redner zu einem

\footnotetext{
${ }^{631}$ In einem Sitzungsprotokoll des VDS-Vorstands heißt es: „Die wissenschaftlich mit der deutschen Sprache beschäftigten Personen hierzulande haben als Nachwirkung der Nazizeit entweder keinen Mumm oder kein Interesse daran, die deutsche Sprache hochzuhalten. Gleiches gilt für die Gesellschaft für deutsche Sprache in Wiesbaden“ (Protokoll der VWDS-Vorstandssitzung vom 10. September 1998). Diese Meinung hat Krämer publiziert: „Die wissenschaftliche, Gesellschaft für deutsche Sprache' erhält jedes Jahr mehr als eine Million Mark aus deutschen Steuermitteln. Dafür kümmert sie sich um alles Mögliche, nur nicht um das, was ihr Vereinsname verlangt“ (Krämer 1998b: 5).
} 
Vortrag einladen könnten“ (Rundbrief von Walter Krämer an die Zweigvorsitzenden der GfdS, 9. September 1998, Dokument 17). In dem Schreiben steht weiter: „Wie Sie im Protokoll der letzten Mitgliederversammlung Ihrer Gesellschaft sehen können, habe ich bereits dort eine engere Zusammenarbeit unserer Vereine angeregt, wenn auch vorläufig noch ohne Erfolg“. Über diese Ablehnung war man beim VDS wohl schwer enttäuscht:

Nachdem die Bemühungen um eine Kooperation mit der Gesellschaft für deutsche Sprache betr. die inflationäre Zunahme von Amerikanismen und Anglizismen in der deutschen Gegenwartssprache [...] als gescheitert angesehen werden müssen, bleibt dem Verein Deutsche Sprache nichts anderes übrig, als sich nach anderen Bundesgenossen umzusehen (Zabel 2001b: 280). ${ }^{632}$

Es kam dennoch zu kleineren Zusammenarbeiten: Horst Hensel vom VDS hat einmal einen Vortrag bei einem Zweigverein der GfdS gehalten (vgl. Protokoll der VWDS-Vorstandssitzung vom 11. April 1999). Darüber hinaus hat Krämer dem GfdS-Vorsitzenden Hoberg Briefe von Vereinsmitgliedern des VDS zu Forschungszwecken zur Verfügung gestellt (vgl. Hoberg 2001: 300). Krämer und Hoberg treffen sich auch hin und wieder zu Gesprächen, doch darauf beschränkt sich weitgehend die gemeinsame Arbeit. ${ }^{633}$

Im Jahr 2000 kam es bei einer Podiumsdiskussion des IDS zu einer Auseinandersetzung zwischen Krämer und mehreren anwesenden Linguisten (vgl. Zabel 2001b: 280, zur Auseinandersetzung vgl. Kapitel 2.9). Hoberg schrieb später an Krämer:

Wie ich ihnen in Mannheim schon sagte, bedaure ich ihr aggressives

Verhalten sehr, da wir dadurch keine Möglichkeit haben, mit ihnen zusammenzuarbeiten. Aber vielleicht kommen ja bessere Zeiten! (Brief der GfdS an Walter Krämer, 20. April 2000).

Daraufhin wurde Hoberg als Vorsitzendem der GfdS von Seiten des IDS empfohlen, Arbeitskontakte mit dem VDS abzubrechen (vgl. Zabel

\footnotetext{
${ }^{632}$ Mit Bundesgenossen gemeint sind die Sprachpflegevereine des Netzwerks Deutsche Sprache (vgl. Kapitel 1.7.14). Zabel selbst hatte beim VDS keine Funktion, hat aber im Auftrag des Vereins publiziert und als Herausgeber in seinen Publikationen Stellungnahmen des VDS veröffentlicht (vgl. u.a. auch Zabel 2003). Nach meiner Kenntnis gab es zu dieser Situation keine offizielle Äußerung vom Vorstand.

${ }^{633}$ Krämer merkt hierzu an, dass es einige Punkte gibt, in denen er und Hoberg durchaus übereinstimmen, wie zum Beispiel die Bedeutung des Deutschen als Wissenschaftssprache (Brief von Walter Krämer an die Verfasserin, 7. Januar 2009).
} 
2001b: 280). Seitens des VDS wurde der GfdS in diesem Zeitraum auch „sprachpolitische[s] Desengagement“ vorgeworfen (Vilmar 2001: 24). Auf der Vorstandssitzung des VDS vom 4. November 2001 wurde beschlossen, ein sachliches Gespräch mit der GfdS zu suchen (vgl. u.a. VDS 2001g: 1). Dabei wurde festgelegt, dass der VDS in Zukunft auf abfällige Äußerungen gegenüber der GfdS verzichten wolle:

Gegenseitige öffentliche Beleidigungen von Mitgliedern der beiden Vereine sind der Sache, um die sich beide Vereine bemühen, nicht förderlich. Die Vorstandsmitglieder des VDS werden künftig auf öffentliche verunglimpfende Bemerkungen über die GfdS und deren Mitglieder verzichten (Protokoll der VDS-Vorstandssitzung vom 4. November 2001).

Weiter heißt es dort: „Der VDS erwartet eine Stellungnahme der GfdS zu Punkt 2 des VDS-Beschlusses“ (Protokoll der VDS-Vorstandssitzung vom 4. November 2001).

Diese Stellungnahme erfolgte im Jahr 2002: Am 7. März 2002 kam es zu einem Gedankenaustausch zwischen Mitgliedern des VDS und der GfdS. Anwesend waren Karin Eichhoff-Cyrus und Rudolf Hoberg von der GfdS und Walter Krämer, Peter Ambros und Hermann Dieter vom VDS. Während des Treffens einigten sich die Anwesenden in diesem Punkt wie folgt: „Öffentliche Angriffe von Funktionsträgern der GfdS gegen den VDS, wie auch umgekehrt VDS vs. GfdS, sollen in Zukunft unterbleiben“ (Protokoll: Zusammenfassung des Gedankenaustauschs VDS-GfdS, 7. März 2002). In der Vergangenheit waren Begriffe wie "Gesichtserker-Puristen“ (die GfdS über den VDS) und „Nachtwächterbrigade“ (der VDS über die GfdS) gefallen. Auch in den Sprachnachrichten hatte es heftige Kritik an der GfdS gegeben:

Auch die Sprachforscher in der GfdS sollten sich endlich auf eine vielschichtigere Wirklichkeit einlassen und sich breiterer sozialwissenschaftlicher Erkenntnis öffnen. Die bloße Berufung auf ihre verdienstvolle, aber völlig unpolitische sprachpflegerische Arbeit seit 1947 und die Abwehr eines nicht vorhandenen Purismus des VDS helfen da nicht weiter (Dieter et al. 2002: 4).

Man einigte sich darauf, sich gegenseitig vorab über größere Aktionen $\mathrm{zu}$ informieren und darauf, dass die Beratungskompetenz der GfdS auch dem VDS zur Verfügung stehe.

Während des Treffens wurden außerdem die Ereignisse diskutiert, die nach Angaben von Hoberg zur „Frontstellung“ zwischen dem VDS und der GfdS geführt hatten. Schon hier zeigt sich Konfliktpotenzial, denn 
anders als Hoberg sieht Krämer keine „Frontstellung“. Einigkeit herrschte laut Protokoll nur insoweit, dass allen Beteiligten eine empirische Überprüfung dieses Sachverhalts als durchaus nützlich, aber schwer durchzuführen erscheine. Weitere Vorbehalte zeigten sich darin, dass die GfdS dem VDS die „Missachtung elementarer Grundsätze wissenschaftlicher Arbeitsweisen und Umgangsformen“ vorwirft, während der VDS der GfdS den „Rückzug auf reine Beobachtungsrolle“ und somit die Angst vor Werturteilen anlastet. Und auch in der Bewertung der Anglizismenfrage wird von „unüberbrückbaren Differenzen“ gesprochen. Den Vorschlag von Krämer, zukünftig zusammenzuarbeiten und beispielsweise zu aktuellen Themen gemeinsame Pressemitteilungen zu veröffentlichen, lehnte die GfdS ab (Protokoll der Zusammenfassung des Gedankenaustauschs VDS-GfdS vom 7. März 2002). Hier zeigt sich der Einfluss Hobergs, der dem VDS ablehnend gegenübersteht, weshalb Krämer auch versucht hatte, über die Vorstandsmitglieder und deren Kontakte zu GfdS-Mitgliedern die Vorstandswahl der GfdS im Mai 1999 dahingehend zu beeinflussen, dass nicht Hoberg, sondern sein Gegenkandidat Egon Hölder Vorsitzender der GfdS wird (Rundbrief von Walter Krämer an die VWDS-Vorstandsmitglieder, 15. Mai 1999). Doch Hoberg ist nach wie vor Vorsitzender der GfdS. Bisher hat es $\mathrm{m}$. W. keine weitere Zusammenarbeit zwischen dem VDS und der GfdS gegeben. Anzufügen ist an dieser Stelle, dass in der Ursprungssatzung des VDS das Vereinsvermögen im Falle einer Auflösung an die GfdS gefallen wäre (VWDS 1997: 3). Dies ist in der geänderten Satzung nicht mehr so, eingesetzt ist jetzt für diesen Fall die Deutsche Akademie für Sprache und Dichtung (VDS 2003c: 3). Auch bei den Kooperationspartnern auf der Internetpräsenz der GfdS ist der VDS nicht aufgeführt (vgl. GfdS 2006). Walter Krämer ist dennoch Mitglied der GfdS geblieben. ${ }^{634}$

${ }^{634}$ Information von Walter Krämer, aus E-Mail von Christiane Dahl an die Verfasserin, 12. Oktober 2007. 


\subsection{Der Verein Deutsche Sprache und das Institut für Deutsche Sprache}

In den Anfangszeiten des VDS hatte es Kontakte zum Institut für Deutsche Sprache gegeben. Die Möglichkeit einer Kooperation beinhaltete die Planung einer gemeinsamen Aktion „Sprachtelefon für Journalisten“ (Protokoll der VWDS-Vorstandssitzung vom 10. September 1998). Doch daraus ist nichts geworden. Das IDS hat eine Zusammenarbeit mit dem Verein abgelehnt (Brief des IDS an Walter Krämer, 8. September 1999). Der VDS und das IDS stehen mittlerweile in einem schwierigen Verhältnis zueinander, davon zeugen zum Beispiel Aussagen, nach denen der VDS das IDS als „Institut für dumme Sprüche“ (SN 2005e: 9) bezeichnet hat. Auch der Briefwechsel zwischen den Organisationen zeigt dies deutlich: Einer der Gründe für das schwierige Verhältnis ist offensichtlich eine Pressemeldung, die der VDS als Antwort auf eine dpa-Meldung, die ein Interview mit Wilfried Schütte in der Welt am Sonntag sinnentstellend und verkürzt aufgreift, herausgegeben hat. In diesem Telefoninterview erwähnte Schütte nebenbei, „dass Anglizismen wie download ins Wörterbuch gehörten, wenn sie allgemein akzeptiert würden“635 (Brief des IDS an Walter Krämer, 22. Juni 1999). In der daraufhin vom VWDS veröffentlichten Pressemeldung vom 25. Mai 1999 stand unter anderem:

\footnotetext{
Der „Verein zur Wahrung der deutschen Sprache e.V.“ will verhindern, daß englische Computer-Vokabeln [...] durch die Aufnahme in Wörterbücher auch offiziell zum Teil der deutschen Sprache werden. Der Vereinsvorsitzende Prof. Dr. Walter Krämer: „Ich kann die einschlägigen Vorschläge des Instituts für deutschen [sic] Sprache nicht nachvollziehen [...].

Der Verein will über politische Kanäle auf die Führung des Instituts Einfluss nehmen. Krämer: Weit über die Hälfte alle [sic] Bundesbürger lehnen die Überfrachtung unserer Sprache mit Anglizismen ab. Diese Menschen finanzieren mit ihren Steuern auch das Mannheimer Institut. Sie werden es sich nicht bieten lassen, was hier mit ihrem Geld geschieht (VWDS 1999b).
}

Dieser erste größere Konflikt zwischen dem VWDS und dem IDS als Vertreter der Sprachwissenschaft wird in den Medien thematisiert, und bringt den VWDS in die Öffentlichkeit (vgl. auch Spitzmüller 2005:

${ }^{635}$ Hervorhebung im Original. 


\section{7f.). Aber auch fernab der Öffentlichkeit schwelt der Konflikt weiter:}

Im Antwortschreiben des IDS wird Krämer „dumpfeste[r] Populismus“ vorgeworfen:

Die Gewinnung zuverlässiger Informationen ist wohl nicht Ihre Sache. Differenzierte Argumentationen geben nun mal populistisch wenig her. [...] Nachdem Sie nun [...] den Lesern einreden möchten, im IDS wurde mit ihrem Geld Schindluder getrieben - was ist nun Ihr nächster Schritt? Wie wäre es mit einem Aufruf, Brandbomben auf das IDS und dessen Mitarbeiter zu werfen? (Brief des IDS an Walter Krämer, 7. Juni 1999) ${ }^{636}$

In einem weiteren Brief des IDS an Walter Krämer steht:

Übel nehmen wir Ihnen die Drohung mit den „politischen Kanälen“ und den Steuerzahlern, die das „Mannheimer Institut“ finanzieren. Wie schwer es ist, in Deutschland für die Erforschung und Dokumentation der Landessprache öffentliche Mittel zu erhalten, [...] können Sie sich vermutlich kaum vorstellen. [...] Auf Drohungen mit politischer Einflussnahme oder einer Mobilisierung der Steuerzahler reagieren wir deshalb empfindlich (Brief des IDS an Walter Krämer, 22. Juni 1999).

Zudem vergleicht das IDS den VWDS mit dem ADSV/DSV:

Ich etwa halte die Frage nach der Stellung des Deutschen in einem auch künftig hoffentlich mehrsprachigen Europa für erheblich wichtiger als Fremdwortjagd nach dem Vorbild des (Allgemeinen) Deutschen Sprachvereins der Vorkriegszeit (Brief des IDS an Walter Krämer, 22. Juni 1999).

Weitere Vorbehalte Krämers gegenüber dem IDS zeigen sich deutlich in dieser Aussage:

Sie haben eben zu viele Mitarbeiter, die sich als reine Wissenschaftler und nicht als Sprachfreunde begreifen [...]. Das ist das gleiche, als würde ich als Statistiker und Ökonom die Arbeitslosigkeit und die Inflation rein deskriptiv behandeln, ohne Wertungen abzugeben und ohne Möglichkeiten zur Vermeidung aufzuzeigen (Brief von Walter Krämer an das IDS, 16. Juni 1999).

Insgesamt wirft der VWDS/VDS dem IDS „Abstinenz in sprachpolitischen Dingen“ vor: „Eben diese Abstinenz in sprachpolitischen Dingen ist aber genau das, was mich bei deutschen Sprachwissenschaftlern so aufregt“" (Brief von Walter Krämer an das IDS, 16. Juni 1999).

Das IDS grenzt sich deutlich vom VDS ab (vgl. auch Pfalzgraf 2006: 169). Dem Verhältnis zwischen dem VDS und dem IDS sicherlich nicht

${ }^{636}$ In dieser Erwiderung zeigt sich, wie sensibel man beim IDS auf den Vorwurf reagiert, Gelder nicht sinnvoll zu verwenden. 
zuträglich war die Tatsache, dass Krämer auf der Jahrestagung des IDS 2000 ausfällig wurde: Krämer hatte Peter Schlobinski als „Rotzlöffel“ bezeichnet (vgl. Kapitel 2.1.1 und 2.8). ${ }^{637}$

Ein Wandel deutete sich bei der Vorstandssitzung vom 20. Oktober 2002 an:

Gerd Schrammen hat Gerhard Stickel, den scheidenden Direktor des IDS, in Mannheim aufgesucht und ein fruchtbares Gespräch geführt. Mit dem Nachfolger Eichinger soll Kontakt aufgenommen werden (Protokoll der VDS-Vorstandssitzung vom 20. Oktober 2002).

Auch in den letzten Jahren wurden immer wieder Gespräche zwischen Vertretern des VDS und des IDS geführt. ${ }^{638}$ Das ist zumindest ein Anfang. Doch bisher hat sich meines Wissens keine weitere Zusammenarbeit zwischen dem IDS und dem VDS ergeben.

\subsection{Der Verein Deutsche Sprache und die Deutsche Sprachwelt}

Wie im Folgenden dargelegt wird, hat es vereinsintern beim VDS Überlegungen gegeben, mit der Deutschen Sprachwelt zu kooperieren. Thomas Paulwitz, Schriftleiter der Deutschen Sprachwelt, war bis zu seinem Ausschluss wegen vereinsschädigenden Verhaltens aus dem VDS Vereinsmitglied. ${ }^{639}$ Bereits im Protokoll der Vorstandssitzung vom 16. Dezember 1999 ist unter: „Umgang mit problematischen Mitgliedern“ verzeichnet, dass ein Vorstandsmitglied „einen Mahnbrief an das Mitglied Paulwitz [schreibt], sich nicht vereinsschädigend zu verhalten, da dies unserer Sache schadet“ (vgl. Protokoll der VWDS-Vorstandssitzung vom 16. Dezember 1999). 2000 kommt es zum Ausschluss.

${ }^{637}$ Wiechers merkt zu diesem Thema an: „Dazu [gemeint ist die Skepsis seitens der Sprachwissenschaft gegenüber dem VDS, Anm. d. Verf.] mag das ausfallende Verhalten des Vereinsvorsitzenden auf der Jahrestagung des Institut für Deutsche Sprache im März 2000 beigetragen haben, bei der dieser die versammelte Linguistik der Untätigkeit zieh und einzelne Vertreter des Fachs mit unschönen Namen bedachte“ (Wiechers 2001: 156). Unerwähnt bei Wiechers bleibt, dass Krämers Äußerungen anscheinend ein Angriff Schlobinskis auf Krämer vorausgegangen war. Dieser hatte Krämer und seinen Verein nach Krämers Angaben als politisch rechte Vereinigung angegriffen (Gespräch mit Walter Krämer, 17. März 2005).

${ }^{638}$ Brief von Walter Krämer an die Verfasserin, 7. Januar 2009.

${ }^{639}$ Brief von Walter Krämer an die Verfasserin, 7. Januar 2009. 
Es ist unter unserer Würde, hier wieder Kontakt zu suchen oder auf Kontaktwünsche einzugehen. Paulwitz ist aus dem VDS ausgeschlossen, basta. Insofern muss ich also den einschlägigen Auslassungen [...] widersprechen (Brief von Walter Krämer an den VDS-Vorstand, 15. Juni 2001). ${ }^{640}$

Der Ausschluss von Paulwitz hindert aber die Regionalgruppe Lübeck nicht daran, Paulwitz ausführlich auf ihren Internetseiten zu zitieren (VDS Lübeck 2008).

Neben Paulwitz gab und gibt es weitere Doppelmitgliedschaften: Der Vereinsvorsitzende des VfS war zunächst Hans-Manfred Niedetzky, der gleichzeitig VDS-Vorsitzender der Region Pforzheim, Nordschwarzwald war $^{641}$ (vgl. auch Kapitel 1.7.5). Paulwitz war es wohl auch, der eine Zusammenarbeit der beiden Vereine anregte. Er war für eine symbolische Spende vom VDS für die DSW, da er davon ausging, dass in die Überarbeitung der Wortliste des VDS die Wörter aus der zweiten Auflage seiner Publikation „Engleutsch? Nein danke!“ eingearbeitet werden (E-Mail von Thomas Paulwitz an ein VDS-Vorstandsmitglied, 31. Mai 2001). ${ }^{642}$ Einige Vorstandsmitglieder plädierten dafür. Im Verein wurde über eine Zusammenarbeit diskutiert, ein Vorstandsmitglied meinte beispielsweise, dass Kooperationen mit Paulwitz als Person durchaus vorstellbar wären:

\begin{abstract}
Mit Paulwitz als Einzelperson - JA, aber keinesfalls mit der Sprachwelt und allem, was dran hängt [gemeint ist die Kooperation mit dem VDS, Anm. d. Verf.] [...] Paulwitz kann ja durchaus bei beiden mitarbeiten, dagegen ist nichts einzuwenden. [...] Wenn die SW unsere Anliegen mit verbreitet, auch in Form von Beiträgen aus unseren Reihen - desto besser (E-Mail eines VDS-Vorstandsmitglieds an die Vorstandskollegen, 4. Juni 2001).
\end{abstract}

\footnotetext{
${ }^{640}$ Mit den einschlägigen Auslassungen gemeint ist unter anderem ein Schreiben eines Vorstandsmitglieds an Krämer: „[...] hat mir gegenüber erwähnt, es zeichne sich eine Mehrheit gegen eine versöhnliche Lösung mit Herrn Paulwitz ab. Ich fände dies verheerend! Ich möchte nochmals dringend dafür eintreten

1) Herrn Paulwitz aufzufordern, sich von der GbR formal verbindlich zu distanzieren,

2) ihn auf der Grundlage von 1) zu ermuntern, jetzt seine ganze Kraft nunmehr der

Spracharbeit im VDS zu widmen“ (Brief eines VDS-Vorstandsmitglieds an Walter Krämer, 18. Mai 2000).

${ }^{641}$ Mittlerweile hat er diese Funktion nicht mehr inne, ist aber nach wie vor Mitglied des VDS. Diese Information stammt von Sabine Riga, VDS-Geschäftsstelle, 28. November 2008.

${ }^{642}$ Weitergeleitet an den Gesamtvorstand am 31. Mai 2001.
} 
Auf einem Ausdruck der Mail hatte Krämer schon intern den Hinweis auf die Mitarbeit von Paulwitz als Einzelperson mit einem „bin dagegen!“ versehen. Mit seiner Linie hat sich Krämer durchgesetzt. Der Beschluss über die Ablehnung der Zusammenarbeit fiel auf der Vorstandssitzung vom September 2002: „Es soll keine Zusammenarbeit zwischen dem VDS und der Deutschen Sprachwelt geben“ (Protokoll der VDS-Vorstandssitzung vom 20. September 2002). Die DSW wurde darüber und über die sich daraus ergebenden Konsequenzen in Kenntnis gesetzt:

[N]amens des Vorstands des VDS muß ich Sie angesichts der Entwicklung auffordern, keinerlei Bezug zwischen dem Verein Deutsche Sprache (VDS) und Deutscher Sprachwelt (DSW) herzustellen oder eine Zusammenarbeit, gleich welcher Art, zu behaupten oder den Anschein einer Zusammenarbeit zu erwecken (Brief des VDS an die Deutsche Sprachwelt, 21. November 2001).

Dies gilt sowohl für die Druckversion als auch den Internetauftritt der DSW:

Über die bekanntgewordenen politischen Aktivitäten des ,zweiten Schriftleiters' Stefan Wunner ${ }^{643}$ verlieren wir nicht viele Worte. Sie müssen Ihnen bekannt sein. Die DSW ist für uns kein Partner (Brief des VDS an die Deutsche Sprachwelt, 21. November 2001).

Darin wird die Deutsche Sprachwelt aufgefordert, spezielle Links von den Seiten der DSW zum VDS zu unterlassen, und auf eine Nennung des VDS zu verzichten. Dennoch ist der VDS nach wie vor auf den Seiten der DSW verlinkt und genannt (Stand Dezember 2008, vgl. Deutsche Sprachwelt 2003a). Auch bestehen noch Kooperationen zwischen VDSRegionalgruppen und Paulwitz, beispielsweise hält Paulwitz nach wie vor Vorträge bei Veranstaltungen von VDS-Regionalgruppen, so war er im Mai 2010 beim Berliner VDS eingeladen (VDS Berlin 2010). ${ }^{644}$

${ }^{643} \mathrm{Zu}$ Wunner und dessen Kontakten siehe Kapitel 1.7.5.

${ }^{644}$ Dies bestätigt Paulwitz auch in einer E-Mail (E-Mail von Thomas Paulwitz an die Verfasserin, 4. Februar 2010). 


\subsection{Der Verein Deutsche Sprache und der Arbeitskreis Unsere Sprache}

Ursprünglich hatte man im VDS einer Zusammenarbeit mit dem Arbeitskreis Unsere Sprache nicht abgeneigt gegenübergestanden:

[...] betonen, daß deren Vorsitzender Dr. Alfred Mechtersheimer nicht in die rechte Ecke zu ordnen ist, sondern bei allen Gruppierungen Vorträge hält (Protokoll der VWDS-Vorstandssitzung vom 14. April 1998).

Doch ist bei den Mitgliedern des VDS schnell Ernüchterung eingekehrt. ARKUS hatte im Mai 1998 zu einer Tagung nach Frankfurt eingeladen (vgl. Kapitel 1.7.14). In den Sprachnachrichten war zu lesen, dass diese Tagung ein erster Versuch gewesen sei, verschiedene Initiativen zum Schutz der deutschen Sprache zu koordinieren. Gerhard Junker, der als einer von zwei VDS-Vertretern an dieser Tagung teilgenommen hatte, berichtete:

Dieser Arbeitskreis wird von dem immer mehr nach rechts tendierenden Alfred Mechtersheimer gesteuert. Es herrscht Konsens, hier keine weiteren Kontakte anzustreben (Protokoll der VWDSVorstandssitzung vom 8. Juli 1998). ${ }^{645}$

Junker notiert in den Sprachnachrichten:

$\mathrm{Zu}$ groß waren die politischen Unterschiede [...]. Unüberbrückbar waren die Meinungsunterschiede darüber, ob zum Wohle der deutschen Sprache auch die Unterstützung rechtsextremer Parteien und Gruppierungen angenommen werden sollte (Junker 2000: 2).

Dabei ist es auch geblieben, der VDS arbeitet nicht mehr mit dem ARKUS zusammen. Für den VDS und seine Mitglieder kommt eine Zusammenarbeit mit Rechtsextremen nicht in Betracht (Junker 2000: 2, vgl. auch Kapitel 2.6).

\subsection{Der Verein Deutsche Sprache im Netz- werk Deutsche Sprache}

Der VWDS versuchte schon 1998, mit Sprachvereinen in Österreich und der Schweiz zusammenzuarbeiten. Dies war zu Beginn schwierig (vgl.

${ }^{645}$ Dazu, dass sich die VDS-Mitglieder in ihrer Einschätzung der Person Mechtersheimer anscheinend getäuscht haben, vgl. Mecklenburg (1996: 491f.) sowie Kapitel 1.7.8. 
Protokoll der VWDS-Vorstandssitzung vom 10. September 1998). Erst im Jahr 1999 kam es zur Kooperation „Netzwerk Deutsche Sprache“. Der VWDS/VDS ist von Anfang an Mitglied dieses Netzwerks. Auf der Tagung der Interessengemeinschaft Muttersprache vom 9. bis 11. September 1999 waren Vertreter des VWDS anwesend (vgl. VDS 2003b). Der VDS war auch bei allen weiteren Tagungen des Netzwerks dabei, die sogenannte Bodenseekonferenz hatte er sogar ausgerichtet (vgl. VDS 2000b). Auch die Publikation zu dieser Tagung: „Ein See - Drei Länder - Eine Sprache“, herausgegeben von Hermann Zabel, erschienen im IFB-Verlag, kann als VDS-Publikation angesehen werden (vgl. Kapitel 1.7.14). Es gab laut Glück, dem ehemaligen stellvertretenden Vorsitzenden des wissenschaftlichen Beirats des VDS, ${ }^{646}$ Überlegungen im VDS, sich von diesem Netzwerk zu distanzieren. So wurde eine Tagung des Netzwerks im Jahr 2005 vom VDS abgesagt, seither hat keine mehr stattgefunden. Dennoch verweist der VDS nach wie vor im Internet auf das Netzwerk Deutsche Sprache. Die Seiten wurden aber nicht mehr aktualisiert. Schon auf die Klosterneuburger Entschließung im Jahr 2003, die der VDS noch unterzeichnet hat, wird nicht mehr hingewiesen (vgl. VDS 2003b). Dies kann als Indiz dafür gedeutet werden, dass der VDS sich zunehmend vom Netzwerk Deutsche Sprache distanziert. Gegen diese Vermutung spricht, dass es Überlegungen zu einem „VDS international“ gibt (vgl. Kapitel 1.7.14).

${ }^{646}$ Gespräch mit Helmut Glück, 19. Juni 2004. 



\section{Zusammenfassung und Ausblick}

Die Fremdwortdiskussion und die Sprachpflege sind keine Erscheinungen des 20. Jahrhunderts, sondern lassen sich zurückverfolgen über die frühen Lexikographen und die Fruchtbringenden Gesellschaften des Barock bis hin zu Luther oder Schottelius und Klopstock. Einen wesentlichen Beitrag zur Diskussion in Deutschland leistete der (Allgemeine) Deutsche Sprachverein. Mit seinem Slogan „Kein Fremdwort für das, was gut deutsch gesagt werden kann!“ kämpfte er gegen die Verwendung von Fremdwörtern in der deutschen Sprache.

Die Diskussion ist - heute wie früher - im Zusammenhang mit der Globalisierung $\mathrm{zu}$ sehen und eingebunden in einen übergeordneten Diskurs um Nation und Nationalität. Sprache und Nation stehen sowohl in metasprachlicher als auch in politischer Reflexion in einem Wechselverhältnis. Die gegenwärtige Diskussion, hauptsächlich geführt von Linguisten, Journalisten, Mitgliedern von Sprachvereinen und Politikern, ist geprägt durch Unstimmigkeiten bei den Fremdwort- und Anglizismendefinitionen: Während die Sprachwissenschaft darüber diskutiert, ob die Unterscheidung zwischen Fremd- und Lehnwort obsolet ist, betonen einige der sprachpflegenden Vereinigungen, dass sie sich nicht gegen das Fremdwort als solches, sondern nur gegen „überflüssige Anglizismen“ wenden. Häufig haben die Sprachvereine, auch aus der Situation heraus, dass sie keine sprachwissenschaftlichen Vereinigungen, sondern Bürgerinitiativen sind, gar keine Definitionen für sich festgelegt. Die Diskussion ist durch unterschiedliche Standpunkte geprägt. Die Sprachwissenschaft mit ihrem in der Regel rein deskriptiven Wissenschaftsverständnis steht Anglizismen lange Zeit meist neutral gegenüber. Dagegen vertreten viele Journalisten einen puristischen Standpunkt. Auch die Haltung vieler Mitglieder der sprachpflegenden Vereine und Organisationen kann durchaus als puristisch verstanden werden.

In der heutigen Zeit kann man kaum noch von einer Fremdwortdiskussion sprechen, es handelt sich meist um eine reine Anglizismendiskussion. In den ersten Jahren nach dem Zweiten Weltkrieg ist die puristische Haltung des vorher existierenden und die Fremdwortdiskussion maßgeblich mitbestimmenden ADSV/DSV spürbar. In den 60er Jahren veränderte sich dies, die Fremdwortfrage wurde in 
Deutschland neu diskutiert, unter anderem auf dem Münchner Germanistentag im Jahr 1966 (vgl. von Polenz 1967a: 79ff.). Ab diesem Zeitpunkt war in Deutschland eine liberale Haltung gegenüber dem Fremdwort im Deutschen vorherrschend, und nicht nur in der Sprachwissenschaft, auch in den Medien hatte man für Puristen eher Spott als Wohlwollen übrig.

Nach der Wiedervereinigung ist verstärkt eine Rückkehr zum Purismus zu beobachten, einige Sprachwissenschaftler sprechen vom „Neopurismus“, wobei dieser Begriff negativ konnotiert ist. Auch Kampfbegriffe wie „Denglisch“ oder „Engleutsch“ prägen zunehmend die Debatte. Die Anglizismenkritik nimmt ab diesem Zeitpunkt massiv zu. Die Bevölkerung bildet sich eine Meinung zu diesem Thema: Viele Menschen stehen den Anglizismen negativ gegenüber, haben Angst vor einem „Sprachverfall“. Sprachvereinigungen, ab 1997 auch der VDS, üben teils heftige Kritik an der Einstellung einiger Sprachwissenschaftler, umgekehrt ist bei einigen Sprachwissenschaftlern eine steigende Akzeptanz gegenüber der Sprachkritik als Aufgabe der Wissenschaft zu verzeichnen. In der Sprachwissenschaft kommt es hinsichtlich der Einschätzung von Anglizismen im Deutschen teilweise zu einer Wende. Einige Wissenschaftler, wie beispielsweise Harald Weinrich, die früher in der $\mathrm{Zu}$ nahme der Anglizismen keinerlei Gefährdung der deutschen Sprache sahen, haben ihre Meinung geändert. Weinrich ist sogar dem VDS beigetreten. Andere Wissenschaftler, wie Peter Eisenberg, kritisieren dagegen die Argumentation und die Arbeit der puristischen Sprachvereine. Die Anglizismenthematik wird zunehmend Gegenstand der Forschung, wobei zu beobachten ist, dass auch die Sprachpflege, die Diskussion um Sprachpflege und sprachpflegende Vereinigungen in das Blickfeld der Sprachwissenschaftler geraten.

Es kommt zu einer Politisierung des Diskurses. In der Politik waren die Anglizismen nach der Initiative von Eckart Werthebach ebenso ein viel diskutiertes Thema. Doch wie die Antworten auf Anfragen im Bundestag und in den Landesregierungen zeigen, werden die Anglizismen von vielen Politikern nicht als eine Gefahr für die deutsche Sprache gesehen und auch bezüglich einer Änderung der Gesetzgebung wird kein Handlungsbedarf gesehen. Interessant ist jedoch, dass mittlerweile Politiker 
in Reden hin und wieder Stellung gegen Anglizismen im Deutschen oder für eine Sprachreinigungsgesetzgebung beziehen.

Dennoch: Die Diskussion wird hauptsächlich in der Sprachwissenschaft, in sprachpflegerischen Vereinigungen und in den Medien geführt, und zwar in den beiden letztgenannten Gruppen so ausführlich, dass mittlerweile der Begriff der „Laienlinguistik“ oder „Volkslinguistik“ geprägt wurde (vgl. u.a. Antos 1996). Die zunehmende Präsenz in den Medien ist vor allem auf den VDS zurückzuführen, der als der aktivste sprachpflegerische Verein in Deutschland und auch im gesamten deutschsprachigen Raum angesehen werden kann. Neben dem VDS existieren zahlreiche weitere Vereinigungen, die sich der deutschen Sprache widmen. Hervorzuheben sind die GfdS als Nachfolgeorganisation des ADSV/DSV, das IDS, die Deutsche Akademie für Sprache und Dichtung oder auch der Deutsche Sprachrat. Diesen Organisationen ist gemein, dass sie Anglizismen in der deutschen Sprache nicht explizit bekämpfen. Dennoch sind sie sich der Thematik bewusst. Es gibt aber auch Organisationen, die sich explizit gegen Anglizismen wenden, wie der VDS, der BfdS oder der ARKUS. Die beiden letztgenannten Organisationen sind als problematisch zu beurteilen, da sie oder zumindest einige ihrer Funktionäre als politisch rechtsgerichtet gelten.

Der VDS kann als Kind seiner Zeit betrachtet werden: Die Entstehung fällt in die zweite Hälfte der 1990er Jahre, eine Zeit, in der sich der Fremdwortdiskurs in der Öffentlichkeit ausweitet. Der Verein ist eine Art der Auseinandersetzung der Deutschen mit ihrer nationalen Identität und ihrer Kultur, in Zusammenhang mit der Wiedervereinigung und den Entwicklungen in der Europäischen Union. Relativ zeitgleich mit dem VDS sind andere Sprachvereinigungen entstanden, wie der VRS, der Bautzener Sprachrettungsklub, der Verein zum Schutz der deutschen Sprache oder der Verein für Rechtschreibung und Sprachpflege, die teilweise sogar im VDS aufgingen. Das zeigt ein gewisses Bedürfnis der Bevölkerung nach dieser Art der Sprachpflege. Es scheint, als ob Walter Krämer mit der Gründung und der Vereinsarbeit des VDS den Zeitgeist getroffen hat. Die vorteilhaften Bedingungen durch den in der Öffentlichkeit geführten Diskurs erklären einen Teil des Erfolgs, den der Verein von Beginn an mit seiner Arbeit hat. Diese Situation hat sich in der jüngsten Vergangenheit sogar noch verstärkt: 2007 wurde in 
Deutschland noch eine Vereinigung gegründet, die „Neue Fruchtbringende Gesellschaft“, in der verschiedene Akteure der Sprachkritik, darunter Paulwitz, Niedetzky und Neemann (allesamt waren früher im VDS, Neemann sogar im VDS-Vorstand) zusammenarbeiten.

Der Verein Deutsche Sprache blickt auf eine über zehnjährige Vereinsgeschichte zurück. In dieser Zeit hat er sich von einem kleinen zu einem einflussreichen Verein mit mehr als 31000 Mitgliedern in über 70 Ländern gewandelt, der aufgrund der großen Mitgliederzahl eine gewisse Breitenwirkung hat. Ziel des VDS ist, gegen die Anglizismen im Deutschen vorzugehen, beziehungsweise das Thema in die öffentliche Diskussion zu bringen und Medien, Politik und Wirtschaft darauf aufmerksam zu machen. Wenn es auch einige Vereinigungen mit dem gleichen Ziel gibt oder gegeben hat, war und ist keine derzeit so einflussreich wie der VDS.

Im Mittelpunkt der Vereinsarbeit steht und stand dabei immer der Kampf gegen die Anglizismen im Deutschen, dies ist nicht nur die bedeutendste, sondern auch die umfassendste Aufgabe des Vereins. Daneben sind der Schutz des Deutschen als Wissenschaftssprache und die Einführung einer Quote für deutschsprachige Musik im Radio weitere Aspekte der Vereinsarbeit. Ganz vereinzelt beschäftigte sich der Verein mit der Rechtschreibreform oder mit anderen Zielen. Dies fällt jedoch in der Vereinsarbeit nicht ins Gewicht. In jüngster Zeit ist ein weiteres Ziel dazugekommen: die Forderung nach der Verankerung der deutschen Sprache im Grundgesetz. Hier ist zu erkennen, dass der Verein wieder offensiver agiert. Hatte man sich gegen eine Sprachgesetzgebung als Vereinslinie entschieden, so ist mittlerweile die Forderung nach der Verankerung im Grundgesetz im Verein Konsens. Dennoch zeigt sich hier bereits eine Änderung in der Vereinslinie, da man von der Forderung nach einem Gesetz nach dem Vorbild Frankreichs mit Verbot der Verwendung von Anglizismen Abstand genommen hat.

Die Vereinsarbeit des VDS besteht weitgehend aus Veranstaltungen, vor allem zum vom Verein ausgerufenen Tag der deutschen Sprache. Dazu kommen Publikationen, Vorträge, Briefwechsel mit Firmen, Institutionen, Journalisten und Politikern, Pressearbeit und Leserbriefe. Immer wieder ruft sich der Verein auch durch Einzelaktionen wie die Versteigerung der deutschen Sprache auf dem Internetportal eBay ins öf- 
fentliche Gedächtnis. Wichtige Teile der Vereinsarbeit sind zudem der professionelle Internetauftritt des Vereins sowie die Publikation Sprachnachrichten. Ein wesentlicher Aspekt ist die jährliche medienwirksame Verleihung des Sprachpanschers. Hinzu kommt der Kulturpreis Deutsche Sprache, ein Positivpreis, der in den Medien ebenfalls hohe Beachtung findet, und zu dessen positivem Image unter anderem Sympathieträger wie Vicco von Bülow alias Loriot als Preisträger beigetragen haben.

Der VDS zeichnet sich durch eine sehr aktive Vereinsarbeit und der Bundesverband durch eine hochprofessionell organisierte Öffentlichkeitsarbeit aus. Dadurch dürfte sich die Vorreiterrolle des VDS als Anglizismengegner mittlerweile noch gefestigt haben. Nicht zu Unrecht gilt er als Speerspitze der Anglizismenkritik. Von Anfang an verstanden die Mitglieder des VDS, die Medien durch professionelle Pressearbeit für ihre Zwecke zu nutzen. Davon zeugen zahlreiche Zeitungsartikel, mehrere Radio- und Fernsehbeiträge, sogar ein längerer Film, Mitglieder des VDS werden auch zu Talkshows eingeladen. Man kann von einer guten Zusammenarbeit mit den Medien sprechen, kein anderer Sprachverein ist so häufig in den Medien vertreten wie der VDS. Paradoxerweise sympathisieren die Medien, die selbst als Haupteinfallstor der Anglizismen gelten, zunehmend mit dem VDS. In Artikeln wird Krämer bisweilen sogar als anerkannter Sprachexperte tituliert. Dennoch gab und gibt es in den Medien kritische Stimmen.

Negativ anzumerken ist bezüglich der Öffentlichkeitsarbeit, dass die regionalen Internetseiten des Vereins teilweise neben optischen sprachliche Mängel aufweisen. Wegen der professionellen Medienarbeit des Bundesverbands und der meist guten Publicity kann man von einem relativ hohen Bekanntheitsgrad des Vereins ausgehen. Aufgrund der bisherigen Medienpräsenz des VDS und der medienwirksamen Aktionen wie den Sprachpreisen kann angenommen werden, dass der VDS auch in Zukunft maßgeblich den Diskurs mitbestimmen wird und im öffentlichen Bewusstsein verankert bleibt. Zahlreiche Prominente tragen zur Bekanntheit des Vereins bei und verleihen ihm ein positives Image.

Der Verein versteht sich selbst als Bürgerinitiative oder Volksbewegung und keinesfalls als akademischer Zirkel. Dementsprechend ist er ein 
Verein linguistischer Laien ohne wissenschaftlichen Anspruch. Einzig der wissenschaftliche Beirat macht hier eine Ausnahme. Doch dieser berät nur, wenn er ausdrücklich um Rat gebeten wird. Der VDS sieht sich als Interessenvertretung, als Stimme der Sprache, die bei der Sprachwissenschaft nach Meinung der Mitglieder keine Lobby hat. Die Mitglieder des VDS wollen zumeist nicht als Puristen verstanden werden, doch verfolgen sie sprachreinigende Ziele.

Die Vereinsarbeit ist durch eine stark emotionalisierte Einstellung gegenüber der Sprache geprägt (diese gleicht der der GfdS in früheren Jahren). Auch in der Einteilung der Anglizismen sowie in der Metaphorik, die in den Publikationen immer wieder verwendet wird, erinnert der Diskurs des VDS stark an den des ADSV/DSV beziehungsweise an den Diskurs aus den Anfangsjahren der GfdS.

Bei der Definition der Anglizismen und bezüglich der Frage, welche Anglizismen zu bekämpfen seien, gibt es keine Einheitlichkeit. Einzelne Regionalgruppen wandten sich sogar gegen Fremdworte an sich im Deutschen, doch hier ist es wohl zu einem Umdenken gekommen zumindest sind diese Forderungen aus den Internetauftritten der Regionalgruppen verschwunden.

Auffällig ist ein polemischer und teilweise aggressiver Ton in Publikationen und Medienauftritten. So tauchen Kriegs- und Krankheitsmetaphorik sowie Flut- und Überschwemmungsmetaphorik im Diskurs immer wieder auf. Ebenso werden Anglizismen mit Amerikakritik, mit der „Kolonialisierung“ oder „Kolonisierung“ Deutschlands und mit Sprache und Nation in Zusammenhang gesetzt. Negativ zu beurteilen ist, dass der Verein regelmäßig Bedrohungsszenarien aufbaut. Dies geht einher mit einer massiven Schelte der Wissenschaft und der "Sprachsünder“. Der Ton der Publikationen und der Briefe wird von den Mitgliedern des Vereins selbst als „fröhliche Aggressivität“ - eines der Ziele von Veröffentlichungen - verstanden. Doch gerade Briefaktionen gegen sogenannte Sprachhunzer werden von den betroffenen Personen teilweise als regelrechte Attacken empfunden. Auch einige Sprachwissenschaftler werten den Ton der Publikationen nicht als fröhlich, sondern unter anderem als „todernst“. Einige der Texte sind stark amerikakritisch, dies ist Teil des Selbstverständnisses des Vereins. Selbst wenn Krämer Wert 
darauf legt, nicht amerikafeindlich zu sein, die Publikationen des Vereins können teilweise durchaus so gedeutet und verstanden werden.

Als Schwachstelle in der Vereinsarbeit werden die Negativauszeichnungen des Vereins kritisiert, selbst wenn sie den Verein regelmäßig in die Medien bringen. Hier bleibt zu überlegen, ob nicht mit weiteren Positivpreisen mehr gewonnen wäre. Menschen oder Unternehmen an den Pranger zu stellen hat nichts mit der "fröhlichen Aggressivität“ $\mathrm{zu}$ tun, die der Verein immer wieder für sich propagiert, sondern ist gerade in Verbindung mit der Aufforderung, diese Menschen oder Firmen mit Briefen zu überschütten, unangebracht.

Es scheint jedoch, dass sich innerhalb des Vereins ein Bewusstsein für die Problematik aggressiven Auftretens und polemischer Publikationen entwickelt. Ein deutliches Zeichen für eine Veränderung im Verein war die Namensänderung von ursprünglich „Verein zur Wahrung der deutschen Sprache“ zu „Verein Deutsche Sprache“, ebenso die Satzungsänderung im Jahr 2007, in der "das Überleben der deutschen Sprache“ als Vereinsziel gestrichen wurde. In diesem Kontext ist auch die Distanzierung des Vereins von dem Begriff der „Selbstkolonisierung“ zu erwähnen.

$\mathrm{Zu}$ beklagen ist mitunter eine mangelnde Sensibilität beim Umgang mit dem heiklen Thema der Zeit des Nationalsozialismus in Deutschland, wie die Boykott-Aktionen vor einzelnen Geschäften oder die unglückliche Bezeichnung „Bodensee-Konferenz“ in der Vergangenheit gezeigt haben. Ebenso negativ zu bewerten sind die Artikel in den Sprachnachrichten, die deutlich nationalistische Töne anschlagen. Dennoch kann man den Verein als solchen nicht als nationalistisch ansehen: Der Vereinsvorstand wendet sich entschieden gegen rechtsextreme Tendenzen innerhalb des VDS. Die Ausschlussverfahren gegen Personen, denen Verbindungen zur rechtsextremen Szene nachgewiesen werden konnten, zeigen, dass der VDS nicht als rechtslastig gelten kann. Auch kann man die Publikationen und die Argumentationen des Vereins größtenteils nicht als nationalistisch bezeichnen. Ausländerfeindliche Elemente kommen nicht vor. Positiv zu bewerten ist, dass der VDS sich von einer Zusammenarbeit mit dem ARKUS sehr deutlich abgegrenzt hat. Es bleibt an dieser Stelle ein Beigeschmack: Dem Verein ist es bisher nicht gelungen, sei es aus Nichtwissen oder aus Bequemlichkeit, sich deutlich 
von Organisationen wie dem BfdS, die als rechtsgerichtet klassifiziert werden, zu distanzieren.

Nicht immer einfach ist das Verhältnis von Sprachwissenschaftlern zum VDS. Einige Sprachwissenschaftler stehen dem Verein skeptisch gegenüber. Sie kritisieren den Verein für seine antiakademische, unreflektierte und unwissenschaftliche Vorgehensweise, ebenso für den polemischen Ton seiner Publikationen, außerdem wird ihm vorgeworfen, er unterliege einer sprachgeschichtlichen Naivität. Die Kritik ist in weiten Teilen berechtigt. Der VDS wirft seinerseits der Sprachwissenschaft vor, sich nicht genug für die Erhaltung der deutschen Sprache einzusetzen. Eine Zusammenarbeit mit dem IDS und der GfdS ist in der Vergangenheit nicht gut verlaufen. Auch hier gab es viel gegenseitige Kritik und Vorwürfe.

Dass die Arbeit des VDS mittel- oder langfristig Spuren hinterlässt, ist mit hoher Wahrscheinlichkeit anzunehmen, denn es zeigt sich, dass der Verein mit Einzelaktionen durchaus Erfolg hat. Wichtiger aber ist, dass er über das Echo, das seine Arbeit in den Medien findet, relativ großen Einfluss auf die öffentliche Diskussion ausübt und die Anglizismendiskussion katalysiert. Insgesamt ist der Verein durchaus als puristische Vereinigung zu sehen, da Argumente und Einstellungen des puristischen Diskurses, der viele Jahre in Deutschland als nicht mehr vorhanden betrachtet worden war, wieder aufgenommen wurden und die Debatte um Anglizismen, aber auch um Identifikation mit Sprache und Nation, neu belebt haben. Wenn auch der Verein bisher einen geringen Beitrag zur Pflege der deutschen Sprache auf literarischer oder wissenschaftlicher Ebene geleistet hat, ist doch in neueren Protokollen vermerkt, dass dies in Zukunft zu den Zielen des Vereins gehören soll. Gedacht sind unter anderem an eine germanistische Zeitschrift sowie an einen großen wissenschaftlichen Kongress. Dies wäre eine Möglichkeit, der Vereinsarbeit in Zukunft einen positiven Aspekt hinzuzufügen.

Ein erster Schritt hin zu mehr konstruktiver Arbeit und weg von der reinen Sprachkritik ist die Gründung der Stiftung Deutsche Sprache. Auch die Mitarbeit am „Haus der deutschen Sprache“, das neben Lesungen und Kulturveranstaltungen Sprachberatung bietet, ist hier anzuführen; es deutet sich also ein Wandel an, sowohl den Diskurs des Vereins als auch die Arbeit des Vereins betreffend, weg von der Aggressivi- 
tät hin zur Kulturarbeit. Damit sind der Verein und die Vereinsarbeit auf einem guten Weg. Inwieweit sich dieser Wandel auch in Zukunft niederschlägt, wird sich zeigen. 


\section{Bibliographie}

\section{Literatur}

Aden, Menno (2007): Deutsch und Englisch. Zum deutschen sprachlichen und kulturellen Selbstbewusstsein. Paderborn.

Adorno, Theodor W. (1979): Wörter aus der Fremde. In: Braun, Peter (Hg.) (1979a): Fremdwort-Diskussion. München, S. 198-211.

Allenbacher, Peter (1999): Anglizismen in der Fachlexik. Unter Berücksichtigung mündlichen Belegmaterials in der Fachsprache des Fernsehens. Frankfurt.

Ammon, Ulrich (1998): Ist Deutsch noch internationale Wissenschaftssprache? Berlin.

Ammon, Ulrich (2000): Sprache - Nation und die Plurinationalität des

Deutschen. In: Gardt, Andreas (Hg.) (2000). Nation und Sprache. Berlin, S. 509-525.

Ammon, Ulrich (2004): German as an International Language of Science. In: Gardt, Andreas/Hüppauf, Bernd (Hgg.) (2004): Globalization and the Future of German. Berlin, S. 157-173.

Ammon, Ulrich/McConnel, Grant (2002): English as an academic language in Europe. A Survey of its Use on Teaching. Frankfurt.

Antos, Gerd (1996): Laien-Linguistik. Studien zu Sprach- und Kommunikationsproblemen im Alltag. Am Beispiel von Sprachratgebern und Kommunikationstrainings. Tübingen.

Augst, Gerhard (1977): Sprachnorm und Sprachwandel. Wiesbaden.

Bäcker, Notburga (1975): Probleme des inneren Lehnguts; dargestellt an den Anglizismen der französischen Sportsprache. Tübingen.

Bain Stiven, Agnes (1936): Englands Einfluß auf den deutschen Wortschatz. Zeulenroda. 
Bär, Jochen (2002a): Darf man als Sprachwissenschaftler die Sprache pflegen wollen? In: Zeitschrift für Germanistische Linguistik 30, 2002, Nr. 2, S. 222-252.

Bär, Jochen (2002b): Deutsch im vielsprachigen Europa. In: Der Sprachdienst 2002, Nr. 1, S. 33-36.

Barbour, Stephen (2000): Germany, Austria, Switzerland, Luxembourg: The Total Coincidence of Nations and Speech Communities? In: Barbour, Stephen/Carmichael, Cathie (Hg.) (2000): Language and Nationalism in Europe. Oxford, S. 151-168.

Barbour, Stephen (2001): Defending Language and Defending Nations: Some Perspectives on the Use of $>$ Foreign Words $<$ in German. In: Davies, M.C./Ford, J.L./Yeandle, D.N. (Hgg.): Proper Words in Proper Places. Studies in Lexicology an Lexicography in Honour of William Jervis Jones. Stuttgart, S. 361-375.

Baumert, Andreas (2005): Mit der Muttersprache auf Talfahrt. Paderborn.

Bayerisches Staatsministerium des Innern (2004): Verfassungsschutzbericht 2004. München.

Bayerisches Staatsministerium des Innern (2007): Verfassungsschutzbericht 2007. München.

Bernsmeier, Helmut (1977): Der Allgemeine Deutsche Sprachverein in seiner Gründungsphase. In: Muttersprache 87, 1977, S. 369-395.

Bernsmeier, Helmut (1983): Der Deutsche Sprachverein im „Dritten Reich“. In: Muttersprache 93, 1983, S. 35-58.

Betz, Werner (1936): Der Einfluß des Lateinischen auf den althochdeutschen Sprachschatz 1. Der Abrogans. Heidelberg.

Betz, Werner (1949): Deutsch und Lateinisch. Die Lehnbildungen der althochdeutschen Benediktinerregel. Bonn.

Betz, Werner (1974): Lehnwörter und Lehnprägungen im Vor- und Frühdeutschen. In: Maurer, Friedrich/Rupp, Heinz (Hgg.): Deutsche Wortgeschichte. Berlin, S. 135-163. 
Bickes, Hans/Trabold, Annette (1994): Förderung der sprachlichen Kultur in der Bundesrepublik Deutschland. Positionsbestimmung und Bestandsaufnahme. Stuttgart.

Blommaert, Jan (1999): The debate is open. In: Blommaert, Jan (Hg.): Language ideological debates. Berlin, New York, S. 1-38.

Böke, Karin (1996): Überlegungen zu einer Metaphernanalyse. In: Böke, Karin/Jung, Matthias/Wengeler, Martin (Hgg.) (1996): Öffentlicher Sprachgebrauch. Praktische, theoretische und historische Perspektiven. Opladen, S. 431-452.

Braun, Josef/Gawlitta, Kurt/Vilmar, Fritz (2002): Deutsches Sprachgesetz. Eine Kontroverse. In: Gawlitta, Kurt/Vilmar, Fritz (Hgg.) (2002): „Deutsch nix wichtig“?: Engagement für die deutsche Sprache. Paderborn, S. 151-154.

Braun, Peter (Hg.) (1979a): Fremdwort-Diskussion. München.

Braun, Peter (1979b): Fremdwörter als Internationalismen - Ein Beitrag zur interlinguistischen Behandlung von Fremdwortfragen, S. 95104.

Brekle, Herbert E./Lipka, Leonhard (Hg.) (1967): Wortbildung, Syntax und Morphologie: Festschrift zum 60. Geburtstag von Hans Marchand am 1. Oktober 1967. Den Haag.

Brunner, Otto (1951): Sprachwandlung oder Sprachverwilderung. In: Muttersprache 61, 1951, S. 277-289.

Brunner, Margot/Frank-Cyrus, Karin (Hgg.) (1998): Die Frau in der Sprache. Wiesbaden.

Brunner, Otto (1953): Die lieben Fremdwörter. In: Muttersprache 63, 1953, S. 257-259.

Brunow, Siegfried (1990/91): „Liebe Leserin! Lieber Leser!“. In: Die deutsche Schrift. Vierteljahreshefte zur Förderung der deutschen Sprache und Schrift, Sonderheft 1990/1991, S. 2.

Bundesministerium des Innern (2001): Verfassungsschutzbericht 2000. Berlin. 
Bundesministerium des Innern (2007): Verfassungsschutzbericht 2007. Berlin.

Bundeszentrale für politische Bildung (2008). Rechtsextremismus. In: $<$ http://www.bpb.de/themen/CNCDW9,57,0, Glossar.html\#art57> (27. November 2008).

Busse, Ulrich (1993): Anglizismen im Duden. Eine Untersuchung zur Darstellung englischen Wortguts in den Ausgaben des Rechtschreibdudens von 1880 - 1986. Tübingen.

Busse, Ulrich (2007): Englisch als Lingua Franca: Fluch oder Segen für Englisch und andere Sprachen. In: Muttersprache 117, 2007, S. 154-173.

Busse, Ulrich/Görlach, Manfred (2002): German. In: Görlach, Manfred (Hg.): English in Europe. Oxford, S. 13-36.

Buttmann, Rudolf (1933): An die Mitglieder des Deutschen Sprachvereins. In: Muttersprache 48, 1933, Sp. $89 \mathrm{ff}$.

Campe, Joachim Heinrich (1813): Wörterbuch zur Erklärung und Verdeutschung der unserer Sprache aufgedrungenen deutschen Ausdrücke. Ein Ergänzungsband zu Adelung's und Campe's Wörterbüchern. Neue stark vermehrte und durchgängig verbesserte Ausgabe. Braunschweig 1813. (1. Auflage 1801), Nachdruck der 2. Auflage. Hildesheim/New York 1970.

Carstensen, Broder (1965): Englische Einflüsse auf die deutsche Sprache nach 1945. Heidelberg.

Carstensen, Broder (1968): Zur Systematik und Terminologie deutschenglischer Lehnbeziehungen. In: Brekle, Herbert E./Lipka, Leonhard (Hg.): Wortbildung, Syntax und Morphologie: Festschrift zum 60. Geburtstag von Hans Marchand am 1. Oktober 1967. Den Haag, S. 32-46. 
Carstensen, Broder (1984): Wieder: Die Engländerei in der deutschen Sprache. In Joachim-Jungius-Gesellschaft (Hg.) (1984): Die Deutsche Sprache der Gegenwart. Vorträge, gehalten auf der Tagung der Joachim-Jungius-Gesellschaft der Wissenschaften, Hamburg am 4. und 5. November 1983, Göttingen, S. 43-57.

Carstensen, Broder/Busse Ulrich (1993-1996). Anglizismen-Wörterbuch. Der Einfluß des Englischen auf den deutschen Wortschatz nach 1945. 3 Bände. Berlin.

Carstensen, Broder/Galinsky, Hans (1975): Amerikanismen in der deutschen Gegenwartssprache. Entlehnungsvorgänge und ihre stilistischen Aspekte. Heidelberg.

Clay, Gudrun Fahrenkrog (1981): Neuere Versuche der Sprachpflege in den deutschsprachigen Ländern mit historischem Überblick. Ann Arbor.

Daniels, Karlheinz (1959): Erfolg und Mißerfolg der Fremdwortverdeutschung. Schicksal der Verdeutschungen von Joachim Heinrich Campe, II. Teil. In: Muttersprache 69, 1959, S. 105-114.

Däßler, Klaus (2001): Wurzeln der internationalen Sprachzerstörung. In: Hermann Zabel (Hg.) (2001): Ein See - drei Länder - eine Sprache. Tagungsband der Sprachvereine im „Netzwerk Deutsche Sprache“. Paderborn, S. 93-135.

Däßler, Klaus/Tietz, Diethold (2005): Der Klügere spricht Deutsch. VDSFotoaktion 2005. Dortmund.

Debus, Friedhelm (1996): Entwicklungen der deutschen Sprache in der Gegenwart - und in der Zukunft? Stuttgart.

Debus, Friedhelm (1999): Entwicklungen der deutschen Sprache in der Gegenwart - und in der Zukunft? Mainz.

Deubzer, Franz (1980): Methoden der Sprachkritik. München.

Deutsche Welle (2002): Passé und mega-out? Zur Zukunft der deutschen Sprache im Zeitalter von Globalisierung und Multimedia. Köln. 
Deutscher, Guy (2008): Du Jane, ich Goethe. München.

Dieckmann, Walther (1992): Sprachkritik. Heidelberg.

Diels, H. (1918): 4. Juli. Öffentliche Sitzung zur Feier des Leibnizschen Jahrestags. In: Sitzungsberichte der königlich preußischen Akademie der Wissenschaften 33 (1918), S. 677-687.

Dieter, Hermann (2001): Die Deutschen haben ein Sprachproblem. In: Wörter fallen nicht vom Himmel. Berlin/Potsdam, S. 11-18.

Dieter, Hermann (2002a): Ein offener Brief an die Kultusminister zur drohenden Anglisierung der deutschen Wissenschaftssprache und die politischen Reaktionen. In: Gawlitta, Kurt/Vilmar, Fritz (Hgg.) (2002): „Deutsch nix wichtig“?: Engagement für die deutsche Sprache. Paderborn, S. 86-96.

Dieter, Hermann (2002b): Die Unersetzlichkeit der Muttersprache auch für wissenschaftliche Kommunikation und Erkenntnis. In: Gawlitta, Kurt/Vilmar, Fritz (Hgg.) (2002): „Deutsch nix wichtig“?: Engagement für die deutsche Sprache. Paderborn, S. 97-107.

Dieter, Hermann/Gawlitta, Kurt/Meißner, Gernot/Vilmar, Fritz (Hgg.) (2001): Wörter fallen nicht vom Himmel. Berlin/Potsdam.

Dieter, Hermann/Schrammen, Gerd (2005): Reden und Widerreden Argumente für die deutsche Sprache. Paderborn.

Dietzsch, Martin/Maegerle, Anton (1995): Gralshüter der deutschen Schrift und Sprache. In: <http://www.diss-duisburg.de/Internetbibliothek/Artikel/Gralshueter.htm> (5. Februar 2010).

Domke, Wolfram (1999): Lesarten von Wirklichkeit. Eine psychologische Analyse der Druckschriftbilder „Antiqua“ und „Fraktur“. In: Rück, Peter (Hg.) (1999): Methoden der Schriftbeschreibung. Stuttgart.

Drews, Jörg (1999): Auf dem Weg zum Denglitsch. Wieviel Angloamerikanisch verträgt die deutsche Sprache? In: Meier, Christian (Hg.) (1999): Sprache in Not? Zur Lage des heutigen Deutsch. Göttingen, S. 15-32. 
Drosdowski, Günther (1985): Thesen einer kritischen Sprachwissenschaft mit persönlichen Vorbemerkungen. In: Gauger, HansMartin (Hg.) (1985): Sprach-Störungen. Beiträge zur Sprachkritik. München, S. 84-88.

Drosdowski, Günther (1988): Ist unsere Sprache noch zu retten? Mannheim, Wien, Zürich.

Drosdowski, Günther (1991): Deutsch - Sprache in einem geteilten Land. In: Sprache und Literatur in Wissenschaft und Unterricht 22/67, 1991, S. 21-35.

Drosdowski, Günther et al. (Hg.) 1984. Duden. Grammatik der deutschen Gegenwartssprache. Der Duden. Band 4. Mannheim, Wien, Zürich.

Drosdowski, Günther et al. (1996): Duden. Deutsches Universalwörterbuch. Mannheim, Leipzig, Wien, Zürich.

Duckworth, David (1977): Zur terminologischen und systematischen Grundlage der Forschung auf dem Gebiet der englisch-deutschen Interferenz. In: Kolb, Herbert/Lauffer, Hartmut (Hg.) (1977): Sprachliche Interferenz. Festschrift für Werner Betz zum 65. Geburtstag. Tübingen, S. 36-56.

Duhamel, Robert (2007): Wissenschaftlicher Beirat. Der neue Vorsitzende Roland Duhamel über sich selbst. In: Sprachnachrichten 2007, Nr. 1, S. 21.

Dunger, Hermann (1882): Wörterbuch von Verdeutschungen entbehrlicher Fremdwörter, mit besonderer Berücksichtigung der von dem großen Generalstabe, im Postwesen und in der Reichsgesetzgebung angenommenen Verdeutschungen. Mit einer einleitenden Abhandlung über Fremdwörter und Sprachreinigung. Leipzig.

Dunger, Hermann (1886): Welche Fremdwörter sind nicht zu bekämpfen? In: Zeitschrift des Allgemeinen Deutschen Sprachvereins, Nr. 1, 1886, S. 6-10.

Dunger, Hermann (1899): Wider die Engländerei in der deutschen Sprache. Berlin. 
Dunger, Hermann (1909): Engländerei in der deutschen Sprache. Zweite, umgearbeitete und stark vermehrte Auflage des Vortrags „Wider die Engländerei in der deutschen Sprache“. Berlin.

Effertz, Andrea/Vieth, Ulrike (1996): Das Verständnis wirtschaftsspezifischer Anglizismen in der deutschen Sprache bei Unternehmern, Führungskräften und Mitarbeitern der neuen und alten Bundesländer. Frankfurt.

Eichhoff-Cyrus, Karin M. (2001). Zur Diskussion über ein Sprachreinigungsgesetz. In: Der Sprachdienst 45, 2001, Nr. 2, S. 70-73.

Eichler, Richard W. (1994): Glanz und Elend der deutschen Sprache. Ahorn.

Eisenberg, Peter (2002): Fremdwort, Lexikon, Lexikonerweiterung. In: Wiesinger, Peter (Hg.) (2002): Akten des X. Internationalen Germanistenkongresses Wien 2000. Zeitenwende - Die Germanistik auf dem Weg vom 20. ins 21. Jahrhundert. Entwicklungstendenzen der deutschen Gegenwartssprache. Band 2. Bern, S. 65-73.

Eisenberg, Peter (2004a): Grundriss der deutschen Grammatik. Das Wort. Stuttgart.

Eisenberg, Peter (2004b): German as an Endangered Language? In: Gardt, Andreas/Hüppauf, Bernd (Hgg.) (2004): Globalization and the Future of German. Berlin, S. 121-139.

Eisenberg, Peter (2008a): Schweigt stille, plaudert nicht. Mannheim.

Eisenberg, Peter/Baurmann, Jürgen (1984): Fremdwörter - fremde Wörter. In: Praxis Deutsch 67, 1984, S. 15-26.

Engels, Barbara (1976): Gebrauchsanstieg der lexikalischen und semantischen Amerikanismen in zwei Jahrgängen der "Welt“ (1954 und 1964): Eine vergleichende computer-linguistische Studie zur quantitativen Entwicklung amerikanischen Einflusses auf die deutsche Zeitungssprache. Frankfurt.

Etiemble, René (1964): Parlez-vous franglais? Paris. 
Fink, Hermann (1970): Amerikanismen der deutschen Tagespresse dargestellt am Beispiel dreier überregionaler Zeitungen (Süddeutsche Zeitung, Frankfurter Allgemeine Zeitung, Die Welt). Mainz.

Fink, Hermann (1980): Superhit oder Spitzenschlager: Ein Versuch zur Häufigkeit und Funktion von Anglizismen und „Werbeanglizismen“ in deutschen Jugendzeitschriften. In: Viereck, Wolfgang (Hg.) (1980): Studien zum Einfluß der englischen Sprache auf das Deutsche. Tübinger Beiträge zur Linguistik. Tübingen, S. 185-212.

Fink, Hermann (1983): Amerikanisch-englische und gesamtenglische Interferenzen der deutschen Allgemein- und Werbesprache im aktiven und passiven Sprachverhalten deutscher Grund-, Haupt- und Oberschüler. Frankfurt.

Fink, Hermann (1996): Anglicisms in the Debates on Economic Policy of the German Bundestag 1980-1990. A Comparative Study of Comprehension and Usage. Freiberg.

Fink, Hermann (1997): Von Kuh-Look bis Fit for Fun: Anglizismen in der heutigen deutschen Allgemein- und Werbesprache. Frankfurt.

Fink, Hermann (2001): Echt cool - Überlegungen zur Amerikanisierung der Allgemein- und Jugendsprache in der Bundesrepublik Deutschland. In: Zabel, Hermann (Hg.): Denglish, nein danke! Zur inflationären Verwendung von Anglizismen und Amerikanismen in der deutschen Gegenwartssprache. Paderborn, S. 33-50.

Fink, Hermann/Fijas, Liane/Schons, Danielle (1997): Anglizismen in der Sprache der Neuen Bundesländer. Eine Analyse zur Verwendung und Rezeption. Frankfurt.

Fink, Hermann/Fuhrmann, Manfred/Glück, Helmut/Haider, Hans/Knoop, Ulrich/Sauer, Wolfgang-Werner/Schmitz, HeinzGünther/Stark, Franz/Urbanek, Ferdinand/Wills, Wolfram (2000): Thesen zur Situation der deutschen Sprache. In: Glück, Helmut/Krämer, Walter (Hgg.) (2000): Die Zukunft der deutschen Sprache. Eine Streitschrift. Leipzig, S. 88-91.

Flamm, Traugott (1994): Eine deutsche Sprachakademie. Gründungsversuche und Ursachen des Scheiterns. Frankfurt. 
Förster, Uwe (1989): Praktische Sprachpflege. Ein Sprachberater gibt Auskunft. In: Der Sprachdienst 33, 1989, Nr. 4, S. 105-128.

Förster, Uwe (2000a): Sprachpflege auf wissenschaftlicher Grundlage. Beiträge aus drei Jahrzehnten. Mannheim.

Flessner, Axel (2002): „Wissenschaftliche Selbstbeschränkung durch Englisch“. In: „'Deutsch nix wichtig’?“, S. 117-121.

Förster, Uwe (2000b): Die Gesellschaft für deutsche Sprache. Ein Überblick. In: Karin. M. Eichhoff-Cyrus und Rudolf Hoberg (Hg.): Die deutsche Sprache zur Jahrtausendwende. Sprachkultur oder Sprachverfall?. Thema Deutsch, Band 1. Mannheim, S. 330-340.

Foucault, Michel (1971): L'ordre du discours. Mayenne.

Foucault, Michel (1981): Archäologie des Wissens. Übersetzt von Ulrich Köppen. Frankfurt.

Frank-Cyrus, Karin M./Steinhauer, Anja/Wiechers, Silke/Trabold, Annette/Beckmann, Silke (1999): Förderung der Sprachkultur in Deutschland. Eine Bestandsaufnahme. Wiesbaden.

Fröhlich, Armin (1962): $\mathrm{Zu}$ den verborgenen englischen Einflüssen. In: Muttersprache 72, 1962, S. 19-22.

Galinsky, Hans (1972): Amerikanisch-deutsche Sprach- und Literaturbeziehungen. Frankfurt.

Galinsky, Hans (1975): Stylistic Aspects of Linguistic Borrowings. In: Carstensen, Broder/Galinsky, Hans (Hg.) (1975): Amerikanismen der deutschen Gegenwartssprache, Entlehnungsvorgänge und ihre stilistischen Aspekte. Heidelberg, S. 35-72.

Galinsky, Hans (1977): Amerikanisch-englische und gesamtenglische Interferenzen mit dem Deutschen und anderen Sprachen der Gegenwart: Ein kritischer Forschungsbericht 1945 bis 1976. In Kolb, Herbert/Lauffer, Hartmut (Hg.) (1977): Sprachliche Interferenz. Festschrift für Werner Betz zum 65. Geburtstag. Tübingen, S. 463517. 
Gardt, Andreas (1997): Das Fremdwort in der Sicht der Grammatiker und Sprachtheoretiker des 17. und 18. Jahrhunderts. Eine lexikographische Darstellung. In: Zeitschrift für deutsche Philologie 116, 1997, S. 388-412.

Gardt, Andreas (Hg.) (2000). Nation und Sprache. Berlin.

Gardt, Andreas (2001a): Das Fremde und das Eigene. Versuch einer Systematik des Fremdwortbegriffs in der deutschen Sprachgeschichte. In: Stickel, Gerhard (Hg.): Neues und Fremdes im deutschen Wortschatz. Aktueller lexikalischer Wandel. Jahrbuch 2000 des Instituts für deutsche Sprache. Berlin, S. 30-59.

Gardt, Andreas (2001b): Zur Bewertung der Fremdwörter im Deutschen. In: Deutsch als Fremdsprache 38, Nr. 3, 2001, S. 133-143.

Gardt, Andreas (2002): Sprachkritik als Sprachwissenschaft. Zur Geschichte und Unumgänglichkeit einer Einflussnahme. In: Jürgen/Roth, Kersten Sven/Leweling, Beate/Frohning, Dagmar (Hgg.) (2002): Streitfall Sprache. Bremen, S. 39-58.

Gardt, Andreas (2004). Language and National Identity. In: Gardt, Andreas/Hüppauf, Bernd (Hgg.) (2004): Globalization and the Future of German. Berlin, S. 197-213.

Gardt, Andreas/Hüppauf, Bernd (Hgg.) (2004): Globalization and the Future of German. Berlin.

Gauger, Hans-Martin (1985): Brauchen wir Sprachkritik? In: Knoop, Ulrich/Schmitz, Heinz-Günter (Hgg.) (1985): HenningKaufmann-Stiftung zur Pflege der Reinheit der deutschen Sprache. Jahrbuch 1984. Marburg, S. 31-63.

Gauger, Hans-Martin (1999): Die Hilflosigkeit der Sprachwissenschaft. In: Meier, Christian (Hg.) (1999): Sprache in Not? Zur Lage des heutigen Deutsch. Göttingen, S. 85-102.

Gawlitta, Kurt (2001a): Einführung. In: Dieter, Hermann/Gawlitta, Kurt/Meißner, Gernot/Vilmar, Fritz (Hgg.) (2001): Wörter fallen nicht vom Himmel. Berlin/Potsdam, S. 1-2. 
Gawlitta, Kurt (2001b): Days for Kids. Zwischen Überwältigung und Selbstaufgabe. Ein Plädoyer für eine aktive Schutzpolitik für die deutsche Sprache. Gastkommentar (aus: Der Tagesspiegel vom 29. April 2000). In: Dieter, Hermann/Gawlitta, Kurt/Meißner, Gernot/Vilmar, Fritz (Hgg.) (2001): Wörter fallen nicht vom Himmel. Berlin/Potsdam, S. 3-4.

Gawlitta, Kurt (2001c): Gesetz über den Schutz der Deutschen Sprache (GSDS). Diskussionsentwurf für den Verein Deutsche Sprache e.V. - Stand: 30.10.01. In: Dieter, Hermann/Gawlitta, Kurt/Meißner, Gernot/Vilmar, Fritz (Hgg.) (2001): Wörter fallen nicht vom Himmel. Berlin/Potsdam, S. 39-77.

Gawlitta, Kurt (2007): Das Wörtermachen nimmt den Deutschen keiner ab! In: Krämer, Walter/Grobe, Myriam/Petros, Dawit (Hgg.) (2007): Festschrift. Eine Stimme für unsere Sprache. 10 Jahre Verein Deutsche Sprache. Paderborn, S. 81-92.

Gawlitta, Kurt/Flessner, Axel (2002). Sprachfreiheit und Sprachverantwortung. In: Gawlitta, Kurt/Vilmar, Fritz (Hgg.) (2002): „Deutsch nix wichtig“?: Engagement für die deutsche Sprache. Paderborn, S. 124-150.

Gawlitta, Kurt/Vilmar, Fritz (Hgg.) (2002a): „Deutsch nix wichtig“? Engagement für die deutsche Sprache. Paderborn.

Gawlitta, Kurt/Vilmar, Fritz (2002b): Bürger gegen Denglisch. In: Gawlitta, Kurt/Vilmar, Fritz (Hgg.) (2002): „Deutsch nix wichtig“? Engagement für die deutsche Sprache. Paderborn, S. 65-72.

Gawlitta, Kurt/Vilmar, Fritz (2002c): Sprachenstatut in der Europäischen Union. In: Gawlitta, Kurt/Vilmar, Fritz (Hgg.) (2002): „Deutsch nix wichtig“? Engagement für die deutsche Sprache. Paderborn, S. 198.

Gawlitta, Ludger (2001): Akzeptanz englischer Werbeslogans. „Let's make things better“. Paderborn. 
Gesellschaft für deutsche Sprache (1999): Stellungnahme der Gesellschaft für deutsche Sprache zum englischen Einfluss auf die deutsche Gegenwartssprache. In: Der Sprachdienst 43, 1999, Nr.6, S. 217-220.

Glahn, Richard (2000): Der Einfluß des Englischen auf gesprochene deutsche Gegenwartssprache. Eine Analyse öffentlich gesprochener Sprache am Beispiel von „Fernsehdeutsch“. Frankfurt.

Glahn, Richard (2001): Anglizismen - Ursachen für den häufigen Gebrauch. In: Muttersprache 111, 2001, S. 25-35.

Glahn, Richard (2002): Englisches im gesprochenen Deutsch. Einfluss und Bewertung. In: Hoberg, Rudolf (Hg): Deutsch, Englisch, Europäisch. Impulse für eine neue Sprachpolitik, S. 220-235.

Glück, Helmut (1987): Schrift und Schriftlichkeit. Stuttgart.

Glück, Helmut (2000a): Dürfen Linguisten werten? In: Glück, Helmut/Krämer, Walter (Hgg.) (2000): Die Zukunft der deutschen Sprache. Eine Streitschrift. Leipzig, S. 62-70.

Glück, Helmut (2000b): Warum sich die Beschäftigung mit Eduard Engel immer noch lohnt. Einige selektive Gedanken zum Sprachpurismus in Deutschland. In: Sauter, Anke (2000): Eduard Engel. Literaturhistoriker, Stillehrer, Sprachreiniger. Bamberg, S. VII-XII.

Glück, Helmut (2000c): Die neuen Medien als Motor des Sprachwandels: Schulenglisch als zweite Landessprache? In: Hoffmann, Hilmar (Hg.) (2000): Deutsch global. Neue Medien - Herausforderungen für die Deutsche Sprache. Köln, S. 108-125.

Glück, Helmut (2001a): Es gibt längst ein Sprachenrecht. In: Die Welt, 10. Februar 2001. Nachdruck. In: Dieter, Hermann/Gawlitta, Kurt/Meißner, Gernot/Vilmar, Fritz (Hgg.) (2001): Wörter fallen nicht vom Himmel. Berlin/Potsdam, S. 9-10.

Glück, Helmut (2006): Anglizismen im Deutschen: Integration und Abstoßung. Peter Eisenberg zum 65. Geburtstag. Unveröffentlichtes Manuskript. Bamberg.

Glück, Helmut (2008a): Deutsch als Wissenschaftssprache. Dortmund. 
Glück, Helmut (Hg.) (2005): Metzler Lexikon Sprache (MLS). Stuttgart.

Glück, Helmut/Krämer, Walter (Hgg.) (2000): Die Zukunft der deutschen Sprache. Eine Streitschrift. Leipzig.

Glück, Helmut/Sauer, Wolfgang Werner (1997): Gegenwartsdeutsch. Stuttgart.

Götze, Alfred (1936): Keß und die Abkürzungssprache. In: Muttersprache 51, 1936, Sp. 7/8.

Grebe, Paul et al. (1973): Duden. Grammatik der deutschen Gegenwartssprache. Der große Duden. Band 4. 3. neu bearbeitete und erweiterte Auflage. Mannheim, Wien, Zürich.

Grebe, Paul et al. (Hg.) (1959): Duden. Grammatik der deutschen Gegenwartssprache. Der große Duden. Band 4. Mannheim.

Greule, Albrecht (1980): Erbwort - Lehnwort - Neuwort: Grundzüge einer genetischen Lexikologie des Deutschen. In: Muttersprache 90, 1980, S. 263-275.

Greule, Albrecht (2002): Sprachloyalität als Aufgabe der Sprachkultivierung. In: Wiesinger, Peter (Hg.): Zeitenwende - Die Germanistik auf dem Weg vom 20. ins 21. Jahrhundert. Akten des X. Internationalen Germanistenkongresses Wien 2000. Aufgaben einer zukünftigen Sprachgeschichtsforschung - Gesprochene Sprache in regionaler und sozialer Differenzierung. Sprache in der Öffentlichkeit. Band 3. Bern, S. 437-443.

Greule, Albrecht/Ahlvers-Liebel, Elisabeth (1986): Germanistische Sprachpflege. Geschichte, Praxis und Zielsetzung. Darmstadt.

Grosse, Siegfried (2000): Fremde deutsche Wörter. Rede anlässlich der Verleihung des Konrad-Duden-Preises der Stadt Mannheim am 15. März 2000. Mannheim

Härle, Gerhard (1996): Reinheit der Sprache des Herzens und des Leibes. Zur Wirkungsgeschichte des rhetorischen Begriffs ,puritas' in Deutschland von der Reformation bis zur Aufklärung. Tübingen. 
Hartmann, Silvia (1999): Fraktur oder Antiqua. Der Schriftstreit von 1881 bis 1941. Frankfurt.

Haß, Ulrike (1987): Zum Beispiel recykeln. In: Sprachreport 1987, Nr. 4, S. 5.

Haße, Wolfgang (2002): Ärzteschaft gegen Anglisierung ihrer Fachsprache. In: Gawlitta, Kurt/Vilmar, Fritz (Hgg.) (2002): „Deutsch nix wichtig“?: Engagement für die deutsche Sprache. Paderborn, S. 108-116.

Haß-Zumkehr, Ulrike/Kallmeyer, Werner/Zifonun, Gisela (Hgg.) (2002): Ansichten der deutschen Sprache. Gerhard Stickel zum 65. Geburtstag. Tübingen.

Haugen, Einar (1950): The Analysis of Linguistic Borrowing. In: Language. Journal of the Linguistic Society of America 26, 1950, S. 210-231.

Hayakawa, Tozo (1995): Die Fremdwortfrage und der Deutsche Sprachverein in der NS-Zeit. In: Popp, Heidrun (Hg.) (1995): Deutsch als Fremdsprache. München, S. 429-436.

Heald, David (1978): Deutschlitsch oder Engleutsch - Has German a Future? In: Modern Languages 59, 1978, S. 139-142.

Heeger, Heinrich (1966a): Von der wortschöpferischen Kraft der deutschen Sprache. In: Der Sprachpfleger 4, 1966, Sonderheft 1/2, S. 14 .

Heeger, Heinrich (1966b): Sprachpflege in unserer Zeit. In: Der Sprachpfleger 4, 1966, Sonderheft 1/2, S. 15.

Heinemann, Gustav W. (1973): Pflege der deutschen Sprache. In: Presse- und Informationsamt der Bundesregierung (Hg.) (1973): Heinemann, G.W.: Reden und Interviews (IV). 1. Juli 1972 - 30. Juni 1973. Bonn, S. 144-150.

Heller, Klaus (1966): Das Fremdwort in der deutschen Sprache der Gegenwart. Untersuchungen im Bereich der Gebrauchssprache. Leipzig. 
Heller, Klaus (2002): Was ist ein Fremdwort? Sprachwissenschaftliche Aspekte einer Definition. In: Hoberg, Rudolf (Hg.): Deutsch Englisch - Europäisch. Impulse für eine neue Sprachpolitik. Thema Deutsch. Band 3. Mannheim, S. 184-198.

Hendlmeier, Wolfgang (1991): Sprachpflege einst und heute. In: Die Deutsche Schrift. Vierteljahreshefte zur Förderung der deutschen Sprache und Schrift. Sonderheft 1990/1991, S. 12-14.

Hendlmeier, Wolfgang (2002): Sprach- und Schriftpflege dienen der Kultur. Seelen.

Henscheid, Eckhard (1993): Dummdeutsch. München.

Hensel, Horst (1999): Sprachverfall und kulturelle Selbstaufgabe. Eine Streitschrift. Bönen.

Hensel, Horst (2000): Sprachverfall und kulturelle Selbstaufgabe. In: Glück, Helmut/Krämer, Walter (Hgg.): Die Zukunft der deutschen Sprache. Eine Streitschrift. Leipzig, S. 43-52.

Hillen, Ingrid (1982): Untersuchungen zu Kontinuität und Wandel der Sprachpflege im Deutschen Reich, in der Bundesrepublik und in der DDR. Diss. Bonn.

Hoberg, Rudolf (1996a): Fremdwörter: Wie soll sich die Gesellschaft für deutsche Sprache dazu verhalten. In: Der Sprachdienst 40, 1996, Nr. 5, S. 137-142.

Hoberg, Rudolf (1996b): Linguistik für die Öffentlichkeit. Wörter und Unwörter des Jahres. In: Böke, Karin/Jung, Matthias/Wengeler, Martin (Hgg.) (1996): Öffentlicher Sprachgebrauch. Praktische, theoretische und historische Perspektiven. Opladen, S. 90-98.

Hoberg, Rudolf (2000a): Sprechen wir bald alle Denglisch oder Germeng? In: Eichhoff-Cyrus, Karin M./Hoberg, Rudolf (Hgg.): Die deutsche Sprache zur Jahrtausendwende. Sprachkultur oder Sprachverfall? Thema Deutsch. Band 1. Mannheim, S. 303-316.

Hoberg, Rudolf (2000b): Die deutsche Sprache zur Jahrtausendwende, Leipzig. 
Hoberg, Rudolf (2001): Englisches im Deutschen: Take it easy, but not too easy. Beitrag zur Podiumsdiskussion: Neues und Fremdes im heutigen deutschen Wortschatz - Was halten wir davon, was halten andere davon? In: Stickel, Gerhard (Hg.) (2001): Neues und Fremdes im deutschen Wortschatz. Aktueller lexikalischer Wandel. Jahrbuch 2000 des Instituts für deutsche Sprache. Berlin, S. 299-302.

Hoberg, Rudolf (2002a): Braucht die Öffentlichkeit Sprachwissenschaft? In: Spitzmüller, Jürgen/Roth, Kersten Sven/Leweling, Beate/Frohning, Dagmar (Hgg.): Streitfall Sprache. Bremen, S. 19-39.

Hoberg, Rudolf (2002b) (Hg.): Deutsch - Englisch - Europäisch. Impulse für eine neue Sprachpolitik. Thema Deutsch. Band 3. Mannheim.

Hoberg, Rudolf (2003): Deutscher Sprachrat. Seine Ziele und Aufgaben. In: Der Sprachdienst 47, 2003, Nr. 5, S. 181-183.

Hoffmann, Hilmar (Hg.) (2000): Deutsch global. Neue Medien - Herausforderungen für die Deutsche Sprache. Köln.

Hofmann, Dirk (2002): Do you understand Denglisch? Eine Umfrage zum Anglizismenverständnis. In: Hoberg, Rudolf (2002b) (Hg.): Deutsch - Englisch - Europäisch. Impulse für eine neue Sprachpolitik. Thema Deutsch. Band 3. Mannheim, S. 236-246.

Hohenhaus, Peter (2002): Standardization, language change, resistance and the question of linguistic threat. 18th century English and present-day German. In: Linn, Andrew R./McLelland, Nicola (Hgg.) (2002): Standardization. Studies from the Germanic languages. (Amsterdam studies in the theory and history of linguistic sciences. Series IV. Current issues in linguistic theory. Band 235.). Amsterdam, S. 153-178.

Ihlenburg, Karl Heinz (1964): Entwicklungstendenzen des Wortschatzes in beiden deutschen Staaten. In: Weimarer Beiträge 10, 1964, S. 372-397. 
Jablonski, Miroslav (1990): Regularität und Variabilität in der Rezeption englischer Internationalismen im modernen Deutsch, Französisch und Polnisch. Aufgezeigt in den Bereichen Sport, Musik und Mode. Tübingen.

Jahn, F.L./ Eiselen, E. (1916): Die deutsche Turnkunst zur Einrichtung der Turnplätze. Berlin.

Jäger, Siegfried (1991): Text- und Diskursanalyse. Eine Anleitung zur Analyse politischer Texte. Dortmund.

Janich, Nina (1997): Sprachkultivierung - Aufgabe der Zukunft oder nur ein Generationenproblem. Bericht vom Internationalen Kolloquium „Europäische Sprachkultur und Sprachpflege vom 9.11. Oktober 1996 in Regensburg. In: Muttersprache 107, 1997, S. 76-88. Tübingen.

Jansen, Silke (2005): Sprachliches Lehngut im world wide web. Tübingen.

Jones, William Jervis (1998): Germanic Virginity or Teutonic Virility? Attitudes to Language among Earlier German Purists. In: London German Studies, VI, 1998, S. 33-70.

Jung, Matthias (1995): Amerikanismen, ausländische Wörter, Deutsch in der Welt. Sprachdiskussion als Bewältigung der Vergangenheit und Gegenwart. In: Stötzel Georg/Wengeler, Martin (Hgg.): Kontroverse Begriffe. Geschichte des öffentlichen Sprachgebrauchs in der Bundesrepublik Deutschland. Berlin, Jung, S Matthias (2000): Diskurshistorische Analyse als linguistischer Ansatz. In: Sprache und Literatur in Wissenschaft und Unterricht 86, 2000, Nr. 2, S. 20-38.

Junker, Gerhard/VDS-Arbeitskreis Wörterliste/Sprachkreis Deutsch, Bern (Hgg.) (2008): Der Anglizismen-Index. Paderborn.

Klärner, Andreas/Kohlstruck, Michael (Hgg.) (2006): Moderner Rechtsextremismus in Deutschland. Bonn. 
Keller, Rudi (2003): Sprachwandel. Tübingen.

Keller, Rudi (2004): Ist die deutsche Sprache vom Verfall bedroht? Düsseldorf. In: <http.//www.phil-fak.uni-duesseldorf.de/uploads/media/Sprachverfall.php> (20. Januar 2009).

Keller, Rudi (2006): Ist die deutsche Sprache vom Verfall bedroht. In: Aptum 2, 2006, S. 193-205.

Keßler, Christine (2000): Für und wider das Fremdwort: Ein alter und neuer Streit. In: Der Deutschunterricht 53, 2000, Nr. 3, S. 51-60.

Keßler, Karoline (2003): Anglizismen in der Jugendsprache am Beispiel von BRAVO GIRL! und Mädchen. Unveröffentlichte Diplomarbeit. Bamberg.

Kettemann, Bernhard (2002): Anglizismen allgemein und konkret: Zahlen und Fakten. In: Muhr, Rudolf/Kettemann, Bernhard (Hgg.) (2002): Eurospeak. Der Einfluss des Englischen auf europäische Sprachen zur Jahrtausendwende. Frankfurt, S. 55-88.

Kieselbach, Eva-Maria (2007a): Vom Operator, der Weinkönigin und Kraft durch Freude. Die Erfolge des VDS. In: Krämer, Walter/Grobe, Myriam/Petros, Dawit (Hgg.) (2007): Festschrift. Eine Stimme für unsere Sprache. 10 Jahre Verein Deutsche Sprache. Paderborn, S. 71-79.

Kieselbach, Eva-Maria (2008). Lichtblicke. Ein Kalender sprachlicher Erfolge. 1997 bis 2008. Kassel.

Kirchhof, Paul/Kreuter-Kirchhof, Charlotte (2008): Staats- und Verwaltungsrecht Bundesrepublik Deutschland. Heidelberg.

Kirkness, Alan (1975): Zur Sprachreinigung im Deutschen 1789-1871. Eine historische Dokumentation. Teil I und II. Tübingen.

Kirkness, Alan (1983): Fremdwort und Fremdwortpurismus. In: Sprache und Literatur in Wissenschaft und Unterricht 14, 1983, Nr. 52, S. 14-29. 
Kirkness, Alan (1998): Das Phänomen des Purismus in der Geschichte des Deutschen. In: Besch, Werner/Betten, Anne/Reischmann, Oskar/Sonderegger, Stefan (Hgg.): Sprachgeschichte. Ein Handbuch zur Geschichte der deutschen Sprache und ihrer Erforschung. HSK 2.1. Berlin 1998, S. 407- 416.

Klatte, Holger (2008a): Nachwort. In: Klatte, Holger/Pogarell, Reiner/Schrammen, Gerd (2008): Walter Krämer. Aggressiv und fröhlich für unsere Sprache. Worte des Vorsitzenden. Paderborn, S. 104-106.

Klein, Wolf Peter (2001): Fehlende Sprachloyalität? Anmerkungen zur jüngsten Entwicklung des öffentlichen Sprachbewusstseins in Deutschland. In: Linguistik Online 9, 2001, Nr. 2, <http://www.linguistik-online.de/9_01/Klein.html> (23. Oktober 2008).

Klein-Zirbes, Anja (2001): Die Défense de la langue française als Zeugnis des französischen Sprachpurismus. Frankfurt.

Knoop, Ulrich (1985): Laudatio auf Hans-Martin Gauger, Preisträger 1984. In: Knoop, Ulrich/Schmitz, Heinz-Günter (Hgg.) (1985): Henning-Kaufmann-Stiftung zur Pflege der Reinheit der deutschen Sprache. Jahrbuch 1984. Marburg, S. 23-31.

Knoop, Ulrich (1996): Die Henning-Kaufmann-Stiftung zur Pflege der Reinheit der deutschen Sprache. In: Knoop, Ulrich (Hg.) (2001): Henning-Kaufmann-Stiftung Deutscher Sprachpreis. Jahrbuch 1995-1999. Schlingen, S. 174-188.

Knoop, Ulrich (Hg.) (2001): Henning-Kaufmann-Stiftung Deutscher Sprachpreis. Jahrbuch 1995-1999. Paderborn.

Knoop, Ulrich (Hg.) (2007a): Henning-Kaufmann-Stiftung Deutscher Sprachpreis. Jahrbuch 2006. Paderborn.

Knoop, Ulrich (Hg.) (2007b): Henning-Kaufmann-Stiftung Deutscher Sprachpreis. Jahrbuch 2007. Paderborn, S. 43. 
Knoop, Ulrich (2007c): Die Henning-Kaufmann-Stiftung zur Pflege der Reinheit der deutschen Sprache. In: Knoop, Ulrich, im Auftrag der Henning-Kaufmann-Stiftung (Hg.) (2007): Henning-KaufmannStiftung Deutscher Sprachpreis. Jahrbuch 2007. Paderborn, S. 43.

Knoop, Ulrich/Schmitz, Heinz-Günter (Hgg.) (1985): HenningKaufmann-Stiftung zur Pflege der Reinheit der deutschen Sprache. Jahrbuch 1984. Marburg.

Kolde, Gottfried (1986): Sprachkritik, Sprachpflege und Sprachwissenschaft. In: Muttersprache 96, 1986, S. 171-189.

Koller, Werner (2000): Nation und Sprache in der Schweiz. In: Gardt, Andreas (Hg.) (2000). Nation und Sprache. Berlin, S. 563-609.

Korlén, Gustav (1976): Die Couch, Hitler und das Fremdwort. In: Hedberg, Johannes/Korlén, Gustav/Börje Schlyter (Hgg.): Moderna Språk LXX, 1976, Nr. 1, S 329-342.

Krämer, Walter (1998a): Me Tarzan, you Jane. In: Forschung und Lehre, 1998, Nr. 8, S. 418.

Krämer, Walter (1998b): Vorwort. In: Pogarell, Reiner (1998) (Hg.): „Sitzung“ oder "Meeting“? Historische und aktuelle Fragestellungen zur Sprachreinigung in Deutschland. Paderborn, S. 5-7.

Krämer, Walter (2000a): Modern Talking auf Deutsch. Ein populäres Lexikon. München, Zürich.

Krämer, Walter (2000b): Der 51. Bundesstaat: Die deutsche Sprache als Opfer deutscher Selbstverleugnung. In: Erlberg, Gabi/Frank, Rainer/Steffens, Rudolf (Hgg.) (2000): Deutsch 2000. Aachen, S. 5661.

Krämer, Walter (2007a). In: Warum ich den VDS gegründet habe. Krämer, Walter/Grobe, Myriam/Petros, Dawit (Hgg.) (2007): Festschrift. Eine Stimme für unsere Sprache. 10 Jahre Verein Deutsche Sprache. Paderborn, S. 9-22.

Krämer, Walter/Grobe, Myriam/Petros, Dawit (Hgg.) (2007): Festschrift. Eine Stimme für unsere Sprache. 10 Jahre Verein Deutsche Sprache. Paderborn. 
Krämer, Walter/Kaehlbrandt, Roland (2007): Die Ganzjahrestomate und anderes Plastikdeutsch. München.

Krämer, Walter/Kaehlbrandt, Roland (2009): Plastikdeutsch: Ein Lexikon der Sprachverirrungen. München.

Krämer, Walter/Pogarell, Reiner (2003): Sternstunden der deutschen Sprache. Paderborn.

Kristensson, Göran (1977): Angloamerikanische Einflüsse in DDRZeitungstexten. Stockholm.

Langer, Nils/Davies, Winifred (Hgg.) (2005a): Linguistic Purism in the Germanic Languages. Berlin, New York.

Langer, Nils/Davies, Winifred (Hgg.) (2005b): An Introduction to Linguistic Purism. In: Linguistic Purism in the Germanic Languages. Berlin, New York, S. 1-17.

Langer, Ninja (1996): Anglizismen in der deutschen Pressesprache. Untersucht am Beispiel von den Wirtschaftsmagazinen „CAPITAL“ und „DM“. Wettenberg.

Langner, Heidemarie (1995): Die Schreibung englischer Entlehnungen im Deutschen. Frankfurt.

Laurent, Jacques (1988): Le française en cage. Paris.

Law, Claudia (2002): Das sprachliche Ringen um die nationale und kulturelle Identität Deutschlands. In: Muttersprache 112, 2002, S. 6784 .

Lehnert, Martin (1986): Der anglo-amerikanische Einfluß auf die deutsche Sprache in der DDR. In: Akademie der Wissenschaften der DDR (Hg.): Der anglo-amerikanische Einfluß auf die deutsche Sprache der DDR. Dem Wirken Martin Lehnerts gewidmet. Sitzungsbericht der Akademie der Wissenschaften der DDR, Gesellschaftswissenschaften, Berlin, 1986, Nr. 6, S. 8-90.

Lehnert, Martin (1990): Anglo-Amerikanisches im Sprachgebrauch der DDR. Berlin. 
Lewandowski, Theodor (1990): Linguistisches Wörterbuch 3. 5. Auflage. Heidelberg.

Linke, Uli (2003): “There is a Land where Everything is Pure”. Linguistic Nationalism and Identity Politics in Germany. In: Moore, Donald S./Kosek, Jane, Pandian, Anand (Hgg.) (2003): Race, Nature, and the Politics of Difference. S. 149-174.

Linke, Uli (2004): Ethnolinguistic Racism: The Predicaments of Sovereignty and Nationhood Under Global Capitalism. In: Anthropological Theory 2004, Nr. 4, S. 205-228.

Lubeley, Rudolf (1993): Sprechen Sie Engleutsch? Eine scharfe Lanze für die deutsche Sprache. Isernhagen.

Lüllwitz, Brigitte (1972): Interferenz und Transferenz. In: Germanistische Linguistik, 1972, Nr. 2, S. 159-291.

MA. (1953): Häßliche Eindringlinge. In: Der Sprachfreund 2, 1953, Nr. 1, S. 2.

Maas, Utz (1984): „Als der Geist der Gemeinschaft eine Sprache fand.“ Sprache im Nationalsozialismus. Opladen.

Mackensen, Lutz (1935): Sprache und Rasse. In: Nationalsozialistische Monatshefte 1935, Nr. 6, S. 306-315.

Mackensen, Lutz (1980) (Hg.): Gutes Deutsch in Schrift und Rede. Reinbek.

Maercker, Patrizia (2006): Das Sprachverfallsdenken und seine Institutionalisierung. In: Aptum 2, 2006, Nr. 3, S. 206-237.

McArthur, Tom (2002): Oxford Guide to World English. Oxford.

Mecklenburg, Jens (Hg.) (1996): Handbuch deutscher Rechtsextremismus. Berlin.

Meier, Christian (1999): Sprache in Not? Zur Lage des heutigen Deutsch. Göttingen.

Meinunger, André (2008): Sick of Sick? Ein Streifzug durch die Sprache als Antwort auf den „Zwiebelfisch“. Berlin. 
Meißner, Gernot (2001): Organisierte Entwicklungen des Wortschatzes in der deutschen Sprachgeschichte. In: Wörter fallen nicht vom Himmel. Berlin/Potsdam, S. 81-105.

Meyer, Hans Günther (1974): Untersuchungen zum Einfluß des Englischen auf die deutsche Pressesprache - dargestellt an zwei deutschen Tageszeitungen. In: Muttersprache 84, 1974, S. 97-134.

Meyn, Hermann (2004): Massenmedien in Deutschland. Konstanz.

Micko, Stefan/Paulwitz, Thomas (1998): „Engleutsch, Nein Danke! Wie sag ich's auf deutsch? Ein Volks-Wörterbuch“. Erlangen und Wien.

Miebach, F. (1934): Mehr Kampfgeist! Neue Wege für die Zweigvereinsarbeit. In: Zeitschrift des Deutschen Sprachvereins 1934, Sp. 146.

Mindner, Tobias (Hg.) (2003a): Schillernde Verse. Paderborn.

Muhr, Rudolf (2004): Anglizismen als Problem der Linguistik und Sprachpflege in Österreich und Deutschland zu Beginn des 21. Jahrhunderts. Muhr, Rudolf und Kettemann, Bernhard (Hgg.): Eurospeak. Der Einfluss des Englischen auf europäische Sprachen zur Jahrtausendwende. Zweite korrigierte Auflage. Wien, S. 9-54.

Muhr, Rudolf/Kettemann, Bernhard (Hgg.) (2002): Eurospeak. Der Einfluss des Englischen auf europäische Sprachen zur Jahrtausendwende. Frankfurt.

Munske, Horst Haider (2001): Fremdwörter in deutscher Sprachgeschichte: Integration oder Stigmatisierung? In: Stickel, Gerhard (Hg.) (2001): Neues und Fremdes im deutschen Wortschatz. Aktueller lexikalischer Wandel. Jahrbuch 2000 des IDS. Berlin, S. 7-30.

N. (1980): 17. Mitgliederversammlung der GfdS. In: Der Sprachdienst XXIV, 1980, S. 177-121.

Niehr, Thomas (2002a): Rezension. Denglisch, Nein danke! In: Der Sprachreport 2002, Nr. 1, S. 30-31.

Niehr, Thomas (2002b): Linguistische Anmerkungen zu einer populären Anglizismen-Kritik. In: Der Sprachreport 2002, Nr. 4, S. 4-10. 
Niehr, Thomas (2003): Besprechungen einer VDS-Publikation. Thomas Niehr. In: Zabel, Hermann (Hg.) (2003): Denglisch, nein danke! Zur inflationären Verwendung von Anglizismen und Amerikanismen in der deutschen Gegenwartssprache. Paderborn, S. 299304.

Niehr, Thomas (2006): Investigativer Lingualismus. In: Aptum 2, 2006, Nr. 2, S. 186-192.

Nussbaumer, Markus (2003): Die Zukunft der deutschen Sprache. Eine Streitschrift. Hrsg. von Helmut Glück und Walter Krämer. Leipzig: Ernst Klett Schulbuchverlag 2000, 93 S. Kommentar. In: Zeitschrift für Germanistische Linguistik 31, 2003, S. 105-108.

Nüssler, Otto (1979): Nachbemerkungen. In: Muttersprache 89, 1979, S. 379-381.

Olt, Reinhard (1986): Die „Sprachpflegearbeit“ des Deutschen Sprachvereins. In: Muttersprache 96, 1986, S. 147-170.

Olt, Reinhard (1991): Wider das Fremde? Das Wirken des Allgemeinen Deutschen Sprachvereins in Hessen 1885-1944. Darmstadt und Marburg.

Oschlies, Wolf (1988): Hat der Dispatcher die Broiler abgecheckt? Anglizismen im sprachlichen Alltag der DDR. In: Muttersprache 98, 1988, S. 205-213.

Otto, Karl F. (1972): Die Sprachgesellschaften des 17. Jahrhunderts. Stuttgart.

Overmanns, Rüdiger (2002): ,Hunnen' und ,Untermenschen' - deutsche und russisch/sowjetische Kriegsgefangenschaftserfahrungen im Zeitalter der Weltkriege. In Thoß, Bruno/Volkmann, Hans-Erich (Hgg.) (2002): Erster Weltkrieg. Zweiter Weltkrieg. Ein Vergleich. Krieg, Kriegserlebnis, Kriegserfahrung in Deutschland. Paderborn, S. 335-369.

Palmer, Philipp (1950): The Influence of English on the German Vocabulary. Berkeley. 
Paul, Jean (1826): Hesperus oder Fünfundvierzig Hundsposttage. Eine Lebensbeschreibung von Jean Paul. Erstes Heftlein. In: Jean Paul's sämtliche Werke 7-9. VII. Berlin. Zweite Lieferung. Zweiter Band. Berlin.

Peschel, Corinna (2000): Campes Erben oder Purismus heute? In: Erlberg, Gabi/Frank, Rainer/Steffens, Rudolf (Hgg.) (2000): Deutsch 2000. Aachen, S. 62-70.

Pfalzgraf, Falco (2003a): Fremdwortdiskussion und Rechtsextremismus. In: German Life and Letters 56, 2003, Nr. 1, S. 102-116.

Pfalzgraf, Falco (2003b): Recent Developments concerning language protection organizations and right wing-extremism in Germany. In: German Life and Letters 56, 2003, Nr. 4, S. 398-409.

Pfalzgraf, Falco (2006): Neopurismus in Deutschland nach der Wende. Frankfurt.

Pfalzgraf, Falco (2008): Bestrebungen zur Einführung eines Sprachschutzgesetzes seit der Deutschen Vereinigung. In: German Life and Letters 61, 2008, Nr. 4, S. 451-469.

Pfannhauser, Werner (1976): Unser Turnen. Der österreichische Turnerbund. Wien.

Pfeiffer, Thomas (2000): Medien einer neuen sozialen Bewegung von rechts. In: <http://www-brs.ub.ruhr-unibochum.de/netahtml/HSS/Diss/PfeifferThomas/diss.pdf>, (8. Februar 2010).

Pfitzner, Jürgen (1978): Der Anglizismus im Deutschen. Ein Beitrag zur Bestimmung seiner stilistischen Funktion in der heutigen Presse. Stuttgart.

Pflug, Günther/Frank-Cyrus, Karin (1998): Niederschrift über die 26. ordentliche Mitgliederversammlung der Gesellschaft für deutsche Sprache am 10. Mai 1998 im Rathaus der Stadt Wiesbaden. In: Der Sprachdienst 42, 1998, Nr. 4, S. 143-151. 
Plümer, Nicole (2000): Anglizismus - Purismus - Sprachliche Identität. Eine Untersuchung zu den Anglizismen in der deutschen und französischen Mediensprache. Frankfurt.

Pogarell, Reiner (Hg.) (1998): „Sitzung“ oder „Meeting“? Historische und aktuelle Fragestellungen zur Sprachreinigung in Deutschland. Paderborn.

Pogarell, Reiner (2007a): Jede Sprache braucht eine Lobby. In: Festschrift. Eine Stimme für unsere Sprache. 10 Jahre Verein Deutsche Sprache. Paderborn, S. 23-34.

Pogarell, Reiner/Schröder, Markus (2001): Wörterbuch überflüssiger Anglizismen. Paderborn.

Pogarell, Reiner/Schröder, Markus/Bartzsch Rudolf (2008): Wörterbuch überflüssiger Anglizismen. Paderborn.

Polenz, Peter von (1967a): Sprachpurismus und Nationalsozialismus. Die „Fremdwort“-Frage gestern und heute. In: von Wiese, Benno/ Henß, Rudolf (Hgg.): Germanistik - eine deutsche Wissenschaft. Nationalismus in Germanistik und Dichtung. Dokumentation des Germanistentages in München vom 17.-22. Oktober 1966. Berlin, S. 79-112.

Polenz, Peter von (1967b): Fremdwort und Lehnwort sprachwissenschaftlich betrachtet. In: Muttersprache 77, 1967, S. 65-80.

Polenz, Peter von (1978): Geschichte der deutschen Sprache. Berlin.

Polenz, Peter von (1999a): Fremdwortpurismus und Sprachpflege Sprachvereine und Sprachinstitutionen. In: Peter von Polenz (1999): Deutsche Sprachgeschichte vom Spätmittelalter bis zur Gegenwart, Bd. 3, Berlin, S. 264-297.

Polenz, Peter von (Hg.) (1999b): Deutsche Sprachgeschichte vom Spätmittelalter bis zur Gegenwart. Berlin. 
Pörksen, Uwe (2000): Mehrsprachigkeit und Selbststand. Über die staatsunabhängige Herausbildung einer deutschen Gemeinschaft und ihre Zukunft: Sieben Thesen. In: Strocka, Volker Michael (Hg.) (2000): Die Deutschen und ihre Sprache. Reflexionen über ein unsicheres Verhältnis. Bremen, S. 7-34.

Presse- und Informationsamt der Bundesregierung (Hg) (1973): Heinemann, G.W.: Reden und Interviews (IV). 1. Juli 1972 - 30. Juni 1973. Bonn.

Pretscher, Sabine/Hoppe, Florian (2008): Aktion Lebendiges Deutsch. Bamberg.

Pusch, Luise (Hg.)(1989): Alle Menschen werden Schwestern. Frankfurt. Raffaelli, Sergio (1983): Le parole proibite. Purismo di stato e regolamentazione della pubblicità in Italia (1812-1945). Bologna.

Rash, Felicity (1998): The German Language in Switzerland: multilingualism, diglossia and variation. Bern.

Rash, Felicity (2001): The Schweizerische Verein für die deutsche Sprache and linguistic purism in twentieth-century German-speaking Switzerland. In: Davies, M.C./Flood, J.L./Yeandle. D.N. (Hgg.): Proper Words in Proper Places. Studies in Lexicology and Lexicography in Honour of William Jervis Jones. Stuttgart, S. 254177.

Rash, Felicity (2002): Die deutsche Sprache in der Schweiz. Mehrsprachigkeit, Diglossie und Veränderung. Bern.

Rash, Felicity (2006): Attitudes to the use of English in Swiss German advertising language. In:

<http://wjmll.ncl.ac.uk/issue01/rash5.htm> (4. März 2006).

Rau, Johannes (2002): Eröffnung des Kongresses „Gutenbergs Folgen. Von der ersten Medienrevolution zur Wissensgesellschaft“. Grußwort von Bundespräsident Johannes Rau anlässlich der Eröffnung des Kongresses „Gutenbergs Folgen. In: Stiftung Lesen (Hg.): „Gutenbergs Folgen. Von der ersten Medienrevolution zur Wissensgesellschaft“. Baden-Baden, S. 19-25. 
Rehtmeyer, Viktor (1937): Fremdwort, Deutschheit und Schrifttumsgeschichte. In: Muttersprache 52, 1937, Sp. 141-143.

Rehbein, Jochen (2001): Konzepte der Diskursanalyse. In: Brinker, Klaus/Antos, Gerd/Heinemann, Wolfgang/Sager, Sven F. (Hgg.) (2001): Text- und Gesprächslinguistik. Ein internationales Handbuch zeitgenössischer Forschung. HSK 16.2, S. 927-945.

Reiners, Ludwig (1943): Stilkunst. Ein Lehrbuch deutscher Prosa. München.

Reiners Ludwig (1944): Deutsche Stilkunst. München.

Reiners, Ludwig (1951): Der sichere Weg zum guten Deutsch. Eine Stilfibel. München.

Reiners, Ludwig (1959): Stilfibel. Der sichere Weg zum guten Deutsch. München.

Reisigl, Martin (2007): Zum innerlinguistischen Status der Diskursanalyse. In: Redder, Angelika (Hg.) (2007): Diskurse und Texte. Festschrift für Konrad Ehlich zum 65. Geburtstag. Tübingen, S. 71-80.

Rettig, Wolfgang (1989): Die Wortbildungszusammenhänge im allgemeinen einsprachigen Wörterbuch. In: Hausmann, FranzJosef/Reichmann, Oskar/Wiegand, Herbert Ernst/Zgusta, Ladislav (Hgg.): Wörterbücher. Ein Handbuch zu Lexikographie. HSK. 5.1. Berlin, New York, S. 642-649.

Riebe, Manfred (o.D.): Was bedeuten „Wahrung“ und „Förderung“ der Sprache und der Sprachkultur? Kritik einer sprachpolitischen Begriffsverdrängung. In: <http://www2.tu-berlin.de/fb1/AGiW/Cricetus/SOzuC1/SOVsRSR/ArchivSO/MRiebe1.htm> (12. Oktober 2007).

Riegel, Hermann (1883): Ein Hauptstück von unserer Muttersprache, der Allgemeine Deutsche Sprachverein und die Errichtung einer Reichsanstalt für deutsche Sprache. Mahnruf an alle nationalgesinnten Deutschen. Berlin. 
Rock, Ze do (2009): Nichtdeutschis seen da keine löcher. In: Schrammen, Gerd (2009) (Hg.): Ich spreche gern Deutsch. Paderborn, S. 91-95.

Rück, Peter (1993a): Der schöne Schein des Dritten Reiches. Faszination und Gewalt des Faschismus. Frankfurt.

Rück, Peter (1993b): Die Sprache der Schrift - Zur Geschichte des Frakturverbots von 1941. In: Baurmann, Jürgen et al. (Hg.) (1993): homo scribens. Tübingen, S. 271-282.

Ruprecht, U. (1933): Geschäftsbericht des Deutschen Sprachvereins (E.V.) für die Zeit vom 1. Januar 1932 bis zum 30. Juni 1933. In: Muttersprache 48, 1933, S. 289ff.

Saalfeld, Günther (1904): Bücherschau. In. Zeitschrift des Allgemeinen Deutschen Sprachvereins 19, 1904, Nr. 9. S. 262f.

Salewksi, Michael (2005): Deutschland und der Zweite Weltkrieg. Paderborn.

Sarrazin, Otto (1896): Verdeutschungswörterbuch. Berlin.

Sarrazin, Otto (1914): Kriegsaufruf an unsre Zweigvereine und alle 35000 Sprachvereinsmitglieder. In: Zeitschrift des Allgemeinen Deutschen Sprachvereins 29, 1914, Nr. 10, S. 337-343.

Sauer, Wolfgang-Werner (2000): Berufsbezeichnungen zwischen Customer Service Specialist und Kundenberater. In: Thesen zur Situation der deutschen Sprache. In: Glück, Helmut/Krämer, Walter (Hgg.) (2000): Die Zukunft der deutschen Sprache. Eine Streitschrift. Leipzig, S. 52-61.

Sauter, Anke (2000): Eduard Engel. Literaturhistoriker, Stillehrer, Sprachreiniger. Bamberg.

Saxer, Ulrich (1989): Kommunikationsprobleme in der mehrsprachigen Schweiz. In: Nationale schweizerische UNESCO-Kommission (Hg.) (1989): Seminar „Regionalsprache und Massenkommunikation“. Bern, S. 91-115. 
Schiewe, Jürgen (1988): Sprachpurismus und Emanzipation. Joachim Heinrich Campes Verdeutschungsprogramm als Voraussetzung für Gesellschaftsveränderungen. Hildesheim.

Schiewe, Jürgen (1998): Die Macht der Sprache. Eine Geschichte der Sprachkritik von der Antike bis zur Gegenwart. München.

Schiewe, Jürgen (2000): Sprachpurismus als Aufklärung: Soll man Fremdwörter verdeutschen? In: Strocka, Volker Michael (Hg.) (2000): Die Deutschen und ihre Sprache. Reflexionen über ein unsicheres Verhältnis. Bremen, S. 35-68.

Schiewe, Jürgen (2001): Aktuelle wortbezogene Sprachkritik in Deutschland. In: Neues und Fremdes im deutschen Wortschatz. Aktueller lexikalischer Wandel. Jahrbuch 2000 des IDS. Berlin, S. 280-296.

Schiewe, Jürgen (2003): Sprachwissenschaft und Sprachkritik. In: Wiesinger, Peter (Hg.) (2003): Akten des X. Internationalen Germanistenkongresses Wien 2000. Zeitenwende - Die Germanistik auf dem Weg vom 20. ins 21. Jahrhundert. Übersetzung und Literaturwissenschaft. Aktuelle und allgemeine Fragen der germanistischen Wissenschaftsgeschichte. Bd. 11. Bern, S. 327-332.

Schiewe, Jürgen/Wengeler, Martin (2005): Zeitschrift für Sprachkritik und Sprachkultur. Einführung der Herausgeber zum ersten Heft. In: Aptum 1, 2005, Nr. 1, S. 1-13.

Schmitz, Heinz-Günter (1999): Die Amerikanisierung und Internationalisierung der deutschen Sprache nach dem Zweiten Weltkrieg. Starnberg.

Schmitz, Heinz-Günter (2001): Das Versagen der deutschen Sprachwissenschaft und Sprachpflege in der Fremdwortfrage. In: Zabel. Hermann (Hg.) (2001): Ein See - drei Länder - eine Sprache. Tagungsband der Sprachvereine im "Netzwerk Deutsche Sprache“. Paderborn, S. 23-31.

Schmitz, Heinz-Günter (2006): Die Globalisierung der deutschen Sprache mit dem Verlust der Sprachloyalität. Starnberg. 
Schmitz-Berning, Cornelia (1998): Vokabular des Nationalsozialismus. Berlin, New York.

Schmöe, Friederike (1998): Italianismen im Gegenwartsdeutschen. Bamberg.

Schneider, Jan Georg (2005): Was ist ein sprachlicher Fehler? Anmerkungen zu populärer Sprachkritik am Beispiel der Kolumnensammlung von Bastian Sick. In: Aptum 1, 2005, Nr. 2, S. 154-177.

Schneider, Jan Georg (2006): Von free-floatendem Kapital, Hardlinern und Instructions Linguistische Anmerkungen zur populären Anglizismenkritik. In: LEO. Lingua et Opinio. Studentische Zeitschrift zu Sprache und Kommunikation, 19. Dezember 2006. In:

$<$ http://www.tu-chemnitz.de/phil/leo/rahmen.php?seite=r_wiss/schneider_anglizismen.php> (27. Dezember 2006).

Schneider, Jan Georg (2007): Linguistische Anmerkungen zum SpiegelTitel „Rettet dem Deutsch!“. In: Aptum 3, 2007, Nr. 1, S. 1-23.

Schneider, Wolf (2008): Speak German! Warum Deutsch manchmal besser ist. Reinbek.

Schönfelder, Karl-Heinz (1956): Probleme der Völker- und Sprachmischung. Halle/Saale.

Schoebe, Gerhard (2003). Besprechungen einer VDS-Publikation. In: Zabel, Hermann (Hg.) (2003): Denglisch, nein danke! Zur inflationären Verwendung von Anglizismen und Amerikanismen in der deutschen Gegenwartssprache. Paderborn, S. 295-297.

Schottelius, Justus Georg (1663): Ausführliche Arbeit von der Teutschen HaubtSprache. In: Hecht, Wolfgang (Hg.) (1967): Justus Georg Schottelius. Ausführliche Arbeit von der Teutschen HaubtSprache. I. Teil. Tübingen.

Schrammen, Gerd (2003): Brauchen wir englische Wörter? Ein Plädoyer für den Gebrauch der deutschen Sprache. In: Forschung und Lehre 10,2003 , S. 538-539. 
Schütte, Wilfried (2000): Sprachentwicklungen und Kommunikationsformen in den interaktiven Diensten des Internet. In: Hoffmann, Hilmar (Hg.) (2000): Deutsch global. Neue Medien - Herausforderungen an die Deutsche Sprache, S. 77-95.

Schulz, Rüdiger (2008): Wie denken die Deutschen über ihre Muttersprache und über Fremdsprachen? Erkenntnisse aus einer repräsentativen Bevölkerungsumfrage 2008. Allensbach.

Sick, Bastian (2004): Der Dativ ist dem Genitiv sein Tod. 2. Auflage. Köln.

Sick, Bastian (2005): Der Dativ ist dem Genitiv sein Tod 2. 2. Auflage. Köln.

Sick, Bastian (2006): Der Dativ ist dem Genitiv sein Tod 3. Köln.

Sick, Bastian (2007): Happy Aua. Köln.

Sick, Bastian (2009): Der Dativ ist dem Genitiv sein Tod 4. Köln.

Sijs, Nicoline van der (Hg.) (1999): Taaltrots. Amsterdam.

Simon, Gerd (1986): Hundert Jahre „Muttersprache“: Die Idee eines Museumsdirektors und ihre Folgen. In: Der Deutschunterricht 38, 1986, Nr. 5, S. 83-98.

Skasa-Weiß, Ruprecht (2006): Fünf Minuten Deutsch. Stuttgart.

Skasa-Weiß, Ruprecht (2007): Weitere fünf Minuten Deutsch. Stuttgart.

Spitzmüller, Jürgen (2002): Selbstfindung durch Ausgrenzung: Eine kritische Analyse des gegenwärtigen Diskurses zu angloamerikanischen Entlehnungen. In: Hoberg, Rudolf (Hg.): Deutsch - Englisch - Europäisch, Dudenverlag Mannheim, S. 247-265.

Spitzmüller, Jürgen (2005): Metasprachdiskurse: Einstellungen zu Anglizismen und ihre wissenschaftliche Rezeption. Berlin.

Spitzmüller, Jürgen (2007): Staking the claims of identity: Purism, linguistics and the media in post-1990 Germany. In: Journal of Sociolinguistics 11, 2007, Nr. 2, S. 261-285. 
Spitzmüller, Jürgen/Roth, Kersten Sven/Leweling, Beate/Frohning, Dagmar (Hgg.) (2002): Streitfall Sprache. Bremen.

Stark, Franz (2000): Sprache als Instrument der Außenpolitik. In: Thesen zur Situation der deutschen Sprache. In: Glück, Helmut/Krämer, Walter (Hgg.) (2000): Die Zukunft der deutschen Sprache. Eine Streitschrift. Leipzig, S. 19-42.

Stark, Franz (2007a): „Sprache - ,Sanftes' Machtinstrument in der globalen Konkurrenz. Wo, wie und wieweit wir Deutsch verteidigen sollten. Zehn Thesen für eine deutsche Sprachenpolitik.“ Paderborn.

Steinfeld, Thomas (2002): Tierleben im Eismeer. In: Deutsche Welle (2002): Passé und mega-out? Zur Zukunft der deutschen Sprache im Zeitalter von Globalisierung und Multimedia. Köln, S. 13-18.

Sternberger, Dolf/Storz, Gerhard/Süskind, W.E (1957): Aus dem Wörterbuch des Unmenschen. München.

Stickel, Gerhard (1984): Einstellungen zu Anglizismen. In: Besch, Werner/Hufeland, Klaus/Schuppe, Volker/Wiehl, Peter (Hgg.): Festschrift für Siegfried Gosse zum 60. Geburtstag. Göppingen, S. 279-309.

Stickel, Gerhard (1985): Das „Fremdwort“ hat ausgedient. IDSMitteilungen 1985, Nr. 11, S. 7-18.

Stickel, Gerhard (1987): „Was halten Sie vom heutigen Deutsch? Ergebnisse einer Zeitungsumfrage“. In: Wimmer, Rainer (Hg.): Sprachtheorie - Der Sprachbegriff in Wissenschaft und Alltag. Jahrbuch 1986 des IDS. Düsseldorf, S. 280-318.

Stickel, Gerhard (1994): Engleutsch. In: Sprachreport 1994, Nr. 4, S. 1314.

Stickel, Gerhard (1999): Zur Sprachbefindlichkeit der Deutschen. Erste Ergebnisse einer Repräsentativumfrage. In: Derselbe (Hg.): Sprache - Sprachwissenschaft - Öffentlichkeit. Jahrbuch 1998 des IDS. Berlin, S. 16-44. 
Stickel, Gerhard (2007): Deutsche und europäische sprachliche Interessen. In: Muttersprache 117, 2007, S. 134-144.

Stickel, Gerhard (Hg.) (2001): Neues und Fremdes im deutschen Wortschatz. Aktueller lexikalischer Wandel. Jahrbuch 2000 des IDS. Berlin.

Stickel, Gerhard/Volz, Norbert (1999): Meinungen und Einstellungen zur Deutschen Sprache. Ergebnisse einer bundesweiten Repräsentativerhebung. Mannheim.

Stöckhardt, Julia (2000): Sprachpflege: Was, wozu, für wen, wie? Vier Fragen, vier Thesen. In: Der Sprachdienst 44, 2000, Nr. 6, S. 204209.

Stoll, PH. (1903): Zeitungsschau. Aufsätze in Zeitungen und Zeitschriften. In: Zeitschrift des Allgemeinen Deutschen Sprachvereins 18, 1903, Nr. 4, Sp. 117.

Stoltenberg, H.L. (1933): Deutsche Weisheitssprache. Lahr.

Stoltenberg, H.L. (1934): Der eigendeutsche Wortschatz der Weisheitslehre. Frankfurt.

Strauß, Gerhardt et al. (2004): Deutsches Fremdwörterbuch. Begonnen von Hans Schulz, fortgeführt von Otto Basler. Völlig neubearbeitet im Institut für deutsche Sprache von Gerhardt Strauß u.a. Berlin.

Strock, Christopher (2001): Kulturnation und Nationalkunst. Strategien und Mechanismen tschechischer Nationsbildung von 1860 bis 1914. Köln.

Strocka, Volker Michael (Hg.) (2000): Die Deutschen und ihre Sprache. Reflexionen über ein unsicheres Verhältnis. Bremen.

Stukenbrock, Anja (2003): Zur Untersuchung sprachnationalistischer Diskurse in Deutschland. In: Wiesinger, Peter (Hg.) (2003): Akten des X. Internationalen Germanistenkongresses Wien 2000. Zeitenwende - Die Germanistik auf dem Weg vom 20. ins 21. Jahrhundert. Übersetzung und Literaturwissenschaft. Aktuelle und allgemeine Fragen der germanistischen Wissenschaftsgeschichte. Bd. 11. Bern, S. 321-327. 
Stukenbrock, Anja (2005a): Aus Liebe zur Muttersprache? Der VDS und die fremdwortpuristische Diskurstradition. In: Aptum 1, 2005, Nr. 3, S. 220-247.

Stukenbrock, Anja (2005b): Sprachnationalismus. Sprachreflexion als Medium kollektiver Identitätsstiftung in Deutschland (1617 1945). Berlin.

Tesch, Gerd (1978): Linguale Interferenz. Theoretische, terminologische und methodische Grundfragen zu ihrer Erforschung. Tübingen.

Thierse, Wolfgang (2004): The German Language and the Linguistic Diversity of Europe. In: Gardt, Andreas/Hüppauf, Bernd (Hgg.) (2004): Globalization and the Future of German. Berlin, S. 187196.

Thomas, George (1991): Linguistic Purism. London.

Toubon, Jacques (2000): Wozu dient künftig eine Nationalsprache? In: Thesen zur Situation der deutschen Sprache. In: Glück, Helmut/Krämer, Walter (Hgg.) (2000): Die Zukunft der deutschen Sprache. Eine Streitschrift. Leipzig, S. 11-18.

Trabant, Jürgen (1995): Zur Einführung: Fremde Sprache in Babel und Paris. In: Trabant, Jürgen (Hg.): Die Herausforderung durch das Fremde in der Sprache. Berlin.

Trabant, Jürgen (2002): Der Gallische Herkules. Studien über Sprache und Politik in Frankreich und Deutschland. Tübingen, Basel.

Trabold, Annette (1993): Sprachpolitik, Sprachkritik und Öffentlichkeit. Anforderungen an die Sprachfähigkeit des Bürgers. Wiesbaden.

Trask, Larry R. (1999): Key Concepts in Language and Linguistics. London.

Ülkü, Vural (1975): Sprachreinigungsbestrebungen in Deutschland seit den 80er Jahren des 19. Jahrhunderts bis zur Gegenwart. Ankara. 
Ülkü, Vural (2002): Sprachnationalismus und Sprachpolitik. Deutsche und türkische Modelle. In: Haß-Zumkehr, Ulrike/Kallmeyer, Werner/Zifonun, Gisela (Hgg.) (2002): Ansichten der deutschen Sprache. Gerhard Stickel zum 65. Geburtstag. Tübingen, S. 419-438.

Ury, Else (1916). Nesthäkchen und der Weltkrieg. Berlin.

Viereck, Karin (1980): Englisches Wortgut, seine Häufigkeit und Integration in der österreichischen und bundesdeutschen Presse. Frankfurt.

Viereck, Wolfgang (Hg.) (1980): Studien zum Einfluß der englischen Sprache auf das Deutsche. Tübingen.

Vilmar, Fritz (2001): Niemand will eine Sprachpolizei. Die Sprachdiskussion über das Stammtischniveau erheben. In: Dieter, Hermann/Gawlitta, Kurt/Meißner, Gernot/Vilmar, Fritz (Hgg.) (2001): Wörter fallen nicht vom Himmel. Berlin/Potsdam, S. 1925.

Vilmar, Fritz (2002a): Sprachimperialismus: Analyse; Widerstand. In: Gawlitta, Kurt/Vilmar, Fritz (Hgg.) (2002): „Deutsch nix wichtig“?: Engagement für die deutsche Sprache. Paderborn, S. 12-34.

Vilmar, Fritz (2002b): Verschwindet das Deutsche als Wissenschaftssprache? In: Gawlitta, Kurt/Vilmar, Fritz (Hgg.) (2002): „Deutsch nix wichtig“?: Engagement für die deutsche Sprache. Paderborn, S. 78-96.

Vilmar, Fritz (2002c): Die Amerikanisierung der deutschen Sprache. Bericht über ein Blockseminar der FU Berlin (Juni/Juli 2001). In: Gawlitta, Kurt/Vilmar, Fritz (Hgg.) (2002): „Deutsch nix wichtig“?: Engagement für die deutsche Sprache. Paderborn, S. 206-207.

Weber, Daniel Erich (1984): Sprach- und Mundartpflege in der deutschsprachigen Schweiz. Sprachnorm und Sprachdidaktik im zweisprachformigen Staat. Frauenfeld.

Weinreich, Uriel (1974): Languages in Contact - Findings and Problems. New York. 
Weinrich, Harald (1969): Kritik der linguistischen Kompetenz. In: Akzente 16, 1969, Nr. V, S. 371-383.

Weinrich, Harald (1988): Wege der Sprachkultur. München.

Weisgerber, Leo (1960): Das Fremdwort im Gesamtrahmen der Sprachpflege. In: Muttersprache 70, 1960, S. 1-6.

Weiß, Sarah (2007): Verstehenshilfe für die Klassikerlektüre. Der Differenzwortschatz und seine Erklärung als Lesemotivation. Hamburg.

Werthebach, Eckart (2001): Die deutsche Sprache braucht gesetzlichen Schutz. In: Wörter fallen nicht vom Himmel. Berlin/Potsdam, S. 5-8.

Wiechers, Silke (2001): „Wir sind das Sprachvolk“ - aktuelle Bestrebungen von Sprachvereinen und -initiativen. In: Muttersprache 111, 2001, S. 147-163.

Wiechers, Silke (2004): Die Gesellschaft für deutsche Sprache. Vorgeschichte, Geschichte und Arbeit eines deutschen Sprachvereins. Frankfurt.

Wieners-Horst, Barbara (1998a): Sprachkultur oder Sprachverfall? Die deutsche Sprache vor der Jahrtausendwende. Ein Symposium der Gesellschaft für deutsche Sprache und des Arbeitskreises selbständiger Kultur-Institute (AsKI). In: Der Sprachdienst 42, 1998, Nr. 1, S. 31-36.

Wieners-Horst, Barbara (1998b): Sprachkultur oder Sprachverfall? Die deutsche Sprache vor der Jahrtausendwende. Ein Symposium der Gesellschaft für deutsche Sprache und des Arbeitskreises selbständiger Kultur-Institute (AsKI). Fortsetzung von Heft 1/1998, S. 36. In: Der Sprachdienst 42, 1998, Nr. 2, S. 70-75.

wise guys (2006): Denglisch. Aus dem Album „Radio“. In: <http://www.wiseguys.de/liedtexte.shtml> (29. Mai 2008).

Wyss, Johannes (2005): Einige grössere und kleinere Ereignisse aus der 100-jährigen Geschichte des Schweizerischen Vereins für die deutsche Sprache. In: Sprachspiegel 2005, Nr. 1, S. 12-16. 
Yang, Wenliang (1990): Anglizismen im Deutschen: Am Beispiel des Nachrichtenmagazins DER SPIEGEL. Tübingen.

Zabel, Hermann (Hg.) (2001a): Denglisch, nein danke! Zur inflationären Verwendung von Anglizismen und Amerikanismen in der deutschen Gegenwartssprache. Paderborn.

Zabel, Hermann (2001b): Ziele und Aktivitäten des Vereins. In: Zabel, Hermann (Hg.)(2001): Denglisch, nein danke! Zur inflationären Verwendung von Anglizismen und Amerikanismen in der deutschen Gegenwartssprache. Paderborn, S. 243-285.

Zabel, Hermann (2001c): Die gebrannten Kinder - Fremdwortprobleme der Sprachwissenschaftler. In: Zabel, Hermann (Hg.) (2001): Ein See - drei Länder - eine Sprache. Tagungsband der Sprachvereine im „Netzwerk Deutsche Sprache“. Paderborn, S. 31-43.

Zabel, Hermann (Hg.) (2003): Denglisch, nein danke! Zur inflationären Verwendung von Anglizismen und Amerikanismen in der deutschen Gegenwartssprache. Paderborn.

Zabel et al. (2001): Leitlinien. Worum es geht. In: Denglisch, nein danke! Zur inflationären Verwendung von Anglizismen und Amerikanismen in der deutschen Gegenwartssprache. Paderborn, S. 223-228.

Zabel et al. (2003): Sprachpolitische Leitlinien. In: Denglisch, nein danke! Zur inflationären Verwendung von Anglizismen und Amerikanismen in der deutschen Gegenwartssprache. Paderborn, S. 347 -354 .

Zbinden, Peter (2007): Deutsch: Von Jubiläum zu Jubiläum. In: Krämer, Walter/Grobe, Myriam/Petros, Dawit (Hgg.) (2007): Festschrift. Eine Stimme für unsere Sprache. 10 Jahre Verein Deutsche Sprache. Paderborn, S. 63-70.

Zifonun, Gisela (2002): Überfremdung des Deutschen: Panikmache oder echte Gefahr? In: Sprachreport 2002, Nr. 3, S. 2-9.

Zimmer, Dieter. E. (1997): Deutsch und anders: Die Sprache im Modernisierungsfieber. Reinbek. 
Zindler, Horst (1959): Anglizismen in der deutschen Presse nach 1945. Kiel. 


\section{Amtliche Dokumente}

Barthel Eckhardt et al. (2001): Große Anfrage der Abgeordneten Eckhardt Barthel (Berlin), Hans-Werner Bertl, Christel Deichmann, weiterer Abgeordneter und der Fraktion der SPD sowie der Abgeordneten Dr. Antje Vollmer, Kerstin Müller (Köln), Rezzo Schlauch und der Fraktion Bündnis 90/Die Grünen - Drucksache 14/6659, 6. Juli 2001.

Bundesregierung (1999): Schriftliche Fragen mit den in der Woche vom 7. Juni 1999 eingegangenen Antworten der Bundesregierung. Drucksache 14/1124, 11. Juni 1999.

Bundesregierung (2000a): Antwort der Bundesregierung auf die Schriftliche Anfrage des Abgeordneten Jürgen Türk vom 3. Juli 2000. Arbeitsnummern 7/7, 7/8, 7/9, 7/10.

Bundesregierung (2000b): Antwort der Bundesregierung auf die Schriftliche Anfrage des Abgeordneten Jürgen Türk vom 13. November 2000. Arbeitsnummern 11/75, 11/76, 11/77.

Bundesregierung (2001): Antwort der Bundesregierung auf die Große Anfrage der Abgeordneten Dr. Norbert Lammert, Bernd Neumann (Bremen), Renate Blank, weiterer Abgeordneter und der Fraktion der CDU/CSU - Drucksache 14/5838, 31. Oktober 2001. Drucksache $14 / 7250$.

Bundesregierung (2002a): Antwort der Bundesregierung auf die Große Anfrage der Abgeordneten Eckhardt Barthel (Berlin), HansWerner Bertl, Christel Deichmann, weiterer Abgeordneter und der Fraktion der SPD sowie der Abgeordneten Dr. Antje Vollmer, Kerstin Müller (Köln), Rezzo Schlauch und der Fraktion BÜNDNIS90/DIE GRÜNEN - Drucksache 14/6659, 7. Februar 2002, Drucksache 14/8203.

Bundesregierung (2002b): 212. Sitzung des Deutschen Bundestags in Berlin vom 24. Januar 2002. In: Plenarprotokolle. In: <http://www.bundestag.de/bic/plenarprotokolle/pp/2002/ index.html> (25. Oktober 2007). 
Gauweiler, Peter et al. (2003): Antrag der Abgeordneten Dr. Peter Gauweiler u.a. und der Fraktion der CDU/CSU: Deutsch als dritte Arbeitssprache auf europäischer Ebene - Verstärkte Förderung von Deutsch als lernbare Sprache im Ausland. Drucksache 15/468, 18. Februar 2003.

Koschyk, Hartmut (1999): Schriftliche Frage des Abgeordneten Hartmut Koschyk an die Bundesregierung, 31. Mai 1999. In: Bundesregierung (1999): Schriftliche Fragen mit den in der Woche vom 7. Juni 1999 eingegangenen Antworten der Bundesregierung. Drucksache 14/1124, 11. Juni 1999, S. 11.

Lammert, Norbert et al. (2001): Große Anfrage der Abgeordneten Dr. Norbert Lammert, Bernd Neumann (Bremen), Renate Blank, weiterer Abgeordneter und der Fraktion der CDU/CSU: Verbreitung, Förderung und Vermittlung der deutschen Sprache. Drucksache $14 / 5835$.

Schneider, Christiane (2008): Schriftliche Anfrage der Abgeordneten Christine Schneider (DIE LINKE) an den Senat der Freien und Hansestadt Hamburg vom 23. Mai 2008.

Türk, Jürgen (2000a): Schriftliche Anfrage des Abgeordneten Jürgen Türk (FDP) an die Bundesregierung vom 3. Juli 2000.

Türk, Jürgen (2000b): Schriftliche Anfrage des Abgeordneten Jürgen Türk (FDP) an die Bundesregierung vom 13. November 2000. 


\section{Gespräche und Schreiben}

Im Folgenden findet sich eine Liste von Gesprächen, persönlich oder telefonisch, die die Verfasserin im Laufe der Recherchen geführt hat. Aufzeichnungen und Gesprächsprotokolle, meist handschriftlich, finden sich im Privatarchiv der Verfasserin. Außerdem sind E-Mails und Schreiben, die auf Anfragen der Verfasserin eingegangen sind, im Folgenden aufgeführt. Diese befinden sich ebenfalls im Privatarchiv der Verfasserin.

Gespräch mit Helmut Glück, Stellvertretender Vorsitzender des Wissenschaftlichen Beirats des VDS, 19. Juni 2004.

Gespräch mit Walter Krämer, Vorsitzender des VDS, 17. März 2005.

Gespräch mit Walter Krämer, Vorsitzender des VDS, 25. März 2005, aufgezeichnet auf Minidisk.

Gespräch mit Christiane Dahl, Mitarbeiterin der VDS-Geschäftsstelle, 25. März 2005.

Gespräch mit Thilo Machotta, Moderator des VDS-Forums, 21. März 2005, aufgezeichnet auf Minidisk.

Gespräch mit Holger Klatte, Geschäftsführer des VDS, 28. November 2008.

Gespräch mit Sabine Riga, Mitarbeiterin VDS-Geschäftsstelle, 28. November 2008.

Telefongespräch mit Helmut Heiter, IG-Muttersprache, 11. September 2007.

Telefongespräch mit Peter Heisch, Aktuar vom SVDS, 11. September 2007.

Telefongespräch mit Sabine Riga, Mitarbeiterin der VDSGeschäftsstelle, 10. Oktober 2007.

Telefongespräch mit Christiane Dahl, Mitarbeiterin der VDSGeschäftsstelle, 15. Oktober 2007. 
Telefongespräch mit Peter Zbinden, Vorsitzender des Sprachkreis Deutsch, 17. April 2008.

Telefongespräch mit Manfred Riebe, Pressesprecher des VRS, 24. Juli 2008.

Telefongespräch mit Heinz-Günter Schmitz, Mitglied des Wissenschaftlichen Beirats des VDS, 12. November 2008.

Telefongespräch mit Diethold Tietz, Sprachrettungsklub Bautzen, 8. Januar 2009.

Telefongespräch mit Hermann Dieter, VDS Berlin/Potsdam, 9. Februar 2009.

Telefongespräch mit Ulrike Johanning-De Abrew, Henning-KaufmannStiftung, 28. September 2009.

E-Mail von Corinna Blattmann von der Deutschen Akademie für Sprache und Dichtung an die Verfasserin, 16. Januar 2008.

E-Mail von Christiane Dahl, Mitarbeiterin der VDS-Geschäftsstelle, an die Verfasserin, 12. Oktober 2007.

E-Mail von Elke Blohm, BfdS, an die Verfasserin, 5. Mai 2008.

E-Mail von Ulrich Knoop, ehemaliger Vorsitzender des Wissenschaftlichen Beirats des VDS, an die Verfasserin, 1. Mai 2008.

E-Mail von Holger Klatte, VDS-Geschäftsführer, an die Verfasserin, 12. Oktober 2009.

E-Mail von Holger Klatte, VDS-Geschäftsführer, an die Verfasserin, 18. November 2009.

Brief von Holger Klatte, VDS-Geschäftsführer, an die Verfasserin, 7. Januar 2009.

Brief von Walter Krämer an die Verfasserin, 7. Januar 2009.

E-Mail von Thomas Paulwitz, DSW, an die Verfasserin, 4. Februar 2010.

E-Mail von Thomas Paulwitz, DSW, an die Verfasserin, 9. Februar 2010. 


\section{Internetpräsenzen}

\section{Internetpräsenz der Aktion Deutsche Sprache:}

Neemann, Hermann (2008). Über uns. <http://www.aktion-deutschesprache.de/> (28. Juli 2008).

Internetpräsenz Aktionsseite gegen verfassungsmäßig unzulässige Sprach- und Schriftregelungen:

Aktionsbündnis (2000): Aktionsseite gegen verfassungsmäßig unzulässige Sprach- und Schriftregelungen.

$<$ http://deposit.ddb.de/ep/netpub/91/53/58/964585391/_data_dyna/_snap_stand_2000_02_27/Cricetus/SOzuC1/Aktion.htm> (20. Januar 2009).

Internetpräsenz des ARKUS:

Mechtersheimer, Alfred (2005a). Schutz der deutschen Sprache. $<$ http://www.unser-land.com/index.html?/arkus.html> (28. Mai 2006).

Mechtersheimer, Alfred (2005b). Selbstverpflichtung. <http://www.unser-land.com/index.html?/arkus.html> (28. Mai 2006).

Mechtersheimer, Alfred (2007). Veröffentlichungen. <http://www.unserland.com/index.html?/arkus.html> (13. September 2007).

Internetpräsenz des Asta der Freien Universität Berlin:

Morgenthau, Henry/Harris, Arthur (2001): Sprachpflege und nationale Erweckung. <http://www.astafu.de/inhalte/artikel/a_2001/vds> (13. Januar 2008). 


\section{Internetpräsenz von Baer, Oliver:}

Baer, Oliver (2008a): Bärentatze. Sprachspuren in Marketing, Kultur, Ethik. <http://www.baerentatze.de> (14. Juli 2008).

\section{Internetpräsenz von Borsch, Robert:}

Borsch, Robert (2005): Die Seiten für gutes Deutsch. $<$ http://www.home.t-online.de/home/robert.borsch/< (23. Januar 2005).

\section{Internetpräsenz Bremer Sprachblog:}

Stefanowitsch, Anatol (2007a): Body-Bag-Blues. <http://www.iaas.unibremen.de/sprachblog/2007/02/16/body-bag-blues/> (13. Januar 2009).

Stefanowitsch, Anatol (2007b): Can you English? (Nachtrag). <http://www.iaas.uni-bremen.de/sprachblog/2007/06/14/can-youenglish-nachtrag/> (13. Januar 2009).

Stefanowitsch, Anatol (2007c): Happy Hour. <http://www.iaas.unibremen.de/sprachblog/2007/07/05/happy-hour/> (13. Januar 2009).

Stefanowitsch, Anatol (2008): Kaffepaussi. <http://www.iaas.unibremen.de/sprachblog/2008/11/06/kaffepaussi/> (13. Januar 2009).

Internetpräsenz des Europäischen Bürger-Netzwerks EUROPA JETZT!:

Grützke, Horst (2007): Internetportal Europäischer Webseiten. $<$ http://europa-jetzt.org/> (30. Juli 2008). 
Internetpräsenz des Bunds für deutsche Schrift und Sprache:

Blohm, Hanno (2003a): Zielsetzung. <http://www-ewelt.net/bdfs_2003/bund/zielsetzung.htm> (13. September 2007).

Blohm, Hanno (2003b): Häufige Fragen. Nazischrift? <http://www.ewelt.net/bfds_2003/bund/fragen/18_Nazischrift.pdf> (30. April 2008).

Blohm, Hanno (2003c): Häufige Fragen. <http://www-ewelt.net/bfds_2003/bund/fragen.htm> (16. Juli 2008).

Blohm, Hanno (2003d): Verweise. <http://www.ewelt.net/bfds_2003/verweise.htm> (29. Mai 2006).

Blohm, Hanno (2007): 50 Jahre Bund für deutsche Schrift und Sprache. $<$ http://www.bfds.de> (13. September 2007).

Blohm, Hanno (2008): Stiftung Deutsche Schrift. $<$ http://www.deutscheschrift.de/> (30. April 2008).

\section{Internetpräsenz der Deutschen Akademie für Sprache und Dichtung:}

Deutsche Akademie für Sprache und Dichtung (2005a): Satzung. <http://www.deutsche-akademie.de/satzung.html> (30. Oktober 2007).

Deutsche Akademie für Sprache und Dichtung (2005b): Mitglieder. $<$ http://www.deutsche-akademie.de/ akademie_mitglieder_einfuehrung.html> (30. Oktober 2007).

Deutsche Akademie für Sprache und Dichtung (2007): Aktuell. <http://www.deutscheakademie.de> (30. Oktober 2007).

Deutsche Akademie für Sprache und Dichtung (2008): Pressemitteilungen und Stellungnahmen. <http://www.deutscheakademie.de/presse.html> (17. Juni 2008). 


\section{Internetpräsenz des Deutschen Sprachkampfs:}

Deutscher Sprachkampf (2003): Unsere Unterstützer. <http://www.despka.piranho.de/unter.htm> (17. Dezember 2003).

\section{Internetpräsenz des Deutschen Sprachrats:}

Deutscher Sprachrat (2006): Was will der Deutsche Sprachrat?. $<$ http://www.deutscher-sprachrat.de/> (25. August 2006).

Deutscher Sprachrat (2009): Ziele und Aufgaben. $<$ http://www.deutscher-sprachrat.de/index.php?id=311> (18. November 2009).

\section{Internetpräsenz der Deutschen Sprachwelt:}

Deutsche Sprachwelt (2000a): Protestanrufe bei Sprachpanschern. $<$ http://www.deutsche-sprachwelt.de/sprachpanscher/ protest2.shtml> (23. Februar 2003).

Deutsche Sprachwelt (2000b): Die Sprachwahrer des Jahres 2000. $<$ http://www.deutsche-sprachwelt.de/sprachwahrer/ sdj_2000.shtml> (13. September 2007).

Deutsche Sprachwelt (2002): Die Sprachwahrer des Jahres 2002. $<$ http://www.deutsche-sprachwelt.de/sprachwahrer/ sdj_2002.shtml> (13. September 2007).

Deutsche Sprachwelt (2003a): Netzwerk Deutsche Sprache. $<$ http://www.deutsche-sprachwelt.de/berichte/netzwerk/ inhalt-netzwerk.shtml> (10. Dezember 2008).

Deutsche Sprachwelt (2003b): Was ist Engleutsch? $<$ http://www.deutsche-sprachwelt.de/engleutsch/ wasistengleutsch.shtml> (23. Februar 2003).

Deutsche Sprachwelt (2007a): Buchdienst. <http://www.deutschesprachwelt.de/buchdienst/> (13. September 2007). 
Deutsche Sprachwelt (2007b): Verkauf: Deutsche Sprache. $<$ http://www.deutsche-sprachwelt.de/neues/ neues_detail.php?id=486> (21. Januar 2009).

Deutsche Sprachwelt (2008): Die Sprachwahrer des Jahres. $<$ http://www.deutsche-sprachwelt.de/sprachwahrer> (10. Dezember 2008).

dsw (2005): Sprachpreis für Pforzheimer Fachhochschüler. $<$ http://www.deutsche-sprachwelt.de/nachrichten/neues_detail.php?id=320> (3. März 2006)

dsw (2006): Welttag der Muttersprache. Deutschpflicht für Politiker gefordert. <http://www.deutschesprachwelt.de/nachrichten/neues_detail.php?id=342> (3. März 2006).

Limberg, Peter (2003): Verstehen Sie Engleutsch? $<$ http://www.deutsche-sprachwelt.de/sprachpanscher/ limberg.shtml> (13. September 2007).

Paulwitz, Thomas (2003): Impressum: <http://www.deutschesprachwelt.de/impressum/> (11. Februar 2003).

Internetpräsenz der Deutsch-Freiburgischen Arbeitsgemeinschaft:

Deutsch-Freiburgische Arbeitsgemeinschaft (2002): DFAG. <http://www.dfag.org/DStatuten.htm> (4. März 2006). 
Internetpräsenz des Dokumentationsarchivs des österreichischen Widerstands:

Dokumentationsarchiv des österreichischen Widerstands (2002): Chronik.

<http://doew.at/frames.php?projekte/rechts/chronik/2002_05/dke g.html> (27. Dezember 2006).

Dokumentationsarchiv des österreichischen Widerstands (2006a): Organisationen.

$<$ http://doew/at/frames/.php?/projekte/rechts/organisation. html> (13. Mai 2008).

Dokumentationsarchiv des österreichischen Widerstands (2006b): Neues von ganz rechts - Februar 2006.

<http://www.doew.at/projekte/rechts/chronik/2006_02/

content02.shtml>, 31. Oktober 2008.

\section{Internetpräsenz von Dr. Hensel, Horst:}

Hensel, Horst (2001): Pressestimmen.

$<$ http://www.horst.hensel.albert.schweitzer-

gs.de/html/pressestimmen.html> (29. Mai 2008).

Internetpräsenz der European Federation of National Institutions for Language (EFNIL):

European Federation of National Institutions for Language (2008): EFNIL. European Federation of National Institutions for Language $<$ http://www.efnil.org> (13. Januar 2009).

\section{Internetpräsenz „Finanzplatz Frankfurt“:}

Hessisches Ministerium für Wirtschaft, Verkehr und Landesentwicklung, Referat Finanzplatz Frankfurt Rhein-Main, Förderung und Entwicklung (2008). <http://www.finanzplatzfrankfurt.de> (28. Juli 2008). 


\section{Internetpräsenz von Geist, Thomas:}

Geist, Thomas (2001): Kauderwelschseite.

$<$ http://www.kauderwelschseite.de> (13. Januar 2008).

Internetpräsenz der Gesellschaft für deutsche Sprache:

Gesellschaft für deutsche Sprache (2001): Wir über uns. <http://www.gfds.de/wir-ueber-uns/> (13. Mai 2008).

Gesellschaft für deutsche Sprache (2006): Kooperationspartner. <http://www.gfds.de/index.php?id=62> (17. Dezember 2006).

Gesellschaft für deutsche Sprache (2007): Mitgliedschaft <http://www.gfds.de/index.php?id=26> (25. Oktober 2007).

Internetpräsenz der Gesellschaft für Freie Publizistik:

Molau, Andreas (2006): Referenten. <http://www.gfpnetz.de/html/referenten.html> (7. August 2008).

Internetpräsenz des Hauses der deutschen Sprache:

Haus der deutschen Sprache (2008a): Wir bieten an. $<$ http://www.hausderdeutschensprache.eu/angebote.php> (17. April 2008).

Haus der deutschen Sprache (2008b): Literarischer Salon. $<$ http://www.hausderdeutschensprache.eu/salon.php> (17. April 2008).

Haus der deutschen Sprache (2008c): Der Verein Deutsche Sprache stellt sich vor.

$<$ http://www.hausderdeutschensprache.eu/VDS.html> (17. April 2008). 


\section{Internetpräsenz der Huttenbriefe:}

Huttenbriefe (2006): Huttenbriefe für Volkstum, Kultur, Wahrheit und Recht. <http://www.huttenbriefe.com> (27. Dezember 2006).

\section{Internetpräsenz des IFB-Verlags:}

IFB-Verlag (2008): IFB Verlag. Der Fachverlag für Betriebslinguistik und Sprachkultur. <http://www.ifb-verlag.de> (17. April 2008).

Internetpräsenz des Innenministeriums des Landes NordrheinWestfalen:

Innenministerium Nordrhein-Westfalen (2008): Theo-Münch-Stiftung. $<$ http://im.nrw.de/stiftungsverzeichnis/

MainServlet?'Transaction=stiftungsverzeichnis.Suchen \&aktion=Details\&suchmuster=\&st_name=tucher\&live=3\&lastaktio $\mathrm{n}=$ alleSt\&Anfangsposition=2040\&stID_2062> (27. November 2008).

\section{Internetpräsenz des Instituts für Deutsche Sprache:}

Institut für Deutsche Sprache (2005a): Aufgaben. <http://www.idsmannheim.de/org/aufgaben.html> (27. November 2005).

Institut für Deutsche Sprache (2005b): Aktuell. <http://www.idsmannheim.de/aktuell/\#top> (27. November 2005).

Steffens, Doris (2000): Im Blickpunkt: Aktueller lexikalischer Wandel. $<$ http://www.ids-mannheim.de/pub/laufend/sprachreport/sr002a.html> (27. Dezember 2006).

Internetpräsenz der Interessengemeinschaft Muttersprache:

Pfannhauser, Werner (1998a): Satzungen der IG Muttersprache. $<$ http://www.pfannhauser.at/muttersprache/> (11. September 2007). 
Pfannhauser, Werner (1998b): Unsere Zeitung. $<$ http://www.pfannhauser.at/muttersprache/> (11. September 2007).

Pfannhauser, Werner (1999): Pressemitteilung. Tagung der Sprachvereine am 9./10.09.1999 in Graz. <http://pfannhauser.at/muttersprache/> (11. September 2007).

\section{Internetpräsenz der Internationalen Medienhilfe}

Internationale Medienhilfe (2009): deutschsprachig.de. $<$ http://www.imh-deutschland.de/page/ index.php?rubrik=0029> (8. Oktober 2009).

\section{Internetpräsenz der Jungen Freiheit}

Junge Freiheit (2008): Autoren.

$<$ http://www.jungefreiheit.de/Autoren.52.0.html> (13. Januar 2009).

Internetpräsenz des Kulturpreises Deutsche Sprache:

Jury des Kulturpreises Deutsche Sprache (2008a) Grundlagenpapier der Jury. <http://www.kulturpreisdeutschsprache.de/ index.php?id=40>, (16. Juli 2008).

Jury des Kulturpreises Deutsche Sprache (2008b): Preisträger. $<$ http://www.kulturpreisdeutschsprache.de/ index.php?id=48> (16. Juli 2008).

Jury des Kulturpreises Deutsche Sprache (2008c): Verein Deutsche Sprache. <http://www.kulturpreis-deutschesprache.de/index.php?id=47> (29. November 2008).

Jury des Kulturpreises Deutsche Sprache (2008d): Jacob-Grimm-Preis. $<$ http://www.kulturpreisdeutschesprache.de/ index.php?id=72 (28. Juli 2008). 
Jury des Kulturpreises Deutsche Sprache (2009): Preisträger. $<$ http://www.kulturpreisdeutschsprache.de/ index.php?id=48> (8. Oktober 2009).

\section{Internetpräsenz von Mahnert, Detlev:}

Mahnert, Detlev (2002a): Detlev Mahnerts Homepage. $<$ http://www.detlev-mahnert.de/> (13. Januar 2008).

Mahnert, Detlev (2002b): Anglizismen im Deutschen - Argumente und Gegenargumente. <http://www.mahnert-online.de/debatte.htm> (28. Juli 2008).

Mahnert, Detlev (2002c): Bitte auf Deutsch! <http://www.mahnertonline.de/debatte.htm> (28. Juli 2008).

\section{Internetpräsenz der Neuen Fruchtbringenden Gesellschaft:}

Neue Fruchtbringende Gesellschaft (2007a): Köthener Erklärung zur Gründung der Neuen Fruchtbringenden Gesellschaft zu Köthen/Anhalt e.V.. <http://www.fruchtbringendegesellschaft.de/nfg_koethener-erkläarung.pdf> (14. November 2008).

Neue Fruchtbringende Gesellschaft (2007b): 1. Köthener Sprachtag. $<$ http://www.fruchtbringende-gesellschaft.de/ProgrammSprachtag_2007.pdf> (14. November 2008).

Neue Fruchtbringende Gesellschaft (2007c): Veranstaltungen. $<$ http://www.fruchtbringendegesellschaft.de/veranstaltungen.html> (14. November 2008).

Neue Fruchtbringende Gesellschaft (2007d): Aktivitäten. $<$ http://www.fruchtbringende-gesellschaft.de/aktivitaeten.html> (14. November 2008).

Neue Fruchtbringende Gesellschaft (2007e): Satzung. $<$ http://www.fruchtbringende-gesellschaft.de/nfg_satzung.pdf> (14. November 2008). 
Neue Fruchtbringende Gesellschaft (2007f). Über uns. $<$ http://www.fruchtbringende-gesellschaft.de/ueberuns_alt.html> (14. November 2008).

Neue Fruchtbringende Gesellschaft (2007g): Vorstand. $<$ http://www.fruchtbringende-gesellschaft.de/vorstand.html> (14. November 2008).

Internetpräsenz „Nörgeln, immer nur nörgeln“:

Falk (2008): VDS-Kochstudio.

$<$ http://immernurnoergeln.wordpress.com/2008/10/03/vdskochstudio/> (13. Januar 2009).

Internetpräsenz des Österreichischen Turnerbundes:

Österreichischer Turnerbund (2008): Kommende Veranstaltungen. $<$ http://www.jtf08.oetbwein.at/termine/index.php> (31.Oktober 2008).

Internetpräsenz von Prof. Dr. Pohl, Heinz Dieter:

Heinz Dieter Pohl (2008): Lebenslauf.

$<$ http://members.chello.at/heinz.pohl/Lebenslauf.htm> (10. Dezember 2008).

Internetpräsenz des Schweizerischen Vereins für die deutsche Sprache:

Schweizerischer Verein für die deutsche Sprache (2007a): Was ist der Schweizerische Verein für die deutsche Sprache (SVDS)? $<$ http://www. sprachverein.ch> (11. September 2007).

Schweizerischer Verein für die deutsche Sprache (2007b): Sprachspiegel. <http://www.sprachverein.ch> (11. September Schweizerisisher Verein für die deutsche Sprache (2007c): Partnerorganisationen. <http://www.sprachverein.ch> (11. September 2007). 


\section{Internetpräsenz des Sprachbündnisses Franken:}

Sprachbündnis Franken (2005a): Das Sprachbündnis Franken. $<$ http://www.sprachbuendnis-franken.de/index.php?wir-ueberuns> (10. Dezember 2008).

Sprachbündnis Franken (2005b): Senioren-Initiative Nürnberg. $<$ http://www.sprachbuendnis-franken.de/index.php?sin> (27. Dezember 2006).

Sprachbündnis Franken (2005c): Nein zu Denglisch. $<$ http://www.sprachbuendnis-frankende/index.php?nein_zu_denglisch> (27. Dezember 2006).

Sprachbündnis Franken (2005d): Prominente Unterstützer. $<$ http://www.sprachbuendnis-franken.de/index.php?prominente> (27. Dezember 2006).

\section{Internetpräsenz des Sprachkreises Deutsch:}

Sprachkreis Deutsch (2002): Satzungen. <http://www.sprachkreisdeutsch.ch/index_id\%3Dverein\%21satzungen.html> (11. September 2007).

Sprachkreis Deutsch (2003a): Leitbild. <http://www.sprachkreisdeutsch.ch/index.php?id=verein!leitbild> (3. März 2006).

Sprachkreis Deutsch (2003b): Klosterneuburger Entschliessung 2003. $<$ http://www.sprachkreisdeutsch.ch/index.php?id=verein!entschliessungen\& year=\&item=2026> 3.März 2006).

Sprachkreis Deutsch (2006a): Startseite. <http://www.sprachkreisdeutsch.ch/index.php?id=startseite> (3. März 2006).

Sprachkreis Deutsch (2006b). Der Sprachkreis Deutsch stellt sich vor. $<$ http://www.sprachkreisdeutsch.ch/index.php?id=verein!wirueberuns> (3. März 2006). 
Sprachkreis Deutsch (2008a): Neue Fruchtbringende Gesellschaft. Zweiter Sprachtag in Köthen/Anhalt 20. - 21. Juni 2008.

$<$ http://www.sprachkreis-

deutsch.ch/index_id\%3Daktuelles\%21artikel\&26year\%3D2008\%2 Gartikel\%3D3064.html> (12. November 2008).

Sprachkreis Deutsch (2008b): Sprachvereine und Zugewandte. $<$ http://www.sprachkreis-

deutsch.ch/index_id\%3Dverein\%21partnervereine.html>

(12. November 2008).

\section{Internetpräsenz „Sprachpflege.info“:}

Sprachpflege.info (2008a): Theo-Münch-Stiftung. $<$ http://www.sprachpflege.info/index.php/Theo-M\%C3\%BcnachStiftung-f\%C3BCr-die_Detusche_Sprache> (28. Juli 2008).

Sprachpflege.info (2008b): Kulturpreis Deutsche Sprache. $<$ http://www.sprachpflege.info/index.php/Kulturpreis-DeutscheSprache> (28. Juli 2008).

\section{Internetpräsenz des Sprachrettungsklubs Bautzen/Oberlausitz:}

Sprachrettungsklub (2005a): Herzlich willkommen im

Sprachrettungsklub Bautzen/Oberlausitz e.V.

<http://www.sprachrettungsklub.de/vu> (27. Dezember 2006).

Sprachrettungsklub (2005b): Satzung des Sprachrettungsklubs Bautzen/Oberlausitz e.V.

$<$ http://www.sprachrettungsklub.de/satzung.htm> (27. Dezember 2006).

Sprachrettungsklub (2008): Wir freuen uns auf Ihre Kontaktaufnahme mit dem Sprachrettungsklub Bautzen/Oberlausitz e.V. $<$ http://www.sprachrettungsklub.de/kontakte.htm> (14. November 2008). 


\section{Internetpräsenz der Stiftung Deutsche Sprache:}

Stiftung Deutsche Sprache (2005a): Herzlich willkommen auf den Seiten der Stiftung Deutsche Sprache! <http://www.stiftungdeutsche-sprache.de/index.php> (3. März 2006).

Stiftung Deutsche Sprache (2005b): Aktion „Lebendiges Deutsch“. $<$ http://www.stiftung-deutsche-sprache.de/aktion.php> (3. März 2006).

Stiftung Deutsche Sprache (2006a): Was will die Stiftung? $<$ http://www.stiftung-deutsche-sprache.de/stiftung.php> (3. März 2006).

Stiftung Deutsche Sprache (2006b): Sprachberatung. $<$ http://www.stiftung-deutsche-sprache.de/sprachberatung.php> (3. März 2006).

Stiftung Deutsche Sprache (2009): Wer leitet und kontrolliert die Stiftung? <http://www.stiftung-deutschesprache.de/personalia.php> (13. Januar 2009).

\section{Internetpräsenz des Vereins Deutsche Sprache:}

Dey, Heinz Dieter (2003): Ziele des Tages der deutschen Sprache. $<$ http://www.vds-ev.de/verein/aktive/ projektbeschreibung_dey.php> (28. Mai 2007).

Mindner, Tobias/Pogarell, Reiner (2008a): VDS-Sprachsiegel. >http://www.sprachsiegel.de/> (20. Januar 2009).

Mindner, Tobias/Pogarell, Reiner (2008b): Preise. $<$ http://www.sprachsiegel.de/preise.htm> (20. Januar 2009).

Mindner, Tobias/Pogarell, Reiner (2008c): Träger. <http://www.sprachsiegel.de/traeger.htm> (20. Januar 2009).

Schmitz, Heinz-Günter (2005a): Über die Sprachloyalität der Deutschen. $<$ http://www.vds-ev.de/denglisch/ anglizismenliste/texte/sprachloyalitaet.php> (28. Mai 2007). 
Schrammen, Gerd/Dieter, Hermann/Föhr, Dieter/Gawlitta, Kurt (2003): Argumente zur deutschen Sprache. <http://vdsev.de/denglisch/index.php> (19. Januar 2004).

Verein zur Wahrung der deutschen Sprache (1998a): 23. 11. 1998: Ron Sommer Sprachpanscher des Jahres 1998. <http://vdsev.de/presse/pressemitteilungen/archiv/ pressemitteilungen1998.php> (11. September 2007).

Verein zur Wahrung der deutschen Sprache (1998b): Pressespiegel 1998. <http://vds-ev.de/presse/pressespiegel1998.php> (14. Juli 2008).

Verein zur Wahrung der deutschen Sprache (1998c): Überflüssige Anglizismen. <http://vds-ev.de/presse/pressemitteilungen/ archiv/pressemitteilungen1998.php> (20. Januar 2009).

Verein zur Wahrung der deutschen Sprache (1999a): 1. 9. 2000 [sic]: Johannes Ludewig Sprachpanscher des Jahres 1999. <http://vdsev.de/presse/pressemitteilungen/archiv/ pressemitteilungen1999.php\#Sprachpanscher99> (11. September 2007).

Verein zur Wahrung der deutschen Sprache (1999b): Kein Denglisch in deutschen Wörterbüchern. <http://vdsev.de/presse/pressemitteilungen/archiv/pressemitteilungen1999.p hp\#W\%F6rterb\%Fccher> (14. Juli 2008).

Verein zur Wahrung der deutschen Sprache (1999c): Pressespiegel 1999. $<$ http://vds-ev.de/presse/pressespiegel1999.php> (10. Dezember 2008).

Verein Deutsche Sprache (2000a). Rektor der Uni wird Sprachpanscher 2000. <http://vds-ev.de/presse/pressemitteilungen/archiv/ 2000_31_08.php> (11. September 2007).

Verein Deutsche Sprache (2000b): Protokoll der 2. Internationalen Tagung der Sprachvereine im „Netzwerk Deutsche Sprache“ $<$ http://www.vds-ev.de/netzwerk-deutschesprache/bodensee_protokoll.php> (27. Dezember 2006). 
Verein Deutsche Sprache (2001a): Verein Deutsche Sprache tritt Verleumdungen entgegen. <http://www.vdsev.de/pressemitteilungen/archiv/2001_15_05.php> (27. Dezember 2006).

Verein Deutsche Sprache (2001b): Verein Deutsche Sprache gründet Berliner Sprachbündnis. <http://www.vdsev.de/presse/pressemitteilungen/archiv/2001_03_02.php> (14. Dezember 2006).

Verein Deutsche Sprache (2001c): Sprachpanscher des Jahres 2001. $<$ http://vds-ev.de/presse/pressemitteilungen/ archiv/2001_31_08.php> (11. September 2001).

Verein Deutsche Sprache (2001d): Würdelose Anbiederung. <http://vdsev.de/presse/pressemitteilungen/ archiv/2001_31_12.php> (13. Dezember 2003).

Verein Deutsche Sprache (2002a): Pressespiegel 2002. <http://vdsev.de/presse/pressespiegel2002.php> (18. Juli 2008).

Verein Deutsche Sprache (2002b): „Kunden auf Denglisch angepöbelt“ Zumwinkel wird Sprachpanscher 2002. <http://vdsev.de/presse/pressemitteilungen/archiv/2002_08_30.php>

(11. September 2007).

Verein Deutsche Sprache (2003a): Präsident des Deutschen Fußballbundes wird Sprachpanscher 2003. <http://vdsev.de/presse/pressemitteilungen/archiv/2003_09_01.php> (11. September 2007).

Verein Deutsche Sprache (2003b): Netzwerk Deutsche Sprache. $<$ http://vds-ev.de/verein/netzwerk-deutschesprache/entstehung.php> (12. November 2008)

Verein Deutsche Sprache (2003c): Netzwerk Deutsche Sprache. Die Entschließung von Graz. <http://www.vds.ev.de/verein/ netzwerk-deutsche-sprache/graz.php> (5. August 2005).

Verein Deutsche Sprache (2003d): Bibliothek. <http://www.vdsev.de/literatur/bibliothek.php> (30. November 2007). 
Verein Deutsche Sprache (2003e). VDS in Kürze. <http://www.vdsev.de> (23. Juni 2003).

Verein Deutsche Sprache (2003f): Leitlinien. <http://vdsev.de/Verein/leitlinien.php> (12. Oktober 2003).

Verein Deutsche Sprache (2003g): Präambel. <http://www.vdsev.de/verein/aktionen/berliner-sprachbuendnis/praeambel.php> (27. Dezember 2006).

Verein Deutsche Sprache (2003h): Sieben Thesen. <http://www.vdsev.de/verein/aktionen/berliner-sprachbuendnis/7thesen.php> (27. Dezember 2006).

Verein Deutsche Sprache (2003i): Pressespiegel 2003. <http://vdsev.de/presse/pressespiegel2003.php> (10. Dezember 2008).

Verein Deutsche Sprache (2003j): VDS vorgestellt. < http://vdsev.de/verein.php> (19. Januar 2004).

Verein Deutsche Sprache (2004a). Sprachpanscher 2004. <http://vdsev.de/denglisch/sprachpanscher/ sprachpanscher04.php> (30. Juli 2008).

Verein Deutsche Sprache (2004b): Eckpunkte. <http://www.vdsev.de/verein/eckpunkte.php> (27. Dezember 2006).

Verein Deutsche Sprache (2004c): Satzung. <http://vds-ev.de /verein/satzung.php> (10. November 2004).

Verein Deutsche Sprache (2005a): Sprachschützer fordern Verankerung von Deutsch im Grundgesetz. <http://vdsev.de/presse/pressemitteilungen/archiv/2005_04_23.php> (11. September 2007).

Verein Deutsche Sprache (2005b): Sprachpanscher 2005. $<$ http://www.vds-ev.de/presse/pressemitteilungen/archiv/ 2005_08_31.php> (30. Juli 2008).

Verein Deutsche Sprache (2005c): VDS in Kürze. <http://www.vdsev.de/> (23. Januar 2005). 
Verein Deutsche Sprache (2005d): Pressespiegel 2005. <http://vdsev.de/presse/pressespiegel2005.php> (10. Dezember 2008).

Verein Deutsche Sprache (2005e): Sprachhunzer. <http://vdsev.de/denglisch/sprachpanscher/sprachhunzer.php> (27. August 2005).

Verein Deutsche Sprache (2006a): Günther Oettinger ist Sprachpanscher 2006. <http://vds-ev.de/presse/pressemitteilungen/archiv/ 2006_08_25.php> (11. September 2007).

Verein Deutsche Sprache (2006b): Prominente Mitglieder. <http://vdsev.de/verein/prominente-mitglieder.php> (14. Juli 2008).

Verein Deutsche Sprache (2006c): Weltweite Sprachaktion des Vereins Deutsche Sprache. 2000. Wortpatenschaft vergeben. <http.//vdsev.de/presse/pressemitteilungen/ archiv/2006_08_10.php> (12. November 2008).

Verein Deutsche Sprache (2006d): Weltweite Sprachaktion des Vereins Deutsche Sprache. 4000. Wortpatenschaft vergeben. <http://vdsev.de/presse/pressemitteilungen/ archiv/2006_12_12.php> (12. November 2008).

Verein Deutsche Sprache (2006e): Regionalvorsitzende. <http://vdsev.de/verein/aktive/regionalvorsitzende/ regionalvorsitzende7.php> (27. Dezember 2006).

Verein Deutsche Sprache (2006f): VDS in Kürze. <http://vds-ev.de> (23. März 2006).

Verein Deutsche Sprache (2006g): Argumente zur deutschen Sprache. $<$ http://www.vds-ev.de/denglisch/index.php> (7. Juni 2006).

Verein Deutsche Sprache (2006h): Pressespiegel 2006. <http://vdsev.de/presse/pressespiegel2006.php> (10. Dezember 2008).

Verein Deutsche Sprache (2006i): Denglisch. <http://www.vdsev.de/denglisch/index.php> (20. Juni 2006). 
Verein Deutsche Sprache (2007a). Der Petitionsausschuss des Bundestages beurteilt die Bedeutung der deutschen Sprache in der EU und in Deutschland unterschiedlich. <http://vdsev.de/presse/pressemitteilungen/archiv/2007_01_04.php>

(11. September 2007).

Verein Deutsche Sprache (2007b). Hartmut Mehdorn ist

Sprachpanscher 2007. <http://vds-

ev.de/presse/pressemitteilungen/archiv/

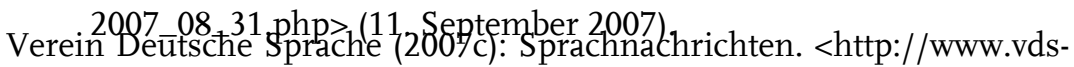
ev.de/verein/sprachnachrichten/index.php>, (12. September 2007).

Verein Deutsche Sprache (2007d). Pressemitteilungen 2007. <http://vdsev.de/presse/pressemitteilungen/ archiv/pressemitteilungen2007.php> (14. Juli 2008).

Verein Deutsche Sprache (2007e): Satzung. <http://vdsev.de/verein/satzung.php> (13. Januar 2009).

Verein Deutsche Sprache (2008a): Prominente Mitglieder. $<$ http://www.vds-ev.de/verein/prominente-mitglieder.php> (14. Juli 2008).

Verein Deutsche Sprache (2008b): Aktuelle Meldungen. $<$ http://www.vds-ev.de/index.php> (30. Juli 2008).

Verein Deutsche Sprache (2008c): Wissenschaftlicher Beirat. $<$ http://www.vds.ev.de/verein/wissenschaftlicher_beirat.php> (5. April 2008).

Verein Deutsche Sprache (2008d): Denglisch. <http://www.vdsev.de/denglisch/> (30. Mai 2008).

Verein Deutsche Sprache (2008e): Anglizismen-Index. <http://vdsev.de/anglizismenindex> (18. Juli 2008).

Verein Deutsche Sprache (2008f): Internationale Zusammenarbeiten. $<$ http://vds-ev.de/verein/international.php> (30. Juli 2008). 
Verein Deutsche Sprache (2008g): Korporative Mitglieder. <http://vdsev.de/verein/aktive/korporative_mitglieder.php> (30. Juli 2008).

Verein Deutsche Sprache (2008h): Deutschlehrerbörse. <http://www.deutschlehrerboerse.de> (30. Juli 2008).

Verein Deutsche Sprache (2008i): Denglisch im Unterricht. <http://vdsev.de/denglisch/unterricht> (30. Juli 2008).

Verein Deutsche Sprache (2008j): Forum. <http://vds-ev.de/forum/> (13. Januar 2008).

Verein Deutsche Sprache (2008k): Wowereit ist Sprachpanscher 2008. $<$ http://www.vds-ev.de/index.php> (10. Dezember 2008).

Verein Deutsche Sprache (20081): CDU folgt dem VDS. <http://www.vds-ev.de/index.php> (10. Dezember 2008).

Verein Deutsche Sprache (2008m): Sprachpolitische Leitlinien. <http://www.vds-ev.de/verein/leitlinien.php> (13. Januar 2009).

Verein Deutsche Sprache (2008n): Aktion Sprachtest. <http://www.vdsev.de/denglisch/sprachtest.php> (20. Januar 2009).

Verein Deutsche Sprache (2009a): Stellenbörse. <http://www.kulturnuetzt.de> (30. Januar 2009).

Verein Deutsche Sprache (2009b): Deutscher Turner-Bund ist „Sprachpanscher des Jahres“. <http://vds-ev.de/presse/ pressemitteilungen/archiv/2009_08_28.php> (30. Januar 2010).

Verein Deutsche Sprache (2009c): Erfolg für den VDS. <http://vdsev.de/presse/pressemitteilungen/ archiv/2009_10_09.php> (8. Februar 2010). 


\section{Internetpräsenz der VDS-Region Berlin/Potsdam:}

Verein Deutsche Sprache Region Berlin/Potsdam (2002): Herzlich Willkommen. $\quad<$ http://www.vds-berlin-potsdam.de/vds.htm> (27. Dezember 2006).

Verein Deutsche Sprache Region Berlin/Potsdam (2008a): Kontakt. <http://www.vds-ev-berlin.de/kontakt.html> (16. Juli 2008).

Verein Deutsche Sprache Region Berlin/Potsdam (2008b): Quellen. $<:$ http://www.vds-ev-berlin.de/quellen.html> (13. Januar 2009).

Verein Deutsche Sprache Region Berlin/Potsdam (2010): Termine. <http://www.vds-ev-berlin.de/termine.html> (04. Februar 2009).

\section{Internetpräsenz der VDS-Region Dresden:}

Verein Deutsche Sprache Region Dresden (2005): Wir wollen klares Deutsch, kein Denglisch. <http://www.vds-dresden.de> (23. Januar 2005).

Verein Deutsche Sprache Region Dresden (2008): Wir wollen klares Deutsch, kein Denglisch. <http://www.vds-dresden.de> (28. November 2008).

\section{Internetpräsenz der VDS-Region Kassel:}

Verein Deutsche Sprache Region Kassel (2008): VDS - Verein Deutsche Sprache e.V. <http://www.vds-kassel.de/> (16. Juli 2008).

\section{Internetpräsenz der VDS-Region Leipzig:}

Verein Deutsche Sprache Region Leipzig (2005): Verein. <http://www.vds-leipzig.de> (23. Januar 2005).

\section{Internetpräsenz der VDS-Region Lübeck:}

Verein Deutsche Sprache Region Lübeck (2008): Willkommen. <http://www.vds23neu-12see.de/> (16. Juli 2008). 
Internetpräsenz der VDS-Region Münsterland:

Verein Deutsche Sprache Region Münsterland (2008): Steinfurter Sprachpreis 2006(2008). <http://www.vds-ms.de/start.html> (17. Juli 2008).

Internetpräsenz der VDS-Region Wortreich, Siegen/Wittgenstein, Olpe, Altenkirchen:

Verein Deutsche Sprache Region Wortreich, Siegen/Wittgenstein, Olpe, Altenkirchen (2008): Netzverweise. <http://www.vdswortreich.de/> (18. Juli 2008).

Internetpräsenz des Vereins Muttersprache:

Verein Muttersprache (2007): Verein Muttersprache. $<$ http://www.muttersprache.at> (13. September 2007).

Verein Muttersprache (2009): Der Verein.

http://www.muttersprache.at/uber-den-verein/ (11. November 2009).

Fischer, Gottfried (2007a): Aufgabengebiete.

$<$ http://www.muttersprache.at/uber-den-verein/aufgabengebiete> (20. März 2007).

Fischer, Gottfried (2007b): Ziele. <http://muttersprache.at> (12. November 2008).

Internetpräsenz des Vereins für Rechtschreibung und Sprachpflege:

Melsa, Christian (2003a): Aktionen. <http://www.vrsev.de/aktionen.php> (2. Juni 2006).

Melsa, Christian (2003b): Wer, wie, was, wieso, weshalb, warum? $<$ http://www.vrs-ev.de/portrait.php> (2. Juni 2006).

Melsa, Christian (2003c): Flugblätter. <http://www.vrsev.de/flugblaetter.php> (2. Juni 2006). 
Melsa, Christian (2006a): VRS-Vorstand. <http://www.vrsev.de/vorstand.php> (2. Juni 2006).

Melsa, Christian (2006b): Pressemitteilungen. <http://www.vrsev.de/pressemitteilungen.php> (2. Juni 2006).

Melsa, Christian (2007): Thematisch Verwandtes im Internet. $<$ http://www.vrs-ev.de/links.php> (12. November 2008).

Verein für Rechtschreibung und Sprachpflege (2003a): Die Satzung des VRS <http://www.vrs-ev.de/satzung.php\#par_2> (2. Juni 2006).

Verein für Rechtschreibung und Sprachpflege (2003b): Meldungen. $<$ http//www.vrs-ev.de/meldungen.php> (12. November 2008).

Verein für Rechtschreibung und Sprachpflege (2006): Sind Sie Sprachliebhaber... <http://www.vrs-ev.de/> (2. Juni 2006).

Internetpräsenz der Wiener Nachrichten Online (WNO):

Wiener Nachrichten Online (2003): Sonnwendfeiern in Wien und Österreich. <http://www.wno.org/newspages/cul08.html> (31. Oktober 2008).

Internetpräsenz von Winklhofer, Ruth:

Winklhofer, Ruth (2008): Anglizismen - Ein paar Gedanken. $<$ http://www.anglizismus.de> (10. Dezember 2008). 


\section{Berichterstattung in den Medien und Pressemitteilungen}

3Sat (ohne Verfasser): „[tsent] oder [sent]?“. In: Kulturzeit, 3Sat, 7. Januar 2002.

Aden, Menno (2005): Deutscher Patriotismus heute. In: Sprachnachrichten 2005, Nr. 3, S. 4-5.

Aden, Menno (2006): Brauchen wir ein Sprachgesetz? In: Sprachnachrichten 2006, Nr. 2, S. 6-7.

Aden, Menno (2008): Internationalistisches Imponiergehabe. In: Junge Freiheit, 17. Oktober 2008, S. 13.

Akstinat, Björn (2004): Musikquote - zum Greifen nah! In: Sprachnachrichten 2004, Nr. 3, S. 2.

Akstinat, Björn (2006): Raab für deutschsprachige Musik. In: Sprachnachrichten 2006, Nr. 2, S. 13.

Akstinat, Björn (2008): Deutschsprachiges im internationalen Äther. In: Sprachnachrichten 2008, Nr. 4, S. 19.

Alexander, Nicole/von Festenberg, Nikolaus/Mohr, Reinhard (2001) „Welcome in Blabylon“. In: Spiegel 29/2001, 16. Juli 2001, S. 160162.

Ambros, Peter (1999): Brief an die Deutsche Telekom. In: VWDSNachrichten 1999, Nr. 1, S. 4.

Ambros, Peter/Neemann, Hermann (2003): Wahlprüfsteine in Hessen und Niedersachsen. In: Sprachnachrichten 2003, Nr. 1, S. 2.

Andersen, Frank-Uwe (2006): Hetzartikel. Leserbrief. In: Sprachnachrichten 2006, Nr. 1, S. 20.

Appel, Holger (2000): Hilfe, ich verstehe meine Bank nicht mehr. Sexy Business Models generieren Cash und Performance/Die Leiden eines Kunden. In: Frankfurter Allgemeine Zeitung, 3. November 2000, S. 25. 
Aschenbrenner, Franz (2006): Aus den Arbeitsgruppen. Schüler führen Politiker von. Denglisch im Unterricht. In: Sprachnachrichten 2006, Nr. 1, S. 19.

Asmuth, Gereon (1999): Unterschriften für die Rechts-Schreiber. In: taz, 6. Juli 1999, S. 19.

Aßhoff, Heide (1999): Anekdoten aus dem Sekretariat des ersten Vorsitzenden. In: Sprach-Nachrichten 1999, Nr. 2, S. 5.

Augstein, Jakob (2001): „Deutsch oder Denglish - das nationale Anliegen?" Sendung im DeutschlandRadio Berlin, im Ressort Politisches Feuilleton, 26. Juli 2001.

Badenhop, Peter (1999): „Kein Eis und Schnee - aber Süßes für Petra Roth. Vom Winter war auch im Februar keine Spur/Aufregung nur um "City of the Euro“ In: Frankfurter Allgemeine Zeitung, 3. März 1999, S. 58.

Baer, Oliver (2005): Podiumsdiskussion in Dresden. Energisches Kopfnicken. Alle einig. In. Sprachnachrichten 2005, Nr. 4, S. 11.

Baer, Oliver (2007a): Gesucht: Wiki für den VDS. In: Sprachnachrichten 2007, Nr. 4, S. 23.

Baer, Oliver (2008b): Viel Lärm um nichts. In: Sprachnachrichten 2008, Nr. 1, S. 9.

Barthold, C. (2002): Deutsch für Schimpansen. In: Sprachnachrichten 2002, Nr. 2, S. 4.

Baumann, Franz (2000): „Kollektive Psychopathologie“. In: SprachNachrichten 2000, Nr. 1, S. 1.

Bayern2 Radio (ohne Verfasser) (2004): Fränkischer Kulturladen, 4. Juli 2004.

Bayern2 Radio (ohne Verfasser) (2007): Zur Herbsttagung der Akademie für Sprache und Dichtung. Gespräch mit Prof. Peter Eisenberg. 25. Oktober 2007.

Behland, Max (2008a): Schade, Herr Schirrmacher! In: Sprachnachrichten 2008, Nr. 1, S. 16. 
Behland, Max (2008b): Ist die Sprache noch zu retten? In: Sprachnachrichten 2008, Nr. 3, S. 1.

Bellinger, Ines (2008): Emotional und martialisch, aber kein Spiel auf Leben und Tod. In: Deutsche Sprachwelt. <http://www.deutschesprachwelt,de/\#echo> (14. Juli 2008).

Bettermann, Stella (1999): „Deutsch für Schimpansen“. In: Focus 14/1999, 2. April 1999, S. 192-195.

Billing, Tilmann (2008): Traveln zum Service Point. Gefährden Anglizismen die deutsche Sprache? In: Kulturzeit, 3Sat, 13. November 2008.

Bischof, Anika (2005): Sprachpreis 2004 vergeben. Hauptschulen des Kreises Steinfurt nahmen teil. In: Wir in Steinfurt, 16. Februar 2005, S. 1-2.

Bomba, Ursula (2000): Die Proteste bündeln. Wie wir arbeiten sollten. In. Sprach-Nachrichten 2000, Nr. 3, S. 8.

Brandner, Stephan (2000). Mitgliederversammlung am 15.04.2000 im Audi Max der Universität Dortmund. In: Sprach-Nachrichten 2000, Nr. 2, S. 2.

Braunshausen, Erika (1999): Reiner Pogarell. „Sitzung oder Meeting?“. In: Sprach-Nachrichten 1999, Nr. 2, S. 2.

Brinkmann, Uwe (2001): „Sprache kommt mit Kultur und umgekehrt. In: Sprachnachrichten 2001, Nr. 4, S. 8.

Bullermann, Joachim/Hensel, Horst/Junker, Gerhard/Krämer, Walter/Neemann, Hermann/ Schäferhoff, Heiner/Schrammen, Gerd/Tschiersch, Lars (1999): Mitgliederversammlung 1999 des VWDS in Hannover. In: Sprach-Nachrichten 1999, Nr. 3, S. 6.

Burkert, Dieter (2005): Ohne Titel. In: Sprachnachrichten 2005, Nr. 2, S. 12.

Burkert Dieter (2006a): Guter Rat. Die Nachsilbe „-bar“. In: Sprachnachrichten 2006, Nr. 1, S. 16. 
Burkert, Dieter (2006b): Guter Rat. „widerspiegeln“. In: Sprachnachrichten 2006, Nr. 1, S. 16.

Büttner, Manfred (2001): Lächerlich: Kassel und der VDS. In: <http://www.wurfsache.de> (30. April 2006).

Christiansen, Sabine (2001): Man spricht Deutsch - aber wie? Fernsehsendung Sabine Christiansen (ARD), 29. Juli 2001.

Cordes, Gerd (2002) „Fachchinesisch beim Gerätekauf. Und niemand versteht die Technik.“ NDR, 27. Januar 2002.

Däßler, Klaus (2000): Am Ende führt Euch ein Narr. In: Deutsche Sprachwelt 2, 20. September 2000. <http://www.sprachkreisdeutsch.ch/index_id\%3Daktuelles\%21artikel\%26year\%3D2001\%2 Gartikel\&3D2322.html> (13. September 2007).

Däßler, Klaus (2005): Der Klügere spricht Deutsch. Lustige Geschäftsideen mit deutschen Namen. In: Sprachnachrichten 2005, Nr. 3, S. 27.

Däßler, Klaus (2006): Die Sprachen von Harry und Martin. Leserbrief. In: Sprachnachrichten 2006, Nr. 1, S. 21.

Dengler, Christoph C. (2001). Musterbrief. In: Sprachnachrichten 2001, Nr. 4, S. 12.

Dennes, Rolf (2007): Nationalistische Machtphantasien für völkische Ziele. Leserbrief. In: Sprachnachrichten 2007, Nr. 3, S. 21.

Der Spiegel (ohne Verfasser) (1990): Auf den wings der fantasy. In: Der Spiegel 19/1990, 7. Mai 1990, S. 278-280.

Der Spiegel (ohne Verfasser) (1998a): „It’s a trick“. In: Der Spiegel 17/1998, 20. April 1998, S. 124-125.

Der Spiegel (ohne Verfasser) (1998b): >>Time frame<< im Auge behalten. In: Der Spiegel 46/1998, 9. November 1998, S. 135.

Der Spiegel (ohne Verfasser) (1999): The City of the Äppelwoi. In: Der Spiegel 5/1999, 1. Februar, S. 20. 
Der Spiegel (ohne Verfasser) (2001): „Lasst die Leute schnacken“. In: Der Spiegel Jahresrückblick 2001, S. 92.

Der Spiegel (ohne Verfasser) (2005): „Hohes Prestige“, Christoph Schubert, 34, Anglist an der Universität Würzburg, über den Trend, in Deutschland die Originaltitel britischer und amerikanischer Filmproduktionen beizubehalten. In: Der Spiegel 19/2005, 9. Mai 2005, S. 183.

Deutscher Bundestag (2001): Ansprache von Bundestagspräsident Wolfgang Thierse über „Sprachenvielfalt als politische Verpflichtung“ vor dem Deutschen Philologenverband (Berlin, Humboldt-Universität). Pressemitteilung des Deutschen Bundestags, 16. März 2001.

Dey, Heinz-Dieter (2002): Ideenreichtum beim Tag der deutschen Sprache. In: Sprachnachrichten 2002, Nr. 4, S. 7.

Dey, Heinz-Dieter (2005): Schule und sprachliche Vielfalt. Überlegungen zum Fremdsprachenunterricht. In: Sprachnachrichten 2005, Nr. 4, S. 2.

Die Welt (ohne Verfasser) (1998): Warum Herr Krämer die Telefonrechnung nicht mehr bezahlt. In: Die Welt, 2. Mai 1998, Dieter, Hermann (2000a): Brief von Hermann Dieter an Johannes Rau, Berlin, 21. März 2000. In: Sprach-Nachrichten 2000, Nr. 2, S. 2.

Dieter, Hermann (2000b): Eine starke Sprachfraktion. Aktion Wahlprüfsteine: Sprachfreundliche Politiker quer durch alle Parteien. In: Sprach-Nachrichten 2000, Nr. 4, S. 6.

Dieter, Hermann (2002c): „The future of the German Language”. In: Sprachnachrichten 2002, Nr. 2, S. 4.

Dieter, Hermann (2005): Alle Parteien für Deutsch als Wissenschaftssprache. In: Sprachnachrichten 2005, Nr. 4, S. 7.

Dieter, Hermann/Gawlitta, Kurt/Vilmar, Fritz (2002): Auszug aus dem Elfenbeinturm. VDS und Darmstädter Akademie ziehen in Zukunft am selben Strang. In: Sprachnachrichten 2002, Nr. 3, S. 4. 
Heckmann, Carsten (1999): Sprachschützer wollen Nachtbus fahren und nicht „Night-Liner“. In: Leipziger Volkszeitung, 10. Februar 1999, Stadtausgabe, S. 4.

dpa (1999): Se sitty of se juro. In: Süddeutsche Zeitung, 27. Januar 1999, S. 12.

dpd (2001): Akademiepräsident Christian Meier warnt vor Fremdwortsucht. In: Sprach-Nachrichten 2001, Nr. 3, S. 6.

Eckartbote (Ohne Verfasser) (1999): Die Mehrheit hat mit Anglizismen nichts am Hut. In: Eckartbote, 30. Oktober 1999, S. 7.

edo (2000): Das Schwein und das Bewusstsein. Der Verein Deutsche Sprache lobt einen hochdotierten Preis aus. In: Süddeutsche Zeitung, 11. Juli 2000, S. 17.

Eisenberg, Peter (2004c): Deutsch als dritte Geige. In: Frankfurter Allgemeine Zeitung, 7. Oktober 2004, S. 35.

Eisenberg, Peter (2008b): Gute Nachrichten. Sieben Thesen zur deutschen Sprache. In: Süddeutsche Zeitung, 3. Juli 2008, S. 11.

Ernst, Daniel (2000): Deckert sitzt jetzt im Hörsaal der Uni. Badisches Tagblatt, 18. November 2000, S. 6.

Esser, Dominic (2006): Keine Patriotismusdebatte im VDS. Leserbrief. In: Sprachnachrichten 2006, Nr. 1, S. 21.

Eylmann, Horst (2006): Dümmlich - NS-Ideologie. Leserbrief. In: Sprachnachrichten 2006, Nr. 1, S. 21.

FAZ (2006): Lammert für Deutsch als Landessprache. In: Frankfurter Allgemeine Zeitung, 26. Juni 2006, S. 1.

Fischer, Gottfried (2005): Dem Vater sein Hut. In: Sprachnachrichten 2005, Nr. 2, S. 18.

Focus (Ohne Verfasser) (1998): Kampf dem Kauderwelsch. In: Focus 2/1998, 5. Januar 1998, S. 138.

Föhr, Dieter (1999): Selbstkolonisierung des Deutschen. In: SprachNachrichten 1999, Nr. 3, S. 2. 
Forster, Karl (2000): Gegen alles Undeutsche. Sprach-Kulturpreis wird in München vergeben. In: Süddeutsche Zeitung, 10. November 2000, S. 43.

Frank, Helmar G. (2000): Wir-Gefühl mit „Europisch“. Europäische Optionen deutscher Sprachpolitik. In: Sprach-Nachrichten 2000, Nr. 3, S. 3.

Fried, Nico (2008): „Von den Halunken nicht vorführen lassen“. In: Süddeutsche Zeitung, 3. Dezember 2008, S. 5.

Gaumitz, Winfried (1998): Englisch muß sein. Leserbrief. In: Frankfurter Allgemeine Zeitung, 14. November 1998, S. 66.

Gawlitta, Kurt (2001d): Gegen diesen Wahnsinn muss etwas geschehen. In: Sprach-Nachrichten 2001, Nr. 3, S. 8.

Geissler, Cornelia (1998): Deutsch für deutsche Bürger. In: Berliner Zeitung, 7. November 1998, S. 9.

Geschonneck, Fina (1999): Wenige unterschrieben gegen Rechtschreibreform, In: Berliner Zeitung, 11. Mai 1999, S. 23.

Glück, Helmut (1999): Kampf fürs Deutsche. In: Berliner Morgenpost, 9. August 1999, S. 4.

Glück, Helmut (2000d): Wir brauchen eine Sprachakademie. Denn unsere Sprache ist zu wichtig, um sie Kultusministern und ihren Experten zu überlassen. In: Die Welt, 29. Juli 2007, S. 31.

Glück, Helmut (2001b): Es gibt längst ein Sprachenrecht. In: Die Welt, 10. Februar 2001, S. 29.

Glück, Helmut (2001c): Der Tod spricht Englisch. In: Die Welt, 5. September 2001, S. 34.

Glück, Helmut (2002a): Hermann Fink verstorben. In: Sprachnachrichten 2002, Nr. 1, S. 11.

Glück, Helmut (2002b): XtraPac mit TellySmile. In: Die Welt, 6. Dezember 2002, S. 28. 
Glück, Helmut (2003a): Mit Luther durchs Bibeljahr. In: Sprachnachrichten 2003, Nr. 1, S. 5.

Glück, Helmut (2003b): well, weller, Wellness. In: Die Welt, 23. Juli 2003, S. 12.

Glück, Helmut (2008b): Untauglicher Versuch. In: <http://dresaden.de/A_Veröffentlichungen/1_Bucherund_Buchbeitrage/Untauglicher_Versuch.pdf> $\quad(9$. Dezember 2008).

Götz, Claudia (2008): Los oder Strafe. In: Sprachnachrichten 2008, Nr. 4, S. 5.

Goy, Martina/von Taube, Dagmar (2003): „Ich werde mitbestimmen.“ In: Die Welt am Sonntag, 25. Mai 2003, S. 30.

Grobe, Hans-Joachim (1999): Wider die Sprachpuristen. In: SprachNachrichten 1999, Nr. 3, S. 1.

Grobe, Hans-Joachim (2001): Kulturnotstand Deutsche Sprache. Deutschlehrer im Ausland schlagen Alarm. In: SprachNachrichten 2001, Nr. 3, S. 1-2.

Günther, Christoph (2006): Amerikahörigkeit. In: Sprachnachrichten 2006, Nr. 1, S. 21.

Hahn, Daniela/Dieter, Hermann (2001): „Ganze Wortfelder kahlgeschlagen“. Sprachtest:

Versandhauskataloge. In: Sprachnachrichten 2001, Nr. 4, S. 10.

Haitzinger (1999): Haitzingers Ansichten. Dem Vater grauset's, er reitet geschwind, durchs Goethe-Jahr, im Arm das Kind... In: SprachNachrichten 1999, Nr. 2, S. 1.

Hanke, Renate (2000): Verein Deutsche Sprache E.V. (VDS) Bürger für die Erhaltung der sprachlichen und kulturellen Vielfalt Europas (Früher: Verein zur Wahrung der deutschen Sprache) Arbeitsausschuss der Region Berlin. Gesetz über die polnische Sprache vom 7. Oktober 1999 (Zeitpunkt des Inkrafttretens: 09.05.2000) Übersetzung: Marek Maciag (Krakau) unter Mitarbeit von Kurt Gawlitta. In: Sprach-Nachrichten 2000, Nr. 2, S. 7. 
Hanke, Renate (2001): Widerstand gegen die anglizistische Sprachinvasion. Einige Vorschläge jenseits von neuen Verordnungen. In: Sprachnachrichten 2001, Nr. 4, S. 4.

Hellebronth, Jonas (2005): „Auf Deutsch kann ich mich am besten ausdrücken“, In: Sprachnachrichten 2005, Nr. 1, S. 4.

Heringlehner, Ralph (2004): Kreuzritter der deutschen Sprache. Verein kämpft gegen Denglisch - Arzt aus Wiesentheid leitet die Regionalgruppe. In: Mainpost, 9. September 2004, S. D1.

Herrmann, Günter (2005): Denglisch mindert Lust auf Deutsch. Befremden in der Slowakei über Verhunzung der Muttersprache in Deutschland. In: Sprachnachrichten 2005, Nr. 3, S. 31.

Hildebrandt, Wolfgang (2008): Sprache in der Schule - Sprache ohne Schule? In: Sprachnachrichten 2008, Nr. 1, S. 6-7.

Hinrichsen, Torkild (2008): Sprachlos im Alltag. In: Sprachnachrichten 2008, Nr. 4, S. 8-9.

Ho, Chong Si (2006): Dolchstoß aus Deutschland. In: Sprachnachrichten 2006, Nr. 1, S. 29.

Hornhardt, Michael (2003): Schwieriger Zugang zu Schulen. Warum das Anliegen des VDS von der Lehrerschaft kaum beachtet wird. In: Sprachnachrichten 2003, Nr. 1, S. 14.

HR4 (ohne Verfasser) (1998): Rhein-Main-Journal, 29. Oktober 1998, 16.05 bis 17 Uhr.

Hutter, Hans (2002): $\mathrm{Zu}$ Besuch bei Professor Euro-Point. In: Finanzplatz 2002, Nr. 4, S. 16.

Jipp, Karl E. (2005): Preis für gutes Deutsch in Schleswig-Holstein. In: Sprachnachrichten 2005, Nr. 4, S. 26.

Junge Freiheit (Ohne Verfasser) (1999): Sprachschützer wollen Verbot von Anglizismen. In: Junge Freiheit 43/1999, 22. Oktober 1999, S. 12.

Junker, Gerhard H. (2000): „Rent a Brain“ und der Schwur von Graz. In: Sprach-Nachrichten 2000, Nr. 1, S. 2. 
Kartnig, T. (2007): Firmen nehmen Anglizismen aus Ihren Werbetexten [sic]. In: Unsere Sprache 2007, Nr. 2, S. 6-7.

Keienburg, Johannes (2004): Denglisch. Beitrag über die Sprache der EM-Fußball-Kommentatoren. In: Bayerischer Rundfunk, Sendung Quer, 1. Juli 2004.

Kellner, Friedrich (2008): Liebenswerte Leserzuschrift. In: Sprachnachrichten 2008, Nr. 4, S. 25.

Kieselbach, Eva-Maria (2004a): Politik für die deutsche Sprache. In: Sprachnachrichten 2004, Nr. 2, S. 10.

Kieselbach, Eva-Maria (2005a): Unterschriften für Grundgesetzänderung. In: Sprachnachrichten 2005, Nr. 3, S. 28.

Kieselbach, Eva-Maria (2007b): Mageres Ergebnis. Bundestag über eine Petition zur deutschen Sprache. In: Sprachnachrichten 2007, Nr. 1, S. 8.

Kinder, Dietmar (2005): „Lehrer-Welsch-Sprachpreis 2005“. In: Sprachnachrichten Nr. 4, S. 20.

Kistenmacher, Gert (1976): Nur Sex lässt er gelten. In: Süddeutsche Zeitung, 28. April 1976, S. 3.

Klatte, Holger (2008b): Tomte füllt Hallen. In: Sprachnachrichten 2008, Nr. 4, S. 20.

Klawitta, Nils/Tuma, Thomas (2003): „Wir können nicht ohneeinander“. In: Der Spiegel 22/2003, 26. Mai 2003, S. 94-96.

Klemm, Michael (2005): „Wenn die Sorre in Gilbhart durch die Zeugemutter fährt... Kleine Geschichte der sprachpflegerischen Eindeutschungen - von erfolgreich bis skurril“. In: LEO. Lingua et Opinio. Studentische Zeitschrift zu Sprache und Kommunikation. 22. Februar 2005. <http://www-tu-chemnitz.de/phil/leo/ rahmen.php?seite=r_wiss/klemm_deutsch2.php> (23. Mai 2008). 
Klonovsky, Michael/Scherer, Martin (2005): Bestes Globalesisch. Denglisch, Rechtschreibstreit, Wissenschafts-Anglisierung: Nicht nur Puristen sorgen sich um die Zukunft des Deutschen. In: Focus 11/2005, 14. März 2005, S. 63-66.

Knoop, Ulrich (2006): Neue VDS-Sprachberatung. In: Sprachnachrichten 2006, Nr. 2, S. 21.

Korthuis, Marlies (1999): Sprachenschutzgesetz - könnte es eine Mehrheit finden? In: Sprach-Nachrichten 1999, Nr. 2, S. 4.

Krämer, Walter (1998c): Babylonische Verwirrung der deutschen Sprache. In: Die Welt, 4. Mai 1998, S. 4.

Krämer, Walter (1999a): Liebe Mitstreiter. In: VWDS-Nachrichten 1999, Nr. 1, S. 2.

Krämer, Walter (1999b): Liebe Mitstreiter. In: Sprach-Nachrichten 1999, Nr. 2, S. 2.

Krämer, Walter (1999c): Liebe Mitstreiter. In: Sprach-Nachrichten 1999, Nr. 3, S. 2.

Krämer, Walter (1999d): Liebe Mitstreiter. In. Sprach-Nachrichten 1999, Nr. 4, S. 2.

Krämer, Walter (2000c): Liebe Mitstreiter. In: Sprach-Nachrichten 2000, Nr. 1, S. 2.

Krämer, Walter (2000d): Liebe Mitstreiter. In: Sprach-Nachrichten 2000, Nr. 2, S. 2.

Krämer, Walter (2000e): Mein Standpunkt: Keine „departments“ an unseren Universitäten. In: Sprach-Nachrichten 2000, Nr. 3, S. 3.

Krämer, Walter (2000f): Buchbesprechung. Entlarvung des Sprachmülls. In: Sprach-Nachrichten 2000, Nr. 3, S. 7.

Krämer, Walter (2001): Der Vorsitzende meint. In: Sprachnachrichten 2001, Nr. 4, S. 2.

Krämer, Walter (2002a): Der Vorsitzende meint. In: Sprachnachrichten 2002, Nr. 1, S. 2. 
Krämer, Walter (2002b): Der Vorsitzende meint. In: Sprachnachrichten 2002, Nr. 2, S. 2.

Krämer, Walter (2002c): Der Vorsitzende meint. In: Sprachnachrichten 2002, Nr. 3, S. 2.

Krämer, Walter (2002d): Der Vorsitzende meint. In: Sprachnachrichten 2002, Nr. 4, S. 2.

Krämer, Walter (2003a): Der Vorsitzende meint. In: Sprachnachrichten 2003, Nr. 1, S. 2.

Krämer, Walter (2003b): Der Vorsitzende meint. In: Sprachnachrichten 2003, Nr. 2, S. 2.

Krämer, Walter (2003c): Der Vorsitzende meint. In: Sprachnachrichten 2003, Nr. 3, S. 2.

Krämer, Walter (2003d): Der Vorsitzende meint. In: Sprachnachrichten 2003, Nr. 4, S. 2.

Krämer, Walter (2004a): Der Vorsitzende meint. In: Sprachnachrichten 2004, Nr. 1, S. 2.

Krämer, Walter (2004b): Der Vorsitzende meint. In: Sprachnachrichten 2004, Nr. 2, S. 2.

Krämer, Walter (2004c): Der Vorsitzende meint. In: Sprachnachrichten 2004, Nr. 3, S. 2.

Krämer, Walter (2004d): Rechenschaftsbericht. Wir schaffen die Trendwende! In: Sprachnachrichten 2004, Nr. 3, S. 24.

Krämer, Walter (2005a): Der Vorsitzende meint. In: Sprachnachrichten 2005, Nr.1, S. 2.

Krämer, Walter (2005b): Deutsch ins Grundgesetz. In: Sprachnachrichten 2005, Nr. 2, S. 1.

Krämer, Walter (2005c): Der Vorsitzende meint. In: Sprachnachrichten 2005, Nr. 2, S. 2.

Krämer, Walter (2005d): Der Vorsitzende meint. In: Sprachnachrichten 2005, Nr. 3, S. 2. 
Krämer, Walter (2005e): Der Vorsitzende meint. In: Sprachnachrichten 2005, Nr. 4, S. 2.

Krämer, Walter (2006a): Der Vorsitzende meint. In: Sprachnachrichten 2006, Nr. 1, S. 2.

Krämer, Walter (2006b): Der Vorsitzende meint. In: Sprachnachrichten 2006, Nr. 2, S. 2.

Krämer, Walter (2006c): Der Vorsitzende meint. In: Sprachnachrichten 2006, Nr. 3, S. 2.

Krämer, Walter (2006d): VDS-Delegiertenversammlung. Der Rechenschaftsbericht des 1. Vorsitzenden. In: Sprachnachrichten 2006, Nr. 3, S. 14-16.

Krämer, Walter (2006e): Der Vorsitzende meint. In: Sprachnachrichten 2006, Nr. 4, S. 2.

Krämer, Walter (2007b): Der Vorsitzende meint. In: Sprachnachrichten 2001, Nr. 1, S. 2.

Krämer, Walter (2007c): Der Vorsitzende meint. In: Sprachnachrichten 2001, Nr. 2, S. 2.

Krämer, Walter (2007d): Der Vorsitzende meint. In: Sprachnachrichten 2001, Nr. 3, S. 2.

Krämer, Walter (2007e): Nicht abwarten, sondern selbst kreativ werden. Aus dem Rechenschaftsbericht von Walter Krämer am 16. Juni 2007 in Mühlhausen. In: Sprachnachrichten 2007, Nr. 3, S. 27.

Krämer, Walter (2007f): Der Vorsitzende meint. In: Sprachnachrichten 2001, Nr. 4, S. 2.

Krämer, Walter (2008a): Der Vorsitzende meint: In: Sprachnachrichten 2008, Nr. 1, S. 2.

Krämer, Walter (2008b): Berliner Philharmoniker. In: Sprachnachrichten 2008, Nr. 1, S. 18.

Krämer, Walter (2008c): Der Vorsitzende meint: In: Sprachnachrichten 2008, Nr. 2, S. 2. 
Krämer, Walter (2008d): Der Vorsitzende meint: In: Sprachnachrichten 2008, Nr. 3, S. 2.

Krämer, Walter (2008e): Der Vorsitzende meint: In: Sprachnachrichten 2008, Nr. 4, S. 2.

Krämer, Walter (2009a): Der Vorsitzende meint: In: Sprachnachrichten 2009, Nr. 2, S. 2.

Krämer, Walter (2009b): Der Vorsitzende meint: In: Sprachnachrichten 2009, Nr. 3, S. 2.

Kreimeier, Klaus (1999): Der Untergang der deutschen Sprache. In: VDWS-Nachrichten 1999, Nr. 1, S. 5.

Krüger, Sönke (2007): Ärgerliche Anglizismen. In: Welt am Sonntag, 23. September 2007, S. 78.

Krüger, Sönke (2008a): Darf man Deutsch erfinden? Wortgefecht. In: Welt am Sonntag, 27. April 2008, S. 77.

Krüger, Sönke (2008b): Bildergalerie Kolumne „Wortgefecht“. In: Welt Online. $<$ http://www.welt.de/wams_print/ article1655963/Kolumne_Wortgefecht.html> (20. Oktober 2008).

Leffers, Jochen (2001): Rechtsextremist Günter Deckert. Erst Gefängnis, dann Jurastudium. In: Spiegel Online, 31. April 2001. $<$ http://www.spiegel.de/unispiegel/studium/ 0,1518,130557,00.html>, (30. Oktober 2008).

Lehmann, Axel (2005): VDS verdient Preis für Engstirnigkeit. In: Sprachnachrichten 2005, Nr. 3, S. 25.

Leopold, Bettina (2005): VDS wofür? Leserbrief. In: Sprachnachrichten 2005, Nr. 2, S. 22.

Liefländer, Irene (2000): Der Wandel kann erkämpft werden. Wie der politische Wille die Sprachentwicklung lenkt. In: SprachNachrichten 2000, Nr. 3, S. 5.

Lippe von der, Jürgen (2008): Frei von der Lippe. In: MDR, 3. Oktober 2008. 
love (1998): „Let’s be a little gemütlich“. In: Süddeutsche Zeitung, 11. März 1998, S. 17.

Luck, Harry (2006): „Niemand bestellt cooles Bier“. In: Focus-Online, 10. Mai 2006. <http://www.focus.de/politik/deutschland/ sprachverband_aid_108766.html>, (13. Januar 2009).

Mai, Jochen (1999): „Reinster Sprachgulasch“. In: Sprach-Nachrichten 1999, Nr. 3, S. 1.

Martens, René (2003): „Mein Gott, Walter“ in: Jungle World 5, 22. Januar 2003. In: <http://www.jungle-world.com/seiten/ 2003/04/152.php>, (13.September 2007).

MDR (2000): MDR-Sommerinterview mit Dr. Bernhard Vogel. In: <http://www.dr-bernhard-vogel.de/interview.htm> (30. Oktober 2007).

medfux.de (2006): Bild und Ton für die Muttersprache. Deutscher Rockund Popmusikerverband (DRMV) und Fernsehproduktionsgesellschaft probono.tv treten dem Verein Deutsche Sprache bei. In: Sprachnachrichten 2006, Nr. 1, S. 13.

Meier, Christian/Reichert, Klaus (2002): Pressemitteilung der Deutschen Akademie für Sprache und Dichtung, 17. Januar 2002.

Mey, Bernd (2005): Weltsprache mit Harry-Potter-Syndrom. In: Sprachnachrichten 2005, Nr. 4, S. 1.

Meyer, Hans-Joachim (2002): Untermieter und Bürger zweiter Klasse. Hans-Joachim Meyer über Werbefuzzis und journalistische Schnösel. In: Sprachnachrichten 2002, Nr. 2, S. 3.

Meyer, Simone (2008): Sprecht deutsch! Wider die Anglizismen. Seit zehn Jahren kämpft Walter Krämer für den Erhalt der deutschen Sprache. In: Berliner Morgenpost, 9. Januar 2008, S. 16.

mhs (1999): Jeanne d`Arc kam in den Römer“, In: Frankfurter Neue Presse, 24. Februar 1999, S. 14.

Michel, Alexander (1999): Sprache und Geschwätz. In: VWDSNachrichten 1999, Nr. 1, S. 5. 
Mindner, Tobias (2003b): Der Goethe-Rocker. In: Sprachnachrichten 2003, Nr. 3, S. 10.

Mindner, Tobias (2005): Von Büchern und Würmern. VDS erstmals auf Leipziger Buchmesse. In: Sprachnachrichten 2005, Nr. 3, S. 20.

Mindner, Tobias (2006a): „Funke“ statt Handy. Sprachpflege in Berliner Wohngemeinschaft. In: Sprachnachrichten 2006, Nr. 2, S. 3.

Mindner, Tobias (2006b): „Menschlichkeit“ und „Freiheit“: Wörter für alle. In: Sprachnachrichten 2006, Nr. 2, S. 8.

Mindner, Tobias (2008): Deutsch eiskalt. Pomoren-Universität ist neues VDS-Mitglied, S. 23.

Mosebach, Martin (1996): Jil Sander. In: FAZ-Magazin 838, 22. März 1996, S. 21-24.

Muschg, Adolf (2005): Mangel an Selbstachtung. Die Indifferenz gegenüber der Nationalkultur muss aufgegeben werden. In: Sprachnachrichten 2005, Nr. 2, S. 2.

Natter, Alice (2004): Fröhlicher Kampf gegen Schluderei und Sprachgulasch. Sprachschützer feiern den vierten „Tag der deutschen Sprache“. In: Main-Post, 11. September 2004, S. 1.

Natter, Alice (2008): Mit Humor gegen Schwafelei. Herbert Scheuring mit Sprachpreis ausgezeichnet. In: Main-Post, 15. September 2008, S. 9.

Netzwerk Deutsche Sprache (ohne Verfasser) (2001): Berner Entschließung der Sprachvereine im Internationalen Netzwerk Deutsche Sprache am 14. September 2001. In: Sprach-Nachrichten 2001, Nr. 3, S. 4.

Neubacher, Alexander (2005): „Die Begriffswelt des Béla Anda“. In: Der Spiegel 16/2005, 18. April 2005, S. 164.

Nma (1999): Main Haus. Main Auto. Main Boot. In: Süddeutsche Zeitung 7. Mai 1999, S. 17.

NDR (Ohne Verfasser) (1999): Interview mit Gerd Schrammen, 18. Januar 1999. 
Paulwitz, Thomas (2006): Aktion „Deutschpflicht für Politiker“ bleibt streng überparteilich. Der Einflußnahmeversuch der NPD wird zurückgewiesen. In: Deutsche Sprachwelt Mai 2006.

$<$ http://www.deutsch-sprachwelt,de/forum/

parteien.shtml> (30. Oktober 2008).

Paulwitz, Thomas (2008): Klartext auf deutsch. In: Junge Freiheit, 17. Oktober 2008, S. 32.

Pfützner, Rufus (2002): Überflüssiger Sprachbrei. Sprachtest: Rufus Pfützner hat sich Prospekte von Einkaufsmärkten angeschaut. In: Sprachnachrichten 2002, Nr. 4, S. 8.

Peter, Simon (2005): Sinnvolleres Betätigungsfeld. Leserbrief. In: Sprachnachrichten 2005, Nr. 3, S. 25.

Pickert, Philipp (1999): Horst Hensel: Sprachverfall und kulturelle Selbstaufgabe. Deutsch - eine sterbende Sprache. In: Junge Freiheit, 43/1999, 22. Oktober 1999, S. 14.

Pohl, Heinz-Dieter (2005): Anglizismen - Gewinn oder Zumutung? In: Sprachnachrichten 2005, Nr. 3, S. 34.

Pogarell, Reiner (2007b): Innovation und Kreativität. In: Sprachnachrichten 2007, Nr. 2, S. 18.

Richter, Christine (2001): Germanisten gegen Sprachschutzgesetz. In: Berliner Zeitung, 29. Januar 2001, S. 18.

Riebe, Manfred (2000a): Die Sprache gehört dem Volk. Manfred Riebe über die Rechtschreibreform und den Streit unter Sprachschützern. Junge Freiheit, 23. Juni 2000, S. 4.

Riedel, Anne (2001): „Deutschtümelisten“ auf den Leim gegangen? Kassel und der „Kulturpreis Deutsche Sprache“. In: Frankfurter Rundschau, 22. März 2001, Nr. 69, S. 30.

Ringsgwandl, Georg (2009): Angriff der Käuze. In: Süddeutsche Zeitung, 11. Januar 2009, S. I.

Rosenkranz, Boris R. (2006): Aus „Scheiße“ Geld machen. In: taz, 28. Februar 2006, S. 4. 
Rübenkamp, Lisa und Hartmut H. (2006): Inquisitorische Besessenheit. In: Sprachnachrichten 2006, Nr. 1, S. $20 \mathrm{f}$.

Sartorius, Joachim (2000): Muss es denn immer Englisch sein? Plädoyer für die Sprachenvielfalt in Europa und die Förderung des Deutschen. In: Sprach-Nachrichten 2000, Nr. 2, S. 1.

Schäferhoff, Heiner (1999): Lufthansa-Tochter dreht durch. In: VWDSNachrichten 1999, Nr. 1, S. 6.

Schmitz, Heinz-Günter (2005b): Die amerikanische Sprachinvasion nach 1945 und ihre Ideologen. In: Sprachnachrichten 2005, Nr. 3, S. 10 .

Schmitz, Heinz-Günter (2008): Zur Intensität des englischen Einflusses. In: Sprachnachrichten 2008, Nr. 3, S. 5.

Schneider, Wolf (1994): Sohn Fritz darf kein Bergrad fahren. In: Rheinischer Merkur, 13. Mai 1994, S. 21.

Schneider, Wolf (2006): Wie aus einem Countdown die „Startuhr“ wurde. In: Sprachnachrichten 2006, Nr. 2, S. 2.

Schneider, Jens (2007): Ruf ein Fahrrad. In: Süddeutsche Zeitung, 20. März 2007, S. 1.

Schöck, Eberhard (2005): Worte zur Patriotismus-Debatte. In: Sprachnachrichten 2005, Nr. 2, S. 4.

Schomaker, Gilbert (2007): Experten starten Feldzug für die deutsche Sprache. In: Die Welt, 13. September 2007, S. 34.

Schrammen, Gerd (2000): Musterbriefe „Sprachhunzer“. In: SprachNachrichten 2000, Nr. 1, S. 3.

Schrammen, Gerd (2002): Die Russen mögen Deutsch. In: Sprachnachrichten 2002, Nr.4, S. 14.

Schrammen, Gerd (2004): Loriot ante portas. In: Sprachnachrichten 2004, Nr. 2, S. 28.

Schrammen, Gerd (2005a): Sprachhunzer aufgespießt. In: Sprachnachrichten 2005, Nr. 2, S. 10. 
Schrammen, Gerd (2005b): Hochschulpolitik. Warum nicht „Baccalaureus“ und „Magister“?. In: Sprachnachrichten 2005, Nr. 3, S. 7.

Schrammen, Gerd (2005c): Sprachhunzer aufgespießt. In: Sprachnachrichten 2005, Nr. 4, S. 11.

Schrammen, Gerd (2006a): Schönes Deutsch. Über Liebe, Mütter und Mädchen, Rosen, den Mond und Deutschland. In: Sprachnachrichten 2006, Nr. 1, S. 14-15.

Schrammen, Gerd (2006b): Gewinkt wie gewunken. In: Sprachnachrichten 2006, Nr. 1, S. 16.

Schrammen, Gerd (2006c): Briefwettbewerbe 2005. In: Sprachnachrichten 2006, Nr. 2, S. 20.

Schreiber, Mathias (2006): Deutsch for sale. In: Der Spiegel 40/2006, 2. Oktober 2006, S. 182.

Schroeder, Manfred (2005a): Zwischenbilanz. Wir rennen offene Türen ein. In: Sprachnachrichten 2005, Nr. 3, S. 28.

Schroeder, Manfred (2005b): Offene Arme in Polen. In: Sprachnachrichten 2005, Nr. 4, S. 29.

Schroeder, Manfred (2007): Deutsche Sprache und deutsche Spuren. In: Sprachnachrichten 2007, Nr. 1, S. 22.

Schroeder, Manfred (2008): VDS im Ausland - Belastung oder Bereicherung? In: Sprachnachrichten 2008, Nr. 1, S. 27.

Schwarz, Moritz (2000): „Achtlos und unterwürfig“ Walter Krämer über den Umgang der Deutschen mit der eigenen Sprache und seinen Kampf für die Erhaltung des Deutschen. In: Junge Freiheit 20/2000, 12. Mai 2000, S. 3.

Schwarz, Moritz (2004): „Der Klügere spricht Deutsch“. Diethold Tietz, Vorstandsmitglied des Vereins Deutsche Sprache, über Rechtschreibreform und den Kampf gegen Anglizismen. In: Junge Freiheit 36/04, 27. August 2004, S. 3.

sda/spn (2007): Schweiz: Konsens in der Rechtschreibung zeichnet sich ab. In: Sprachnachrichten 2007, Nr. 4, S. 2. 
Sick, Bastian (2008): Bastian-Sick-Schau. In: WDR, 13. September 2008. Skornig, Ekkehard (2008): Sprachhunzerseite und C für Z. In: Sprachnachrichten 2008, Nr. 4, S. 28.

spn (2004): Stabile Mehrheit für Vorstandspolitik In: Sprachnachrichten 2004, Nr. 2, S. 20.

spn (2005): Ehe vollzogen. Mühlhausen ist Mitglied im VDS. In: Sprachnachrichten 2005, Nr. 4, S. 28.

spn (2007): Schmähpreis für einen Sprachhunzer. In: Sprachnachrichten 2007, Nr. 3, S. 24-25.

spn (2008): Evangelische Akademie Villigst: Tagung: Deutsch der „Jeckes“ in Israel. In: Sprachnachrichten 2008, Nr. 4, S. 35.

Spörr, Kathrin (2002): Rechtschreibreform in Frage gestellt. Kathrin Spörr in der „Welt“. In: Sprachnachrichten 2002, Nr. 3, S. 14.

Spörri, Balz (2008): „Wer nichts zu sagen hat, sagt es auf Englisch“. In: Sonntagszeitung, 20. Januar 2008, S. 79.

Sprach-Nachrichten (ohne Verfasser) (1999a): Sprachhunzer des Monats. In: Sprach-Nachrichten 1999, Nr. 3, S. 3.

Sprach-Nachrichten (ohne Verfasser) (1999b): Deutsche Firmen, die mit englischen Werbesprüchen in Deutschland um deutsche Kunden werben. In: Sprach-Nachrichten 1999, Nr. 3, S. 4.

Sprach-Nachrichten (ohne Verfasser) (2000a): Zur Sache. Neuer Name und neue Satzung. In: Sprach-Nachrichten 2000, Nr. 1, S. 1.

Sprach-Nachrichten (ohne Verfasser) (2000b): Sprachhunzer des Monats (Juli bis Oktober 2000). In: Sprach-Nachrichten 2000, Nr. 2, S. 3.

Sprach-Nachrichten (ohne Verfasser) (2000c): VDS gegen Duden. In: Sprach-Nachrichten 2000, Nr. 3, S. 1.

Sprach-Nachrichten (ohne Verfasser) (2000d): Rektor der Uni München zum „Sprachpanscher 2000“ gewählt. In: Sprach-Nachrichten 2000, Nr. 3, S. 3. 
Sprach-Nachrichten (ohne Verfasser) (2000e): Unser 10.000 Mitglied. In: Sprach-Nachrichten 2000, Nr. 3, S. 5.

Sprach-Nachrichten (ohne Verfasser) (2000f): VDS intern. In: SprachNachrichten 2000, Nr. 3, S. 12.

Sprach-Nachrichten (ohne Verfasser) (2001a): Tagebuch Juli 2001. In: Sprach-Nachrichten 2001, Nr. 1, S. 12.

Sprach-Nachrichten (ohne Verfasser) (2001b): 1000 000. Wir brauchen 1 Million Unterschriften. In: Sprach-Nachrichten 2001, Nr. 1, S. 14.

Sprach-Nachrichten (ohne Verfasser) (2001c): Impressum. In: SprachNachrichten 2001, Nr. 3, S. 2.

Sprach-Nachrichten (ohne Verfasser) (2001d). Sprachgesetz - ja oder nein?. In: Sprach-Nachrichten 2001, Nr. 3, S. 8.

Sprach-Nachrichten (ohne Verfasser) (2001e): Werbematerial. In: Sprach-Nachrichten 2001, Nr. 3, S. 9.

Sprach-Nachrichten (ohne Verfasser) (2001f): Vom Schatzmeister. In: Sprach-Nachrichten 2001, Nr. 3, S. 16.

Sprach-Nachrichten (ohne Verfasser) (2001g): Englisch im Unternehmen?. In: Sprach-Nachrichten 2001, Nr. 4, S. 4.

Sprach-Nachrichten (ohne Verfasser) (2001h): Aktionspaket für alle Mitglieder des VDS. In: Sprach-Nachrichten 2001, Nr. 4, S. 7.

Sprachnachrichten (ohne Verfasser) (2002a): Politik einig: Denglisch ist lächerlich. Wendepunkt: eine Bundestagsdebatte zur Situation der deutschen Sprache. In: Sprachnachrichten 2002, Nr. 1, S. 1.

Sprach-Nachrichten (ohne Verfasser) (2002b): „Keine Anglizismen, wenn es auch auf Deutsch geht. PDS-Antrag im sächsischen Landtag. In: Sprach-Nachrichten 2002, Nr. 1, S. 2.

Sprachnachrichten (ohne Verfasser) (2002c). Am Pranger. In: Sprachnachrichten 2002, Nr. 1, S. 7.

Sprachnachrichten (ohne Verfasser) (2002d): Aktion 26 000. In: Sprachnachrichten 2002, Nr. 1, S. 8. 
Sprachnachrichten (ohne Verfasser) (2002e): Kurzprotokoll der Delegiertenversammlung in Bautzen. In: Sprachnachrichten 2002, Nr. 2, S. 5.

Sprachnachrichten (ohne Verfasser) (2002f): Elfjährige diskutieren. In: Sprachnachrichten 2002, Nr. 3, S. 6.

Sprachnachrichten (ohne Verfasser) (2002g): VDS mit Stand auf der Frankfurter Buchmesse. In: Sprachnachrichten 2002, Nr. 3, S. 13.

Sprachnachrichten (ohne Verfasser) (2003a): Zehn Millionen Euro für die Deutsche Sprache. In: Sprachnachrichten 2003, Nr. 1, S. 1.

Sprachnachrichten (ohne Verfasser) (2003b): „Esperanto wär’ mir lieber“. In. Sprachnachrichten 2003, Nr. 1, S. 3.

Sprachnachrichten (ohne Verfasser) (2003c): Bachelor abgeblitzt. Anbiederung von Universitäten an die Welt von Donald Duck wird nicht belohnt. In: Sprachnachrichten 2003, Nr. 1, S. 6.

Sprachnachrichten (ohne Verfasser) (2003d): Stuttgarter Sprachpreise 2003. In: Sprachnachrichten 2003, Nr. 1, S. 15.

Sprachnachrichten (ohne Verfasser) (2003e): Wird DFB-Chef MayerVorfelder Sprachpanscher des Jahres? In: Sprachnachrichten 2003, Nr. 2, S. 7.

Sprachnachrichten (ohne Verfasser) (2003f): Heidi Sander hat Deutsch gelernt. In: Sprachnachrichten 2003, Nr. 2, S. 7.

Sprachnachrichten (ohne Verfasser) (2003g): Leserforum. Sind wir amerikafeindlich? In: Sprachnachrichten 2003, Nr. 2, S. 13.

Sprachnachrichten (ohne Verfasser) (2003h): Kein englischer Werbespruch für Olympia. In: Sprachnachrichten 2003, Nr. 4, S. 6.

Sprachnachrichten (ohne Verfasser) (2003i): „Deutsch-Englisch in Politik und Bildungswesen“. In: Sprachnachrichten 2003, Nr. 4, S. 20.

Sprachnachrichten (ohne Verfasser) (2004a): Europa denkt mehrsprachig. In: Sprachnachrichten 2004, Nr. 1, S. 1. 
Sprachnachrichten (ohne Verfasser) (2004b): VDS-Musikpreis geht nach Rumänien. In: Sprachnachrichten 2004, Nr. 3, S. 2.

Sprachnachrichten (ohne Verfasser) (2005a): Mitteilungen aus der VDSZentrale. In: Sprachnachrichten 2005, Nr. 1, S. 19.

Sprachnachrichten (ohne Verfasser) (2005b): VDS-Aktive gründen neue Arbeitsgruppen. In: Sprachnachrichten 2005, Nr. 2, S. 21.

Sprachnachrichten (ohne Verfasser) (2005c): Impressum. In: Sprachnachrichten 2005, Nr. 3, S. 28.

Sprachnachrichten (ohne Verfasser) (2005d): Die Verwahrlosung des Denkens beginnt mit dem falschen Gebrauch der Sprache. Interview mit Minister Hirche. In: Sprachnachrichten 2005, Nr. 4, S. 3.

Sprachnachrichten (ohne Verfasser) (2005e): Peinliche Stellenausschreibung. In: Sprachnachrichten 2005, Nr. 4. S. 9.

Sprachnachrichten (ohne Verfasser) (2005f): Anzeige: Sternstunden der deutschen Sprache. In: Sprachnachrichten 2005, Nr. 4, S. 16.

Sprachnachrichten (ohne Verfasser) (2005g): Auszeichnung für MDR 1 Radio Sachsen. In: Sprachnachrichten 2005, Nr. 4, S. 25.

Sprachnachrichten (ohne Verfasser) (2006a): Patriotismus 8. 12 Thesen für Deutschland. In: Sprachnachrichten 2006, Nr. 1, S. 5.

Sprachnachrichten (ohne Verfasser) (2006b): Eigenanzeige des VDS. In: Sprachnachrichten 2006, Nr. 1, S. 10.

Sprachnachrichten (ohne Verfasser) (2006c): „Verlag für Sprachkultur“. Interview mit Myriam Grobe, Leitern des IFB-Verlages Paderborn. In: Sprachnachrichten 2006, Nr. 1, S. 29.

Sprachnachrichten (ohne Verfasser) (2006d): Wichtigtuerdeutsch. Karriere-Netzwerk-Studie: Wirtschaftsstudenten wollen keine Anglizismen. In: Sprachnachrichten 2006, Nr. 2, S. 11.

Sprachnachrichten (ohne Verfasser) (2006e): Grundgesetz. 21 Staaten als Vorbild. In: Sprachnachrichten 2006, Nr. 3, S. 6. 
Sprachnachrichten (ohne Verfasser) (2006f): Bugi. In: Sprachnachrichten 2006, Nr. 3, S. 27.

Sprachnachrichten (ohne Verfasser) (2007): Feige Tat. In: Sprachnachrichten 2007, Nr. 1, S. 17.

Sprachnachrichten (ohne Verfasser) (2008a): Hamburger Wahlprüfsteine. In. Sprachnachrichten 2008, Nr. 1, S. 11.

Sprachnachrichten (ohne Verfasser) (2008b): „Typisch Deutsch!“ Bier. In: Sprachnachrichten 2008, Nr. 1, S. 18.

Sprachnachrichten (ohne Verfasser) (2008c): Israel. Tokio Hotel im Heiligen Land. In: Sprachnachrichten 2008, Nr. 1, S. 20.

Sprachnachrichten (ohne Verfasser) (2008d): Pressekonferenz für Deutsch ins Grundgesetz. In: Sprachnachrichten 2008, Nr. 3, S. 2.

Sprothen, Vera (2004): Dummes Deutsch. In: Handelsblatt, Junge Karriere 8/2004, S. 70.

Staatsministerium Baden-Württemberg (2007): Pressemitteilung 151/2007, 8. Mai 2007.

Stark, Franz (2007b): Sprache als Herrschaftsinstrument. In: Sprachnachrichten 2007, Nr. 2, S. 1-2.

Steinhoff, Jürgen (1999): Sprach-Störung. In: Stern 36/1999, 9. September 1999, S. 56-60.

Steinhoff, Volker (2002): Stimmenfang mit falschen Parolen - Stoiber bei den Ostpreußen. In: Panorama, ARD, 18. Juli 2002.

Stemmler, Theo (1999): Nehmen wir Deutsche unsere Sprache nicht mehr ernst? In: VWDS-Nachrichten 1999, Nr. 1, S. 6.

Stilkenboom, Julia (2000): Auszug aus der Fleißarbeit des Projektes S4Leistungskurses Deutsch der Gesamtschule Horn [sic]. In: SprachNachrichten 2000, Nr. 2, S. 4.

Süddeutsche Zeitung (ohne Verfasser) (1998a): Sprachbösewicht küren. In: Süddeutsche Zeitung, 2. Mai 1998. S.12. 
Süddeutsche Zeitung (ohne Verfasser) (1998b): Wider die Kolonisierung der Muttersprachler. Wissenschaftler befürchten, Deutsch verkomme mehr und mehr zu einem Pidgin-Englisch und ergreifen selbst die Initiative. In: Süddeutsche Zeitung, 31. Oktober 1998. S. 12.

Süddeutsche Zeitung (ohne Verfasser) (1999): Leute. Peter Vogelgesang. In: Süddeutsche Zeitung, 14. August 1999, S. 12.

Süddeutsche Zeitung (ohne Verfasser) (2001): Streiflicht. In: Süddeutsche Zeitung, 26. September 2001, S. 1.

Süddeutsche Zeitung (ohne Verfasser) (2003): Streiflicht. In: Süddeutsche Zeitung, 1. September 2003, S. 1.

Süddeutsche Zeitung (ohne Verfasser) (2008a): Streiflicht. In: Süddeutsche Zeitung, 14. Mai 2008, S. 1.

Süddeutsche Zeitung (ohne Verfasser) (2008b): Streiflicht. In: Süddeutsche Zeitung, 10. November 2008, S. 1.

Thuma, Thomas (2003): „Die Sense stimuliert“. In: Der Spiegel 38/2003, 15. September 2003, S. 87.

Tietz, Diethold (2000): Testrennen: Lausitzring contra Eurospeedway. In. Sprach-Nachrichten 2000, Nr. 3, S. 6.

Tietz, Diethold (2003): Kleine Sternstunde. 150.000 Unterschriften „Für gutes Deutsch - gegen Denglisch.“ In. Sprachnachrichten 2003, Nr. 3, S. 15.

Tschapke, Reinhard (2005a): „Lieber ein halber Ami sein“. Sprachschützer Walter Krämer über Denglisch und Patriotismus. In: Nordwest-Zeitung, 26. Januar 2005, S. 12.

Tschapke, Reinhard (2005b): Ein Totengräber wird Funeralmaster. In: Nordwest-Zeitung, 23. Februar 2005, S. 12.

Tschiersch, Lars (2002): Kassenbericht 2001. In: Sprachnachrichten 2002, Nr. 1, S. 5. 
Unger, Ludwig (1998): Niedergang der deutschen Sprache? Aus: Fränkischer Tag, 6. November 1997. In: Der Sprachdienst 42, 1998, Nr. 1, S. 24-25.

Unterstöger, Hermann (2000): Modern Talking. In: Süddeutsche Zeitung, 17. März 2000, S. 10.

Urbanek, Ferdinand (2000): Auch Sprachpflege betreiben. In: SprachNachrichten 2000, Nr. 3, S. 9.

Verein Deutsche Sprache (ohne Verfasser) (1998c): Anzeige in der Frankfurter Allgemeinen Zeitung, 7. Mai 1998, S. 19.

Verein Deutsche Sprache (ohne Verfasser) (2005f): Eigenanzeige des VDS für die Aktion Wortpatenschaft. In: Sprachnachrichten 2005, Nr. 2, S. 6.

Voslamber, Dietrich (2004): Physiker zeigt Reue. In: Sprachnachrichten 2003, Nr. 2, S. 13.

Voslamber, Dietrich (2006): Der lange Weg einer Beschwerde. In: Sprachnachrichten 2006, Nr. 3, S. 5.

Voslamber, Dietrich (2008a): Deutsch an der Fünf-Prozent-Hürde. In: Sprachnachrichten 2008, Nr. 1, S. 10.

Voslamber, Dietrich (2008b): Europaparlament auf der Seite des VDS. In: Sprachnachrichten 2008, Nr. 4, S. 3.

VWDS-Nachrichten (ohne Verfasser) (1999a): Stoppt die Anglisierung unserer Sprache durch die Karstadt AG. In: VWDS-Nachrichten 1999, Nr. 1, S. 3.

VWDS-Nachrichten (ohne Verfasser) (1999b): Ohne Titel. Formular zum Vereinsbeitritt. In: VWDS-Nachrichten 1999, Nr. 1, S. 6.

VWDS-Nachrichten (ohne Verfasser) (1999c): Gestorben. Wilfried Portzehl, Friedrichshafen. In: VWDS-Nachrichten 1999, Nr. 1, S. 6.

Walledorf, Claudia (1998): Wenn ein „Meeting“ zum „Event“ wird. In: Bonner Generalanzeiger, 19. März 1998, S.13. 
Walter, Carsten (2008): Denglisch auf dem Vormarsch - vor allem bei den Autos. In: Nano, 3Sat, 13. November 2008.

Weinrich, Harald (2008): Elefanten beim Aufräumen im Porzellanladen. In: Sprachnachrichten 2008, Nr. 4, S. 6-7.

Wermelskirchen, Axel (1999): Sprachreinigung statt Magengeschwür. Ein Verein kämpft gegen Bezeichnungen wie „The City of the Euro“. In: Frankfurter Allgemeine Zeitung, 16. Februar 1999, S. 12.

Werthebach, Eckart (2000): Die deutsche Sprache braucht gesetzlichen Schutz. In: Berliner Morgenpost, 31. Dezember 2000, S. 6.

Willmann, Urs (2003): Prof. Besserwisser. In: Die Zeit, Nr. 30/3, Wissen, 17. Juli 2003. Einsehbar in: Die Zeit auf CD-Rom 2007, 19952006. Hamburg.

Woetzel, Harold (2005): Wer rettet die deutsche Sprache?“, Sendung im SWR, am 24. November 2005.

Wolffsohn, Michael (2005): Patriotismus 4. Patriotismus? Ja, bitte! In: Sprachnachrichten 2005, Nr. 2, S. 5.

Zabel, Hermann (2000): Buchbesprechung. Wörterbuch überflüssiger Anglizismen. Bestseller soeben in 2. Aufl. erschienen. In: SprachNachrichten 2000, Nr. 1, S. 5.

ZDF (ohne Verfasser): Modern Talking - wer rettet die deutsche Sprache? Berlin Mitte, 15. Februar 2001.

Zehetmair, Hans (2000): Kultusminister Zehetmair: Eigene Sprache stellt Wert dar. In: Sprach-Nachrichten 2000, Nr. 3, S. 1.

Zick, Rolf (2005a): Überzeugungsarbeit: Mehr als 200 Unterschriften in Hannover. In: Sprachnachrichten 2005, Nr. 1, S. 22.

Zick, Rolf (2005b): Minister Hirche macht mit bei Aktion in Hannover. In: Sprachnachrichten 2005, Nr. 4, S. 23.

Zimmer, Dieter E. (1981): Von Sdilaffis, Sdimusis und Sdileimis. In: Die Zeit, 17. April 2004, S. 50-60. 
Zips, Martin (1999): Vom Mief der kleinen engen Welt. Wer Frankfurt nicht „The City of the Euro“ nennen will, hat von Sprachgeschichte keine Ahnung. In: Süddeutsche Zeitung, 27./28. Februar 1999. S. 12.

Zugaro-Merim, Tiziana (2002): Zuwanderungsgesetz für Fremdwörter gefordert. In: Märkische Allgemeine Zeitung, 7. März 2002, MAZspezial, Themenbeilage der Märkischen Allgemeinen Zeitung, S. V8. 


\section{Dokumente des Vereins Deutsche Sprache, Dortmund}

Dies ist eine Auflistung der Dokumente aus dem Archiv des VDS in Dortmund. Briefe, Rundschreiben und Protokolle werden im Folgenden in chronologischer Reihenfolge aufgeführt.

Aden, Menno (2007): Arbeitsgruppe „Vision 2017“. In: Protokoll der Tagung Idensen 2 in Paderborn, S. 10-12.

Analyse des VDS-Erscheinungsbildes - Kurzfassung der IMH Service Internationale Medienhilfe, ohne Datumsangabe.

Auswertung Fragen zur Wahl des 15. Niedersächsischen Landtages, Januar 2003.

Baer, Oliver (2007b): Arbeitsgruppe VDS und die Wirtschaft In: Protokoll der Tagung Idensen 2 in Paderborn, S. 3-5.

Baer, Oliver (2007c): Arbeitsgruppe VDS und die Bildungseinrichtungen. In: Protokoll der Tagung Idensen 2 in Paderborn, S. 6-7.

Berufungsbegründung der Anwälte des Klägers Peter Vogelgesang an das Landesarbeitsgericht Frankfurt, 5. August 1999.

Brief des Notars an Walter Krämer, 17. November 1997.

Brief eines Nicht-VWDS-Mitglieds an den VDS, 15. Dezember 1997.

Brief von Walter Krämer an einen BR-Journalisten, 9. Januar 1998.

Brief eines BfdS-Mitglieds an den VWDS, 22. Januar 1998.

Brief eines VDS-Mitglieds an die Deutsche Telekom, 13. März 1998.

Brief eines Ehepaars (VWDS-Mitglieder) an die Deutsche Telekom, 9. Mai 1998.

Brief von Hartwig Fischer, CDU-Generalsekretär in Niedersachsen, an den VWDS, 20. August 1998.

Brief von Walter Krämer an die Zweigvorsitzenden der GfdS, 9. September 1998. 
Brief von Peter Vogelgesang an den VWDS, 29. September 1998.

Brief von Walter Krämer an einen potentiellen Regionalleiter in Portugal, 20. Oktober 1998.

Brief der Barmer Ersatzkasse an Walter Krämer, 14. Januar 1999.

Brief eines Mitglieds des Bundestags an Walter Krämer, 5. März 1999.

Brief von Walter Krämer an den Deutschen Musikverlegerverband, 14. April 1999.

Brief eines VWDS-Vorstandsmitglieds an Bundespräsident Roman Herzog, 6. Mai 1999.

Brief des ZDF an Walter Krämer, 13. Mai 1999.

Brief des IDS an Walter Krämer, 7. Juni 1999.

Brief von Walter Krämer an das IDS, 16. Juni 1999.

Brief des IDS an Walter Krämer, 22. Juni 1999.

Brief eines VWDS-Vorstandsmitglieds an Walter Krämer, 22. Juni 1999.

Brief vom Büro Roman Herzogs, Bundespräsident, an den VWDS, 22. Juni 1999.

Brief eines VWDS-Mitglieds an Walter Krämer, 5. August 1999.

Brief des IDS an Walter Krämer, 8. September 1999.

Brief eines VWDS-Vorstandsmitglieds an einige Vorstandskollegen, 21. September 1999.

Brief vom Büro Renate Schmidts an ein VWDS-Vorstandsmitglied, 21. September 1999.

Brief eines VWDS-Mitglieds an den VWDS, 25. Oktober 1999.

Brief eines VWDS-Mitglieds an Axa Colonia, 7. November 1999.

Brief von Bundespräsident Johannes Rau an den VWDS, 7. Dezember 1999.

Brief eines VDS-Mitglieds an Gerd Schrammen, 24. Februar 2000. 
Brief von Hermann Dieter an Bundespräsident Johannes Rau, Berlin, 21. März 2000.

Brief von Walter Krämer an Wolfgang Gerhardt, FDP, 23. März 2000.

Brief von Wolfgang Gerhardt, FDP, an Walter Krämer, 17. April 2000.

Brief der GfdS an Walter Krämer, 20. April 2000.

Brief von Walter Krämer an die VDS-Vorstandsmitglieder, 16. Mai 2000.

Brief eines VDS-Vorstandsmitglieds an Walter Krämer, 18. Mai 2000.

Brief eines VDS-Vorstandsmitglieds an Regionalbeauftragte und Aktivisten, 27. Mai 2000.

Brief des Arbeitskreises Wörterliste an die Vorstandsmitglieder, 29. Oktober 2000.

Brief eines VDS-Vorstandsmitglieds an die Vorstandskollegen, 29. Oktober 2000.

Brief eines VDS-Vorstandsmitglieds an den VDS, 20. November 2000.

Brief der FDP an Walter Krämer, 13. Dezember 2000.

Brief eines VDS-Mitglieds an den VDS, 24. Januar 2001.

Brief von Walter Krämer an Günter Deckert, NPD, 24. Januar 2001.

Brief eines VDS-Mitglieds an die ARD, 6. Februar 2001.

Brief von der ARD-Zuschauerredaktion an ein VDS-Mitglied, 8. Februar 2001.

Brief eines VDS-Mitglieds an Walter Krämer, 16. Februar 2001.

Brief eines VDS-Mitglieds an die VDS-Geschäftsstelle, 7. März 2001.

Brief eines VDS-Vorstandsmitglieds an die Deutsche Forschungsgemeinschaft, 6. April 2001.

Brief von Helmut Glück an Eckhardt Barthel und Michael Müller, SPD, 8. Mai 2001.

Brief von Michael Müller an Helmut Glück, 30. Mai 2001. 
Brief eines VDS-Mitglieds an earsandeyes GmbH, Mai 2001.

Brief der earsandeyes GmbH an ein VDS-Mitglied, Mai 2001.

Brief der Stadtwerke Hannover an Walter Krämer, 17. Juli 2001.

Brief der VDS-Geschäftsstelle an ein VDS-Mitglied, August 2001.

Brief von der Niedersächsischen Landesbibliothek an ein VDSVorstandsmitglied, 6. November 2001.

Brief eines VDS-Vorstandsmitglieds an die Deutsche Sprachwelt, 21. November 2001.

Brief eines VDS-Vorstandsmitglieds an Julian Nida-Rümelin, 31. Dezember 2001.

Brief von Helmut Glück an Walter Krämer, 20. Januar 2002.

Brief von Walter Krämer an die McKinsey Company vom 11. März 2002.

Brief eines VDS-Mitglieds an Walter Krämer, 29. Mai 2002.

Brief eines VDS-Mitglieds an den VDS, 15. Juni 2002.

Brief von Dieter Kinder an den Kölner Stadtanzeiger, an die Kölnische Rundschau, den Kölner Express sowie Bild Köln, 8. Juli 2002.

Brief eines VDS-Vorstandsmitglieds an Walter Krämer, 23. Juli 2002.

Brief von Ulrich Knoop, Vorsitzender des Wissenschaftlichen Beirats, an Walter Krämer, 18. September 2002.

Brief der ARD-Zuschauerredaktion an ein VDS-Mitglied, 6. Dezember 2002.

Brief einer Politikerin an den VDS, 18. Juli 2003.

Brief von Walter Krämer an die VDS-Vorstandsmitglieder, Juni 2005.

Brief eines VDS-Vorstandsmitglied an die Vorstandskollegen, 17. Juni 2005.

Brief eines VDS-Vorstandsmitglieds an Walter Krämer, 24. Juli 2007.

Brief von Walter Krämer an Peter Müller, Ministerpräsident des Saarlands, 9. Dezember 2008. 
Brief einer VDS-Regionalvorsitzenden an den VDS, ohne Datumsangabe.

Dey, Heinz-Dieter (2004): Tag der deutschen Sprache. Dokumentation 2004. Raunheim.

Dieter, Hermann (2003): Auswertung der Fragen zur Wahl des 15. Niedersächsischen Landtages, Januar 2003.

Dieter, Hermann/Simonis, Udo/Vilmar, Fritz (2001): Presseerklärung. Wissenschaftlergruppe fordert Deutsch (neben Englisch) auf internationalen Tagungen in Deutschland. Dortmund.

E-Mail eines VWDS-Mitglieds an Walter Krämer, 24. November 1998.

E-Mail von Thomas Paulwitz an ein VDS-Vorstandsmitglied, 31. Mai 2001, weitergeleitet an den Vorstand, 31. Mai 2001.

E-Mail eines VDS-Vorstandsmitglieds an die Vorstandskollegen, 4. Juni 2001.

E-Mail eines VDS-Vorstandsmitglieds an die Vorstandskollegen, 4. Februar 2003.

E-Mail eines VDS-Vorstandsmitglieds an die Vorstandskollegen, im Anhang der Mail, 4. Februar 2003.

Fax eines Nicht-VWDS-Mitglieds an den VDS, 5. Mai 1998.

Gawlitta, Kurt (2002): Verfahrensregeln für eine kooperative Zusammenarbeit im VDS“ und „Anhang der Verfahrensregeln“ von Kurt Gawlitta, 4. August 2002.

Kieselbach, Eva Maria (2004b): Lichtblicke - Ein Erfolgskalender, $1 / 2005$.

Kieselbach, Eva Maria (2005b): Lichtblicke - Ein Erfolgskalender, 2/2004.

Kinder, Dieter (2002): Antrag an die Stadt, Köln den Namen der Stadt von bislang „Köln“ in „Cologne“ umzubenennen, 8. Juli 2002. 
Klatte, Holger (2007): Protokoll der Sektion VDS und die Wissenschaft/Deutsch als Wissenschaftssprache. In: Protokoll der Tagung Idensen 2 in Paderborn, S. 14-17.

Liste mit Unterschriften der Gründungsmitglieder vom 17. November 1997. Dortmund.

Nähle/Boss: Klageschrift von Siegfried Piotrowski, 4. August 2000.

Offener Brief an Julian Nida-Rümelin vom Bundesvorstand des VDS, 5. Februar 2001.

Pogarell, Reiner (2007c): VDS International. Protokoll Tagung Idensen 2. Paderborn, S. 8.

Pogarell, Reiner (2007d): VDS als Machtfaktor. Protokoll Tagung Idensen 2. Paderborn, S. 18-19.

Presseerklärung der stellvertretenden Kreisverbandsvorsitzenden der FDP Agnes Müller Lang in Bremen, 2. Juli 2002.

Protokoll der ersten bundesweiten VWDS-Mitgliederversammlung vom 24. Oktober 1999.

Protokoll der VWDS-Gründungsversammlung vom 12. November 1997.

Protokoll der VWDS-Vorstandssitzung vom 4. Februar 1998.

Protokoll der VWDS-Vorstandssitzung vom 14. April 1998.

Protokoll der VWDS-Vorstandssitzung vom 8. Juli 1998.

Protokoll der VWDS-Vorstandssitzung vom 10. September 1998.

Protokoll der VWDS-Vorstandssitzung vom 11. April 1999.

Protokoll der VWDS-Vorstandssitzung vom 16. Dezember 1999.

Protokoll der VDS-Vorstandssitzung vom 9. Februar 2000.

Protokoll der Ad-hoc-VDS-Vorstandssitzung vom 15. April 2000.

Protokoll der VDS-Vorstandssitzung vom 19. Juli 2000.

Protokoll der VDS-Vorstandssitzung vom 2./3. Februar 2001.

Protokoll der VDS-Vorstandssitzung vom 11. März 2001. 
Protokoll der VDS-Vorstandssitzung vom 4. November 2001.

Protokoll der VDS-Vorstandssitzung vom 26. Mai 2002.

Protokoll der VDS-Vorstandssitzung vom 20. Oktober 2002.

Protokoll der VDS-Vorstandssitzung vom 31. Januar 2003.

Protokoll der VDS-Vorstandssitzung vom 2. März 2005.

Protokoll der VDS-Vorstandssitzung vom 10. Juni 2005.

Protokoll der VDS-Vorstandssitzung vom 12. November 2005.

Protokoll der VDS-Vorstandssitzung vom 21. Oktober 2006.

Protokoll der Zusammenarbeit VDS-IFB-Verlag, ohne Datumsangabe.

Protokoll zur Zusammenfassung des Gedankenaustauschs VDS-GfdS vom 7. März 2002.

Protokoll eines Treffens des geschäftsführenden VDS-Vorstands vom 16. September 2005.

Protokoll der Tagung Idensen 2 in Paderborn. 2007.

Protokoll der VDS-Delegiertenversammlung vom 16. Juni 2007.

Rundschreiben von Walter Krämer an die VWDS-Vorstandsmitglieder, 20. November 1998.

Rundschreiben von Walter Krämer an die VWDS-Vorstandsmitglieder, 15. Mai 1999.

Rundschreiben von Walter Krämer an die VWDS-Vorstandsmitglieder, 25. Mai 1999.

Rundschreiben von Walter Krämer an die VWDS-Vereinsmitglieder, August 1999.

Rundschreiben eines VDS-Vorstandsmitglieds an die Mitglieder, 3. August 2000 .

Rundschreiben von Walter Krämer an die VDS-Regionalleiter, Juni 2001. 
Rundschreiben von Walter Krämer an die Regionalleiter und Delegierten des VDS, 29. April 2002.

Rundschreiben des VDS-Vorstands an die Regionalvorsitzenden, Ende März 2002.

Rundschreiben von Walter Krämer an die VDS-Mitglieder, 24. September 2002.

Rundschreiben zweier VDS-Vorstandsmitglieder an die Vorstandskollegen, 29. September 2002.

Rundschreiben von Walter Krämer an die Regional- und Arbeitsgruppenleiter des VDS, ohne Datumsangabe.

Schroeder, Manfred (2002): Jahresbericht 2001/2002 der Arbeitsgruppe „Internationale Deutschlehrer-Initiative“ von Manfred Schroeder, 30. April 2002.

Schulz, Wolfgang F. (2008): Mittelherkunfts- und Mittelverwendungsrechnung. Wunstorf.

VDS-Bundesvorstand: Stellungnahme des VDS-Bundesvorstandes zu den Berliner „Verfahrensregeln für eine kooperative Zusammenarbeit im VDS“. Ohne Datumsangabe.

Verein zur Wahrung der deutschen Sprache (1997): Satzung Verein Deutsche Sprache. Dortmund. Original aus Vereinszentrale.

Verein zur Wahrung der deutschen Sprache (1999d): VDS vorgestellt. Dortmund.

Verein Deutsche Sprache (2000c): Vereinssatzung. Dortmund. Original aus Vereinszentrale.

Verein Deutsche Sprache (2001e): VDS-Tagebuch, 14. Lieferung, September 2001.

Verein Deutsche Sprache (2001f): VDS-Tagebuch, 15. Lieferung, Oktober 2001.

Verein Deutsche Sprache (2001g): VDS-Tagebuch, 16. Lieferung, November 2001. 
Verein Deutsche Sprache (2003k): Deutsch oder Denglisch? Der VDS stellt sich vor. Dortmund.

Verein Deutsche Sprache (2004d): Stiftung Deutsche Sprache. In: Verein Deutsche Sprache (2004): Informationen für Neugierige. Dortmund. S. 7.

Verein Deutsche Sprache (2005g): Vorläufige Schiedsordnung 2005 des Vereins Deutsche Sprache e.V. Dortmund.

Verein Deutsche Sprache (2008o): Satzung Verein Deutsche Sprache. Dortmund.

Verein Deutsche Sprache (o.D.a) Empfehlungen zur Durchführung von VDS Regionalversammlungen. Dortmund.

Verein Deutsche Sprache (o.D.b): Eckpunkte. Dortmund.

Verein Deutsche Sprache (o.D.c): Strategische Leitlinien. Dortmund.

Wissenschaftlicher Beirat des Vereins zur Wahrung der deutschen Sprache (1999): Gründungserklärung des Wissenschaftlichen Beirats. 23. Oktober 1999, Hannover.

Wissenschaftlicher Beirat des Vereins Deutsche Sprache (o.D.): Statut des wissenschaftlichen Beirats des Vereins deutsche Sprache e.V. 


\section{Weitere Materialien der Vereine und Organisationen}

Bund für deutsche Schrift und Sprache (Hg.) (2000): Der Bund für deutsche Schrift und Sprache stellt sich vor. Werbeprospekt des BfdS. In: <http://archiv.pfalzgraf.net/diss/bfds001.pdf> (22. Mai 2003).

Gizewski, Christian (1999): Einspruchsschrift des Berliner Vereins für deutsche Rechtschreibung und Sprachpflege e. V. vom 7. 9. 1999 (Inhaltsangabe). In: <http://www2.tu-berlin.de/fb1/ AGiW/Cricetus/SOzuC1/SOVsRSR/ArchivSO/Einspr.htm> (20. Januar 2009).

Kommunalverein Molfsee (Hg.) (1998): Jahresblätter des Kommunalvereins Molfsee 1998.

Riebe, Manfred (2000b): Bericht Manfred Riebes zur Jahreshauptversammlung des Vereins für deutsche Rechtschreibung und Sprachpflege e.V./Initiative gegen Rechtschreibreform (VRS) am 30. Sept. und 1. Okt. 2000 in Aschaffenburg. In: <http://www2.tuberlin.de/fb1/AgiW/Cricetus/SOVsRSR/ ArchivSO/VRSJTOO.htm> (13. September 2007).

Verein für deutsche Rechtschreibung und Sprachpflege (1998): Rundschreiben an die Mitglieder des Vereins für deutsche Rechtschreibung und Sprachpflege, September 1998. 


\section{Abbildungsverzeichnis}

Abbildung 1: Lehngutgliederung nach Betz (1974: 137) ........................21

Abbildung 2: Interesse an Sprache (Stickel 1999: 21) .............................80

Abbildung 3: Interesse an Sprache nach Geschlecht der Gefragten

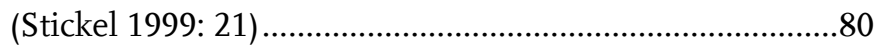

Abbildung 4: Sprachentwicklung (Stickel 1999: 25) .................................81

Abbildung 5: Auffällige Sprachveränderungen Ost/West (Stickel/Volz

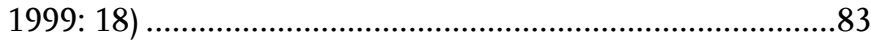

Abbildung 6: Bewertung der Veränderungen (Stickel/Volz 1999: 18)....83

Abbildung 7: Erwartung, dass die deutsche Sprache immer mehr

verkomme (Schulz 2008: 4) ..................................................84

Abbildung 8: Gewöhnung an englische Ausdrücke West/Ost (Schulz

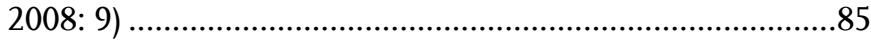




\section{Abkürzungsverzeichnis}
ADS
Aktion Deutsche Sprache
ADSV
Allgemeiner Deutscher Sprachverein
ARKUS
Arbeitskreis Unsere Sprache
Awb
Anglizismen-Wörterbuch
BfdS
Bund für deutsche Schrift und Sprache
BR
Bayerischer Rundfunk
DASD
Deutsche Akademie für Sprache und Dichtung
DFWB
Deutsches Fremdwörterbuch
DÖW
Dokumentationsarchiv österreichischer
Widerstand
dpa
Deutsche Presseagentur
dpd
Deutscher Pressedienst
DSK
Deutscher Sprachkampf
DSV
Deutscher Sprachverein
DSW
Deutsche Sprachwelt
FAZ
Frankfurter Allgemeine Zeitung
GI
Goethe-Institut
GfdS
Gesellschaft für deutsche Sprache
GfP
Gesellschaft für freie Publizistik
IDGR
Informationsdienst gegen Rechtsextremismus
IDS
Institut für Deutsche Sprache
IG Muttersprache
Interessengemeinschaft Muttersprache
MDR
Mitteldeutscher Rundfunk
MLS
Metzler Lexikon Sprache
NDR
Norddeutscher Rundfunk
NFG
Neue Fruchtbringende Gesellschaft
SKD
Sprachkreis Deutsch
$\mathrm{SN}$
Sprachnachrichten
SWR
Südwestdeutscher Rundfunk
SZ
Süddeutsche Zeitung 
VDS

VfS

VRS

VWDS

WDR

ZADS

Zs.
Verein Deutsche Sprache

Verein für Sprachpflege

Verein für Rechtschreibung und Sprachpflege

Verein zur Wahrung der deutschen Sprache

Westdeutscher Rundfunk

Zeitschrift des Allgemeinen Deutschen

Sprachvereins

Zeitschrift des Deutschen Sprachvereins 


\section{Dokumentenanhang}

\section{Dokument 1: Jil Sander im FAZ-Magazin}

[...] Die Sprache eines Künstlers ist seine Kunst, deren Farben, Klänge und Akkorde. Aber was ein Künstler über seine Kunst sagt, sagt er nicht immer in seiner Sprache. Wenn er erklären soll, was er, wenn es erklärbar wäre, nicht geschaffen hätte, spürt er oft ein Ungenügen an den Wörtern, die plötzlich nicht mehr passen wollen. Jil Sander hat diese Schwierigkeit entschlossen besiegt. In ihren Ateliers arbeitet sie mit Menschen vieler Nationalitäten, und so ist eine ihr gehörende neue Sprache entstanden, die vielleicht nur in dem von ihr geformten Umkreis vollständig verstanden wird.

"Ich habe vielleicht etwas Weltverbesserndes. Mein Leben ist eine giving-story“, sagt Jil Sander, „ich habe verstanden, daß man contemporary sein muß, das Future-Denken haben muß. Meine Idee war die handtailored-Geschichte mit neuen Technologien zu verbinden. Und für den Erfolg war mein coordinated concept entscheidend, die Idee, daß man viele Teile einer collection miteinander combinen kann. Aber die audience hat das alles von Anfang an auch supported. Der problembewußte Mensch von heute kann diese Sachen, diese refined Qualitäten mit spirit eben auch appreciaten. Allerdings geht unser voice auch auf bestimmte Zielgruppen. Wer Ladyisches will, searcht nicht bei Jil Sander. Man muß Sinn haben für das effortless. das magic meines Stils." Man muß sich diesen Text mit sanfter Bestimmtheit gesprochen vorstellen. Jil Sander muß die Stimme nicht heben, um eindringlich zu sein, sie ist von ihrem Thema gefangen. Manchmal inspiriert ihre innere Vision, die von der Sprache kaum mehr erreicht wird, eine Art Gedicht wie von Paul Celan oder Erich Fried: ...Pure ist zu wenig. Minimalistisch.

Pure ist auch opulent.

Einfach ist

zu einfach.

Was ich reintue

in das Einfache

das macht es reich.“ [...] 
Dokument 2: Satzung des Vereins zur Wahrung der deutschen Sprache 1997

Verein zur Wahrung der deutschen Sprache e.V.

Satzung

『1 Sitz und Name des Vereins

Der Verein heißt „Verein zur Wahrung der deutschen Sprache“. Er hat seinen Sitz in Dortmund und soll in das Vereinsregister des Amtsgerichtes Dortmund eingetragen werden.

\section{『2 Zweck des Vereins}

Der Verein soll dazu beitragen, daß die deutsche Sprache als selbständige Kultursprache erhalten bleibt. Insbesondere soll er die Kolonisierung des Deutschen durch das Englische bekämpfen. Er verfolgt ausschließlich und unmittelbar gemeinnützige Zwecke im Sinne des Abschnitts „steuerbegünstigte Zwecke“ der Abgabenordnung. Seine Mittel sind nur entsprechend dieser Satzung zu verwenden. Insbesondere dürfen keine Personen durch satzungsfremde Ausgaben oder durch unverhältnismäßig hohe Vergütungen begünstigt werden.

\section{『3 Verwirklichung des Satzungszwecks}

Der Zweck der Satzung wird u.a. durch folgende Aktionen angestrebt: Wahl und öffentliche Bekanntgabe des "Sprachschusters des Jahres“, Anzeigen in der Presse, Appelle an Personen des öffentlichen Lebens und an Firmen, in der Werbung und in Reden unnötige Anglizismen zu vermeiden.

\section{『4 Gemeinnützigkeit}

Der Verein ist selbstlos tätig. Er verfolgt nicht in erster Linie eigenwirtschaftliche Zwecke. Mitglieder erhalten keine Zuwendungen aus Mitteln des Vereins. 


\section{『5 Mitglieder}

Mitglieder können alle natürlichen und juristischen Personen aller Nationalitäten werden, denen die Pflege und das Überleben der deutschen Sprache am Herzen liegt.

Für die Mitgliedschaft ist kein formeller Antrag nötig. Sie beginnt mit dem Eingang des ersten Mitgliedsbeitrags auf dem Konto des Vereins und endet durch Tod, Austritt (schriftlich beim Vorstand), Ausschluß oder Nichtbezahlung des Vereinsbeitrags (konkret: mit Ablauf des Kalenderjahres, in dem erstmals kein Mitgliedsbeitrag gebucht oder überwiesen wurde).

Mitgliedsbeiträge sind jährlich zu entrichten und am Anfang jeden Jahres auf das Konto des Vereins zu überweisen oder per Lastschrift einzuziehen.

\section{\6 Organe des Vereins}

Die Organe des Vereins sind der Vorstand und die Mitgliederversammlung. Der Vorstand besteht aus dem ersten und zweiten Vorsitzenden sowie dem Schatzmeister (der geschäftsführende Vorstand) sowie weiteren geeigneten Personen. Er wird durch die Gründungsversammlung gewählt und danach (sofern nicht die Mitglieder anders beschließen) durch Zuwahl erweitert bzw. ergänzt. Jedes Mitglied des geschäftsführenden Vorstandes vertritt den Verein nach außen. Feste Amtsperioden sind nicht vorgesehen.

Der Vorstand kann zur Unterstützung seiner Arbeit einen hauptamtlichen Geschäftsführer bestellen. Dieser wird dann Mitglied des geschäftsführenden Vorstands

\section{『 7 Aufgaben des Vorstands}

Der Vorstand organisiert das Umsetzen der Vereinsziele in konkrete Arbeit. Ferner beschließt er über Mitgliedsbeiträge und den Ausschluß von Vereinsmitgliedern (nur möglich, wenn Vereinsmitglieder die Pflege der deutschen Sprache als Vorwand zum Verunglimpfen anderer Sprachen und Kulturen nutzen). 
『8 Aufgaben der Mitgliederversammlung

Die Mitgliederversammlung wird vom Vorstand nach Bedarf bzw. vom Vorstand auf schriftlichen Antrag von mehr als einem Drittel der Vereinsmitglieder mit einer Frist von mindestens zwei Wochen schriftlich einberufen. Sie kann den Vorstand neu- und umbesetzen. Ferner beschließt sie über Satzungsänderungen und die Auflösung des Vereins. Für letztere ist eine 3/4-Mehrheit der erschienenen Vereinsmitglieder nötig.

\section{『9 Auflösung des Vereins}

Bei Auflösung des Vereins oder Wegfall der Gemeinnützigkeit fällt das Vereinsvermögen an die "Gesellschaft für deutsche Sprache e.V.“ in Wiesbaden. Es darf von dieser nur für gemeinnützige Zwecke verwendet werden.

$\int 10$ Inkrafttreten

Diese Satzung tritt mit der Eintragung in das Vereinsregister in Kraft.

\section{Dokument 3: Satzung Verein Deutsche Sprache 2000}

$\int 1$ Sitz und Name des Vereins

Der Verein heißt „Verein Deutsche Sprache e.V.“ Er hat seinen Sitz in Dortmund und ist unter der Nummer 4996 in das Vereinsregister des Amtsgerichtes Dortmund eingetragen.

\section{『2 Zweck des Vereins}

Der Verein verfolgt das Ziel, die deutsche Sprache als eigenständige Kultursprache zu fördern. Insbesondere tritt er dafür ein, daß sich die deutsche Sprache gegen die Überhäufung mit Wörtern aus dem Englischen behauptet.

Der Verein verfolgt ausschließlich und unmittelbar gemeinnützige Zwecke im Sinne des Abschnitts „steuerbegünstigte Zwecke“ der Abgabenordnung. Seine Mittel sind nur entsprechend dieser Satzung zu verwenden. Insbesondere dürfen keine Personen durch satzungsfremde 
Ausgaben oder durch unverhältnismäßig hohe Vergütungen begünstigt werden.

\section{『 3 Verwirklichung des Satzungszwecks}

Das Ziel des Vereins wird $u$. a. durch folgende Maßnahmen angestrebt: Vortragsveranstaltungen, Anzeigen und Artikel in der Presse, Erarbeitung von Übersetzungshilfen, Wahl des „Sprachpanschers des Jahres“, Aufrufe an die Medien, an Firmen, Parteien und Personen des öffentlichen Lebens, sich in der Werbung und in sonstigen Verlautbarungen auf die Ausdruckskraft der deutschen Sprache zu besinnen.

\section{『4 Gemeinnützigkeit}

Der Verein ist selbstlos tätig. Er verfolgt nicht in erster Linie eigenwirtschaftliche Zwecke. Mitglieder erhalten keine Zuwendungen aus Mitteln des Vereins.

\section{『5 Mitglieder}

Mitglieder können natürliche und juristische Personen aller Nationalitäten werden, denen die Pflege und das Überleben der deutschen Sprache am Herzen liegt.

Die Mitgliedschaft beginnt mit dem Eingang des ersten Mitgliedsbeitrags auf einem Konto des Vereins. Sie kann vom Vorstand ohne Angabe von Gründen verweigert werden.

Die Mitgliedschaft endet durch Austritt (schriftlich beim Vorstand), Ausschluß oder Tod.

$\int 6$ Mitgliedsbeiträge

Mitgliedsbeiträge sind jährlich zu entrichten und am Anfang jedes Jahres auf ein Konto des Vereins zu überweisen oder per Lastschrift einzuziehen.

\section{\ 7 Organe des Vereins}

Die Organe des Vereins sind der Vorstand, die regionalen Arbeitsgruppen und die Delegiertenversammlung. Der Vorstand besteht aus dem Vorsitzenden, seinem Stellvertreter sowie dem Schatzmeister (der ge- 
schäftsführende Vorstand) sowie sechs weiteren Personen. Er wird durch die Delegiertenversammlung gewählt. Die Amtszeit beträgt drei Jahre. Wiederwahl ist zulässig.

Jedes Mitglied des geschäftsführenden Vorstandes vertritt den Verein nach außen.

\section{\8 Aufgaben des Vorstands}

Der Vorstand setzt die Vereinsziele in konkrete Maßnahmen um. Hierüber legt er einmal jährlich der Delegiertenversammlung Rechnung ab. Ferner beschließt er über Mitgliedsbeiträge und den Ausschluß von Vereinsmitgliedern.

Mitglieder können ausgeschlossen werden, wenn sie den Vereinsbeitrag nicht zahlen, wenn sie die Förderung der deutschen Sprache zur Verunglimpfung von anderen Sprachen und Kulturen nutzen, oder wenn sie auf andere Weise öffentlich den Zielen des Vereins zuwiderhandeln.

Der Vorstand kann einen wissenschaftlichen Beirat bestellen, der den Verein in sprachwissenschaftlichen Angelegenheiten berät.

\9 Aufgaben der regionalen Arbeitsgruppen

Die regionalen Arbeitsgruppen bestehen aus den Mitgliedern mit Wohnsitz in der entsprechenden Postleitzahlregion. Sie wirken in dieser Region im Sinne des Vereins.

Regionale Arbeitsgruppen wählen aus ihrer Mitte einen Leiter und einen stellvertretenden Leiter; diese unterstützen den Vereinsvorstand beim Umsetzen der Vereinsziele in der jeweiligen Region und vertreten die Mitglieder in der Delegiertenversammlung.

Ab 200 Mitgliedern wählen die regionalen Arbeitsgruppen je angefangene Zahl von 100 Mitgliedern einen weiteren Delegierten. Im Ausland wohnende Mitglieder gehören zur Postleitzahlregion 44 (Dortmund).

Benachbarte regionale Arbeitsgruppen können sich zusammenschließen.

Die Kosten der regionalen Vereinsarbeit werden nach Absprache mit dem Schatzmeister von der Vereinskasse getragen. 
『10 Aufgaben der Delegiertenversammlung

Die Delegiertenversammlung wird vom Vorstand jährlich mit einer Frist von mindestens 3 Wochen über die Vereinszeitung einberufen. Sie befindet über den Jahresbericht des Vorstands und die Rechnungslegung des Vereins. Sie wählt den Vorstand und die Kassenprüfer und beschließt über Satzungsänderungen und die Auflösung des Vereins. Für letztere ist eine Zweidrittelmehrheit der erschienenen Delegierten nötig. Die Mitglieder des Vorstands nehmen mit Stimmrecht an der Delegiertenversammlung teil.

\section{『11 Geschäftsjahr und Kassenprüfung}

Das Geschäftsjahr des Vereins ist das Kalenderjahr. Im ersten Quartal nach Ablauf des Kalenderjahres wird die Kassenführung des Vereins von zwei durch die Delegiertenversammlung gewählten Kassenprüfern überprüft.

\section{『12 Auflösung des Vereins}

Bei Auflösung des Vereins fällt das Vereinsvermögen an die „Deutsche Akademie für Sprache und Dichtung e. V." in Darmstadt. Es darf von dieser nur für gemeinnützige Zwecke verwendet werden.

\section{『13 Inkrafttreten}

Diese Satzung tritt mit der Eintragung in das Vereinsregister in Kraft.

\section{Dokument 4: Geplante Änderungen Satzung Verein Deutsche Sprache 2004}

』3 Verwirklichung des Satzungszwecks

Das Ziel des Vereins wird u.a. durch folgende Maßnahmen angestrebt: Vortragsveranstaltungen, Anzeigen und Artikel in der Presse, Übersetzungshilfen oder Auszeichnungen für gutes Deutsch. [...] 


\section{『5 Mitglieder}

Mitglieder können natürliche und juristische Personen aller Länder werden, denen die Pflege der deutschen Sprache am Herzen liegt. Die Mitgliedschaft beginnt mit dem Eintrag in die Datenbank des Vereins.

Sie kann vom Vorstand ohne Angabe von Gründen verweigert werden, und endet durch Austritt (schriftlich beim Vorstand), Ausschluß oder Tod.

\6 Mitgliedsbeiträge

Mitgliedsbeiträge sind jährlich $\mathrm{zu}$ entrichten. Die Einzelheiten regelt eine Beitragsordnung.

\section{『7 Organe des Vereins}

Die Organe des Vereins sind der Vorstand und die Delegiertenversammlung.

Der Vorstand besteht aus dem 1. Vorsitzenden, dem 2. Vorsitzenden sowie dem Schatzmeister (der geschäftsführende Vorstand) sowie bis zu acht Beisitzern. Seine Amtszeit beträgt drei Jahre. Danach bleibt der Vorstand bis zur Wahl eines neuen Vorstandes im Amt. Wiederwahl ist zulässig.

Jedes Mitglied des Vorstandes vertritt den Verein nach außen.

\section{\8 Aufgaben des Vorstands}

Der Vorstand setzt die Vereinsziele in konkrete Maßnahmen um.

Hierüber legt er einmal jährlich der Delegiertenversammlung Rechenschaft ab. Ferner beschließt er über Mitgliedsbeiträge und den Ausschluß von Vereinsmitgliedern. Die Einzelheiten werden in Beitrags- und Schiedsordnungen geregelt. Mitglieder können ausgeschlossen werden, wenn sie den Vereinsbeitrag nicht zahlen oder auf andere Weise den Zielen des Vereins zuwiderhandeln.

Der Vorstand kann einen wissenschaftlichen Beirat bestellen, der den Verein in sprachwissenschaftlichen Angelegeneheieten [sic] berät. Er trifft seine Beschlüsse auf Sitzungen oder im schriftlichen Umlaufverfahren. 


\section{Dokument 5: Satzung Verein Deutsche Sprache 2007}

\section{\1 Sitz und Name des Vereins}

Der Verein heißt „Verein Deutsche Sprache e.V.“ Er hat seinen Sitz in Dortmund und ist unter der Nummer 4996 in das Vereinsregister des Amtsgerichtes Dortmund eingetragen.

\section{『2 Zweck des Vereins}

Der Verein verfolgt das Ziel, die deutsche Sprache als eigenständige Kultursprache zu fördern. Insbesondere tritt er dafür ein, daß sich die deutsche Sprache gegen die Überhäufung mit Wörtern aus dem Englischen behauptet.

Der Verein verfolgt ausschließlich und unmittelbar gemeinnützige Zwecke im Sinne des Abschnitts „steuerbegünstigte Zwecke“ der Abgabenordnung. Seine Mittel sind nur entsprechend dieser Satzung zu verwenden. Insbesondere dürfen keine Personen durch satzungsfremde Ausgaben oder durch unverhältnismäßig hohe Vergütungen begünstigt werden.

\section{『 3 Verwirklichung des Satzungszwecks}

Das Ziel des Vereins wird $u$. a. durch folgende Maßnahmen angestrebt: Vortragsveranstaltungen, Anzeigen und Artikel in der Presse, Erarbeitung von Übersetzungshilfen, Wahl des „Sprachpanschers des Jahres“, Aufrufe an die Medien, an Firmen, Parteien und Personen des öffentlichen Lebens, sich in der Werbung und in sonstigen Verlautbarungen auf die Ausdruckskraft der deutschen Sprache zu besinnen.

\section{』4 Gemeinnützigkeit}

Der Verein ist selbstlos tätig. Er verfolgt nicht in erster Linie eigenwirtschaftliche Zwecke. Mitglieder erhalten keine Zuwendungen aus Mitteln des Vereins.

\section{『5 Mitglieder}

Mitglieder können natürliche und juristische Personen aller Länder werden, denen die Pflege der deutschen Sprache am Herzen liegt. Die Mitgliedschaft beginnt mit dem Eintrag in die Datenbank des Vereins. Sie kann vom Vorstand ohne Angabe von Gründen verweigert werden 
und endet durch Austritt (schriftlich beim Vorstand), Ausschluß oder Tod.

\section{\6 Mitgliedsbeiträge}

Mitgliedsbeiträge sind jährlich zu entrichten und am Anfang jedes Jahres auf ein Konto des Vereins zu überweisen oder per Lastschrift einzuziehen.

\section{『 7 Organe des Vereins}

Die Organe des Vereins sind der Vorstand, die Regionalgruppen und die Delegiertenversammlung. Der Vorstand besteht aus dem Vorsitzenden, seinem Stellvertreter sowie dem Schatzmeister (der geschäftsführende Vorstand) sowie acht weiteren Personen. Er wird durch die Delegiertenversammlung gewählt. Die Amtszeit beträgt drei Jahre. Wiederwahl ist zulässig.

Jedes Mitglied des geschäftsführenden Vorstandes vertritt den Verein nach außen.

\section{\8 Aufgaben des Vorstands}

Der Vorstand setzt die Vereinsziele in konkrete Maßnahmen um. Hierüber legt er einmal jährlich der Delegiertenversammlung Rechnung ab. Ferner beschließt er über Mitgliedsbeiträge und den Ausschluß von Vereinsmitgliedern.

Mitglieder können ausgeschlossen werden, wenn sie den Vereinsbeitrag nicht zahlen, wenn sie die Förderung der deutschen Sprache zur Verunglimpfung von anderen Sprachen und Kulturen nutzen, oder wenn sie auf andere Weise den Zielen des Vereins zuwiderhandeln.

Der Vorstand kann einen wissenschaftlichen Beirat bestellen, der den Verein in sprachwissenschaftlichen Angelegenheiten berät.

\section{『9 Aufgaben der Regionalgruppen}

Die Regionalgruppen bestehen aus den Mitgliedern mit erstem Wohnsitz in einer Postleitregion (gekennzeichnet durch die ersten beiden Ziffern der Postleitzahl). Sie wirken in dieser Region im Sinne des Vereins. Die Regionalgruppen wählen einen Leiter und einen stellvertretenden Leiter; diese unterstützen den Vereinsvorstand beim Umsetzen der Ver- 
einsziele in der jeweiligen Region und vertreten die Mitglieder in der Delegiertenversammlung. Ab einer Mitgliederzahl von 201 wählen die Regionalgruppen je angefangenes Hundert einen weiteren Delegierten. Regionalleiter und andere Delegierte müssen Vereinsmitglieder sein; sie haben eine Amtszeit von drei Jahren. Benachbarte regionale Arbeitsgruppen können sich zusammenschließen. Im Ausland wohnende Vereinsmitglieder bilden pro Land eine eigene Regionalgruppe. Die Kosten der regionalen Vereinsarbeit werden nach Absprache mit dem Schatzmeister von der Vereinskasse getragen.

\section{『10 Aufgaben der Delegiertenversammlung}

Die Delegiertenversammlung wird vom Vorstand jährlich mit einer Frist von mindestens 3 Wochen über die Vereinszeitung einberufen. Sie befindet über den Jahresbericht des Vorstands und die Rechnungslegung des Vereins. Sie wählt den Vorstand und die Kassenprüfer und beschließt über Satzungsänderungen und die Auflösung des Vereins. Für letztere ist eine Zweidrittelmehrheit der erschienenen Delegierten nötig. Die Mitglieder des Vorstands nehmen mit Stimmrecht an der Delegiertenversammlung teil.

\section{』11 Geschäftsjahr und Kassenprüfung}

Das Geschäftsjahr des Vereins ist das Kalenderjahr. Im ersten Quartal nach Ablauf des Kalenderjahres wird die Kassenführung des Vereins von zwei durch die Delegiertenversammlung gewählten Kassenprüfern überprüft.

\section{\12 Auflösung des Vereins}

Bei Auflösung des Vereins fällt das Vereinsvermögen an die „Deutsche Akademie für Sprache und Dichtung e. V." in Darmstadt. Es darf von dieser nur für gemeinnützige Zwecke verwendet werden.

\section{』13 Inkrafttreten}

Diese Satzung tritt mit der Eintragung in das Vereinsregister in Kraft. 


\section{Dokument 6: Satzung des Vereins Deutsche Sprache 2008}

$\int 1$ Sitz und Name des Vereins

Der Verein heißt „Verein Deutsche Sprache e. V.“ Er hat seinen Sitz in Dortmund und ist unter der Nummer 4996 in das Vereinsregister des Amtsgerichtes Dortmund eingetragen.

\section{『2 Zweck des Vereins}

Der Verein verfolgt das Ziel, die deutsche Sprache als eigenständige Kultursprache $z u$ fördern. Insbesondere tritt er dafür ein, daß sich die deutsche Sprache gegen die Überhäufung mit Wörtern aus dem Englischen behauptet.

Der Verein verfolgt ausschließlich und unmittelbar gemeinnützige Zwecke im Sinne des Abschnitts „steuerbegünstigte Zwecke“ der Abgabenordnung. Seine Mittel sind nur entsprechend dieser Satzung zu verwenden. Insbesondere dürfen keine Personen durch satzungsfremde Ausgaben oder durch unverhältnismäßig hohe Vergütungen begünstigt werden.

\section{『 3 Verwirklichung des Satzungszwecks}

Das Ziel des Vereins wird $u$. a. durch folgende Maßnahmen angestrebt: Vortragsveranstaltungen, Anzeigen und Artikel in der Presse, Erarbeitung von Übersetzungshilfen, Wahl des "Sprachpanschers des Jahres", Aufrufe an die Medien, an Firmen, Parteien und Personen des öffentlichen Lebens, sich in der Werbung und in sonstigen Verlautbarungen auf die Ausdruckskraft der deutschen Sprache zu besinnen.

\section{$\int 4$ Gemeinnützigkeit}

Der Verein ist selbstlos tätig. Er verfolgt nicht in erster Linie eigenwirtschaftliche Zwecke. Mitglieder erhalten keine Zuwendungen aus Mitteln des Vereins.

\section{\5 Mitglieder}

Mitglieder können natürliche und juristische Personen aller Länder werden, denen die Pflege der deutschen Sprache am Herzen liegt. Die Mitgliedschaft beginnt mit dem Eintrag in die Datenbank des Vereins. Sie kann vom Vorstand ohne Angabe von Gründen verweigert werden 
und endet durch Austritt (schriftlich beim Vorstand), Ausschluß oder Tod.

\section{\6 Mitgliedsbeiträge}

Mitgliedsbeiträge sind jährlich zu entrichten und am Anfang jedes Jahres auf ein Konto des Vereins zu überweisen oder per Lastschrift einzuziehen.

\section{\ 7 Organe des Vereins}

Die Organe des Vereins sind der Vorstand, die Regionalgruppen und die Delegiertenversammlung. Der Vorstand besteht aus dem Vorsitzenden, seinem Stellvertreter sowie dem Schatzmeister (der geschäftsführende Vorstand) sowie acht weiteren Personen. Er wird durch die Delegiertenversammlung gewählt. Die Amtszeit beträgt drei Jahre. Wiederwahl ist zulässig.

Jedes Mitglied des geschäftsführenden Vorstandes vertritt den Verein nach außen.

\section{$\int 8$ Aufgaben des Vorstands}

Der Vorstand setzt die Vereinsziele in konkrete Maßnahmen um. Hierüber legt er einmal jährlich der Delegiertenversammlung Rechnung ab. Ferner beschließt er über Mitgliedsbeiträge und den Ausschluß von Vereinsmitgliedern.

Mitglieder können ausgeschlossen werden, wenn sie den Vereinsbeitrag nicht zahlen, wenn sie die Förderung der deutschen Sprache zur Verunglimpfung von anderen Sprachen und Kulturen nutzen, oder wenn sie auf andere Weise den Zielen des Vereins zuwiderhandeln.

Der Vorstand kann einen wissenschaftlichen Beirat bestellen, der den Verein in sprachwissenschaftlichen Angelegenheiten berät.

\section{『9 Aufgaben der Regionalgruppen}

Die Regionalgruppen bestehen aus den Mitgliedern mit erstem Wohnsitz in einer Postleitregion (gekennzeichnet durch die ersten beiden Ziffern der Postleitzahl). Sie wirken in dieser Region im Sinne des Vereins. Die Regionalgruppen wählen einen Leiter und einen stellvertretenden Leiter; diese unterstützen den Vereinsvorstand beim Umsetzen der Ver- 
einsziele in der jeweiligen Region und vertreten die Mitglieder in der Delegiertenversammlung. Ab einer Mitgliederzahl von 201 wählen die Regionalgruppen je angefangenes Hundert einen weiteren Delegierten. Regionalleiter und andere Delegierte müssen Vereinsmitglieder sein; sie haben eine Amtszeit von drei Jahren. Benachbarte regionale Arbeitsgruppen können sich zusammenschließen. Im Ausland wohnende Vereinsmitglieder bilden pro Land eine eigene Regionalgruppe. Die Kosten der regionalen Vereinsarbeit werden nach Absprache mit dem Schatzmeister von der Vereinskasse getragen.

\section{『10 Aufgaben der Delegiertenversammlung}

Die Delegiertenversammlung wird vom Vorstand jährlich mit einer Frist von mindestens 3 Wochen über die Vereinszeitung einberufen. Sie befindet über den Jahresbericht des Vorstands und die Rechnungslegung des Vereins. Sie wählt den Vorstand und die Kassenprüfer und beschließt über Satzungsänderungen und die Auflösung des Vereins. Für letztere ist eine Zweidrittelmehrheit der erschienenen Delegierten nötig. Die Mitglieder des Vorstands nehmen mit Stimmrecht an der Delegiertenversammlung teil.

\section{『11 Geschäftsjahr und Kassenprüfung}

Das Geschäftsjahr des Vereins ist das Kalenderjahr. Im ersten Quartal nach Ablauf des Kalenderjahres wird die Kassenführung des Vereins von zwei durch die Delegiertenversammlung gewählten Kassenprüfern überprüft.

\section{『12 Auflösung des Vereins}

Bei Auflösung des Vereins fällt das Vereinsvermögen an die „Deutsche Akademie für Sprache und Dichtung e. V." in Darmstadt. Es darf von dieser nur für gemeinnützige Zwecke verwendet werden.

\section{『13 Inkrafttreten}

Diese Satzung tritt mit der Eintragung in das Vereinsregister in Kraft. 


\section{Dokument 7: Statut des wissenschaftlichen Beirats}

Statut des wissenschaftlichen Beirats des Vereins deutsche Sprache e.V. 1. Ziele des Beirats

1.1. Der Beirat unterstützt den Verein zur Wahrung der deutschen Sprache e.V.

durch fachliche Beratung und Anregungen. Er weiß sich mit ihm einig in dem Bemühen, die deutsche Sprache vor Gefährdungen zu schützen, künstliche Eingriffe in ihre Entwicklung abzuwehren und sie für die Zukunft funktionsfähig zu erhalten.

1.2. Der Beirat ist den Grundsätzen der wissenschaftlichen Objektivität und der Wahrung der methodischen Standards der Sprachforschung verpflichtet.

1.3. Der Beirat ist parteipolitisch neutral. Er ist keinen Weisungen unterworfen.

\section{Aufgaben des Beirats}

Aufgaben des Beirats sind:

2.1. die Beratung des Vereins in allen sprachwissenschaftlichen Angelegenheiten, namentlich in Fragen der Sprachplanung;

2.2. auf Aufforderung des Vereinsvorstands die sprachwissenschaftlich begründete Bewertung und Kommentierung von Beschlußvorlagen und Beschlüssen des Vereins;

2.3. die Beratung von Einrichtungen und Projekten des Vereins in sprachwissenschaftlichen Angelegenheiten;

2.4. die Beratung des Vereins bei Publikationsprojekten;

2.5. die Erstattung von Gutachten in sprachwissenschaftlichen Fragen;

2.6. auf Beschluß des Vereinsvorstands die Planung und Entwicklung einer Einrichtung, die der wissenschaftlich begründeten Sprachplanung dient und sich mit der Dokumentation der wissenschaftlichen Literatur und publizistischer Beiträge zur Entwicklung der deutschen Sprache und mit selbständigen Sprachplanungsaktivitäten befaßt;

2.7. auf Beschluß des Vereinsvorstands die Vertretung des Vereins und die Wahrnehmung von Mandaten des Vereins in anderen Institutionen und Einrichtungen. 


\section{Zusammensetzung}

3.1. Dem Beirat gehören ausgewiesene Sprachwissenschaftler aus Hochschule und beruflicher Praxis, Journalisten und Schriftsteller an.

3.2. Der Beirat wird für drei Jahre vom Vorstand berufen. Eine erneute Berufung ist zulässig.

3.3. Der Beirat ist berechtigt, mit der einfachen Mehrheit der Stimmen seiner Mitglieder neue Mitglieder zu kooptieren. Jedes Beiratsmitglied hat das Recht, einmal während einer Amtszeit ein Veto gegen einen Aufnahmekandidaten einzulegen. Die Zahl der Neuberufungen während einer Amtszeit darf die Zahl der vom Vorstand eingesetzten Mitglieder nicht übersteigen.

\section{Sprecher des Beirats}

4.1. Der Beirat wählt aus seiner Mitte einen Sprecher und zwei stellvertretende Sprecher, von denen einer die Aufgaben eines Schriftführers wahrnimmt. Sie fuhren in Zusammenarbeit mit der Geschäftsstelle des Vereins die Geschäfte des Beirats und berufen die Sitzungen des Beirats ein.

4.2. Einer der Sprecher des Beirats kann jederzeit ohne Stimmrecht an den Sitzungen des Vereinsvorstands teilnehmen und dort Anträge einbringen.

4.3. Der Vereinsvorstand kann die Teilnahme eines Sprechers des Beirats an seinen Sitzungen verlangen. Er nimmt an diesen Sitzungen mit Antragsrecht, aber ohne Stimmrecht teil.

4.4. Der Beirat kann die Teilnahme eines Mitglieds des Vereinsvorstands an seinen Sitzungen verlangen. Es nimmt an diesen Sitzungen mit Antragsrecht, aber ohne Stimmrecht teil.

\section{Organisation}

5.1. Die Mitarbeit im Beirat ist ehrenamtlich.

5.2. Die Mitglieder des Beirats erhalten für ihre Tätigkeit eine Aufwandsentschädigung, deren Höhe im Benehmen mit dem Vorstand festgesetzt wird.

5.3. Die Sitzungen des Beirats sind nicht öffentlich. Sie finden mindestens einmal im Jahr statt. Die Sprecher berufen weitere Sitzungen des Beirats ein, wenn sie dies für notwendig halten oder wenn wenigstens 
die Hälfte der Mitglieder des Beirats oder der Vereinsvorstand dies schriftlich verlangt.

5.3. [sic] Der Beirat kann sich eine Geschäftsordnung geben.

5.4. Der Beirat kann im Benehmen mit dem Vereinsvorstand Kommissionen einsetzen und Arbeitsaufträge an sie vergeben. In solche Kommissionen können auch externe Fachleute berufen werden, die dem Beirat nicht angehören. Der Beirat kann Arbeitsaufträge an einzelne seiner Mitglieder vergeben.

5.5. Für wissenschaftliche Gutachten und Stellungnahmen werden angemessene Gebühren erhoben.

\section{Dokument 8: Satzung Stiftung Deutsche Sprache}

„Stiftung Deutsche Sprache“ Satzung

『1 Name, Sitz, Rechtsform

(1) Die Stiftung führt den Namen "Stiftung Deutsche Sprache".

(2) Sie ist eine rechtsfähige Stiftung des bürgerlichen Rechts.

(3) Die Stiftung hat ihren Sitz in Berlin.

\section{『2 Stiftungszweck}

(1) Der Zweck der Stiftung ist die Förderung von Forschung, Bildung und Erziehung durch die Weiterentwicklung und Pflege der deutschen Sprache.

(2) Der Stiftungszweck wird verwirklicht durch

- die Durchführung oder Förderung von wissenschaftlichen Veranstaltungen (zum Beispiel Vorträge, Seminare, Kolloquien) und wissenschaftlichen Untersuchungen zum Thema „Deutsche Sprache“

- die Herausgabe oder Förderung von dem Stiftungszweck dienenden Publikationen.

- die Unterstützung der Arbeit des gemeinnützigen „Vereins Deutsche Sprache e.V.“, z. B. durch gemeinsame Veranstaltungen, Publikationen oder durch die finanzielle Förderung von Vorhaben des Vereins.

(3) Soweit in der Satzung nichts anderes vorgesehen ist, entscheidet der Vorstand, auf welche Weise der Stiftungszweck am besten zu erreichen ist. 
(4) Ein Rechtsanspruch auf die Zuwendung von Stiftungsmitteln besteht nicht.

\section{『3 Gemeinnützigkeit}

(1) Die Stiftung dient ausschließlich und unmittelbar gemeinnützigen Zwecken im Sinne der Abgabenordnung. Sie ist selbstlos tätig und verfolgt nicht in erster Linie eigenwirtschaftliche Zwecke.

(2) Niemand darf durch Verwaltungsausgaben, Leistungen und Zuwendungen, die dem Stiftungszweck fremd sind, oder durch unverhältnismäßig hohe Vergütungen begünstigt werden.

『4 Stiftungsvermögen

(1) Das Anfangsvermögen der Stiftung beträgt DM 100.000.

(2) Das Anfangsvermögen der Stiftung soll durch Zustiftungen Dritter erhöht werden.

(3) Die Mittel der Stiftung dürfen nur für die satzungsmäßigen Zwecke verwendet werden.

\section{『5 Stiftungsorgane}

(1) Organe der Stiftung sind der Vorstand und der Beirat.

(2) Die Mitglieder der Stiftungsorgane üben ihre Tätigkeiten ehrenamtlich aus.

$\int 6$ Vorstand

(1) Der Vorstand besteht aus einem Sprecher und zwei bis vier weiteren Mitgliedern.

(2) Der erste Vorstand ist im Stiftungsgeschäft benannt. Er besteht aus dem Sprecher und zwei weiteren Mitgliedern und kann sich mit Zustimmung aller Mitglieder auf bis zu fünf Mitglieder erweitern.

(3) Die Amtszeit der Vorstandsmitglieder endet mit der Niederlegung des Amtes oder ihrer Abberufung durch den Beirat gemäß \8 Abs. 6 .

(4) Bei Ausscheiden von Vorstandsmitgliedern schlägt der Vorstand dem Beirat geeignete Kandidaten für die Nachfolge vor. 
(5) Bei Ausscheiden des Sprechers des Vorstands wählen die verbliebenen Vorstandsmitglieder einen Nachfolger aus ihrer Mitte.

(6) Besteht der Vorstand infolge des Ausscheidens von Vorstandsmitgliedern aus weniger als drei Personen, so fuhren die verbliebenen Vorstandsmitglieder die unaufschiebbaren Aufgaben der laufenden Stiftungsverwaltung bis zur Wahl der Nachfolger allein weiter.

\section{『7 Aufgaben des Vorstandes}

(1) Der Vorstand verwaltet die Stiftung und entscheidet über die Vergabe der Mittel. Er vertritt die Stiftung gerichtlich und außergerichtlich. Jedes Vorstandsmitglied ist allein vertretungsberechtigt.

(2) Für die laufenden Geschäfte können ein Geschäftsführer und Hilfskräfte angestellt werden.

(3) Mitglieder des Vorstandes können nicht Angestellte der Stiftung sein.

(4) Der Vorstand faßt seine Beschlüsse auf Sitzungen, fernmündlich oder im schriftlichen Verfahren jeweils mit Mehrheit der abgegebenen Stimmen, soweit die Satzung nichts anderes bestimmt.

(5) Auf Sitzungen können Beschlüsse gefaßt werden, wenn mindestens zwei Drittel aller Vorstandsmitglieder anwesend sind. Für die fernmündliche und schriftliche Beschlußfassung ist erforderlich, dass mindestens zwei Drittel aller Vorstandsmitglieder eine Erklärung abgeben. Als Erklärung in diesem Sinne zählt auch die ausdrücklich erklärte Stimmenthaltung.

(6) Vorstandsbeschlüsse sind schriftlich zu protokollieren und von einem Vorstandsmitglied zu unterzeichnen.

\section{\8 Beirat}

(1) Der Beirat besteht aus Personen, die der Stiftung eine Spende von DM 50.000,- oder mehr zuwenden (sofern diese das wünschen und der Vorstand zustimmt), sowie aus weiteren vom Vorstand zu bestimmenden, sprachpolitisch interessierten und ausgewiesenen Personen.

(2) Der Sprecher und einige weitere Mitglieder des Beirates sind im Stiftungsgeschäft benannt.

(3) Die Amtszeit des Beiratsvorsitzenden endet mit der Niederlegung des Amtes oder wenn mehr als die Hälfte der Beiratsmitglieder dies ver- 
langen. Bei Ausscheiden des Sprechers des Beirats wählen die Beiratsmitglieder einen Nachfolger aus ihrer Mitte.

(4) Der Beirat faßt seine Beschlüsse, soweit die Satzung nichts anderes bestimmt, mit einfacher Mehrheit der abgegebenen Stimmen, in der Regel im schriftlichen Verfahren. Der Sprecher des Beirats kann aber auch dann Sitzungen einberufen, wenn mehr als die Hälfte der Beiratsmitglieder oder der Vorstand der Stiftung dies verlangen.

(5) Auf Sitzungen können Beschlüsse gefaßt werden, wenn mehr als die Hälfte der Beiratsmitglieder anwesend sind. Für die schriftliche Beschlußfassung ist erforderlich, dass mindestens die Hälfte aller Beiratsmitglieder eine Erklärung abgibt; als Erklärung in diesem Sinne zählt auch die ausdrücklich erklärte Stimmenthaltung.

(6) Der Beirat kann Vorstandsmitglieder aus wichtigen Gründen abberufen. Dafür ist eine Mehrheit von zwei Drittel der Stimmen aller Beiratsmitglieder erforderlich.

\9 Aufgaben des Beirats

(1) Der Beirat überwacht die Geschäftsführung des Vorstands und stellt die Beachtung des Stifterwillens sicher.

(2) Bei Ausscheiden von Vorstandsmitgliedern wählt der Beirat deren Nachfolger.

『10 Geschäftsführung

(1) Bei der Verwaltung und Anlage des Stiftungsvermögens ist die Sorgfalt eines ordentlichen Kaufmanns zu beachten.

(2) Das Geschäftsjahr ist das Kalenderjahr.

(3) Der Vorstand erstellt innerhalb von 4 Monaten nach Ablauf des Geschäftsjahres einen Jahresbericht und eine Jahresrechnung und gibt diese an den Beirat weiter. Die Jahresrechnung ist durch einen vom Beirat zu bestimmenden Prüfer, der nicht Mitglied des Vorstandes ist, zu überprüfen.

『11 Stiftungsaufsicht

(1) Die Stiftung unterliegt der Staatsaufsicht Berlins gemäß den Vorschriften des Berliner Stiftungsgesetzes. 
(2) Die Stiftungsaufsicht ist auf Wunsch jederzeit über alle Angelegenheiten der Stiftung zu unterrichten. Ihr ist unaufgefordert der Jahresbericht vorzulegen.

(3) Satzungsänderungen bedürfen der Zustimmung der zuständigen Aufsichtsbehörde.

\section{『12 Änderungen der Satzung}

Vorstand und Beirat können gemeinsam Änderungen der Satzung beschließen.

\section{『13 Aufhebung der Stiftung}

(1) Vorstand und Beirat können gemeinsam die Aufhebung der Stiftung beschließen, wenn die Umstände es nicht mehr zulassen, den Stiftungszweck dauernd und nachhaltig zu erfüllen.

(2) Im Falle der Aufhebung der Stiftung fällt deren Vermögen an den

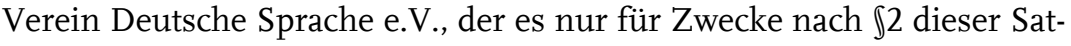
zung verwenden darf.

\section{Dokument 9: Eckpunkte des Vereins Deutsche Sprache}

Wir

...wenden uns gegen die unkritische Übernahme von Anglizismen, insbesondere wenn sie aus Effekthascherei oder zur Vorgaukelung von Weitläufigkeit in unsere Sprache eingeschleust werden.

...sind nicht grundsätzlich gegen den Gebrauch von Fremdwörtern. Wenn sie eine Lücke füllen oder wegen ihrer Prägnanz eine Bereicherung unserer Sprache darstellen, sind sie willkommen.

...vertreten einen gesunden Sprach- und Kulturpatriotismus, lehnen es aber ab, daß ein Einsatz für die Sprache zur Verfolgung nationalistischer Ziele mißbraucht wird.

...sind für ein vereintes Europa mit föderalen Strukturen, besonders in Kultur und Sprache.

Wir

...sind überparteilich, bei demokratischer und liberaler Grundeinstellung. 
...sind amerikakritisch, aber nicht amerikafeindlich, und für die Stärkung eines europäischen Selbstbewußtseins.

...fordern, daß der deutschen Sprache in der Europäischen Union die ihr zustehende Geltung verschafft wird und daß sie Wissenschaftssprache bleibt.

...wenden uns gegen die sprachliche Ausgrenzung von Bevölkerungsgruppen, die wegen unzureichender Kenntnis der englischen Sprache den deutsch-englischen Sprachmischmasch (Denglisch) in Werbung, Warenauszeichnung und den Medien nicht mehr verstehen.

\section{Dokument 10: Protokoll der Vorstandssitzung vom 8. Juli 1998}

Presse und Medien berichten weiterhin sehr positiv über uns. Es gab Artikel über die Regionalbeauftragten Limberg, Will und SchmidtEndrulat im Darmstädter Echo, im Nürnberger Anzeiger, Ausgabe Nordost und in der Neuen Osnabrücker Zeitung, ein Dutzend RadioInterviews des ersten Vorsitzenden in diversen regionalen und überregionalen Sendern, Berichte über den Verein in fast allen deutschen Zeitungen, von Bild- bis Süddeutsche Zeitung sowie Fernsehberichte bzw. Interviews mit den Regionalbeauftragten v. Pappenheim und Tietz und dem Vereinsvorstand in SAT1, WDR, Phoenix, NDR (zweimal), MDR (zweimal) und ZDF (Hallo Deutschland).

[...] Es sind diverse Politiker angeschrieben worden, und es hat Kontakte zum Institut für deutsche Sprache in Mannheim gegeben. Als gemeinsame Aktion wäre hier ein „Sprachtelefon“ zur Beratung von Journalisten, die nach deutschen Wörtern für neu eingeführte Anglizismen suchen.

[...] Weiterhin berichtet Herr [...] von der Tagung eines „Arbeitskreises Unsere Sprache“ (ARKUS) in Frankfurt, an der er und Herr [...] teilgenommen haben. Dieser Arbeitskreis wird von dem immer mehr nach rechts tendierenden Alfred Mechtersheimer gesteuert. Es herrscht Konsens, hier keine weiteren Kontakte anzustreben.

[...] berichtet über die unverlangte Zusendung der „Hutten-Briefe“, einer von offenbar NPD-nahen Kreisen herausgegebenen Publikation. Auch 
andere Teilnehmer haben dergleichen Post erhalten. Es ist unklar, wie die Absender an die Adressen gekommen sind.

[...] Verschiedene Anwesende regen an, auch den Namen des Vereins nochmals zu überprüfen. Der Name „Bürgerforum deutsche Sprache“ unseres Schwestervereins in Köln wird allgemein für publikumswirksamer gehalten. [...] schlägt vor, anläßlich der Eingliederung des Bürgerforums auch dessen Namen anzunehmen, ersatzweise einen Doppelnamen zu führen: Verein zur Wahrung der deutschen Sprache e.V. Bürgerforum deutsche Sprache. Herr Krämer sagt zu, diese Alternative ernsthaft zu überprüfen.

\section{Dokument 11: Protokoll der Vorstandssitzung vom 10. September 1998}

[...] Medienresonanz:

Es hat zahlreiche Berichte über unseren Verein in Zeitungen, Rundfunk und Fernsehen gegeben. Die Medien stehen überwiegend auf unserer Seite. Außerdem hat der Verein eine Reihe von Anzeigen in regionalen und überregionalen Tages- und Wochenzeitungen geschaltet (Einwand: Anzeigentexte sind zu muffig! Wir brauchen peppigere Texte).

[...] a) Sprachwissenschaft und deutsche Sprache: Die wissenschaftlich mit der deutschen Sprache beschäftigten Personen hierzulande hätten als Nachwirkung der Nazizeit entweder keinen Mumm oder kein Interesse daran, die deutsche Sprache hochzuhalten. Gleiches gelte auch für die Gesellschaft für deutsche Sprache in Wiesbaden.

Sprachhunzer des Monats für Oktober 1998 bis Februar 1999

Vorschlag: Diese Übeltäter besser sanft, nicht grob attackieren; Grobattacken provozieren nur Oppositionshaltung. Immerath: Besser konstruktive Vorschläge machen, nicht nur schlechtes Deutsch verurteilen. $[\ldots]$.

Unter den Anwesenden scheint sich eine Mehrheit für eine eher sanfte und fürsorgliche Behandlung von Sprachverhunzern abzuzeichnen. W. Krämer: nein, auf einen groben Klotz gehört ein grober Keil. 
Umbenennung des „Sprachschusters“

Eine Reihe von Anwesenden wenden sich gegen den „Sprachgimpel“, der bisher im Vorstand eine Mehrheit hatte. [...] Warum nicht „Sprachpanscher“? Warum nicht „Sprachkasper“? [...] Nächste Woche entscheidet der Vorstand per Abstimmung über Rundruf.

\section{Dokument 12: Protokoll der Vorstandssitzung am 2/3. Februar 2001}

[D]as Goethe-Institut ist von seinem Angebot, die Sprachpreisverleihung in München auszurichten, zurückgetreten. Nächste Woche wird mit der Stadt Kassel verhandelt, kommt es zu keiner Einigung, wird der Preis in Berlin vergeben.

Trotz Spendenaufrufs in der FAZ ist bisher nicht genügend Geld eingegangen, um die Stiftung Deutsche Sprache gründen zu können. Joachim Bullermann erklärt sich spontan bereit, 10.000 DM zu stiften.

[...] Senator Werthebach vertritt entschieden das Anliegen des VDS.

[...] Die Abstimmung, ob der VDS der Stiftung Deutsche Sprache 50.000 DM Gründungskapital übergeben soll, ergibt: eine Nein-Stimme, eine Enthaltung und sechs Ja-Stimmen.

[...] Ebenfalls ausgeschlossen (auf Antrag von W. Krämer) wird Herr G. Deckert (8 Ja-Stimmen, keine Enthaltung). Er hat brieflich angedroht, den VDS mit der NPD in Verbindung zu bringen und damit vereinsschädigend gehandelt.

\section{Dokument 13: Protokoll der VDS-Vorstandssitzung vom 4. November 2001}

a) Erarbeitung eines Sprachgesetzes im Sinne eines Verbraucherschutzes - eine Auflistung aktuell schon existierender Sprachvorschriften anbei (nicht vollständig). Hier ist unsere Arbeitsgruppe „Verbraucherschutz" gefordert

b) Einrichtung einer „Deutschen Sprachakademie“ - daran arbeiten der Kollege [...] und ich mit Hochdruck

Einwerbung von öffentlichen Fördermitteln. Von unseren Mitgliedsbeiträgen können wir trotz Erhöhung nicht leben. Fernziel: ein Teil der 1.5 
Mio. DM jährlich, welche die Wiesbadener Gesellschaft für Deutsche Sprache jedes Jahr kassiert, muß auf unser Konto fließen.

\section{Dokument 14: Protokoll der Tagung Idensen 2 in Paderborn}

[...] Im VDS wachsendes Bedürfnis, ernstgenommen zu werden, Kompetenzen zu beweisen

Öffentlichkeit nimmt VDS wahr als Bürgerinitiative (z.T. gegen Fremdwörter),

außerdem als Betreiber von Positivaktionen

Populäre Aktionen in der Zielgruppe Wirtschaft tendenziell eher schädlich (haben wichtigere Sorgen)

Akzentverschiebung im Markenkern erforderlich: Wo bietet VDS Kompetenz?

Dokument 15: Brief eines VDS-Mitglieds an die Telekom, 13. März 1998 Sehr geehrte Damen und Herren,

habe soeben Ihre Rechnungen erhalten und muß Ihnen sagen, daß ich es für eine Zumutung halte, in meinem eigenen Land diesen Anglokauderwelsch à la "German Call", "Global Call" usw [sic] vorgesetzt zu bekommen. Dazu kommt, daß es wohl auch noch Leute gibt, die kein Englisch können, und es ist wohl selbstverständlich für eine gute Dienstleistung, daß sie allgemeinverständlich ist und die jeweilige Landessprache respektiert. Sollten Ihre Deutschkenntnisse unvollständig sein, rate ich zu einem Deutschkursus. Möglichkeiten dazu gibt es ausreichend.

\section{Dokument 16: Brief Barmer}

[...] Mit Schreiben vom 20.11.1998 hatten wir Ihnen unsere Gedanken zu dem von Ihnen zu recht kritisierten Einsatz von Anglizismen dargestellt.

Mit den heutigen Zeilen will ich die damaligen Aussagen unterstreichen. So kann ich Ihnen mitteilen, daß inzwischen die für den Umdenkungsprozeß erforderlichen Gespräche mit den Vertretern der Fachver- 
lage stattgefunden haben. Auch hausintern haben wir erfolgreich gekämpft und, wo wir dies unmittelbar beeinflussen können, die Weichen in die neue Richtung gestellt.

Unser jüngstes Produkt dieser 'neuen Linie': Der wieder aufzulegende Jugendkalender der BARMER. Die ursprünglich vorgeschlagene Bezeichnung "fine timer“ wurde ausgetauscht gegen den neuen Titel „Gute Zeit“.

In diesem Sinne machen wir auch weiter. Das Ergebnis werden Sie in unseren Medien 'bunt oder schwarz auf weiß' nachlesen können.

Mit gleicher Post werde ich den Regionalbeauftragten des Vereins, Herrn Joachim Bullermann, Konstanz und Herrn Hermann H. Dieter, Berlin entsprechend informieren.

Wenn Sie im Zusammenhang mit dieser Thematik noch weitere Fragen haben, bin ich auch künftig gerne Ihr Ansprechpartner.

\section{Dokument 17: Rundbrief GfdS}

[...] beiliegend schicke ich Ihnen ein Memorandum des von mir gegründeten „Vereins zur Wahrung der deutschen Sprache e.V.“, der sich als eine Art „weltlicher Arm“ der "Gesellschaft für deutsche Sprache e.V.“ in Wiesbaden versteht (ich selbst, wie auch viele unserer Mitglieder gehören zugleich der Gesellschaft für deutsche Sprache an). Ich würde mich freuen, wenn Sie dieses Memorandum und eventuell auch einige der anderen beiliegenden Materialien in Ihrem Zweig diskutieren und vielleicht sogar einen unserer Redner zu einem Vortrag einladen könnten.

Wie Sie im Protokoll der letzten Mitgliederversammlung Ihrer Gesellschaft sehen können, habe ich bereits dort eine engere Zusammenarbeit unserer Vereine angeregt, wenn auch vorläufig noch ohne Erfolg. Aber wozu sind Entscheidungen denn da, wenn nicht dazu, überdacht $z u$ werden. [...]

\section{Dokument 18: Enercity}

Aktion Sprachtest Energiedienstleister

Sehr geehrter Herr Prof. Dr. Krämer,

der Verein Deutsche Sprache e. V. hat mit dem Sprachtest Energiedienstleister die bisherigen Vergleichstabellen um eine zusätzliche er- 
weitert und dabei mit der Sprache einen Aspekt in den Vordergrund gestellt, der bisher nicht berücksichtigt worden ist. Die Stadtwerke Hannover AG bzw. ihre Produkte haben dabei einen Platz im Mittelfeld Ihrer Tabelle erzielt. Dies erscheint in Anbetracht der von Ihnen genutzten Kriterien durchaus plausibel.

Produktnamen merkt man üblicherweise nicht an, wie er zustande gekommen ist. In unserem Hause hat es durchaus vor der Festlegung auf die verwendeten Produktnamen intensive Diskussionen gegeben gerade auch $\mathrm{zu}$ der Frage, ob deutsche oder englische Bezeichnungen gewählt werden sollen. Wir haben uns. schließlich für englische Bezeichnungen entschieden, dabei allerdings Wert darauf gelegt, englische Begriffe zu nutzen, die bereits Vielen geläufig sind. So ist die Wahl dann auf die Namenszusätze „\&more“ „\&care“ und „\&go“ gefallen.

Wie gesagt: Wir haben uns die Entscheidung für diese Namen nicht leicht gemacht und sind uns auch der Nachteile, die die englischen Begriffe mit sich bringen, durchaus bewusst. Ein Blick in Ihre Übersichtstabelle zeigt uns aber zugegebenermaßen auch, welche interessanten und charmanten deutschen Begriffe und Sprüche unsere Mitbewerber geschaffen haben.

Bitte gestalten Sie uns mal einen konstruktiv gemeinten Hinweis zu Ihrer Aktion: Die Abkürzung für Kilowattstunde ist - kWh -. Diese 3 Buchstaben werden direkt zusammengeschrieben und es gehört kein Formelzeichen zwischen diese Buchstaben, auch kein Schrägstrich für "geteilt durch". Denn ein solcher Schrägstrich würde bedeuten, die Kilowatt $(\mathrm{kW})$ nicht mit der Stunde (h) malzunehmen, sondern sie durch die Stunde zu teilen. Die Formelzeichen für die physikalischen Einheiten werden international einheitlich verwendet, wobei Klein- und Großschreibung zu beachten sind. 


\section{Dokument 19: Brief ARD}

Sehr geehrter Herr [...],

vielen Dank für Ihren Brief.

Wir bedauern ihre Kritik am Sprachgebrauch unserer Mitarbeiter. Den Programmverantwortlichen des Ersten ist durchaus am korrekten Gebrauch der deutschen Sprache gelegen.

Jede lebende Sprache nimmt Lehnworte aus anderen Sprachen auf. Den aktuellen Rahmen bestimmen landeseigene Regelwerke. Ein gutes journalistisches Produkt sollte sich bei der Wahl von Wörtern von folgenden Vorgaben leiten lassen; strikte Anlehnung an Regelwerke der deutschen Sprache, genaue Begriffe, allgemeine Verständlichkeit und dosierte Modernität. Das äußerst korrekte Deutsch von Sprachwissenschaftlern oder Bürokratendeutsch wären den Zuschauern nicht zuzumuten.

\section{Dokument 20: Brief von Walter Krämer an Günter Deckert}

Sehr geehrter Herr Deckert, durch Ihren Brief vom 27.01.2001 haben Sie kundgetan, daß Sie Ihren früheren radikalen Überzeugungen weiterhin anhängen. Außerdem stellen Sie in Aussicht, den VDS mit einem rechtsextremen Verein in Verbindung zu bringen. Das ist ein vereinsschädigendes Verhalten im Sinn unserer Satzung. Daher hat der Vorstand in seiner Sitzung vom 2. Februar 2001 einstimmig beschlossen, Sie wegen vereinswidrigen Verhaltens aus dem Verein Deutsche Sprache e.V. auszuschließen.

Prof. Dr. Walter Krämer

\section{Dokument 21: Antrag an die Stadt Köln}

Antrag an die Stadt Köln den Namen der Stadt von bislang „Köln" In "Cologne“ umzubenennen

Begründung:

Köln wurde einst als römische Stadt „Colonia" gegründet und wuchs sehr schnell zur wichtigste Kolonie des römischen Imperiums diesseits der Alpen heran. Nach dem Untergang des .Römischen Reichen" hat sich die Stadt im Mittelalter bis in die Neuzeit unter dem Namen "Cöln" 
als .Freie Reichsstadt" zu einem bedeutenden Zentrum des Geistes und Handels entwickelt. Der Name der Stadt hatte, auch nachdem das „C“ im Namen in „K“ geändert wurde, noch bis ins späte 20. Jahrhundert einen hervorragenden Klang.

Doch nun, in der Epoche der sog. Globalisierung, geht man in weiten Kreisen der Kölner Gesellschaft (Politik. Wirtschaft. Kirche, Kultur, Sport usw.) immer mehr dazu Ober, Köln so zu bezeichnen und abzusprechen, wie es die Engländer und Amerikaner tun. Nicht nur viele offizielle und inoffizielle Einrichtungen, Institutionen und Unternehmen führen nun bereits deutlich die Bezeichnung "Cologne* im Namen, auch bei wichtigen kulturellen und sportlichen Ereignissen vermeldet man im häufiger die als altertümlich empfundene Bezeichnung .Köln“. Einige wenige Beispiele: .Cologne Science Center“, .CologneTower, ,Cologne Congress, „Cologne Container Coaches“, „Cologne Crocodiles“ (Die Auflistung weiterer „Cologne“- Adressen finden Sie auf der Rückseite).

[...] Zeugt es nicht von einer geradezu einmaliger Weitläufigkeit [sic], nicht langer der eigenen Bevölkerung kölntümelnd nach dem Mund zu reden und nun endlich so $\mathrm{zu}$ heißen, wie die Angloamerikaner einen heißen?

Daher stellt der Kölner Regionalverband des „Verein Deutsche Sprache e V.“ (VDS) den Antrag, den geänderten Verhältnissen endlich Rechnung zu tragen und nun auch ganz offiziell den überholten Namen „Köln“ abzulegen, um sich als kommende Weltstadt mit dem neumodischen Namen "Cologne“ (in der anglo-amenkanischen Fassung) zu schmücken. [...]. 
Dokument 22: Foto Walter Krämer

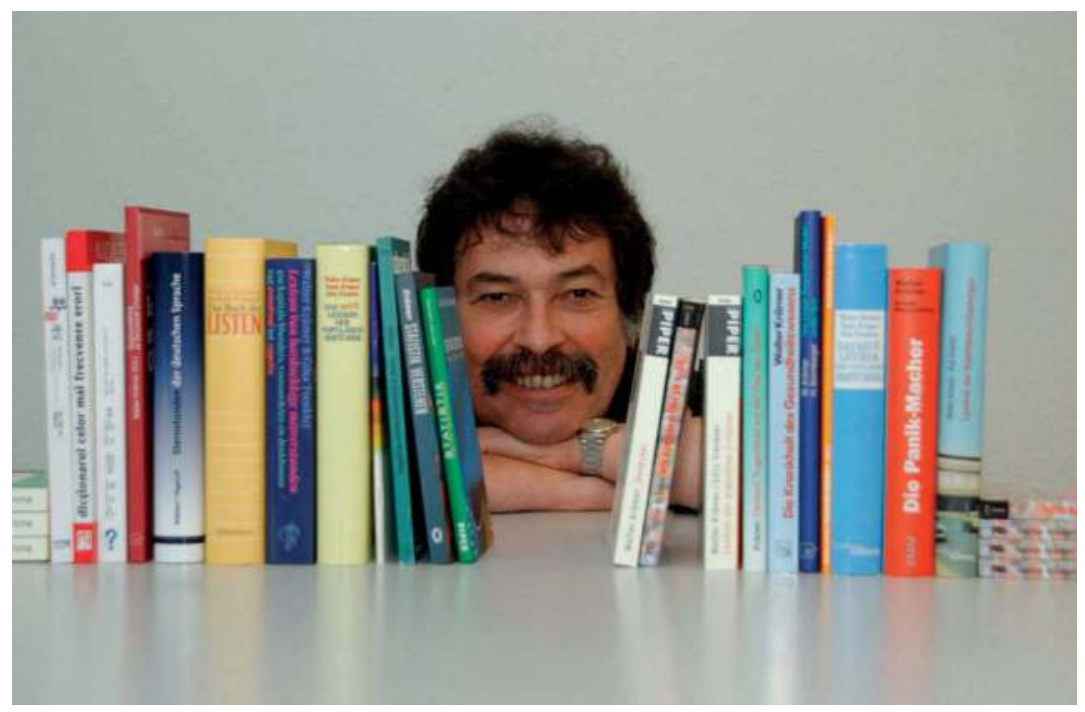

Dokument 23: Schriftzug und Logo Verein Deutsche Sprache Verein Deutsche Sprache e.V. If 
Bestrebungen, die Sprache von Einflüssen anderer Sprachen freizuhalten, haben in Deutschland eine lange Tradition. Der englischsprachige Einfluss und damit einhergehend die Anglizismenkritik sind in den letzten Jahren wieder verstärkt in den öffentlichen Diskurs gerückt, die derzeitige Entwicklung mit der Neugründung von Sprachvereinen ist als neue Phase des Purismus in Deutschland zu sehen. Die größte Vereinigung, die sich gegen Anglizismen im Deutschen wendet, ist der 1997 gegründete Dortmunder Verein Deutsche Sprache (VDS).

Der VDS blickt auf eine über zehnjährige Vereinsgeschichte zurück. In dieser Zeit hat er sich von einem kleinen zu einem einflussreichen Verein mit mehr als 31.000 Mitgliedern in über 70 Ländern gewandelt. Er wird portraitiert anhand seiner Entstehung, Organisation und Vereinsarbeit. Dies geschieht vor dem Hintergrund der Fremdwortdiskussion und der sprachpflegenden Vereine in Deutschland.

Ziel des VDS ist, gegen die Anglizismen im Deutschen vorzugehen, beziehungsweise Medien, Politik und Wirtschaft auf das Thema aufmerksam zu machen und von den Standpunkten des Vereins zu überzeugen.

Die Ergebnisse der vorliegenden Untersuchung dokumentieren, dass der VDS nicht zu Unrecht als Speerspitze der Anglizismenkritik gilt. 